

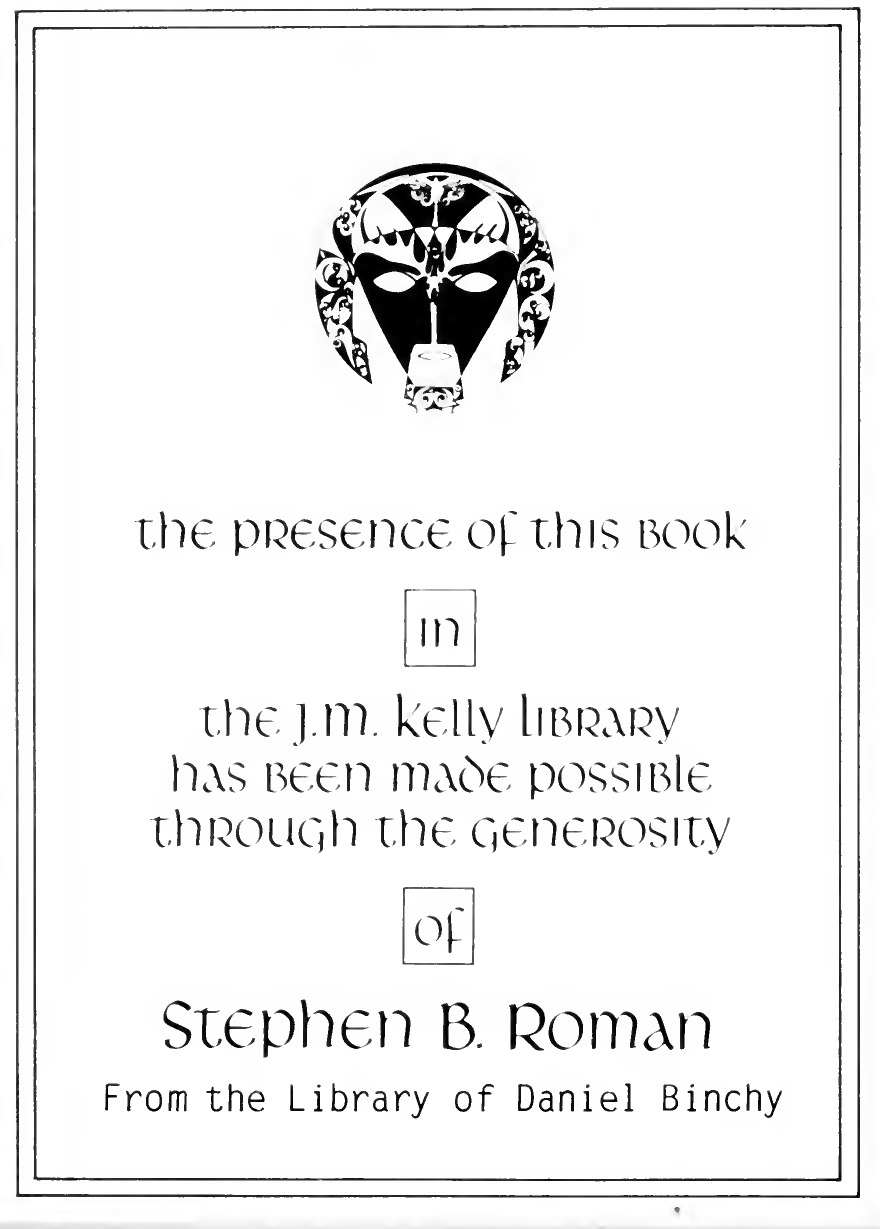




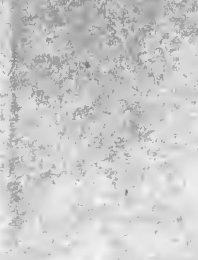

a

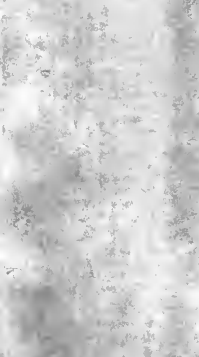

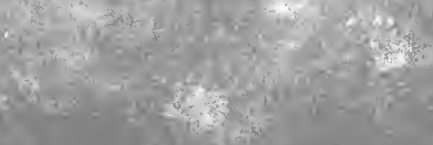


. 


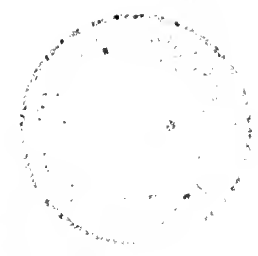


4

.

.

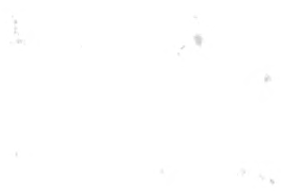

is
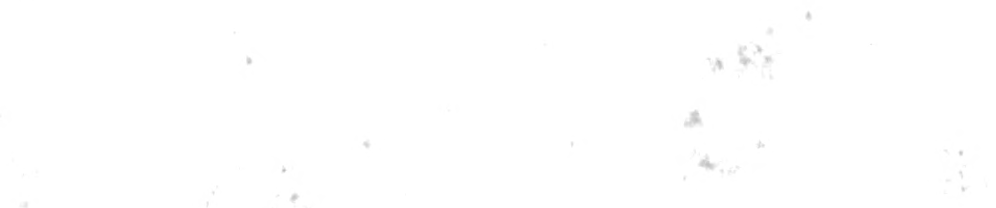

$2+1$

4 .
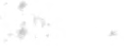

*

1 


\title{
SCHOLASTICISM OLD AND NEW
}

AX INTRODUCTION TO

\section{SCHOLASTIC PHILOSOPHY}

\author{
MEDIEVAL AND MODERN \\ BY \\ M. DE WULF \\ DOCTOR OP LAWS, DOCTOR OF PHILOSOPHY AND LETTERS, PRORESSOR \\ AT THE UNIVERSITY OF LOUVAIN \\ TRANSLATED BY \\ P. COFFEY, D.Ph. \\ PROFESSOR OF PHILOSOPHY, MAYNOOTH COLLEGE, TRELAND
}

PRESS NOTICES.

"Dr. Coffey has conferred a service on all Catholics who are interested in philosophic questions, by translating Prof. de Wulf's work on Scholasticism. The book is a vindication of that important intellectual movement, the Neo-scholasticism of Louvain. It sets before us the aims of the leaders ... and the conditions they regard as essential to their attainment. . "- The Tablet (London).

"Readable, living, in close and direct contact with the currents of historical, scientific and philosophical movements at present swaying the minds of men, it cannot fail to impress its readers with the greatness of the work associated with the name of Cardinal Mercier and the Neoscholastic school of Louvain. . .

"There is not a page that does not teem with suggestive thoughts, and those who are interested to know how scholastic principles emerge from the contest with modern thought will find here much to their purpose. The only favour it asks is to be allowed to indicate its superiority in open intellectual discussions; 'inheriting as it does the traditional spiritualism of a Plato, an Aristotle a St. Augustine and a St. Thomas, it bases its claim neither on the tradition which it perpetuates, nor on argument from authority. . . . On the contrary, it is after an examination of the facts that are engaging the attention of onr contemporaries, after interpreting the results achieved by the sciences, after testing critically its own principles, that the New Scholasticism lays down its conclusions, and invites the philosopher of the 20 th century to recognise them and deal with them on purely the same titles as they deal with those of Neo-Kantism and Positivism.' The importance of the book to Catbolics and non-Catholics alike, if they wish to do justice to scholastic thought, is evident."-Dublin Review.

"The great advantage of Professor de Wulf's introduction is its accuracy and simplicity. It is compressed into a short space, but nothing of the outline of scholastic philosophy is wanting. In itself, with a little thought on the part of the reader, it will amply repay a perusal. ... The scholastic system is presented as it really is. Misconceptions as to its meaning and teaching are brusbed deftly aside. . . . We certainly owe the translator a debt of gratitude for his having rendered de Wulf's scholarly book accessible to English readers. It is to be hoped that it will meet with the welcome it deserves, for it is one of our most valuable contributions to our growing stock of anti 'rationalistic' and soundly rational literatures."-The Rev. E. AvELING, D.D., in the Catholic Herald (London).

"The whole subject is well divided; the treatment is full of detaih and in spite of the loftiness of the subject-matter the book is for the most part easy reading. From the beginning to the end there is no dearth of freshness or actuality. No one who takes an interest in the subject of scholastic philosophy, and its relations to other systems of thought or to science, can afford to be unacquainted with this valuable and unique monograph."-Catholic Book Notes (London).

"There is no doubt that the work meets a distinct want. For Catholic students in our seminaries it will be of great value for two reasons. First, it will synthesise into a unity, and present as a comprehensive whole their course of studies, which is only too apt to be viewed piecemeal, without any perceived connection between part and part.

"Secondly, by presenting the matter in an English dress it will afford a bridge between the technical language of the schools and the untechnical language of ordinary life, and will thus help the student to render his doctrines into terms which the ordinary outsider will understand."Bombay Examiner.

\section{LONDON: LONGMANS, GREEN, \& CO. DuBLIN: M. H. GILL \& SON} New York, Cincinnati, and Chicago: BENZIGER BRothers 


\section{WORKS BY THE SAME AUTHOR.}

SCHOLASIICISM OLD AND NEW (La Philosophie Néo-Scolastique, tr. by P. Coffey, D.Ph.); an Introduction to Scholastic Philosophy, Medieval and Modern. 1907. Dublin: Gill \& son. New York: Benziger Brothers.

HIS'TOIRE DE LA PHILOSOPHIE SCOLANTIQUE DANS LES PAYS-BAS ET LA PRINCIPAUTE DE LIÉGE JUSQU'A LA REVOLUTION FRANÇAISE (Mém. Couronné par l'Acad. de Belgique). 1895. Louvain; Paris, Alcan.

ETUDES SUR HENRI DE GAND, extract from the preceding.

ETUDE SUR LA VIE, LES OEUVRES ET L'INFLUENCE DE GODEFROID DE FONTAINES (Mém. Couronné par l'Acad. de Belgique). Louvain, 1904.

LE TRAITE DES FORMES DE GILLES DE LESSINES (Vol. I. of the series, Les Philosophes Belges). Louvain, $190 \mathbf{1}$

LES QUATRE PREMIERS QUODLIBETS DE G. DE FONTAINES (in con junction with Dr. A. Pelzer; Vol. II. of same series). Louvain, I904.

LES QUODLIBETS V.-X. DE GODEIROID DE FONTAINES (Vol. III. of same series).

[In preparation.

LE MOUVEMEN'T PHILOSOPHIQUE EN BELGIQUE (Illustrated). Louvain, 1909.

HISTOIRE DE LA PHILOSOPHIE EN BELGIQUE (One vo'. gr. 8vo. Edit. de luxe.)

[In the press.

PRECIS D'HISTOIRE I)E PHILOSOPHIE (in the Manuel de Philosophie, published by Louvain Professors, vol. II., and edit., 1909).

LA VALEUR ESTHÉTIQUE DE LA MORALITÉ DANS L'ART. Brussels, 1892.

ÉTUDES HISTORIQUES SUR LESTHFTIQUE 1899.

QU'EST-CE QUE LA PHILOSOPHIE SCOLASTIQUE? Louvain, r899.

ARTICLES IN REVIEWS.

[Out of print.

A. Revue név-scolastique (Louvain).

L'cremplarisme et la théorie de l'illumination speciale dans la théorie de Henri de Gand. (1904.)-L'enseignement de la philosophie en Firance. (1894.)-Les théories esthetiques propres ì saint Thomas. (1805 et 1896.) Tiré à part: Louvain et Paris; 66 pages in 8vo. - L'enseigne'ment de la philosophie en France et en Allemagne. (r 896.)L'office international de bibliographie. (1895.)-Quelques formes contemporaincs du pantheisme. (1897.)-l.es récents trau'aux sur l'histoire de la philosophie médievale. (1893.) Qu'est-ce que la philosothie scolastique?' (1899 et 1900.) 'liné à part: Louvain et Paris; 75 pages in 8vo.- La philosophie scolastique au Congres de l'Exposition universelle de Paris. (1900.) - Récents travaux sur l'histoire de la philosophie méditíale en Occident. (1898-1899.) (1900.)-Ausustinisme et Aristotélisme a u XIlle siacle. (1901.)-Comment faut-il juger M. Hiauráau? (1901.)-Kantismé et néo-scolastique. (1902.)-Récents travaux sur l histoire de la philosophie médievale. (1002, 1904, $1905 \mathrm{et} 1907$.$) - Methodes scolastiques$ d'autrefois et d'aujourd'hui. (1903.)-La décadence de la philosophie scolastiquc au moyen âge. (1903.) - Un preux de la parole au XllJe siecle. (1904.) - Un scolastique inconnu de la fin du XIIJe sidcle Thierry de Friburg. (1906.)-Premiere lecon d'esthétzque. (1907.) -Le moni'ement philosophique en Belsique. (1908.)-La revanche de I'intellectualisme. (1909.) Bulletin a'histoire de philosophie médiéuale. (1909.)-L'histoire de l'Esthétique et de ses grandes orientations. (1909.)

La notion de la scolastique. (Juin rgo2.)

$$
\text { B. Revue philosophique (M. Ribot). }
$$

C. Archiv für (ieschichte der philosophie (M. Stein, Berlin).

Le probleme des universaux dans son évolution historique du IXe au XIIle siecle. (1896.)-Les lois organiques de Thistoire de la psychologie. (1897.)

D. Revue d'histoire et de litterature religieuse.

Chronique d'histoire de la philosophie médiévale. L'état actuel de la science. (1900.) - La doctrime de la pluralité des formes dans l'ancienne scolastique du XIIIe sidcle. (1901.) -Chronique d'histoire de philosophie médiérale. (1902, 1904, 1905 et 1907.)

E. Divus Thomas (Plaisance).

De speciebus intentionalibus, dissertatio historico-critica. (1907.)

$$
\text { F. Études franciscaines. }
$$

4 propos du libéralisme philosophique. (Juillet 1905.)

G. Revue critique d'histoire et de lattérature (Chuquet, Paris).

Notice sur des ouvrages de Concetti Marchesi et de Lucquet. (Janvier 1905.)

$$
\text { H. Revue a'histoire ecclésiastique. }
$$

Lettre ouverte à propos de la notion de la scolastique. (Louvain, 1904, pp. 716-720.)

I. Encyclopedia of Religion and Ethics (James Hastings).

Art. on Aesthetics, Beauty. 
HISTORY OF MEDIEVAL PHILOSOPHY 


\section{HISTORY}

\section{OF \\ MEDIEVAL PHILOSOPHY}

BY

\section{MAURICE DE WULF}

PROFESSOR AT THE UNIVERSITY OF LOUVAIN

DOCTOR OF PHILOSOPHY AND LETTERS; DOCTOR OF LAWS

MEMBER OF THE ROYAL ACADEMY OF BELGIUM

THIRD EDITION

TRANSLATED BY

P. COFFEY, D.PH.

FROFESSOR OF PHILOSOPHY, MAYNOOTH COLLEGE, IRELAND

L O N M A N S, GREEN, A N C O.

39 PATERNOSTER ROW, LONDON

NEW YORK, BOMBAY, AND CALCUTTA

Igog

All rights reserved 


\section{AUTHOR'S PREFACE.}

THE present English version forms a Third Edition of our Histoire de la Philosophie Médiévale, of which the first French edition appeared in 1900 and the second in 1905 . The general plan of the second edition has been preserved unchanged : our aim being to place in their proper historical setting the numerous philosophical systems of the Middle Ages and to trace their mutual doctrinal relations. The intimate connections of the medieval with the ancient Grecian philosophies are becoming daily more evident: notably the importance of Neo-Platonic influences has been proved by recent works, published since 1905. This affords us a further justification for approaching the history of medieval philosophy by an introductory outline of Grecian philosophy regarded from the special standpoint of the influence of some of its systems and theories on philosophical speculation in the Middle Ages. So, too, it is only in their relations with the latter that we deal with the philosophies of the Renaissance period.

The. second edition of the present work has been pretty widely noticed: while expressing our thanks to those with whom it has found favour, we wish at the same time to state that we have endeavoured to profit as far as we could from the criticisms of all. The various sections have been enlarged by the addition of the main results achieved in monoyraphs and general works published since 1905 .

Notwithstanding the controversies aroused by our general manner of conceiving scholasticism and the philosophy of the Middle Ages, we are still convinced that 
during those centuries there was throughout the schools of the West a body of doctrines common to the majority of the great medieval doctors, and that those common teachings serve to characterize scholastic philosophy;-Dr. Baeumker happily describes them as the "Gemeingut der Scholastik". However, we willingly lessen the possibly undue importance we gave to scholasticism, in this sense, that systems of other inspiration and tendencies obviously call for equal attention from the historian. Feeling this, we have described some of the latter as non-scholastic, rather than anti-scholastic, philosophies. The Thomistic synthesis is, no doubt, developed at considerable length, but it must not be inferred from this-with some of our critics-that we conceive all medieval philosophy as a function of 'Thomism and that the study of 'Thomism is the sum and substance of our work. We have simply given our exposition of the theories common to all the scholastics in close connection with the interpretation they received from the finest and most comprehensive intellect of the thirteenth century. And we have done so simply as a matter of method: it would have been wearisome and superfluous to set down repeatedly the common stock of scholastic theories à propos of each separate writer. And when it came to a question of choosing a typical scholastic, the preëminence of St. Thomas Aquinas rendered the selection of the Angelic Doctor imperative. ${ }^{1}$

In addition to those few general observations, we may direct attention here to some of the more important modifications in the present edition. The relations between philosophy and theology down to the twelfth century have been reconsidered : also the realist and anti-realist systems of that century and the classification of the theological schools. The divisions of philosophy in the thirteenth century have been modified. A new section has been

\footnotetext{
${ }^{1}$ Dr. Baeumker has adopted the same procedure in his recent work: Die Europäische Philosophie des Mittelalters (Die Kultur der Gegenwart, i., 5, 1909).
} 
devoted to the Neo-Platonic current of thought, represented mainly by Witelo and Theoderic of Freiburg. Finally, a considerable number of special questions have been more fully and definitely treated.

As regards bibliography, we have followed the plan of the previous editions. At the end of each article or section will be found a special bibliography on the matters therein treated. These references will supplement the occasional special paragraphs devoted to ancient and modern sources. They everywhere include the works that have appeared since the publication of the second edition of the present work (1905). Of course the reader will understand that the bibliographical portion of the book does not purport to be entirely complete, the author having confined his attention to the works that he deemed to be most worthy of notice. 


\title{
CONTENTS.
}

Author's Preface

\section{HISTORICAL IN'TRODUCTION.}

\author{
GRECIAN AND PATRISTIC PHILOSOPHIES.
}

\section{GRECIAN PHILOSOPHY.}

Chapter I. Pre-Socratic Philosophy

$\S$ I. General View

§ 2. First Group of Pre-Socratic Schools - - - - - - 5

\$3. Second Group of Pre-Socratic Schools - - - - - - - 7

§ 4. The Sophists - - - - - - - - - - 12

Chapter II. Grecian Philosophy from Socrates to Aristotle - - - $\quad$ - 15

$\S \mathrm{I}$. Socrates - - $\quad-\quad-\quad-\quad-\quad-\quad-\quad-\quad-\quad-15$

§ 2. Plato - - - - - - - - - - - - 16

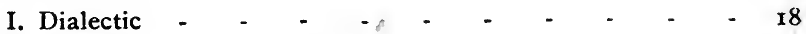

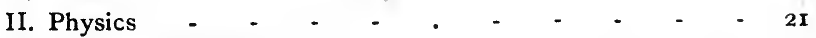

III. Ethics and Esthetics - - - - - - - 25

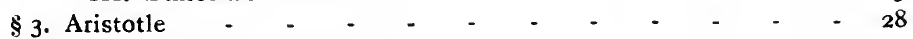

I. Logic - - - - - - - - - - - 3 I

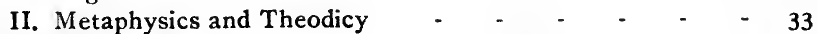

III. Mathematics - $\quad$ - $\quad$ - $\quad$ - $\quad$ - $\quad$ - $\quad$ - $\quad$ - $4 \mathrm{I}$

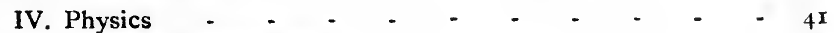

V. Practical Philosophy - - - - - - - -50

VI. Poetics - - - - - - - - - $\quad$ - $5 \mathrm{I}$

Chapter III. Grecian Philosophy from the Death of Aristotle to the Rise of the Neo-Platonic School - - - - - - - 53

§ I. Preliminary Notions - - - - - - - - $\quad 53$

§2. The Philosophical Schools of the Third and Second Centuries B.c. 54

§ 3. Eclecticism - - - - - - - - - - - 63

\$ 4. Scepticism and the Neo-Pyrrhonic School - - - - - 67

Chapter IV. Neo-Platonism and the Systems which led up to it - - - 70

§ I. General Notions - - - - - - - - - - 70

\$2. The Precursors of Neo-Platonism - - - - - - - $\quad 71$

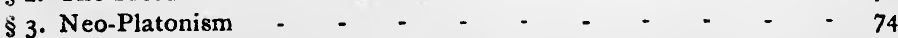


8 I. General View - _ _ _ _ _ _ _ _ $\quad$ - 85

\$2. Patristic Philosophy during the First Three Centuries A.D. - _ - 86

§3. Patristic Philosophy from the Fourth to the Seventh Century. St.

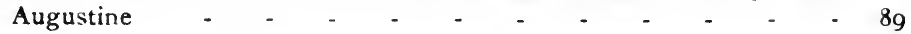

\section{MEDIEVAL PHILOSOPHY.}

INTRODUCTORY CONSIDERATIONS.

\$ I. General Remarks

2. Division of Medieval Philosophy -

3. Ancient and Modern Sources of a General Nature - - II

\section{FIRST PERIOD.}

\section{MEDIEVAL PHILOSOPHY TO THE END OF THE TWELFTH} CENTURY.

First Section: Western Philosophy - - - - - 125

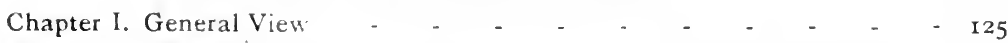

Chapter II. The Philosophy of the Ninth, Tenth and Eleventh Centuries - 149

Art. I. Scholastic Philosophy - - - - - - - $\quad$ - I49

$\S \mathrm{r}$. The Question of the Universals : its Historical Development 149

§ 2. St. Anselm - - - - - - - - - - 162

Art. II. Anti-Scholastic Philosophy. John Scotus Eriugena - - I67

Art. III. Philosophy and Theological Controversies - _ - $~-~ r 73$

Chapter III. Philosophy in the Twelfth Century - _ - _ - - 178

Art. I. Scholasticism - - _ _ - - _ - - - 178

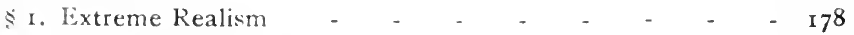

\$2. Anti-Realism - - - - $\quad$ - $\quad$ - $\quad$ - $\quad$ - $\quad$ I 86

\$3. Peter Abelard and Gilbert de la Porrée - _ _ - - 19 I

$\$ 4$. John of Salisbury and Alan of Lille - - _ - - $\quad$ - 198

Art. II. The Theological Novement in the Twelfth Century - - 206

$\$$ I. Schools of Sicholastic Theology - - - - - - 206

\$2. Scholastic Mysticism - - - _ _ - - - 2 I2

Art. III. The Non-Scholastic Philosophies of the Twelfth Century - 2 I9

Second Section: Brzantine Philosophy - - - $\quad 223$

Third Section: Oriental Philosophies - - - - 225

\section{SECOND PERIOD.}

MEDIEVAL PHILOSOPHY IN THE THIRTEENTH CENTURY.

Chapter I. General View - - _ - - - - - - -240

Chapter II. The Philosophical Renaissance of the Thirteenth Century - - 243

$\S$ I. The New Philosophical Revival in the West - - _ - $\quad 243$

$\S 2$. The Rise of the Universities - _ _ - _ _ - $\quad$ - 254

$\$ 3$ The Mendicant Orders - $\quad$ - $\quad$ - $\quad$ - $\quad$ - $\quad$ - $\quad$ - 259 


\section{Chapter III. Scholastic Philosophy}

$-265$

Art. II. The Earlier Scholasticism : Pre-Thomistic Theories - - 269

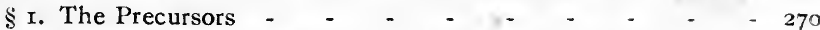

$\S 2$. Earliest Franciscan Schools. Alexander of Hales - - 277

§3. St. Bonaventure - - $\quad$ - $\quad$ - $\quad$ - $\quad$ - $\quad$ - $\quad$ - $\quad 232$

$\S$ 4. The Disciples of St. Bonaventure - - - - - 290

§ 5. The Dominican Masters and the Earlier Scholasticism - 296

Art. III. The Peripateticism of Albertus Magnus and St. Thomas: the

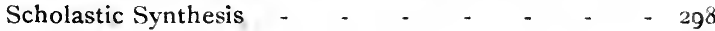

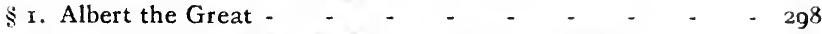

$\S 2$. St. Thomas of Aquin and the Scholastic Synthesis - - 306

I. Propædeutic - - - - - - - - 3rr

II. Logic - $\quad-\quad-\quad-\quad-\quad-\quad-\quad-3 \mathrm{r} 6$

III. Metaphysics and Theodicy - - - - - 3 r 6

IV. General Physics - - - - - - $\quad$ - 329

V. Psychology - - - - - - - - $\quad-332$

VI. Moral Philosophy - - - - - - - $34 \mathrm{r}$

VII. Esthetics - $\quad-\quad-\quad-\quad-\quad-\quad-342$

VIII. Conclusion - - - _ - - - - 343

Art. IV. Conflict between Thomism and the Earlier Scholasticism - $34^{8}$

$\$$ I. Adversaries of Thomism - - - - - - - $\quad-348$

§. Supporters of Thomism - - - - $\quad$ - $\quad-\quad-353$

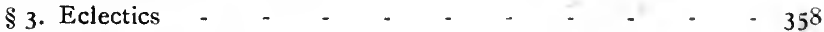

Art. V. John Duns Scotus - - - - - - - - - - $\quad-367$

Chapter IV. Anti-Scholastic Systems of Philosophy - _ - - - $\quad 379$

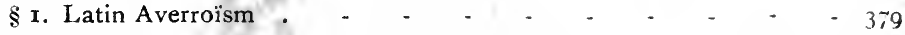

$\S 2$. Other Forms of Anti-Scholastic Philosophy - - - - - - - 388

Chapter V. Some Non-Scholastic Directions in Philosophy - - - - 390

§ I. Experimental Direction. Roger Bacon - . - - - 390

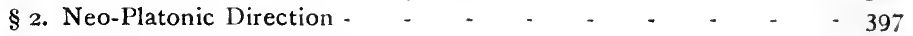

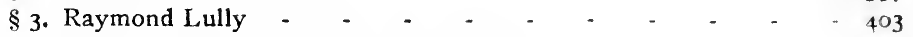

$\S 4$. Certain other Directions in Philosophy - . _ _ _ - tor

\section{THIRD PERIOD.}

\section{MEDIEVAL PHILOSOPHY DURING THE FOURTEENTH AND FIRST HALF OF THE FIFTEENTH CENTURIES.}

Chapter I. General Outline

Chapter II. Scholastic Philosophies

Art. I. General Outline

Art. II. The Terminist School

$\S$ I. General Outline -

Art. III. The Scotist School

$-\quad-\quad-433$

Art. IV. The Thomist School - - - - - - - - $\quad$ - 434

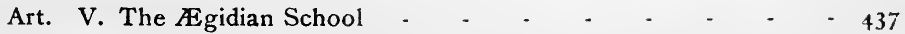

Art. VI. Orthodox Mysticism - - $\quad$ - $\quad$ - $\quad$ - $\quad$ - $\quad$ - $_{43}^{3}$ 
Chapter IIl Anti-Scholastic Philosophies

$\checkmark$ I. Latin Averroïsm

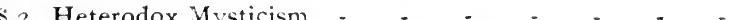

$\$ 2$. Heterodox Mysticism -

\$3. Other Forms of Anti-Scholasticism - - - - - - 445

Chapter IV. Some Non-Sicholastic Lines of Philosophical Thought - - 452

$\$$ I. Infiltrations of Averroism - - - - - - - - 452

\$2. Master Eckhart and German Mysticism - - - - 453

$\$ 3$. Raymond of Sabunde and Theosophy - - - - - - $\quad 455$

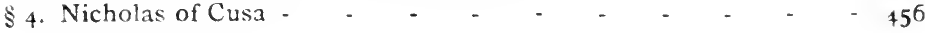

\section{FOUR'TH PERIOD.}

MEDIEVAL, PHLOSOPHY FROM THE MIDDLE OF THE FIFTEENTH TO THE SEVENTEENTH CENTURY.

Chapter I. General Outline

Chapter II. Non-Sicholastic Philosophies

$\$$ 1. Cieneral Notions

\$2. Humanism

§. Platonism

4. Aristotelianism

\$5. Stoicism and Atomism

\&6. Naturalism

\$. The Philosophy of Natural and Social Right _ - - - $\quad 478$

\$8. Protestant Philosophy and Mysticism - - _ - - 479

$\$$ 9. Theism or the Philosophy of Religion - _ _ _ _ _ + + + _

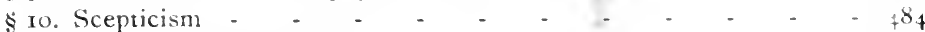

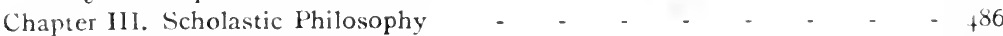

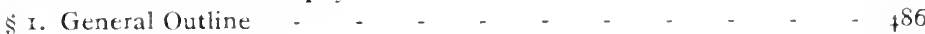

\$2. The Thomist School - _ - _ _ - - - - $\$ 88$

\$3. Spanish Scholasticism - - _ - - - - - - + $+9 \mathrm{I}$

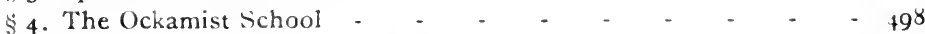

5. The Scotist School - $\quad$ - $\quad$ - $\quad$ - $\quad$ - $\quad-\quad 499$

\$6. Other Scholastic Groups - - - - - - - 500

$\$ 7$. The Misunderstanding between Scholastics and Scientists in the

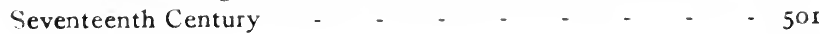

INDEX - - - - - - - - - - - - 507 


\section{HISTORICAL INTRODUCTION.}

\section{GRECIAN AND PATRISTIC PHILOSOPHIES.}

I. Object and Standpoint of Introductory Study.-The Philosophy of any one period bears a genealogical relation both to the past and to the future : every movement in the intellectual world embraces something of those that have preceded it, and prepares the way for those that are to follow. The truth of this law of the continuity of philosophic thought is verified by the study of the Middle Ages. The medieval philosophers appeal to the philosophies of the Ancients and of the Fathers of the Christian Church with a readiness for which they are reproached. Their teaching contains, side by side with original and characteristic elements, borrowed and traditional ones as well. Now it is important for any one who would appreciate the historical obligations of medieval to ancient philosophy, and especially for the student who would estimate with any fair show of exactness the originality of the medieval systems, to keep in view those of the Grecian and Patristic systems which exerted most influence on the philosophy of the Middle Ages.

These considerations, which suggest and justify the object of this introductory study, fix at the same time the view-point from which it ought to be approached. We do not aim at giving a complete exposition of the Grecian and Patristic Philosophies, an account of all the schools, assigning to each the relative importance due to it, but merely a short study of a few systems, notably those which have more directly influenced medieval thought. But in order to avoid any interruption of historical sequence, a passing glance at the connecting-links will outline those parts 
which present a less degree of interest for the student of medieval philosophy.

Our historical introduction to the Philosophy of the Middle Ages will deal successively with (I) the Philosophy of Greece, and (2) the Philosophy of the Fathers of the Church. 


\section{GRECIAN PHILOSOPHY.}

2. Division of Periods. - The Philosophy of Greece, embracing the six centuries before and the six centuries after Christ, forms a closed cycle in the history of human thought. Its beginnings coincide with the dawn, its decline with the wane of a civilization. It furnishes a remarkable illustration of the constant, rhythmic evolution of a movement of thought within the civilization of a single race of people.

Grecian Philosophy may be divided into four periods on the basis of the great fundamental questions which came up successively for discussion :-

First Period: from Thales of Miletus to Socrates (from the seventh to the fifth century B.C.).

Second Period: Socrates, Plato and Aristotle (fifth and fourth centuries B.C.).

Third Period: From the death of Aristotle to the rise of the Neo-Platonic School (from the end of the fourth century B.C. to the third century of the Christian Era).

Fourth Period: The Neo-Platonic School (from the third century A.D., or, including the systems immediately preceding the Neo-Platonic, from the end of the first century B.C., to the close of the Ancient Grecian Philosophy in the sixth century A.D.).

The distinguishing characteristics of each of those four periods will be respectively outlined in the following four chapters. 


\section{CHAPTER I.}

PRE-SOCRATIC PHILOSOPHY.

(From Thales of Miletus to Socrates, seventh to fifth century B.C.)

I. Generai, View.

3. Characteristics and Subdivision. - The earliest Grecian philosophers confined themselves to the study of the external world, the non-ego, not yet reaching the psychological aspect of the problems raised. П€є $i \Phi \dot{v} \sigma \epsilon \omega s$ is the title of a large number of their works: thence comes the name, Nature-Philosophers, sometimes given to them. Their whole concern is to explain by a few simple principles the inner nature and manifest changes of the Universe.

Before the period of Socrates, Grecian Philosophy had no one common centre. According to the places where it flourished, historians usually distinguish four schools, which differ, moreover, in their teachings: (I) The Ionic School, the first representatives of which were natives of Miletus, and which contained both a dynamist and an atomist section ; (2) The Italian or Pythagorean School; (3) The Eleatic School; (4) The School of Abdera or the Atomist School.

By getting at the inner kernel of the various systems we may be able to establish a more logical division. ${ }^{1}$ Two great questions face a philosophy which fixes its attention on external nature: the study of the change or succession of things and the determination of what exactly remains stable throughout this change. Of those two problems it was the second that excited the curiosity of the originators of Grecian Philosophy (seventh and sixth centuries). We find all of them absorbed in a search for the stable, intrinsic principle of things, studying their changes

${ }^{1}$ ZelLER, Die Philosophie der Griechen, i., pp. 147 sqq. 
only to arrive at the fixed element which these changes presuppose. Later on, this twofold study recurred in the inverse order: attention was then mainly concentrated upon the manifest succession of things. Heraclitus it was who thus altered the viewpoint of cosmological studies (fifth century).

Taking into consideration this twofold tendency, the schools mentioned above may be re-divided into two groups without interfering with their chronological order. The first group will comprise the earlier Ionians down to Heraclitus, the Pythagorean School and the Eleatic School; the second group will include the mechanicist section of the Ionic School and the Atomist School. ${ }^{2}$

\section{$\$$ 2. First Group of Pre-Socratic Schools.}

4. The Ancient Ionians. - The philosophers of the earliest schools set out to discover in nature a primordial element to which the manifold and changeable may be traced. As they pursue their investigation they are led to seek the foundation of things first in a principle of the concrete order, then in a mixed element partaking at once of the concrete and of the abstract, and finally in a purely abstract element. These three viewpoints characterize respectively the three schools comprising the first group of Pre-Socratic philosophers: (I) the Ancient Ionian School; (2) the Pythagorean School; (3) the Eleatic School.

Water for Thales of Miletus (about 624-548 P.C.), infinite

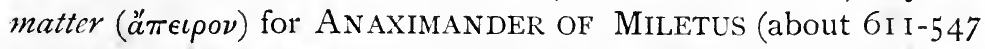
B.C.), air for AnAXimenes of Miletus (588-524), air endorued with intelligence for DIOGENES OF APOLlONIA, were the respective cosmic elements whose fluidity and mobility seemed likely to explain the incessant flux or change of all things.

5. Pythagoras. - Legend is practically our sole informant on the life of Pythagoras of Samos. Neither the date of his birth (c. 580-570 B.C.) nor of his death (end of sixth century) can be exactly fixed, nor that of his emigration into Italy. His numerous voyages, and notably his sojourn in Egypt, are not proven.

The Pythagorean doctrine holds a middle course between the 
teaching of the Ionians and that of the Eleatics. It is at once an explanation of the unity and of the order of the universe. Everything may be reduced to numbers. The regularity manifested in the harmonious movements of the spheres is also found in the phenomena of the terrestrial world and in those of the moral life, so that the manifold relations which exist between beings and their activities may be expressed numerically. But, furthermore, number is not only the principle of order but also the principle of reality. Number is the very substance of things: whether number is to be here understood in a strict, abstract sense, or to be identified with the sense-intuition of the material figure geometrically numbered or measured.

Number is the origin of things. But how? Since the combination of units which constitute a whole number can form odd or even series, Pythagoras held that all number is a mixture of odd and even, or of indeterminate and determinate. The conflict of odd and even explains the presence of opposing properties in one and the same subject $\left(\boldsymbol{c}_{.} g\right.$. , repose and movement, right and left, good and bad, etc.). If these conflicts do not break up the unity of being and the harmony of the universe, it is because the odd and the even are united by a third principle of number, viz., hamony. Every being is a determinate harmony, that is to say, a fixed and definite compound of odd and even. From the combinations of numbers the various elements of the world arise,-by an arbitrary plan of determination.

As for the psychological and moral theories of Pythagoras on the soul, the future state, the union of the soul with the body, etc., they belong rather to the mysteries and religious dogmas of Pythagorism. Aristotle has clearly shown that Pythagorism as a scientific system is confined to Cosmology.

Pythagoras founded a School. And his disciples were not merely philosophers and men of science, but moralists and mystics, initiated into secret rites and ceremonies. Identified with an aristocratic doctrine, the Pythagoreans were, after the death of their master, subjected to violent persecutions. In Italy their schools were broken up; but their doctrines survived in other places, notably in Thebes and Tarentum where PHilolats and KLEINIAS collected together all the old Pythagorean traditions. In the fourth century Pythagorism disappeared as a School.

Pythagorism, moreover, coloured the views of several other 
philosophical speculators who opened their systems to heterogeneous elements. Finally, isolated Pythagorean theories, like that of number, have found their way through the centuries, passing from school to school even down to modern times.

6. The Eleatic School.-Conceive being in the abstract and universal, endowed with the logical attributes of unity, eternity and immobility; then transfer the object of your concept from the logical to the ontological order; and you have the cosmological system of the School of Elea. But, if everything is reduced to one, immovable, eternal being, how explain the multiple, changeable, ephemeral phenomena of nature? These phenomena, say the Eleatics, do not exist: they are illusions of our senses; and we must take heed only of the findings of reason.

This very decisive conception of things appears only with PARMENIDES (born about 544 or 540 ). His predecessor, XENOPHANES ( $576-480$ ), had confined himself to establishing the unity of being, which he identified with God, without, however, denying the coexistence of one unique, substantial substratum for reality, and of a multitude of ephemeral things. In formulating this latter denial, Parmenides gave the Eleatic theory a characteristic attitude and tendency. Everything is: nothing becomes: nothing ceases. Being has neither past nor future; for past and future are not-being, and not-being is irreconcilable with being. All is full: there is no void or emptiness; a vacuum does not exist, for it would introduce a division into being. But being is indivisible, for a thing cannot be separated from itself: it is unchangeable, for it is always equal to itself, one with itself.

Zeno of Elea, the favourite disciple of Parmenides, was the apologist of the School. He defended the Eleatic theory by showing the contradictions into which those are led who follow the evidence of common sense. His arguments against plurality, and especially against the possibility of movement or motion, are famous for all time.

After Melissus, the Eleatic School declined, but the influence of its thought is traceable in Empedocles the Atomist, in the Sophists, and even in Plato and Aristotle.

\section{§ 3. Second Group of Pre-Socratic Schools.}

7. Dynamism and Mechanicism or Atomism, in General.Of the two problems raised by the study of Nature, that of the 
change of things occupies the attention of the representatives of this second group. Here we meet: (I) Ionic Dynamism, or the theories propounded by the new Ionic School after Heraclitus; and (2) the Mechanicist or Atomist theories of (a) Empedocles, (b) of the Atomist School, (c) of Anaxagoras.

Dynamism is opposed to Mechanicism or Atomism. Both systems were, no doubt, contemporaneous with the earliest speculations of Grecian philosophy, but as they regard the processus of things the exposition of their principles belongs rather to this second phase of Pre-Socratic Cosmology.

In its widest sense, physical dynamism embraces these two propositions: (I) the things of nature develop under the influence of one or more internal principles of activity; (2) where these principles are manifold they differ among themselves qualitatively' in the various beings and their phenomena.

The fundamental ideas of atomism can be also reduced to two principles: (I) In the various things of nature there is material mass, and there is motion. The parts of the material mass are qualitatively homogeneous, and their differentiation in size and shape explains the diversity of the various beings and phenomena in the world. This differentiation of parts results from mechanical motion. (2) The motion that animates the various parts of the whole mass of matter is communicated, that is to say, it is not the product of any energy proper to the mass, this latter being inert.

8. The Dynamism of Heraclitus.-HERACLITUS (535-475 B.C.), sprung from a noble family of Ephesus, marks an epoch in the history of Pre-Socratic Philosophy. His system is an original blend of Phenomenism, Dynamism and Pantheism. A contemporary of the Eleatics, he opposed their speculations or rather counteracted them by his own : instead of placing the fundamental essence or being of things in some immutable reality, he identifies it with the mutable as such. According to Parmenides, nothing changes. For Heraclitus everytling changes. The whole world is like a river which is never exactly identical with itself, because new particles of water ever replace those that have passed by. This phenomenism has a cosmological, and not a psychological signification: the phenomenon has an extra-mental reality. This perpetual flow of things is symbolized in the mutable element par excellence,-fire. Not that fire is a substance; it is simply an ever-changing something, for it is nothing apart from its 


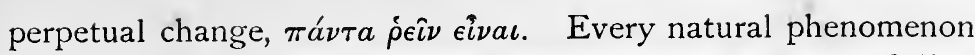
is fire at some stage or other of development, and what we believe to be the stable element in things is merely "a point of intersection where various currents meet and divide".

To explain this incessant "fire evolution" Heraclitus adopts the two fundamental axioms of dynamism and accommodates them to his phenomenism. An internal principle of activity accounts for the perpetual flow of the "fire" phenomena; whatever "becomes" or appears is itself the principle of its appearance and development. Since all change is transition from some definite state to an opposite one, the phenomenon modifies itself at every instant under the influence of the opposing positions of which it is the resultant.

Finally, the dynamism of Heraclitus is a plain assertion of pantheism: the fire-principle is unique, it is God; it is endowed with intelligence and regulates the process of its own evolution.

9. The Atomism of Empedocles.-EMPEDOCLES OF AGRIGENTUM (about 495-435) embodies in his physics the two leading ideas of atomism: (I) The elements of material nature exist eternally, exempt from all change. Differing from earlier philosophers, he regarded as the original material not any one of the four elements but all four together. Mutually irreducible, they decompose each into homogeneous parts which mingle together to form the various beings of the visible universe. What we call the production or formation of a substance is simply a new arrangement of the particles of the four elements $(\mu i \xi \iota s)$; what we term the disappearance or dissolution of a substance is the separation of those same particles to form new alliances ( $\delta \iota a ́ \lambda \lambda a \xi \iota \varsigma$ ). (2) Where does the motion of the mass of matter come from? The answer given by Empedocles is an enigmatic one: love and hatred attract and repel the particles of matter.

10. The Atomism of the School of Abdera. Democritus. LEUCIPPUS is the founder, but DEMOCRITUS (about 460-370) is the accredited representative of the atomist school. He himself tells us that in his early youth he knew Anaxagoras as an old man. Democritus was a man of science as well as a philosopher; he travelled in search of knowledge through Egypt and possibly as far as Babylonia. At Abdera, his birthplace, he knew Leucippus and followed his lectures.

Here are the fundamental principles of the teaching of Demo- 
critus: (I) Matter is composed of an unlimited multitude of tiny corpuscles qualitatively homogeneous but differing in shape and size: these are the atoms (äтона). The atom is of itself inert, eternal, indivisible, solid, continuous; it encloses no vacant space within it, for vacuum is the principle of divisibility (Parmenides). Not merely are the formation and dissolution of bodies explained by the accumulation and separation of atoms, but all phenomena are reduced to more or less transitory atomic structures.

(2) Democritus does not accept the fiction of love and hatred as an explanation of motion; he attributes this phenomenon to the action of weight and the existence of vacuum or empty space. This latter is essential for motion: if all space were full of matter, as Parmenides had taught, the atoms would be all packed together and no change would be possible (6). On the other hand, admit an interatomic vacant space and the atoms are free to move if there be any agency to move them. Weight draws the atoms downwards and thus sets them in motion; and since they are of unequal sizes, the larger, which are also the heavier, strike the smaller ones and impress on them a non-vertical motion: the shocks due to those impulses provoke a constant eddying movement and give rise to the formation of atomic combinations or worlds. Motion being eternal, space being without limits, and the multitude of the atoms being infinite, there are in existence innumerable worlds.

Democritus applies those general principles to the world we live in, and especially to man himself. His psychology is without any special psychological method; it is a mere chapter of his physical atomism. Man's soul, like his body, is an assemblage of atoms of a lighter and subtler order. Sensation and thought are only vibrations of atoms; they are stirred up in us by material emanations from outer objects, emanations which pass through the intervening space and enter our organs: this is the famous theory of the atomic images or species ( $\epsilon i \delta \omega \lambda a)$. These same images are fertile seeds of scepticism, for the medium modifies the material emanations, which are accordingly incapable of giving us a knowledge of things as they are. The philosophy of Democritus is a clear and emphatic assertion of materialistic atomism.

11. The Atomism of Anaxagoras.-Born 500 B.C. at Clazomenae, a contemporary of Leucippus and Empedocles, ANAXA- 
GORAS spent most of his life at Athens, where his great learning secured for him the friendship of many illustrious men. Towards the end of his career, however, owing to political revolutions, he was forced to leave Athens, and settling down at Lampsacus he died there in 428 .

The atomism of Democritus, more scientific in its tendencies than that of Empedocles, had neglected the question of the efficient cause of movement. To Anaxagoras belongs the notable merit of having sought the source of material movement in an immaterial, intelligent being. The moving and guiding agency is intelligence,-mind, endowed with simplicity and the power of knowledge. This is the agency which unites and separates the material particles with set purpose and design. Anaxagoras did not pass beyond the cosmic point of view in studying this intelligence; nor is it likely that he endowed it with the attributes of personality.

Not less remarkable is the difference between his notion of the original matter and the view of his predecessors. He regards it as composed of parts constitutive of all possible substances. But the portions in this primitive mixture are so exceedingly small that none of them can reveal any of its specific properties.

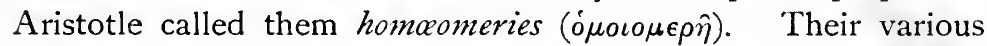
motions give rise to the different material beings of the universe. The specific properties of a body appear when that body is composed principally of particles corresponding to those properties, but it never possesses such particles to the exclusion of the other sorts. "There are parts of all in all things," and hence the possibility of the mutual transformation of bodies generally.

The significance of Anaxagoras in philosophy does not lie so much in his having felt and proclaimed the necessity of an intellectual being in the universe-Anaximenes had already done this-but in having so clearly asserted the irreducibility of the material and the immaterial. His philosophy marks the final stage in the evolution of cosmological speculations in Greece anterior to Socrates. It is wholly physical ; yet, the study of a directive intelligence suggests considerations of a psychological nature. Anaxagoras may be accordingly regarded as closing the period of formation and leading up to the Sophists and Socrates. 


\section{$\$$ 4. THE Sophists.}

12. Protagoras and Gorgias. - The nature-philosophers had fixed their attention on the external world exclusively, paying no heed to the knowing subject,- - to the nature and working of his cognoscitive faculties. A group of controversially minded thinkers seized on this popular physical philosophy for the purpose of proving that it really led to the destruction of all knowledge: they got the name of Sof hists. Their scepticism has in it no independent or absolute value, for it is inspired by the philosophies of Heraclitus and Parmenides. Rather it prepares the way for a fuller and richer dogmatism by convincing Socrates of the need to compare and complete cosmological researches by psychology.

The leading sophists are PROTAGOKAs (born at Abclera, about 480) and Gorgiss (about 4SO-375). Heraclitus had declared that all is change. Protagoras now added: this change itself depends on our subjective state. The external world is a creation of the mind: and since two men may construct their world in contradictory ways, it follows that truth is relative and science impossible.

Gorgias, a contemporary of Protagoras, followed the latter to Athens, where his oratorical gifts won him much celebrity. Starting from the Eleatic doctrines, he ended by asserting the utter bankruptcy of science. The negation of absolute truth as a fixed standard for all should naturally lead to the denial of a uniform moral code. And Protagoras and Gorgias were only logical when they taught that right and wrong depend on each man's own sweet will.

The sophists exposed the weaknesses of the philosophy of their day, but they made no attempt to remedy them. It remained for Socrates to rebuild the tottering fabric of science on safer foundations; his teaching both completes the work of the nature-philosophers and refutes the theories of the sophists. 
CHAPTER II.

GRECIAN PHILOSOPHY FROM SOCRATES TO ARISTOTLE.

(Fifth and fourth century B.C.)

$\S$ I. SOCRATES.

13. Characteristics of Grecian Philosophy during this Period.The genius of the Greeks attained to its full maturity in the fifth and fourth centuries (B.C.). Previously philosophers had studied only the external world, the non-ego. Now and henceforth we find them engrossed in the study of man, his activities, his nature, his destiny. They do not indeed neglect the external world, but they explore it in and through the investigation of man's cognoscitive faculties.

Grecian philosophy remains, as before, dogmatic. Its leading representatives never doubt the veracity of their faculties and the possibility of certain, scientific knowledge.

As in all other philosophical cycles, the golden age of Grecian philosophy is filled rather by personalities than by schools: Socrates, Plato and Aristotle are among the profoundest thinkers the human race has ever produced.

14. Life of Socrates. - The figure of SOCRATES appears surrounded by a halo of moral grandeur. He has left us no writings: for our acquaintance both with his personality and with his teaching we are indebted to his disciples, Plato and Xenophon, who profess an enthusiastic admiration for their master. Born about 470 , Socrates lived through that period of Athenian splendour associated with the glorious name of Pericles. Scarcely anything is known about his life. Absolutely indifferent to that external repute for which the Athenians were so sensitive, he set himself up as a moralist inspired from on high (the Socratic $\Delta a i(\mu \omega \nu)$, as one with a divine mission to teach men the way of righteousness. In the Athenian society of the fifth century, 
whose vices he scourged so relentlessly, belief in the gods was already in ruins; their worship was regarded as a mere official ceremony, devoid of all inner meaning. The unguarded language of Socrates thereon aroused a deep, suspicious discontent. This finally was his undoing: in 399 he was condemned to drink the hemlock.

15. Socratic Dialogue and Method.-(1) The Socratic Dialogue and Irony. Socrates has given its name to an original method of research invented and utilized by him. He taught in the form of a dialogue. In the streets, squares and other public places, he accosted whomsoever he happened to meet and asked their opinion on some philosophical question or other. Usually finding their replies to be inaccurate, he was wont to take them delicately to task, show the inadmissible consequences that followed from their answers, and so gradually lead up the discussion to a more explicit and emphatic assertion of his own opinion: such was the procedure since known by the name of Socratic Irony. It is in keeping with the method of his philosophy.

(2) The Socratic Induction. Socrates' method is based altogether on what is termed Socratic Induction. The cardinal point of all philosophy, nay, of all science whatever, is, he tells us, the forming of general intellectual representations of things. To attain to this, he scrutinizes the concrete experiences of ordinary daily life, and by the aid of numerous comparisons draws out the universal idea that lies hidden away under the various appearances of particular things and events. Simultaneously he establishes the objectivity of human knowledge-against the sophists, whom he consistently and perseveringly opposes. This induction of his is a simple derivation of the general from the particular, a means by which we form for ourselves the notion and definition of a thing. It has not yet the demonstrative character it assumed later on with Aristotle. Socrates himself describes it as the art

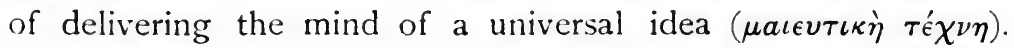
Such is the method, or formal side, of his philosophy. What now is its content?

16. Philosophical Teaching.--Socrates is before all else a teacher of morals. He was convinced that his predecessors had followed a false track in neglecting the phenomena of the moral life. The root principle of Socratic ethics is the reduction of virtue to knowledge: to possess science, that is, universal notions, 
is to act righteously. Knowledge is not alone, as with Plato and Aristotle, the prerequisite condition of all moral conduct; the possession of genuine universal ideas (as opposed to the commonplace and erroneous ideas of the crowd) actually constitutes the morality of our conduct. His meaning is, according to Piat, ${ }^{1}$ that reason should rule supreme over human conduct and that the full and healthy development of the $\nu o v$ s will always secure a righteous will. "Know Thyself" is the first practical precept of conduct, for all reasoning involves growth in self-knowledge, and this knowledge is the first and most potent factor of morality. According to others, ${ }^{2}$ it is the knowledge itself of the good, as a thing known, an object of science, that Socrates identifies with virtue. $\mathrm{He}$, then, would be good and just, who knows what is good and just. But behind this lies the further question: what is the good? It is the universal notion regarded as end or aim of our activity; to do good is to conform our conduct to this universal knowledge. He thus returns to his earlier formula identifying knowledge and virtue, but neither explains nor justifies it. We find him formulating here and there, especially in Xenophon, another concept of goodness at variance with the preceding one: he reduces both the good and the beautiful to the useful-in deference to the popular idea of virtue. And it is on this idea that he bases his defence of the immortality of the soul.

The study of the external world occupies a place of minor importance in the philosophy of Socrates. He could not well neglect it altogether, since man is in constant touch with his external surroundings. But it is only on account of these relations of man to the visible world that he gives it any consideration, and with a view to arriving at this conclusion: that the external universe, by the order which reigns in it, gives manifest evidence of the intervention of a supreme guiding intelligence, which has appointed and destined the whole universe for the well-being of man. As regards the Divinity, he shows little or no anxiety to speculate about the nature of the Divine Being, but very much for the discovery of motives, in the contemplation of the Divinity, to elevate man to a higher and loftier moral plane. 
17. Influence of Socrates. - Socrates made a very profound and lasting impression on philosophic thought. As the first fruit of his teaching, there arose a number of lesser Socratic Schools, which kept only part of his moral legacy, and even continued to draw from the Sophists whom their master had consistently opposed. The Schools of Megara and Elis (fourth and third centuries) formulated an abstract and Eleatic doctrine on the Good; the Cynic school sought the realization of practical virtue; the Cyrenaic school returned to the sensualist ethics of Protagoras. Socrates' greatest influence was felt elsewhere. It came from his dialectic of definition and from his original conception of science. From this conception Plato and Aristotle were destined to elaborate a complete philosophical synthesis.

\section{PLATO.}

18. His Life.-Plato was born at Athens, of an aristocratic family, in 427 . His meeting with Socrates definitely decided his vocation to philosophy. On the death of his master, Plato first went to Megara, then sailed for Egypt, and later for Cyrene. After an eight years' sojourn at Athens, he repaired to Italy (388), where he encountered the disciples of Pythagoras; thence he went to Sicily to the court of Dionysius the Elder. The monarch, offended at the too severe language of the philosopher, gave him over to a Spartan, who sold him as a slave. Set free by a Cyrenean, Plato returned to Athens and founded a school in the gymnasium of the Academy. His teaching was interrupted by a second sojourn at the Sicilian court, after the death of Dionysius the Elder. Plato had hoped to become the tutor of Dionysius the Younger; deceived in this hope, he returned once more to Athens, where he continued to teach till his death in $3+7$.

19. General Characteristics of his Philosophy.-Plato worked on the principles of Socrates but completed the latter's philosophy. The universal idea, the fruit of Socratic induction and the basis of definition, is the keystone of Plato's system. He carried it into regions of research that Socrates had never explored. He made an attempt at philosophical systematization,an attempt that was new and original in conception, and in which he touched on all the fundamental problems that an integral philosophy can deal with. In this constructive effort he utilized the various systems of his predecessors.

The confusion betwecn science and virtue disappears. By a closer study of science, Plato got a juster notion of its true value. However, he was too deeply imbued with the teaching of Socrates not to seek in virtue the necessary complement of science. It remained for Aristotle to establish the independence of each, and to show forth their true relations. 
Among the extrinsic apparatus of Plato's philosophy, we must call attention to the use of dialogue and myth. In the Platonic dialogue each speaker embodies and expresses a theory, and all the conversations converge and lead up to the opinion of the principal character, Socrates, under whose name Plato gives expression to his own views. The use of dialogue in philosophy has disadvantages which Plato himself seems to have felt. Freely used in his earlier works, it appears in his later writings merely as an introduction to an easier style and a more pleasing form of exposition. It is sometimes even dispensed with altogether, as is the case in his Laws. In domains where he lacked data, Plato was fond of falling back upon myth. It is often very difficult to distinguish reasoning from fancy in his writings.

2o. His Conception of Philosophy. Philosophical Propedeutic. -Philosophy is science par excellence $\left(\dot{\epsilon} \pi \iota \sigma \tau \eta^{\prime} \mu \eta\right)$. We reach its heights only by a series of initiations, which are so many successive steps or stages in knowledge :-

(I) The masses seek knowledge in the domain of sense, and virtue in conduct guided by those concrete sense-representations.

(2) But reflection soon convinces one that opinion, based on mere sense-perception, cannot lead to truth. To be guided by sensation, according to the Theaetetus, is to say with Protagoras that man is the measure of truth and falsehood, and, therefore, also of right and wrong: starting with such premisses, the Sophist is logical in his conclusions.

(3) To arrive at true science or philosophy, we must cast overboard the false principle which inspires common life and action, and seek for reality beyond the sense-world and outside it, that is, in the Idea. For opinion is only the shadow of science, just as the sense-world is but a shadow of the Ideal world (Republic, vii.). An irresistible impulse of our nature ('є $\rho \omega s)$ urges us to rise above and beyond perishable things to the only true reality. It is the dialectic method ( $\left.\delta \iota a \lambda \epsilon \kappa \tau \iota \kappa \eta \dot{\eta} \mu \theta^{\prime} \theta o \delta o s\right)$ that leads us to the contemplation of the Idea, by the process of forming and decomposing universal representations. Plato has traced and mapped out the lines of an education corresponding to this ladder of knowledge. Education commences by putting young people into contact with the sense-world by teaching them the arts, especially music and gymnastics. With the study of the natural sciences and of mathematics, they next learn how to 
detach themselves from the sense-world in order to arrive at the contemplation of the only true reality, the Idea. Philosophy is the final stage of education. Socrates, in the Euthydemus, calls it the royal art.

True morality is based upon the knowledge of the Idea. The "Good" is simply the Idea regarded as the term of the irresistible tendency of our being. Firtue is the love of that confused vision of the Absolute which in a former state we were contemplating face to face, and the insatiable clesire to exchange this mortal life for immortality. Thus, philosophy, with l'lato as with Socrates, embraces life in its entirety; it closely unites speculation and action without at the same time confounding them.

21. Division of Plato's Works and Philosophy. - The works of Plato comprise thirty-five dialogues, fifteen letters, and a collection of definitions bearing chiefly on Ethics. As he had no clear conception of an exact division of the various philosophical branches, it is hard to group his works, embracing as they do the most widely different questions. Aristotle distinguishes, in the philosophy of his master, dialectics, ethics, and physics. This classification is not explicitly found in Plato, but it corresponds with his thought. We will therefore adopt it, adding to it a few principles of esthetics. ${ }^{1}$

The Idea is the comer-stone of Plato's philosophy; dialectic studies the Idea in itself; physics, ethics, and esthetics consider its applications to nature, to human conduct and to works of art."

\section{I.-Dialectic.}

22. Existence and Nature of the Ideas.-Dialectic-the word is Plato's-is the science of objective reality, and this latter is called the Idea ( $\left.\epsilon i \delta o s, i \delta \delta^{i} a\right)$. Dialectic is therefore taken in the sense of metaphysics (and not in the more usual meaning,-logic).

1 Strictly speaking, Plato has no system of Formal Logic; this science is one of Aristotle's greatest achievements. Yet we find in Plato some notions on logic. Notably, he has dealt ex professo with the dialectic method, with its twofold process, induction and deduction ( $\sigma \nu \nu \alpha \gamma \omega \gamma \dot{\eta}, \delta / \alpha i \rho \epsilon \sigma \iota s)$. By the dialectic method, we learn how to free ourselves from exterior things, in order to rise to the contemplation of the Idea. Plato's preference is for deduction. His induction is the development of the Socratic induction; it leads up to and ends in definition.

${ }^{2}$ If we take account of the chief topics treated in the most important of his works, we may classify as Physics the Timaens and the Phafd): as Ethics, the Republic, the Law's, the Politics, Philebus and Gorgias: as Dialectic, the Theaetetus, Sophist and Parmenides. 
To establish the existence and the nature of those Ideas, Plato sets out with a fact of consciousness and with a postulate, both of which he takes from Socrates. The fact of consciousness is the presence in us of intellectual representations, whose object is both universal, necessary, and immutable. The postulate is the sincerity or validity of these mental representations, or, in other words, the thesis of dogmatic philosophy, that all or some of our mental representations have an extra-mental objectivity.

What is this reality which is the object of our conceptions? Whatever it be, the sense-world cannot contain it, because everything there is contingent, particular, changing and unstable (here we see the influence of Heraclitus); while real being, as we conceive it, must be endowed with the attributes of necessity, universality, unity, and immutability (here we see the influence of Parmenides and Pythagoras).

Plato infers, accordingly, that the real exists above and beyond the sense-world: the Idea is absolutely stable and exists by itself

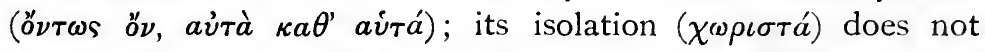
permit of its being considered either as the subjective product of the human understanding or as an operation of the Divine understanding. This latter interpretation of Plato, put forward by the Neo-Platonic philosophers and taken up enthusiastically in the Middle Ages by all those who would fain see in the Platonic dialectic an adumbration of the exemplarism of St. Augustine, conflicts with the most formal declarations of the founder of the Academy,-as indeed Aristotle had already pointed out. This exaggerated Realism which invests real being with the attributes of thought, and proceeds to mould the real world according to the character of our mental representations, is at once the guiding principle and the fundamental error of Plato's metaphysic of Ideas.

23. Multiplicity and Order. The Idea of the Good.-Faithful to this extreme realism, Plato gives a corresponding Idea-entity to each and every one of our abstract representations. Not only natural kinds or species of things, but artificial works; not only substances, but even properties, relations, grammatical forms ; and, to complete the list, even negations and nothingness itself: all have their corresponding ideas in the suprasensible world. ${ }^{1}$

${ }^{1}$ We have it from Aristotle that Plato suppressed, later on, the Ideas of negations, relations, and artificial works. 
The real world being modelled on the world of thought, the Ideas are hierarchically arranged like our representations of them. The Idea of the Good is enthroned at the apex of the ascending scale of essences. Plato lingers with an undeniable sense of complacency and delight in contemplating the Idea of the Good, the archetypal essence, "the sun of the ideal world ". ${ }^{1}$ Its role is an all-important one, for it is: (I) the Final Cause of the Universe: the phenomena of the sense-world and the Ideas tend, all alike, towards the Good; (2) especially the Formal Cause of all things. All Ideas, even the Ideas of the True, the Just, the Beautiful, derive their intelligibility and their reality from the Idea of the Good, and have no being except from the Good. Logically followed out, Plato's realism seems to end necessarily in Monism.

24. God and the Idea of the Good.-Plato's theodicy is intimately connected with his metaphysics. In fact, since there is nothing above the Idea of the Good, which is the sovereign essence, it is important to determine what precisely are its relations to God,- to the personal God, the intelligent Demiurge, the ruler of the lesser gods and of men, the provident director and guide of the world, as Plato describes Him in the Timacus, clothing his thought with all the rich phraseology of his exuberant poetic inspiration. We touch here on one of the most obscure problems in the whole Platonic philosophy.

We must refuse either to make the Idea of the Good subordinate to God (Trendelenburg), or to make God subordinate to the Idea of the Good (Orges), under pain of overthrowing the supremacy of either. To identify the Idea of Good with God (Zeller), would be to admit the identity of the most impersonal of abstractions with the highest incarnation of personality, and to endow the same being with contradictory attributes. It seems preferable to maintain the coexistence of the Idea of the Good and of God (Hermann), the dyarchy of two independent sovereigns, both alike free from the laws of change." This dualism may be rendered a little less unacceptable by determining somewhat more exactly the respective roles of these two concepts-of the Good, and of God. While the Idea of the Good is the final and formal cause of all things, God is regarded chiefly

${ }^{1}$ See especially Republic, book vi.

${ }^{2}$ For the details of this controversy see $Z_{\text {ELLER, }} o p$. cit., II., i., pp. $767 s q q$. 
as the prudent ruler of the visible world. $\mathrm{He}$ is the cause that applies the Idea to the phenomenon, i.e., the efficient subordinate cause. Both being sovereigns of distinct kingdoms, we may call them, on different titles, the principles of things. This is not the only example of unexplained dualism that Platonic philosophy offers us.

\section{II.-Physics.}

25. General Principles. Matter and World-Soul.-Under the title of Physics we may group all the studies relating to the manifestations of the Idea in the visible universe. Before examining the structure of the corporeal world and of man in particular, we must first find out the general relations of the phenomenal world to the world of Ideas. Visible things, the objects of opinion, are a partial and incomplete manifestation of the Ideas: for which latter Plato has jealously guarded the monopoly of reality. What is it that compels the Idea to come down from the "high estate" which it occupies in the absolute world, and to appear under shadowy and contingent forms? Or can it infold itself in ever-varying and perishable things without losing thereby, eo ipso, its unity and immutability? Plato does not concern himself with either of these difficulties; he assumes the fact of a reflection of the Idea in the sense-world; and he exerts all his efforts in explaining it. With a view to this, he appeals to matter and to world-soul.

Matter accounts for all nature's imperfections; these, as such, could not be ascribed by Plato to the Idea. While the Idea is reality, matter is non-being $(\mu \grave{\eta}$ ö $\nu){ }^{1} \quad$ It is not a mass already formed,-as one might be inclined to think from reading the poetical descriptions of the Timaeus-but the indeterminate thing (ă $\pi \epsilon \iota \rho \nu)$, the "shapeless and invisible" element, the necessary condition for the visible materialization of the Idea. This receptacle in whose bosom are evolved all sense phenomena, is empty space, or place devoid of all content. While matter for Aristotle is that from which all sensible things are made, for Plato it is that in which they appear. In this way sensible

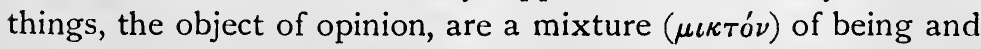
non-being, a projection of the Idea into space. But space is

${ }^{1}$ Historians are not agreed as to the proper interpretation of the term " matter" in Plato's philosophy. 
only a condition for the appearance of the Idea. How is the latter reflected in phenomena? By the agency of the worldsoul, is Plato's answer.

The soul of the world is the connecting-link between the Idea and matter. It is formed by the Demiurge of an alloy of two elements, the immutable and the mutable, which he calls the one

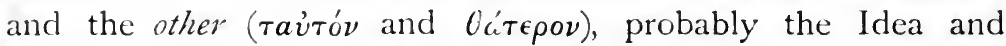
Matter ${ }^{1}$ (and cut through the centre into two parts that overlap each other surrounding the world). At once divisible and incorporeal and harmoniously constituted in geometrical ${ }^{2}$ proportions, it accounts for the beauty of the visible world and for the continuous conservation of its order. Evidently influenced by the constitution of man, Plato makes the world a huge animal ( $\zeta \hat{\omega} \circ \nu)$ composed of a visible body and an invisible soul. The soul sets the colossal machine in motion,-circular motion, ${ }^{3}$ which was considered by all antiquity as the most perfect of all motions. Finally, the soul of the world is endowed with knowledge, and the spherical movement by which it folds back on itself, as it were, and returns to the point from which it started, is at once the symbol and the sensible expression of conscious life.

It is an original and poetical conception, this theory of a world-soul; but it only emphasizes, without explaining, the initial affirmation of Plato's physics. It does not show the channel by which the Idea communicates itself to the phenomenon: the Idea and the phenomenon still stay side by side in an irreconcilable dualism.

26. Structure of the Corporeal World. Mechanicism.-(I) Corporeal substances consist of configurations of simple bodies. In accordance with earlier scientific notions, Plato admits the existence of four elementary bodies, water, air, fire, and earth; all of which, however, he reduces to regular geometrical figures: the regular tetrahedron is the fundamental form of fire, the regular octahedron that of air, the regular icosahedron that of water, the regular cube that of earth. The plane surfaces which form the sides of these four regular solids have, as generating forms, triangles; and these triangles realize the most perfect propor-

${ }^{1}$ V. Stöckl, tr. by Fr. Finlay, S.J., p. 84 .

2 Mathematics holds an intermediate place between vulgar knowledge and philosophical knowledge (20).

"With this conception, Plato connects his system of astronomy. 
tions : the right-angled scalene triangle for fire, air, and water; the right-angled isosceles triangle for earth. ${ }^{1} \quad$ Thus Plato seeks for the reason of the world's beauty in what he regards as the deepest and ultimate elements of its constitution.

It is important to bear in mind that these surfaces are only sections of space and do not form the boundaries of any material mass. Suppress these geometrical forms and you obtain as a residue, not a formless substratum, but the $\mu \grave{\eta}$ oै $\nu$, i.e., void or vacuum: the elements of nature are not irreducible bodies, but irreducible surfaces-a conception that harmonizes with the Platonic notion of matter.

Natural bodies are compounds of simple bodies. The phenomena of substantial change, of increase and decrease, are the outcome of a simple change in the disposition of the primary forms. Since water, air, and fire have the same scalene triangle as their source, a new arrangement of the polyhedric surfaces is all that is needed to bring about an interchange of water, air, and fire among themselves. ${ }^{2}$ The earth, on the contrary, having as base the isosceles triangle, which cannot be reduced to the scalene, may doubtless be mixed with the other elements, but cannot be changed into them, nor vice versâ. In like manner, increase and diminution result from the union and separation of surfaces respectively. ${ }^{3}$ What determines these phenomena of change, of growth and decay? Motion.

(2) Motion is extrinsic to the elementary bodies: it comes from the world-soul. This latter in fact surrounds the whole world of sense (25) and exerts a mechanical pressure on all the bodies within it. As these are of unequal dimensions owing to their different shapes and different degrees of cohesiveness; and as on the other hand their plane surfaces give rise to projecting angles or corners by which they pierce one another in their never-ending motions: these many-sided figures cleave to one another and arrange themselves in ever-varying forms.

1 The equilateral triangle is the basis of the regular tetrahedron, octahedron, and icosahedron; for, it may be resolved into six right-angled scalene triangles (the hypotenuse of each of which is double the smallest side). On the other hand, the square -which is the base of the cube-is resolvable into right-angled isosceles triangles.

${ }^{2}$ For example, the unit of water (an icosahedron, i.e. with twenty sides) can be transformed into two units of air (octahedrons) together with one unit of fire (tetrahedron), $8+8+4=20$.

${ }^{3} Z_{\text {ELLER, }} o p$. cit., II., i., pp. $7^{89} s q q$. 
Thus, we find in Plato the two fundamental theses of Mcchanicism (7). ${ }^{1} \quad$ The originality-and weak point-of his presentation of it is his geometrical conception of the simple body. For, the real bodies in Nature around us are something very different from a mere collection of empty figures: Platonism has no justification to offer for its unwarranted transition from an empty circumscription of space to a positive, circumscribed content."

27. Anthropology.- In no other part of Plato's writings do we encounter a closer or more misleading mixture of myths and facts than in his anthropology. His teaching on man may be said to centre around a theory of intellectual cognition: selfconsciousness and will occupy a very secondary place. And then, finally, his whole ideology is subordinate to, and inspired by, his dialectic of the Ideas.

Since the Ideas are not immanent in the sense-world, the mere consideration of sense phenomena can never give rise to a knowledge of immutable reality. Still, we do in fact possess such knowledge. Whence, then, does it come? Plato answers in this wise: The soul previously enjoyed a term of existence apart from the body, and while in that state it could contemplate the world of Ideas face to face; but it forgot them at the time of its migration or banishment to earth; and now sense-perceptions are required to awaken its memory of them and thus to arouse the soul from its lethargic slumber. Our knowledge, then, is only reminiscence; sense-perception is the occasion of thought, but exerts no real causality in its genesis: here we have the germ of occasionalism.

If the soul's knowledge is obscured and clouded, if sensation is needed to arouse it from its lethargy, this is because the body is an obstacle to the free contemplation of the Idea. Here be-

1 We must, however, make this reserve: elementary bodies of the same kind move, in virtue of an internal tendency (weight), towards a place of their own, the latter differing for each kind.

2 The universe is geocentric and spherical (which conflicts with the angular shape of the polyhedron); it includes the earth and seven concentric spheres surrounding the earth. The stars are beings endowed with life and intelligence, more perfect the nearer they are to the world-soul; the rotation of each around an axis is the index and correlative of its power of conscious self-reflection. Thus Plato descends gradually to the psychology of man and the animal kingdom. So the entire universe becomes a vast collection of living things, each one endowed with a soul of its own,-a fact which does not seem to hinder the whole collection as such from being, itself a perfect $\zeta \hat{\varphi} o \nu$ or living thing. 
low, the soul is in an unnatural state of duress. It is like the sea-god, Glaucus, impossible to recognize under the grimy accretion of sea-shells and creeping things that adhere to his monster body (Republic, x., 6I I). This is why the soul longs to be freed from the burden of its bodily encumbrance.

Though the union of soul and body is considered artificial and extrinsic, Plato is forced to admit the evident mutual intercourse there is between them, and more especially the influence of the merely organic functions on the intellectual and moral life of man. To explain this rather complex interaction Plato has recourse to a division of the soul into two, or even three parts: the intelligent and immortal part, or vov̂s, and the perishable portion. This latter comprises, in turn, the better element, or $\theta v \mu o$ s, embracing all those appetitive and emotional factors that are summed up in the sentiment of personal dignity, and the lower or less noble department of purely organic activities. The intellectual soul has its seat in the brain, the nobler part of the mortal soul in the breast, and its lower element in the abdomen. It is mainly with the first or intelligent soul that Plato's dialogues deal. They aim at establishing its immortality by arguments drawn almost exclusively from metaphysics.

In short, there are in man three souls; and though one of them may conceivably predominate, still their coexistence in one and the same being destroys unity of consciousness and is fatal to personality. And so, Plato's anthropology, like his dialectic and his general physics, leads him in the end to a selfcontradictory dualism.

\section{III.--Ethics and Esthetics.}

28. General Ethics. - Plato does not use the word Ethics, but Politics. As a matter of fact, however, he deals not merely with social but also with domestic and individual morality, and with the principles of general Ethics. As a whole, his ethics, like his anthropology, is dependent on his dialectic.

The end of man consists in the soul's contemplation of pure Ideas in a state of complete separation from the body. The wise man longs for deliverance, and in this life tries to free himself from the fetters of bodily existence by the earnest pursuit of science (Theaetetus and Phaedo). Occasionally (as in the Philebus) 
sense-life is represented as capable of acquiring some degree of moral value, though this as a rule is denied it: the knowledge of the phenomenal world, in which the Idea is dimly shadowed forth, and-even more so-a moderate and well-regulated degree of pleasure, may become supplementary elements of happiness.

For those two practically irreconcilable notions of the supreme good, Plato has two corresponding views on the nature of virtue. It is the disposition of a soul that acts in conformity with its end. Strictly speaking, that soul alone is virtuous which lives on the contemplation of the Idea (according to the first conception of man's end). In this sense, virtue is necessarily the outcome or prolongation of science, and is its own reward (Socrates). But again, later on, a plurality of virtues is admitted, corresponding to the various activities whose harmonious working together gives rise to happiness (according to the second conception of happiness) ; but science always holds the place of honour above all other virtues.

29. Politics. - Plato merely touches, without going into, individual and domestic ethics; on the other hand, he compiles an exhaustive code of politics or public ethics (Republic). He puts the individual above the multitude, though there he runs counter to the politics practised by the Greek states: furthermore, it is the moral formation of the individual that mainly occupies his attention. The powerlessness of the isolated individual to provide for the wants of life (second book of the Republic) and to attain to his moral end, is the primordial fact which accounts for the origin, mission, and organization of the State. Men live in society only in order to promote and safeguard the silent and peaceful intercourse of the soul with eternal realities. The State should be a school of education and instruction for inculcating that true virtue which is the knowledge of the Ideas. This is the mission that should inspire all political and social organization. And to secure all this, Plato commits the government of the State to the philosophers, that is to say, to an oligarchy composed of the most select of all aristocracies-the aristocracy of intellect. The rulers are to be guided not by the will but by the interests of the people. They may be left completely free to stir up revolutions, to rule despotically, to disregard the laws and constitutions, the liberties and even the very lives of the peopie: even so; if only the true philosopher is invested with this absolute 
and unlimited power, it will be impossible for him to act otherwise than wisely. Since the State has also the secondary duty of providing for the material well-being of the people and looking after the national defences, it must maintain, along with the philosophers, a class of agriculturists and a class of soldiers.

It is manifest that esthetical considerations influenced all Plato's politico-social theories: they appear in the analogy he draws between the three social classes in the State and the tripartite division of the soul and of the entire cosmos. The State is at once an enlarged likeness of the individual man and a miniature image of the universe. In virtue of their supreme dominion, and to suppress all cause of discord in the State, the philosopher-rulers can decree public education, State-ownership in children, the suppression of all family life, equality of the sexes, community of women and goods, etc. Plato's State is utopian, reared, as it is, on the narrow and exclusive principles of his dialectic. ${ }^{1}$

30. Art and the Beautiful.-Plato is the world's first great theorist of the beautiful. His esthetics, however, partake of the fragmentary character common to all Greek esthetics. He leaves in obscurity all the subjective problems suggested by the psychological, fascinating element of the beautiful, and discusses by preference the various metaphysical questions regarding the objective elements of beauty. These latter are identified with order and the constituents of order, namely, proportion, symmetry, and harmony. ${ }^{2}$ In fact, arithmetical and geometrical relations are regarded by Plato as the very essence of beauty $(\mathbf{2 5}, \mathbf{2 6})$.

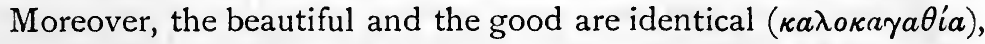
for the former is merely an aspect or manifestation of the latter in the physical, and more especially in the moral, orders.

Art is simply the imitation of visible nature: its value is insignificant in comparison with dialectic. It is the shadow of a

${ }^{1}$ In his later work, the Laws, written in his old age and apparently retouched by the hand of some disciple, Plato outlines another theory of the State, which is incompatible with his earlier and better-known theory. He admits that his philosophical State did not meet the needs of human nature, that it was made for gods and the children of gods. His second State is based, not on philosophical virtue or the science of Ideas, but on common virtue and the knowledge of the world of sense.

2See our Études historiques sur l'Esthétique de S. Thomas d'Aquin, Louvain, 1896, pp. $96 s q q$. 
shadow, since physical nature itself is nothing more than a faint reflex of supra-material reality. It is unworthy of being cultivated for its own sake. Strange words these in the mouth of a poet! The value of art lies solely in its educative and moralizing influence: it falls, accordingly, under State control. The State can veto all art innovations and is bound to see that art does not become an instrument of moral corruption.

31. Conclusion.- In laying down the fundamental principle of his dialectic, Plato shows himself wanting both in moderation and in largeness of view. And since the remainder of his philosophy is of a piece with the dialectic, all alike is marred by a sort of narrow exclusiveness which leads him over and over again to the juxtaposition of extremes that are irreconcilable: to the dualism of God and the Good, of Matter and Idea, of the phenomenal and the Ideal worlds, of body and soul, of common virtue and philosophical virtue, of the individual and the State. Nor are those reconciling or intermediary principles to which Plato has recourse (world-soul, composition of the soul in man, philosophical despotism) equal to the task of removing, diminishing or even successfully concealing the inconsistencies of his system.

Plato's philosophy found a long line of supporters in the earlier and succeeding Academicians: but these are as dwarfs beside the giant figure of Aristotle.

\section{\$. ARISTOTLE.}

32. Life and Works.-ARISTOTLE was born at Stagira (whence the name, Stagirite) in the year $3 S_{4}$ B.C. Coming to Athens, he studied philosophy for twenty years under Plato. From that time he concelved the plan of his own system while continuing to profess a sincere respect for his master's teaching. After the death of the latter, Aristotle went to Atarneus and Mitylene; but the second important event in his life is his sojourn at the Macedonian court, whither he was called in $34^{2}$ to direct the education of Alexander. About the year 335 he opened the peripatetic school in Athens. After the death of Alexander he was obliged to fly the city; he died in Chalcis in the year 322.

His literary activity was prodigious. Apart from apocryphal and less important works we may classify his scientific writings under the following main headings:-

I. Works on Logic, collected later on under the title of the Organon: (I) The

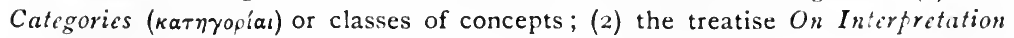
( $\pi$. '́ $\rho$ $u \eta \nu \epsilon$ is) or on judgments and propositions-authenticity sometimes questioned;

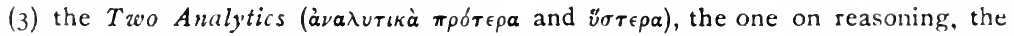
other on demonstration; $(4)$ the Topics ( "dialectical" arguments, and to which he attaches his work on Rhctoric; (5) the

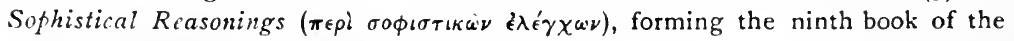
Topics and dealing with sophisms in reasoning. 
II. Works on Natural Philosophy and the natural sciences: (I) The Physics ( $\phi v \sigma \iota k \grave{\eta}$ a $\kappa \rho \delta \alpha \sigma \iota s)$; comprising eight books, of which the seventh is apparently spurious; the Book on the Heavens ( $\pi \in \rho l$ oupavov); the Book on Generation and Cor-

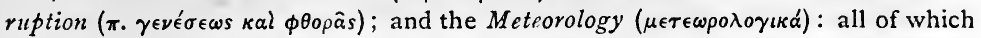
treat of the general principles of the corporeal world. (2) The History of Animals

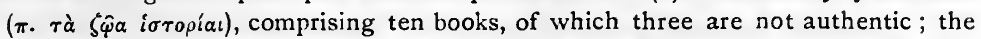

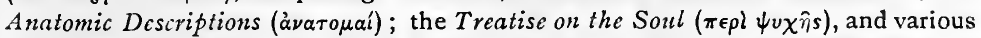
minor treatises called the Parva Naturalia dealing with the soul; the Parts of

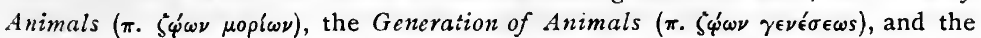
Motion of Animals ( $\pi$. $\zeta \varphi^{\prime} \omega \nu$ nopeías) : all bearing on the study of living things. Of all Aristotle's works, the Treatise on the Sonl is the best written and most methodical.

III. Works on Metaphysics : the Metaphysics ( $\tau \grave{\alpha}, \mu \epsilon \tau \grave{\alpha} \tau \grave{\alpha} \phi v \sigma \iota k \dot{)})$. The word, Metaphysics, probably comes from Andronicus of Rhodes, who placed this portion of Aristotle's work after his writings on physics, $\tau \grave{\alpha}\left(\beta \iota \beta \lambda \iota^{\prime} \alpha\right) \mu \epsilon \tau \grave{\alpha} \tau \grave{\alpha} \phi v \sigma \iota k \alpha$.

IV. Works on Moral Philosophy: (I) the Nicomachean Ethics (’่̀

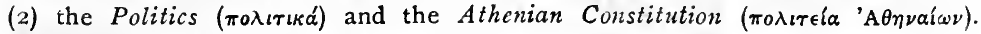
The Greater Ethics and the Eudemian Ethics are probably the work of pupils.

V. Works on Poetry: the Poetics ( $\pi . \pi \circ \imath \eta \tau \iota k \hat{\eta} s)$.

Aristotle's works were edited by Andronicus of Rhodes, towards the middle of the first century B.c. Among modern editions we may mention those of Didot ( 5 vols., Paris, I848-1870), and the Berlin Academy (5 vols., I83I-1870).

On Aristotle, see $Z_{\text {ELler, }} o p$. cit., ii., 2; Boutroux, Etudes d'histoire de philosophie. Aristote (Paris, I9or); PIAT, Aristote (Paris, 1903).

33. General Characteristics of Aristotle's Philosophy.-He allows its full value to speculative science, and does not subordinate it, as Socrates and Plato do, to the practical needs of life. All men, he says on the first page of his Metaphysics, have not only a natural but a disinterested desire for knowledge,-for its own sake.

The poetic imagery and diffuseness of Plato's style gives place to a diction that is concise and solid,- - so condensed, indeed, as to be at times obscure and difficult.

Aristotle respects the opinions of others, and makes it a duty to study them carefully. In fact, he may well be called the first historian of philosophy; for the first book of his Metaphysics gives an exposition of all the philosophical doctrines which were taught from Thales to Plato. If he did not fully develop the historical method, it was because of the conception he had of the object of such history: the history of Philosophy should not be cultivated for its own sake, he held, but only in so far as it contributes to the discovery of the truth.

He elaborates a full and complete system of philosophy, based upon the two-fold method of analysis and synthesis. 
The employment of observation as a method of procedure in philosophy, first introduced by Socrates and applied but timidly by Plato, is here established on a scientific basis. Aristotle is above all an observer of nature. He has all that reverence for fact of which modern science boasts. Astronomy, meteorology, botany, zoology, biology, physiology, politics and political history, literary history and archæology, philology, grammar, rhetoric, poetry: he shows a profound practical knowledge of all these particular sciences,- - profound for his time; and more than one of them owes to his intellect either its first constitution or even its final organization. He aims at possessing all the elements of knowledge, because he wishes to explain nature in its entirety.

And, in fact, after having collected those mighty stores of materials, which make him the first scholar of antiquity, Aristotle constructed a vast general synthesis which justifies us in regarding him as the prince of ancient philosophy. Everything that is, is the object of philosophy, or of science in the higher sense which he gives this word $(\mathbf{3 4}, \mathbf{3 5})$; and, accordingly, his encyclopedic researches are all systematized under a higher threefold unifying principle which will serve as a basis for the division of speculative philosophy.

Aristotle is a scientist and a philosopher of the highest order. In him we find united the two temperaments whose combination means genius. With the exception of certain weak points, we may say that everything is of a piece in his vast synthesis. While Plato is full of contradictions, rigorous order and logical unity dominate the work of Aristotle. He not only surpasses his master by all that distance which separates a solid philosophy of reality from a dreamy philosophy of abstraction; he even takes his place above and beyond all classifications of age or race, in the ranks of those great thinkers who are the glory of humanity. And, besides, the whole course of subsequent history has borne witness to his genius, for no one has exercised an influence equal to his on the progress of human thought.

34. Division of Philosophy.-Philosophy, or science par excellence, is the investigation of the principles and causes of things (Metaph., I., i., 98I); or again: it is the study of that which is necessary in things: in fact, there is no science except about the universal. Aristotle has indicated various ways of dividing philosophy. The best known is his classification of the philosophical 


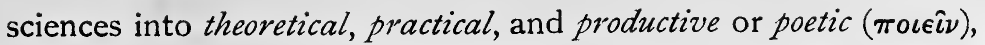
according as the term or object of our knowledge is pure speculative information, or conduct $(\pi \rho \hat{a} \xi \iota s)$, or the production ( $\pi \circ \circ i \eta \iota \varsigma)$ of some exterior work.

Theoretical philosophy is subdivided so as to include :-

(I) Physics, or the study of corporeal things, subject to change

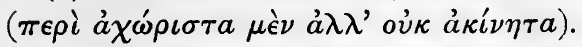

(2) Mathematics, or the study of extension, that is, of a corporeal property not subject to change, and considered, by abstraction,

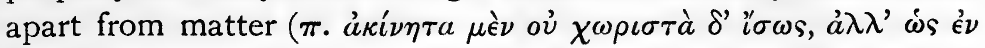
vै $\lambda \eta$ ).

(3) Metaphysics, called Theology or First Philosophy, or the study of being in its incorporeal (by abstraction or by nature) and

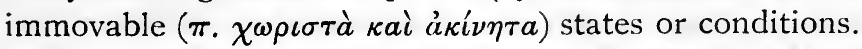

Practical Philosophy includes ethics, economics, and politics, the second often going with the third.

It is difficult to insert the treatises of the Stagirite himself in this classification, on account of the disordered condition in which many of them have come down to us. Besides, it leaves no room for Logic, the vestibule of philosophy, and the object of Aristotle's deepest study. We will follow the division as outlined, adding logic as a preliminary, and we will examine successively: (I) Logic; (2) Theoretical philosophy: (a) Metaphysics; and Theodicy, its complement; (b) Mathematics; (c) Physics, general and special; (3) Practical philosophy: (a) Ethics; (b) Politics; (4) Poetics.

\section{I.-Logic.}

35. Notion of Logic.-Aristotle is the creator of logic or the "analytic" of the mind. Going beyond Socrates and Plato who had investigated only the formation of general concepts, Aristotle made out a whole system of laws which the human mind must follow in order to acquire scientific knowledge. His point of view was chiefly methodological, and although in the constitution of his system logic is closely connected with psychology and metaphysics, it is treated primarily as an instrument of knowledge; it determines the form of science, abstracting altogether from its content. What is the meaning of knowing scientifically? It is to ascertain what a thing is, its essence; to get at the causes of its reality. Scientific demonstration, and the syllogism which is its 
basis, enable us to discover the essences of things and their causes. That is why these processes form the main topic of Aristotle's logic, and the subject-matter of his principal logical treatise, the Analytics. But both these processes of the mind presuppose a study of the elementary operations into which they resolve themselves: conception and judgment.

36. Concept and Judgment. - The concept represents things under their abstract and general determinations, some proper to a single species of things, others common to different species of one and the same genus. Logic treats of the concept in so far as it becomes the element of the judgment. Thus, when Aristotle introduces into his logic the classification of beings into Categories, he takes the latter not for classes of things as they exist outside us (4o), but for classes of objective concepts, in so far as these can become the predicate or the subject of a judgment. The Postpradicamenta are an addition made by the Aristotelian school.

The judgment or enunciation (anó $\phi a \nu \sigma \iota s)$ results from the union of two concepts, one of which (the predicate) is affirmed (or denied) of the other (the subject). The Perihermeneias

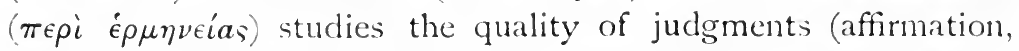
negation), their quantity (universality, particularity), their modality (necessity, possibility, contingency).

37. Syllogistic Reasoning.-It is principally the syllogism that engages Aristotle's attention (Prior Analytics). He was the first to describe this process by which the human mind, not perceiving immediately the relation between two concepts, the terms of a judgment, compares them successively with a middle term. The syllogism is a form of reasoning in which certain things being supposed (the premisses), something else necessarily follows (the conclusion). To join ideas one with another by deducing the particular from the general, to co-ordinate and subordinate our mental notions according to their degree of universality: such is the mental process which leads us to science. The syllogism makes it clear to us that the predicate of the conclusion is contained in or excluded from the comprehension of a third idea, which includes in its extension the subject of the conclusion. The rules of the syllogism, its figures and moods are laid down with such wonderful exactness and precision that posterity has had little or no occasion to improve on the lessons of the Stagi- 
rite. Induction, opposed to the syllogism, is a process which goes from the particular, i.e., from the observation of facts, to the general, i.e., to the abstraction of the essence or type realized in the particular cases. It may be said that Aristotle laid down the principles of scientific induction.

38. Demonstration. Probable and Sophistical Reasonings. Syllogistic reasoning is the basis of demonstration $(\dot{a} \pi \dot{\delta} \delta \epsilon \iota \xi \iota \varsigma)$ with which Aristotle deals in the Posterior Analytics. $\mathrm{He}$ calls demonstration " the syllogism which produces science". Demonstration must stop at some indemonstrable first principles which the mind enunciates on account of their immediate evidence as soon as it abstracts them from the data of sense. Aristotle also

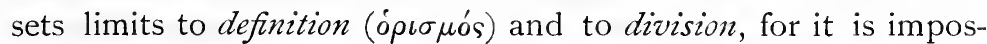
sible to define everything and to divide things ad infinitum.

Demonstration, which begets certitude, is opposed to probable reasoning and to erroneous reasoning. Aristotle devotes a separate treatise to this latter (the Sophistical Reasonings). To probable arguments he attaches, in the Topics, the theory of the тómo or de locis dialecticis, as also the study of the aporiae (ámopía $\iota$ ), i.e., the statement of the reasons for and against, prior to the finding of the middle term of the syllogism. ${ }^{1}$

\section{II.-Metaphysics and Theodicy.}

39. Concept of Metaphysics. - Speculative philosophy aims at attaining to a knowledge of everything that is, by a contemplation of things in their successive and ascending degrees of abstractness: the physical, the mathematical, and the metaphysical.

While the special sciences cover each only a portion of reality, metaphysics treats of everything that is; and the intelligible aspect under which it grasps all things is the widest possible, namely, that of being. It is the science of being considered as

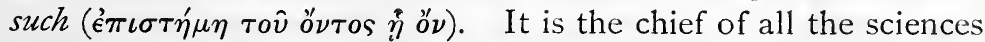
in virtue of its generality, and also because it furnishes all the other sciences with their principles.

From the way in which he raises the problems of Metaphysics it is easy to recognize from what parent stock the genius of Aristotle springs. Is reality, he asks himself, corporeal or incorporeal? Can the permanent be reconciled with the changeable,

1 "Rhetoric is the application of dialectics to government or politics, i.e., to certain practical ends."-Boutroux, op. cit., p. 184 . 
the one with the manifold? The Greek mind stands revealed with the utmost clearness in such formula as these. Aristotle crushes the systems of his predecessors with unanswerable objections: the universal flux of Heraclitus, the immobilism of Parmenides, the number theory of Pythagoras, the separated Ideas of Plato. Scepticism also suffers at his hands a refutation so thorough that it well deserves to be regarded as a masterpiece (Metaph., iv., I). But we must also add,- - to the great honour of the Stagirite,- - that he knew how to separate truth from falsehood in the doctrines of his predecessors. His fresh and penetrating grasp of reality enabled him to complete the theories of some of them by those of others: In real being there is something stable (Parmenides), and something changing (Heraclitus); and Plato's "Real" is now seen to dwell in an immanent manner in the individual objects of sense.

40. Being and the Ten Categories. -Individual things alone having reality $(\mathbf{4 3})$; the being which metaphysics studies by seizing on its general determinations, is simply the substance of the individual things ( $\tau o ́ \delta \epsilon \tau$ ) presented to us in our sense-experience. There is in every being a primordial, constitutive element or basis, able to subsist by itself, and which serves as a subject of inherence for all adventitious realities. Hence the first classification of beings into two categories, substance (ovं $\boldsymbol{i}^{\prime} a$ ) and accident $\left(\sigma v \mu \beta \in \beta \eta \kappa \sigma^{\prime}\right)$. Socrates is a substance; his virtue is an accident. The accident is next divided into nine categories; quality, quantity, relation, place, time, posture ( $\kappa \epsilon \hat{\imath} \sigma \theta a \iota)$, habit $\left({ }^{\prime} \chi \epsilon(\nu)\right.$ which is the possession resulting from change, action

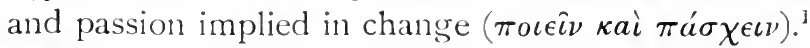

But to understand fully the scope of peripatetic metaphysics we must set this division, which is a statical one, over against another, which is a dynamic classification based on the change or flux of being: for the being which we know best and most fully is subject to change. Besides, each of the ten categories of being can be considered as in a state of change; it may be actual or potential.

41. Potency and Act.-All change implies passing from one state to another. Consider a being $\mathrm{B}$ passing from the state $a$

\footnotetext{
${ }^{1}$ Piat, op. cit., pp. 15 and 16 . Historians are not agreed upon the sense of the last Categories, nor as to whether the nine accidents were reduced by Aristotle to one category, " accident".
} 
to the state $b$. If we analyse this change we see it demands that $\mathrm{B}$ already possess in $a$ the real principle of its change to $b:$ before being $b$ it was capable of becoming $b$ : it was really susceptible of a new determination: it was in the state of potency to be what it now is actually. Act is, therefore, the present sum of perfection

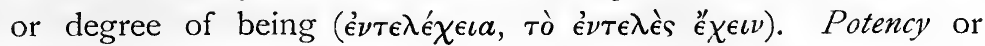
potentiality, is the aptitude to receive perfection ( $\left.\delta v^{\prime} \nu \mu \mu \iota\right)$ : it is imperfection and non-being if you will; but it is not mere nothingness, because this non-being is endowed with the germ of future actualization. This actualization or passage from a potential to an actual state is called motion or movement, and is defined by Aristotle: "the act of a being in potency, in so far as

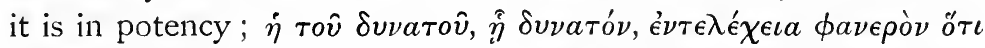

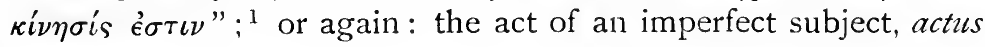
imperfecti.

Three great theses of peripatetic metaphysics are, as it were, the offspring of this distinction between potency and act: the relation of parentage can be traced in the theory of composition from matter and form; in the composition of universal and individual; and finally in the theory of the four causes, - a theory which is the fruit of an analysis of motion.

42. Matter and Form.-Although it belongs primarily to physics $(\mathbf{5 0}, \mathbf{2})$, the theory of matter and form assumes a metaphysical meaning, in so far as it is an explanation of motion or change in general. In the essence of all being that is subject to change, we must find: (I) a potential principle, indeterminate as such, which becomes actual by the process of change; or, in other words, a fixed substratum which successively receives contrary determinations; this is matter $;^{2}$ (2) a principle which determines this amorphous substratum, and which is of a special kind for each actuation of the matter; this is the form.

The theory is, of course, primarily and properly applicable to corporeal, terrestrial substances; but Aristotle extends the concept of matter and form even to mathematical entities, and to the heavenly bodies. Not only does he make it co-extensive with the notion of change; he generalizes the notions connoted

${ }^{1}$ Physics, iii., $201 \mathrm{~b}$.

${ }^{2}$ On this twofold conception of the matter in Aristotle, $c f$. CL. Baeumker, Das Problem der Materie in der Griechischen Philosophie (Münster, Igoo), pp. 213 sqq., and p. 257. 
by matter and form so far as to apply them to everything that is determinable on the one hand or determining on the other; e.g., to the genus as compared with the species, to body as compared with soul, to the passive intellect as opposed to the active, to the premisses in relation to the conclusion. The theory of matter and form becomes, in fact, convertible with the theory of

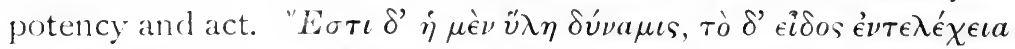
(De Anima, ii., I). Matter is potency or potentiality; form is act. Let us see what is their nature and what sort is the bond which unites them.

As a constitutive principle of being, form gives the composite entity its specific determinateness; it makes the thing to be what

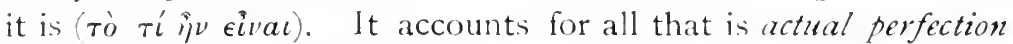
in a being, its organiaation, its unity; in the composite being it is above all the frinciple of the operations of that being, and as these all tend towards an end $(\mathbf{4 4}, \mathbf{4})$, it is consequently the seat of the impulse directing the activities of the being. It alone being kinorable, it is the sole object of definition.

The matter fulfils various functions. Undetermined itself, it is unknowable in itself. and we know it only by analogy. It is because the indeterminate cannot exist that the indefinite

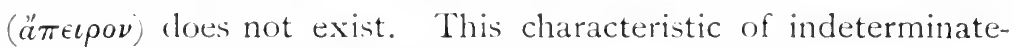
ness or of absolute potentiality is the object of one single, homogeneous concept of matter; but there are, in fact, as many different matters as there are beings. While the form is the principle of unity and the seat of impulse towards an end, matter is subject to multiplication and division $(\mathbf{4 3})$; it is connected with what is fortuitous and teratological ; it is, in general, the principle of limitation, of imperfection and of evil. Notion being eternal (4, 3), matter must be likewise eternal. "Generation could not have had a beginning nor can it have an end; because the reason why there is generation is ever identical with itself, and is of abiding efficacy." " Individuals pass away, but the species has always been and will remain for ever.

In the physical order, matter and form are real elements of being ; matter is not, then, the $\mu \grave{\eta}$ oै $\nu$ of Plato. Form and matter constitute but one reality owing to their very close union. Form is immanent in matter against flato) and can no more free itself from matter "than the roundness can from a ring".? Similarly,

$$
{ }^{1} \text { PIAT, of. cit., p. } 28 . \quad 2 \text { Ibid., p. } 29 .
$$


matter cannot exist without form : the concept of matter existing as such, is that of a being, determined, yet undetermined, which is self-contradictory.

Outside the physical order, in whatever domain they are employed, the two notions of matter and form are bound together by the same close correlation.

43. The Common Essence and the Individualized Essence.The individual being, which is the only real substance, is alone capable of existing as such ; the universal is not a thing in itself; but it is immanent in the individuals, reproduced in all the representatives of a class; it gets its independence, its isolation from individuals, only by means of the subjective consideration of it by our minds $(\mathbf{5 3}, 3)$; such is the solution of the problem of the universals. This teaching, which supplements the metaphysics of Heraclitus by that of Parmenides, is the very antithesis of Platonism, and we must recognize in it one of the highest achievements of the peripatetic philosophy.

Besides the common essential notes or attributes which we find repeated in all the individuals of the same species, each individual being possesses its own proper characteristics: these affect it in its essence, and give it the stamp of individuality. Between the common essence and the individualized essence there is a relation of determinable to determinant, of potency to act; thus an organic bond is seen to unite the two main theories of the peripatetic school.

The Principle of Individuation, in the things of Nature, is not the form : this of itself tends to realize the fulness of its act, and would exhaust its formative causality were it not prevented by the matter. It is the matter that individualizes the being, for it is at once quantified and limited (42); and besides, it fixes, for each being, the share of determinable reality demanded by the determinative power of the form.

44. The Doctrine of Causes. - The theory of causes is closely connected with that of motion; for the term "cause" is applied to whatever exercises any real and positive influence on the actuality of a being at any stage whatever of its development. Aristotle distinguishes four causes, the material, the formal, the efficient, and the final.

(I and 2) Material and Formal Causes.-Primal or primary matter and substantial form, which are the constitutive elements 
of being, are also, under another aspect, its causes; for their union gives rise to the substantial compound. Material and formal causes are of the accidental order when they constitute a mode of being of something already supposed to be complete substantially.

(3) Efficient or Moving Cause.--A substantial compound, or any one of its stages, is realized by its passing from power to act.

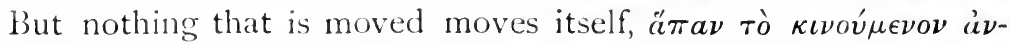

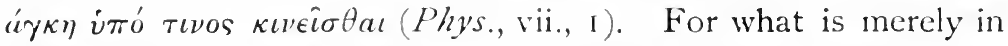
potentiality does not, as such, contain the sufficient reason of its own actualization. Therefore the transition from power to act, or from matter containing a form potentially to matter actually determined by that form, demands the influence of a moving cause, which latter could not influence or move the former unless it were itself in act. By reason of its continuous influence $(\theta i \xi \iota s)$, this cause is the principle of all evolution in matter: the efficient cause, or more properly speaking, the motive cause (to $\delta$ '

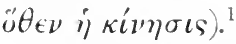

Aristotle, therefore, confines efficiency to the production of movements or changes, and these follow a real, internal virtuality or tendency of the matter to unite with the form that corresponds to the natural exigency of the compound. But the chain of changes has never had a beginning and can never have an end: motion is eternal. So also is matter, the substrate of all change: matter is simply there, though never produced, nor does Aristotle account for its existence."

(4) Final Cause. - The co-ordination of activities in the things of Nature, and the stability of the universal order to the realization of which every single thing in the cosmos contributes something, are indications that the substantial forms of things are endowed with an intrinsic tendency towards some end which draws out their latent energies (final cause). This notion of purpose, design, finality, is of fundamental importance in Aristotle's metaphysics. It justifies and explains for him the regular

${ }^{1}$ In modern scientific language a motor or moving cause denotes merely a cause productive of local movement. We use the term here in the wider sense of Aristotle, as the cause of any change whatever.

'In certain passages Aristotle places the reality, the finality and all the intrinsic activities of the being in its form; and in the ambiguous language he uses, some historians, notably $Z_{\text {ELLER }}(o p$. cit., ii., 2, p. 328), wrongly think they see traces of a confusion of the three causes,-formal, final, and efficient or motor cause. 
recurrence of natural phenomena and the fixity of natural kinds in the domain of physics, the innate tendency of the mind towards truth in criteriology, the inclination of the will towards the good in ethics.

45. The Being that is Pure Act. Proofs of its Existence.Above all changing things, which are mixtures of act and potency, there reigns supreme one immovable Being, which is Pure

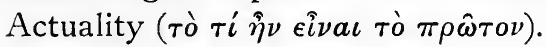

The principal proof of the existence of God is based on the existence of change (motus). Movement, though eternal, is unintelligible without a Prime Mover, itself immovable. For, as nothing can pass, of itself, from potency to act $(\mathbf{4 4}, 3)$, all movement or change necessarily supposes a mover; and unless we grant some one prime mover, itself entirely beyond and free from the influence of all change whatsoever, we are forced to admit - for the explanation of actual change-that there exists an infinite series of moving causes: which is absurd. Aristotle adds to this a second proof, based on the order, harmony and unity of the world,- known afterwards in philosophy as the teleological proof.

46. Nature of God.-The Deity may be considered in Himself and in His relations to the universe.

The attributes of God considered in Himself, are all referred to two fundamental notions, immobility and thought.

Immobility. - The Prime Mover is absolutely and eternally quiescent. Eternal like movement itself ( $\left.\sigma v \nu \epsilon \chi \eta^{\prime} s\right), \mathrm{He}$ is pure actuality or form, for any admixture of potency or of matter would involve change in His being. Hence $\mathrm{He}$ is indivisible. all division involving transition from potency to act; and incorporeal, all corporeal things being composed of matter and form.

Thought.-Since the Purely Actual Being involves all that is most perfect, $\mathrm{He}$ must needs be intelligent. By virtue of $\mathrm{His}$ own substantial, undivided and indivisible thought, He comprehends His own eternal actuality. $\mathrm{He}$ is thought of thought ( $\nu \operatorname{l}^{\prime} \sigma \iota \varsigma \nu \eta^{\prime} \sigma \epsilon \omega \varsigma$ ). His conscious self-contemplation is His end, and $\mathrm{His}$ happiness is perfect. $\mathrm{He}$ is unaware of this world of changing things, for $\mathrm{He}$ could not know the latter without changing along with them.

God is the cause of all worldly change. How, or on what title? 
Inasmuch as He gives the initial impulse to cosmic movement, the Prime Mover ought to be described as a motor cause. And indeed Aristotle would seem to place the prime mover in contact with the world (I) Gen. et Corr., i., 6, 323); but contact is the necessary condition for motor causality $(\mathbf{4 4}, 3)$. Furthermore, the motion imparted by God to the world is circular motion, that is to say, perfect and eternal motion $(\mathbf{5} \mathbf{I}, \mathbf{I})$. The point of contact is the periphery or the world's outer sphere (Phys., viii., IO). But does not contact between the corporeal world and its mover imply that the latter is located in space? And is the reaction of the thing moved upon the mover, reconcilable with the immutability of God? 'To avoid these difficulties Aristotle explains the influence of God upon the world as exerted not by way of mechanical impulse but by way of the attraction exercised by a final cause.

God is the final cause of the world, the good towards which all things tend; and it is this natural tendency of matter towards a higher and better state that sets up the eternal series of evolutions in earthly things. ${ }^{1}$

Everything moves, because ererything tends towards God. But as the final cause attracts by love, the inclination originated in the creature by God in no way touches or changes God Hinself. Final causality does not interfere with the Divine intangibility, whereas motor causality in the strict sense would seriously compromise it. This eternal, irresistible attraction of all things towards the perfect and immutable actual being, leads to an optimistic conception of the cosmos and excludes the idea of evolution or progress from the good to the better.

47. Lacunz in Aristotle's Theodicy. - The theodicy of Aristotle is a bold and powerful presentation of theism; but it reveals, on some fundamental questions, lacunxe afterwards filled in by the genius of scholasticism. It is darkened by a persistent doubt about the personality of the Divinity; the notion of the Divine personality is necessarily vitiated by the supposition that willactivity is incompatible with the immutability of a purely actual

1 "On this Thought which thinks Itself, depends the world, as a thought which does not think itself but tends to do so. . . . God moves the world as final cause without moving Himself. . . This theology is a sort of abstract monotheism. All the things and facts of nature are referred to natural causes. It is only nature taken as a whole that is made to depend on the divinity."-Boutroux, Etudes d'histoire de philosophie. Aristote, pp. 149 and 140. 
being. Then, too, the relations between God and the world are by no means happily handled: God does not know the world; hence $\mathrm{He}$ cannot be its providence. Efficient or motor activity in the strict sense is regarded as incompatible with the Divine nature. On the other hand, the final causality of the prime mover is not easy to grasp, and it lands its author into a theory of Nature (5o) at variance with some of his metaphysical teaching. Finally the existence itself of any beings outside God remains an enigma.

\section{III.-Mathematics.}

48. Object of Mathematics.-While metaphysics deals with what is immaterial either by abstraction or of its nature, mathematics deals with extension in the abstract, and with the relations this gives rise to. It passes over all corporeal attributes in so far as these are subject to change, and deals with aspects that are in a sense immovable, aspects isolated by mental abstraction from the corporeal substance whose permanent and inseparable attributes they are. Besides pure mathematics-arithmetic and geometry-Aristotle also mentions applications of mathematics to the practical arts, such as surveying, and to the natural sciences, optics, mechanics, harmonics, astrology. His mathematical works are lost. ${ }^{1}$

Descending another step in the scale of abstraction, we find ourselves in the domain of physics.

\section{IV.-Physics.}

49. Object of Physics. - In the wide sense in which the word is used by Aristotle, Physics embraces the study of all corporeal beings in so far as they are subject to change. After referring to the general principles bearing on corporeal being (general physics) we shall examine in detail the various classes of corporeal beings (special physics): the heavenly bodies; terrestrial bodies; and among these latter, man. Psychology is, according to Aristotle's classification, a section of physics.

50. General Principles.-Nature and kinds of corporeal motion. Metaphysics studies motion in general; physics is concerned with corporeal motion and its kinds. These are four in number; ap- 
pearance and disappearance of substantial compounds ( $\gamma \in \dot{\nu} \nu \sigma \iota s$ and $\phi \theta o \rho a ́)$, qualitative change or alteration ( $\left.\dot{a} \lambda \lambda \operatorname{li}^{\prime} \omega \sigma \iota \varsigma\right)$, the quantitative change of growth and decay ( $a$ $\xi^{\prime} \eta \sigma \iota s$ and $\left.\phi \theta i \sigma \iota s\right)$, and finally' local motion (申opá) - the motion par excellence, which the three former sorts presuppose. To the concept of local motion Aristotle attaches the study of the infinite, of time and of space.

The theory of matter and form belongs properly and primarily to physics, for it is the peripatetic interpretation of the evolution of the cosmos and of the incessant change that goes on in the world of sense. In opposition to the atomism of Democritus, which accounts for the visible diversities in corporeal things by different arrangements of the same identical elements, Aristotle contends that the facts of nature proclaim the existence of specific differences in corporeal things themselves and in their properties. Earthly substances are being continually transformed into one another; they combine with one another to form compounds specifically distinct from the components, and those compounds are themselves in turn resolved into their constituent elements. We must needs therefore recognise in corporeal substances a permanent substratum, primal or primary matter (i) $\pi \rho \dot{\omega} \tau \eta \ddot{v} \lambda \eta$ ) identical throughout all stages of the process, and another principle peculiar to each one of these stages, the substantial form ( $\epsilon i \delta o s)$. The substantial form is so called because it is the first in order of all corporeal determining principles or influences, the one which fixes the substantiality and determines the kind or species of the thing; while the primal matter is the absolutely indeterminate substrate, incapable even of existing without the initial determination of the form. The succession of different forms in the same matter furnishes an explanation of the fundamental theory which Aristotle opposed to Plato,- the theory of a real evolution taking place within the very entrails of corporeal things themselves. An actually constituted, existing corporeal substance is regarded as second or secondary' matter with respect to the ulterior modifications or accidental forms it may receive.

The material world is therefore plunged in a whirlpool of incessant change, as Heraclitus had already proclaimed, and yet none the less must we recognise, with Parmenides, a certain stability in its elements. To get an accurate insight into the mind of Aristotle regarding the process of cosmic change we must take careful cognisance of a twofold influence affecting the 
elements of the substantial compound,-the rhythmic evolution of forms and the prevalence of purpose or finality.

Rhythmic Evolution of Forms.-The theory is not fully and explicitly developed by Aristotle, but he has certainly the germs of a doctrine that was elaborately evolved and illustrated in the Middle Ages. In various passages in the Physics and Metaphysics Aristotle refers to a third principle, in explanation of the genetic process of nature,一privation $(\sigma \tau \hat{\epsilon} \rho \eta \sigma \iota \varsigma)$. By this he means the absence of a form demanded by the matter. This peculiar exigency on the part of the matter springs from a special tendency it has to divest itself, so to speak, of one form in order to assume another, when, under the influence of the surrounding natural agencies, the compound is in process of transformation. This gradual transition from form to form is regulated by the principle of the rhythmic evolution of substances. "You cannot make a silk purse out of a sow's ear." 1 The plasticity of matter has therefore its laws and limits. This is merely the natura non facit saltus transported into philosophy.

The finality inherent in all being guides this process at every single step. Just as each individual step in the cosmic evolution tends to some new actualization of a potentiality of matter, so also is the sum-total of all these stages governed by a fixed purpose which Nature unswervingly and uninterruptedly pursues. Admirably equipped as he was-for his time-with a fund of scientific observations, Aristotle followed out in detail the applications of teleology to all the facts of Nature. There is in ancient philosophy no more eloquent advocate of final causes than he.

And what is this final term, this end towards which all Nature tends? It is that which is the most perfect, the Purely Actual (45), Aristotle replies. But this gives rise to many questions for which he has no satisfactory answer: Does this impulse of the creature towards God imply some vague sort of knowledge of its end in every existing being? Does the unity of order, which combines the various substances of Nature and harmonizes their activities, involve a sort of organic unity in nature ( $\phi v \sigma \iota s)$, a "world-soul" endowed with some faint perception of its evolutions and of their term? And if so, how are we to reconcile such unity with the individuality of the beings included in it (43), or

1 "A thread of wool won't make a saw" is Aristotle's expression (Metaph., vii., 4, 1044 a ; $f$. Piat, op. cit., pp. 25 and foll.). 
to recognize the distinction between the organic and the inorganic worlds? (52).

51. Celestial Substances and Terrestrial Bodies. $-A$ grandiose and imposing spectacle confronts us in the regular revolutions of the heavens and the seeming immutability of the stars. Aristotle held the substance of the stars to be of a nobler order than that of the earth,-influenced, no doubt, by the popular superstition which regarded them as gods. And this distinction accounts for the various sections of his special physics: celestial substances, sublunary bollies, and the action of the former on the latter.

(1) The Cielestial Sulstance--Its perfection is evidenced by its local motion and by its inner constitution.

The motion of the heavenly bodies is circular motion. This is the most perfect of all motions, for it has neither begrinning, middle, nor end; hence it is the only motion that is eternal. Circular rotation is uniform, and hence invariable, like the action of the Prime Mover on whom it depends. And since all substantial change supposes a certain opposition between startingpoint and term, it follows that the heavenly bodies cannot pass throngh contrary states: they are above and beyond all change, immutalle, unproducible, incorruftite. The peculiar element of which they are composed he calls cther, a substance purely

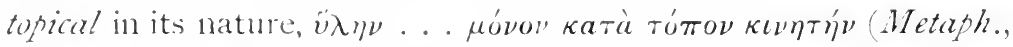
riii., 4, IO 44 b, and possessing nothing in common with the matter of the terrestrial elements.

The stars are fixed upon one single sphere, and their daily motion round the earth is performed in the same time as that of the sphere to which they belong. On the other hand, in order to explain the intricate motion of the planets it was found necessary to consider them as attached to different spheres. ${ }^{1}$ Comets were regarded as aerial will-o'-the-wisps. The internal motivepower of each sphere is an eternal intelligence, a principle of the mental order, ever tending towards the Prime Mover. The most perfect sphere is the highest, remotest of the whole firmament

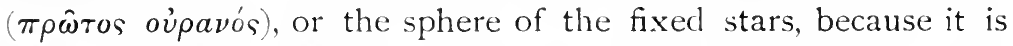
nearest the Prime Mover and farthest from the earth. The relations of these motor-intelligences with the world-soul and with the Prime Mover are not clearly defined.

(2) The Sublunary or Terrestrial Body.-The four terrestrial

${ }^{1}$ Aristotle held the opinions of Eudoxus and Callippus in astronomy. 
elements are: earth in the centre-absolutely solid and heavywater which surrounds the earth, air which surrounds the water, and fire-absolutely light-in the higher altitudes. Each of these elements has a natural rectilinear motion (upwards and downwards respectively) and tends towards a natural position (locus naturalis), which is at once its form and its end ; to become fire and to move upwards, to become earth and to move downwards, are for Aristotle one and the same thing. ${ }^{1}$ Owing to their mutual opposition as regards motion and as regards their sensible qualities (the active couple, hot and cold, and the passive couple, dry and wet, may be united disjunctively, and so give rise to a fourfold combination), the four elements can explain, by their changes, combinations, and mixtures, the formation of sublunary bodies.

(3) The Action of the Heavens on Terrestrial Bodies.-The sky, being the source of the earth's motion, is also the source of all sublunary generation or change. The immediate cause of the latter is the heat produced by the friction of the astral spheres with the atmosphere or the upper part of the terrestrial world. This friction changes the air into fire. The ecliptic declination of the sun explains, by its periodical approach to, and withdrawal from, certain parts of the earth, the rhythmical alternation of generation and dissolution in existing things. From the absence of a vacuum, from the oneness of the primary circular movement, and from the tendency which draws all the portions of the same elements towards the same place, Aristotle infers the unity of the world. From the accumulation and the sinking of the various parts of the earth, he deduces the geocentric theory of the universe. From the perfectly spherical system in which everything is contained he concludes that the world is finite. And we know already that in his view the world is eternal like motion, Nature, and the Prime Mover.

Among sublunary bodies, living organisms, and man above all, take a special place: this brings us to Aristotle's psychology.

52. Psychology.-Psychology as a distinct science owes its origin to Aristotle; for he did not subordinate his study of man to a general understanding of the world as his predecessors had done: he employed the method-proper to psychologyinternal and external observation and reasoning. Even at the 
present day Aristotle's researches on psychology retain their value.

The soul is the first act (entelechy) of a natural body, i.e., a body potentially possessing life, $\dot{\eta} \psi v \chi \chi^{\prime} \dot{\epsilon} \sigma \tau \iota \nu$ é $\nu \tau \epsilon \lambda \epsilon \in \chi \epsilon \iota a \dot{\eta} \pi \rho \omega \dot{\tau} \tau$

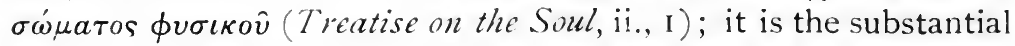
form of the living thing, as the body is the primary matter of the latter. Since, then, every living being possesses a soul, we might distinguish animal and vegetative psychology from human; but, as in the hierarchy of beings the higher species have the perfections of the lower, a complete study of man will take in life under all its aspects.

The soul, though fundamentally one, manifests itself by different faculties. Aristotle has not explained himself clearly on the distinction between them, but he seems to have considered them as different aspects of the same reality, the soul. The question is one that was to be studied more fully in the Middle Ages. The following are the main problems relating to the activities and to the nature of the soul.

53. First Group of Problems: The Activities of the Soul._All the phenomena of life are found united in man. Aristotle attaches them sometimes to four, sometimes to five faculties, basing his division on the irreducible forms of vital activity: nutrition, sensation, locomotion, understanding, and sometimes appetition.

(I) Nutrition, whose psychological aspect was carefully studied by Aristotle, is in point of view of finality the primordial vital function, since it preserves the life of the living thing. Nutrition is an assimilation of the unlike to the like; it requires heat, which is supplied by the heart. The $\pi \nu \epsilon \hat{v} \mu a$ is the air which we breathe and which gets warm by contact with the organic heat. The functions of generation are akin to those of nutrition.

(2) Sense-knowledge.-Plato had neglected this domain, and his predecessors had reduced the function to a mere mechanical action of like upon like. Aristotle's theory is a new and masterly one, in conformity with undeniable facts of observation.

There are different forms of Sense-knowledge. Aristotle dis-

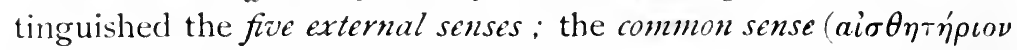
кoเvó $\nu$, which is a central organ that takes cognisance of the action of the external senses and associates our special sensations with one another; memory ( $\left.\mu \nu \eta^{\prime} \mu \eta, \dot{a} \nu a ́ \mu \nu \eta \sigma \iota\right)$, or the imagination, 
which retains and reproduces the impressions made on the senses; and the constructive imagination ( $\phi a \nu \tau a \sigma i a)$.

The most important of Aristotle's theories concerns the nature of actual sensation ( $a$ il $\sigma \theta \eta \sigma \iota s)$. The sense faculty represents sensible, particular, contingent properties; these constitute either the proper object of the scope or activity of some one particular sense (the "proper sensibles"), or an object which this sense perceives in common with other senses (the "common sensibles"). The union of the knowing with the known belongs to the psychical, not the physical, order; the sentient subject and sense-perceived object are one in the act of sensation, for this latter is the common act of both. The nature of sensation will be best understood by taking account of its genesis.

Genesis of Sensation: The senses do not act of themselves; they need to be stimulated and internally determined by some external object, which will thus become the term of the perceptive act. When the motion caused from without (the "sensible in potency") strikes the passive faculty within, this latter passes into act (the "sensible in act"), and this immanent act is sense-knowledge. The living image imprinted by the object on the organs of sense becomes a known image. This double phase of knowledge-the action of the external object on the faculty, and the reaction of the latter-takes place within us and is of the psychical order.

Aristotle engrafted on this philosophical theory a scientific theory, that of the milieu or medium. The external object, he says, does not act directly on the organs of sense, but only through some medium, air and water for sight, hearing, smell, and taste; the flesh for the sense of touch (the sensations of touch not taking place on the surface of the body, but having their seat in the heart). Whether this direct influence on the faculty of knowledge comes from the object itself or from a physical medium, the psychological difficulty remains the same. In either case, a material agent contributes to the production of a psychical phenomenon, the nature of which is unexplained.

The determinant of the psychical phenomenon, or the action of the object received in the faculty, was called later on, the intentional species (species intentionalis). Now, the Greek commentators of Aristotle misinterpreted his theory of the species intentionalis. After the manner of Democritus (10), and under the pretext that 
this transmission of influence through a medium should preserve during its whole course a likeness with the object, they imagined a veritable generation by the external object in the physical medium, of a succession of small, shadowy entities, the last of which became incorporated with the faculty previous to the act of knowledge. It is important to note that this false interpretation, which has played such an important part in the history of philosophy, has nothing in common with the real thought of the Stagirite.

Sensation is objectively valid. As the senses are determined only by the influence of an object, it follows that the latter must have a real existence outside us. Furthermore, it must resemble the forms of knowledge which it produces in our faculties.

(3) Intellectual Knowledge.-Intelligence ( $\nu$ ôs s) does not belong to animal nature, it is proper to man. We must first consider the nature of thought. Whilst the senses know only the concrete, particular, contingent object, the intellect perceives the "quiddity" (or "essence") of the sensible thing, apart from its individual characteristics and its limitation in time and space. It discerns the reality under abstract, and therefore also universal and immutable, aspects. The theory of abstraction, the keystone in the arch of peripatetic ideology, accounts for the distinctive properties of thought, whilst avoiding the errors of Plato's " dialectic".

Next as regards the grenesis of thought. We have no innate ideas (Plato). The understanding is a capacity for knowing everything. Indeterminate and passive in its nature, like the sense-faculties, it resembles a "virgin sheet of paper" (Treatise on the Soul, iii., 4, I). This is the passive intellect. As soon as this intellect receives the determining action of the object of cognition it reacts, and by reacting knows. But whence comes this action? What is its source,--seeing that the abstract object of the intellect does not exist as such in nature? (43). It results from two causes: the sense-image which is a necessary antecedent and concomitant of all thought; and an active faculty which co-operates with the sense-image-in which the intelligible object is contained "potentially," - and renders this image capable of determining the intellect. Besides the passize intellect which is the "receptacle of the determining forms" and which "can become everything," there is an active intellect which "produces everything" (Treatise 
on the Soul, iii., 5, I). This is yet another application of the theory of potency and act. To make use of a well-known comparison, the active intellect "illuminates" the sense-image just as light renders colours visible and "makes the medium actually transparent". The concept of a psychical determinant reappears here, built on the pure notion of passive potency.

What is the nature of this Trofold Intellect? On the strength of the principle that what acts is superior to what is acted upon (op. cit., iii., 5, 2), Aristotle establishes between these two intellects fundamental points of difference. The active intellect alone is independent of the body, having existed before it, and surviving dissolution; it comes from without $(\theta \dot{v} \rho a \theta \epsilon \nu)$. On the other hand, the passive intellect is akin to sensibility, is born with the organism and dies with it. The active intellect, being a "divine" principle, is impassible; it is always in act but is never acted upon; it has no power of memory and can give us no information about its state of pre-existence.

This theory of the two intellects is very obscure in many points, and full of difficulties: Is the passive intellect,-and, as a corollary, is thought itself,-material or spiritual? Is the active intellect one for all men, or is it part of the soul? Can it have knowledge by itself apart, or, since knowledge is a mode or quality of the passive intellect, does it not find itself condemned to absolute inaction on its separation from the body? How are we to explain its union with the passive intellect, and how does this union harmonize with the personality and unity of the individual man? What are the relations between the active intellect and the Pure Act? These questions will be seen to provoke in the course of later history very diverse and conflicting answers.

What of the objectivity of thought? Thought reproduces reality, faithfully but not adequately. The quiddity, which the intellect grasps in the sense-image, constitutes the thing known; but the abstract and universal form in which thought grasps it, is the product of the intellect itself (43).

(4) Appetition follows and depends on knowledge; it is a tendency of the being towards a known object which presents the character of goodness. Besides the sense-appetite, there is an intellectual one: the will (55). Liberty is a result of the will's autonomy; it entails responsibility. 
(5) Knowledge and appetite direct the executive faculties,of locomotion or change in space.

54. Second Group of Problems: The Nature of the Soul.Soul and Body. The definition of the soul states exactly its relations to the body: since the soul is the form of the body, it is its intrinsic determining principle. Psychology is not the study of the soul (Plato), but of man composed of body and soul. Not the soul (Plato), but the organism is the seat of the vegetative and sentient vital functions.

Spirituality and Immortality.-By reason of the functions which it performs without the intrinsic and immediate help of the organism, the intellect ( $\nu$ ov $s$ ) is spiritual; and its immateriality proves its immortality. Aristotle's theory of immortality has been the source of endless controversies among his commentators. It presents serious difficulties owing to the complete separation of the passive intellect from the active. This latter alone is imperishable. But is there question of personal or impersonal immortality? Speaking of the happiness of the future life, the Stagirite compares it to a sort of insensibility; the dead, he says, being incapable of activity. In reality, however, he refrained from hazarding any definite solution of the perplexing problem, and confined himself to merely teaching the survival of the thinking principle. The separation of man from God continues in the future life.

\section{V.-Practical Philosophy.}

55. Ethics.-Practical philosophy subordinates knowledge to the guidance of conduct. Under the general name of Politice Aristotle includes the whole science of the order to be established in our acts. But he distinguishes Ethics from Politics properly so called.

Ethics has for its object the study of an individual's acts in their relation to his last end. The thesis that human activity tends towards a last end is merely an application of the law of finality (50). Now, man's end consists adequately in the harmonious exercise of all his faculties including those of sense, and formally in the expansion of his noblest faculties, namely, the intellectual. The actual possession of one's last end constitutes happiness; and as virtue is only the well-balanced exercise of an activity, man's end is sometimes called virtue, sometimes happiness. 
Just as there is a theoretical reason and a practical one, so also is there a twofold series of virtues, the dianoetic (intellectual) virtues which are the noblest; and the moral virtues which are subordinate to the former, but no less essential to happiness. There are other elements in happiness, such as fortune and pleasure, but they are secondary. Aristotle's ethical system is a rational eudemonism.

The moral virtues form the proper object of Ethics; they are defined as dispositions of the will to follow the judgments of reason which tell us what is the proper mean to follow between the opposing tendencies of our nature. In his psychology Aristotle admits liberty, without, however, touching on the diffculties raised by this doctrine. Nor does he make any further enquiries on the subject in his Ethics. He simply makes a detailed study of several of the special moral virtues, chiefly of love $\left(\phi i \lambda_{i}^{\prime} a\right)$ and of friendship, the respective foundations of the family and of society.

56. Politics.-Politics is the study of social activity. Man is

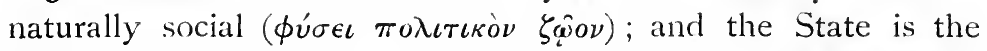
perfect form of society. To secure the happiness of the citizen in society, and hence to train up the people to the practice of virtue which is the only road to happiness: such is the mission of the State. As regards the form of government, the republican is not necessarily the best (Plato), but whichever best suits the character and needs of the people: a principle which does not prevent Aristotle from believing that the absolutely ideal form of government is the aristocratic.

The family is an element in the State. It comprehends the relations between husband and wife, between parents and children, between master and servant. The wife is the free companion of the husband, but still is subject to him; the child has no rights against the father, of whom he is a part ; slavery is necessary and lawful.

\section{VI.-Poetics.}

57. Art and the Beautiful.-The science of poetics has for its object the production of external works, and especially of works of art. Aristotle devoted his attention to the study of the beautiful, of the fine arts, especially the art of poetry. Like Plato he seeks for the essence of the beautiful in the objective elements 
of order: "beauty consists in the union of order with magnitude". Ontologically it is identical with what is good, particularly with what is morally good. Art is an imitation-not of a shadow as Plato held-but of the reality, of the internal essences of things. Aristotle lays stress on the moral significance of art, and by taking account of this view we may understand better his obscure theory of the satalasıs in his definition of tragedy. By inspiring terror and pity in the theatre, the drama stifles in the spectator's soul the unruly passions whose portrayal on the stage calls forth those sentiments: judged by this standard, the drama is an instrument of moral purification.

Aristotle's Esthetics do not differ from Plato's in their fundamental principles; the differences between them are due to the influence of the general points of divergence between the two philosophical systems. 


\section{CHAPTER III.}

GRECIAN PHILOSOPHY FROM THE DEATH OF ARISTOTLE TO THE RISE OF THE NEO-PLATONIC SCHOOL.

(From the end of the fourth century B.C. to the third century A.D.)

\section{$\$$ i. Preliminary Notions.}

58. General Features. - The fundamental characteristic of philosophy after the death of Aristotle was the predominance of moral speculations. External causes were not without their influence in developing this new tendency. The battle of Chæronea (B.C. 338) put an end to the political independence of Greece. Henceforth her destinies were bound up with those of Macedonia, and later on with those of the Roman Republic. National troubles weakened the synthetic power of the Greek mind; and the thinkers of the period, shrinking back within themselves, became solicitous chiefly for personal security. They likewise felt all the more keenly the pressing need of seeking the secret of happiness in philosophy, now that religious scepticism was gaining ground steadily every day.

A theory of personal morality was most in demand. Happiness was considered by every one to consist in tranquillity of soul, but all were not agreed as to the best means of attaining this. Social and political morality was scarcely studied.

Theoretical speculations were made subordinate to ethics. All felt inclined rather to borrow their doctrines ready-made from the past, than to take the trouble of thinking out anything new for themselves.

Grecian philosophy, like Grecian civilization, became cosmopolitan, and shook off all sentiment of nationality. The Macedonian conquest scattered the Greeks ; the cities of the mothercountry were forsaken and the emigrants directed their steps 
towards other important centres: Alexandria, Rome, Rhodes, and Tarsus soon became rivals of Athens.

59. Division of this Period.-(I) The opening years of the third century saw four great schools of philosophy in existence: the Peripatetic, the Stoic, the Epicurean, and the New Academy which perpetuated the Platonic tradition. For a century and a half those different schools flourished side by side, each pursuing its own ideal with absolute independence.

(2) But from the second half of the second century B.C. the disciples began to deviate from the absolute purity of doctrine professed by the founders of their respective schools. In general, we may give them the title of Eclectics.

(3) Eclecticism was more especially the fruit of the scepticism of the New Academy. And it in tum gave rise during the last years of the first century B.C. to a new form of scepticism, which for two centuries onward developed on lines parallel to those of eclecticism itself. The phases of this historical and logical evolution will form the subject-matter of the following three sections.

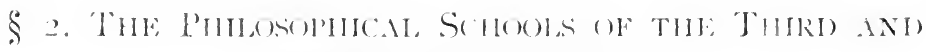
SECOND CENTURIE B.C.

6o. The Peripatetic School.-. This school, sprung from the teaching of Aristotle, gave its attention for two centuries to logic, ethics, and physics. It gravitated steadily towards naturalism, so much so that STRATO OF LAMPSA(CS +270$)$ identifies God with $\phi \dot{v} \sigma s$ and denies finality. The development which this school underwent from the first century B.C. is of greater historical importance (174).

61. The Stoic School. - The Stoics unanimously inculcated the supreme importance of Ethics. Some of them even went so far as to forbid all other study. That, however, was not the attitude of the leading representatives of stoicism. LENO OF CITILM (about 342-270), the founder of the school, CindNTHus, his inlmediate successor (about 33I-25I), CHRIsIlpus (about 28I-208), the popular exponent and systematizer of the Stoic doctrines, all three expressly recommend the study of Physics in its relation to morals. They also recognized the necessity of Logic among the philosophical sciences: for it teaches us how to discern truth from falsehood, and it is all-important that our conduct be based 
upon certain knowledge. ${ }^{1}$ We shall outline the principal doctrines of the Stoics on physics and ethics.

62. The Stoic System of Physics. - The Stoic physics may be summed up in four principal theses: Materialism, Dynamism, Pantheism, and Determinism.

(I) Materialism.-Corporeal things are the only real things. By the word body (Corpus) we must understand not only corporeal substances, but also their properties,-even the knowledge, feelings, and virtues which affect these substances. However, the Stoics elsewhere relax the rigour of this very extreme teaching, and, despite the contradiction involved, admit that certain incorporeal things exist, amongst which is the $\lambda_{\epsilon \kappa} \tau^{\prime} \nu$ or the object of our universal ideas (63). Since the properties of things can be reduced to matter, and are nevertheless distinct from the substance in which they appear, the Stoics admit the compenetration of material particles in the same place. This is the $\kappa \rho \hat{a} \sigma \iota \varsigma \delta \iota$ ö $\lambda \omega \nu .^{2}$

(2) Dynamism (7).-The principle of the internal force which energizes matter is warm air $(\pi \nu \epsilon \hat{v} \mu a)$, often identified with heat or fire. The different degrees of tension (тóvos) of this $\pi \nu \in \hat{v} \mu a$ explain the various properties and states of bodies (Heraclitus).

(3) Pantheism.-The $\pi \nu \epsilon \hat{v} \mu a$ is one. If we make an exhaustive analysis of the various forms of activity, we find that they all spring from one supreme and perfect cause whose unity of action can alone explain the beauty, harmony, and finality of the world. God is air, heat, fire; $\mathrm{He}$ is also intelligence, goodness, worldsoul. Thus, combining physical and intellectual attributes, we might say that God is the intelligent-fire-soul of the world. And as force $(\pi \nu \epsilon \hat{v} \mu a)$ is an internal principle of matter (2), and is itself material (I), God is both the primal matter and the dynamic principle of all things. The things of nature are but overflowings of the Divine matter, breathings of the Divine spirit.

To signify this plastic force of the supreme $\pi \nu \epsilon \dot{v} \mu a$, the Stoics

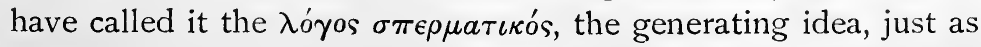

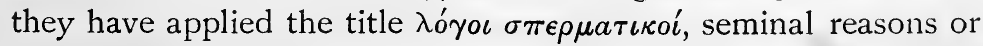

${ }^{1}$ The Stoics took up a large number of the problems of formal logic treated by Aristotle, notably those on the categories and the syllogism. Without having much intrinsic value, their system of logic is none the less original. It is entirely conceptualist.

${ }^{2}$ The Stoics worked out a very remarkable philosophical terminology. 
principles, to the various natural forces in bodies, and especially to that which is inherent in the human soul.

(4) Cosmic Determinism follows as a corollary from dynamic pantheism. The world is a closed system of connected phenomena, each of which is representative of a certain stage of the Divine evolution. The Deity evolves itself naturally and of absolute necessity; and this absolute necessity of every phase of

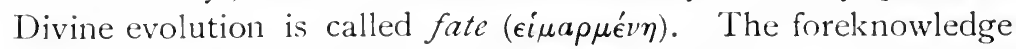
of God extends to all this, but He has to undergo it. The Stoics attempted in vain to reconcile the existence of physical and moral evil with this theory.

63. Applications of Physics to Psychology. - Nature and Origin of Knowledge. - Before the soul acquires actual knowledge it resembles a sheet of paper on which no letters have yet been traced. Sensation is the source of all knowledge. Sensation, by practice, gives rise to memory; from repeated acts of memory comes experience; from reasonings on experience arise the concepts by which we pass beyond the bounds of experience; the combination of these concepts is science. It seems, therefore, that thought is only an elaborated or collective sensation. The

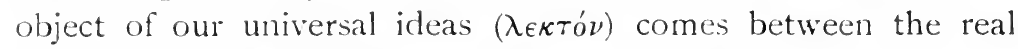

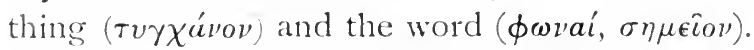

The Stoics believed in the possibility of certitude and defended it against the Sceptics. Neither party, however, place the question on its proper basis: the analysis of our cognoscitive activities. They reduce it to a corollary in ethics. Whilst the Sceptics deny the existence of certain knowledge, because they consider it superfluous in their system of ethics, the Stoics affirm it as indispensable for morality. Without certain knowledge, they say, it would be impossible for us to conform our conduct to true ideals. Practical necessity is thus made the decisive argument against all scepticism.

The criterion of certitude is purely subjective. It is the con-

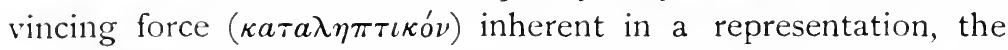
power which knowledge possesses of winning our firm adherence. By a strange contradiction, they attribute this power to concepts $(\lambda \epsilon \kappa \tau a ́)$ and not to sensations, though the general concept must be essentially false since it corresponds to nothing corporeal $(62$, I).

The Will.-Determinism in human acts is only a particular 
application of cosmic determinism. The Stoics try in vain to safeguard liberty by confounding free with voluntary acts.

Nature of the Soul.- The soul is an emanation from God or the world-soul : it is simply a little warm air, a $\pi \nu \epsilon \hat{v} \mu a$. Grecian authorities on physiology and medicine had long sought an explanation of normal and abnormal vegetative functions in warm air $(\pi \nu \epsilon \hat{v} \mu a){ }^{1} \quad$ The Stoics improved on this conception by confounding the $\pi \nu \epsilon \hat{v} \mu a$ with the soul itself,-activity with the principle of activity. We see traces of this confusion in their theories relative to the soul's origin, location, constituent parts, and future life. The soul of the infant is a particle of matter separated from the soul of the parents. The soul has its locus in the breast where respiration produces warm air. From the breast also comes forth speech which is the immediate expression of the thinking soul. By means of the air which the heart sends through the organism the soul occupies and penetrates the whole body. (See above, the $\kappa \rho \hat{a} \sigma \iota \varsigma \delta \imath^{\prime} o^{\prime} \lambda \omega \nu$.) The Stoics seem to have multiplied the parts of the soul just as the whim seized them. Reason, however, was

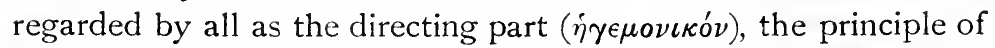
the $E g o$ and of personality. At the end of time when the world will be consumed by fire, all human souls will be absorbed in the Divine $\pi \nu \epsilon \hat{v} \mu a$. It follows then that the soul will for some time survive the body. Is this survival the privilege of the virtuous, or is it the common destiny of all? Their answers to this question are contradictory. The whole theory of survival is a concession to moral exigencies at the expense of their materialist principles.

64. Moral System of the Stoics. - Virtue and Happiness. - Man is superior to all other things in this, that he has a knowledge of the cosmic laws to which fate compels him to submit himself. Conformity of our life with these cosmic laws, regulation of our conduct by our strictly intellectual nature, obedience to reason as

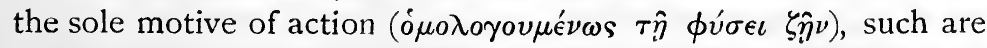
the leading principles of Stoic morality and virtue. Furthermore, if we subordinate all our acts to the dictates of reason, we reach that happiness towards which our natural aspirations spontaneously lead us. It follows that virtue is the highest and only good.

Virtue considered on its positive side is a self-determination of

'Siebeck, Geschichte der Psychologie, i., 2 (1884), p. I33; $f f .53$ (1), Aristotle's idea of the $\pi \nu \in \hat{v} \mu a$. 
the will to act in conformity with our knowledge of the true, abstracting altogether from every other motive. Virtue begins in knowledge and is consummated in action. It is not to be confounded with science (Socrates), which it surpasses; for speculation has no other raison d'être than to serve as a guide of conduct. The wise man retires within himself and professes an absolute indifference to every motive that does not come from reason. This apathetic sort of tranquillity which keeps the troubles of the external world shut out from the soul is the negative element of Stoic virtue. Just as virtue is the only good, so vice, or the act of volition contrary to reason, is the only evil. Between these two qualities there is an essential incompatibility which Stoicism exaggerates out of all due proportion. Good and bad have an absolute value, they either exist or they do not: they ardmit of no degrees. Since they are what they are of themselves, it follows that under no respect can one become the other. To this sharp distinction the Stoics add an equally absolute and radical difference between grood and bat people; the change from bad to good is instantaneous.

Everything that is neither good in itself nor bad in itself has

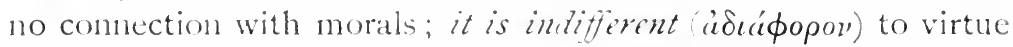
and hence unworthy of the wise man. These austere moralists of the portico blamed Aristotle for making external goods an element in happiness $\mathbf{5 5}$, but they reserved their most vehement attacks for the Epicureans (68). They regarded pleasure as morally indifferent; it can be a consequence, but not a motive of our actions.

Virtue and Duty.-Virtue is obligatory because it has a cosmic significance: it is the form of man's natural activity. But it is a necessity of fate that beings should be subject to the laws of the cosmos in their activity. The general tone of Stoic morality is, therefore, to diminish the value of human personality.

Virtue and the Passions. - As man is not pure intelligence, he bears within his breast not only a rational tendency but also irrational motions or passions $(\pi \dot{a} \theta \eta)$. Passion is a disorderly movement of reason towards irrational things. It starts with a false representation of something. and ends in a consequent consent of the will. As such it depends on our will, and therefore on our liberty (63). All the passions are bad; they are psychical diseases (in opposition to Aristotle). The sage is master of him- 
self, resists his passions and tries to extirpate them from his soul; he becomes apathetic, that is to say, passionless ( $\dot{a} \pi \dot{a} \theta \epsilon l a){ }^{1}$

The Stoic philosophy presents a close communion between the practical and the theoretical elements of life. It sought the triumph of virtue in a profound knowledge of cosmic order. It borrowed its chief moral theories from the Cynics, and from Heraclitus several of its physical theories; but while the Cynical school despised speculative research, and Ionian dynamism lost sight of the moral value of life, Stoicism completed the one by the other, whilst renewing both.

65. The Epicurean School.-EPICURUS (342-270), who had been brought up in the philosophies of Democritus and of Plato, opened a school on his own account at Athens in 306. Soon his popularity attracted growing crowds of admiring and faithful followers. Never, in fact, did disciples cling more scrupulously to the teachings of a master. Though Epicureanism held its place for a period of six centuries, it preserved unchanged the primitive form given it by its founder. Springing into favour in the second century B.C. its theories spread with equal popularity in both the Grecian and Roman worlds. The poet LUCRETIUS (94-54) was a disciple of Epicurus. The third century A.D. saw it still flourishing, but during this century the popularity of the system began to wane, and finally in the following century it lapsed into obscurity. Some fragments, however, of its teaching survived the wreck and were brought to light again in the Middle Ages.

Epicurus emphasizes the exclusively practical side of philosophy: his essential aim is to assist us by means of language and thought in the realization of happiness. To this moral conception of philosophy he subordinates all the theoretical sciences, treating Grammar, History, and Mathematics with disdain. $\mathrm{He}$ attaches importance to the study of Nature merely because it frees the soul from the dejection arising from a superstitious belief in God and death."

${ }^{1}$ In practice, the most ardent pupils of stoicism had to relax the excessive and impossible austerity of their moral system. After defining virtue, they describe in detail the particular virtues, notably justice, love of our neighbour, and friendship.

${ }^{2}$ Epicurus adopted the then commonly received division of philosophy into Logic (which he called Canonic), Physics, and Moral Philosophy. It was only incidentally he touched on questions of Formal Logic, to which, unlike the Stoics, he attached practically no importance. 
66. Epicurean Physics. - The physical theory of Epicurus was that everything in Nature is ruled by general natural forces, that there is no such thing as purpose or finality, and that consequently man may lay aside all fear of a Divine interference. He explains the sensible world after the mechanical principles of Democritus (10): that there exist only material, homogeneous atoms, infinite in number. Owing to their weight, these are set in motion in the infinite void of space. There is, however, this difference between the two systems. In that of Democritus, the atoms interfere with each other in their fall, thus producing eddying motions; while in that of Epicurus, all fall with the same speed perpendicularly and without touching each other through the void which can offer them no resistance. Epicurus, however, influenced by moral considerations, attributes to the atoms a discretionary power of declination (the clinamen of Lucretius) by which they can deviate a little from the perpendicular. It is the natural play of these atomic movements, independent of gravity, that produces the shocks and eddies in them.

The accumulation of atoms, under the action of gravity, produces worlds separaterl from one another by vacant spaces. The different shapes of the atoms explain the appearance of the different elements,-especially of the earth, from which are generated plants, animals, and man.

67. Application to Psychology.--Knowledge, its Origin and Nature.-All knowledge is sensation, and this latter owes its origin to atomic emanations (1o). The repetition of sensations engenders the concept or general image ( $\left.\pi \rho \rho^{\prime} \lambda \eta \psi \iota \varsigma\right)$ which becomes fixed in the memory. We pass from the known to the unknown by opinion $\left(\delta^{\prime} \xi \xi\right)$ which is merely a judgment or reasoning about sensations. Certitude exists: Epicurus proves this like the Stoics by appealing to moral considerations. What is the criterion of certitude? The very existence of the sensation. By the very fact that it exists, a sensation is true, in conformity with its object. For its object is not the exterior thing, but the image produced in us by that exterior thing. In Epicurus' system of criteriology, errors of the senses find no place. Error arises only when by judgment we attribute to the things themselves what is only true of their images in us. This theory leads logically to the subjectivism of Protagoras (12). In practice, however, 
Epicurus admitted that our perceptions attain not only to the things as represented, but also to the things in themselves. The concept has the same claim to certitude as the sensation. As for opinion, it is true or false according as it is confirmed or not by experience.

The Will is a mechanical movement of the soul ; but Epicurus does not attempt to explain it. All his attention is concentrated on the problem of liberty. Just as the Stoics, who held that morality consists in man's submission to the cosmic laws, insisted on psychological determinism, so the Epicureans, who placed happiness in man's individualism and absolute independence, based their belief on free will. It is just in order to safeguard the possibility of a free act in his exaggerated mechanical theory, that Epicurus attributed to the atoms a quasi-voluntary power to deviate from the perpendicular. Logic would oblige him to endow every atom of matter in the universe with liberty, the monopoly of which he reserves so jealously for the human being.

Nature of the Soul.-The soul is corporeal. The atoms which compose it are the lightest and most mobile: it results from a mixture of fire, air, $\pi \nu \epsilon \hat{v} \mu a$, and another element infinitely mobile. It permeates the whole body, but the intellectual part rules supreme. The soul comes into the world with the body; at death it dissolves into the ether: a consoling thought seeing that death is thus the end of all painful sensations!

68. Epicurean Ethics. - While the Stoics subordinated personal inclination to cosmic law, Epicureanism made individual, egoistic well-being the cardinal point of all morality. The pleasure of the individual is the supreme good,--but by this we must understand not the mere sum-total of his pleasures, and especially his sensible pleasures, as the Cyrenaic school taught (17), but the harmonious pleasure of his whole existence. This latter consists much more, according to Epicurus, in repose and the absence of pain (a negative enjoyment, if we may so call it), than in any positive satiation of the soul (Cyrenaic school). And as mental trouble is more destructive of quiet than physical pain, Epicurus makes the intellect the supreme judge of pleasure. It is by reason that we drive away the annoying suggestions of all sorts of prejudices. In the Epicurean idea of happiness, sensible pleasure is not ostracized as in the Stoic idea; it is regarded as the 
primordial pleasure, but reason tempers and moderates it. This weighing and controlling of pleasure by reason is the very essence of virtue. ${ }^{1}$

Epicurean Physics was a renewal of the Physics of Democritus; Epicurean Ethics, an enlargement of the Cyrenaic Ethics. Physics and Ethics together constitute a specific philosophy in which we may easily detect the general orientation of the postAristotelian systems.

The Stoics and Epicureans differ in their principles but arrive at the same definition of happiness. Starting with doctrines widely opposed, Epicurus and Zeno manage to depict the ataraxy of the sage in practically the same colours. And, as this final issue alone is of importance, the conclusion soon followed that speculative knowledge is useless for happiness. This was the theory upheld by the Sceptics.

69. Sceptical Schools; The Later Academies. - The Sceptics of the third and second centuries assign as the only aim of philosophy the search for happiness: and happiness for them, as for the Stoics and Epicureans, consists in the soul's rest,--atarary. If they deny the possibility of certain knowledge, it is because in their view speculative certitude is not indispensable for happiness.

Three Sceptic Schools appeared during this period: (I) The Pyrrhic School founded by PYRRHO (OF LiLs (about 360-270), which, however, was of short duration and little influence. 'The Second or Middle Academy', established by ARCEsildus OF PITANE (315-240), who gave the ancient Platonic school an inclination towards scepticism and concluded like Pyrrho that, certitude

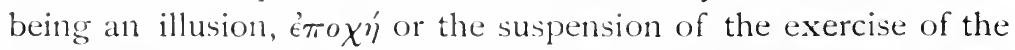
judicial faculty is the only legitimate attitude for the philosopher. (3) The Third or New Academy, founded a century later by CARneAdes OF CrRene (2 I 3-I 29), who developed the scepticism of the Academy and amassed objections against Dogmatism in general and Stoicism in particular. Following Arcesilaus, Carneades endeavours to find in the probability of certain representations, a sufficient but indispensable motive of conduct.

'Like Zeno, Epicurus gives friendship a place of honour but sees in domestic and political cares an obstacle to enjoyment. 
\$ 3. ECLECTICISM.

(From the latter half of the second century B.C. to the third century A.D.)

70. Causes of the Rise of Eclecticism.-The philosophical systems studied in the preceding section were inspired by one underlying principle, the predominance of ethics. Developing on parallel lines, with Athens as their centre, it was but natural that they should influence one another. Eclecticism is, in a certain sense, the outcome of scepticism. The Sceptics, in reality, did not stop at negative doubt; they had been led by practical needs to a theory of probability bordering on dogmatism. But this probability, according to the Sceptics, belonged equally to the different systems then in vogue; any one of these was sufficient to engender a subjective conviction, and to serve as a basis of conduct. As a matter of fact, eclecticism made its first appearance among the disciples of Carneades. A political event facilitated its development: the conquest of Greece by the Romans (146). The vanquished imposed on the victors their philosophy, their science, and their education; but they had to respect the root tendencies of the Roman mind and thought. Now, in philosophy the Romans sought mainly for practical utility, for ethical precepts, for instruction in the arts of oratory and politics. To the speculative theories, with which these precepts were bound up, they paid little attention, adopting one or the other theory indifferently.

71. General Character and Division.- - The Eclecticism of this period chose its theories by submitting them to the test of convergence towards the practical ends of life; and the supreme criterion of this convergence is our immediate consciousness of it, the instinctive conviction we have of it independently of all other considerations, such as the real objectivity of knowledge. An interior voice makes itself heard, and its whisperings are accepted as dictates above dispute. This is subjectivism: here again the Eclectics are at one with the Sceptics.

Eclecticism occupied a century and a half before, and three centuries after Christ. The philosophical systems of this epoch may be divided a potiori, according to the different schools with which each was most closely allied. For, notwithstanding the reciprocal infiltrations of the four post-A ristotelian systems, each 
of these latter preserved its individuality distinct, and traced for itself a well-marked furrow. Under the Empire even, the Platonic and Aristotelian schools might be seen affirming energetically each its original distinctive individuality, by a profound study of the works of their respective founders. In addition to this, public courses of philosophy were established, and Marcus Aureliui officially sanctioned the distinction between the four schools by assigning to each a special chair at Athens (I 76 A.D.). But it was not a matter of groing back to the past; irresistible forces conspired to combine together those movements, which had issued from different starting-points. Passing over the eclecticism of the Epicurean school, where the master's doctrines were perpetuated almost intact, let us come to study the Stoic, Platonic, and Peripatetic forms of Eclecticism.

72. The Eclecticism of the Stoics. Seneca.-From the first century B.C. Stoicism gave a ready welcome to foreign doctrines. Its preoccupations were confined more and more within the domain of ethics; but new theories, better suited to the real needs of life, took the place of the harsh and hollow doctrines of Zeno's earlier disciples. These tendencies, which had already appeared with PANAETIUS OF RHODEs, the founder of Roman stoicism (about I 85-III), and his disciple Posmonius, became more marked in the theories of SENECA, of EPICTETLS, and of MARCUs AURELIUs, the recognized representatives of stoicism under the Roman Empire.

SENECA was born in the first years of the Christian era and was put to death in the year 65 , by order of Nero whose counsellor he had long been. He does not think much of the Logic of the Stoics; and if he does not oppose the fundamental theses of their Physics, he prefers, at least, to confine his attention to the application of those principles to Ethics. Thus, while subscribing to their materialistic pantheism, he insists nevertheless on the providence of $\operatorname{God}(\mathbf{6 2}, 4)$ and on the future life of the soul. Studying the nature of man, he dwells with pleasure now on the materiality and divinity of the soul-the emanation of the divine $\pi \nu \epsilon \hat{v} \mu a$, -and again on the opposition between the moral and the physical side of man's nature. In the end, it is anthropological dualism that wins the adherence of the Roman moralist: he sees in man a compound of two heterogeneous elements, soul and body, whose struggle is incessant and implacable. Seneca's 
psychology is a mixture of Stoicism and Platonism; and his doubts on the inner nature and destiny of the soul give his teachings a tinge of scepticism.

His Ethics bear the stamp of a most rigorous puritanism. But he was too well aware of human imperfection not to accommodate the impracticable precepts of the earlier Stoicism to the needs of his time. Thus, while he boasts of the autarchy of the wise man, he yet allows him the enjoyment of external goods $\left(6_{4}, n\right.$ n.), and this in deference to those lower inclinations whose tyrannical sway is an index of the merely natural man. Seneca also glories in the cosmopolitanism of human sentiments; he extols the love of neighbour; and he speaks in moving language of the miseries of life and the necessity of an hereafter.

73. The Eclecticism of the Academy. Cicero.-The Academy became the focus of a full and complete fusion of all the prevalent philosophical systems. To this it lent itself admirably, for its scepticism had a peculiar affinity with the eclectic philosophy of the time.

The eclecticism of the Academy in the first century B.C. assumed its specific form in the philosophy of PHILO OF LARISSA (died about 80 B.C.), the founder of the Fourth Academy, and of Antiochus (died 68 B.C.). The former contended that the Academic scepticism was only a weapon against the Stoic criterium and did not exclude an innate certitude about things. The latter achieved the complete return of the Platonic school to dogmatism, turned his back on Carneades, professed his adherence all at once to Plato, Aristotle, and Zeno, and held that all the dogmatic systems of his predecessors did nothing more than express the same truths in different ways : this is the most complete form of eclecticism, such as we find it in CICERO (I06-43), the celebrated disciple of Philo and Antiochus.

Although he displays a preference for the New Academy, Cicero is in touch with all the systems of his time, and all find a welcome in his assimilative mind. Amongst the many works through which his philosophical ideas are scattered, we may mention the De Officiis, De Republica, De Legibus, De Finibus Bonorum et Malorum, De Natura Deorum. He shines less by originality of ideas than by a remarkable aptitude for accommodating Grecian ideas to the Roman civilization. Cicero sets out from a theoretical scepticism, which he bases on the want of agree- 
ment between the various philosophies in the solution of the most important problems. This theoretical, neo-academic scepticism runs hand in hand with a practical dogmatism. In all moral questions-and they are the main object of philosophyas well as in all those which have a bearing on ethics, we act on a positive conviction which, though not indeed an absolute certitude, far surpasses the probability of Carneades. And where are we to find this assurance which is to be the mainspring of our actions? In the consciousness, the intimate and immediate feeling, that some things are, that others are not: the first truths of the moral order are innate.

As soon, however, as Cicero comes down to the details of the problems raised by ethics, his eclectical wavering reasserts itself. He belieres in the identity of the Platonic and Aristotelian doctrines on the sovereign good, but he has some difficulty in reconciling them with the theory of the Stoics. With Zeno he admits the autarchy of wisdom, but he cannot bring himself to exclude corporeal enjoyments from his concept of the good (peripateticism). Epicureanism alone is rigorously excluded from his theory of happiness.

74. The Eclecticism of the Peripatetics. Aristotle's Interpreters and Commentators. - To arrange, annotate, and popularize the great philosophical work of Aristotle, was from the first century B.C. the great preoccupation of the peripatetic school. Andronicus of Riodes, head of the Athenian School from 60 to 40 B.C., gave a powerful impetus to this work of exegesis by publishing, in conjunction with the grammarian TrRANNIO, a complete, annotated edition of the master's works (32). BOETHus of Sidon and ARIsto are two other commentators of note. Not that these men followed scrupulously on the lines of Aristotle in their own philosophy: no less than the others, the peripatetic school was susceptible to infiltrations from foreign sources. Under the Empire, the peripatetics continued to gravitate towards eclecticism while clinging more than ever to the works of Aristotle, whose Logic they took a special delight in commentating. The most celebrated among them was Alexander of ApHroDISIAS (about 200 A.D.), the great commentator whom posterity has called the second Aristotle. Yet he also deviates in some capital points from Aristotelian philosophy. He emphasizes the individuality of substances so far as to reduce the universal to 
a pure concept without objective worth. He teaches that the

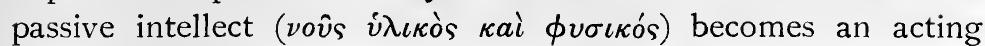

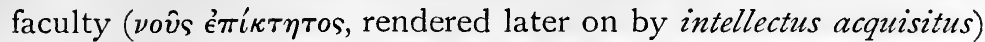
through an extrinsic illumination ( $c f$. the $\theta \dot{v} \rho a \theta \epsilon \nu$ of Aristotle) which it receives from the "active intellect" or Divine being

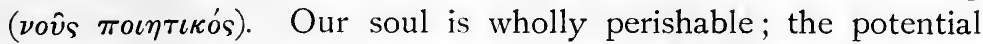
intellect born with the body disappears with it: this is a denial of the immortality of the soul. Alexander thus decides, in the materialistic sense, a point of doctrine left in doubt by Aristotle (54). Whole schools of philosophy in the Middle Ages and during the Renaissance, accepted his interpretation. We may add that the Aristotelian commentator is a convinced defender of human liberty: in the name of liberty, he denies Providence. ${ }^{1}$ From the second half of the third century Aristotle found numerous commentators and admirers in the Neo-Platonic School $(\mathbf{8 6}, \mathbf{8 8})$. The latter, however, had not at any time a monopoly of the commentaries on the Stagirite.

\section{\$4. The Scepticism of the Neo-Pyrrhonic School.}

75. Reappearance of Scepticism.-The eclecticism which, in the New Academy, had taken the place of scepticism early in the first century B.C., contained within it the very germs of the theory it wished to supersede. The instability of the mind that goes foraging into all systems, is an index of the doubt that troubles it. The new converts to scepticism were, for the most part, medical doctors. In the name of medical empiricism, they confined themselves to the observation of phenomena, and attaching no importance to speculative knowledge they contented themselves in the domain of practical maxims. Scepticism was but one step farther.

The scepticism of this period claims to follow Pyrrho, but it owes much more to Arcesilaus and Carneades. Its influence was neither great nor lasting. Through exhaustion of thought there arose a thirst for dogmatism-indeed, it may be said that Neo-Pyrrhonic scepticism was an approach towards the ideas that inspired Neo-Platonism.

${ }^{1}$ To peripatetic eclecticism we may also assign Adrastus of ApHrodisias (close of second century) and Claudius Galen of Pergamum (13i-201), at once a physician and a philosopher. 


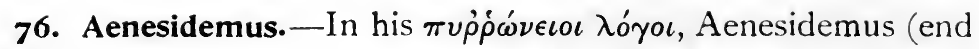
of first century B.C.) professes in absolute terms a real and universal doubt. He not only rejects the dogmatism of the later academicians, but he even rejects the theory of opinion or probability (69). Neither sense knowledge nor intellectual knowledge can give us any certitude. Aenesidemus drew up his proofs under ten heads, which constitute the classic code of ancient scepticism. Sextus Empiricus subdivides these according as they pertain to the nature of the knowing subject, to the nature of the known object, or to the relation between subject and object. All the objections of Aenesidemus are centred in this fundamental idea: our representations being relative, we can have no criterion of truth. Consequently, we should abstain from all judgment. He himself does not pretend to prowe the correctness of his thesis - that would have been a contradiction-but merely to give information on our internal condition of mind. His philosophy is not a doctrine (aip $\rho \sigma \iota \varsigma)$, but a principle of conduct, a tendency

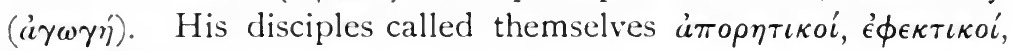

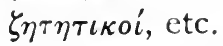

In practical life, this attitude of mind is held to produce calmness of soul, happiness. Like the other sceptics, Aenesidemus admits that sensations can serve as a guide for conduct.

77. Sextus Empiricus. - At the close of the second century A.D., Sextus Empiricus recapitulated, in lengthy treatises (especially the Pyrrhonic Hypotyposes), the extensive work of the sceptical school: these form a repertory, rich in documents, but not very orderly, of arguments against all forms of dogmatism.

Sextus attacks both the formal methods of science and its real contents. Its methods are powerless, for there is neither an infallible criterion of truth, nor any legitimate means of demonstration. Its contents are hollow and useless, for the concept of cause can give no information about any external reality. Even Ethics itself is not a science: the contradictory views of philosophers on the nature of the good, are enough to show that nothing is good in itself. All these theses are supported by prolix commentaries, of unequal value, in which Sextus very often merely repeats the views of Aenesidemus and of the New Academy. Since every enunciation may be met by another based on arguments of equal force ( $\left(\sigma o \sigma \theta \theta^{\prime} \nu \epsilon \iota a \tau \hat{\omega} \nu \lambda o^{\prime} \gamma \omega \nu^{\prime}\right)$, we must only remain in doubt and suspend our judgment ( $\left.\dot{\epsilon} \pi \circ \chi \eta^{\prime}\right)$. 
Although our knowledge, being relative, cannot tell us what external things are, it is capable of guiding our practical life and leading us to happiness.

This scepticism, like the eclecticism which enjoyed a parallel development, plainly confined itself to repetitions of the past: an evidence of the philosophic bankruptcy of the epoch. Still, Grecian genius was yet to take one last flight, by changing for a fourth time the general orientation of its intellectual activity. 


\section{CHAPTER IV.}

NEO-PLATONISM AND THE SYSTEMS IVHCH I.ED UP TO IT.

(From the end of the first century B.C. to the sirth century A.D.)

\$. General Notions.

78. General Character.-Philosophy becontes Theurgic and Religious. - The predominance of moral studies had produced, during the period just examined, an extreme distrust for all speculative knowledge. Abandoning all hope of finding certitude and happiness by way of rational speculation, philosophy began to seek for them in communication with the Divine. On the one hand, it placed God far away on heights inaccessible to reason. On the other, it admitted a direct communication of this inscrutable God with the human soul. This communication necessitated the recognition of new processes of knowledge in the soul : ecstatic and mystic intuitions of the subjective order; and the creation, in the objective or real order, of a series of intermediary beings in a descending scale between the inaccessible God and man. Influenced by those tendencies, it was natural that philosophy should incline towards religious doctrines, and towards those systems of the past which betrayed the closest affinities with religion.

External events favoured this characteristic evolution of Grecian philosophy in a very striking way. On the one hand, the philosophical centre of the age was Alexandria, the general rendervous for three-fourths of the civilized world, a centre in which Grecian philosophy naturally felt the influence of oriental doctrines. On the other hand, in the second century A.D., the decadence of the Roman Empire was rapid. The people and the Cæsars alike turned to strange religions, principally Eastern, for that principle of moral force which the depopulated Pantheon no longer afforded; and the introduction of these religions into the public life of the Romans exercised an indirect influence on philosophy. 
79. Division.-The characteristic just referred to appears conspicuously in Neo-Platonism, the most interesting and most important philosophy of this period. Neo-Platonism filled the last three centuries of Grecian philosophy. It formulated a powerful synthesis, remarkable for the unity and coherency of its theories. This it is that distinguishes it from the similar systems which led up to it.

These latter imperfectly co-ordinated systems began to appear towards the end of the first century B.C. They influenced NeoPlatonism, and the new spirit lived in them : hence it is preferable to place them in the fourth period of this history, even though chronologically they were contemporary with the eclectic and sceptic systems treated above. We may, therefore, distinguish in the fourth period of Grecian philosophy: (I) the precursors of Neo-Platonism (\$2); (2) Neo-Platonism itself (\$3).

\section{\$2. The Precursors of NeO-Platonism.}

\section{(From the end of the first century B.C. to the third century A.D.)}

8o. Two Groups of Precursory Systems.-The philosophical currents which developed, mainly at Alexandria, before the appearance of Neo-Platonism are two in number: (I) A current of Grecian philosophy, having its origin in a revival of Pythagorean ideas, and comprising Neo-Pythagorism and Pythagorean Platonism; (2) a current of Graeco-Judaic philosophy. There was besides, in the later years of the second century, and especially in the third century, a current of Christian Philosophy whose tendencies naturally connect it with the Patristic Philosophy (96).

81. Neo-Pythagorism and Pythagorean Platonism.-At a time when ancient doctrines of a philosophico-religious character were being revived Pythagorism was sure to attract the attention of philosophers. In the last century of the pagan era the Pythagorean philosophy reappeared (5), not indeed in the purity of its archaic form, but modified by compromises with other systems.

There were those, however, who would fain restore the Pythagorean doctrine just as it had been delivered by the philosopher of Samos: these were the Neo-Pythagoreans. But their NeoPythagorism is in reality an eclectic system, founded on Platonism and Aristotelianism, supplemented by fragments of Stoicism; its only Pythagorean attributes being its marked fondness for mathe- 
matics, for the symbolism of numbers, and for the mystic phenomena of religious asceticism. Indeed, its ascetical theories constitute the most original part of Neo-Pythagorism. Inferior gods and the daemons serve as intermediaries between man and the Supreme Divinity. God is so far above us that we could not know His wishes if He had not revealed them to us Himself: the mantic art puts man in communion with God; purificatory practices prepare him for commerce with the Divinity.

On the other hand, a group of eclectic Platonists (73) produced a remarkable medley of Platonic, Stoic, and Peripatetic doctrines, mingled with theurgic and religious speculations. PLUTARCH OF ChaEronea is responsible for this complex philosophy. In metaphysics he supports the Platonic dualism of God and the worldsoul, but between these two opposing principles he interposes a whole legion of daemons as emissaries of Divine providence. $\mathrm{He}$ believes in the immortality and transmigration of souls (Plato); he teaches that the immediate intercourse of man, detached from himself, with God, makes up for the inadequacy of reason; he lays stress on religious practices (Pythagoras). Maximus, Apuleius of Madaura, Albinus whose lessons Galen had followed at Smyrna in I $5 \mathrm{I}-2$, develop still more the role of those daemonbeings, intermediaries between God and matter. On this conception Ceisus bases a justification of polytheism. Numenius (about 160) borrows from the Magi, the Egyptians, the Brahmins and Moses. Combined with Egyptian theories, we find again the same body of Platonico-Pythagorean doctrine in a series of works dated from the end of the third century, and transmitted to posterity under the name of HERMES TRISMEGISTUS. They contain a remarkable apology for national-especially Egyptian-polytheism, in which there is evidence of a vigorous though disheartened defence of paganism against triumphant Christianity. The writings of this Pseudo-Hermes Trismegistus figure largely in the Middle Ages.

82. Origin and Character of Graeco-Judaic Philosophy.-Of all the oriental peoples whom Alexander's conquests brought into touch with Hellenic civilization, the Jews alone may be said to have assimilated the Grecian philosophy, by harmonizing it with their religious teachings. This assimilation was achieved in Alexandria. Sprung from religion, the philosophy of the Jews has ever been largely dependent on religion. It was at first con- 
sidered as a means for the thorough study of the Sacred Books, though it soon outstepped this purely exegetic role. The Jews naively endeavoured to find in the Old Testament itself the ideas they had borrowed from the Greeks; and to this end they introduced the allegorical interpretation of the Scriptures. Like Neo-Pythagorism, the Graeco-Jewish philosophy looks for an opposition between the Divine and the terrestrial and emphasizes the contact of man with God by revelation. But these theories underwent very characteristic modifications, because they were adapted to Jewish dogmas and to the philosophical conceptions which these dogmas upheld. Considering it as a whole, this movement of ideas was in its tendency Jewish on the religious side, Grecian on the philosophic side.

83. Philo. - The complete fusion of Jewish theology and Grecian philosophy was the work of PHILO the Jew (30 B.C.-50 A.D.). The following are the most characteristic of Philo's theories :-

(I) General relations of Jewish theology to Grecian philosophy.Philo proclaims the absolute infallibility of the Sacred Books and the subordination of philosophy to theology. But if philosophy is to be subject to theology, the latter cannot do without the aid of the former. Philo sets great store on Grecian science: it is in fact, for him, the very incarnation of rational speculation : Grecian philosophy, even down to its polytheism, is an incomplete and imperfect form of the doctrine contained in the sacred writings. To overcome the difficulties which must beset this contention, Philo has recourse to the allegorical interpretation of the Bible, and thus establishes an affiliation between the teachings of the Bible and Grecian philosophy.

(2) The dualism of the Infinite God and the finite world.-His idea of the Divine transcendence forces Philo to hold that God is without attributes (ămoıs), that $\mathrm{He}$ is inconceivable and ineffable. We know that $H e$ is, not what He is. But these very negations have for basis the perfection of Jehovah; and Philo not only emphasizes the negative concept of God but strongly insists on the positive concepts of Goodness (Plato) and Omnipotence. Imperfection and limitation, being irreconcilable with the notion of God, cannot find their principle in Him. Their principle is matter (Plato and the Stoics).

Philo explains the action of God on the world, by having recourse 
to a series of intermediary beings which he calls forces ( $\delta v \nu a ́ \mu \epsilon \iota \varsigma$ ). These Divine forces are not only exemplar-forms, but immanent principles of activity, proper to each natural substance (Stoicism). Philo identifies them with the angels (Judaism) and the daemons (Grecian religion). His notion of these Divine forces is not at all clear: on the one hand, they are distinct from God, since they are to communicate with a world essentially distinct from Him; on the other hand, they partake of the nature of God, since they are the intermediaries of His action on the world. Philo considers them as somehow proceeding from God, without adopting the theory of strict emanation. The primordial Divine force is the $\lambda$ óyos, the wisdom of God. Is this a personal being, like God Himself? Philo gives no definite answer to the question. The world is the result not of creation properly. so called, but of an application of Divine power to matter preexisting in a chaotic state. The Jewish philosopher was apparently so engrossed in Grecian speculations that he could not shake himself free of them and give philosophical expression to the fruitful doctrine of creation, which is written so clearly on the first page of Genesis. The same dualism is prominent in Philo's psychology: the soul is a Divine principle, an angel, a daemon, united to a material body which is antagonistic to it (Plato). This opposition is made the principle of a religious mysticism.

(3) Religious Mysticism.-The trammels of the body prevent man from knowing God in Himself; $\mathrm{He}$ is known only in the Divine forces in which He manifests Himself. The more a man becomes detached from the body, the nearer he approaches knowledge and virtue (Stoicism). Nevertheless, we can rise to the knowledge of God as He is in Himself if a supernatural illumination unveils the Infinite to us. In this higher state in which God reveals Himself to us human consciousness disappears: this is the annihilation of man in the presence of God, the state of ecstasy, the prophetic state, to which any one may possibly be called.

\section{NEO-PLATONISM.}

(From the third to the sixth century A.D.)

84. General Features. Division.-The most striking feature of Neo-Platonism is religious mysticism. Man must conquer his 
sense-feelings by struggling against them; he must draw near to God by a series of steps or stages, and unite himself to the Infinite by employing aids of a religious nature.

Dependently on this mystic conception a whole system of metaphysics is developed: a system which is the expression of the most absolute pantheistic monism. Although the opposition between the Infinite and the finite is emphatically and even extremely stated, yet God is the living force whence all finite substances proceed by emanation, matter included. It might be said that Neo-Platonism consists in a strictly systematic description of the development or processus of the Divine being into the universe, and of the return of the soul to God.

Neo-Platonism is an original syncretism or mixture of the different systems of Grecian philosophy, because it interprets all previous theories in a mystico-religious sense. It reflects the Graeco-Judaism of Philo, as well as the Neo-Pythagorism and the Platonism of the Alexandrian period; it also bears the impress of Stoicism; and it betrays the influence of Aristotle to whom it is indebted for its method. But it owes its character principally to Plato who supplied it with important metaphysical elements,-and whose doctrines it claims to restore in their ancient purity. However, we need only compare its fundamental theses with those of the head of the Academy in order to convince ourselves that Neo-Platonism mistakes the true spirit of the Platonic system.

We can discern three periods in the development of NeoPlatonism, according to the forms which it successively assumed: (I) the philosophic and scientific period (third century A.D.); (2) the religious period (fourth and fifth centuries A.D.); (3) the encyclopedic period (fifth and sixth centuries A.D.).

\section{The Philosophic Phase of Neo-Platonism. Plotinus.-} Plotinus was an Egyptian by birth (204-5 A.D.). After having spent eleven years attending the lectures of Ammonius Saccas, who is regarded as the founder of Neo-Platonism, he came to Rome where he conducted a school of philosophy with extraordinary renown until his death in 270 . His works were collected by Porphyry under the title of the Enneads. Plotinus has given its fullest development to Neo-Platonism. We will follow his working out of the two fundamental ideas which, in his view, sum up all philosophy. 
(1) The Process of Emanation from a Supreme Principle, the one source of all existing things, explains the physical and the metaphysical worlds. According as this principle gives out its energy, it exhausts itself; its determinations follow a descending scale, becoming less and less perfect. The following are the successive steps in the process :-

(a) The One.-At the head of the intelligible world, far removed from the world of sense (Plato), reigns One Supreme Essence. To safeguard its transcendence, Plotinus states it to be absolutely

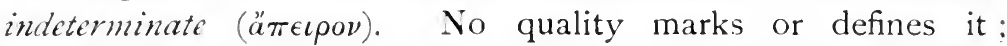
nothing can determine it, for all determination implies limitation (negative theodicy). The Supreme Being has no attribute, not even intellect or will: knowledge and volition suppose a duality of knower and thing known, of that which wills and that which is willed; and all duality is irreconcilable with the infinitely perfect. However, as this negative concept has for basis the Divine perfection, Plotinus has recourse to positive descriptions, the insufficiency of which, moreover, he fully recognises. By preference he describes the Supreme Being as the First ( $\tau$ ò $\pi \rho \hat{\omega} \tau o \nu$ ), the One, the Universal Cause, Goodness (Plato), Light. Immutable in itself, this First Unitary Being does not diffuse its substance into other beings, as the advocates of substantialist pantheism maintain; but it permeates them by its activity (dynamic pantheism); and what we call the proper, specific substantiality of things is simply the product of this activity. Furthermore, this outflow of the Divine activity into all other beings is not direct and immediate; it is effected through the agency of intermediary forces which emanate successively from one another. And as the effect is always less perfect than the cause, these activities are arranged in gradation according to their respective degrees of perfection, each one occupying a position which is lower the greater the number of intermediate steps by which it communicates with the Divine energy. What are these intermediaries into which the Divine energy flows, as it were, by cascades? Plotinus reduces them to three: Intelligence and the World-Soul in the suprasensible order; and, in the sensible order, Matter.

(b) Intelligence.-The One Primary Being by knowing Itself gives birth to a second principle, Intelligence ( $\nu$ ovs), the generation of which introduces duality into the Deity. The vovs is its 


\section{PLOTINUS}

own proper object, and under this aspect its object is one; nevertheless, this unity admits a plurality of representations. This must be the case, because in virtue of the principle of progressive decadence, the $\nu$ ov $s$, less perfect than the One, cannot absorb in one single act of knowledge the energy communicated to it by the First Being; this energy is dispersed and radiated into a

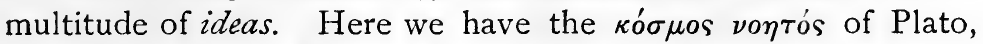
with this essential difference, that with Plato the ideas are sub-

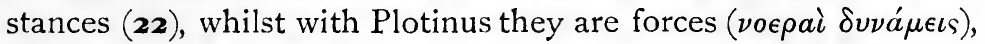
clustering together in the unity of the $\nu o \hat{s}$, but destined to become in turn generative principles of further activities.

(c) The World-Soul.-The vov̂s or second principle necessarily produces a third, the Soul of the World. This World-Soul is of a hybrid nature, on the one hand intelligent like the vovs in which it contemplates the ideas, on the other hand tending to realize in the sensible world the image of those same eternal ideas. $^{1}$ The plurality which it embodies is still held together, just as in the vovis, but it is on the point of scattering itself abroad in the outer world.

The universal World-Soul generates the particular souls or plastic forces ( $\lambda$ ó $^{\prime}$ ou $\sigma \pi \epsilon \rho \mu a \tau \iota \kappa o i, c f .6 \mathbf{6 2}, 3$ ), which are the forms of all things. These forces are themselves wavelets of the universal life which circulates through all things, and whose primordial source is ultimately found to be the First Being (

(d) Matter.-How does Plotinus pass from the suprasensible to the sensible, material world? How does he reduce the one to the other, after his having with Plato insisted on the fundamental diversity which separates the Idea from Matter? He does so by an ingenious theory which avoids the dualism into which all the Platonists had fallen: The World-Soul, with forces which are native to it, generates matter, and by uniting itself with the matter, produces corporeal and sensible beings. Matter, according to Plotinus, is merely the space which conditions all corporeal existence ; it is a pure possibility of being, mere nothingness, the $\mu \grave{\eta}$ ö $\nu$ of Plato (25), which Plotinus identifies with

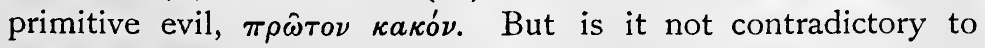

${ }^{1}$ In several passages, where he endeavours to explain how the Soul of the World serves as a transition stage from the immaterial to the material world, Plotinus distinguishes a double World-Soul, the purely suprasensible soul, and the soul already in contact with sensible matter. $-Z_{\mathrm{ELLER}}$, op. cit., iii., 2, pp. 539 sqq. 
make matter the evolution-term of the idea, to make nothingness a manifestation of being, to make evil a product of good? No, answers Plotinus, for every generative process implies a decadence or inferiority in the generated product. And in the series of Divine generations there must he a final stage, at which the primal energy, weakened by successive emissions, is no longer capable of producing anything real. A limit is necessarily reached beneath which there cannot be anything less perfect: this limit is matter.

In the sensible world plurality predominates, whilst in the suprasensible world all plurality is confined within the bonds of a unity more or less perfect. The world of sense, imprisoned in matter, is only a faint reflection of suprasensible principles whose unity is as unchangeable as that of the sun reflected by many mirrors. It is engendered and sustained at each moment by the World-Soul : this explains how and why it is the prolongation of reality. Plotinus made use of this explanation to defend the beauty and order of the material universe against the attacks of the Gnostics.

All the parts of the universe are soldered together by a cosmic sympathy; and the vibrations of the World-Soul, even in the tiniest things, have their influence on the whole universe. The sensible world is eternal, as is also the generation of the Divine activities. Plotinus analyzes in detail the efflorescence of the plastic forces of the World-Soul in sensible nature: from the heavens, whose soul presents the most perfect form of sensible life, the stars or the visible gods of the universe, and the dacmons who are intermediaries between celestial and terrestrial things,-down to the organic and inorganic lodics of the earth itself.

Man occupies a definite place in this hierarchy. Souls existed before bodies; they dwelt in the bosom of the World-Soul until the needs of the cosmic evolution demanded their union with matter. On these principles Plotinus easily engrafts the Platonic theories of the survival and migration of souls, and of the extrinsic union of soul with the body (27). Those souls alone will be restored to their primitive state, which, at the moment of death, will be completely detached from sensible things ; the others will animate new bodies proportionate in dignity to the degree in which each is found detached from matter. This is why the 
great end of life and of all philosophy is to achieve the mystic return of the soul to God.

(2) The Mystic Return of the Soul to God.-The whole metaphysical system of Plotinus depends on this mystic union, and is a preparatory step towards its realization. Happiness results from the perfect exercise of intellectual activity; but real science is independent of experience and opinion,-it is the fruit of thought. Hence Plotinus sees the essence of virtue in detachment from the world of sense, self-purification ( $\kappa a \dot{\theta} \theta a \rho \sigma \iota s)$ and the elevation of the soul to the invisible world.

The Understanding has being as its object ; and in its subjective development it mounts in succession the different degrees of the metaphysical order. First, by way of reasoning it understands ideas and genera suprema. Then, looking inward, it contemplates directly, and without reasoning, the intelligible world. At this second stage the soul becomes united to the $\nu$ ovs, to which it belongs: it is through the vovs, and in it, that the soul arrives at this knowledge; it still, however, retains the consciousness of its separate personality. Finally, in a third stage, the soul contemplates the Primal Being itself: it becomes God. This contemplation is indistinct and unconscious, for the soul is now rapt above all knowledge and change, like the Supreme Being itself. Thus the highest form of intellectual activity is an unconscious form : the ecstasy (" $\kappa \sigma \tau a \sigma \iota s)$ by which the ravished soul is lost in God.

We can easily understand then why Plotinus turns to religion as a means to facilitate the ecstatic union. In spite of his pantheistic monism, he adheres to polytheism and to magic, for he deifies several of the energies of the Primal Being. By their interposition man more easily raises himself up to the Absolute One. This thought became the fundamental dogma of the polytheistic mysticism of Plotinus's successors.

86. Porphyry.--PORPhyry OF TyRe (232-33 to 304) is the most famous among the immediate disciples of Plotinus. He it was who popularized the master's tenets by collecting them into a

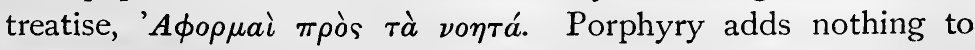
Plotinus either in physics or metaphysics, but he develops the religious and ascetic side of Neo-Platonism. He tries to establish the doctrine of mystic union on the worship of divinities and the mortification of the body,-which he subjects to purificatory privations in order to detach the soul from the senses. Porphyry 
serves in this twofold way as a link between Plotinus and Iamblichus.

Porphyry is also the first of the Neo-Platonic commentators on Aristotle. Neo-Platonism, in fact, considered the study of the Organon of Aristotle as an introduction to the philosophy of Plato. Porphyry devoted himself chiefly to formal logic, and he owes to the influence of the Stagirite the clearness and accuracy which posterity has always admired in his commentaries.

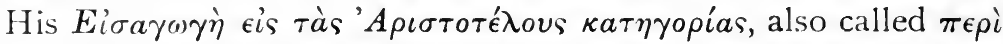
$\tau \hat{\omega} \nu \pi \hat{\epsilon} \nu \tau \epsilon \phi \omega \nu \hat{\omega} \nu$, met with unique success : it was not only commentated by the Neo-Platonists of the succeeding centuries but afforded food for discussion to several generations in the Middle Ages. Porphyry wrote two commentaries on the Categories, defending them against Plotinus, and probably also a commentary on the Prior Analytics.

87. Religious Phase of Neo-Platonism.-Porphyry's successors retained nothing of Neo-Platonism but a mystic craving after the supernatural. A sort of religiosity is the sole preoccupation of the Syrian IAmblichus (died about 330), who reared on the foundations of Neo-Platonism a regular international Pantheon in which he placed all the divinities he ever heard of. The long line of philosophers who constitute the theurgical school of Iamblichus, extends to the fifth century A.D., that is, to the very end of the era of Grecian philosophy. Before Neo-Platonism finally disappeared it rallied for a time: this last manifestation of life reveals a third phase of its history, the encyclopedic period.

88. Encyclopedic Phase of Neo-Platonism. Wane of Grecian Philosophy. ${ }^{1}$-During the closing period of its history, Grecian philosophy presents the characteristics common to all declines. Powerless to create, it merely commentates: it tries to make up for lack of originality by the great prolixity and excessive subtlety of its works. On the one hand, it amasses compilations of Neo-Platonism; on the other, it shows an increasing predilection-ever more and more pronounced-for commentaries on Aristotle. Porphyry had made this exegesis fashionable in the Neo-Platonic school (86); and his imitators were numerous. But still, not all Aristotle's commentators were recruited from the same ranks during this epoch of decline. Side by side with

${ }^{1}$ Cf. Tannery, "Sur la période finale de la philosophie grecque" (Revue Philosofhique, 1896, pp. 266 sqq.). 
the Neo-Platonic interpreters, we have Peripatetic interpreters of the school of Andronicus of Rhodes and Alexander of Aphrodisias (74). While the successors of Porphyry try to reconcile Aristotle with Plato, the philosophers of the Lyceum, on the other hand, strongly accentuate the points of difference which separate the two great Grecian sages.

The philosophers of these later centuries are found in the three chief centres in the Eastern Empire: Constantinople, Athens, and Alexandria. With them we may also mention a few writers belonging to the period of the Latin decadence.

89. The School of Constantinople. Themistius. - The Christian emperors of the East made numerous attempts to start a school of philosophy at Constantinople and to set up the new capital as a rival of Athens and Alexandria. In the second half of the fourth century we find there THEMISTIUS, one of the great commentators on Aristotle.

Though remaining an ally of paganism, Themistius, who held public office, made some concessions to the new religion which his personal protectors, the princes, were patronizing. The commentaries of Themistius on Aristotle reveal the disciple of the Lyceum; without any hostility to Plato, he combats the innovations engrafted on Platonism by Neo-Platonism. Themistius had no immediate successors, and the philosophic movement at Constantinople lapsed into a slumber that lasted for centuries. In 618 the emperor Heraclius summoned an Alexandrian teacher to Constantinople in the hope that his lessons might arouse the Byzantine genius from its lethargy. The attempt was futile; the awakening was to be witnessed only by yet far-distant generations.

90. The School of Athens. Proclus. Simplicius.-A ristotle reigned as uncontested master at the school of Athens; it was there also that the most complete blending of Aristotelian dialectics with the mystic theosophy of the Neo-Platonists was finally effected.

PROCLUS (410-485) is the most influential and characteristic representative of Athenian Neo-Platonism. He includes in his encyclopedia of Neo-Platonism ( $\Sigma_{\tau o \iota \chi} \epsilon i \omega \sigma \iota s \theta \epsilon o \lambda o \gamma \iota \kappa \eta \dot{~ a n d ~} E$ is

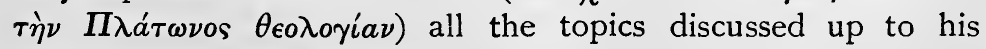
time,-pantheistic metaphysics, mysticism, asceticism, divination, theology. Possessed of a systematic mind, and at the same time a fruitful writer, endowed with a striking talent for assimila- 
tion though powerless to create, Proclus embodies as it were in himself all the successive phases of the evolution of Neo-Platonism.

Triadic evolution is the vital idea in his philosophy. Every

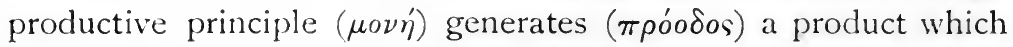
finally returns $\left(\dot{\epsilon} \pi \iota \sigma \tau \rho \circ \phi \eta^{\prime}\right)$ into the bosom of the producing agent. For the term produced, although distinct from that which produces it, is only the continuation of this latter, and is consequently endowed with a fatal impulse to become absorbed in it again. This dynamic monism is the law of the world: the universal order is only its application. From the indeterminate One springs the vove (Plotinus), but this emanation is possible

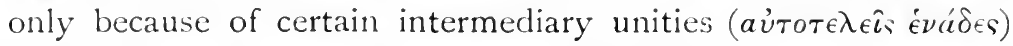
which Proclus makes personal gods (Iamblichus). In the vov̂s he distinguishes three spheres, each of which he subdivides into groups of three and of seven, so as to form collections suitable for the pagan Pantheon. Matter is a direct product of one of the triads of the voves and not, as Plotinus taught, a final outflow from the World-Soul. Upon this system of metaphysics Proclus engrafts a mystic psychology; its basic principles being the ecstatic illumination of the soul by God and the deification of the soul by (polytheistic) religious practices (Plotinus and I amblichus).

DAMASCIUS-a disciple of Ammonius of Alexandria-gave the Athenian school, about 520-530, a tendency in the direction of the dreamings of lamblichus. Finally we come to the last notable personage of this pagan generation of philosophers, Simplicius, the fourth and last of the great Greek commentators of Aristotle.

Simplicius, a disciple of Ammonius and of Damascius, is the author of a voluminous commentary, several portions of which have come down to us. His commentaries are personal. $\mathrm{He}$ professes the greatest respect for Plato. He has left us many fragments and items of information, which are of the greatest possible utility for the elucidation of the teachings of his predecessors.

When the pagan spirit of the teaching at Athens could be no longer reconciled with the convictions of the majority of the hearers, now become Christians, the emperor Justinian, by his famous decree of 529 A.D., ordered the school to be closed. It is to this date historians refer the celebrated exodus from Athens of a group of incensed philosophers-Damascius and Simplicius were of the number-into the kingdom of a "barbarian" prince 
who sympathized with the spirit of the Grecian civilization. Their sojourn at the Persian court of Chozroës Nuschirwan was of short duration. Home-sickness drove them back to Grecian realms when the king of Persia concluded a treaty of peace with Justinian in 553. The school of Athens, however, remained closed for good; its old masters drifted apart and continued their labours in the obscurity of private life. It was mostly after 529 that Simplicius wrote the commentaries which are preserved to us from his hand.

91. The Alexandrian School. Ammonius.-Ammonius, a disciple of Proclus, is the most striking personality in the Alexandrian school of this later period. He perpetuated the tradition of scientific Neo-Platonism, and took up the interpretation of Aristotle in the spirit of Porphyry. During his long and influential career, Ammonius formed the minds of most of the philosophers of this closing epoch. Damascius was his disciple, and later on John Philoponus, Asclepius, Simplicius and Olympiodorus. Christians attended his lectures and he always avoided wounding their religious susceptibilities. Not only in fact did the Alexandrian school display a considerate sympathy with the Christian beliefs, but-unlike that of Athens-it even tended daily more and more in the direction of Christianity. JoHn Philoponus, who wrote Aristotelian commentaries, and a treatise on the Eternity of the World directed against Proclus, within the first third of the sixth century, expressly professed the Catholic religion. Olympiodorus was also a convert; indeed we might say that from the middle of the sixth century the Alexandrian school was mainly Christian.

A new cycle of speculations was thus gathering force when in 640 the Arabs invaded Egypt and burned the Alexandrian schools and the famous library which had long been the glory of the Cæsars.

92. Philosophy in the West.-When Rome ceased to be the political capital of the world, she also lost her scientific preeminence. The fourth century produced in the West only a few insignificant commentaries on logic and a few Latin translations of Greek works. Vegetius Praetextatus and Marius VICTORINUS (who lived as a rhetorician under Constantius about 350) are the only writers worthy of mention. In the fourth or fifth century CHALCIDIUS, and in the fifth MaCroBIUS, devoted 
themselves to Platonic and Neo-Platonic compilations which were afterwards widely read and consulted in the early Middle Ages. As for Martianus Capella and Bö̈ThiUs, although they are both products of Grecian culture, they belong rather to the medieval period.

The influence of Grecian philosophy extended down through the medieval period, making itself felt in three separate centres: in the Byzantine, in the Asiatic, and in the Western philosophy. Accordingly, we find it in the philosophy of the Fathers of the Church, which marks the transition from Grecian philosophy to the philosophy of the Middle Ages. 


\section{PATRISTIC PHILOSOPHY.}

\section{§. GenERAL VIEW.}

93. General Features of Patristic Philosophy. - The advent of Christianity gave a new direction to speculative studies. The Fathers of the Church had to indicate what were the dogmas of the Christian Religion and to preserve them from the heretical alloy of Jewish and Pagan doctrines; just as in another department they had to protect from schism the unity of discipline and ecclesiastical government. Bearing in mind that this was the chief aim of all Patristic speculation, we can understand at once that philosophy held only an incidental and secondary place in it, and that the choice of the questions discussed was usually determined by the exigencies of polemics.

Hence it is that Patristic philosophy is a religious philosophy, subservient to dogma: not only in the sense that dogma excels philosophy as revelation excels reason, but also in the sense that philosophy is considered to have no other general function than that of assisting dogma with its own proper teaching. This attitude merely continued the tradition of the contemporary Neo-Platonic schools, which in like manner confounded philosophy with religion ( $c f . \mathbf{8 5}, \mathbf{8 6})$.

The Fathers study preferably the problems connected with Christian dogma. Although Christ is not regarded as the head of a school of philosophy, still the religion He founded offers us solutions on quite a number of the questions which philosophy proposes and solves by other methods. ${ }^{1}$ We may note, for example: God's supremacy over the world; creation; providence; the essential dependence of man on God; the individuality of things; the finality of the universe; the distinction of soul and body; personal immortality.

1 This is true of every religion, for many questions dealt with by religion also belong to the domain of philosophy. The material object, in the case of philosophy and religion, is in part common to both. 
Owing to the very fact that their philosophic labours were fragmentary and incidental, the Fathers of the Church never succeeded in building up a harmonious system of organically connected doctrines. We have no Patristic synthesis to compare with the later Scholastic synthesis. Of course the new teachings of Christianity on a few of the problems discussed by philosophy found credence with all, and so far constituted a unifying element. But those few points were unable to effect a general synthesis; moreover, in the interpretation even of them we can perceive a wide diversity of thought.

Patristic Philosophy was propagated in a civilization permeated with Grecian ideas, and was influenced by them. In this way it became attached to a waning world-view; it fostered and perpetuated an old-time mentality. Its writers were influenced, in varying degrees, by the then prevalent doctrines of the NeoPlatonists. Through the medium of these latter they inherited more or less of Plato's spiritualism, which they endeavoured to interpret consistently with Catholic doctrine. They took isolated tenets from Aristotle, but, in the main, distrusted or repudiated his theodicy, physics and psychology. They also borrowed theories from Pythagoras and Socrates, from Seneca, Cicero and Philo Judaeus.

94. Division. - We may divide Patristic philosophy on the basis of the religious controversies which produced it. The history of those struggles naturally falls into two periods, following the doctrinal questions which originated them and the results to which they led.

The first period comprises the controversies of the first three centuries, from the foundation of the Church to the Council of Nice (325): the period of fixation of the fundamental dogmas. The second embraces the struggles of the fourth to the seventh centuries, from the Council of Nice to that of Trullo (692): the period of the development of Christian dogma.

\section{\$2. Patristic Philosolhy DURing the First Three Centuries.}

95. Gnosticism.-Gnosticism, which is the principal heresy of the early Christian centuries, ${ }^{1}$ presents many points of contact

\footnotetext{
1 There were many other heretical sects: the Manichaeans, the Ebionites, the Elcesaïtes, the Monarchists, the Millenarians, the Montantists, etc.
} 
with the declining Grecian philosophy, and, like the latter, offers us a syncretic alloy of all the then existing theories. The origin of evil and of the world in which it reigns is the fundamental problem of all the Gnostic systems. To solve this problem they have recourse to a pretended science higher than even revealed faith, a special religious knowledge which they called $\gamma \nu \hat{\omega} \sigma \iota s$. The essential dualism of God, the principle of all being and of all good, and Matter, the principle of evil (Philo); the evolution of the Divine Being producing by emanation $\left(\pi \rho \circ \beta o \lambda \eta^{\prime}\right)$ a series of aeons less and less perfect (Plotinus); the mixture of Divine and material elements giving birth to the world: such are the fundamental ideas of Gnostic metaphysics and cosmology. Creation and Christian redemption are, accordingly, natural and necessary phenomena, mere episodes in the struggle of the Divine element with matter from which it tries to set itself free. Redemption will be completed by the cosmic return of everything to its proper

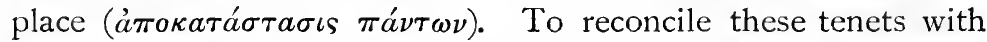
the teaching of Scripture, the Gnostics interpret the latter in an allegorical sense (Philo), so as to bend the text to their preconceived ideas. ${ }^{1}$ Gnosticism assumed many forms. In the third century it was strenuously opposed by the Christian school of Alexandria.

96. Christian School of Alexandria.-Founded by PANTAEnus ( $\dagger 200$ ), the Christian school of Alexandria was made famous by two great men, Clement of Alexandria ( $†$ prior to 2 I6) and ORIGEN (1 85-254). We have extant a tripartite work of

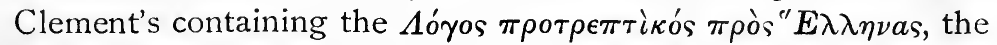

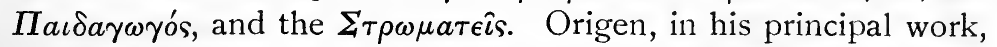
the $\Pi \epsilon \rho \dot{i} \dot{a} \rho \chi \hat{\omega} \nu$, attempts the first systematic exposition of dogma. Of all the Alexandrian Fathers he was the most deeply influenced by the dominant theories of his time: first by the Graeco-Judaic philosophy, especially of Philo, from which he borrowed his theory of the allegorical interpretation of the Bible; then, through the medium of Neo-Platonism, by the Platonic, Aristotelian and Stoic philosophies, and even by the Gnostic systems. There is reason for what has been said of Origen : that he was a Christian in his practical life and social intercourse, but a Greek in his conceptions of the world and of God. When refuting Gnosticism he subscribed

${ }^{1}$ We find the same philosophical principles underlying Manichaeism, although their application to Catholic dogma is not the same as in Gnosticism. 
to many theories repudiated afterwards by his successors. Their theories in theodicy, anthropology and morals are the most remarkable portions of the philosophies of Clement and Origen :-

(I) Divine Transcendence is energetically asserted in opposition to the monists. On the other hand, God is not relegated to an absolutely inaccessible region, nor is $\mathrm{He}$ such an indeterminate being as Philo and the Gnostics make Him. He is accessible to the human intelligence, which recognizes Him in His creatures.

(2) The Theory of Creation, which the predecessors of Clement and Origen had already interpreted in a Biblical sense, is eloquently defended by these two masters. And so the hesitating conjectures of Grecian philosophy, unable to explain the mutual relations of God and the universe, were at last replaced by a definite and decided teaching. Plato and Aristotle had subscribed to the dualism of God and matter without explaining the origin and independence of the latter; the Stoics and NeoPlatonists had advocated a fatalistic emanation of the Divine substance or of the Divine activity into finite being; but monistic pantheism could not explain why God communicates Himself to the contingent, whilst dualistic individualism was discredited by its arbitrary juxtaposition of God and matter. The doctrine of creation or the production of the world ex nihilo by an act of the free will of the All-Powerful, offered a far more perfect philosophical solution; it maintained with Aristotle the substantial distinction between the Pure Act and the act mixed with potentiality, and it maintained with Plotinus the absolute dependence of the world on God. The creationist theory was bound to be taken up and developed by all the writers of the patristic and medieval epochs.

(3) The soul is spiritual and is of a nature superior to that of the body (against Epicurus), - though certain passages from Origen seem to contradict this thesis; the existence of moral liberty is asserted against Gnostic determinism; a natural moral order is the standard or rule of human conduct. ${ }^{1}$

${ }^{1}$ The most celebrated of the Latin writers of this period is Tertullian of CARThage (169-220). His works (principally De Idololatria, Apologeticus, De Anima, Libri Duo ad Nationes, and several treatises on Gnosticism), written in bold and vigorous language, contain some fierce diatribes against Gnosticism, against the artistic and scientific products of Roman society, nay even against all rational knowledge. Every one knows of that hard saying attributed to him: credo quia absurdum. Taken in its narrower literal sense this would destroy the philo- 


\section{§3. Patristic Philosophy from the Fourth to the Seventh Century. St. Augustine.}

\section{Patristic Philosophy in the Fourth and Fifth Centuries. -} The Edict of Milan (313) had given practical expression to the zeal of Constantine the Great for the Christian Religion by establishing the latter throughout the Empire. The Council of Nice (325) had defined its principal dogmas. It could now convoke solemn assemblies to promulgate its teaching. The schools of Antioch, of Alexandria and of Cappadocia were the principal seats of theological learning in the East. The energy of all the ablest men of this time was engaged in the exposition and defence of Christian doctrine. According to their objects we may distinguish three chief controversies : the Trinitarian, the Christological and the Anthropological.

The Trinitarian controversies were the result of Arianism. The most formidable adversaries of Arianism were ST. Athanasius, Bishop of Alexandria ( $\uparrow 373)$, and the "Three Lights of Cappadocia," St. Gregory OF NySSA (33 I-394), his brother ST. BASIL the Great (†379) and St. Gregory Nazianzen (329-390). In the West, Arianism was combated by ST. Hilary of PoItIERS († 366) and St. Ambrose (about 340-397). The writings of St. Ambrose reveal the practical bent of their author's mind: the learned Bishop of Milan considered the man of knowledge as at the service of the man of action. Of all the writings of the Fathers, the Hexaemeron of St. Ambrose was perhaps the most widely read in the Middle Ages. The De Officiis Ministrorum, in which he recasts the De Officiis of Cicero in a Christian sense, has won him a high place amongst writers on morals.

The Christological controversies commenced with NESTORIUS (428) and Nestorianism, which found an able opponent in ST. Cyril of Alexandria († 444).

The Anthropological controversies appeared with Pelagianism,

sophical basis of the act of faith. Not all the doctrines of Tertullian are above suspicion. He held Traducianism as regards the human soul, and believed the latter to be of a certain corporeal nature. After Tertullian, but of less importance, came St. Cyprian of Carthage (about 200-258), Commodius, Arnobius, who wrote in the first years of the fourth century (Adversus Gentes), and Lactantius (about 260-340, Institutiones Divinae). 
which encountered an adversary of extraordinary genius in the person of St. Augustine.

98. St. Augustine. His Life and Works.-St. Augustine is not only one of the most famous of the Fathers of the Church, he is also the greatest philosopher of the Patristic period. He was born at Tagate in Numidia in 354, of a Christian mother, Monica, who contributed very much to the formation of his character. While yet young he abandoned the teaching of rhetoric, which he had practised in different towns of Asia Minor and Italy, to devote himself to theological studies. He adhered for a time to Manichaeism, and also for some time favoured the scepticism of the New Academy. He was converted to Catholicism by St. Ambrose of Milan, who baptised him in 387. Later on he became Bishop of Hippo (395). Up to his death in 430 he wrote and worked to propagate Catholicism and to refute contemporary heresies, particularly Pelagianism and the Manichaeism whose errors he had himself previously professed.

His principal philosophical works are: (1) Confessionum Libri XIII., an autobiography written about 400 , in which he gives a history of his intellectual and moral development down to his mother's death in $387 ;(2)$ Retractationum Libri I) uo, written about 127 , containing a critical risume of the works he had written since his conversion; (3) Contra Academicos, directed against those Neo-Sceptics whose doubts he had for a short time shared; (4) Soliloquiorum Libri II.: (5) Liber de Immortalitate Animae; (6) De Quantitate Animac: (7) De Magistro: (8) De Libero Arbitrio: (9) De Anima ef Ejus Origine: (IO) and (I I) the celebrated works De Civitate Dei and De Trinitate, whose scope is primarily dogmatic and apologetic, but which are also rich in philosophical teaching.

Works which may be consulted on St. Augustine: Willmaxi, Geschiehte d. Idialismus, Brunswick, and edit., Igo8, vol. ii., \$\$ 6 I-66 (general views); J. MARTIN, S. Augustin, Paris, rgor, in the collection "Les Grands Philosophes" (a much discussed monograph on St. Augustine's philosophical and theological teaching); Portalié, Saint Augustin, article in Vacant's Dictionn. de Théol. Cathol. vol. i., col. $2268-2+72$ (an excellent general study from the theological and philosophical points of view). On a special question: Grandgeorge, Suint A ugustin et le Néo-platonisme, Paris, 1896 (well treated).

99. General Features of the Philosophy of St. Augustine.St. Augustine was familiar with a great number of the doctrines of antiquity and transmitted them to the Middle Ages in his writings. He was acquainted especially with the Neo-Platonism of Plotinus and Porphyry; but he read these in the versions of Marius Victorinus. Plato, on whom he heaps the highest eulogiums, was probably known to him only through Neo-Platonic sources. He makes mention of Aristotle only three times (vir excellentis ingenii et eloquii, Platoni quidem impar, De Civit. Dei, viii., I2), and seems not to have known his system. But the importance he attached to dialectic, for the explanation of the Scriptures, contributed not a little to the veneration with which the logic of Aristotle was regarded in the Middle Ages. Then 
again, he gathered his knowledge of Pythagoras, the Stoics, the Epicureans and the Academicians, in the main from what Cicero had written of them. ${ }^{1}$

With St. Augustine, all the Neo-Platonic theories, though sufficiently marked, lose their specific character, and are adapted to the genius of a new philosophy. Polytheism with its inferior deities, the world-soul and its eternity, metempsychosis, and, above all, emanation-pantheism, are expressly set aside. Several theories, especially amongst those attributed by him to Plato, are bent to serve the needs of the Augustinian theodicy.

The philosophy of St. Augustine has God as its centre. His metaphysics, his ethics, and above all his psychology, converge steadily to the study of God. "Deum et animam scire cupio. Nihilne plus? Nihil omnino" (Soliloq., i., 7). And his study of God is permeated through and through by the closest blending of intellectualism and mysticism. We must seek the truth, not only to know it, but to love it. ${ }^{2}$ Philosophy is the love of wisdom, that is to say, the love of God. "Si sapientia Deus est . . . verus philosophus est amator Dei" (De Civit. Dei, viii., I). And this God, whom philosophy teaches us to love, is the Holy Trinity as taught in the Christian faith (De Ordine, II., v., r6).

Finally, St. Augustine's philosophy follows, step by step, the development of his dogmatic teaching according as the various phases of his polemics demand its gradual unfolding. Faith renders service to reason, just as reason does to faith. The intellige ut credas and the crede ut intelligas are the first faint outlines of that system of relations which the Middle Ages were to mould into scientific form. Reason furnishes us with the concepts that are at the root of what we are to believe: it establishes the existence and infallibility of revelation. But on the other

${ }^{1}$ Grandgeorge, Saint Augustin et le Néo-platonisme, pp. 30 sqq.

2 "O veritas, veritas! quam intime etiam tum medullae animi mei suspirabant tibi" (Confess., I, iii., c. vi.). "The genius of St. Augustine consists precisely in this marvellous gift of embracing the truth with all the fibres of the soul; not by the heart alone, for the heart does not think; not by the mind alone, for it apprehends truth only in its abstract and, as it were, lifeless state. St. Augustine seeks the living truth: even when he is combating certain Platonic ideas, he is still of the stock of Plato, not of Aristotle. In all this, doubtless, he is good and suitable for all time, for he holds communion with the souls of all; but he is so in a special degree for modern times; because his doctrine is not the cold, clear light of the Schools; it is warm, living, palpitating with strong personal feeling" (Portalié, op. cit., col. 2453). 
hand, there are truths that reason would not even suspect if God had not proposed them for our belief.

From the facts themselves of his life, it is apparent that the Doctor of Hippo had to pass through many stages before he reached the full and complete development of his philosophical ideas. We will pass over these stages here, but they must be taken into account in a special study of the life-work of St. Augustine.

Ioo. Theodicy and Metaphysics.-St. Augustine proves the existence of God a posteriori, from the contingency of the world, from the order of the universe, from the voice of conscience and from the common consent of mankind. His favourite proof is that derived from an interpretation of the characters of necessity and immutability to be found in our intellectual representations and in those root-verities which serve as criterions for our knowledge and conduct. The objects of those judgments and principles can be necessary and immutable only because they are adumbrations of the necessary and immutable essence of God. Therefore God exists (De Lib. Arbitrio, ii., I 2 and I 5).

Against the Manichaeans he upholds the primordial oneness of an infinitely good and perfect God; against the Neo-Platonists he defends the theory of creation: and creation must have taken place in time, not ab aeterno. Various Alexandrian doctrines are incorporated into St. Augustine's theodicy,-with, of course, the modifications demanded by his anti-pantheistic attitude. Such, for example, are the inability of man to comprehend God ; the transcendence of God above and beyond all categories ; His simplicity, eternity, goodness. From the unity of God St. Augustine does not infer Divine unconsciousness (Plotinus). On the contrary, the Divine knowledge is one of the favourite themes of his philosophy. It is here we meet the theory of Exemplarism (see especially L. 83 qq., q. 46), so intimately associated with the name of St. Augustine.

Before building an arch, the architect must first conceive a plan or model of it. In the same way, before creating the universe, God must have conceived its vast design. He knows all possible essences in their relation to His own Divine essence, of which they are the far off imitations (principales formae quacdam vel rationes rerum in divina intelligentia continentur). There is a Divine idea corresponding to each individual contingent thing, 
the standard or norma of its reality (singula igitur propriis sunt creata rationibus).

As being the primary source of all contingent reality, the Divine ideas are also the ultimate foundation of the intelligibility of all essences, and therefore it is on them finally that the certitude of human knowledge reposes, since our ideas are in conformity with the things around us : neither in these things around us, nor in ourselves, can we discover any sufficient reason for the immutable and necessary truths we possess concerning them.

This Augustinian Exemplarism makes a vital change in the Platonic theory of the Isolated Ideas (22),-no matter how much St. Augustine may have claimed to be inspired by the Chief of the Academy. Nor does the Augustinian differ any less from the Neo-Platonic theory, wherein the Ideas are a sort of product or inferior emanation of the One Supreme Essence $(\mathbf{8 5}, \mathrm{I}, b)$.

I01. Physics. - To explain the constitution of corporeal substances, St. Augustine admits the matter and form theory. Though in some places his idea of matter seems to be that of a chaotic mass brought forth from nothingness by an act of the Creator, still in several passages of his Confessions he refers to matter as to an undetermined something, incapable of existing without a form,in language that recalls the doctrine of Aristotle. Mindful of the matter and form starting-point he speaks of a quasi materia in referring to the angels. The relation of matter to the quantitative state of being is not referred to in St. Augustine's cosmology.

God has deposited in matter a hidden treasure of active forces, constituted according to the exemplars which correspond, in the eternal knowledge, with material essences. These are the seminal principles or rationes seminales (cf. 62, 3), whose successive germination, in the womb of matter, when circumstances are favourable,-acceptis opportunitatibus (De Gen. ad litt., vii., 28),produces the different species of corporeal beings. There is a distinct germ corresponding to each natural kind or species of body.

St. Augustine frankly subscribes to an esthetic and metaphysical optimism regarding the world, and assigns as a reason for such optimism the perfection of the Divine thought, which must necessarily have conceived harmonious relations between the various created essences.

102. Psychology.-St. Augustine is a psychologist in the 
fullest sense of the word. His analysis of psychical states testifies to his extraordinary power of introspection.

(I) Nature of Man.-The soul is spiritual. St. Augustine proves its spirituality from the peculiar abstract, universal, necessary character of our intellectual representations, and from the knowledge which the soul has of itself; its immortality he proves from its spirituality and from its possession of those same immutable and necessary truths. But about the problem of the soul's origin the African philosopher is evidently agitated by embarrassing doubts, - which were transmitted from his time down to the earlier epochs of the Middle Ages. On the one hand, the doctrine of the propagation of original sin inclines him towards traducianism or generationism, in which the soul of the child is supposed to be sprung from the souls of its parents. On the other hand, he does not explicitly reject creationism, which teaches that human souls are created by God $e x$ nihilo at the moment of their union with the body. Man has only one soul, single and simple (against Plato, 27), present throughout the whole body. United with the body it constitutes the human being.

The soul and the body preserve each its own substantiality. The soul makes use of the body ("homo anima rationalis est mortali atque terreno utens corpore," De moribus Eccl. Cath., I., xxvii.) and governs it ("regendo corpori accommodata," De Quant. Animae, xiii.). These statements clearly reveal their Platonic inspiration. St. Augustine never fully freed himself from Platonic influences, though here and there he makes use of formulas which are apparently inspired from other sources.

(2) The soul reveals itself in numerous activities which are not really distinct from its substance. Three faculties especially he recognizes, the memory, the understanding and the will,- - one of the numerous trichotomies in his psychology, and one in which he readily sees an image of the Holy Trinity. Let us consider a little more fully his teaching on intelligence and will.

(3) Intelligence.-A certain dogmatic postulate lies at the basis of his theory of intellectual cognition. Against the scepticism of the Academy, which he had at one time professed, he lays down the thesis that certitude exists and is necessary for happiness. A primordial certitude is that of our own consciousness ("noli foras ire, in te redi, in interiori homine habitat veritas," De 
Vera Relig., 72) and of the reality of a thinking self ("omnis qui se dubitantem intelligit, verum intelligit, et de hac re quam intelligit certus est," ibid., 73). We are also certain of the first principles of the logical, metaphysical and ethical orders, and of our intellectual representations of the external world (ratio, intellectus). If we repose in these latter a confidence which we refuse to our sense-perceptions with their fugitive and ever-varying data (Plato), it is because we know the rule or standard of their truth. This norma is the resemblance of our ideas to the Divine ideas, and, consequently, to objective reality (1oo). Our intellects were made to know the truth, because they are finite participations of the infinite intelligence. So that St. Augustine solves the criteriological problem by connecting it deductively with his theodicy.

The role of Divine illumination in intellectual knowledge deserves very special notice. St. Augustine is fond of calling God the sun of the soul, the light of the intellect, in which we see the immutable truth of things ("ea non posse intelligi nisi ab alio quasi suo sole illustrentur," Solil., I., i., c. 8 ; " in quadam luce sui generis omnia quae cognoscit intueatur," De Trinit., xii., I 5). The De Magistro represents God as the secret tutor of the soul. In the De Trinitate (xii., c. I-7) he distinguishes the ratio inferior (quae intendit temporalibus) from the ratio superior (quae intendit aeternis conspiciendis aut consulendis).

These expressions and others like them had an important influence-historically-in the Middle Ages: the difficulty of interpreting them explains why advocates of opposing systems quoted them in turn, each in support of himself. It is certain that St. Augustine did not use them in an ontologistic sense,-as if our intellects directly contemplated immutable truths in the Divine essence. It is no less certain that in several passages the illuminative action of God has reference to the creative act, to which the soul and intellect owe their reality (e.g., De Civit. Dei, x., 2). But it is a far more delicate point to decide whether St. Augustine meant to solve the question of the origin of our ideas, or whether those formulas of his are only so many paraphrases of his favourite doctrine on the nature of intellectual knowledge and the ultimate foundation of its certitude. Is God the efficient cause of our ideas, impressing them on our intellects as the seal leaves its impress on the wax (De Trinit., xiv., I 5),-or does 
he simply mean that the necessity and immutability of those objective concepts and judgments spring from the fact that the essences of all things are necessarily and immutably conformable with their uncreated exemplar, the foundation of all truth (incommutabilia vera)? ${ }^{1}$ The latter explanation-commonly accepted, ${ }^{2}$ and demanded by a certain number of passages,- - is more in keeping with the general spirit of the Augustinian theory of Ideas (10o), which is manifestly borrowed from Plato. But this perhaps does not exclude the former interpretation, which is likewise supported by other passages, and harmonizes quite as well with the data of the Augustinian ideogeny, and with the saint's proofs of the existence of God.

What is the origin of our ideas? - The Bishop of Hippo at first pronounced in favour of the Platonic theory of reminiscence (De Quantitate Animae, 20); and afterwards when he retracted this ideology, it was only because he rejected the Platonic theory of the pre-existence of souls. He substituted the view that the soul, by virtue of its rational nature, can discover its knowledge by reflection on itself. ${ }^{3}$

The function attributed by St. Augustine to the bodily senses in the production of sensation fits in with this innatist ideogeny. The psychic phenomenon is accomplished in the soul ("sensum puto esse non latere animam quod patitur corpus," De Quantitate Animae, c. 23, 4I): the body does not act on the soul at all, for what is inferior cannot act on what is superior. ${ }^{4}$ It is not the body that by its causal action impresses its image on the soul, but the soul that engenders in itself an image of the body. Our

${ }^{1}$ See the exposition of this question by Portalié (op. cit., vol. i., col. 2234 and fol.), who gives to this theory of St. Augustine an exclusively ideogenic sense: God produces in us successively our different ideas.

${ }^{2}$ It is very well expounded and defended in KLeutgen, La Philosophie Scolastique (1869), vol. ii., pp. 4 I I-5I.

3 “Illud quod dixi 'omnes artes animam secum attulisse mihi videtur . . .' non sic accipiendum est, quasi ex hoc approbetur, animam vel hic in alio corpore, vel alibi ... aliquando vixisse : et ea quae interrogata respondet, cum hic non didicerit, in alia vita ante didicisse" (L. xii., De Trinit., c. I5). "Fieri enim potest, sicut jam in hoc opere supra diximus (c. 4 ), ut hoc ideo possit, quia natura intelligibilis est, et connectitur non solum intelligibilibus, verum etiam immutabilibus rebus, eo ordine facta, ut cum se ad eas res movet quibus connexa est, vel ad seipsam, inquantum eas videt, intantum de his vera respondeat" (Retract., i., 8).

${ }^{4}$ Cf. Oтт, Des hl. Augustinus Lehre über die Sinneserkenntniss (Philos. Jahrb., I900, p. 50). 
ideas then are innate (Plato). ${ }^{1}$ And this being so, their actual presence in consciousness is explained by the repeated intervention of God, according as our intellects develop; as well as by one single act of $\mathrm{His}$ when, at the instant of its union with the body, He deposited in the soul a hidden treasure of knowledge.

(4) The Will plays a preponderating role in our psychic life.St. Augustine declares himself for its primacy of honour over the intellect. Not only do the inner senses and the intellect act at its command, but purity of the will and its desires is a condition of knowledge. Only the soul that is pure and holy ("quae sancta et pura fuerit," Lib. 83 qq., 66) can aspire to a knowledge of truth by the ratio superior. Truth is a good that every one must love with all the energy of his soul (99). Further, the adherence of the mind to certain difficult truths-like that of the union of soul and body-is secured only by the intervention of the will. Lastly, the will enjoys this other prerogative: it is psychologically and morally free.

ro3. Moral Philosophy.-Every being is good in so far as it is, or has being (Plato). God, or the Supreme Goodness, is the ultimate end of man, and the union of the soul with God is its supreme happiness (Eudemonism). The justice of God, and the necessary relations of essences are the basis of the absolute distinction between good and evil. The polemics in which St. Augustine was successively engaged with the Manichaeans, the Pelagians and the Semi-Pelagians, led him to the study of the problems of evil, liberty, grace and predestination. Evil does not share the metaphysical Empyrean with Good (Manichaeism). It is nothing positive; if it were, the scorpion would die of its own poison. It is a privation of good, and, in consequence, affects only contingent things which are endowed with a certain degree of goodness. As to the conciliation of human liberty with grace and predestination, the passages of St. Augustine's writings bearing on these points have given rise to centu ried controversies, principally theological ; and the most widely diverging systems quote the Doctor of Hippo each in its own favour. ${ }^{2}$

St. Augustine has exercised an immense influence on the

1 "When he began to write, St. Augustine taught the doctrine of innate ideas, and he clung to it to the end".-J. Martin, S. Augustin, p. 5 r.

2 On the Ethics of St. Augustine, see the recent work by J. Mausbach, Die Ethik des hl. Augustinus, 2 vols., Freiburg, Herder, rgog. 
destinies of theology (speculative and mystical), and of scholastic philosophy. ${ }^{1}$

104. Nemesius. - Bishop of Emesa in Phoenicia about the end of the fourth and beginning of the fifth century, Nemesius wrote a popular treatise $\pi \epsilon \rho \grave{i} \phi \dot{v} \sigma \epsilon \omega s \dot{\iota} \nu \theta \rho \omega \dot{\omega} \pi 0 v$, used in the Middle Ages, and which may be considered as the first complete and systematic manual of anthropology." The author endeavours to adapt to Christian dogma the psychological theories of antiquity. Eclectic like all the philosophers of his time, he borrow's from the Neo-Platonists their doctrine on the nature of the soul and its union with the body, from Galen his new physiological data, from the Stoics their system of the passions, from the Epicureans their theory of pleasure, and, finally, from Aristotle his conception of the will. From this syncretism obscurities and contradictions necessarily arise. Though he did not openly profess his sympathies for the Stagirite,-fearing to oppose the views of his contemporaries who preferred the spiritualism of Plato to the empirical naturalism of Aristotle,-still this homage quietly paid to peripateticism is significant, and heralds an approaching change in the trend of thought. ${ }^{3}$

105. The Writers of the Fifth Century. Pseudo-Denis.-From the beginning of the fifth century Patristic philosophy began to decline. The return of Neo-Platonism-reconciled with Christianity-is perceptible in the works of SYNESIUS OF CYRENE (363370 to 430). PRocolius, of the school of Gaza, wrote a treatise to combat the $\Sigma_{\tau o \iota \chi} \epsilon i \omega \sigma \iota s \theta \epsilon o \lambda o \gamma \iota \kappa \dot{~ o f ~ P r o c l u s . ~ F r o m ~ t h e ~ p o i n t ~}$ of view of the general movement of ideas, we find in this period only one notable man in Oriental literature: the author falsely

${ }^{1}$ Amongst other writers of the fourth century less directly connected with polemics, we may mention ST. Jerome ( ${ }_{4}+20$ ), author of the Vulgatc (translation of the Bible), of the Libcr de Viris Illustribus and of a translation of the Chronicles of Eusebius. His letters were in high favour with the clerics of the Middle Ages, and his history remained for many centuries the model for the annalist and chronicler. Rufinus (about 346-410), who was at first the friend of St. Jerome but later on severed this friendship owing to a dispute over Origen, translated a great many Greek works into Latin, notably the Ecclesiastical History of Eusebius, some homilies, and the $\Pi \epsilon \rho l \grave{\alpha} \rho \chi \hat{\omega} \nu$ of Origen. He wrote also some original treatises in Latin.

${ }^{2}$ Translated into English (The Nature of Man) by George Withers, London, I636.-TURner, History of Philosophy, p. 223.

"See Domanski, Die Psychologie des Nemesius (in the Beitr. z. Gesch. d. Phil d. Mitt., iii., I), Münster, rgoo. 
known under the name of St. Denis the Areopagite, the disciple of St. Paul. There has been a considerable amount of controversy about the real identity of this writer, and the question is not yet quite settled. His writings must apparently be ascribed to the end of the fifth or the beginning of the sixth century. They were unknown before the time of the great religious conference at Constantinople. The treatises of PSEUDO-DENIS on the Divine Names, Mystical Theology, the Celestial Hierarchy and the Ecclesiastical Hierarchy, largely inspired mysticism and scholasticism down to the time of the Renaissance. They contain a systematic exposition of the Christian Religion based largely upon allegory. One of the first imitators and admirers of this Pseudo-Denis was MAXimus THE CONFEssor (about 580-662).

The philosophy of Pseudo-Denis centres around the thought of God and of mystic union with God.

God in Himself has all the perfections of creatures. $\mathrm{He}$ is goodness, beauty, power, unity (treatise on the Divine Names). But by reason of His transcendence (treatise on Mystical Theology), $\mathrm{He}$ is to a certain extent ineffable, obscure, non-being (Plotinus).

God the Origin of things is, above all, goodness and love. Other beings are effusions of His goodness (processiones divinæ), just as light is an effusion from the sun (Plato, Plotinus); they are the object of His providence. Between man and God there is a hierarchy of celestial spirits (treatise on the Celestial Hierarchy), of which the ecclesiastical hierarchy is an imperfect copy (treatise on the Ecclesiastical Hierarchy).

God the End of things draws all things towards Himself. Goodness, after descending to the creature, returns to its source. The deification which results from this return extends even to organic and inorganic beings. For man the return to God is realized by raptures of knowledge and transports of love.

Numerous parallels ${ }^{1}$ go to show that Pseudo-Denis was influenced principally by Proclus, not only in a multitude of individual doctrines, but also in his general terminology and formulas. His mysticism, moreover, reveals the symbolism, the allegories, the mystic states and ways of the Alexandrians, their theory of prayer and of the Divine character of ecstasy "where like is known by like". But, notwithstanding those borrowed

\footnotetext{
${ }^{1} \mathrm{H}$. Косн, Pseudo-Dionysius Areopagita in seinen Beziehungen zum NęoPlatonismus und Mysterienwesen (Mainz, r9oo).
} 
elements, the philosophy of the Pseudo-Denis is theistic, not pantheistic; for it affirms a substantial distinction between God and the creature. And his mysticism is Christian ; for it is based on Divine grace. It is true, however, that the obscure and exalted terms in which the author expresses himself may be interpreted in a pantheistic as easily as in an individualistic sense. ${ }^{1}$ They misled many in the Middle Ages, when the heterodox mystics appealed to Pseudo-Denis just as freely as the orthodox (see Medieval Mysticism).

By their race, their mode of thought and the influence they exercised, the writers who flourished from the fifth century onward belong rather to the medieval period proper than to any earlier epoch. 


\section{MEDIEVAL PHILOSOPHY.}

\section{INTRODUCTORY CONSIDERATIONS.}

\section{$\S$ I. General Remarks.}

106. Scholastic Philosophy and Scholastic Theology.-Scholastic philosophy, which represents medieval philosophy par excellence, naturally consists, like every other philosophy, in a rational investigation of all or some of the problems raised by any attempt to explain fully the universal order of things. We find that scholastic philosophy is almost always confounded with scholastic theology, which, in its dogmatic aspect, is a body of doctrines received through a positive revelation from God.

This confusion would entirely pervert the meaning of the historical study we have undertaken in those pages; for it would make the history of medieval philosophy a department of the history of religions. It is expressly condemned by the princes of philosophy in the thirteenth century, who laid down clearly the distinction between the philosophical and theological sciences. Their theory on this point will be expounded when we come to treat of the scholastic synthesis (see Second Period).

In the present history there is question of scholastic philosophy, and of scholastic philosophy alone. When we employ the term scholasticism simply, it is to be taken as synonymous with scholastic philosophy.

107. Definition of Scholastic Philosophy.-We may define the name given to scholastic philosophy, or the thing which the name represents. The former definition would be nominal, the latter real. To define a thing is to tell what the thing is, and what exactly distinguishes it from every other thing. Real definition is more perfect the more completely it expresses the nature of the thing under consideration.

We may employ this criterion of the relative perfection of real definitions in estimating the value of two groups of them, viz.: 
intrinsic and extrinsic definitions. Everything in fact is capable of receiving both these kinds of definition. If we investigate what the thing is in itself, what are its constitutive elements, and how these are characterized, we get at the thing to be defined as it is in itself, in an absolute and intrinsic way. On the other hand, if we examine it in its relations to other things we arrive at a knowledge of it that is relative and extrinsic.

Now, as a philosophy is constituted by its doctrinal content, those definitions only, of scholastic philosophy, which are based on its doctrines, are intrinsic or absolute. To seek extrinsic or relative ideas of scholasticism would be to turn one's back on its doctrinal content, and to neglect its real meaning and character for the sake of establishing relations between itself and doctrines foreign to it. But it is to comparisons of this latter kind, sometimes even to an etymological study of words, that the definition of scholasticism has been hitherto confined by almost all its historians. We possess, in consequence, a collection of erroneous or imperfect definitions. It will be necessary to reject the former, and to determine the elements of truth contained in the latter.

We may arrange all of them under three heads. First, we shall examine verbal definitions (108). Next come real, extrinsic definitions. Scholastic philosophy has been described by establishing its relations: (I) with its language and methods of exposition (109); (2) with the Middle Ages, or the period of its historical development (Iro, II); (3) with scholastic theology $(\mathbf{1 2 = 1 1 5})$; (4) with ancient philosophy (116). Under a third head we shall deal with certain definitions that are real and intrinsic to the doctrinal content of scholasticism, but which are incomplete and inadequate (1/7).

ro8. Verbal Definition. Scholasticism and the Schools.-By "scholasticism" Hauréau understands philosophy as it was taught in the schools of the Middle Ages." Picavet also calls "scholasticism" the "child of the schools". 2 This definition is purely etymological and verbal; for in the Middle Ages whoever was titular of a lectureship in a schola received the title of scholasticus. It does not convey any information on the subject of our enquiry. We may know that by schola is meant the lectureship par

${ }^{1}$ Hist.philos. scol., i., p. $3^{6}$; Dictionn. sciences philosoph. (Franck), under the word scolastique.

${ }^{2}$ Revue Philos., 1902, p. 185; Grande Encycl., under the word scolastique. 
excellence, that of philosophy and theology, the two sciences which were regarded as the crown of all knowledge; but this will not help us to understand or form any opinion on the teaching itself that proceeded from those medieval chairs. Moreover, as all knowledge was imparted orally in the Middle Ages, scholasticism, understood as the "child of the schools," might not mean philosophy or theology any more than medicine or law. And it would appertain no more to the Middle Ages than to our own time, seeing that the publication of books has not put an end to oral teaching. By a logical extension of the meaning of the term, it can be and has been said that "there are scholastics among the Neo-Platonists, and among the followers of Kant, of Hegel and of Cousin ". ${ }^{1}$ But the term has no recognized application outside the Middle Ages, and we doubt if it ever will have.

109. Definition of Scholasticism by the use of certain Teach = ing Methods. - It is unnecessary to dwell on the superficial truisms emphasized by those who define scholasticism by the "peripatetic" language it used, ${ }^{2}$ or the technical terminology it cultivated. ${ }^{3}$ We might as well define Grecian philosophy as the philosophy taught in Greek, or Kantism as the philosophy that can be studied only with the aid of a certain specially compiled glossary.

Others regard scholasticism as simply a method, a certain scientific manner of discovering and propagating truth. By method they understand either this or that particular procedure, or else the whole pedagogic system in all its branches:-

(I) Scholasticism is the preparation of (any) science for the purpose of school teaching (Schulwissenschaft), its "cut-anddried" arrangement in the rigid and highly artificial compartments of the medieval schools, as opposed to the chaotic disorder in which its materials were left by the Fathers of the Church. ${ }^{4}$

(2) Scholasticism is sometimes defined not as pedagogical arrangement in general, but as one special type of such arrangement. Thus, we find it described as the syllogistic method

\footnotetext{
${ }^{1}$ Picavet, in the Moyen age, I902, p. 34. In this he is more consistent than Haureau, who would have the decay of scholasticism synchronize with the invention of printing.

${ }^{2}$ E.g., HuEt, Recherches hist. et crit. sur la vie, les auvres et la doctrine de Henri de Gand (Ghent, $\mathrm{r} 838$ ), p. 95.

${ }^{3}$ Hogan, Clerical Studies, p. 67.

${ }^{4}$ See Willmann, Gesch. d. Idealismus, ii., $\$ 67$, nn. 2 and 4.
} 
"drawing inferences ad indefinitum," ${ }^{1}$ or again as the use of dialectic in defence of catholic dogma.

Those definitions have this defect in common that they regard merely the formal arrangement without touching the material, the doctrine itself, of scholasticism. Pedagogic arrangement in general, and indeed a definite, specific method, may be applied to any philosophy, to Kantism no less than to Thomism. Moreover, the application of method in the Middle Ages was not confined to philosophy: in accordance with the spirit of the scholastic logic, it was extended to all branches of knowledge. Then, as regards the syllogism, we may observe that it was not the sole procedure employed by the scholastics. Finally, the application of dialectic to the elucidation and defence of dogma concerns not philosophy, but exclusively scholastic theology. A fuller exposition of these various methods below will illustrate these few remarks (113, 14, and farther on: The Theological Movement in the Twelfth Century)."

110. Identification of Scholastic with Medieval Philosophy : State of Opinion.- Numerous historians understand by scholasticism the philosophy of a whole epoch, describing it as the philosophy of the Middle Ages. For Cousin, Hauréau, Ueberweg-Heinze, Erdmann, Picavet, etc., all who lived and philosophized in the Middle Ages are scholastics. This chronological definition in the domain of philosophy corresponds to the definition of the literary or political Middle Ages as the ages that lie between antiquity and modern times. It is easy to account for its origin.

Up to the comparatively recent date at which original historical researches into medieval philosophy were commenced, it was customary to regard the speculations of the Middle Ages as one homogeneous whole with certain common characteristics of a very vague and general sort; and to this "whole" the no less indefinite title of scholasticism was given. This designation has been retained even by those whose works show clearly that the

\footnotetext{
${ }^{1}$ Fouillee, Hist. de la philos., p. I98 (Paris, I883). Cf. Diderot, "Scholasticism is less a philosophy than a certain dry and rigid sort of argumentation" (Oeuvres complìtes, t. xix., p. 362).

2 We might classify with the above "definitions by method," the notion that scholasticism is a sort of vague and ill-defined mentality, a bias or tendency or spirit, peculiar to the whole intellectual output of the Middle Ages-a mentality that is almost invariably understood in an unfavourable sense.
} 
supposed homogeneity of medieval thought is merely apparent, giving place, on closer analysis, to very real diversity. For, a fact of capital importance has been brought to light: there existed in the Middle Ages numerous philosophical systems, some connected with, others isolated from, one another; and by the assertion of contradictory principles many of these systems came into inevitable conflict. Nor is this fact, which new researches every day confirm, in any way surprising. It was a priori unlikely, to say the least, that the twenty generations of the Middle Ages would have remained satisfied with one and the same conception of the universe-the scholastic - and that no dissentient voice should have marred the intellectual harmony. Such a phenomenon would indeed have been unique in history, for history everywhere offers us the spectacle of dominating, but nowhere of monopolizing, systems.

Now this new fact should evidently influence a history which purports to give a narrative of the logical evolution of ideas and not merely a catalogue of philosophical names and events. Should it not therefore also influence the terminology and bend it to its own special needs? Two points of view are legitimate: Just as the title "Grecian Philosophy" is given to the whole collection of different systems which saw the light in Greece, so too might we take the term "Scholastic" as a huge label for the whole complex and chaotic collection of medieval systems. But it is also possible to restrict and confine the term "Scholastic" to one group of medieval systems, excluding all the others. And this latter is what we purpose to do, both because it obviates many difficulties and especially because it harmonizes fully with the few great conclusions which form the kernel of the present book and sum up the philosophical history of the Middle Ages. The question of terminology thus becomes one with the main problem of the doctrinal interpretation of the medieval systerns.

III. Correct View. Scholastic Philosophy forms one Group among many Medieval Systems.-(I) Disadvantages of identifying scholastic with medieval philosophy.-The first is that of applying the same name to things that are different and opposite. Whithersoever we turn in medieval philosophy we find the doctrinal horizon expanding and varying. Western philosophy branches into many systems. From the ninth century onward a well-defined pantheism, arising out of the Neo-Platonic, is seen 
in conflict with numerous more or less developed forms of Aristotelian individualism. The thirteenth century marks the commencement of a long drawn-out struggle between the Averroist system, with its vehement defenders, and the great body of doctrine to which Albertus Magnus, St. Bonaventure, St. Thomas Aquinas, Duns Scotus have attached their names. The farther we advance from the thirteenth century the greater was the ferment of ideas-until the coalition of all the Renaissance forces delivered a final assault on the philosophy that had been dominant for centuries.

Nor is this all. For, side by side with Western philosophy there developed, down through the Middle Ages, other and independent lines of thought: the Byzantine philosophy on the one side, the Eastern philosophies on the other. These were important currents and all of them gave birth to many systems, each with a well-marked individuality of its own. All those various medieval efforts at philosophical synthesis stand apart from one another, irreconcilable. Even though some particular theories may be found common to two or more of the various groups, still these theories will always be found to have got special and characteristic colourings in each group, and to be more or less modified by the contexts of which they form a part.

Therefore, from the doctrinal point of view - which is the only one that regards philosophy for its philosophical content-it is quite impossible to find in those heterogeneous systems of the Western, Eastern and Byzantine Middle Ages any kindred characteristics, any common spirit or genius that would allow us to call them all alike by the common name "scholastic". ${ }^{1}$

The title "scholastic" is, moreover, by universal agreement, applied first of all to certain exceptionally great and noted philosophers-Anselm of Canterbury, Alexander of Hales, Bonaventure, Thomas Aquinas, Duns Scotus-those precisely whose giant figures alone emerge like so many lofty pinnacles from out the thick mist that darkens the Middle Ages. Can we, then, to-day, when we know the struggles in which these men were

\footnotetext{
${ }^{1}$ It only leads to confusion to describe all the conflicting Eastern, Western and Byzantine philosophies of the Middle Ages as "scholastic". In order to find a basis for such a classification one is obliged to import extra-doctrinal, i.e., nonphilosophical considerations of a vague and general kind,--marks which might perhaps suffice to indicate a civilization, but which are too wide to serve as the real and intrinsic definition of a philosophy.
} 
engaged, apply their family name to those who made war upon them,-or to philosophers of other climes, men of whose very existence they were often unaware?

But if we restrict the term scholastic philosophy to one group of medieval systems, those inconveniences will disappear. Names are conventional substitutes for things. When the thing indicated by the name is simple and unique, the name is intelligible to all and easily fulfils its function of substitute. But when the apparent simplicity is found to conceal a real complexity, language must both grow and grow accurate. The terminology of the biologist will become richer according as the microscope reveals new and strange constituents in a living cell where the latter was heretofore believed to have been homogeneous. The historian of medieval philosophy feels the same necessity. When he gives distinct names to distinct systems he is merely obeying the law that governs the development of all scientific vocabulary.

Besides, when we come to determine which of the medieval systems is best entitled to be called scholastic we shall find that the choice we have made is most in keeping with the language of tradition. There is no question of changing the latter but only of making it clearer. ${ }^{1}$ Ceteris paribus, those who have been for centuries, and are still at the present day, commonly designated as the princes of scholasticism, have obviously the prior right to the title they have always borne in the past. And, last though not least, our solution of this problem of historical terminology will emphasize several leading facts of history, facts which may be summed up in the following propositions: There exists a definite, specific philosophy which was taught in common by a group of the leading Western philosophers of the Middle Ages. This common synthesis does not sterilize originality of thought in its various propounders. It occupies the leading place among medieval systems, and it rightly claims the name of scholastic philosophy.

(2) There exists a philosophy which was taught in common by a group of the leading Western philosophers of the Middle Ages,

${ }^{1}$ We entirely endorse these apt observations of RousseLot, l'Intellectualisme de S. Thomas (Paris, rgo8), p. ix.: "The fact is that the current usage, deceived by superficial analogies, has included incompatible elements under one and the same term and carried this contradiction into the very concept for which the term is made to stand". 
among whom the names of Anselm of Canterbury, Alexander of Hales, Thomas Aquinas, Bonaventure, Duns Scotus and William of Ockam are perhaps the most widely known. These men present close family likenesses: they all subscribe to a large number of fundamental theories, the very theories, in fact, which determine the whole structure of a philosophical system because they deal with the great leading problems which every philosophy has to face.

And the system of which we speak is not the work of any one day, or of any one man. It was not born of the genius of an Albertus Magnus or of a Thomas Aquinas: centuries were needed to build up the vast body of doctrine known as scholasticism. It is a family inheritance which was slowly amassed in the eleventh and twelfth centuries, which was consolidated in the thirteenth, and which was wasted and squandered little by little from the end of the fourteenth. It was defended against invaders who would fain demolish it and build upon its ruins. Wars were waged around it; and the defence of it, energetic and triumphant in its golden age, feeble and unsuccessful in the age of its decay, will explain how men like Thomas Aquinas, Bonaventure and Duns Scotus, while plunged in endless controversies with one another about particular questions, went ever hand in hand when there was question of protecting their essential and common convictions from the attacks of common enemies. The ultimate reason for the existence of such a common intellectual patrimony - not only in the domain of philosophy, but also in theology, science and art-lies in this characteristic medieval conviction: that truth is not a personal acquisition discovered by each individual for himself, but a great treasure which is handed down and increased from generation to generation.

(3) The unity of scholastic philosophy does not involve sterility of thought among its various representatives. - A monument in ideas, scholasticism is comparable with those monuments of stone erected during the same centuries, and of which men of many generations were the architects and builders. The comparison is a suggestive one: for the corporations in charge of these edifices left the stonecutters a free hand to follow out each his own artistic inspiration in executing the designs entrusted to him. It was thus that the men of the Middle Ages succeeded in giving a unity of plan to their cathedrals, while inviting even the lowliest 
of their artisans to contribute something original to the vast design.

So, in scholastic philosophy, all were agreed on the organic and essential questions, on a doctrinal minimum which differentiates the scholastic from every other system. But though this fundamental unity had its influence on the solutions proposed for special questions, it proved no bar to diversities of opinion and divergencies of interpretation: and hence the distinction between the individual systems of an Alexander of Hales, a Bonaventure, a Thomas Aquinas, a Duns Scotus, a William of Ockam. The common scholasticism, as we purpose to outline it, is the product of abstraction; the living reality was always this or that individual's system, worked out in all its details. So too, while Gothic Cathedral is a notion that applies equally to the churches of Amiens, Beauvais, Paris, etc., every real Gothic cathedral is, needless to say, a definite, individual building.

We see, then, how scholasticism may mean, according to the point of view from which we regard it, either one (abstract) system or a group of (concrete) systems closely related with one another. Like the various members of a single family, each of the scholastics reveals his own individuality, and some among them are far superior to others.

(4) This common scholasticism was the dominating system in the Western World.-It claims the allegiance of all the greatest names. It likewise boasts of having the vast majority of followers; for, prior to the twelfth century most philosophers were contributing in one way or another to its construction, and subsequent to the thirteenth it was advocated by hundreds of distinguished teachers who published and perpetuated its leading solutions.

(5) There existed down through the Middle Ages non-scholastic (or $a$-scholastic) systems, that is to say, philosophies whose fundamental principles were other than those of scholasticism. ${ }^{1}$ The appellation is a relative one. In fact, the philosophies opposed to scholasticism-the two principal being Eriugenian pantheism and Latin Averrorsm-are of very secondary importance when we compare their influence, their merit and the number of their adherents with those of the great system they endeavoured to supplant. From another point of view those systems are antischolastic, for, existing side by side with the scholastic systems, 
they came into unavoidable conflict with the latter. Needless to say, the non-scholastic systems deserve the same attention from the historian as the scholastic: their study is of the highest utility for a proper and adequate presentation of the whole mentality of the period.

Hence we conclude: the name scholastic philosophy will be used with advantage to indicate, not all the philosophies of the Middle Ages, but one definite system, and that the most widespread in the whole intellectual history of the IVestern Middle Ages. Scholasticism is the philosophy par excellence, but not the only philosophy, of the Middle Ages.

112. Definition of Scholasticism by its Relations with Scholastic Theology: State of the Question.-Of all the current notions about scholastic philosophy the one most commonly entertained is that which connects scholasticism with Christian dogma. Servant or handmaid for some, philosopliza ancilla theologiae (Cousin, Ueberweg-Heinze, Freudenthal, Windelband, etc.), companion or helper for others (Gonzalez, Erdmann, Willmann, Picavet, Blanc), scholasticism is conceived by all as philosophy under the direction and control of catholic theology. Some authors ingeniously widen the scope of such statements. Just as we might call scholastic whatever is a product of the schools (1o8), so do they call scholastic all philosophy subject to any dogma whatsoever. The scholasticity of a philosophy would be measured by the extent of its subjection, and the diversity of the ruling dogma would determine the different species of scholasticism. Thus it is we hear of a Jewish scholasticism (Zeller), of an Arabian scholasticism (Carra de Vaux) and of a Protestant scholasticism (E. Blanc).

To understand and appraise aright the attitude here revealed, we must outline, in its broad, leading features, the system of relations established in the Middle Ages between philosophy and theology. In virtue of this system, adumbrated in the early Middle Ages and completed in the thirteenth century, these two sister sciences developed on parallel lines and were indeed interdependent in their evolution. The relations in question are of various kinds, non-doctrinal and doctrinal.

113. General Relations of Philosophy to Theology in the Middle Ages.- - ( I) Non-doctrinal relations: (a) of origin.--It was in the domain of theology that numerous problems of scholastic 
philosophy had their origin, especially in the early Middle Ages (172).

(b) Relations based on Methods of Teaching.-Theology being regarded as the queenly and sacred science, the whole organization of teaching was devised and developed with a view to securing its fullest cultivation. Of this we have ample evidence in the programmes of the monastic schools and, later, of the universities. It was every one's ambition to become a theologian either after having been, or while still remaining, a philosopher (131, 132 and Second Period).

(2) Doctrinal relations: (a) of Co-ordination.-Philosophy was regarded as distinct from theology in the thirteenth century (106); each science had its own constitutive methods and principles. At the same time there are certain constitutive methods which resulted from a positive collaboration of both sciences. Such, for instance, is the dialectic method in theology (see below, The Theological Movement in the Twelfth Century).

(b) Relations of Subordination.-Philosophy was, in certain matters, subordinate to theology. It is from this historical thesis, which we shall explain and demonstrate in its proper place (see Second Period, exposition of scholastic system), that the definitions we are now considering are all derived. But can an adequate or satisfactory definition of scholastic philosophy be derived from the theological control to which its doctrines were subjected? This is the question we have here and now to consider.

114. The Primacy of Scholastic Theology yields an Unsatisfactory Definition of Scholastic Philosophy,-whether we make the scholasticity of a philosophy a generic notion and differentiate it by this or that ruling theology, or call scholastic those philosophies only which were in harmony with the religions of the Middle Ages, and notably with catholicism. And that for the following reasons :-

(I) Although the reality of this subordination of philosophy to medieval theology is beyond all question, nevertheless to define scholasticism by this subordination would be to leave unmentioned that precisely which constitutes it,-its doctrinal content. Such a definition would include only attributes external to the thing to be defined: and such attributes are of necessity quite secondary in importance, For, 
(2) Whatever be the cause, the nature and the extent of this subordination of scholasticism to theology, is it not evident that the philosophy will have a meaning of its own-apart altogether from the dogma which it may illustrate-in the measure in which it offers a rational explanation of things, of reality? Even in regard to the theories that have a direct bearing on dogma there are and there must be grounds for judging and valuing them, other than their dependence on dogma.

(3) This is all the more evident when we remember that medieval scholasticism is largely made up of doctrines having no direct bearing on catholicism. There was nothing, for example, in catholic dogma to oblige the scholastics to explain the constitution and development of physical nature by the theory of primary matter and substantial form. Aristotle, who first formulated the theory, did not concern himself about its conformity with catholicism-and for a very good reason-or with any other religion; and, on the other hand, many of the early medieval philosophers embraced atomism, notwithstanding their catholicity. But will any one say that a theory so fundamental in scholasticism as the matter and form theory is, should be ignored in an account of the scholastic explanation of the cosmos; or that the theory has no purely philosophic value in the philosophy of Aristotle; or that it ceases to have any such value by the simple fact of its adoption in the Middle Ages and its co-ordination, in a common synthesis, with theories controlled by dogma? And examples of this kind could be multiplied. The fact is that the ground which is common to scholastic philosophy and theology is very much narrower than these sciences themselves: and outside this common territory an attitude of subordination of either to the other would be meaningless. Such subordination is accordingly insufficient of itself for a definition of scholastic philosophy.

(4) If we take "scholastic" in the sense of "a philosophy subordinate to any dogmatic code whatever," the very same difficulties reappear in a more general way. Catholic scholasticism would be a variety analogous to the Jewish, the Arabian and the Protestant varieties. The specifying element of each would be a religious and dogmatic element, a non-philosophic element, therefore; and a philosophy would be thus-inadequately (I) - defined by something not philosophic. Moreover, whether the ruling dogma be Brahminism or Mahometanism or Catholicism 
or Protestantism, the subordinate philosophical theories will still have a sense of their own from the exclusively rational or properly philosophical point of view (2),-not to mention the fact that a complete system like scholasticism will embody a large number of solutions entirely uncontrolled by any dogma, for the simple reason that dogma has got nothing to say to the questions concerned (3).

(5) Finally, were we to define scholasticism as a philosophy in harmony with dogma, we should stumble on this unexpected consequence, that in one and the same scholasticism, - the catholic, for example,-we should meet with many conflicting and contradictory types. For, who would venture to assert that the Augustinian is reducible to the Thomistic philosophy? And yet, is St. Augustine less catholic, or otherwise catholic, in his theology than St. Thomas? In the Middle Ages no one openly opposed dogma, but each interpreted it after his own fashion. The pantheists introduced their allegorical or figurative interpretation of the Scriptures, and the Averroists their doctrine of the two truths, in order to safeguard-or make believe of safeguarding-their orthodoxy; and all of them boasted of possessing the real sense and spirit of the Gospels. At the threshold of the Renaissance, Nicholas of Cusa, a cardinal of the Roman Church, could find the most ingenious connections between his doctrine on the coincidentia oppositorum and his catholicism. The accommodation is not so happy, we may grant, in these latter cases, but that is the fault of the unsoundness of the philosophies themselves and does not touch our argument.

115. Corollary.-It appears then that the relation of scholastic philosophy to theology is real, but insufficient to define the former. This philosophy should accordingly be studied from two distinct points of view :-

(I) In and for itself; and with this study the historian of philosophy is mainly concerned;

(2) In its relation to theology; a secondary study, though one that may not be neglected.

I16. Scholastic Philosophy Defined by its Relation to Ancient Philosophy (cf. 227).-(I) Scholasticism and Aristotelianism.An old prejudice, born of the Renaissance, would see in scholastic philosophy a mere servile imitation of the peripatetic philosophy. If this were true, to define the one would be to define the other. 
It is incontestible that the scholastics gave their allegiance to Aristotle, not only in the thirteenth century, but even in the earlier Middle Ages. John of Salisbury calls him "The Philosopher," just as Rome was "The City," par excellence (Polycrat., vii., 6). For Albertus Magnus, Aristotle is the "archidoctor philosophiae" (De propriet. element., I, i., tr. I, c. I). And, what is more, the scholastics had a knowledge of Aristotle that many of our moderns might envy.

But the Aristotelianism of the scholastics is entirely free from the reproach of servility that has been so long and so readily cast at it. The scholastics as a rule attached little weight to the argument from authority, regarding it in fact as the weakest of all arguments in matters of philosophy. On this point we have numerous testimonies. And, as a matter of fact, many of Aristotle's theories were rejected by the scholastics; while of those that were adopted by them some were perfected, others corrected and all alike submitted to an independent examination on their merits, and incorporated into a new setting that was the genuine and original creation of the medieval scholastics. What we have to say in the sequel will, we hope, bear out this sufficiently to bring conviction to the mind of the reader.

Besides, the accusation of servility cannot stand before the fact that scholasticism draws on quite a number of other antecedent systems besides that of Aristotle.

(2) Scholasticism and Neo-Platonism.-Through the Fathers of the Church and Pseudo-Denis, and in the thirteenth century through the Liber de Causis, the writings of Proclus and the Arabian philosophers, many Neo-Platonic theories were imported into scholasticism. But in the process they were stripped of all elements of pantheism and emanation, that is to say, of the very soul of Neo-Platonism. Hence we must hold as false the contention of M. Picavet, that Plotinus was "the real father of scholasticism". ${ }^{1}$

(3) Scholasticism, Platonism and Augustinism.-Plato and St. Augustine excited an admiration as enthusiastic as that of which Aristotle was at any time the object. St. Augustine especially, the greatest and best known of the Fathers of the Church, did in truth deeply inspire scholasticism: down to the close of the

${ }^{1}$ Picavet, Esquisse d'une histoire générale et comparée des philosophies médiívales, 1907, ch. v. 
twelfth century his influence on scholastic thought was distinctly preponderant. And even in the thirteenth century which saw the triumph of peripateticism, an important group of scholastics clung steadily to the Augustinian tradition.

(4) Scholasticism and the other systems of Grecian and Patristic philosophy.-Pythagorism, the Atomism of Democritus, Epicureanism and Stoicism occupy a place, secondary indeed but for a long time entirely ignored, in the philosophical controversies of the Western Middle Ages.

To sum up: What guided the scholastics in their borrowing from the past was not the blind cult of a few figures of history, but the pursuit of truth for its own sake. Scholasticism sought light from all the philosophies that went before it, but to none of them did it become a slave.

117. Incomplete Intrinsic Definitions.-All the definitions hitherto examined contain a soul of truth, but they likewise contain the common error of defining scholastic philosophy by something that is not philosophy. An intrinsic definition, one based on the doctrine itself propounded by scholasticism, can alone lead us to a knowledge of the constitution of the latter systems. Now, philosophy, in regard to its doctrinal content, ${ }^{1}$ may be taken in a stricter sense to denote a system, i.e., a completely unified body of theories concerning the universal order of things; or in a wider sense to denote one or more special doctrines in reply to one or more of the problems raised in the whole course of philosophical inquiry.

The latter is the point of view of those who reduce scholasticism to a dispute about Universal Ideas (Taine; Hauréau, who calls this the scholastic problem par excellence). But a philosophy cannot be appreciated by merely indicating the problems it deals with: these are the same for all philosophies; we must go farther and examine the solutions ${ }^{2}$ it offers us. And apart from all this, scholasticism can be shown to have dealt with quite a number of questions altogether distinct from the Universals. A definition of scholasticism that would limit the latter to the "Universals"

1 Our point of view is not doctrinal but geographical or chronological when we speak of Grecian, Western, Byzantine, Asiatic, Modern philosophy, etc.

${ }^{2}$ Willmann takes account of the solutions when he finds the leading characteristic of scholastic philosophy in the reconciliation of idealism and realism through the immanence of the intelligible (ideal) in the sensible (op. cit., p. 322). This, let us repeat, though correct, will not suffice to define scholasticism fully. 
problem, might indeed be correct so far as it went, but would be of necessity incomplete.

The same objection militates against the definition of scholasticism as the philosophical "problem of the ontological constitution of being". ${ }^{1}$ This formula, though wider than Willmann's, embraces only metaphysics, passing over all the questions and investigations that constitute the other important branches of scholastic philosophy.

118. Elements of a Complete Doctrinal Definition.- Scholastic philosophy is a synthesis or system, wherein all the questions of philosophy are treated and all their solutions harmonized, co-ordinated and made $(\sigma \dot{v} \nu \tau i \theta \eta \mu \iota)$ to stand together. An intrinsic, doctrinal definition of scholasticism should be based on these solutions. It must needs be complex, like the thing itself to be defined. Since the problems and answers were slowly evolved during the whole scholastic epoch, it will be better to hold over our suggested definition or outline of scholasticism until we have become acquainted with its doctrine as conceived by its ablest exponents at the period of its highest development. (See Second Period.)

119. Conclusion.-The definition we have chosen, though intrinsic and doctrinal, does not exclude all notions of a relative character. Moreover, to know a thing in its entirety, we must not only analyze the thing in itself, but examine its relations with other things. And therefore the historian, after having studied the philosophy itself of any epoch, and after having weighed and measured the significance of all the other manifestations of the intellectual life of the time, has a right to institute a third group of researches into the reciprocal influences of all these various departments of a civilization. Scholasticism is related not with theology and ancient philosophy alone, but with the scientific, artistic, political, economic and social life of the Middle Ages; for in the concrete reality of man's social life all human events and activities are interwoven and interconnected.

120. Bibliography. - Introductory, leading ideas are to be found in the opening pages of most general treatises (\$3). De Wulf, La notion de la scolastique (Revue philosoph., June, I902); Scholasticism Old and New. \$\$ I-ro (Dublin, Gill; New York, Benziger, 1907), where the reader will find a fuller development of the ideas in the foregoing paragraphs, together with a complete bibliography.-

${ }^{1}$ Morinus, Dictionnaire de philosophie et de théologie scolastique (1856), p. 23. 
PiCavet, works referred to in footnotes, and also: La valeur de la scolastique (in the Bibliothèque du Congrès de Philos., t. iv., I902); L'origine de la phil. scol. en France et en Allemagne (Biblioth. école htes. études, t. i., I888); La Scolastique (R. internat. enseignement, April, I893). We have referred to the author's views.Freudenthal, Zur Beurtheilung d. Schol. (Archiv f. Geschichte d. Philos., iii., I89o). Somewhat vague.

JACQuin and De Wulf, Discussion de la notion de la scolastique, in the Revue d'histoire ecclésiastique, t. iv., I904, pp. 429. 7 I6.-RICHARD, Étude critique sur le but et la nature de la scolastique (R. Thomiste, Ig04).-P. von Holtum (in Philos. Jahrh., I905, I906), Sur rapports de philosophie et théologie, approximates to views in our text.-Diego, Libéralisme philosophique (Études francisc., Oct., I904). Confused. Replies of Pìre Hadelin, Diego, and De Wulf, ibid., I905.-Dewey, Scholasticism (in Baldwin's Dict. of Philos. and Psychol.). Weak.-Delacrorx, La Philos. médiévale latine jusqu'au xive siècle (Revue synth. histor., 1902). Revue bibliogr. génér. des ouvr. récents.-Lindsay, Scholastic and Medieval Philosophy (Arch. f. Gesch. d. Philos., rgor). Weak.-Blanc, Introduction à la philosophie (in the Pensée contemporaine, I904, 1906). Disputes our conclusions and makes scholasticism a harmony of reason with faith.-Rickaby, Scholasticism (London, Constable, I908). General sketch; borrows our views.-J. L. PERrier, The Revival of Scholastic Philosophy (New York, I9og, ch. i., viii.). Also adopts many of our views.MANSER, Ueber Umfang $u$. Charakter der mitteralterlichen Scholastik (HistorischPolitische Blätter, Bd. I39, I907).

Talamo, L'aristotelismo della scolastica, etc., 3rd edit., Siena, r889. (French trans., 1876.) Good, though might be more methodic.-Schnerd, Aristoteles in der Scholastik (Eichstädt, I875).-CHollet, L'aristotélisme de la scolastique (in Vacant's Dictionn. de Théol. cath.). A general view in the light of recent works.

Huir, a series of articles on Platonism in the Middle Ages in the Annales de la philosophie chrétienne, New Series, t. 20-2I.-PICAvet, in his works, points to various influences other than Aristotelianism.

\section{§ 2. Division of Medieval Philosophy.}

121. Chronological Limits of Medieval Philosophy.-According to the generally received chronology, the Middle Ages extend from the death of Theodosius, in 395, to the capture of Constantinople by the Turks, in I 453. But it is only with a twofold reservation that we can accept these chronological limits in regard to medieval philosophy when once we realize that the evolution of scholasticism was the great event of capital importance in the philosophy of those centuries. On the one hand, the earliest writings in which we can detect any trace of a fresh line of thought, are posterior to 395. Precocious and wildly flavoured fruit of the new civilization, they did not make their appearance until the fifth century, or even later. ${ }^{1}$ And on the other hand, medieval

${ }^{1}$ Willmann (op.:cit., ii., 342) sees the beginnings of scholasticism in the early half of the eighth century, in the $\kappa \in \phi \alpha$ גaı ment of each part of St. John Damascene's $\pi \eta \gamma \eta \dot{\eta} \gamma \nu \omega \sigma \epsilon \omega s$ (see below). 
and modern philosophy overlapped each other for a long time, not having been rent apart by any such violent social upheaval as that which compassed the destruction of the Roman Empire and the rise of the Germanic nations. The destiny of medieval philosophy may thus be clearly traced far beyond I453, even down to the seventeenth century.

The autonomous evolution of medieval philosophy, and more especially of scholasticism, will be our test in fixing the limits of what we are to regard as the Middle Ages. Were we guided by any other consideration we should run the risk of upsetting some fundamental facts of chronology. ${ }^{1}$ Those who commence the Middle Ages of philosophy, not even with the first Christian philosophies, but with Neo-Pythagoreans, Neo-Platonists and Platonic eclectics, because they confound religion with philosophy, find themselves thus obliged to "commence the Middle Ages at the end of the first century before the Christian era" and to prolong it down to our own days. ${ }^{2}$

122. Division of Medieval Philosophy. - Philosophy during the Middle Ages developed simultaneously in the West, at Byzantium and at various centres in the East ; but of these three philosophies, Western, Byzantine and Eastern, the first is by far the most important. And in Western philosophy the main current of ideas is represented by scholasticism. We may therefore frame our divisions of medieval philosophy a potiori, according to the development of scholasticism.

From this point of view the scientific renaissance of the thirteenth century marks an epoch; the period that led up to it was a period of long and laborious elaboration: in the thirteenth

${ }^{1}$ BRUCKER fixes on the twelfth century for the commencement of medieval philosophy (Historia critica philosophiae, iii., 709). But he wrote in the eighteenth century when little or nothing was known about the early Middle Ages.

2 Picavet, Entre camarades, pp. $7 \mathrm{I}$ and 74 . It will be observed, as regards the " terminus a quo," that Picavet's point of view would compel him in consistency to push back the beginnings of the Middle Ages beyond Neo-Platonism to the time of Aristotle, whose influence on Christian thought was far greater than that of the Neo-Platonists. His view would likewise seem to imply, as regards the "terminus ad quem," that medieval and modern civilization coexist at the present day. We believe, on the contrary, that there was a time which saw the cessation of scholastic philosophy, when, in the seventeenth, eighteenth and nineteenth centuries, it was abandoned, even by Catholics, for other systems. The revival of the scholastic philosophy, the new scholasticism, is in spirit not medieval but modern, $C f$. our volume on Scholasticism Old and New, part ii, 
century scholasticism unfolded all the rich resources of its peculiar genius; but the splendour of its triumphant reign was of short duration. Signs of its decadence appeared in the fourteenth century and multiplied in the fifteenth. From the middle of the fifteenth down to the seventeenth century, scholasticism languished, assaulted on all sides by the new systems that prepared the way for modern philosophy. It was in vain that a few distinguished men attempted in the sixteenth century to reinstate the dethroned sovereign: their influence was but local and ephemeral compared with that of the glorious past towards which they turned in vain.

Thus, we distinguish four periods in medieval philosophy:-

The first, or Period of Formation (from the ninth to the end of the twelfth century);

The second, or Period of Culmination (thirteenth century);

The third, or Period of Decline (fourteenth and first half of fifteenth century);

The fourth, or Period of Transition from medieval to modern philosophy (fifteenth to seventeenth century).

We will deal with the history of Byzantine and Eastern thought in the sections devoted to the various divisions of Western philosophy. During the first period each of the three currents developed in absolute independence of the others. Paris, Byzantium and Bagdad were the three great isolated centres of philosophical thought : to each of these a separate section will be devoted. But from the early years of the thirteenth century the separate currents united: Western philosophy drew a new and lasting vitality from the assimilation of Arabian and Byzantine ideas; while on the contrary the Jewish-Arabian philosophy quickly disappeared, and the Byzantine only languished down to the time of its total extinction in the fifteenth century. In the last three periods, accordingly, it will be sufficient to deal incidentally with the Byzantine, Arabian and Jewish philosophies, without devoting special sections to them.

Finally, there is no need of a geographical classification of Western philosophy, seeing that philosophy was no less international than the general scientific culture and civilization of the Middle Ages.

123. Bibliography.-PiCaver, Le moyen age, caractéristique théologique et philosophico-scientifique. Limites chronologiques. In Entre Camarades (Paris, Igor). Merely general observations. See numerous divisions of philosophy in the treatises already indicated. 


\section{Ancient and Modern Sources of a General NATURE.}

124. Ancient Sources. - For a history of medieval philosophy the manuscripts of the Middle Ages are evidently the primary source. These are scattered in very large numbers all through the unexplored recesses of European libraries. Many of them are unedited and even unknown. The history of philosophy is sure to benefit by the work-now being pretty extensively promoted-of publishing catalogues of the manuscripts lying in the various libraries. And besides this, the editing of hitherto unpublished texts, the critical re-editing of those already edited though defectively, and, above all, their authentication-a peculiarly delicate task in regard to medieval philosophy-have been progressing with remarkable vigour for some years past.

Besides works dealing $e x$ professo with philosophy or its history -for of those the Middle Ages produced very few-we must consult the general sources of the history of ideas. It is in these sources, very numerous and very unequal as they are in value, that we find some most important information: in works like those of the ancient annalists, continuators of the De Viris Illustribus of St. Jerome (Isidore of Seville, Sigebert of Gembloux, Honorius of Autun, etc.), men whose writings were gathered up by Trithemius in the fifteenth, Miraeus in the seventeenth and Fabricius in the eighteenth century. Of special importance are the biographical histories of the various religious orders: each order had its annalists. These were often inclined to magnify the past; but compilations like QueTIF-Echard's Scriptores Ordinis Praedicatorum (Paris, I719, 2 vols.) and WADDING'S Scriptores Ord. Minor. (with supplement by SBARAGLEA) have a high historical value. Then too, there are the dictionaries of national biography, compiled according to countries (or provinces), like the Histoire litteraire de France, commenced by the Benedictines of St. Maur in the eighteenth century, and the Dictionary of National Biography (London); while the numerous collections of Scriptores Ecclesiae contain much useful and indispensable information on account of the close connection of philosophy with theology.

As those ancient sources are not confined to medieval philosophy, we must refer the reader to the modern bibliographies 
that deal with them professedly, confining ourselves to an occasional reference in treating special questions. The principal modern works on the general bibliography of the Middle Ages are the following: EBERT, Allgemeine Geschichte d. Litteratur des Mittelalters im Abendlande (3 vols., I 874-1887); H. OESTERLEY, Wegweiser durch die Litteratur der Urkundensammlungen (2 vols., I885, I886); Chevalier, U., Répertoire des sources historiques du moyen âge, I. Bio-Bibliographie (2nd édit.); PotThast, A., Bibliotheca Historica Medii Aevi (2 vols., I 896); BERnHEIM, E., Lehrbuch der historischen Methode und d. Geschichts-philosophie (4th edit., 1903); bibliographies relating to special countries, like WatTEnbaCH, Deutschlands Geschichtsquellen im Mittelalter bis zur Mitte d. I 3 Jahrh. (7th edit., 1904); LoRENZ, O., Deutschlands Geschichtsquellen im Mittelalter seit der Mitte des $\mathrm{r} 3$ Jahrh. (3rd edit., 2 vols., I 886).

125. Modern Works. - The following bibliography contains only the works and writings that deal with the philosophy of the Middle Ages in general. Special works will be indicated in their proper places. Besides, the present list is not complete : it embraces only the more important and more recent works.

(I) General works on the history of medieval philosophy.STÖCKL, Geschichte der Philosophie des Mittelalters, Bd. i.-iii. (Mainz, I864-I866). An excellent doctrinal work, but now inadequate from bibliographical point of view. HAURÉAU, Histoire de la philosophie scolastique (3 vols., I 872-1880). Scholarly, but misleading in regard to philosophical doctrines, which are badly handled; rationalist point of view ; to be consulted with caution. UeberweG-HeInze, Grundriss der Geschichte der Philosophie, II. Die mittlere oder die patristische und scholastische Zeit (9 Aufl, 1905). Invaluable for its bibliography; revised in part by $M$. BAUMGARTNER and in part by M. WeHOFER. WINDELbAND, Zur Wissenschafts-geschichte der romanischen Völker (in GRöBER'S Grundriss der Geschichte der romanischen Philologie). Objective, very condensed, follows chronological order. WILlmann, Geschichte der Idealismus, v. ii., Fathers of the Church and Middle Ages (Brunswick, 2nd edit., 1908). A study of systems. Excellent. GonZalez, Histoire de la Philosophie, v. ii. Good, but insufficient. ERdmann, Grundriss d. Geschichte d. Philosophie (4th edit., 1896). Sums up modern works. WERNER'S works embrace practically the whole of the Middle Ages; but they are 
rather superficial. ADLHOCH, B., Praefationes ad artis Scholasticae inter Occidentales fata (Brunae, I898). Interesting. The author insists too much on the doctrinal elements, at the expense of chronological order. DE WULF, Histoire de la philosophie scolastique dans les Pays-Bas, etc. (Louvain, I895): a second edition is in the press; Histoire de la philosophie en Belgique (1910); Scholasticism Old and New (tr. Dublin and New York, 1907). The first part contains general views on scholasticism and the Middle Ages. M. PICAVET, Esquisse d'une histoire générale et comparée des philosophies médiévales (2nd edit., Paris, I907): confounds scholastic philosophy with the religion of the Middle Ages; thinks,-wrongly, in our opinion,-- that Plotinus is the real founder of medieval scholasticism. BALLMKER, Die Europäische Philosophie des Mittelalters, in Die Kultur der Gegenwart, i., v. (Berlin, 1909), pp. 288-390. Excellent general views. ENDRFs, Geschichte der mittelalterlich. Philosophie im Abendlande (Kempten, 1908). Elementary.

(2) Histories of special branches.-PRANTL, Geschichte der Logik im Abendlande, Bd. ii.-iv. (Leipzig, 1885, I867, I 870). Abounds in quotations of texts. Good bibliography. A valuable work. Siereck, Geschichte d. Psychologie, i, 2, Die Psychologie von Aristoteles bis zum Thomas von Aquino (Gotha, I 884). The medieval section is cramped. Articles from same author in the Archiv f. Gesch. d. Philosophie, Bd. i.-ii. (I 888-1 890). Oтто Willmann, Didaktik als Bildungslehre (3rd edit., Brunswick, 1903). The first vol. contains, after the introduction, an historical study, Die geschichtlichen Typen des Bildungszuesens, in which are to be found some excellent sections on medieval didactics and pedagogy. Werner, Entwicklungsgang der mittelalterl. Psychol. (1876). Very subjective, like all Werner's work. MabilleaU, Histoire de l'atomisme (Paris, 1905). K. LAsswitz, Geschichte d. Atomistik vom Mittelalter bis Newton (1890).

On the history of the sciences: BERTHELOT, La Chimie au moyen age (1893). CANTOR, Vorlesungen über d. Geschichte d. Mathematik, ii. and iii. (I 894). HOFER, Histoire de l'astronomie (1873). Jessen, Botanik d. Gegenwart u. Vorzeit (1864). Carus, Geschichte d. Zoologie (1872). Haser, Lehrbuch $d$. Geschichte d. Medecin (1875).

(3) Collections of texts and monographs.-Migne, Patrologiae Cursus Completus. (I) Series Latina, 221 vols., I844-1845. 
(2) Series Graeca, I6I vols., I857-1866, containing numerous editions of medieval works,- - a well-known and very valuable collection. SIGMUND BARACH, Bibliotheca philosophorum mediae aetatis, 2 vols. appeared in 1876-1878; interrupted; Notices et extraits des mss. de la Bibliothèque nationale: very rich in information about the Latin philosophical MSS. HAURÉAU, Notices et extraits de quelques mss. latins de la Biblioth. nationale, 6 vols., I890-1893: a collection of notes on the philosophical MSS. in numerical order: valuable. Studies by the same in the Journal des Savants, I888-90. EHRLE, Bibliotheca theologiae et philosophiae scholasticae, 2 vols. published; interrupted; very reliable. DE WULF, Les Philosophes Belges (forming portion of a wider collection: Les philosophes du moyen âge, Louvain and Paris, 1900-1909), 4 vols. published. Scriptores rerum Britannicarum, contains poems, essays, philosophical works, etc., by English medieval authors. Beiträge zur Geschichte der Philosophie des Mittelalters, edited at Münster, by BAEUMKER and VON HertLing: a collection of the greatest value. From I89 I to 1909 , forty-one numbers have appeared.

(4) Works on civilization and the general history of medieval thought.-REUTER, Geschichte der religiösen Aufklärung im Mittl., 2 Bd. (I875-1877). POOLE, R. L., Illustrations of the History of Medieval Thought (I884): a series of monographs. VON EICKEN, Geschichte und System d. mittelaltr. Weltanschaunng (1887). W. Dilthey, Einleitung in die Geisteswissenschaften (I883), i., 338 and foll. BAEUMKER has promised a work on Die mittelalterliche Weltanschaung in the collection of Below and Meinecke. Handbuch der Mittelalterlichen und neueren Geschichte (Munich, Oldenburg). See collections of EHRHARD and KIRSCH, Forschungen zur Litteratur und Dogmengeschichte (Paderborn); of SDRALEK, Kirchengeschichtl. Abhandlungen (Breslau); and of KNÖPFLER, Veröffentl. aus d. Kirchengesch. Seminar (Munich).

(5) Works on the history of theology and religion.-FERET, La faculté de théologie de Paris et ses docteurs les plus célèbres. Le moyen age, Paris, I894-I 897,4 vols. The first is devoted to the sources and schools of the eleventh and twelfth centuries; the second to the later portion of the thirteenth century; the third to the fourteenth; the fourth to the fifteenth century. Well documented ; but not very critical, nor sufficiently full on the history of ideas. HEFELÉ, Histoire des Conciles. ScHWANe, Dogmen- 
geschichte der mittleren Zeit (Freiburg, I882), from Catholic point of view. HARNACK, Lehrbuch d. Dogmengeschichte, Bd. iii., 3rd edit., 1894 (tr. History of Dogma), Protestant point of view.

(6) Dictionaries.-FRANCK, Dictionn. des sciences philosoph. (2nd edit., I 875); many articles by M. Hauréau, inspired by the general views of the author. BALDwIN, Dictionary of Philosophy and Psychology (I90I), weak in all that concerns the Middle Ages. Articles on the philosophy of the Middle Ages in the Grande Encyclopédie, and in the Real-Encyclopedie fiir Protestant. Theologie u. Kirche, 3 rd edit., by HAUCK. Dictionnaire de théologie catholique, by VACANT and MANGENOT, commenced in I 899, 28 nos. appeared up to July, I909: contains many articles of value on the philosophy of the Middle Ages. HURTER, Nomenclator littcrarius theologiae catholicae; vol. i. (down to I I09), 3 rd edit. in I903: valuable. New edit. of vol. ii. (I I o9I 563). Wetzer u. Welte, Kirchenlexicon, and edit. Dictionary of Christian Biography', by SiITH and WACE.

(7) Auriliary sciences.-DuCANGE, Glossarium mediae et infimae latinitatis (1840), 6 vols. So far as we know, there is no special treatise on philosophical paleography: there is need of one, for the philosophical MSS. abound in abbreviations peculiar to themselves. ErIRLe, Das Studium der Handschriften $d$. mittelalterlichen Scholastik mit besondere Berïcksichtigung $d$. Schule d. hl. Bonaventura (Zeitschr. f. Kath. Theol., I 883, pp. I-50). On Philology, the collection of TRAUBE, Quellen und Untersuchungen zur lateinischen Philologie des Mittclalters.

(8) Reviews. - There are no special reviews devoted to the history of medieval philosophy, but numerous articles are to be found in the following: Archiv fiir Litteratur- und Kirchengeschichte des Mittclalters, by EHRLE and Denifle; the Philosophisches Jahrbuch, by GUTBERLET; the Annales de philosophie chrétienne; the Revue Thomiste, of Fribourg; the Revue Néoscolastique, of Louvain ; the Archiv fiir Geschichte der Philosophie, by STEIN ; the Zeitschrift fiir katolische Theologie, of Innsbruck: the Jahrbuch fiir Philosophie und spekulative Theologie, of Paderborn; the Revue des Sciences philosophiques et thiologiques, of Kain (Belgium); the Revista di philosophia neo-scolastica, of Florence (since 1909). We may also mention a review devoted to the Middle Ages in general: Bibliothèque de l'école des chartes; Le moyen $\hat{a} g e$ (original studies and analyses). 


\section{FIRST PERIOD.}

\section{MEDIEVAL PHILOSOPHY TO THE END OF THE TWELFTH CENTURY.}

First Section. Western Philosophy.

\section{CHAPTER I.}

\section{General View.}

\section{The Main Characteristics of Scholasticism during this} Period.-(I) The domain of philosophy is marked out slowly.-The building up of the medieval societies on the ruins of the barbarian invasions is like the founding of a new civilization. Science at first tends to be encyclopedic.

In the seventh century, ISIDORE OF SEville (Hispalensis, 560-636), in his Originum seu Etymologiarum Libri $X X$, treats not only of the seven liberal arts, but actually of all the subjects about which he could amass any information: medicine, jurisprudence, written traditions, languages, literatures, etymologies, fragments of anthropology, zoology, general and local geography, architecture, agriculture and gardening, the art of war, descriptions of metals, of weights and measures, of navigation, of dress, etc., everything in fact that was deemed worth knowing, finds a place in this sort of universal review. ${ }^{1}$

We see the same tendency in the works of VENERABLE BEDE, the famous monk of Jarrow in Northumberland, regarded as the greatest scholar of his time. His monumental work, Historia Ecclesiastica Gentis Anglorum, reflecting the exuberant life and movement of the kindred works of Gregory of Tours, is recognized as the first serious attempt at English history. Besides theological treatises, Bede is the author of various scientific and

1 The same encyclopedic tendency is to be found in the theological writings of Isidore's great contemporary, Pope St. Gregory the Great (540-604) (V. Hurter, Nomenclator, etc., i., 557). 
chronological works, notably of a small book called De Orthographia Liber, and of another inspired by the work of St. Isidore of Seville and entitled De Natura Rerum. ${ }^{1}$

But in philosophy the leading representative of this encyclopedic literature is Rraban MAUR (Rhabanus Magnentius Maurus, 776-856), abbot of Fulda and archbishop of Mainz, whose work, De Clericorum Institutione, has won for him the title of "Praeceptor Germaniae". His treatise De Universo is still more extensive than the work of Isidore of Seville, and constitutes in fact the great encyclopedic dictionary of the early Middle Ages. Among other texts from the ancients Rhaban Maur discovered a hundred lines from Lucretius, on which was based the only knowledge possessed by the pre-scholastics about Lucretius and Epicurus. Influenced probably by the Latin poet, Rhaban taught that with the exception of God alone, all beings are in their nature corporeal. ${ }^{2}$

Not oniy was the scholarship of those early centuries encyclopedic, but the title of philosophy was given to its promiscuous productions. Alcuin merely follows the prevalent view when he defines philosophy as " Naturarum Inquisitio, rerum divinarum humanarumque cognitio, quantum possibile est homini aestimare" (Migne, P.L., t. IOI, col. 952, A). Hence in the ninth century there was no line of demarcation between theology, philosophy and the liberal arts. This came later on as the result of a slow division of labour: philosophy freed itself from the sister sciences and commenced to grow and develop. ${ }^{3}$

(2) Gradual formulation of the problems of philosophy.-The Middle Ages did not discuss all the problems of philosophy in its entirety from the start. The threads of tradition had been rudely snapped asunder by devastating wars; and so even the very form and framework of philosophical investigation had to

${ }^{1}$ The Middle Ages were mistaken in attributing to Bede the Liber de Constitutione Mundi, and a collection of philosophical aphorisms, Axiomata Philosophica Venerabilis Bedae, gathered from various authors, some posterior to Bede's time.

${ }^{2}$ Cf. Phillipe, Lucrèce dans la théologie chrétienne du IIIe au XIIIe s., p. $5^{8}$ (Paris, r8g6).

3 'The Hortus Deliciarum, written in the twelfth century by Herrad of Landsberg, may be classed with the encyclopedic works of this earlier period. But it has all the advantages of the progress achieved by scholasticism at the time of its compilation. It contains, for instance, the division of philosophy into Ethics, Logic and Physics, and the seven liberal arts as an introduction to philosophy (r3I) (Willmann, Didaktik, i., 278, note I). 
be reconstructed piece by piece: a slow and laborious task that needed deep and earnest reflexion.

The early Middle Ages professed an altogether undue esteem for dialectic, and we shall see below that the principal manuals in use in the schools of those centuries tended to aggravate this exclusive attachment to formal logic. From this we may infer that among the branches recognized nowadays as strictly philosophical dialectic was the only one then taught as such. But we cannot conclude that it constituted the whole of the philosophy of the eighth and ninth centuries. At first, this dialectic, overshadowing the rhetoric and grammar of the trivium, confined its attention too exclusively to the study of words and logical forms, while neglecting the real bearing of those forms on external reality. This unfortunate tendency was the result of the philosophical education of the earlier scholastics and of the authors whom they read and imitated. But notwithstanding all this we can detect, even from the beginning, the steady struggle on the part of genuine philosophical speculations to shake themselves free of the limitations of mere dialectic. From the eighth century philosophical questions began to arise out of theological controversies; the growing discussion as to the nature and significance of universal ideas led up to the treatment of questions proper to ontology, questions about external nature, about God and about being in general. It was in the nature of things that problems in cosmology and theology should present themselves. The rich and rapid development of studies in psychology in the eleventh century is an unequivocal sign of philosophical progress.

Before the close of the twelfth century, the date of the great intellectual movement which separates the history of scholastic philosophy into two great phases or epochs of development, all the great, vital questions of philosophy were being freely and fully discussed. The slow and gradual elaboration of the scholastic system is one of the most interesting and instructive facts of the earlier period.

(3) Absence of systematic arrangement.-According as scholasticism pushed forward its researches it constructed a framezwork for its teaching. When or how did it fill in and fully furnish this framework? The thirteenth century reveals to us a superbly finished system, in which all the parts are knit together and dominated by a principle of unity. But we fail to discern this 
harmonized convergence of philosophical theories in works anterior to the thirteenth century. This is mainly because the scholasticism of the earlier period drew its teaching from various and conflicting sources. Borrowing an extract from one author, misinterpreting another, ignoring the historical and logical affinities of all alike, it produced theories that were heterogeneous and often contradictory. The scholasticism of this earlier period was wanting in that commanding and comprehensive genius that would vivify its eclecticism and assimilate its borrowed elements. It was fostering and maturing that genius for the thirteenth century, the period of the full bloom of scholasticism.

The various influences at work in the earlier scholasticism may be traced to their respective sources. The Platonic-Augustinian influence was predominant, overshadowing that of Aristotelianism. Then, less important indeed than either of those, but none the less real, were the impressions made upon scholasticism by Pythagorean, Epicurean, Stoic, Neo-Platonic and Arabian ideas.

The division of philosophy into branches was not uniform in this period, but most of the classifications follow the Platonic division of philosophy (into Logic, Ethics and Physics), and some of them reproduce it. The Aristotelian classification (into Metaphysics, Mathematics and Physics) was known through Boëthius, but was not attended to.

In dialectic Aristotle reigns supreme: the Platonic commentators known to the scholastics yielded a willing homage to that supremacy, which extrinsic circumstances tended (133) to accentuate. St. Augustine himself recommended the study of dialectic, and thereby promoted the knowledge of Aristotle (99). But unfortunately the metaphysics of this period were not sufficiently developed to counterbalance the study of dialectic. The deductive or synthetic method was also in high esteem down to the close of the twelfth century, because the value of external observation and psychological reflexion was not yet duly appreciated. John Scotus Eriugena among anti-scholastics and St. Anslem among scholastics, were types of the pure deductive philosopher. As reflexion grew riper the excessive use of pure deduction gradually disappeared, but it was not until the thirteenth century that philosophy was fully subjected to the double or analytico-synthetic method.

Metaphysics remained fragmentary and incoherent until the 
thirteenth century. ${ }^{1}$ This branch reveals a curious mixture of Platonic and Aristotelian theories. To the Timaeus it owes its formulation of the Principle of Causality, to Aristotle its scheme of the four causes, but from those sources it fails to work out a consistent theory of causes. ${ }^{2}$ The fascinating theory of the Platonic Ideas-the fertile source of exaggerated realism-is set forth alongside the Aristotelian theories on the categories, substance, accident, nature, person, etc.; and the work of centuries is needed for a satisfactory solution of the metaphysical problem of the Universals. The matter and form theory of composition is also known, but only indirectly through St. Ambrose and Boëthius and in the uncertain utterances of St. Augustine (Ior). All-important in the organic structure of the peripatetic philosophy, it plays only an insignificant role here, and is almost invariably misunderstood. By "matter" some understand the original chaos of the elements (Alcuin), others the material atom which is the ultimate residue after division (William of Conches and the atomists), cthers again a mass endowed with physical qualities and force and motion (school of Chartres). A few (Isidore of Seville, Rhaban Maur, Gilbert de la Porrée) seem to suspect the character of absolute indeterminateness and passivity accorded to "matter" by Aristotle, but seem equally incapable of catching the meaning or grasping the significance of this view. Nor is the "form" taken in the true Aristotelian sense as a substantial principle of the being, but as the sum of its properties. ${ }^{3}$ And hence inception, evolution, change, do not affect the fundamental reality of things, but merely the appearance and disappearance of properties which supervene on this reality. Indeed the hylemorphic theory as presented during the early Middle Ages reveals a fairly evident antinomy between the real spirit of the formulas that embodied it and the erroneous meanings read into these formulas. ${ }^{4}$

${ }^{1}$ This is the view of Espenberger, Die Philos. d. Petrus Lombardus, 'etc. (Beitr. z. Gesch. d. Phil. d. Mittel., iii., 5), Münster, Igor, p. 36; also of DoMET DE Vorges, S. Anselme, pp. I49 sqq. passim.

. $C f$. Espenberger, $o p$. cit., pp. $67 s q q$, for the notion of causality in the time of Peter Lombard, with sources indicated.

${ }^{3}$ V. Baumgartner, Die Philosophie des Alanus de Insulis, im Zusammenhange mit den Anschauungen des 12 Falirh. dargest. (Beitr. zur Gesch. d. Philos. d. Mittel., ii., 4), Münster, I896. This excellent monograph is rich in useful information on the history of scholastic ideas.

4 This wrong interpretation of the hylemorphic teaching is due to the transposition of a logical theory into metaphysics. Instead of basing the study of matter 
In physics, or cosmology, the teachings are characterized by the same sort of indecision and uncertainty. We have just seen that an erroneous conception of the primal "matter" served to support atomistic theories. Similarly, the Anima Mundi or world-soul of Plato, or the Fatum of the Stoics, inclined these scholastics to ascribe to external nature as such an autonomous being and life peculiar to itself : an attitude which, nevertheless, did not prevent some of the best of them (e.g., Abelard and John of Salisbury) from holding with Aristotle the individuality of every natural substance in this universe: two contradictory and irreconcilable theses.

In psychology we have still further instances of the prevalence of mutually inconsistent and opposing theories. We may say that down to the thirteenth century the psychology of the scholastics is mainly Augustinian and Platonic. ${ }^{1}$ Man is a microcosm, mirroring the universe. Their theory of knowledge is borrowed from St. Augustine: some interpret even the doctrine of abstraction in an Augustinian sense! The majority also espouse his classification of the faculties of the soul, together with his denial of a real distinction between the former and the latter. The Metalogicus of John of Salisbury (iv., 9) mentions the theory of a real multiplicity of the powers of the soul as held by some in opposition to the Augustinian conception." From the time of Constantine the African ( $v$. below) the study of psychic activities began to be supplemented by physiological informations of Arabian origin: these latter, however, often reveal a confusion of the psychical with the physiological phenomenon, thus according ill with other ideological theories. In regard to the nature of man, everything touching the origin and destiny of the soul is studied with a very marked predilection. St. Augustine's hesitations between creationism and traducianism find expression among the earlier scholastics. Down to the twelfth century we meet with traducianists who are apparently unconscious of their inconsistency in

and form on the processes of cosmic change the scholastics of this period base it on the logical analysis of judgment. Beings are composed of matter and form just as the judgment is composed of subject and predicate. Cf. Baumgartier, op. cit., pp. 57 and foll.

${ }^{1}$ See a monograph by B+EUMKER in his work on Witelo (353).

${ }^{3} \mathrm{Cf}$. FrIEDRICH, Geschichte d. Lehre von den Seelenvermögen bis zur Niedergange der Scholastik (in the Pädagog. Abhandl., v., r), 33 pp. He collects the materials but does not elaborate them. 
defending at the same time the spirituality of the soul, - a thesis universally accepted on the authority of Plato. The problem of the relations between soul and body is also treated according to the spirit of the Platonic psychology. The soul is united to the body by a relation of number (Pythagoras), or as the pilot is to his ship, or the rider with his steed. And yet, alongside the independence of the composing substances, we find asserted the unity of man. Though the Aristotelian definition of the soul (as the "entelechy of the body") is known " to the scholastics of the period, they refuse to regard the soul as the substantial form of the body, - which would mean, according to the current interpretation, that the soul would be a property of matter! There is no doubt whatever that the easy triumph of the Platonic psychology during this period was due in part to this widely prevalent false interpretation of the matter and form theory. ${ }^{2}$

Moral philosophy is treated mainly from the point of view of theology: the few who attempt a philosophical treatment confine themselves to a description of the particular virtues, after the manner of the Stoics.

There remains theodicy: this was at all times regarded by scholastics as one of the most important sections of philosophy. St. Augustine, Pseudo-Denis and Boëthius left long dissertations on the existence ${ }^{3}$ and nature of God, on Creation and Exemplarism. Besides these we find Pythagorean traditions on harmony and number. Aristotle is laid under contribution for the doctrine of a Prime Mover and blamed for his denial of Providence. ${ }^{4}$ Plato is preferred, he is the symmystes veri, because, as John of Salisbury tells us, he holds the existence of God or the Supreme Good, the distinction between time and eternity, between the Idea and Matter. ${ }^{5}$ All these Platonic teachings were interpreted in the Augustinian sense, and were believed especially to

1 Through Chalcidius, who takes the same exception to the definition as the scholastics of this first period.

${ }^{2}$ For the same reason they would not use the theory to explain the composition of other living things. Some denied that beasts have souls, others made of the latter a sort of corporeal spiritus, etc.

"See Grunwald, Geschichte der Gottesbeweise im Mittelalter bis zum Ausgang der Hochscholastik (Beitr. z. Gesch. d. Philos. d. Mittel., Münster, 1907).

${ }^{4} v$. J. of Salisbury, Metalogicus, iv., 27 : Quod Aristoteles in multos erravit.

${ }^{5}$ Principio docet esse Deum, distinguit ab aevo. -Tempus et ideas applicat, aptat hylen (J. Salisbury, Entheticus, 94I-42). 
embody the doctrines of Creation, Exemplarism and Divine Science.

Finally, the scholasticism of this period follows St. Augustine in fixing the relations of philosophy to theology; but it develops and supplements his teaching. After having confounded, under the title of philosophy, philosophy itself and the study of dogma, the Middlle Ages began to draw a practical distinction between the two domains from the dawn of the eleventh century $;^{1}$ without, however, expressly formulating a systematic body of doctrine on their mutual relations, such as we find set forth in the theological Summae of the thirteenth century.

We may sum up by saying that, with the exception of theodicy, the philosophy of this period is like the contents of a crucible in which many dissimilar materials are melted together. John of Salisbury might have applied to all the men of the time what he said about the philosophers of Chartres who were trying to reconcile Plato with Aristotle: "they have laboured in vain to reconcile when dead those who were in opposition as long as they lived" (Metal., ii., I 7). With the growth of scholasticism, conflicting elements were graclually eliminated: its efforts towards unity are an index of the intellectual development of the ninth to the twelfth centuries. Even the language of the scholastics indicates the tentative gropings of their thought: slowly but surely it works its way to the admirable precision it displays in the great century. Comparing the philosophy of the earlier medieval schools with the elaborated systems of the thirteenth century we realize that we are witnessing a great creative work: the gradual formation of the great scholastic solutions. A detailed study of the individual philosophers of the present period will lead us to the same conclusions. Still, a want of proper systematization is noticeable even in the latest productions of the twelfth century, though these are the most remarkable of the period. More than this, there are some antinomies which obstinately resisted elimination and lasted into, if not through, the thirteenth century.

127. Organization of Philosophical Schools. - In the early Middle Ages there were two or even three classes of schools; and in these philosophy was taught equally with the other sciences (131). These were:-

Cf. Brunhes, La foi chrétienne et la Philosophie au temps de la Renaissance Carolingienne (Paris, 1903), pp. 173-80. 
(I) The monastic schools, each comprising (a) the schola interior or schola claustri, reserved for the monks, and (b) the schola exterior, open to the laity. During the epoch of Charlemagne and the Othos the majority of the great educators belonged by training or profession to the Benedictine order: commencing with Venerable Bede, the scholastic monk of Jarrow, whom tradition represents as the master of Alcuin. From the sixth and seventh centuries the monks of St. Benedict spread their schools all over Western Europe. They were joined in the tenth century by the monks of Cluny, and in the eleventh by other branches of the great family of the monks of the West.

(2) The episcopal, cathedral or capitular schools.-In the eighth century Chrodegang, a canon of Met $z(\dagger 766)$, organized a common mode of life, after the model of the monastic, for the clergy of the episcopal churches. We find here the same division into interior and exterior schools.

Professorships (scholasticum officium) were sought by persons of the highest eminence. Oftentimes, especially in the earlier period, we find abbots of monasteries, bishops and chancellors exercising the function of scholasticus. Later on this title was given (with the office of teaching) to simple magistri scholae or "schoolmasters".

(3) The court or palace schools, scholae palatinae or scholae palatii, the most famous of which was the court school of the French kings. These recruited their professors from the Church and admitted clergy and laity alike to their lectures. The school being attached to the court, would accompany the latter in its various changes of abode.

128. The Carlovingian Renaissance. Alcuin.-In 778 Charlemagne, influenced no doubt by Alcuin, whom he had summoned from Great Britain, gave to Bangulf, Bishop of Fulda, the famous capitulary in which he encouraged the foundation of monastic and episcopal schools. This was the signal for that brilliant revival of learning which is the emperor's greatest title to renown. The renaissance of the ninth century was not exclusively philosophical: it extended to all the branches of learning then known. And furthermore, it was in more direct connection with classic antiquity than with patristic learning.

Alcuin (735-804) was the leading spirit in the emperor's educational reforms. Himself a former pupil of the school of 
York, Alcuin met Charlemagne in $78 \mathrm{I}$ and taught for eight years at the imperial court. The monarch himself and his sons and daughters attended the master's lectures. After a life of feverish activity, Alcuin retired to the seclusion of the abbey of St. Martin of Tours. There he founded a school in which he spent the remainder of his days. Alcuin was rather a compiler and grammarian than a philosopher. There is nothing in his logical works beyond what may be found in Boëthius and Cassiodorus. His high repute as a philosopher is undeserved: but a great and powerful originator of an intellectual revival he undoubtedly was. He introduced the trivium and quadrizium into the palace school, and his books were retained as manuals. The schools that sprang from the movement inaugurated by him, prevented philosophy from monopolizing the attention of the learned down to the erection of the University of Paris.

His principal works in philosophy are: De Virtutibus et Vitiis ad Widonem comitem; De Animae Ratione Liber ad Eulaliam virginem (a collection of Augustinian theses on psychology); Grammatica; Dialectica.

129. Principal Schools. - Among the most notable schools were the following:-

In England, the abbey school of York (Alcuis).

In the Low Countries, the chapter schools of Utrecht (ADALBOde); of Liége (RAtherus, Notger, Adelman); of Tournai (ODO); the abbey schools of Lobbes (ERACLE); and of St. Lawrence (RUPERT OF DEUT\%).

In Germany, the school of Fulda (RHABAN MAUR); of Münster (LudGer); of Salzburg (ARNOLPII); of St. Gall (Notker LABEO, died in IO22, translated into German the then known portions of the Organon, the De Consolatione Philosophiae of Boëthius, the De Nuptiis Mercurii et Philologiae of Martianus Capella); and of Reichenau (WaLfred STRABO).

In France especially, the palace school, made illustrious by Alcuin, John Scotus Eriugena, Fredegis ( $†$ 834), Agobari, Candidus, Rhaban MaUR ; the abbey schools of Tours (Alcuin, REYNOLD OF TOURS); of Corbie (PASCHASIUS RADBERT); of Ferrières (Lupus of FERRIÈres); of Cluny (ODO); of Bec (LANFRANC, ST. ANSELM); of Fleury (ABBO); of Auxerre (REMI and ERIC); the episcopal schools of Lyons, of Rheims (GERBERT); of Laon (ANSELM, † I I 7 , and RALPH). The schools of Chartres, 
under the wise direction of Bishop FuLBERT (960-1028), the greatest teacher of his time, and of IVES OF CHARTRES ( $\dagger$ I I I 5 ) after him, passed through two separate periods of unrivalled excellence. Ahead of all the other schools, they competed with those of Paris itself down to the middle of the twelfth century. Adelman of LiEge and Berengar of TOURS studied under Fulbert at Chartres. In the twelfth century, the chancellors, BERNARD OF Chartres, Gilbert DE LA PORRÉE and TheOderiC OF CHARTRES, were among the most remarkable personalities of their time. In the ninth century Paris was the seat of three schools, Ste. Geneviève, S. Germain des Prés and the Cathedral school. The fame of these went on increasing steadily until, about the middle of the twelfth century, the French metropolis began to attract the elite of the whole learned world, and by its superior lustre to extinguish gradually all rival centres of culture.

130. Programme of Studies. - The studies were arranged progressively on the following plan: liberal arts; sciences; philosophy; theology. (I) The liberal arts. Prior to the Middle Ages ${ }^{1}$ the classification of the seven liberal arts (artes liberales, supposed to be derived from liber, a book) was commonly known through the compendiums of Boëthius, Cassiodorus, Martianus Capella and Alcuin. They were divided into two groups:-

(a) The Trivium (artes triviales, sermonicales, rationales) was the more important group, comprising grammar, rhetoric and dialectic or logic. Grammar included the study of the grammarians-especially Donatus and Priscian-and of the ancient Latin classics, Virgil, Seneca, Horace, Terence, Juvenal and others. Rhetoric was not cultivated quite so fully as among the Romans. Cicero, Quintilian and Marius Victorinus are mentioned in the Heptateuchon of Theoderic of Chartres ( $v$. below) as the favourite models in Rhetoric. ${ }^{2}$ Dialectic filled the largest space in the trivium and grew in importance according as the various parts of the Organon became known (132). This rapid development of logic had an injurious effect on the study of grammar and rhetoric. Classical Latin was partly abandoned for the barbarisms of

${ }^{1}$ Ammonius Saccas gives the branches of the Quadrivium as subdivisions of Mathematics (ZELLER, op. cit., ii. ${ }^{2}$, p. I77, n. r). Mariétan claims to have discovered the origin of the full classification of the liberal arts in St. Augustine (Probl. de la classific. des sciences, etc., pp. 54 sqq.).

${ }^{2}$ Clerval, Les écoles de Chartres au moyen age du Ve au XVIes., pp. 221 sqq. 
scholastic Latin ; and this latter was submitted to logical analyses by the "modists" in their treatises de modis significandi. Two tendencies asserted themselves: in some of the schools, as at Orleans and Chartres, all three branches continued to be cultivated; in others dialectic was gradually allowed to usurp the place of its two sister sciences. ${ }^{1}$

(b) The Quadrivium (artes quadriviales, reales, physica, mathematica) comprised arithmetic, geometry, astronomy and music. The encyclopedic data of ancient authors, and, from the time of Adelard of Bath, the theories of Euclid, formed the basis of instruction in mathematics and astronomy; music was studied in connection with religious ceremonial. The quadrivium was not so popular nor so extensively taught as the trivium, because its branches were more technical, abstruse and difficult. The study of medicine was annexed at an early period to the four branches of the quadrivium.

(2) Natural and historical sciences. - The scientific culture of the early Middle Ages was, as a rule, confined to a knowledge of the quadrivium. Original natural research was, however, prosecuted, mainly by the alchemists. Then we find among the earlier encyclopedists of this period (126) collections of facts, borrowed mainly from Pliny. Gerbert dealt with questions in the natural sciences (I4I); and questions of this kind were largely investigated in the monastery of Monte Cassino and in the school of Chartres. As for history, it was not cultivated as a branch of study for its own sake, and those who occupied themselves with it merely re-edited the writings of St. Jerome or Eusebius (Io3, n. 2).

(3) Philosophy.-The philosophical problems proper, which were gradually raised for solution from the eighth century onward (126, 2), and which formed a remarkable and quite distinct domain of speculation at the end of the twelfth, should not be considered as a mere off-growth or annexe of dialectic, so as to include philosophy in the trivium (with Ferrère, Mariétan and the majority of historians). Rather should we regard philosophy as a stage above the liberal arts, as a new discipline, which came

${ }^{1}$ A trouvere of the thirteenth century, Henry of Andely, in an allegorical poem on the conflict of the seven arts, represents the grammarians as Orleanists and the dialecticians as Paris teachers: to the latter he awards the victory (WILlmanN, Didaktik, i., 272). 
to have a place allotted to it on the scholastic programme between the liberal arts below and theology above ${ }^{1}$ (Willmann). This hierarchy was of course slow in asserting itself explicitly, but it was unmistakably recognized in the twelfth century by Hugh of St. Victor (Erud. Didasc., I, iii.) and universally adopted in the thirteenth.

(4) Theology was taught simultaneously with philosophy in the leading schools.

13I. Methods of Teaching.-We must distinguish between scholastic methods of discovery or elaboration of doctrine and scholastic methods of teaching. The former have been already dealt with (126). The methods of teaching were of very gradual evolution. They were also remarkably uniform throughout the schools of the West. The adoption of an identical programme of studies in the monastic and abbey schools of every country, involved a similar organization of teaching methods; and the frequent migration of teachers and pupils from school to school facilitated the spread of every change adopted. The leading characteristics of the scholastic method of teaching are the following :-

(I) The teaching was done through the medium of one single language-the scholastic or philosophical Latin, which was slowly formed during this period.

(2) Making a commentary on a text-book was the first and most natural form of teaching. But monographs soon began to make their appearance: not in the modern sense of treatises devoted ex professo to the study of some one single question or group of questions; but opuscula or smaller works on philosophy, having each its own proper plan.

(3) The didactic arrangement of each separate question, at first unfixed and doubtful, began to take definite shape after Abelard: he first outlined the formal scheme which all subsequent scholasticism adopted.

(4) The liberal arts and philosophy were regarded as a preparation for theology. This involved a peculiarity in medieval philosophy, and one that became more marked with time,-the intermixture of matters and arguments in philosophy with theological questions and arguments. And hence the need of seeking for certain philosophical reasonings within the lines of the pro-

$$
{ }^{1} C_{f} \text {. 126, } 3 \text {. }
$$


gramme traced for theological studies. But, needless to say, this intermingling of questions and arguments does not in the least compromise the distinction between the two sciences, any more than the origin of philosophy within the domain of theology militates against the autonomous development of the former discipline. In the same way, notwithstanding their similarity and equal development, theological methods remained distinct from philosophical ( $v$. below).

(5) With teaching methods we may connect the means and measures for the transmission of literary work achieved. The medieval doctors, especially the earlier ones, regarding history simply as an instrument in the service of truth, attached little importance to the historical fact as such. Hence all the plagiarism and mutilations of manuscripts; the habit of copying from second-hand copies, and often of modifying the copies: the mania for referring to contemporaries by veiled or anonymous indications; the ease with which apocryphal works were put in circulation, with which texts were truncated and interpolated, and all sorts of historical errors perpetuated.

132. Library of Works on Philosophy.-We may classify as foliows the principal works in use in the teaching of philosophy during this period:-

I. Grecian Philosophers.-Few indeed were there who read Greek in the original: Latin translations were in use everywhere.

(i) Aristotle.-(a) Logic.-In the ninth century the De Interpretatione was known in the translations of Marius Victorinus and Boethius: and from the end of the tenth, the Categories also, in the translation of Boëthius. Abelard knew of no other Aristotelian treatise in I 36 ; but the Heptateuchon of Theoderic of Chartres, completed about II4I, contains, besides those mentioned, the first book of the Prior Analytics, the Topics and the Sophistical Arguments, i.e., all the remaining parts of the Organon, with the exception of the Posterior Analytics and the second book of the Prior Analytics. ${ }^{1}$ According to a chronicle of Robert de Monte for the year I I28, James of Venice had already translated from Greek to Latin the Topics, the two Analytics and the Sophistical Arguments; but these translations passed unnoticed. About the same time, Otto of Freising made known the newly

1 This point of history has been established by CLERval, Les icoles de Chartres, etc., p. 244 . 
discovered treatises in Germany. The second half of the twelfth century was in possession of the entire Organon of Aristotle: thus with the middle of the century commenced a new and fuller introduction of the Organon, marking the distinction between the Logica vetus (or treatises known before I I 4 I) and the Logica nova (or treatises known after I I4I).

(b) The Metaphysics, the Physics and the De Anima,-which form the very groundwork of the Aristotelian philosophy,-were unknown in this period. From an isolated study of the Organon it was very easy to mistake the thought of Aristotle and reduce his philosophy to a collection of rules of logic. The scholastics of the first period knew Aristotle only as a logician : and bitterly did they complain of his obscurity. ${ }^{1}$

(2) Plato was known only through a fragment of the Timaeus, translated by Chalcidius (92). The famous dialogue was quoted by John Scotus Eriugena and got a rapid and extensive circulation. The metaphysical character of the Timaeus would have, in a certain measure, counteracted the excessive and exclusive influence of the Aristotelian dialectic. But the Timaeus is obscure; it is often misleading as regards the real thought of Plato; the eclectic commentaries of Chalcidius made it still more difficult to understand: it was, in fact, generally misunderstood during this period. Of the other works of Plato, only the titles (through Chalcidius) and occasional stray fragments were known. It was not until the twelfth century that some copies of the Phaedo and of the Meno found their way into circulation. Henricus Aristippus translated them in Sicily. But, on the other hand, many of Plato's theories were transmitted by St. Augustine, and also-though not without modification and even disfigurement-in the commentaries of the Neo-Platonists.

(3) Commentaries on Aristotle.-(a) PORPHYRY's Isagoge ${ }^{2}$ (also called the Institutio, or Introduction, or Treatise on the Five Words), already extensively commentated by the later Grecian philosophers, enjoyed an immense popularity among the earlier scholastics in the translation of Marius Victorinus, and afterwards in that of Boëthius with the double commentary of the latter.

${ }^{1}$ Boëthius calls him turbator verborum; an unknown author of the tenth century speaks of the Aristotelicus labyrinthus (BAUMGARTnER, op. cit., pp. Io, II).

${ }^{2}$ Re-edited by A. Busse, Berlin, 1887 (vol. iv., p. $x$, of the Commentaria in Aristatelem Graeca, edited by the Berlin Academy). 
Porphyry passed for a supporter of Aristotle: his connection with a pantheistic school of philosophy does not seem to have been even suspected (86).

The Isagoge studies the five predicables (genus, species, specific difference, property, accident): it served as an introduction to the study of the Categories. The predicables are an expression of the various ways in which a predicate may be announced about a subject. In the Isagoge, Porphyry does not go beyond this logical aspect of the predicables; he does not inquire into the real or ontological significance of the categories. He merely hints at the great problem of the objectivity of universal notions: and his statement of the question became later on the starting-point of the Universals controversy (Ch. II., art. i., $\$$ I).

(b) Bö̈rHius wrote commentaries on the Categories and the De Interpretatione. Other commentaries of his, on the Topics, Analytics and Sophistical Arguments, are lost. So too is the translation of these three works, alleged by Robert de Monte about II 28 to have been undertaken by JAMES OF VENICE.

(4) The other monuments of Grecian philosophy were unknown; but the names of many of its leading personalities were familiar to the scholastics of this period from the Latin writings and the Fathers of the Church. They possessed fragments of several Grecian systems, especially of the Epicurean, the Stoic and the Pythagorean. They were acquainted with no original work of the Neo-Platonists: but they were indirectly influenced by Neo-Platonism through St. Augustine and the Platonic commentators of Pseudo-Denis. ${ }^{1}$

II. Latin Philosophers. - The otherwise abundant literary output of Latin antiquity was represented in philosophy by the following meagre legacy:-

(I) A collection of Latin compilations dating from the period of decadence. Among them: the works of MARIUS Victorinus (92), including a version of the Isagoge and various treatises and commentaries on logic; the works of MACROBIUS (92), author of the Saturnalia and of a commentary on the Dream of Scipio, often referred to in the Middle Ages; the works of Claudius Mamertus of Vienne, in Gaul (about 450), who wrote the De

${ }^{1}$ John of Salisbury also quotes extracts from a letter of Plutarch, Polycraticus, v., I. 
Statu Animae in defence of the immortality of the soul against Faustus the Semi-Pelagian; the works of Donatus, to whom, with Macrobius, medieval scholars owed much of their knowledge of the facts of ancient history.

(2) A number of Platonic and Neo-Platonic Commentaries.-(a) A commentary on the De Interpretatione and a treatise De Dogmate Platonis were circulated under the name of APULEIUS OF MADAURA (8r). A dialogue entitled Asclepius was also widely attributed to him. It was, however, regarded by the better informed as one of the "hermetic" or occult writings, and identified, under the title of Liber de Deo Deorum, as the work of an Egyptian philosopher, Mercukius Trismegistus. Other works of the same character were also known (8I); such, for

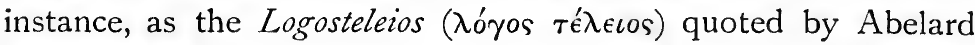
and Alan of Lille.

(b) To the same group we may refer the commentary added by Chalcidius (92) to his version of the Timaeus. It is a mere compilation, without originality, after the manner of the Platonic eclecticism of the second century of the Christian era. The compiler ransacks Posidonius, Adrastus and Albinus (72, 74, 8r) among others; quoting extracts from the other works of Plato; incorporating Aristotelian theories; quoting the Stoics, Chrysippus and Cleanthus, and comparing their teachings; borrowing ideas from the Pythagoreans, from Philo, Numenius, etc.,--not forgetting the Greek physicians ; laying under contribution the Ionians, Eleatics and Atomists of the pre-Socratic period: so that in the twelfth century his commentary was one of the main sources of the history of Grecian philosophy. Hence the enormous influence attaching to it during this period.

(3) Certain works or portions of works of CiCERo (the Topics, the De Officiis, the De Inventione Rhetorica, the two Libri Rhetoricorum ad Herennium, the De Partitione Oratoria); of SeneCa (the De Beneficiis); and of LuCretius.

Cicero was considered an authority on logic and rhetoric. Seneca's Stoic maxims were reproduced with a ready approval by the few scholastics who gave their attention to ethics. From the dawn of the Middle Ages apocryphal works in abundance were freely circulated under the name of Seneca : his pretended correspondence with St. Paul, the Formula Honestae Vitae (or, De Quatuor Virtutibus Cardinalibus), the De Moribus, etc., all 
belonging to the fourth century of our era. ${ }^{1}$ Lucretius, $^{2}$ being on the other hand the accredited exponent of Epicureanism, was not looked on with favour by the scholastics, but was rather the auxiliary of their adversaries. Thus, the Cathari borrow arguments for their materialistic psychology from him (Ch. III., art. ii.).

III. The Fathers of the Church have handed down to the Middle Ages in their theological writings both their own philosophical theories and those of the ancients.

(I) Amongst them St. Augustine holds the first place. His psychology especially was appropriated by the earlier scholastics; metaphysical theses were also borrowed from him. An important group of Platonico-Augustinian doctrines were supported on his authority $(126,3)$.

(2) Pseuno-Augustine.-The reputation of St. Augustine as a philosopher and exponent of dogma, accounts for the number of apocryphal works attributed to him,- -works often teeming with anti-scholastic and even anti-Augustinian theories. The principal pseudo-Augustinian treatises are the following: $(a)$ Categoriae Decem, a synopsis of the Categories of Aristotle; (b) Principia Dialecticae, a monograph by some grammarian on the distinction between simple and compound terms; (c) Contra Quinque Haereses, the author of which quotes "hermetic" texts, giving them a Christian meaning; (d) later, the De Spiritu et Anima, a really faithful manual of Augustinian psychology, in high favour among the scholastics. It is simply a compilation from the works of Isidore of Seville, Alcuin, Hugh of St. Victor and Isaac de Stella, and is identified by Stöckl and Hauréau with the work of Alcher of Clairvaux."

(3) We find among the scholastics of this period quotations from the writings of ORIGEN (in the version of Rufinus (103, n. 2)), Clement of Alexandria, Lactantius, St. Ambrose; the Hexaemeron of the latter embodying a number of Aristotelian theories. CASSIAN, the Semi-Pelagian, against whom St. Augustine directed his latest writings, transmitted some philosophical notions

${ }^{1}$ Hauréau, Not. et Extr. de qqes MSS. latins, ii., 202, iv., 15 and 267.

${ }^{2}$ Isidore of Seville and Rhaban Maur, two compilers, treat him with exceptional favour (I 26, I).

${ }^{3}$ StöckL, Gesch.d. Phil. d. Mittelalters, i., pp. $3^{\varepsilon_{4}} s q q$. HAUREAU, op.cit., v., p. Ir3 (Paris, r892). 
to the Middle Ages, through the writings of Alcuin and Rhaban Maur.

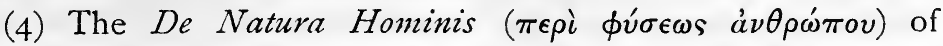
Nemesius (104) was current in the twelfth century in the version of Alfanus (1058-1085), Archbishop of Salerno. The same work was again translated in I I 59, under Frederick Barbarossa, by Richard Burgondio of Pisa. ${ }^{1}$

(5) Finally we may mention the writings of PSEUDO-Denis THE AREOPAGite and of MAXIMUS THE CONFESSOR. The treatises De Nominibus Divinis and De Hierarchia Coelesti were translated from the Greek in the ninth century by John Scotus Eriugena; they were placed high in the general estimation by St. Anselm in the eleventh, and they appear again in still greater esteem in the twelfth. ${ }^{2} \quad$ Medieval mysticism and esthetics were steeped in the spirit of these pseudo-Dionysian treatises. Commentaries were written on them simultaneously in the interests of NeoPlatonic pantheism and of orthodox individualism.

IV. Arabian and Byzantine Writers.-Some results of Arabian science became known to the Western world in the twelfth century through the monks of Monte Cassino. Notably, CoNSTANTINE THE AFRICAN, or Constantine of Carthage (about IO5O), translated a treatise of ISAAC ISRAELI (about 900) on the elements, together with certain writings of GALEN and HipPoCRATES. Burgondio of Pisa translated the $\pi \eta \gamma \dot{\eta} \gamma \nu \omega \dot{\sigma} \sigma \omega \mathrm{s}$ of St. John Damascene. But these translations were facts of very trifling importance: prior to the thirteenth century there was no real contact between Western culture and the philosophies of Arabia and Byzantium.

V. Writers of the Younger Races.-Besides Isidore of Seville, Gregory the Great, ${ }^{3}$ Venerable Bede and Rhaban Maur, to whom we have referred already, the leading educators of the early Middle Ages were Martianus Capella, Cassiodorus and Boëthius.

MaRTianus Capella, a native of Carthage, flourished in the fifth century. He came to Rome about 430 and there wrote the Satyricon and a treatise entitled De Nuptiis Mercurii et

${ }^{1}$ Baeumker, Nemesius, reprint from the Wochenschrift für klass. Philol., 1896, pp. 2 sqq. Cf. Domanski, Dic Psychol. d. Nemesius, p. xii.

${ }^{2} C f .247, \mathrm{n}$.

${ }^{3}$ In the early Middle Ages St. Gregory the Great was quoted even more extensively than St. Augustine. 
Philologiae, in which he incorporates Varro and other grammarians. This curious encyclopedia was eagerly studied in the Middle Ages on account of its attempt to classify the human sciences and to arrange a complete course of studies. Martianus popularized the trivium and quadrivium, symbolizing the various arts and sciences under the form of mythological personages. His work is more fanciful than scientific and enjoyed a quite unmerited influence in the early Middle Ages. ${ }^{1}$

CASSIODORUS and BOËTHIUS were both ministers of the Gothic king, Theoderic, who was the wise initiator of a scientific renaissance throughout his dominions. ${ }^{2}$ The former (470-570) was, like Martianus Capella, a teacher who collected into his treatises De Artibus ac Disciplinis Liberalium Litterarum and De Institutione Divinarum Litterarum, all that he had learned about the trivium and quadrivium, chiefly at the school of Boèthius.

Bö̈THIUs (480-525, sometimes referred to as Manlius, consul) was of a much higher order of genius and learning than Cassiodorus and Capella. His literary work is considerable. It includes :-

(I) Translations, especially of Porphyry's lsagoge and of various works of Aristotle. He translated the five parts of the Organon, but the last three (the Analytics, the Topics and the Sophistical Arguments) were apparently lost sight of until the end of the twelfth century. He states himself (in Lib. de Interpr., ii.) that he undertook the translation of all the works of Aristotle. These were unknown in the early Middle Ages. ${ }^{3}$

(2) Commentaries: two on the Isagoge, one each on Aristotle's Categories and De Interpretatione (his chief work on logic), and one on the Topics of Cicero.

(3) Original treatises on Categorical and Hypothetical Syllogisms, on Division, on Definition, on Topical Distinctions: all highly appreciated in the Middle Ages. With equal approval

${ }^{1}$ The seven arts are represented as young maidens, escorting Philologia, the fiancée of Apollo. Grammar appears as a daughter of Memphis, and carries a tray of instruments for loosing the tongues of children, etc. Logic figures $s$ an emaciated female with a serpent in one hand and a hook concealed in the other.

2 It was stifled $b_{v}$ the invasion of the Lombards (568), just as a similar revival inaugurated in Spain by Isidore of Sevile was arrested by the conquest of 7r2.

${ }^{3}$ On the translations of Boëthius see a long note by PÉre Mandoxine, Siger de Brabant, etc. (2nd edit., Louvain, in preparation, Pp. 7-9, and $13-15$ ). 
the scholastics also quote from his works on Mathematics and Music, and more especially from an ethical work which Boëthius wrote in the prison of Ticinum, into which he had been thrown after falling into political disfavour: the De Consolatione Philosophiae. The elegant style of this treatise shows to what an extent its author was imbued with the culture of the ancients. Various other writings on theological subjects (De Trinitate, De Hebdomadibus, De Fide Christiana, De Duabus Naturis in Christo) were circulated under his name, but they are of doubtful authenticity.

The influence of Boëthius on the philosophy of this period was considerable. Down to the end of the twelfth century he was the chief source of Aristotelianism, and was regarded as the equal of Aristotle, or even as his superior. His translations and commentaries, and his original treatises-which long supplied the place of the unknown portions of the Organon-formed the basis of all logical studies. Numerous other Aristotelian ideas were also transmitted by the "barbarian" philosopher: for instance, methodological theories, such as the famous tripartite division of the theoretical sciences into Metaphysics, Mathematics and Physics (34). He affected the mathematical or deductive method himself. We also find, scattered through his works, fragments of ideas on the nature and genesis of knowledge; and imperfect, rudimentary conceptions of matter, substantial form, change, substance, person, causes. The De Consolatione Philosophiae reproduces the argument for the Immovable Prime Mover. The De Trinitate studies the application of grammatical forms to the Divinity, etc.

Boëthius, moreover, was not a slave to the teachings of Aristotle. He transmitted to the Medieval schools quite a number of Platonic, Stoic, Pythagorean and Augustinian doctrines. The theology of the De Consolatione Philosophiae is a study of Divine Goodness and Providence; while theories on number and unity permeate his teachings on the Divine Nature, on Creation and on Exemplarism. In a word, he is the channel through which the scholastics received that varied assortment of theories which we find analyzed and sifted later on by the eclectic spirit of the thirteenth century.

VI. Medieval Writers. - We may set down in conclusion, as forming an integral part of the scholastic library of this first 
period, a few works of medieval philosophers: works of such wide popularity that they came to be regarded as classics. The De Divisione Naturae of John Scotus Eriugena and the Liber Sex Principiorum of Gilbert de la Porrée are, perhaps, the best examples.

133. Division of this Period.- The scholastic labour of this first period was concentrated mainly on the elaboration of the great leading doctrines which were to form the framework of the thirteenth-century synthesis ( $v$. below). This long, laborious process of formation was not accomplished without many uncertain gropings. Numerous early scholastics incorporate unbalanced and inconsistent theories in their system. Nay, some of them attach to clearly scholastic ideas other teachings that would lead to contradictory conclusions if rigorously pushed to their logical issues. But these same philosophers take good care to avoid and even to protest against such issues: ignoring or rejecting the corollaries of their own principles. On this account we will regard all of them alike, though on different titles, as pioneers in the same work: we will call them all by the same family name of scholastics.

But there are other philosophers of opposite tendencies; philosophers in open conflict with scholasticism; committed to principles which are the antithesis of its main, constitutive doctrines. For example, the Monism of Scotus Eriugena is irreconcilably opposed to the Individualistic Realism set forth in the glosses of Eric of Auxerre and in the treatises of Anselm of Canterbury: and this monism is in fact carried out into consequences whose opposition to scholasticism does not escape the notice even of contemporaries. So, too, the Materialism of the Cathari is frankly opposed to the Spiritualism of Alan of Lille: so much so that we find treatises written ex professo in refutation of it.

Now it would be unfair to determine the scholasticity of pre-scholastic doctrines by a crude comparison which would merely tabulate their points of diversity and similarity with the scholasticism of the thirteenth century. In a historical study we must consider doctrines not merely from a static point of view, but also and more especially in their dynamic tendency, in the sense of their development. Under this aspect, a process of doctrinal development is revealed by the history of scholasticism down to the twelfth century, and is seen to reach its culmination in the achievements of the thirteenth. The problem of the Uni- 
versals affords an apt illustration. ${ }^{1}$ We must, therefore, study the process in relation to its term, as the acorn is studied in relation to the oak-tree. The test we have chosen for a classification of the systems-or fragments of systems-of this period, into scholastic and non-scholastic, is their objective conformity or non-conformity with the fundamental tendencies of the great scholastic synthesis of the thirteenth century, which completes, unifies and harmonizes the doctrines transmitted from the early Middle Ages.

To this doctrinal basis of division we may add a secondary chronological basis. The twelfth century being the golden age of philosophical schools, we may divide the present period into two chapters which will deal respectively with: (I) Western philosophy from the Ninth to the Twelfth Century; (2) Western Philosophy in the Twelfth Century. Each chapter will distinguish between scholastic and non-scholastic theories.

134. Sources and Bibliography.-John of Salisbury, Polycraticus and Metalogicus (Migne, P. L., vol. 199). Marius Michel, Le Livre des origines d'Isidore de Séville (Revue internat. enseignement, $189 \mathrm{I}, \mathrm{p}$. $\mathrm{Ig} 8$ ): point of view of Philosophy and study of Grammar. Godet, Bède le Vénérable (art. in Vacant's Diction. Théol. Cath., rgo3) : general. Philosophy and Theology : Bruhnes, op. cit., 126, final note. HeITz, Essai historique sur les rapports entre la philosophie et la foi de Bérenger de Tours à S. Thomas d'Aquin (Paris, 1909): good. On Rhaban Maur: Fr. Kunstmann, Rhabanus Magnentius Maurus (Mayence, $\mathrm{r} 84 \mathrm{r}$ ).

Schools: L. MAISTRE, Les écoles épiscopales et monastiques de l'occident depuis Charlemagne jusqu'à Philippe-Auguste (Paris, 1866). Sреснт, Geschichted. Unterrichtswesen in Deutschland (Stuttgart, 1886): somewhat out of date. Willmann, Didaktik, i., § I8: good. Clerval, Lesécoles de Chartres au moyen âge du $5^{\text {me au }}$ I6mes. (Chartres, 1895): excellent; general review of pre-scholastic schools. LA Forètr, Histoire d'Alcuin (Paris, 1898): deals mainly with his life and work as an organizer. RoBert, Les écoles et l'enseignement de la théol. pdt. la lre moitié du xii.s. (Paris, Igog), Pt. i. General.

Programmes and Methods: MARIÉTan, Problème de la classification des sciences d'Aristote à S. Thomas (Paris, Igor): rich in documents; not always methodic. WillmanN, op.cit., § 19 (extensive bibliography, especially for each of the liberal arts, pp. $267 s q q$.). CleRval, op. cit. The organization of studies at Chartres gives an idea of what obtained elsewhere. Pfister, Etudes sur le règne de Robert le Pieux (Bibl. École Hautes Etudes, Paris, 1885): gives programmes of studies. Picavet, Hist. de l'Enseign. et des écoles du ix. au xiives. (R. internat. enseign., rgor). M. Roger, L'Enseign. des lettres classiques d'Ausone à Alcuin. Ferrère,

${ }^{1}$ M. DomET DE VoRges, writing of one of the leading personalities of this period, remarks very justly that "the peripateticism of the thirteenth century was not, as many seem to think, a complete transformation of the immediately preceding philosophy; its main solutions were in existence for a long time previously in the minds of the scholastic teachers, though not clearly formulated or methodically developed by the latter" (S. Anselme, p. 82). 


\section{WESTERN MEDIEVAL PHILOSOPHY}

De la division des sept arts libéraux (Ann. de phil. chrét., June, rgog): not sufficiently clear. Willmand, Geschichte d. Iiealismus, ii., 67. DE Wulf, Siholasticism Old and Nere, $\S_{S}+$ and 9 (Dublin, Ig07). G. KurTh, Notger de Liege et la civilisation an $x$ me s. (Brussels, 1905), ch. xiv. Grabmann, Die Geschichte d. Scholastisch. Wethode, Bd. i. (Fribourg, I909).

Works on Sources: J. Bernays, Uiber den Unter den Werken d. Apuleius stehenden hermetischen Dialog Asclefins (in the Monatsber. d. K. Akad. d. Wissensch., Berlin, i871, p. 500). Switalski, Des Chalcidius Kommentar zu Plato's Timacus (in the Beitr. z. Gesch. d. Phil. d. Mittelalters, 1902, iii., 6): studies the sources of Chalcidius, not his influence on the Middle Ages. Portalite, Développement historique de l'Augustinisme, in the Dict. Théol. Cath., rgo3: first part very interesting; St. Augustine, art. in the Catholic Encyclopedia (New York, Igo7, vol. ii.). Jourdan, Recherihes critiques sur l'âge et l'origine des traductiones d'Aristote (Paris, $18+3$ ): served as starting-point of such researches, itself insufficient. See complete bibliography down to 1902 in Ueberweg-Heinze.

Migne has edited the works of Alcuin (P. L., Ioo-Ior), Boethius $\left(6_{3}, 6_{4}\right)$, Bede (90 95), Cassiodorus (69, 70), Isidore of Seville (SI-S.t), Rhaban Maur (Io7-I 2). Essknha published a and edition of Martianus Capella in i 893 (Leipzig, Teubner). New edition of the ogical works of Boethius in the Corpus Scriptorum Ecclesiast. (Vienna). 


\section{CHAPTER II.}

THE PHILOSOPHY OF THE NINTH, TENTH AND ELEVENTH CENTURIES.

135. Résumé.-The first forward movement of scholastic thought may be detected in the study of the Universals (Art. I., $\S \mathrm{I})$. We can follow here, step by step, the gradual growth of inquiry, the discovery and cultivation of psychology, and the slow elaboration of a solution which was to be ratified by the researches of subsequent centuries. In the eleventh century St. Anselm (Art. I., § 2) made the first attempt to systematize the results so far achieved. His synthesis, necessarily incomplete, was gradually enriched and perfected by the generations that followed him.

In John Scotus Eriugena we see the father of the anti-scholastics. In his philosophy we find the germs of all the hostile tendencies which troubled scholasticism down to the close of the twelfth century (Art. II.). A separate article (Art. III.) will deal with theological controversies in their relations to philosophy.

\section{ART. I.-SCHOLASTIC PHILOSOPHY.}

§ I. The Question OF THE UNIVERSALS; its HistoriCAI Development.

136. How the Question of the Universals Arose in Philosophy. - Although it would be a mistake to identify scholastic philosophy with one long, monotonous conflict on the problem of universal ideas (II7), still it is true that this problem was among the first to force itself on the attention of the early medieval philosophers and to monopolize the philosophical speculation of this first period. But the question of the Universals belongs to all philosophies, for it is vital to all philosophy: and it was the 
making of scholasticism, inasmuch as it led to the discussion of fundamental theories in psychology and metaphysics.

The problem of the Universals is none other than that of the truth, or objective reality, of our intellectual knowledge. While the data of our sense-perceptions are manifold and individual, the object of our intellectual representations is abstract, universal and independent of all individualizing conditions or determinations. The question is, whether such intellectual conceptions are faithful; whether they correspond adequately with the external objects which give rise to them in our minds; whether, therefore, they teach us anything about what exists outside our minds? It is usual to record four distinct answers to this question. $^{1} \quad$ It is very necessary to state these accurately; all the more so because historians are not agreed about the meanings they attach to the various titles descriptive of these solutions.

(I) Extreme or Exaggerated Realism. - The harmony between concept and objective reality is manifest, if the latter exists in the state of universality in which it is thought. There would then be a strict parallelism between thought and reality. Extreme realism, openly advocated by Plato, offers this solution of the problem. It is complete, no doubt; but unfortunately it is also completely opposed to sound common sense. For, is not every being in Nature individual, and are not natural substances independent of one another in their separate existences? So Aristotle taught, on the first page of his Metaphysics (43), and in this he was followed by all the opponents of extreme realism.

But this bald assertion of the substantiality of the individual is far from being the last word on the problem; for it at once raises a question which was evaded by extreme realism and which contains the real difficulty of the problem: How can a universal representation faithfully reflect a world which contains only individuals? Is there not a complete opposition between the attributes of the real thing and those of the thing represented? Three ways of meeting this difficulty have been suggested by philosophers.

(2) The most drastic of these suggestions is Nominalism. At the opposite pole from the extreme realism which fashions the

\footnotetext{
1 For a full treatment of the question, see MERCIER, Critériologie générale (5th edit., Paris and Louvain, (1906), pp. 328 sqq.
} 
real world after the attributes of the thought-world, we have Nominalism endeavouring to model intellectual thought upon the external thing. It therefore denies the existence of genuinely universal concepts, and refuses to the human mind the power of forming such. But then, what are those concepts or notions that are commonly described as "general"? The nominalists have been accused of holding "the absurd view that the universal is a mere vibration of the air, a mere sound of the voice, flatus vocis. But is it not most highly improbable that a school of philosophy would have formulated and defended for centuries such an empty, puerile doctrine?"1 For our own part, we believe, in opposition to what has been the generally received teaching, that Nominalism, in the sense just defined, never existed in the Middle Ages. ${ }^{2}$

(3) Conceptualism admits the existence of universal concepts and their ideal validity, but not their real validity. Our concepts have for their mental term a universal object (ideal objectivity), but we do not know whether they have any foundation outside us; whether, in Nature, the separate individuals possess de facto the essence which we conceive as realized in each of them (real objectivity).

(4) Moderate or Aristotelian Realism (43), also called Thomistic Realism, claims both an ideal and a real validity for the concept. Things " are individual, but we have the power of representing them in the abstract. But when the abstract type is contemplated by the reflecting mind and referred by the latter to the particular things in which it is realized or realizable, it is seen to be equally applicable to each and every one of them. This applicability of the abstract type to the individuals, constitutes its universality." 3

137. How the Question of the Universals was proposed in the Early Middle Ages.-The classification we have just outlined cannot be applied to the philosophers of this period. And the reason is that the problem of the Universals is very complex. It not merely involves the metaphysics of the individual and of the universal, but also raises important questions in ideology,-

${ }^{1}$ Mercier, op. cit., p. 356.

2 Windelband remarks the same unlikelihood: "Selbst die Behauptung, der Nominalismus sei so weit gegangen, die Universalen für blosse 'flatus vocis' $z u$ erklären, dürfte kaum wortlich zu nehmen sein" (in GRöBER, Grundriss d. roman. Phil., ii. ${ }^{3}$, p. 559, n. ז).

${ }^{3}$ Mercier, op. cit., p. 343. 
questions about the genesis and validity of knowledge. ${ }^{1}$ But the earlier scholastics, unskilled in such delicate matters, did not perceive those various aspects of the problem. It did not grow up spontaneously in the Middle Ages; it was bequeathed in a text of Porphyry's Isagoge, a text that seemed simple and innocent, though somewhat obscure, and one which force of circumstances made the necessary starting-point of the earliest medieval speculations about the Universals [132, I. (3), a].

Porphyry divides the problem into three parts: (1) Do genera and species exist in Nature, or do they consist in mere products of the intellect? (2) (If they are things apart from the mind) are they corporeal or incorporeal things? (3) Do they exist outside the (individual) things of sense, or are they realized in the latter?" Historically the first of those questions was discussed prior to the others: the latter could have arisen only in the event of denying an exclusively subjective character to universal realities. Now the first question was whether genera and species are objective realities or not, sive subsistant, sive in nudis intellectibus posita sint? In other words, the sole point in debate was the absolute reality of the Universals: their truth, their relation to the understanding, was not in question. The text from Porphyry, apart from the solutions he elsewhere proposed in works unknown to the early scholastics, is an inadequate statement of the question; for it takes account only of the $o b$ jective aspect and neglects the psychological standpoint which alone can give the key to the true solution. Moreover, Porphyry, after proposing his triple interrogation, in the Isagoge, refuses to offer an answer, dicere recusabo. Boëthius, in his two commentaries, gives replies that are vague and scarcely consistent. ${ }^{3}$ In the second commentary, which is the more important one, he holds that genera and species are both subsistentia and intellecta

${ }^{1}$ See "The Scholastic Synthesis," below.

${ }^{2}$ Mox de generibus et speciebus illud quidem sive subsistant sive in nudis intellectibus posita sint, sive subsistentia corporalia sint an incorporalia, et utrum separata a sensibilıbus an in sensibilibus posita et circa haec subsistentia, dicere recusabo.

${ }^{3}$ In the thirteenth century we find Godfrey of St. Victor reproaching Boëthius in these words: "Assidet Boëthius stupens de hac lite-Audies quid hic et hic afferat perite-Et quid cui favet non discernit rite-Nec praesumit solvere litem definite" (quoted by LoEwe, Kampf zwischen Realismus u. Nominalismus im Mittelalter, p. 30). 
(Ist question), the similarity of things being the basis (subjectum) both of their individuality in Nature and their universality in the Mind; that genera and species are incorporeal not by nature but by abstraction (2nd question); and that they exist both inside and outside the things of sense ( 3 rd question). ${ }^{1}$

This was not sufficiently clear for beginners: though we can see in it the basis of the Aristotelian solution of the problem. The early scholastics faced the problem as proposed by Porphyry: limiting the controversy to genera and species, and its solutions to the alternatives suggested by the first question: Do the objects of our concepts, i.e., genera and species, exist in Nature (subsistentia), or are they mere abstractions (nuda intellecta)? Are they, or are they not, things? Those who replied in the affirmative got the name of reals or realists; the others that of nominals or nominalists. We will show later why we prefer to call the latter simply anti-realists.

138. Extreme Realism. - This solution. "realizes" the object of our abstract concepts, clothing it, in the extramental order, with the universality under which we conceive it. It seems to have been the first view to gain adherents, for Abelard refers to it as an antiqua doctrina, ${ }^{2}$ and, down to the end of the twelfth century, its opponents are called moderni. We may attribute the popularity of extreme realism for four centuries to two main causes. Firstly, it seemed to offer an intelligible explanation of certain dogmas of the Catholic faith, such as that of the transmission of original $\sin (\mathbf{1 4 2})$. And secondly, it is a categorical and simple solution of a troublesome problem. Indeed of all the solutions it is the least complex, for it asserts an adequate correspondence between the things of Nature and our intellectual representations of them : by its very simplicity it seduced philosophers into embracing it.

\section{Two Groups of Extreme Realists. Medieval Realism and} Platonic Realism.-The scholastic realists of the first four centuries of the Middle Ages fall into two great groups. Some attribute to each species and each genus a universal essence (subsistentia), shared by all the subordinate individuals. Others

ISee Migne, Patr. Lat., t. 64 , cols. 84,85 .

"Similarly an anonymous MS. of the twelfth century, published by HaUrénU (Not. et extr. ms. lat. Bibl. Nat., t. 31, part 21, p. 20r): "Est autem antiqua sententia et quasi antiquis erroribus inveterata". 
go farther, confounding all realities in one single being of the most various and diverse forms. Indeed pantheism is the logical and necessary outcome of extreme realism; for, if the attributes of real objects are modelled on the attributes of conceived objects, the most abstract of all our concepts, - that of "being," in its widest sense--must have its correlative "being" in the order of external Nature: and as all our concepts are determinations of this widest concept, so would all realities be mere determinations of this one real being.

If, therefore, we were to attend, not to the theories themselves as they were actually formulated, but to the remoter consequences involved in them, these statements of extreme realism would lead to the very negation of scholasticism. But with the exception of John Scotus Eriugena, the realists of the ninth, tenth and eleventh centuries, never went so far. Many of them even expressly repudiate pantheism and try to reconcile their realism with individual human personality, with the doctrine of creation and with the dogmas of the Church. Hence we believe that this earliest form of extreme realism ought not to be classified historically as anti-scholastic. Halting and defective as it is, it has its sufficient apology in the express reservations with which its exponents qualified it, and in the feeble and tentative character of all the speculative efforts of this period $(\mathbf{1 2 6}, 3 ; \mathbf{1 4 2})$. On the other hand, another form of realism, openly pantheistic, formed one of the most dangerous teachings of anti-scholasticism. It will be examined in the next article.

When, finally, we compare medieval realists, whether pantheistic or not, with the founder of the Greek Academy, we must not lose sight of an important difference between their theories and the Platonic "dialectic". For Plato the Ideas have an existence apart from the world of sense (22). For the medieval realists the (universal) essence remains wholly in the individual sense world.

140. Principal Realists. Fredegis. Remi of Auxerre. - The Athenian sage (Atheniensis Sophista), whom we meet at the court of Charlemagne, "realizes" death, because death is to receive the price of life. FREDEGIS, the predecessor of John Scotus Eriugena at the palace school, also illustrates this unconscious artlessness in speculation, which is revealed in varying degrees by the realists of this first group. From the statement of Scripture, 
that Egypt was covered with a darkness so thick that it could be felt by the hand, he proceeds, in his work De Nihilo et Tenebris to " realize," to make real, the entia rationis or purely logical entities, darkness, and even nothingness itself. He develops this same teaching in a Letter to Agobard.

At the end of the ninth century, realism was propounded by REMI OF AUXERRE, who succeeded his master, Eric, in the chair of the abbey, abandoning Eric's teaching (144). Later on, Remi taught at Rheims, and he is set down as the first doctor to introduce dialectic into the Paris schools. He has left us a commentary on the Ars Minor of Donatus, a work widely studied down to the twelfth century, and also a commentary on Martianus Capella, in which Remi draws extensively from a similar work of John Scotus Eriugena.

14I. Gerbert. - The tenth century is a century of blood. The Normans spread ruin and destruction around them, and seats of learning pass through a crisis that practically exterminates them. Germany, under the rule of Otto, is the only exception. A few scattered scholars, depositaries of a sacred tradition of learning that barely escaped entire obliteration,--just a few names,emerge from the gloom of a barbarous epoch: ODO OF CLUNY, Reinhard of St. Burchard, Poppo of Fulda, Gunzo, Notker Labeo (129), Bruno of Cologne, Ratbod of TrÈVES, RATGAR OF VERONA who wrote treatises on dialectic. But none of these can compare with Gerbert.

GERBERT (b. about the middle of the tenth century, d. 1003), after having studied for three years in Spain, became successively professor at the court of Otho I., master at Rheims and then at Paris, where he won for himself a world-wide reputation, afterwards abbot of Bobbio, archbishop of Rheims, then of Ravenna, and finally pope under the name of Sylvester II. By one of his contemporaries he was styled the "philosopher pope".

Gerbert commentated more of the works of Aristotle than any of his contemporaries: a century later St. Anselm and Roscelin knew no other works of the Stagirite. Gerbert had also a thorough knowledge of the trivium and quadrivium. $\mathrm{He}$ wrote on geometry, arithmetic and the elements of Arabian science. He was all at once scholar, humanist, writer, orator, savant. His letters show him to have been an entirely superior class of man; and the monk Richer, a contemporary and prob- 
ably a pupil, professes in his History a very legitimate admiration for him. Of Gerbert's philosophical teaching we possess only the account given us by Richer of a dialectical encounter between Gerbert and Otric, a short treatise $D_{\mathcal{E}}$ Rationali et Ratione Uti, and another of less importance, De Corpore et Sanguine Domini. Can Gerbert be classified with the extreme realists? ${ }^{1}$ Certain expressions of his would seem to demand this ; still we must remember that he is writing in the main as a logician, that scraps of metaphysics appear only at rare intervals (we find in him the important distinction of act and potency), and that he gives no clear or decisive answer to the questions of Porphyry. As a moralist, Gerbert had a liking for certain Stoic theories. His moral teaching is fragmentary and specialized; he defends the political subordination of all Christians to the unity of the Church.

Gerbert is the founder of a school: his lectures were frequented by the realist FULBERT, who founded the famous school of Chartres, by the bishops GIRARD, LenTHERIC, perhaps by the historian RiCHER, etc., all well-known workers of the eleventh century.

142. Odo of Tournai. - In the second half of the eleventh century the cathedral school of Tournai was adorned by an eminent scholar who gave a new impetus to realism: ODO OF TournaI ( † I I 3 ). After teaching at the cathedral school he founded the Abbey of St. Martin in Tournai and subsequently became Bishop of Cambrai. Captivated by the study of Plato's Timaeus, he got into a controversy with an anti-realist master, RAIMBERT OF Lille. An account of this polemic is to be found in the contemporary chronicles. ${ }^{2}$

Odo deserves special mention for his interesting applications of the classic realism to certain Catholic doctrines. In his principal work, De Peccato Originali, he applies the theory to:-

(a) The transmission of original sin.-Men form but one substance, one specific reality. When Adam and Eve sinned the entire human substance, in all its ramifications, was vitiated by the fall, and all future generations, living an anticipated life in that vitiated substance, likewise contracted the stain. ${ }^{3}$

${ }^{1}$ Haureau, Hist. de la phil. scolastique, i., p. 2 16 (1880).

'Cf. our Histoire de la philos. scol. dans les Pays-Bas, etc., p. 19.

'De Peccato Originali, Lib. ii., col. 1079, vol. clx., Patrol., Migne. 
(b) The continuous creation of the souls of infants.-What God produces at each birth is not a new substance, but a new property of the one single, already existing substance. At the surface, as it were, of the one abiding substance which constitutes the human species, ever-changing individual properties are incessantly appearing and disappearing: men differ from one another only by properties or accidents. From this attitude of Odo, we can easily understand his appreciation for the arguments of the traducianists.

143. The Anti-Realists. - The realists soon encountered numerous opponents. It is to a negative thesis that all these rally, in the name of Aristotle and common sense: "the Universals are not things, realized in the universal state in nature (subsistentia), for the individual alone exists". And since the problem to be solved was stated in Porphyry's alternative, it was inferred that the Universals must, therefore, be mere constructions of the mind (nuda intellecta). But the import of this anti-realist declaration must be interpreted with cautious reserve. Affirming on the one hand the substantiality of individual beings alone, admitting on the other hand the existence of universal concepts in our minds, the anti-realists had to face inevitably, sooner or later, the real kernel of the Universals difficulty (136). But those of the earlier period with which we are dealing, were satisfied with stating the two great facts which really form only the starting-point of the debate, without espousing any of the characteristic theories which sprang from later attempts to effect a rapprochement or reconciliation of those facts. In holding that Universals are nuda intellecta (and by intellecta we must understand intellectual representations), or verbal forms (flatus vocis, voces), they did not mean to propound nominalism in the sense defined above $(\mathbf{1 3 6}, 2)$. For they also spoke of universal representations; but they did not analyze the genesis of mental processes sufficiently to be able to say whether these representative forms of the understanding have merely an ideal value and significance (conceptualism), or also at the same time a real value (moderate realism). It took four centuries to ripen philosophical speculation on the problem, before these more delicate shades of thought were clearly distinguished and their importance fully appreciated.

We must, then, remember that in the mouth of the early antirealist the statement that the Universals are nuda intellecta, has a 
distinctly negative and limited scope-denying the existence of a universal reality in the sense of one of Porphyry's alternatives. The designation anti-realist is appropriate as marking this negative attitude. Against things, Porphyry set over the creations of the mind: it is because they would not admit the Universals to be things, realities, that the anti-realists described these Universals as abstractions.

144. Rhaban Maur and Eric of Auxerre.-RHABAN MAUK (a pupil of Alcuin at Tours, then teacher at Fulda, where he had among his numerous auditors Servatus Lupus of Ferrières) did not go beyond the general assertions just referred to. There is nothing in his encyclopedic collections (126, I), nor in the glosses which Cousin attributes to him ${ }^{1}$ on the Isagoge and the De Interpretatione, nor in his treatise on The Proposition, that he did not learn from Boëthius. He teaches that universal terms signify neither sensations nor things, but notions, and that the universal has no essence other than that of the individual things of sense."

ERIC OF AUxERRE (who flourished about the middle of the ninth century, studying under Servatus Lupus of Ferrières and Rhaban Maur at Fulda before he opened school at Auxerre) reflects the same general tendencies in the glosses of which he is the reputed author. Hauréau attributes to him commentaries on the De Interpretatione, on Pseudo-Augustine's Dialectic and Book on the Ten Categories, on the Isagoge, on the Latin text De Syllogismo of Apuleius, and on various works of Boëthius. According to Professor Baeumker, only portion of the glosses on the Categories of Pseudo-Augustine can be attributed to Eric. ${ }^{3}$

An anonymous commentary on Martianus Capella, written by a contemporary of Eric and brought to light by Victor Cousin, may be mentioned among the anti-realistic productions of this period.

145. Roscelin.-Roscelin, a monk of Compiègne, flourished towards the end of the eleventh century. He had relations with St. Anselm, Lanfranc and Ives of Chartres. Summoned to a council at Soissons (I 093) on a charge of Tritheism, he repudiated the doctrine imputed to him: but apparently only in order to

${ }^{1}$ According to Prantl and others they are the work of a pseudo-Rhaban.

"Domet de Vorges, S. Anselme, p. 35.

${ }^{3}$ Dr. Baeumker has promised an edition of those glosses. Clerval (op. cit., p. I65) attributes them to a disciple of Rhaban Maur. 
escape excommunication, for he afterwards reasserted his earlier theories. We next find him successively in England, in Rome, and back again in France.

Roscelin's role in the history of medieval thought has been somewhat exaggerated owing to his being regarded as the first to propound the doctrine of Nominalism. His contemporary, Otto of Freising, says of him: "Qui primus nostris temporibus sententiam vocum instituit". "In reality he is less remarkable for his Nominalism in philosophy than for his Tritheism in theology (16r).

A letter addressed to Abelard is the only writing of Roscelin we possess, ${ }^{2}$ and we are obliged to judge of his teaching from a few scattered texts preserved in the works of St. Anselm, Abelard and John of Salisbury. Genera and species are only words, voces. So say the texts; but what does this mean?

One thing is certain: Roscelin figures in them as a demolisher of realism. That is his principal role: and it is a purely negative one. Hence he maintained, as St. Anselm tells us, that the colour of the horse does not exist independently of the horse that supports it; as such, it is not in the objective order, any more than wisdom exists as such outside the mind that is wise. These applications, criticized by St. Anselm (De Fide Trin., 2), show pretty clearly that Roscelin's main concern was to insist emphatically on the reality of the individual. ${ }^{3}$

${ }^{1}$ We learn from an anonymous eleventh-century chronicle that Roscelin had for master and precursor a certain Joun. This latter, identified by some with John Scotus Eriugena (v. Revue Thomiste, July, 1897, art. by Mandonner), by others with John the Deaf or John the Physician, of Chartres, a disciple of Fulbert (Clerval, op.cit., pp. I22 sqq.), is a personage as yet practically unknown. The Liber Miraculorum Sancte Fidis, compiled about the beginning of the eleventh century by Bernard of Angers, mentions a certain Johannes Scottigena, a contemporary of the author, and whom it clearly distinguishes from Eriugena (v. Revue internat. enseignement, r903, p. 193; Nos maîtres, Un Fean Scot inconnu, by A. THOMAS).

${ }^{2}$ HaURÉau connects the name of Roscelin with a recently discovered text, Sententia de Universalibus sec. mag. $R$. (Notices et extr., etc., Paris, r892, v., p. 224); but this is a mere conjecture. Anyhow the text in question admits the ideal validity of Universals, and, therefore, the existence of universal concepts. ( $C f$. v., p. 325.)

${ }^{3}$ The example of the house, mentioned by Abelard, may be understood in the same sense. Roscelin employs it merely as an analogy to illustrate his teaching that species have no objective existence (Abelard, De Divis. et Defin., p. 47r, Cousin's edition). As for the texts in John of Salisbury (Metalog., ii., p. 17, and Polycrat., vii., p. 12), they offer no explanation of the meaning of voces. 
Did he go farther than this? Did he take up the more extreme attitude commonly ascribed to him, of even denying to the intellect the power of forming universal representations, and of thus reducing the latter to mere sounds, mere breathings of the voice (flatus vocis, verba)? Let us bear in mind that, like all his contemporaries, Roscelin had his attention fixed on Porphyry's question, and that his language ought to be interpreted according to the exigencies of the problem in its proper historical setting. Unwilling to make things of the Universals, he makes a mental product of them. Between the two alternatives he sought no middle course, because Porphyry and Boëthius had indicated none. But what is the nature or value of the mental product called the universal? Does the Sententia Vocum of Roscelin mean to assert that those "words" themselves, in their common or universal form, had no universal conceptions corresponding to them? There is nothing in the sources to authorize our giving any such precise and complex interpretation to the Sententia Vocum; and everything inclines us to believe that the monk of Compiègne never troubled himself about the question. The expression Ars sophistica rocalis, found in certain eleventh-century documents, is only another name for the science of logic or dialectic and leaves the ontological problem of the Universals untouched. According to a very plausible explanation of Adlhoch, ${ }^{1}$ Roscelin reduced the controversy to a question of philology or rather of elementary phonetics: voces and flatus vocis, or words in their universal forms, are mere emissions of sound, forms of letters and syllables. All Roscelin's texts assume a plausible meaning if we take him to understand by the universal what we nowadays call the universale in voce as distinct from the universale in mente and the universale in re. If we are to take Nominalism in the exact sense in which it is understood at the present day, the teaching of Roscelin is only pseudo-Nominalism. ${ }^{2}$ Or rather, the medieval world understood the term in the negative and relative sense of anti-realism. And in this anti-realism there was nothing to be rejected by the moderate realism of the thirteenth century.

146. The Dialecticians. - Superficial modes of reasoning, more verbal than real and often verging on sophism, had come into fashion in the early Middle Ages. They grew worse in the

${ }^{1}$ AdLносн, Rosielin u. S. Anselm (Philos. Jahrh., Bd. xx., H. 4, 1907).

a "Vocalistischer Pseudo-Nominalist" (Ant.носн, op. cit.). 
eleventh century. Thus Fredegis is accused of great proficiency in drawing unexpected and sophistical conclusions from his premisses, by his adversary, Agobard of Lyons. Candidus of Fulda (ninth century), another master at the palace school, also indulges in syllogistic feats in his Dicta. ${ }^{1}$ Those displays of formal logic were still more common in the eleventh century. Lay professors, coming up from Italy and travelling from school to school, according to the custom of the age, established those tendencies in the schools of the West. They were called philosophi, dialectici, sophistae, peripatetici. And what we possess of their works goes to show that those logic-choppers well deserved the severe rebukes (scholaris infantiae naeniae) of St. Peter Damian. Anselm of Besate (Anselmus Peripateticus of Parma, first half of eleventh century) is the personification of this tendency, and his Rhetorimachia a model of quibbling.

When those dialecticians turned to theology, proclaiming the absolute rights and efficacy of their procedure, they fell straight away into heresies; and hence we can understand the opposition they encountered from the theologians (162).

147. Conclusion.-Extreme realism attends only to the real element in our concepts and endows this element with actual universality. As against this, the earlier forms of anti-realism urge the negative thesis of the non-existence of universal essences. Both theories alike offer an imperfect solution of the problem; but, whereas the first is vitiated by a fundamental error, the second embodies a true doctrine which a series of more searching investigations and more accurate formulas were destined gradually to bring to light.

From the standpoint of the development of scholastic philosophy, the two parties, "realists" and "nominalists," differed in the lines of influence they exerted. The former, more concerned with the substantial reality of things, contributed powerfully to the study of metaphysics. The latter, bent on demolishing mere chimerical creations, were not at all clear nor sure of their ground when it came to determining the precise relations between reality and thought. In order to discover how a universal concept could represent an individual thing they had to investigate the genesis of knowledge and to bring to light the laws of abstraction and

${ }^{1}$ One of those Dicta contains a very poor attempt at a proof of the existence of God (ENDres, Fridugisius u. Candidus, p. 449). 
reflexion. Thus, it was the gradual study of psychological problems that was fostered in the schools of the anti-realists.

148. Sources and Bibliography. - The works of Fredegis (Migne, v. 105); De Nihilo et Tenebris, in the Monum. German., Epistolae Karolini Aevi, iii., 6I5. There is no complete edition of the works of Remi of Auxerre. V. Migne, vols. I3I and II 7, among the works of Haymon. The Letters of Gerbert (983-997) have been published by M. Havet (Paris, I889). Richer's History is published in the Monumenta Germaniae. (Dispute with Otric, III., lv.-1x.) Migne has published the works of Gerbert, v. I39; of Odo of Tournai, v. I6o; and a poem of Eric of Auxerre, v. I29. Edit. of the Rhetorimachia of Anselmus Peripateticus, by Dummler (1872). The Dicta Candidi in the Monum. German., Epist. Karol. Aevi, ii., $55^{2}$ (1895).

Cousin, Ouvrages inédits d'Abélard (Paris, I839), Introduction. Opened the way for further research. Loewe, Der Kampf zwischen Realismus und Nominalismus im Mittclalter (in Abhandl. d. k. bömischen Gesselsch. d. Wissensch., vi. F., Bd. viii., I876): a valuable study. IE WULF, Le Problime des universaux ds. son évolut. histor. du IXme au XIIIme s. (in the Archiv f. Gesch. d. Phil., ix., \&, Igo6). Richter, Wizo und Bruun, zwei Gelehrte im Zeitalter Karl d. Grossen, etc., Leipzig programme, İgo. Endres, Fridugisius und Candidus (Philos. Jahrh., xix., 4, 1906) : a good monograpi). Willman, Geschichte d.Idealismus, ii., $\$ \$ 69$ and 70. Picavet Gerbert, un pape philosophe, d'apris l'histoire et d'après la légende (Paris, 1897): gool; Roscelin, theologien it fhilosophe (Paris, 1896). See our analysis in the Revue Néo-scolastique, I898, p. 75. S. BARACH, Zur Geschichte d. Nominalismus von Roscelin, I866. ADLносн, Roscelin u. S. Anselm (Philos. Jahrh., Bd. xx., h. 4, 1907). Completes our interpretation of the pseudo-Nominalism of Roscelin. G. Canella, Per lo Studio del Problema d. universali nella scolastica (La scuola cattolica, 1904-1907): generalities. Re1ners, Der Aristotel. Realismus in der Frühscholastik (Ein. Beitrag z. Gesch. d. Universalenfrage im Mittelalter, Aachen, 1907): good. Buovaiuti, Un filosofo della contingenza nel Sec. XI. Roscelino (Revista storico-crit. d. science theol., I908). ExDRes, Die Dialektiker und ihre Gegner im II Fahrh. (Philos. Jahrh., I9o6).

\section{ST. ANSELM.}

149. His Life and Works.-Born of noble parents at Aosta, in I033, ST. Anseli was successively Abbot of Bec (IO78), where he knew Lanfranc, and Archbishop of Canterbury (I093). Down to his death, in I IO9, he spent himself without reserve in the cause of science and the Church.

Among his authentic works the Monologium and the Proslogium, the Liber Apologeticus ad Insipientem (in reply to Gaunilo, see below), the De Fide Trinitatis and the De Incarnatione Verbi, the dialogues, De Grammatico, De Veritate, De Libero Arbitrio, and the Cur Deus Homo, are the most important from the standpoint of philosophy.

We may say of St. Anselm that he was the last of the Fathers of the Church and the first of the scholastics. He was formed on 
the great thinkers of the patristic period, especially on St. Augustine $;^{1}$ and he effected the first systematization of scholastic philosophy, thereby succeeding largely in raising it above the level of discussions in formal logic. His mind was filled with problems, which he built into a system that can rival the antischolastic synthesis of John Scotus Eriugena. He reminds us of Gregory VII., who in the religious and political orders achieved such a wonderful organization of the Church and adjustment of its relations to the State: he is the Gregory VII. of knowledge. The pair of them are figures that adorn the eleventh century and mark it as an epoch of revival and reconstruction.

150. Philosophy and Theology.-The spirit of St. Augustine breathes through the formulas that give expression to St. Anselm's theory here. Crede ut intelligas. That is to say, firstly, that faith goes before reason inasmuch as it is the purifier of the soul; but, secondly and especially, that faith must be perfected and completed by a rational study of the contents of revelation; in other words, that philosophy should be at the service of theology. Applying this principle himself, Anselm undertook to give a rational justification of dogma, making some reserves, however, in regard to the demonstrative force of his arguments. "He borders unconsciously on rationalism, without falling into it." 2

In his investigations he is brought face to face with numerous philosophical questions. "St. Anselm thought he was writing only theology; in reality he was also developing the germ of a distinct system of philosophy." 3

15I. Metaphysics and Theodicy. - In accordance with the tendency of his time, St. Anselm approached the problems of philosophy from the side of metaphysics; and, as a result of the plan he adopts, his metaphysical teachings all circle around a vast system of theodicy. His method is that of the regressive, de-

1 "Nihil potui invenire me dixisse quod non catholicorum Patrum et maxime beati Augustini scriptis cohaereat" (Monologium, pref.).

${ }^{2}$ HeItz, Essai historique sur les rapports entre la philosophie et la foi de Berenger de Tours à Thomas d'Aquin (Paris, rgog), p. 63.

${ }^{3}$ Domet de Vorges, S. Anselme, p. 328. The crede ut intelligas applies then, literally, only to theology. But M. Domet de Vorges remarks that in the thought of St. Anselm the aphorism has a wider scope and applies to the dispositions of all who want to attain to truth: "to believe in the truth is a necessary disposition for discovering it" (op. cit., p. 135). 
ductive synthesis, so dear to St. Augustine: God is there as the supreme exemplar, efficient and final cause of the whole intelligible and real world. St. Anselm's theodicy is, moreover, the first in the present period really worthy of the name. It takes a large, commanding and masterly view of the whole region of speculation. The influence it exerted on subsequent studies in theology is clearly marked and decisive. Indeed, with St. Anselm scholastic theodicy may be said to have reached the status of a finished science, so that subsequently "the body of the doctrine is unvaried, and each scholastic expounds it after his own fashion". In the Proslogium, and still more in the Monologium-which sometimes recalls the Confessions of St. Augustine by the sublimity of its inspiration-we have proofs of the existence of God together with dissertations on the Divine Nature (simplicity, immutability, immensity, etc.), on Creation, Exemplarism, etc. The following points deserve special notice:-

(I) His arguments for the existence of God; many of which are original. For instance: there is something that is in itself good, in itself great, that cannot be merely communicated but must be or exist of itself; and that is God." Again: the vast visible hierarchy of beings proves that there must be a being superior to all others, a supreme being; and that is the Deity. But the name of St. Anselm is inseparably connected with one special argument for the existence of God: the famous ontologica! argument." It may be stated thus: "We possess the idea of a being so great that we cannot conceive a greater. But this idea necessarily implies the existence of that being; for existence, being a perfection, must belong to the greatest conceivable being. Therefore God exists." 4 This argument confounds the subjective or ideal order with the objective or real order. To conceive a being which is the greatest possible and which must therefore be conceived as existing is not at all the same thing as to affirm or prove that such a being exists really and objectively.

The argument was attacked by a contemporary of St. Anselm,

${ }^{1}$ Domet de Vorges, op. cit., p. $26 \mathrm{r}$.

2 Ibid., p. 230.

${ }^{3}$ Historians are not agreed about the meaning and value of this argument. In quite recent times new discussions on it have appeared in abundance.

${ }^{4}$ Proslogium, cap. ii. : "Si enim id quo majus cogitari non potest est in solo intellectu, idipsum quo majus cogitari non potest est quo majus cogitari potest. Sed certe hoc esse non potest. Existit ergo procul dubio aliquid quo majus cogitari non valet, et in intellectu et in re." 
the monk Gaunilo, who contended and rightly that it was worthless for convincing an atheist. One might as well attempt to demonstrate the existence of an island in the ocean, the most beautiful of all islands, from merely imagining such an island. ${ }^{1}$ Most of the great scholastics of the thirteenth century, notably St. Thomas, reject the argument as invalid.

(2) His definition of truth.- " Res sunt verae quando sunt ut debent," writes St. Anselm in the dialogue De Veritate,-which shows that he is thinking only of transcendental or ontological truth (the ut debent is the conformity of things with the destination revealed by their essence, the imitation of the Divine essence); though in order to reach this definition he sets out from the truth of judgment. Truth is the rectitude of what is accessible to intelligence alone ("veritas est rectitudo sola mente perceptibilis," De Veritate, I I). It is eternal, stretching beyond the changing mind and having its foundations in God. This language reveals the faithful disciple of St. Augustine (Ioo). The metaphysical teaching of St. Anselm is sound and accurate, though wanting, of course, in the more perfect precision of the later Thomistic teaching.

(3) Defence of the Divine Unity against Roscelin.-Applying his anti-realism to the dogma of the Trinity, Roscelin fell into tritheism (16I). St. Anselm defended the threatened faith in the name of reason, and maintained the unity of God in the name of $\mathrm{His}$ infinity. Here his thesis was unimpeachable, but his arguments were not always beyond exception. Indeed, in his anxiety to find weapons in the enemy's arsenal he called in the aid of extreme realistic theories (4). To one excess he opposed the opposite.

(4) Exaggerated Realism.-St. Anselm is openly realist. "We might indeed call him an extreme realist, were we to take his language literally. We must, however, bear in mind the lack of precision that characterized the language of philosophy in the eleventh century." ${ }^{2}$ "He who does not see," says the philosopher of Bec, "how on a multitude of men are specifically one only man, can hardly understand that many persons, each of whom are God, are yet one only God." 3 But St. Anselm did not, any more than

${ }^{1}$ Liber pro insipiente adversus Anselmum in Proslogio ratiocinantem.

2 Domet DE Vorges, op. cit., p. 153 .

3 "Qui nondum intelligit quomodo plures homines in specie sint unus homo, qualiter comprehendit quomodo plures personae quarum singula perfectus Deus est sint unus Deus?" (De Fide Trinitatis, 2). 
his predecessors, interpret extreme realism in that rigorous sense which would have led to pantheism and thereby to the destruction of his whole theodicy: which again shows that the solutions of the Universals problem must be judged historically not by their absolute doctrinal value, but rather in relation to the concrete circumstances of each epoch. ${ }^{1}$

152. Psychology and Ethics. - Without writing any special treatise on the subject, St. Anselm deals with isolated questions of psychology, and in a spirit often distinctly reminiscent of St. Augustine. He places an essential distinction between sensible and intellectual faculties; he makes a triple division of the latter into memory, intelligence and love $;^{2}$ he refers to the sense-origin of ideas without however grappling with the difficulties of the problem; he outlines the theory of cognitional determinants (species intentionales) without giving them the erroneous meaning imputed to him by some historians; he dwells with emphasis on the immediate knowledge which the soul has of its own existence ("Semper sui meminit anima," Monol., 46 ; cf. St. Augustine, וo2, 3 ); in explaining intellectual knowledge, he assigns to God, as the light of truth, an efficiency that is not easy to understand. Although he seems unaware of the application of the hylemorphic theory to the composite human being, he is nevertheless deeply convinced of the unity of the latter in its twofold nature, material and spiritual. About the origin of the soul he is doubtful.

The ethics of St. Anselm are mainly theological. He explains the transmission of original sin after the manner of Odo of Tournai, and he adopts the theories of St. Augustine on evil and on predestination. ${ }^{3}$ He devoted much thought to the problem of free will and has left us two treatises on the subject. He defines freedom as the power of preserving rectitude of will for its own sake. ${ }^{4}$

153. Sources and Bibliography.-Gerberon's edition of St. Anselm, I675 (containing his life by his secretary, Eadmer), reprinted in $172 \mathrm{I}$ and again by Migne, 158, r59. On works wrongly attributed to St. Anselm, see HaURÉAu, Not. et Extr., etc., iv., pp. 192, 320.

${ }^{1}$ St. Anselm's realism as expounded in the Monologium, for instance, has nothing in common with the teaching of the De Grammatico, which studies not what things are but what the grammatical forms of language signify.

2 Monologium, c. xxxiii.

${ }^{3}$ De concordantia praescientiae, predestinationis et gratiae cum libero arbitrio.

4 “ Libertas arbitrii est potestas servandi rectitudinem voluntatis propter ipsam rectitudinem" (De lib. arb., I). 
Van Weddingen, Essai critique sur la philosophie de S. Anselme, Paris (memoir crowned by the Belg. Acad., r875). Very valuable, but prolix and not free from historical errors. RAgex, Histoire de S. Anselme, Paris, I89o, 2 vols. Luigi Vigna, San Anselmo filosofo, Milan. Incomplete. Bainvel, S. Anselme (Dict. 'Théol. Cathol., Igor). Studies Anselm's theology mainly. Complete bibliography. Domet DE Vorges, S. Anselme (collect. Les Grands Philosophes, rgor). Excellent. Studies his teaching from standpoint of development of scholasticism. KENT, St. Anselm (in the Catholic Encyclopedia, I907). On the ontological argument, which has a copious recent literature, see BERTin (Brussels Scientific Congress, I894); Hurtaud (Revue Thomiste, r895); Adlhoch (Philosoph. Fahrb., viii., ix. and x.); Fuzier (Fribourg Congress, I898); Adlhoch, Roscelin u. S. Anselm, etc. (148). On reason and faith see Grabmann, op. cit., I34; Marechaux, $A$ propos du fides quaerens intellectum de S. Anselme (Revista Stor. Benedettina, rgog).

\section{ART. II.-ANTI-SCHOLASTIC PHILOSOPHY.}

154. John Scotus Eriugena, the Founder of Anti-Scholasticism. -In opposition to the majority of historians, ${ }^{1}$ who describe Eriugena ${ }^{2}$ as the first of the scholastics, we have no hesitation in calling him the first of the anti-scholastics-and the most formidable of them in the present epoch. For his teaching propounds principles which are opposed to those of scholasticism and which form the starting-point of opposition movements.

Not that we would lessen the historical significance of Scotus Eriugena: on the contrary, he must be regarded as one of the most striking personalities in the world of culture and learning in the early Middle Ages. $\mathrm{He}$ was far in advance of his time. While his contemporaries were only lisping in philosophy, and even his successors for centuries did no more than discuss a small number of disconnected philosophical questions, Eriugena in the ninth century worked out a complete philosophical synthesis. Apart from those incredibly daring speculations which made him the enfant terrible of his time, he reads like a pantheistic contemporary of St. Thomas. He was, in a word, at once the scholar and the man of genius. What was an altogether unique accom-

1 This classification is due to the identification of medieval philosophy with scholastic philosophy. Ueberweg-Heinze, Grundriss d. Geschich. d. Philos., Theil ii. (r898), calls Scotus “der früheste namhafte Philosoph der scholastischen Zeit" (p. I5o). SAINT René TAIllandier: "Not only is Scotus Erigena the father of scholastic philosophy, he seems to embody in himself all its developments" (Scot Erigène et la philosophie scolastique, Paris, 1843).

${ }^{2}$ Not Erigena. Professor BAEUmKer has shown that the ancient manuscripts have the form Johannes Scotus Eriugena (Fahrbuch f. Philos. u. spekul. Theol., 1893, p. 346, n. 2). The texts in which Scotus is referred to by his contemporaries are collected by Traube, Mon. Ger. Histor., Poetae Aevi Carolini, iii., 5 I8 (r896). 
plishment for the ninth century, he read Greek, of which Alcuin scarcely knew the alphabet; and at the request of Charles the Bald he translated into Latin the works of Pseudo-Denis the Areopagite, of which Pope Paul I. had sent a copy to Pepin. ${ }^{\mathrm{I}} \mathrm{He}$ was also familiar with the Fathers of the Church, quoting frequently from St. Gregory Nazianzen, St. Gregory of Nyssa, St. Augustine and Maximus the Confessor,-especially St. Augustine.

155. Life and Works. - The life of Scotus Eriugena is shrouded in mystery. Born between 800 and 815 , in one of the British Islands, more probably Ireland-where he could have the benefit of such an education as the continental schools could no longer furnish-he figures at the court of Charles the Bald as the most distinguished philosopher of the Palatine school. He died at an advanced age (after 877): assassinated by his students, if we are to believe the legend.

We may distinguish two periods in his literary career. Up to $8 j \mathrm{I}$ he studied, almost exclusively, Latin authors and wrote the De Pracdestinatione and the glosses on Martianus Capella. From 858 he studied Greek authors, translating and annotating the works of Pseudo-Denis (858-860), - which had been offered in 827 to Louis the Debonaire by an ambassador from the Byzantine emperor Michael the Stammerer." His great work is the De Divisione Naturae, in which he gave to the world a new presentation of the most thoroughgoing Neo-Platonism, accommodated to the doctrines of Catholicism. Without any apparent acquaintance with the philosophy of Plotinus, he appears to have himself reconstructed the latter's system.

Where did Scotus find his Neo-Platonism? He must have imbibed it in the works of Pseudo-Denis (105) and Maximus the Confessor, but certainly the pantheistic meaning he read into the theories of the former is from himself alone. We will deal briefly with his general principles of metaphysics and psychology,

1" This work, produced at a time when the knowledge of Greek had almost died out in Europe, excited the greatest astonishment among his contemporaries. The learned Librarian of the Vatican Library, Anastasius, exclaimed when he read it: "It is wonderful that this uncivilized man, dwelling on the confines of the world, should have been able to understand such things, and to translate them into another tongue," (Mis; Eleanor Hull, Text-Book of Irish Literature, p. I44, quoted in Irish Ecclesiastical Record, May, I909, p. 175).

${ }^{2} \mathrm{Jac}$ unin, Le Néo-Platonisme de Scot (in the Revue des Sciences philos. et théol., 1907, p. 678). 
in order to ascertain what influence they exerted on medieval philosophy.

156. Metaphysics. - Here is the fundamental principle: There exists one only being, God, Who, by a series of substantial emanations, gives birth to all things. In this processus of the Divine Being (natura, $\phi \dot{v} \sigma \iota \varsigma, \pi \hat{a} \nu$ ) Scotus distinguishes four successive stages :-

(I) Nature uncreated and creating, or, the Deity in His primordial and impenetrable reality. As such, this Being is unknowable even to Himself ( $c f$. Plotinus, Philo and the negative theology of Pseudo-Denis); for otherwise, says Scotus, mindful of certain texts of Boëthius and other logicians, God should conceive Himself in the categories; He should apprehend His diversity from other beings with whom $\mathrm{He}$ would constitute one and the same genus, and should thereby judge Himself to be wanting in infinity. ${ }^{1}$ If God knew Himself $\mathrm{He}$ would cease to be God!

(2) Nature created and creating, or, God as containing in Himself the primordial causes of all things. In virtue of an unavoidable, fatalistic progressio, the Being, in this second stage, apprehends the perfections contained in the abyss (abyssus) of His entity. He sees in Himself the primordial causes of all things that are to appear as phenomenal or visible existences. God becomes or evolves (fieri), or forms Himself in and through this knowledge ${ }^{2}$ ( $c f$. Plotinus). Here we are far indeed from the exemplarism of the scholastics.

Connecting these theories with Catholic doctrine, Scotus holds that the Divine Being in the first stage described is God the Father; that God the Son is the Divine Being knowing Himself as the Primordial Cause of the World ; and we have the appearance of the Holy Ghost in the philosophy of Eriugena when the primordial causes that lie in the bosom of the Divine Unity in the second stage commence to externate themselves in genera, species and individuals. This is:-

(3) Nature created but not creating, or, being as realized and existing in time. All contingent beings, whether material or spiritual, are mere blossomings of the Divine Substance, or, in the

1 "Nam si in aliquo (genere) seipsum cognosceret, non omnino infinitum seipsum judicaret" (De Divis. Nat., i., 2).

2 "Creator enim a seipsa in primordialibus causis, ac per hoc seipsum creat " (ibid., iii., 23). 
energetic language of Scotus, Theophanies : the Divinity careering through the spaces of the phenomenal universe ( $\theta$ cós being derived by him from $\theta \dot{\epsilon} \omega$, to run). The world is thus one vast, continuous undulation of the Divine Evolution-Process. Everywhere, at bottom, is the one, single, all-pervading ov $\sigma^{\prime} i^{\prime}$; the individual beings of the visible world differ from one another only in accidents, not in substance; all nature is but one colossal mass of being, spreading its monster branches throughout all space. True to the conception of a descending or downward emanation, and in order to emphasize the gradations in the outflowing of the Divinity into all life and existence, Scotus teaches that the genus exists prior to the species, and the species prior to the individual: in other words, he is the most extreme of realists in regard to the Universals problem.

Can this expansion of the one Divine Substance throughout all Nature be called creation? Not, certainly, in the strict sense of the word $(96,2)$. To conform to the Catholic teaching, Scotus interprets Scripture in a symbolic sense, explaining that "God creates Himself in the world".

(4) Nature neither creating nor created, or, God as the Ultimate Term of the Universe. Whatever proceeds from a principle tends to return thereto; the end of motion is its return to its source. Finis cnim totius motus est principium sui; non enim alio fine terminatur nisi suo principio a quo incipit moveri. Of fatal necessity God eventually withdraws again into Himself: this is the final cosmic absorption in the bosom of the Great All ( $c f$. Plotinus and P'seudo-Denis).

157. Psychology.-Scotus applies to man the same broad pantheistic principles. His teaching on human knowledge and human nature may be summed up as follows :-

By the exterior sense (sensus exterior) man knows the external sense-world; by the interior sense (sensus interior) he knows the essence throughout its visible or phenomenal realizations; by reason (ratio) he knows the primordial causes of things; by intellect (intellectus) he knows God in His unchanging reality.

Scotus does not seem to have suspected, any more than his contemporaries, the difficulties involved in the problem of the genesis or formation of our knowledge. He recognizes two distinct methods or modes of knowledge: (a) the ascending way, which has its starting-point in sense-experience; and $(b)$ the 
descending way (gnosticus intuitus), in which the mind, as it advances in knowledge, pursues a path parallel to that of the Divine Substance in its process of auto-formation. Here the cognitive faculty, at first unconscious of itself (intellectus), attains to self-consciousness by representing to itself (ratio) the primordial essences. This representation enables it to apprehend the realized essence (sensus interior) and the external sense-attributes (sensus exterior) of the latter. Human thought is at bottom Divine and follows the evolutions of the Divine Being. Nay more, human knowledge is limitless, for it is God Himself Who thinks in man. The rights of Reason are sovereign both in regard to Nature and to Revelation. Scotus is thus among the most daring of all the medieval rationalists.

Man is a projection of God. The absorption of God in Humanity is asserted with an audacity that is amazing: and this Humanity is of course one with the rest of Nature. By the aid of fanciful interpretations of the Scriptures, Scotus explains the whole Catholic doctrine of the Fall and of Original Sin according to Gnostic theories of symbolism. The transmission of original sin finds an easy explanation in his pantheism ( $c f$. Odo of Tournai).

The body in its original state, "as conceived in its second nature," was free from imperfections. In our present nature we are in a violent and fallen condition ( $c f$. Plato, Plotinus). The return of man to his first state in the bosom of God will be effected by the Redemption through Christ; and since the whole universe shares in the same substance with man, it is through Christ that the final cosmic evolution will be brought about. Thus, for Scotus, Redemption becomes a necessary condition or factor of the evolution of Nature. His teaching about the seven degrees of contemplation and the process of Divine deification, is a strange forcing of the speculations of Pseudo-Denis, and reminds us of the German mysticism of the fifteenth century.

158. Influence of the Philosophy of Scotus.-Scotus influenced in a considerable measure the development of medieval philosophy: of scholasticism, as in Abelard, Isaac de Stella, Garnerius of Rochefort, etc. ; and more especially of systems opposed to scholasticism. The main anti-scholastic tendencies for which the philosophy of Scotus is responsible are the following :-

(I) Medieval Rationalism.-Reason, deified, is made the sove- 
reign source of knowledge, excelling and surpassing authority and revelation. The rationalism of Scotus has in it an appreciable tinge of theosophy.

(2) Theosophy.-Theosophy is a form of rationalism peculiar to the Middle Ages. In opposition to modern rationalism, which tries in the name of reason to brush aside as unreal the data of Christian Revelation, medieval theosophy endeavoured, also in the name of reason, to prove to demonstration, as evidently true and real, these same revealed data in their full scope and meaning. Even mysteries were claimed to be so accessible to human intelligence that it could establish them by demonstrative arguments. Adopting the extreme deductive method, in imitation of Plato, Eriugena followed out this naturalistic interpretation of Christian dogma into all its smallest details.

This theosophical rationalism of Scotus is calculated to mislead; for the Palatine philosopher, so far from opposing or defying Christian dogma, proclaimed and protested that he was ever and always loyal to the Catholic faith. ${ }^{1}$ He was constantly quoting Scripture and the Fathers. But in common with the Gnostics he attached to those writings a symbolic sense, which was to be determined in the last resort by reason itself.

(3) Heterodox Mysticism: that, namely, which assigns substantial union of the soul with God as the goal of the mystic life (cf. Ch. III., art. i., \$5). For Scotus is unmistakeably a champion of pantheism.

(4) Pantheism.-This of course denies the real distinction which scholasticism affirms between God and creatures; denying at the same time the separate individuality of each of the latter. So far as we know, Eriugena is the only avowed representative of pantheism prior to the twelfth century. His contemporaries appear to have consulted him merely for his opinion about the questions proposed by Porphyry. And we know his reply : being a pantheist, he was, of course, a fortiori, the standardbearer of extreme realism. Subsequently, those who espoused pantheism were inspired by the Neo-Platonism of Eriugena,

${ }^{1}$ It is owing to such declarations as those, in the mouth of Scotus, that he is classified as a scholastic by historians who regard the agreement of philosophy with Catholic theology as the supreme test of scholasticism. Yet what a veritable abyss there is between the philosophy of Scotus and that of St. Anselm, for example, or of St. Thomas! 
some of them more and some less; and his influence is likewise traceable in all the various popular excesses and distortions of mysticism. ${ }^{1} \quad$ The Church condemned the De Divisione Naturae, but could not banish it from circulation. Even in the thirteenth century it was so extensively studied as to call for solemn censure from Pope Honorius III. (I 225).

159. Sources and Bibliography.-Works apud Migne, v. I22 (Floss' edit.). His commentaries on Martianus Capella have been edited by HAURÉAu, Not. et Extr., etc., t. 20, pt. ii., 1862. Huber, Foh. Scotus Erigena (Munich, 1862). Astier, Mémoire sur Scot Erigène au Congrès des sociétés savantes (Biblioth. École Chartes, t. 62). Draeseke, F. Scotus u. dessen Gewährsmänner in Divisione Naturae (Bonwetsch-Seebergs Studien, ix., 2, Leipzig, I902). TURNER, article in the Catholic Encyclopedia, v., I9og: Eriugena. An exhaustive study of the philosophy of Scotus has not yet been made. On the sources of the De Praedestinatione (an early work in which Pseudo-Denis is not quoted), see Jacquin, op. cit., I55, n.

\section{ART. III.-PHILOSOPHY AND THEOLOGICAL CONTROVERSIES.}

\section{Their Place in the History of Medieval Philosophy.-} From the commencement of the Middle Ages there arose controversies which certainly belong primarily to the history of theology, but which for many reasons may not be passed over in a history of medieval philosophy. In the first place, many of the problems of scholastic philosophy have had their sources in theology, in the sense that they grew out of theological controversies. In the ninth and tenth centuries, the predestination controversy gave rise to the question of human liberty and its relations to Divine providence and Divine justice; the Paschasian controversy on the real presence of Christ in the Eucharist called forth dissertations on substance and accident ; the dogma of the Blessed Trinity suggested discussions on the concepts of nature, individual and person; the mystery of transubstantiation led to the study of change.

The confusion between philosophy and theology, characteristic of the earlier centuries, gives those controversies a mixed complexion. It led the more ardent spirits to carry the purely rational method into delicate dogmatic questions. Moreover,

${ }^{1}$ We might add that the philosophy of Scotus contains the germ of subjectivism, since he endows the human mind with the power of attaining, by the unaided effort of consciousness alone (gnosticus intuitus, 157 ) to a knowledge of the Divine evolution-process as an object of representation. Scotus did not, however, go so far; and no one in the Middle Ages pushed the logic of his system to these consequences. 
those famous theological disputes synchronized with the spread of a diseased dialectic which came to a head in the eleventh century. This was a sort of a parasitic growth on philosophy (146): and it was applied to the disputes about dogma. Men like Gottschalk, Berengar and Roscelin did not escape the contagion. All put into practice, at least to some extent, the motto of Berengar: per omnia ad dialecticam confugere.

There was a reaction against this on the part of the theologians, who were men of a more practical turn, but who blamed dialectic itself for the excesses of the dialecticians. Ecclesiastical authority intervened; and sometimes its prohibitions were too sweeping. The hostility of the more timid among the theologians was excessive. But gradually a new tendency asserted itself in the direction of seeking an adjustment of the respective rights of reason and authority. The true relations between philosophy and theology were thus gradually brought into clearer light.

16r. Some Theologico-Philosophical Controversies of the ninth, tenth and eleventh Centuries.-(I) The Controversy on Predestination and Liberty.-Gottschalk, a monk of Orbais, a contemporary of Rhaban Laur, was led by the study of St. Augustine to doubt about the possibility of reconciling human freedom with Divine grace. Admitting an absolute predestination of the good and the wicked alike, he concluded that man is a mere plaything in the hands of Almighty God and has neither freedom nor responsibility. If we call to mind the disturbances caused by the similar teachings of Jansenius in more recent times, it will help us to realize the intensity of the excitement aroused in the ninth century by Gottschalk. Hincmar of RHems (8O2-S82), RifabAN MAUR and Florus OF LyONs came forward as champions of free will. RATRAMn OF CORbIE and Servatus Lupus took the side of Gottschalk; while both parties combined in attacking John Scotus ERIUGENA who had interfered in the controversy with a theory of his own-against Gottschalk's, only still more erroneous than the latter. The views of Gottschalk were condemned in the synods of Mainz (848) and Quiercy (849).

(2) The Transubstantiation Controversy.-There are two important matters of speculation, in regard to which reason must bow submissively before the teachings of faith: the dogma of the Eucharistic Transubstantiation in connection with our notions 
of substance and accident; and the mystery of the Blessed Trinity in connection with our concepts of person and nature. As rationalism grew bolder in the schools and disturbed the theologians ( $v$. below) by its daring disquisitions on the categories and the Universals, regardless of faith and standing up for reason alone, it came into inevitable conflict with both of these mysteries.

The former was attacked by BERENGAR, or BERENGARIUS, OF TOURS, ${ }^{1}$ a pupil of the school of Chartres, and apparently an antirealist in the Universals question. Of an ardent and impetuous temperament, Berengar (999-1088) soon sowed dissension in the schools. The accidental qualities of the bread and wine (taste, colour, form, etc.), he contended, could not remain without the underlying support which Aristotle had called substance. Hence, he concluded, the Gospels cannot have meant to teach real transubstantiation; the body and blood of Christ are really present, but only hidden beneath the sacramental species. He was attacked by LANFRANC (IOIO-IO89). ADELMAN OF LiÉGE (IO48), Durandus of Troarn, Hugh of Breteuil and other former school-fellows of Berengar's at Chartres, ${ }^{2}$ also opposed the latter's teaching; but it took twenty years of lively controversy and four Church synods to stamp it out successfully.

(3) Roscelin's Tritheism.-Roscelin's name is known rather on account of his tritheism than of his anti-realism (145). He made the three Divine persons three independent beings, like three angels : if usage allowed it, he said, we might speak of three Gods. Otherwise, he went on to argue, God the Father and God the Holy Ghost must have become man with God the Son. To save appearances, he admitted that the three Divine persons have but one will and one omnipotence. ${ }^{3}$

This very marked tritheism, ${ }^{4}$ refuted by St. Anselm and Abelard in common, even after its author's retractation, seems to us a plain application of Roscelin's anti-realism. ${ }^{5}$ If the three

${ }^{1}$ He had precursors in Ratramn and Heriger, abbot of Lobbes, who were opposed by PASchasius RADBert (ninth century).

${ }^{2}$ Clerval, op. cit., pp. 64 and $\mathrm{r} 3 \mathrm{I}-4 \mathrm{I}$.

3 “Audio ... quod Roscelinus clericus dicit in Deo tres personas esse tres res ab invicem separatas, sicut sunt tres angeli, ita tamen ut una sit voluntas et potestas aut Patrem et Spiritum sanctum esse incarnatum; et tres deos vere posse dici si usus admitteret" (Letter of St. Anselm to Fulco).

${ }^{4}$ Against Picavet, Roscelin, etc., p. 25.

${ }^{5}$ Cf. our art. Les récents travaux sur l'histoire de la phil. méd. (Rev. Néo-Scol., r8g8, p. 74). 


\section{76 THEOLOGICO-PHILOSOPHICAL CONTROVERSIES}

Divine persons, he argued, are one and the same God, then all three must have become incarnate, which cannot be admitted. There are, therefore, three Divine substances, three Gods, as distinct as three angels, because each substance constitutes an individuality: which is the fundamental assertion of anti-realism (143). There is an intimate connection here between the thought of the theologian and of the philosopher.

162. The Theologians Opposed to Dialectic. - The pretensions of the extreme dialecticians $(\mathbf{4} \mathbf{6})$ in placing logical and sophistical reasoning above the argument from authority, and the heresies that resulted from this method of dealing with theological questions, aroused the opposition of a party of reactionary theologians, who were more or less suspicious of all philosophy and would countenance no other method in theology than the literal study of the Sacred Scriptures. And this opposition movement was closely connected with an attempted reform of the religious life, with a return to the purer traditions of early monasticism. Evidences of this reform are to be found in the monasteries of the order of Cluny in France and in the Benedictine monasteries of Germany.

The leading figures in this movement belong to the eleventh century: St. Peter Damian in Italy, Manegold of Lautenbach and Otloh of St. Emmeram in Germany. Lanfranc calls for separate mention.

St. Peter Damian, a hermit monk of Ravenna, regarded dialetic as a superflumm, because the principle of contradiction, on which it is based, is inapplicable to theology. Nay more, it cannot produce certitude on any question, because the ground of certitude lies only in the revealed word in the Sacred Scriptures. This is the real sense of the celebrated formula so often misunderstood: philosophiam esse theologiae ancillam; or again: velut ancilla dominae quodam famulatus obsequio subvenire [philosophia debet]. ${ }^{1}$

MANEGOLD OF LAUTENBACH (second half of eleventh century) gives expression to similar views. The tendency of the Opusculum Manegoldi contra $\mathrm{W}$ olfelum Coloniensem is to establish a contradiction between the teaching of the ancient philosophers and Catholic doctrine.

${ }^{1}$ Opusc., 36, quoted by Espenberger, Die Philosophie des Petrus Lombardus und ihre Stellung im zwölften Fahrh., p. 36, n. 2. 
OtLoH of ST. Emmeram, of Regensburg (about roro-ro7o), while not condemning profane science, i.e., the liberal arts and philosophy, in itself, forbids his monks to study it, inasmuch as they renounced the world to give themselves up to Divine science (res divinae).

I62 (b). Lanfranc and the Beginnings of the Dialectic Method. -After having travelled through France, from school to school, Lanfranc settled down in the abbey of Bec. Though he may be classified with the opponents of dialectic, the famous contradictor of Berengar deserves special treatment. The liberal arts and philosophy, he teaches, are not evil in themselves: it is the excessive and exclusive use of them in theology that is alone reprehensible: "non artem disputandi vituperat sed perversum disputantium usum ". ${ }^{1}$ Lanfranc's own works bear witness that he himself in his theological teaching had recourse, in a timid and tentative way, to philosophical reasoning. ${ }^{2}$

Thus appeared the new tendency which was developed by other theologians of this period such as William of Hirschau and St. Anselm, and which was to lead to the formation of a twofold theological method in the schools of Abelard and of St. Victor in the twelfth century (see below).

I62 (c). Sources and Bibliography. - The literature of the Predestination controversy was collected by Gilbert Mauguin in the year I650 ( 2 vols. in 4 to). Works of Lanfranc apud Migne, P.L., I5o. The authorship of the Elucidarium sive Dialogus de summa totius christianae theologiae is doubtful.

ENDREs, Lanfranc's Verhältniss zur Dialektik (Der Katholik, I902, pp. 215-31). Good. Corrects the erroneous view that Lanfranc was hostile to speculation. W. Burger, Rhabanus Maurus, der Begrïnder d. theolog. Studien in Deutschland (ibid., pp. $5 \mathrm{I}$ and r22). Vernet, Bérenger de Tours (Dict. Cath. Théol., xii., p. 729). Picavet, Les discussions sur la liberté au temps de Gottschalc, de Rhaban Maur, d'Hincmar et de F. Scot (Paris, I876). Gabriel Bruhnes, La foi chrétienne et la philosophie au temps de la renaissance carolingienne, Igo3. A good monograph. Endres, Die Dialektiker und ihre Gegner im II Fahrh. (Philos. Jahrb., 1906). Good. Otloh's von St. Emmeram Verhältniss $z u$ den freien Kunsten (Philos. Jahrb., I904, pp. 44, 72; and r9o6, h. I).

${ }^{1}$ Migne, P.L., t. I5o, col. 323. $\quad$ Endres, Die Dialektiker, etc., p. 33. 


\section{CHAPTER III.}

PHLOSOPHY IN THE TWELFTH CENTURY.

163. Summary.-Paris and Chartres were the centres of all the stirring intellectual tournaments of the twelfth century; Paris especially, whose three famous schools rapidly obtained a monopoly of scientific culture, thus leading up to the creation of the great studium generale towards the end of the century. In the domain of scholasticism (Art. I.) we find numerous forms of extreme realism (\$ I) and of anti-realism (\$2). Extreme realism was boldly attacked by a critic of no ordinary stamp, Peter Abelard, whose personality and influence deserve to be thrown into due relief (\$3). At the same time there appeared a tendency to collect and arrange achieved results and produce complete courses of doctrine: the works of two men who collected and summarized the writings of the previous period, John of Salisbury and Alan of Lille (Alanus ab Insulis), are especially noteworthy (\$4).

Non-scholastic philosophy (Art. III.) is represented mainly by pantheistic sects drawing their inspiration directly from John Scotus Eriugena. A materialistic Epicureanism also appears as animating principle in the heresies of the Cathari and the Albigenses. An intense theological movement (Art. II.) developed at the same time. The compilers of the "Sententiae" and "Summae" arranged and codified the data of dogmatic theology $(§ \mathrm{I})$; and the first strong current of orthodox medieval mysticism made its appearance $(\$ 2)$.

\section{ART. I.-SCHOLASTICISM.}

§ i. Extreme Realism (First Half of Twelftu Century).

164. Division. - In the first half of the twelfth century we have to note a revival of that curiously illogical form of extreme realism which attributes a universal entity to our specific and generic concepts, while refusing to admit the pantheistic unity 
of all things. We may divide the realist theories of this period into two main groups: (I) the theory of William of Champeaux; (2) that of the school of Chartres.

165. First Group : The Doctrines of William of Champeaux.The first name we meet is that of William OF CHAMPEAUX, born in I070, died Bishop of Chalons in I 120 . In his youth he had followed the lectures of Anselm (of Laon), at the school of Laon, which was one of the most frequented in Europe early in the twelfth century. In I IO3 he held a chair in the cathedral school at Paris and there taught doctrines diametrically opposed to those of Roscelin, under whom he had studied at Compiègne. He was himself in turn bitterly attacked by one of his own pupils, Peter Abelard.

Our main sources of information regarding the teaching of William of Champeaux are the works of Abelard and the treatise De Generibus et Speciebus. William wrote various treatises on dialectic which are lost ; also a book of Sentences, from which Lefèvre has published extracts. ${ }^{1}$ On the authority of Abelard we have it that William modified his views on the subject of the Universals; and the treatise De Generibus, etc., testifies to a development of opinion. The various phases of his teaching are as follows :-

(I) The "Identity" Theory.-The universal essence is numerically one (unica) in all its subordinate members; the totality of its being is in each of them; individuality is but an accidental modification of the specific substance; and the specific, but an accident of the single generic essence. ${ }^{2}$

It was easy to hold this teaching up to ridicule. If each man is the whole human species, the latter must be whole and entire in Socrates at Rome and in Plato at Athens; hence Socrates, containing the whole human essence, must be wherever the latter is: he will be simultaneously at Rome and at Athens; and similarly Plato; which is surely absurd. ${ }^{3}$

${ }^{1}$ G. Lefìve, Les variations de Guillaume de Champeaux et la question des universaux. Étude suivie de documents originaux (Lille, I898).

2 " Erat autem (Gulielmus) in ea sententia de communitate universalium, $u t$ eamdem essentialiter rem totam simul singulis suis inesse adstrueret individuis : quorum quidem nulla esset in essentia diversitas, sed sola multitudine accidentium varietas" (Abel. Op., edit. Amboise, p. 5). Same formula in the De Generibus et Speciebus (in Cousın's edition of the Ouvr. inéd. d'Abélard), p. 5 I 3.

${ }^{3}$ De Generibus et Speciebus, Cousin's edit., p. 5r4. We find the following re- futation of the elegant inexactitudes (pulchra mentientes) of realism in an anony- 
The satires of his merciless pupil, Abelard, succeeded in driving William from the school of Notre Dame ( I I O8). Some time subsequently we find him teaching a different theory at the school of St. Victor, of which he is the reputed founder.

(2) The "Indifference" Theory._. "Sic autem istam tunc suam correxit sententiam ut deinceps rem eamdem non essentialiter sed indifferenter diceret." 1 This text would make William the propounder of a solution that met with widespread popularity at the opening of the twelfth century, and one which his more experienced successors afterwards defended with great vigour (172, e). But poor William himself, if we are to believe Abelard, beaten back once more from his new entrenchments, gave up the fight and laid down his arms. ${ }^{2}$ We must, however, discount those boastful assertions of Abelard; though the substantial truth of this one seems to be confirmed by the fact that we find in the Sentences of William a third variety of solution to the troublesome Universals question.

(3) The "Similarity" (similitudo essentiarum) Theory.- Essences are really multiplied in the individuals, but are similar in each of the latter. ${ }^{3} \quad$ Here we encounter a theory which is not extreme realism, but rather its negation; which is in fact the theory of William's former master, Roscelin, and is, moreover, identical with the teaching of Abelard himself." The truth is

mous treatise on genera and species published by HAUrÉau (Not. et Exxtr., etc., v., p. 306) : "Sed quotiescumque homo qui est in Socrate agit vel patitur et homo qui est in Platone agit vel patitur, cum sit eadem essentia, et sic (Platone) agente aliquid, agit Socrates et quaelibet alia substantia, et flagellato Socrate, flagellatur quaelibet alia substantia, quod est inconveniens et etiam haeresis" (n. 178 I3, Bib. Nat., fol. I6).

'Cousin, Ouvr. inéd. d'Abélard, p. 6. In the text quoted, M. Hauréau reads individualiter instead of indifferenter (Not. et Extr., etc., v., p. 324, and Hist. phil. scol., i., p. 338). If this be the proper reading, William would not be a promoter of the "Indifference" theory. WVe prefer, with Cousin, to understand indifferenter, for what possible meaning can be attached to Hauréau's formula: " the same reality existing according to its individuality in all the individuals; ut eamdem individualiter rem totam simul singulis suis inesse adstrueret"?

2 "Cum hanc ille correxisset, immo coactus, dimisit sententiam," etc. (Cousis, ibid.).

3 "Ubicunque personae sunt plures, plures sunt et substantiae. . . . Non est eadem utriusque (scil. Petri et Pauli) humanitas, sed similis, cum sint duo homines" (Gulielmi Campellensis Sententiae vel Quaestiones, xlvii., Lefìvre's edit., p. 24).

* This is not the view of M. Lefèvre, to whom is due the credit of having first brought to light this third opinion of William. The latter is not, of course, so explicit as Abelard, for he does not speak of abstraction, but there is nothing in this third view of his to which Abelard could take exception. 
that William, convinced by the arguments of his own troublesome pupil, modified his teaching, out of a loyalty and deference to truth which is worthy of all admiration.

I66. Second Group: Realism of the School of Chartres. Bernard of Chartres. - The school of Chartres, founded by Fulbert, was a stronghold of extreme realism in the twelfth century. ${ }^{1}$ BERNARD OF Chartres, - not to be confounded with BERNARD OF TOURS (Silvestris) nor with BERnARD OF MOÉLAN, ${ }^{2}$-is the first of an interesting line of great masters attached to this school. He was teaching prior to I II 7 , and in that year had Gilbert de la Porrée among his auditors. Later on (towards I I 20), William of Conches and Richard the Bishop attended his lectures. He became chancellor of the Church of Chartres in I I 9 and died towards I I 30 .

He has left a treatise entitled De Expositione Porphyrii. Of other works of his we possess only some fragments preserved in the writings of John of Salisbury, who refers to him as perfectissimus inter Platonicos saeculi nostri (Metal., iv., 3). Bernard is not a psychologist, but some of his theories in cosmology and metaphysics are of interest.

He attributes an objective, universal existence not only to specific and generic essences, but even to accidents. And, strictly speaking, it is only those universal realities that deserve to be called beings, for the things of sense are but fleeting and evanescent shadows: this is the nearest medieval approach to the ancient Platonic realism. Bernard studies those essences of the metaphysical world, recognizing herein three distinct categories of being: God, the Supreme, Eternal Reality; Matter drawn from nothingness by the creative act of God and forming by its union with the Ideas the world of sense; and the Ideas, prototypes or forms by which the world of existences and possibilities is eternally present to the Infinite Intelligence. How Bernard related these three principles is not quite clear. He is said by his historian, John of Salisbury, to have varied his views: at one time interposing between perishable things on the one hand and the Ideas immanent in the Divinity on the other, intermediate principles, the formae nativae, copied in matter from the Divine

${ }^{1}$ There were also anti-realists at Chartres. Clenval, op. cit., p. 266. Cf. infra, Gilbert de la Porrée.

${ }^{2}$ Ibid., pp. ${ }^{1} 8$ sqq. 
Ideas but distinct from these latter; at another time teaching the immediate union of the Idea with Matter, and thus identifying the Ideas with the formae nativae, the native or innate forms. If Bernard espoused this second view he would have been a pantheist, and we should be obliged to place him among the antischolastics. But for this we should need formal declarations of pantheism, and we do not find any such in his teaching. Moreover, he distinctly teaches the creation of matter in time.

Bernard conceives materia primordialis as an already existing but chaotic mass (Timaeus, 25), which is moulded, in a series of transformations, by an immanent principle, the form. This sort of dynamism, distorting the Aristotelian theory of matter and form, is one of the favourite teachings of the Chartres school $(\mathbf{1 2 6}, 3)$. We find it side by side with this other notion of palpably Platonic origin: the personification of Nature. Nature is considered a huge organism, distinct from, and superior to, the individual beings contained in it, and having therefore a soul of its own. The influence of Pythagoras is revealed in preoccupations about numerical relations, supposed to regulate the union of Nature with the world-soul, and of material beings with the Ideas. Bernard of Chartres had a large following ; ${ }^{1}$ not, however, so large as his successors, especially his younger brother, Theoderic, under whom the Chartres schools attained their highest pitch of splendour.

167. Theoderic of Chartres. - Theoderic was magister scholae at Chartres in II II; taught at Paris in II4O, having John of Salisbury among his auditors; returned to Chartres in I I4I, where he succeeded Gilbert de la Porrée as chancellor, and died in I I55. Of his works we have extant the De Sex Dierum Operibus, the Eptateuchon, and a commentary on the De Inventione Rhetorica ad Herennium. Theoderic personifies for us the intense scientific and humanist activity of the Chartres schools in the twelfth century.

The trivium was held in high honour at Chartres (130). The study of the rules of rhetoric and an acquaintance with the great Latin classics were held to be a necessary introduction to all scientific culture. Chartres led the way in attacking the Cornifi-

${ }^{1}$ John of Salisbury mentions, besides William of Conches, RICHARD of CoutANCES, professor at Paris in rr22, died Bishop of Avranches (Ir82), wrote commentaries on Aristotle-no longer extant. 
cians, an obscurantist party who would whittle away the programme of studies and eschew altogether the cultivation of literary form (189). Towards I I 30 Theoderic conducted a vigorous campaign against this set of Boeotians; for which service he won from John of Salisbury the title of artium studiosissimus investigator. We have already referred to the achievements of Theoderic in logic: his Eptateuchon, or manual on the seven liberal arts, makes mention of important portions of the Organon, thus probably introducing the knowledge of them into Western Europe $(\mathbf{1 3 2}, \mathrm{I})$. Where or how he himself came into possession of them is not quite clear. M. Clerval, the discoverer of the Eptateuchon, does not inform us. Theoderic was undoubtedly one of the most learned men of his time, and cultivated scientific relations wherever he possibly could. It was to him that Herman the Dalmatian sent the (Arabic-Latin) translation of Ptolemy's Planisphere, in the year I 144 .

In Metaphysics, Theoderic promptly espoused and vigorously advocated the realism that held sway in Chartres down to the decline of the schools there. Indeed it is the opinion of some (Clerval, Hauréau) that he actually passed through the thin partition that separated extreme realism from pantheism. But he did not go quite so far. We should interpret with a prudent moderation his favourite disquisitions on the superessence of God and the essential dependence of creatures on the Creator. We should especially discount his too ready welcome for Pythagorean notions on the generation of all multitude from the bosom of the One: that God being the Supreme, Eternal One, anterior to all duality, all other things exist only in virtue of compenetration by the Infinite (divinitas singulis rebus forma essendi est). ${ }^{1}$ Such declarations we must accept with reserve, interpreting them in the light of other such statements as this: that if God is for each created being the intrinsic principle of its actual presence

1 " At aeternum nihil aliud est quam divinitas; unitas igitur ipsa divinitas est. At divinitas singulis rebus forma essendi est; nam sicut aliquid ex luce lucidum est, vel ex calore calidum, ita singulae res esse suum ex divinitate sortiuntur. Unde Deus totus et essentialiter ubique esse vere perhibetur. Unde vere dicitur: Omne quod est ideo est quia unum est" (HAURÉau, Not. et Extr., etc., i., p. 63). BaEUmKer has shown that the latter phrase should read ideo est, and not in deo est (Archivf. Geschichte d. Philos., x., p. 138, n. 37). It is a Pythagorean formula, common enough among Theoderic's contemporaries. Thus one of the main arguments for the latter's pantheism falls to the ground. 
in the physical order, each creature has nevertheless an essence distinct from God, an essence that is the work of His creating hand. The declarations of Theoderic on these points are very explicit. ${ }^{1}$ He would have protested against the accusation of pantheism on the same grounds as Master Eckhart and the mystics of the fourteenth century, who established a like distinction between the individual essence proper to each creature, and its divine existence (esse formale). ${ }^{2}$ At the same time it is clear that, despite such protests from their authors, a little logic would easily have converted these systems into anti-scholastic ones. ${ }^{3}$

In Cosmology Theoderic follows the teaching of his brother, reconciling it with the Biblical account of the Creation.

Among Theoderic's disciples the best known are John of Salisbury, Herman the Dalmatian, and Robert of Retines.

168. William of Conches. - We may regard WilliaM of CONCHES (IOSO-I I 54) as a representative of Chartres traditions by reason of his studies under Bernard (I I I O- I 20), his humanism, his opposition to the Cornificians, his devotion to the physical sciences and his earlier philosophical views. After teaching at Paris about I I22, he became tutor to Henry Plantagenet. Besides numerous glosses on the Timacus and the De Consolatione Philosophiae, William composed, among other works, a Magna de Naturis Philosophia, a treatise De Philosophia Mundi, sometimes attributed to Venerable Bede and sometimes to Honorius of Autun, ${ }^{5}$ another treatise entitled Dragmaticon Philosophiae, and a Summa Moralium Philosophorum, quoted under various titles and attributed to various philosophers, especially to Hildebert of Lavardin.

Early in his scholastic career, William leant towards the extreme realism which had become traditional in the Chartres schools. Led astray by a dangerous application of Pythagorism to theology,

1 "Sed cum dicimus singulis rebus divinitatem esse formam essendi, non hoc dicimus quod divinitas sit aliqua forma, quae in materia habeat consistere" (HAURÉau, ibid.).

2 This is Baeumker's suggested explanation, and we believe it to be correct (ibid., F. $\left.13^{S}\right)$.

SSee below, Eckhart and Nicholas of Cusa.

${ }^{4}$ Jourdarn, Excurs. histor. et philosoph. à travers le m. áge, IS88, regards William as the recognized interpreter of the De Consolatione down to the fourteenth century. His commentary was plagiarized by Nicholas Triveth (r258-1358).

${ }^{5}$ Hauréau, Not. et Extr., etc., v., p. 195. 
he went so far as to advocate a strange doctrine, entertained apparently also by Bernard and Theoderic: the identification of the Holy Ghost with the world-soul. Called to account by WILLIAM OF ST. THEODERIC, he retracted this view and abandoned metaphysics for the study of the sciences.

Medical studies were a speciality in the Chartres schools. ${ }^{1}$ Through the versions of Constantine the African, William became familiar with the physiological theories of Galen and Hippocrates, and endeavoured to harmonize them with the process of sense knowledge. It was Constantine who introduced into the schools of the West the study of the physiological concomitant of sensation; and the excessive attention paid to this aspect of knowledge resulted in almost completely losing sight of its distinctly psychical aspect. Adelard of Bath, William of St. Theoderic, William of Hirschau and several others display this tendency to merge the psychical in the physiological side of the conscious process.

While the two previous teachers of Chartres offer us a dynamic explanation of the universe, William presents us in his cosmology with an atomic hypothesis. The four elements are combinations of homogeneous, invisible particles. ${ }^{2} \quad$ From the plasticity of these atoms spring all the works of Nature, including the human body with its highest vital perfections : so that the soul is not at all the constitutive form of the body. We need not wonder at William's professing the theory of the world-soul, traditionally taught at Chartres.

The Summa Moralium Philosophorum of William of Conches claims the attention of the historian as being the first medieval treatise on ethics. It is a mere collection of practical maxims, mainly from Seneca (De Beneficiis) and Cicero (De Officiis). Following their example he went into questions of detail upon the various virtues and upon the difference between the good and the useful; but he had no conception of scholastic ethics as a system, making no attempt to discuss such fundamental questions

${ }^{1}$ They had the De Arte Medica of the physician Alexander, the Isagoge Fohannitii, the Aphorisms of Hippocrates, the De Pulsibus of Philaretes, the De Urinis of Theophilus, the Theorica of Constantine the African, and commentaries on Galen (Clerval, op. cit., p. 240).

2 " Elementa sunt simplae et minimae particulae, quibus haec quatuor constant quae videmus. Haec elementa nunquam videntur, sed ratione divisionis intelliguntur" (Mrgne, P.L., 90, col. rr32). 
as the last end of man and the nature of morality. The scientific study of ethics was not developed until the next (thirteenth) century.

169. The Dawn of Pantheism. - In the course of the twelfth century, extreme realism carried many philosophers over into anti-scholastic pantheism: an inevitable issue, which had been foretold by Abelard, the keenest dialectician of his age and the sworn enemy of extreme realism.

I70. Sources and Bibliography. - Fragments from William of Champeaux in Migne (vol. I63) and in Lefèvre. Fragments from Bernard of Chartres in John of Salisbury (Migne, v. I99, cols. 666 and 938). Theoderic's De Sex Dierum Operibus in HaUrÉAu (Not. et Extr., etc., vol. 32, pt. ii., p. i67) ; P. Тномas, Mélunges, $188_{4}$, prints extracts from the commentary on the De Invent. Rhetorica. William of Conches: the De Philosophia Mundi, in Migne, v. 172, col. 39; Dragmation, v. 9o, under the title Elementorum Philosophiae, L. IV.; fragments of glosses and commentaries in Cousin, Ouvr.inéd. d'Abélard, pp. 669 sqq. ; Jourdain, Notices, etc., v. 2o, p. 2.

LEFÈVRe, Les variations de Guillaume de Champeaux et la question des universaux (Lille, r898). Good; some erroneous renderings of texts. On the Schools of Chartres, see Clerval, op. cit. Werner, Die Kosmologie und Naturlehre $d$. scholast. Mittelalters mit sfecieller Bezichung auf Wilhelm von Conches (Sitzungb. K. Akad. wiss. Philos. Kl. Wien, I873, Bd. 75, p. 309). Good; well documented. Steinschnemer, Constantinus Africanus und scine Arabische Quellen (Archivf. pathol. Anatomie u. Physiol., Bd. 37, p. 351). A study of his works.

\section{$\S 2$. Anti-REALISM.}

171. Anti-Realist Formulas. - Under this head we may classify a number of solutions which appeared early in the twelfth century and which are all inspired by the teaching of Boëthius that genera and species are simply individual things regarded under different aspects. Among these we may place the doctrines of Adelard of Bath and of Walter of Mortagne, the "Indifference" theory and the "Collection" theory.

(a) Adelard of Bath and the Theory of the "Respectus".-The Englishman, AdelaRD OF BATH, professor at Paris and Laon, was one of the first of the medieval scholars to complete his scientific education by travelling in Greece and Spain. The first fruits of this acquaintance with an unknown world were his Quaestiones Naturales. Besides a translation of Euclid from the Arabic (I I 6 ) and other mathematical writings, Adelard also wrote a treatise De Eodem et Diverso ${ }^{1}$ (about I I05-6), which he

\footnotetext{
${ }^{1}$ Das Adelard von Bath Traktat de Eodem et Diverso, edited by $\mathrm{H}$. Willner (Münster, r903).
} 
dedicated to William, Bishop of Syracuse. It is in the form of a dialogue between Philosophia (the unchangeable, De Eodem) and Philocosmia (changeable knowledge, De Diverso). It is saturated with Platonism as found in Chalcidius, St. Augustine, Boëthius, etc., and with the spirit of the contemporary productions of the schools of Chartres. ${ }^{1}$

We find in the De Eodem et Diverso the seeds of anti-realism : the same concrete being is genus, species and individual, all at once, but under different aspects (respectus). ${ }^{2}$ Genus and species are modes of understanding the individual; they are the term of a deeper intuition, altius intuentes, acutius considerata. ${ }^{3}$ Hence the unity of the generic element in a number of individuals is of the conceptual order and not of the real order, and the theory of the respectus is thus one of the forms of anti-realism.

But Adelard did not follow up the psychological aspect of the question. It is the logical point of view that dominates the treatise; and this too is a source of difficulty in interpreting the text. $^{4}$

Adelard of Bath is more than an advocate of the "aspects" theory. His Quaestiones Naturales and De Eodem et Diverso show him to have been a psychologist and man of science. His psychology is distinctly Platonic and Augustinian. He teaches that intellectual knowledge, the sole source of certitude, is innate : the senses have no causal influence in its production. The soul, created by God, is spiritual, entirely independent of the body, to which it is, against its own nature, united. The faculties are identical with the substance of the soul. A theory on the localization of mental functions and a number of physiological informations coming directly from Galen and Hippocrates, are borrowed by

1 The treatise also contains a brief description of the liberal arts, and we may gather from what Adelard there says about dialectic that he must have known the existence of all the parts of Aristotle's Organon (ibid., p. 97. See above, 132).

2 " Si res consideres, eidem essentiae et generis et speciei et individui nomina imposita sunt, sed respectu diverso" (ibid., p. II).

3 " Eosdem autem acutius intuentes, videlicet non secundum quod sensualiter diversi sunt, sed in eo quod notantur ab hac voce 'homo' speciem vocaverunt" (p. II). "Quoniam igitur illud idem quod vides, et genus et species et individuum sit, merito ea Aristoteles non nisi in sensibilibus esse proposuit. Sunt etenim ipsa sensibilia, quamvis acutius considerata" (p. I2).

${ }^{4}$ Willner has published, in an appendix to the work of Hauréau (Notices et Extr., etc., v., pp. 293-96), an anonymous commentary on the Isagoge, from the same point of view as the De Eodem et Diverso. 
Adelard from Constantine the African (168). His whole psychology reveals a careful attention to facts of observation and experience. His cosmology, like that of William of Conches, revives the atomism of Democritus, dwells on the Pythagorean notions of unity and harmony, and regards the whole universe as one vast organism.

(b) Walter of Mortagne and the Theory of the "Status".-Born at Mortagne, in Flanders, in the early years of the twelfth century, WALTER ${ }^{1}$ was educated at the school of Tournai. From I I 26 to II 44 he taught rhetoric and philosophy successively at Ste. Geneviève (Paris), and died Bishop of Laon in I I74. He has left a Tractatus de Sancta Trinitate and six minor works of but little interest to philosophy. His Platonism is revealed in a letter to Abelard, in which he regards the body as an obstacle to the higher conceptions and aspirations of the soul.

It is through John of Salisbury that we learn the formula of the status, defended by Walter of Mortagne. ${ }^{2}$ Plato is, according to different states (status), an individual (Plato), a species (man), a genus, subaltern or supreme (animal or substance). It is true, indeed, that John of Salisbury connects this view with realism. But the text of the latter is laconic and difficult to interpret aright. Are not the status of Walter of Mortagne another way of expressing the respectus of Adelard of Bath? For both use analogous terms to describe the identity of the individual, the species and the genus. ${ }^{3}$ WVe believe this to be so.

According to a hypothesis of Hauréau, Walter would be the author of a text contained in No. I78 I 3 of the Latin manuscripts of the National Library of Paris. ${ }^{4}$ In this text we encounter yet another formula for solving the Universals problem :-

(c) The "Indifference" Theory.-Apart from the document just referred to, "Indifferentism" is expounded and refuted in the $D e$

${ }^{1}$ Cf. our Histoire de la philos. scol. dans les Pays-Bas, etc., p. 32.

${ }^{3}$ Metalog., ii., I7: "Eorum vero, qui rebus inhaerent (the realists), multae sunt et diversae opiniones, siquidem hic, ideo quod omne qu)d est, unum numero est (text incorrect in Migne: omne quod unum est, numero est) aut rem universalem, aut unam numero esse, aut omnino non esse concludit. . . . Partiuntur itaque status duce Gautero de Mauritania, et Platonem, in eo quod Plato est, dicunt individuum ; in eo qued homo, speciem; in eo quod animal, genus, sed subalternum ; in eo quod substantia, generalissimum" (Migne, P.L., vol. I99, pp. 874, 875).

3 John of Salisbury mentions yet another distinct theory of "status".

${ }^{4}$ Notic. et Extr., etc., v., pp. 313 sqq. 
Generibus et Speciebus, printed by Cousin among the works of Abelard, a text in which we find the expression, sententia de indifferentia. ${ }^{1}$ Every existence is individual, but in each individual there are determinations peculiarly its own, constituting its differential quiddity or essence (differens), and also specific and generic realities which are found not-different (indifferens) in all the other individuals of the same species and genus. It is therefore the same being that is called, according to the standpoint (status) from which we view it, individual, species and genus. In so far as they are endowed with life and reason, men form a unum et idem. ${ }^{2}$ Though the text says nothing on the nature of this unity, to be found in Socrates and all other men, the unity in question cannot be any more than a product of thought; for, nothing exists outside the individual : nihil omnino est praeter individuum. ${ }^{3}$ "Indifferentism" should therefore be classified among the anti-realistic solutions of the Universals problem.

(d) The "Collection" Theory.-The same, we believe, may be said about the "Collection" theory, defended by the author of the De Generibus et Speciebus, after he had successively expounded and refuted the theories of Identity (165, I), of Indifference (c) and of Verbalism (146 and 177). Every essence exists in the individual state. We give the name species to the collection (collectio) of individual beings possessing one and the same essence, the unity that we attribute to them being based upon the natural similarity borne by the individuals to one another. ${ }^{4}$

${ }^{1}$ The theory is also referred to in the Glossulae super Porphyrium of Abelard (Ouvr. inéd., Cousin's edit., pp. $55^{2}$ sqq.).

${ }^{2}$ We extract from it this striking passage: "Sed simpliciter attendatur Socrates, non ut Socrates, id est in omni proprietate Socratis, sed in quadam, scilicet quod est animal rationale mortale, jam secundum hunc statum est differens et indifferens: differens a qualibet alia re existente hoc modo, quod ipse Socrates nec secundum statum hominis, nec secundum aliquem alium, est essentialiter aliquod aliorum: item indifferens est, id est consimilis cum quibusdam, scilicet cum Platone et cum aliis individuis hominis in eo quod in unoquoque eorum est animal rationale mortale. Et attende quod Socrates et unumquodque individuum hominis, in eo quod unumquodque est animal rationale mortale, sunt unum et idem. . . ." (HAURÉAU, op. cit., v., pp. 313, Paris, r892).

${ }^{3}$ De Gen. et Spec., Cousin's edit., p. 518.

4 "Et sicut Socratitas quae formaliter constituit Socratem, nusquam est extra Socratem, sic illa hominis essentia quae Socratitatem sustinet in Socrate nusquam est nisi in Socrate. Speciem igitur dico esse non illam essentiam hominis solum quae est in Socrate, vel quae est in aliquo alio individuorum, sed totam illam collectionem ex singulis aliis hujus naturae conjunctam" (pp. 524 and 525). "Neque 
The author considers the species not from the point of view of the comprehension of the concept but from that of its extension; and he is mistaken in not extending the sphere embraced by such a collectio beyond existing things so as to include possible things also. But this peculiarity, from which he draws certain conclusions about logical predication, does not hinder him from subscribing to the fundamental theses of anti-realism. ${ }^{1}$

John of Salisbury attributes to Jocelin of Soissons a "collection" theory which agrees with the teaching of the De Generibus et Speciebus: "Est et alius qui cum Gausleno Suessioni episcopo, universalitatem rebus in unum collectis attribuit, et singulis eamdem demit"."

Whether we consider the respectus of Adelard of Bath, the status of Walter of Mortagne, the non-differens of the indifferentists or the collectio of Jocelin of Soissons, we believe that all these theories, with their various shades of difference, are steps towards the final solution of the problem; and their lack of greater precision explains itself when once they are placed in their proper historical setting. ${ }^{3}$

Anti-realism took a decisive step forward with Abelard.

172. Sources and Bibliography.-See John of Salisbury, Mctal., ii., I7. Adelard of Bath: the Quaestiones Naturales are among the Munich Incunabula; the De Eodem et Diverso has been edited by Willner, Des Adelard von Bath Traktat de Eodcm et Diverso (Beitr. z. Gesch. d. Phil., iv., I, Münster, I9o3), accompanied by a valuable study. The Tractatus de Trinitate of W. of Mortagne is in PEZ, Thesaurus Anecd. Nov., ii., 2: his Letter is in D'ACHery, Specileg., iii. (1723): the De Generibus et Speciebus in Cousin's edition of the unedited works of Abelard.

REINERS, op. cit., I48: interesting and well written, exaggerates the points of difference between the theories expounded. DEHOVE, Qui praccipui fucrint labente $X I I$ s. ante introductam Arabum philosophiam temperati realismi antecessores (Lille, 1908).

enim diversum judicaverunt essentiam illius concollectionis a tota collectione, sed idem, non quod hoc esset illud, sed quia similis creationis in materia et forma hoc erat cum illo" (p. 526).

1 We cannot accept the view of REINERS who sees in this theory a cruder realism than in the indifference theory. ReINERs, Der aristotelische Realismus in der Frühscholastik, 1907, p. 43 .

2 Metal., ii., r7.

${ }^{3}$ John of Salisbury also refers to authors who, instead of status, used the expression " manieres rerum" (Migne prints erroneously materies rerum); which John understands in an ultra-realist sense. It was after referring to this theory of the "manieres rerum" that John concluded his historical remarks in these apologetic terms: "Longum erit, et a proposito penitus alienum, si singulorum opiniones posuero, vel errores; cum ut verbo comici utar: Fere quot homines, tot sententiae" (Metal., ii., r8). 


\section{§ 3. Peter Abelard and Gilbert de la Porrée.}

I73. Life and Works.-Peter Abelard was born at Pallet in ro79. Sprung from a family of warriors he had a stormy and chequered career in the intellectual battlefield of dialectic. From the school of Roscelin he passed to that of William of Champeaux; from Paris to Melun, thence to Corbeil; back once more to Paris, challenging all and sundry to philosophical controversies in which he always boasted of victory in advance. He studied theology under Anselm of Laon. Subsequently, when teaching the sacred science at the French metropolis, elated beyond measure by the applause of an admiring and enthusiastic audience, he believed and proclaimed himself the only philosopher of his time. But "Pride goeth before destruction: and the spirit is lifted up before a fall" (Prov. xvi. I8). After success came misfortune. Forced to quit Paris, Abelard wandered proscribed and almost unbefriended from monastery to monastery until his death, in II42, at the abbey of St. Marcel-lez-Châlons.

Abelard's writings are numerous. In dogmatic theology: Tractatus de Unitate ct Trinitate Divina; Theologia Christiana; Introductio ad Theologiam, which is only the first-and sole surviving-part of the preceding; the Sic et Non. In philosophy: Scito Teipsum seu Ethica; Dialogus inter Philosophum, Fudabum et Christianum; Glosses on Aristotle, Porphyry and Boëthius; Dialectica. His Historia Calamitatum is a long narrative of his own misfortunes. We shall deal only with his philosophy here, postponing our notice of his theology to the next article.

174. Abelard's Philosophy.-Between philosophy and theology Abelard established a system of theoretical relations, scholastic in its spirit. Man cannot demonstrate (comprehendere) mysteries, nor obtain that experimental knowledge of them which he has about the things around him (cognoscere seu manifestare). At most he can reach an approximate knowledge of them by images and analogies (intelligere seu credere). ${ }^{1}$

But no sooner had he laid down these principles than he erred in applying them: The existence of the Blessed Trinity is accessible to reason. The Greeks, he observed, had intuitions about the Blessed Trinity, as we know from the Platonic teaching about God, the vov̂s and the world-soul (Neo-Platonic influence); and he himself fell into Sabellian views which led to his condemnation.

Abelard did much to secure the general recognition of an autonomous value for philosophy; much that survived his errors and excesses. Many were induced by his influence to advocate the cultivation of philosophy for its own sake, without at the same time committing themselves to his rationalism.

To Abelard rightly belongs the honour of inaugurating a

1 Terminology established by KaISer. $C f$. Heitz, op. cit. 
didactic method which had been tentatively broached by various authors in the early years of the twelfth century ${ }^{1}$ and which was destined to meet with a remarkable measure of success in scholasticism. In the Sic et Non he gathered together, for the help of beginners (teneres lectores), various texts from the Fathers, relating to a given question and embodying divergent views about the latter. It was an exposition of the fros and cons, drawn from authority. ${ }^{2}$ Abelard undertook a similar task in his Dialectica, laying this time profane as well as sacred authors under contribution. But he confines himself to the mere exposition of both sides of each question, without making any attempt at a systematic solution of the questions themselves. The method was adopted by the summists and canonists of the twelfth century, and was perfected by Alexander of Hales. ${ }^{3}$

In metaphysics Abelard gathered up and transmitted the main principles embodied in the teachings of Boëthius; he accepted the theory of the world-soul and gave currency to an erroneous interpretation of the theory of matter and form. But it was to the Universals problem that he devoted his most earnest and prolonged attention. By the natural bent of his disposition he was a demolisher of systems. He criticized the doubts and hesitations of Roscelin who would not dare to locate the objects of our universal concepts in individual things: and on the other hand he dealt the finishing blow to extreme realism by the ridicule he heaped on the theories of William of Champeaux (165). His bold assertions and criticisms arrested the attention of contemporary scholastics, while he exposed the latent vices of the realist formulas and showed how they led logically to pantheism. And now for Abelard's own doctrine on the Universals question. Not only does he insist on the fact that the individual being alone has substantial existence, but he explicitly teaches that we possess abstract and universal concepts: by abstraction we represent to ourselves elements common to different things and conceive these elements as distributively realizable in an indefinite multitude of individuals of the same species. ${ }^{4}$ Hence

${ }^{1}$ Notably by Adelard of Bath. Cf. Willner, op. cit., p. 40.

${ }^{2}$ Prosper of Aquitaine and Tajus, a Spaniard (seventh century), had already made collections of texts from the Fathers, but not of contradictory views.

${ }^{3} \mathrm{M}$. Picavet calls this the scholastic method; Endres more properly the scholastic Lehrmethode. It is evidently a method of teaching, and not the only one (I09).

* See texts in De Remusat, Abélard, i., p. 495. 
Abelard is not a nominalist. Is he a conceptualist? According to some he is. But does he really regard the universal concept as a mere subjective form of the mind, having no correspondence with any external reality (136)? His writings contain no evidence of any such restriction. Nay, on the contrary, Abelard teaches that the universal exists in the individual, for he holds that it exists there alone. ${ }^{1}$ Had he justified more explicitly the real validity of concepts when he had established their ideal validity; had he shown that the similarity of individual essences is the basis, the foundation of the process of universalization; he would have won for himself the honour of reaching Aristotle's own solution of the problem proposed by Porphyry. Abelard had grasped the right solution of it in his own thought; his theory marks a decided step in the direction of Thomism; of him and his supporters John of Salisbury was justified in saying: "Amici mei sunt".2 His immediate successors had only to give clearer expression to Abelard's thought in order to dissipate the apparent antinomy between the individual of the sense-world and the universal of the understanding.

In a secondary, indirect way, Abelard is a psychologist and a moralist. He fixed the attention of his contemporaries on the soul, its power of abstraction and its function in the genesis of knowledge. His moral teaching is propounded in the traditional theological framework; but there are signs of a tendency towards purely rational solutions in the Scito Te Ifsum, with its constant reference of ethical problems to the bar of individual consciousness: a notion that holds a central place in his ethical system. He showed a predilection for studies on sin, freedom and grace.

Abelard's influence on scholasticism was profound; he may be regarded as the originator of new and fruitful lines of thought and speculation. John of Salisbury writes of him: "Peripateticus Palatinus... multos reliquit, et adhuc quidem aliquos habet professionis hujus sectatores et testes". Gilbert de la Porrée was among those influenced by his metaphysics.

I75. Gilbert de la Porrée.-Gilbert de la Porrée (Porretanus) was born at Poitiers in ro76, followed the lectures of Hilary of Poitiers and Anselm of Laon,

1 "Neque enim substantia specierum diversa est ab essentia individuorum, nec res ita sicut vocabula diversas esse contingit. . . . Cum videlicet nec ipsae species habeant nisi per individua subsistere, etc." (Dialect., p. 204 in the Ouvr. inćd. d'Abílard).

${ }^{2}$ Metal., ii., I7. 
and was intimately acquainted with Bernard of Chartres, having lectured himself for over twelve years at the famous schools there. Subsequently he became Scholasticus at Paris (I I +1$)$, and John of Salisbury, who followed his lectures there, assures us of the high esteem in which he was held at the great metropolis of learning. In I $4^{2}$ Gilbert was appointed to the see of Poitiers, where he died in Ir 54 . He did not abandon his professorial work immediately on assuming the duties of the episcopate.

Among the numerous theological and philosophical works of Gilbert the most important are the Liber Sex Principiorum and two commentaries on the supposed Boëthian treatises De Trinitate and De Duabus Naturis in Christo. He is not the author of the book $D_{\epsilon} C^{\prime}$ ansis, attributed to him by Berthaud and Clerval.

176. Gilbert's Philosophy. - In addition to an exhaustive study of the logical writings and deductive method of Boëthius, and of the new logical works commentated by Theoderic of Chartres though unknown to Abelard. Gilbert also conceived the idea of completing Aristotle's study of the Categries. Aristotle had studied in detail only the first four categories, substance and the absolute accidents of substance, formac inhacrentes, as Gilbert called them. The remaining six, the accidents which characterize a substance only in relation to another substance. format adjacentes, were analyzed by Gilbert in his Liber Sex Principiorum. The book obtained a rapid celebrity; it was universally adopted as a text-book in the schools, was annotated by Albert the Great, quoted by St. Thomas and retained its popularity in the schools down to the end of the Middle Ages.

The fundamental principle of anti-realism is defended by Gilbert: essences exist only in individuals and are really multiplied in Nature." Then immediately the question arises: what is the origin, and what the value, of universal concepts? Gilbert answers: the mind compares and gathers together (colligit) the essential determinations (diversate subsistentiac) realized in numerous individual beings, and effects a mental union of the similar realities of these beings; and it is this similar element we call the genus or species." These two fundamental theses suggest an

${ }^{1}$ Among those who espoused Gilbert's solution of the Universals question were OTto of FREISING (III5-II58) and the anonymous author of the Liber de Vera Philosophia; also Nicholas of Amiexs, author of a Summa against the Mahometans, De Arca Fidei, free from all trace of excessive realism. On Otto, $c f$. J. HaStagen, Otto von Freising als Geschichtsphilosoph und Kirchenpolitiker (Leipzig, I900). The author examines the influences bearing on Otto's philosophy, pp. 6-22. Also J. Schmidun, Die Philosophie Ottos von Freising (Philos. Jahrb., 1905).

2 “Unus enim homo una singulari humanitate . . . ut pluribus humanitatibus plures homines et substantiae."

3 "Universalia quae intellectus ex particularibus colligit," etc. 
evident kinship between the thought of Gilbert and that of Abelard. The genus and species are the sum-total of the beings in which those similar realities are found, belonging in proper to each of them. ${ }^{1}(C f$. the "Collection" theory, 17I, $d$.) It is certain that Gilbert opposed the extreme realism of Chartres; and it is equally certain that he propounded neither nominalism nor conceptualism in the sense nowadays accorded to these terms. The thesis of the similarity of essences as the foundation of the real validity of universal concepts, is asserted more clearly by Gilbert than by Abelard. Still, there are weaknesses in the metaphysics of the Bishop of Poitiers which forbid us to regard his theory on the Universals as the first clear, definite and decisive formulation of moderate realism: weaknesses which account, in some respects, for the wide diversity we find in the views of historians about Gilbert's teaching. ${ }^{2}$

In every actual being, he distinguishes between the essential realities possessed by that being, and to which there correspond similar realities in other beings (subsistentia, id quo est), and the individual determination which gives that being its real existence (substantia, id quod est). ${ }^{3} \quad \mathrm{He}$ is inclined to exaggerate the distinction we must make between the common essence and the individualized essence and seems to regard the latter as a part really distinct from the former. Yielding to the same unfortunate tendency, he regards as separate and proper subsistentiae in the individual, certain transcendental attributes, such as unity, which are not really distinct from the being

1 "Genus vero nihil aliud putandum est, nisi subsistentiarum secundum totam earum proprietatem ex rebus secundum species suas differentibus similitudine comparata collectio," etc. (Comment. on the De Trinit. in the Boëthii Opera, ed. Basil, 1570, pp. 1238, 1135. Cf. PRAntL, Geschich. d. Logik, ii., p. 219 sqq.).

2 Prantl calls him an ontologistic (?) realist, op. cit., ii., p. $22 \mathrm{I}$; StöckL, a conceptualist, op. cit., i., p. 277; Clenval, an extreme realist, op. cit., p. 262. The laconic judgment of John of Salisbury is not easy to interpret: "Universalitatem formis nativis attribuit. ... Est autem forma nativa, originalis exemplum, et quae non in mente Dei consistit, sed rebus creatis inhaeret. Haec graeco eloquio dicitur eîlos, habens se ad ideam ut exemplum ad exemplar; sensibilis quidem in re sensibili, sed mente concipitur insensibilis, singularis quoque in singularibus, sed in omnibus universalis" (Metal., ii., I7). The in ommibus universalis must evidently be consistent with the singularis quoque in singularibus, which latter phrase can leave no doubt as to Gilbert's anti-realism.

3 “Genera et species, i.e., generales et speciales subsistentiae subsistunt tantum non substant vere" (op. cit., p. 1239). 
itself. ${ }^{1} \quad$ These certainly are errors in metaphysics; they have no direct bearing, however, on the Universals problem: whatever be the nature of the distinction established by Gilbert between the metaphysical elements of being, these elements he endows with an existence that is not universal, but proper to each individual.

The subsistentiae, or formae nativae, are carefully distinguished by Gilbert from the Divine ideas, of which they are copies. ${ }^{2} \mathrm{He}$ makes the form, when contrasting it with the matter, a mere property of the being, thus perpetuating the false notion about matter and form, prevalent at that period. No wonder, then, that Gilbert admits plurality of forms. He condemns pantheism; but in another way his metaphysical errors cause him some trouble in theology (186).

Gilbert was not a thorough thinker - with a full, all-round philosophical system-any more than Abelard was. Alongside pure scholastic doctrines, we find in him illogical drawbacks and shortcomings. So that even the leading philosophers of the middle of the twelfth century bear witness to that want of systematization which is one of the most obvious characteristics of the scholasticism of the period.

177. The Verbalists. - There were so many opinions prevalent about the middle of the twelfth century on the matter of the Universals, so many delicate shades of difference between realist and anti-realist solutions, such a passion for controversy in the schools, that many of the combatants plunged into sad excesses of dialectic quibbling $(c f \cdot \mathbf{1 4} \mathbf{6})$. John of Salisbury has administered some merciless scourgings to those mugiloquos ventilatores, jugglers of words, who would argue for the sake of arguing instead of seeking truth, as if believing that such intemperate discussion was the acme of logical skill, qui safientiam verba putant. ${ }^{3}$ This despotism of purely verbal argumentation synchronized with the

${ }^{\prime} O p$. cit., p. II 8 . "Quod est unum, res est unitati subjecta, cui scilicet vel ipsa unitas inest, ut albo, vel adest, ut albedini. . . . Ideoque non unitas ipsa sed quod ei subjectum est, unum est." $C f$. Prantl, p. 221.

${ }^{2}$ Op. cit., p. I I $4 \mathrm{I}$.

3 Polycrat., vii., I2. Similarly: "Fiunt itaque in puerilibus Academici senes, omnen dictorum aut scriptorum excutiunt syllabam, imo et litteram; dubitantes ad omnia, quaerentes semper, sed nunquam ad scientiam pervenientes" (Mctal., ii., 7). "Debuerat Aristoteles hanc compescuisse intemperiem eorum, qui indiscretam loquacitatem dialecticae exercitium putant" (ibil., ii., \&). 
appearance of the Logica nova (132, I), which offered new nourishment to the passion for quibbling. Among these sophists we may mention ADAM OF PeTitPont, ${ }^{1}$ whose Ars Dialectica (I I32) is a veritable triumph of logic-chopping. Such excesses, however, did not succeed in stopping the march of sound speculation and reasonable discussion.

178. The Dawn of Moderate Realism.-After Abelard's time philosophers were either frankly pantheists or else pursued the trend of thought initiated by the philosopher of Pallet. These latter devoted careful attention to the similarity of essences in the objective order and to the genesis of abstract and universal concepts in the subjective order. For the solution of the Universals problem it was necessary to show that there is a real foundation for referring the general or common representation to the particular being: that things really possess the natures apprehended by abstraction, and that, if the form of universality, as such, is a product of the understanding, the content of that form is truly applicable to an indefinite number of real beings, actual or possible. Therefore what is affirmed of the number is not the concept of a genus or species, but the object itself of this concept, which object is the nature of the things. It is impossible to say who can rightly claim the honour of being the first to offer an adequate formulation of moderate realism. The doctrine of Abelard was again outlined by ROBERT PULLEYN. But towards the close of the century moderate realism had achieved a rapid and final triumph. We find it in the works of Simon of TOURnaI (between I I 76 and I I92), a writer who has been unjustly accused of rationalism and Averroïsm, ${ }^{2}$ who expounds with a striking degree of clearness the Aristotelian doctrine on the sense-origin of ideas and on the nature and real validity of the process of abstraction. Finally, moderate realism is fully and plainly propounded in the writings of John of Salisbury.

179. Conclusions. - Two main conclusions emerge from an historical study of the Universals problem :-

${ }^{1}$ Born at Balsham, near Cambridge. Called $d u$ Petit-Pont (Parvipontanus) because he used to teach the trivium in a school beside the small bridge across the Seine.

${ }^{2}$ Author of a commentary on the Athanasian Creed and of a Summa Theologica in which he quotes a good deal from Scotus Eriugena, but which contains nothing anti-scholastic. Simon was one of the first to make the acquaintance of Aristotle's Physics. Cf. our Histoire de Philos. scol. Pays-Bas, p. 39. 
(I) Neither nominalism nor conceptualism, as these systems were understood later, existed prior to the thirteenth century.

(2) All the anti-realist systems prior to the thirteenth century are more or less imperfect expressions of moderate realism; they are all phases in the organic evolution of one and the same underlying idea.

180. Sources and Bibliography. - The edition of Abelard's works published in 1616 , has been considerably augmented by the researches of DURand, Pez, Cousin, Stölzle. The latter has discovered and published Abaclards IIzI $z u$ Soissons verurtheilter Tractatus De Unitate et Trinitate Dirina, I891. The Theologia Christiana was published by MARTÈNE in 1717 (Thesaurus noz'us ancedot., v., 1139); the Introductio ad Theol. by Amborse in 1616; the Epitome and the Dialogus by Reinwald in 1835 ; the Sic et Non by Henke (1851) in Migne; the glosses and the Dialectica by Cousin, Ouvr. inédits d'Abélard pour servir à l'histoire de la philos. siol. en France, i 836 : with an Introduction by Cousin. Cf. Migne, v. 178. DE Remusat, Abélard, sa rie, sa philosophie et sa théologie, 2 vols., 1855. Deutsch, Peter Abaelard, I883. Portalie, Abélard (Dict. Théol. Cath., v. i.). E. Kaiser, Abélard critique (Fribourg, rgor). Excellent. Hertz, op. cit., pp. 7-30. Picavet, Abélard et Alexandre de Halis, criateurs de la méthode scolastique (Bibl. Ecole Hautes Etudes, Sciences Religieuses, v. vii.). Good. EnnRes, Ucbcr den Ursprung u. die Entwickelung der Scholast. Lehrmethode (Philosophisches Jahrbuch. ii., I). Good. G. ROBERT, Abélard críateur de la méthode de la thcologie scolastique (Rev. Sciences philos. et théol., 1909). TUrner, Abelard (Catholic Encyclopedia, I.).

Wigne has edited Gilbert's $D_{\epsilon}$ Sex Principiis (v. 184) and commentary on Boë:hius (v. 64). A. Brothaun, Gilbert de la Porrie et sa philosofhie, 1892.

\section{JOHN OF SALISBURL AND ALAN OF LILLE.}

181. Life and Works of John of Salisbury.-John of Salisbury (Fohannes Parvus) is one of the most striking figures and remarkable thinkers of his time. Mixed up with the intrigues of politics in Church and State, he became successively secretary to the Archbishop of Canterbury, Theobald, intimate companion of Thomas à Becket, confidential adviser to the English King, Henry II., and trusted friend of Pope Hadrian IV., his fellow-countryman. The intense philosophical movement of the middle of the twelfth century none of his contemporaries followed more closely than he. He arrived in Paris at an early age in the year 1136 and there followed the lectures of the most distinguished professors of the university: Abelard, Alberic, William of Conches, Theoderic of Chartres, Walter of Mortagne, Adam of PetitPont, Gilbert de la Porrée, Robert Pulleyn and many others. In Ir 76 he was made Bishop of Chartres and died there in I 180.

The exceptionally liberal training of John of Salisbury, his numerous connections with men of learning as testified by his letters, and his remarkable position in the public life of his time, all these things combine to give weight and authority to his writings. Besides his Letters, two lives of saints and some minor religious writings, he has left a philosophical poem entitled Enthcticus dc Dogmatc Philoso. phorum, a brochure De Scptem Scptenis and, most important of all, the two treatises, the Polycraticus (1155) and the Metalogicus (I 159), which form a unique monument 
of the history of thought in the twelfth century. No thoroughly exhaustive study of John of Salisbury has yet been made. We will confine ourselves to the more salient points in his personality and life-work.

182. John of Salisbury and the Trivium.-Extending a broadminded and enlightened welcome to all branches of culture, John was an energetic advocate of the seven liberal arts as they were taught at Chartres: for him they were the seven avenues that lead the soul into the sanctuary of science. ${ }^{1}$ But while he would not depreciate the value of Grammar, he would not tolerate the absurd notions of those outré grammarians, who, with Peter Helias, would fain shut themselves up in dry-as-dust analyses of the Grammar of Priscian (131, $a$ ).

John was in fact a typical representative of that school of literary humanism to which a wise extension of studies in Rhetoric had given rise at Chartres. An intimate acquaintance with the great writers of classical Latin, especially with Cicero, made the scholar from England the neatest and most elegant Latin writer of the twelfth century; his prose and verse alike are freshened and flavoured with copious reminiscences of the classics. This cultured literary taste of his will account for the vigorous campaign he waged in conjunction with his Chartres colleagues against the obscurantist party whom he nicknamed "Cornificians," a set who persistently tried to bring discredit not merely on the trivium but on all branches of study, as being only so many sordid expedients for procuring rapid promotion to lucrative offices. The Metalogicus opens with a sweeping attack on these Boeotians, whom John depicts under the figure of a strange being, Cornificius, of which he draws a picture that is anything but flattering. ${ }^{2}$ And when he has shown the importance of dialectic, cum itaque logicae tanta sit vis, he waxes eloquent in his indignation against this ignorant crowd,-logicae incriminator, philosophantium scurra.

But he has other errors to set right here, and he thus takes us by another side into the scholastic movement of the twelfth century. He has to defend dialectic against its own excesses and chastise the logic-choppers who would degrade it into an empty parade of pedantic phrases ${ }^{4}$ (17I). By this same apologetic he ad-

${ }^{1}$ De Septem Septenis, ii.

${ }^{2}$ According to Clerval, op. cit., p. 227, the Cornifician sect arose under the leadership of a monk named Reginald, about rrzo.

${ }^{3}$ Metal., iv., $25 . \quad+$ Ibid., ii., 8, 9. 
ininisters an indirect rebuke to the extreme school of rigorist theologians who would fain banish dialectic altogether from the schools, lest it might find its way into theology (179). Dialectic he holds to be the queen of the trivium $(\mathbf{1} \mathbf{3} \mathbf{I}, a)$; its function is formative; it trains the young scholastic in that art of thinking and speaking without which the study of philosophy is impos-

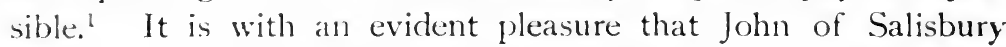
dwells on the notion of logic and its divisions, and on the proper method of reading Aristotle and Porphyry." At the same time he is no less emphatic in declaring the insufficiency of logic if cultivated to the exclusion of the other philosophical sciences: left to itself it is bloodless and sterile. "Sicut dialectica expedit alias disciplinas, sic, si sola fuerit, jacet exsanguis et sterilis, nec ad fructum philosophiae fecundat animam, si aliunde non concipit.": Alan of Lille also uses words to the same effect. Evidently the despotism of logic in the schools is at an end.

183. John of Salisbury, Historian. - The prudence he reveals in constructing his philosophy is worthy of remark. He tries to verify every statement before accepting it as true. He goes back to the sceptics of antiquity, not to shut himself up with them in doubt, but to make himself all the more sure of what he will take for truth. ${ }^{+}$The views of all his distinguished contemporaries were likewise eagerly sought by him, and their opinions noted and discussed. The curriculum of his scholastic career, as described by himself in the Metalogicus, gives us a very full tableau of the schools of the twelfth century and constitutes one of the most precious sources we have of the history of ideas in that age. His careful inquiries about the opinions of others are a dominating feature of all his work and mark him out as the chief historian of the philosophy of his time.

184. John of Salisbury, Philosopher.-In the Metalogicus John gives us the Platonic division of philosophy." The question of the Universals occupies a large place in his writings. It was no wonder, for in treating this question "the world had grown

“ Inchoantibus enim philosophiam, praelegenda est, eo quod vocum et intellectuum interpres est, sine quibus nullus philosophiae articulus recte procedit in lucem "(Metal., ii., 3).

"Ibid., ii., II ; iii. and iv., r-7, etc.

Ibid., ii., Io. Cf. ii., 9: "Quod inefficax est dialectica, si aliarum disciplinarum destituatur subsidio".
"Polycrat., vii., I-6.
sii., ro and 17.
${ }^{6}$ ii.. 2 and 5. 
old, taking more time to solve it than the Caesars took to conqueror and govern the world ". 1 John gives us the same solution as Aristotle: an analysis of our abstract knowledge leads him to moderate realism. $^{2}$ He adds, moreover, that we must not allow ourselves to grow white in the schools over this eternal question : there are many other domains to claim our attention : psychology especially, with the study of our psychic faculties and acts.

Sensation, he teaches, is a movement of the soul, anima pulsata sensibus, ${ }^{3}$ which brings us into conscious contact with the beings of sense, whilst intellectual knowledge attains to immaterial realities besides. ${ }^{4} \quad$ All knowledge originates in the order of sense : ars sive scientia originem trahit a sensu. ${ }^{5}$ Certitude has its basis in the rationes acternae." The dependence of the various powers of the soul upon one another is emphasized, especially the influence of the physiological functions on the higher, conscious activities of our being : the evidences of the tradition coming down from Constantine the African are manifest here. The soul is simple and immortal. ${ }^{\top}$ These and other doctrines are not didactically developed but rather dropped incidentally here and there. Volumes would be needed, the author informs us, for an exhaustive study of the activities and nature of the soul. ${ }^{\mathrm{s}}$ It is a pity he did not write a few !

John of Salisbury is occasionally a moralist. He discusses and condemns Epicurus and gives us a detailed analysis of the vices. ${ }^{9} \quad$ He studies Divine Providence and Foreknowledge, which he endeavours to reconcile with human freedom. ${ }^{10} \mathrm{He}$ has also written long chapters on the State, examining the theories of the ancients in reference thereto. ${ }^{11}$

185. Isaac of Stella and Alcher of Clairvaux.-About the middle of the twelfth century there appeared two small treatises on psychology which are important as summing up the current psychological teaching of this first period. One, entitled $D_{e}$ Anima, is in the form of a letter written about I 62 by ISAAC OF STELlA (born in England, became a Cistercian monk at

1 "In qua laborans mundus jam senuit, in qua plus temporis consumptum est quam in acquirendo et regendo orbis imperio consumpserit Caesarea domus . . ." (Polycrat., vii., 12).

$\begin{array}{llll}{ }^{3} \text { Metal., ii., 20. } & { }^{3} \text { Ibid., iv., }{ }_{5} . & 4 \text { iv., r6. } & { }^{5} \text { iv., } 20 . \\ \text { " iv., } 32 \text { sqq. } & { }^{7} \text { iv., } 20 . & { }^{8} \text { Ibid. } & { }^{9} \text { Polycrat., vii. }\end{array}$

${ }^{10}$ Ibid., ii., 20, $2 \mathrm{r}$.

${ }^{11}$ Ibid., iv., v. He studies Plutarch especially. Cf. I33, I, $3(b)$, n. I. 
Citeaux, abbot of Stella about Ir47, died about Ir69). The other, known as Liber de Spiritu et Anima, is probably the reply of Isaac's correspondent, Alcher of Clairvaux. The De Anima is a collection of rather disconnected views which were apparently drawn from their author by the insistence of Alcher. ${ }^{1}$ The Liber de Sfiritu et Anima, on the contrary, is a well-arranged treatise which must have had a considerable didactic value, and is full of erudition besides." Both authors were manifestly imbued with the spirit of the Augustinian psychology. The soul rules the body; its union with the body is a friendly union, though the latter impedes the full and free exercise of its activities; it is devoted to its prison. ${ }^{3}$ The powers of the soul are manifold, but none of them really distinct from the soul itself. We may decipher in it vestiges of the Blessed Trinity." Alcher gives a long description of all the soul's activities, from the ris ritalis and animalis up to intelligence. Isaac has summarized the solution of the Universals problem in this significant formula: "secundae enim substantiae sunt in primis, sed primae a secundis". 5

186. Alan of Lille Hlamus ab Insulis - - Little is known of the life of this philosopher. Born about I I 28 , he seems to have taught at Paris. He assisted at the third Lateran Council (I I 79). He joined the Cistercian order and died in the abbey of Citeaux (1202). Posterity has griven him the title of Joctor Universalis.

His principal works are the Tractatus contra Hereticos, the Ars Catholicae Fide $i_{,}^{,}$the Theologicae Regulae, the Anticlaudianus, ${ }^{7}$ the De Planctu. Vaturac. In their general drift they are both theological and philosophical. It is from the latter point of view only that we deal with them here.

The philosopher of Lille has ranged over extensive domains

1"Cogis me dilectissime, scire quod nescio; et quod nondum didici docere" (Migne, P.L., t. 194, col. 1875).

${ }^{2}$ In his Quaestio Unica de Anima, art. 12, a. I, St. Thomas attributes this treatise to an anonymous Cistercian monk. This would be Alcher. Cf. 133, iii., 2.

:" Sociata namque illi, licet ejus societate praegravetur, ineffabili tamen conditione diligit illud: amat carcerem suum" (De Spiritu et Anima, Migne, t. 4o, col. 7 Sq).

+ Ibid., cap. $6 . \quad$ "Op. cit., col. $\mathrm{I}^{8} 88_{4}$.

${ }^{6}$ HAURÉAU and V. HerTLing attribute this treatise to Nicholas of Amiens, but BAEUMKer has shown that it belongs to Alan (Handschr. zuden W'rkendes Alauus, Philos. Jahrb., I 894).

'Adam de la Bassée published a work under the same title (Hauréau, Not. et Extr., v., pp. $548,549,559)$. 
of thought in his writings, without, however, constructing any system proper: he was content to gather up and reconcile as far as he could, the scattered theories that sprang from different sources and were accumulating towards the end of the epoch. The gift of quick and logical thought made Alan an adept in the art of controversy; and with this gift he combined the rarer talent of elegant and graceful expression: so that his works, like John of Salisbury's, occupy a high place in the philosophical literature of the twelfth century. $\mathrm{He}$ is fond of clothing his thoughts in poetic imagery, and is indeed often so allegorical as to be misleading. Still, he must not be classified among the mystics (Hauréau); he is fundamentally speculative, not mystic: his tendency is to ally Platonism with Aristotelian and NeoPythagorean conceptions, transforming and colouring the whole with the spirit of Christian thought. Alan was not appreciably influenced by any contact with Arabian literature, though he seems to have known the treatise of Gundissalinus, De Unitate, and to have been the first to quote from the Liber de Causis (see Second Period).

187. The Philosophy of Alan of Lille.-Logic is no longer the despotic suzerain, whom certain unbalanced thinkers would have proclaimed goddess of thought. She is pictured rather as a pale young maiden, worn out by the fatigue of prolonged vigils. The most interesting, perhaps, of Alan's logical theories is that relating to the method of philosophy: he would have the pure deductive, mathematical method reign supreme, and would follow out its applications systematically even into the domain of mysteries in theology. In this he is a witness to the ascendant of Abelard, preferring the argument from reason to that from authority, and regarding the latter as too easily invoked in support of contradictory positions. ${ }^{1}$ He brings his serried lines of syllogisms to bear on mysteries; but after all he sides rather with St. Anselm, and keeps clear of the rationalism of Abelard; for, even if the mind is capable of discovering motives of credibility, he does not regard it as able to demonstrate them scientifically.

Psychology and Metaphysics are studied with evident relish by the philosopher of Lille. The Aristotelian metaphysic occupies

1 "Quia auctoritas cereum habet nasum, i.e., in diversum potest flecti sensum, rationibus roborandum est." $C f$. Baumgartner, Die Philos. d. Alanus de Insulis, pp. 27-38. 
a surprisingly large place in his speculations. He draws his inspiration from Boethius and differs in many points from the peripatetic ontology current in the twelfth century. Following Boethius, he propounds the Aristotelian doctrine on the categories, on personality, and on the four causes of being. Primary matter is not the potential and indeterminate, but a sort of chaos antiquum, an actually existing and therefore already informed mass: a theory that has nothing in common with Aristotle's. And the form, instead of being the constitutive principle of the being, is a property or the sum of the properties of the being (126). In regard to the Universals problem. Alan is an anti-realist after the manner of John of Salisbury.

In psychology he glides orer the problem of the origin of our ideas. He fixes his whole attention on the nature of the soul. He defends its simplicity, spirituality and immortality against the Cathari (207): thus giving his work a polemical turn. On account of his wrong conception of form he does not admit that the soul is the form, i.e., the "property" of the body: it is an independent substance, united to the body by a sort of connubium or unio maritalis. There is a spiritus physicus which serves as a comecting-link between soul and body ; their mutual relations are regulated by number and harmony. It is easy to see how completely Alan's doctrine on the nature of the soul is dominated by Augustinian and Pythagorean theories: Aristotelianism finds no place in it.

The Cosmology of Alan is likewise permeated by the Pythagorean conception of number as the ruling principle of the unity of the cosmic elements and the basis of cosmic order. His Theodicy is Augustinian: but between the Creator and individual creatures he places an intermediary called Nature as the servant of God, Dei auctoris vicavia, a sort of world-soul ruling the universe. $^{\prime}$ Is this a distinct reality, a real being, or merely a poetic personification of the forces of nature? It is difficult to say. ${ }^{2}$

188. Conclusion.- John of Salisbury and Alan of Lille are the last great names of the twelfth century. The development we

' BAUMGarTner, of. cit., pp. 77 sqq.

Alan was held in high estcem by his immediate successors. His works were commentated by Radulfus dF: Longo Campo (i2i6), William of Acxerrb (about I23I) and others. 
have had occasion to notice in psychology is indicative of maturity of thought. In fact scholasticism began to blossom forth in all its splendour from the dawn of the thirteenth century. And unforeseen events contributed to hasten the period of its culmination : notably the initiation of the astonished Western world to all the riches of the newly discovered literatures of Greece and Arabia (Second Period, Ch. I.). One is tempted to speculate as to what would have become of scholasticism if it were left to develop from its own inherent vitality, without the aid of the rich stores of thought which it gathered from the Arabians. Perhaps it would have produced more painfully, yet more gloriously, the giant thinkers who are its pride. For it is but right to recognize the value of the results achieved during this first period; and the best proof of their worth as a preparation for greater things is the very rapidity with which the splendid syntheses of the thirteenth century sprang into existence. Just a few years after the introduction of the new Aristotle into the schools of the West, Alexander of Hales and Albert the Great built up those great philosophical systems which certainly could never have been produced in an age and society not prepared to receive them.

Anyhow the thirteenth century can claim the honour of having constructed the great scholastic edifice on a magnificent scale and on having secured between all its parts the most harmonious proportions.

189. Sources and Bibliography.-For works of John of Salisbury, see Migne, P.L., t. I99; Alan of Lille, t. 210; Isaac of Stella, t. 194; Alcher of Clairvaux, t. 40. For apocryphal writings of Alan, see HaurÉau, Not. et Extr., etc., v., pp. 509, 547, 548, etc. ; BAEUMKer, op. cit., p. 222, n. I.

Besides the older work of SchaARschmidt, F. Saresberiensis nach Lebcn $u$. Studien, Schriften u. Philos. (I862), articles on John of Salisbury have been written by Siebeck (Arch. f. Gesch. Phil., i., p. 520) and Webb (Proceedings of the Aristotelian Society, I894, p. 9I). Buonaruti, G. di Salisbury e le scuole filosofiche del suo tempo (Revista stor. crit. delle Science theol., 1908).

Baumgartner, Die Philosophie des Alanus de Insulis (Beitr. z. Gesch. Philos. Mittelalt., 1896). Excellent; rich in information on the history of theories. HAURÉAu, Mémoire sur la vie et quelques oeuvres d'Alain de Lille (Mém. Acad. Inscript. et B. Lettres, t. 32 , p. I). P. Bliemetzrieder, Isaac von Stella: Beiträge z. Lebensbeschreibung (Jahrb. f. Philos. u. Specul. Theol., xviii., p. I) ; Eine unbekannte Schrift I. von Stella (Studien u. Mittheil. aus d. Benedictin. u. Cistercienserorden, I908, p. 433). 


\section{AR'T. II-THE 'THEOLOGICAL, MOVEMEN'T' IN 'THE TIVELFTH CENTURY.}

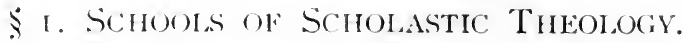

190. Progress of Scholastic Theology.-Scholastic 'Theology made a notable advance in the twelfth century and became clearly distinct from philosophy : the autonomy of each of the two queens of medieval wistom was now fully recognized. Great schools of theology sprang up, in which theology and philosophy were cultivated side by side (13). Two important new departures date from this period: the Summat and the I)ialectic. Method.

The Summat Sententiarum, or libri Sententiurum, which began to appear about the middle of the twelfth century, were encyclopedic synopses of Christian dogma. In St. John Damascene's $\pi \eta \gamma \dot{\eta}, \gamma \nu \omega \sigma \epsilon \omega s$, which prefaces each doctrine by philo-

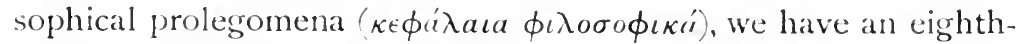
century attempt at theological systematization which was not without its influence on the compilers of the Sentences. These attempts at classification, first thought of in the West about the time of Abelard, were destined to meet with an unqualified success. They supplied the want that was beginning to be acutely felt for some sort of organization of the great and increasing mass of materials. To this rather than to any originality on the part of their compilers, they owed their popularity.

The (didactic) method of exposition or teaching employed by the sententiaries and summists, was that suggested by Abelard's Sic et Non. It was used by them often without any improvement on its original defects : after an exposition of contradictory views on a problem we are often left without any definite solution. This is the defect complained of by Walter of St. Victor when he calls Peter the Lombard one of the four labyrinths of France." But distinct from this didactic method there arose a new constructiz'e or constitistiz'e method, called the "dialectic method". Medieval scholastic theology, being a distinct, independent,

\footnotetext{
'Sententiae: "Aussprïche, Thesen, Quaestionen, Abhandlungen, welche man aus den hl. Vatern, den Kirklichen Lehreren u. Canonensammlungen nahm". Sometimes the work itself of the compiler of such extracts bore the title of $S_{c n}$ tences (Denifle, in the Archivf. Litteratur u. Kirchengesch. d. Mittelalt., i., p. 588).

"The other "labyrinths" were Peter of Poitiers, Gilbert de la Porrée and Abelard.
} 
autonomous science, had its own proper constructive methods, just as philosophy too had its own. They were methods of studying the contents of the Christian Revelation, and were concerned especially with the interpretation of the Scriptures and the Fathers of the Church: they were in common use among theologians from the time of Rhaban Maur, the "founder of theology in Germany". ${ }^{1}$ But in addition to these methods, the more important of the medieval theologians had recourse to a subsidiary method besides,- - the dialectic method. They borrowed it from the sister science of philosophy: after expounding a Christian dogma, they called in the aid of dialectic for the purpose of either demonstrating the dogma or at least showing it to be in harmony with reason. In this way the authority of the Scriptures was supplemented by a veritable apologetic of reason. Lanfranc in his time recommended a wise application of dialectic in theology, while Fulbert of Chartres condemned all intermingling and intermeddling of the two disciplines with each other. ${ }^{2}$ St. Anselm employed the dialectic method with discretion combined with courage. In the twelfth century it underwent considerable developments; and its use and abuse gave rise to lively controversies among theologians, marking them off into groups the main tendencies of which it will suffice to mention here. We may distinguish, as in the preceding century, (I) an abusive theology that overdid the argumentative method, to the detriment of the method of authority; (2) a party of reactionary theologians who opposed all dialectic and all philosophy; and (3) an intermediate group of moderate theologians who admitted the dialectic method into theology in subordination to the method of Scripture interpretation. But while some of these considered that the only use of philosophy was to throw into relief the rational element in dogma (e.g., Peter the Lombard), others recognized in philosophy a value of its own and cultivated it for its own sake (e.g., Hugh of St. Victor). These latter are the true representatives of the scholastic genius and the real forerunners of the great doctors of the thirteenth century.

Instead of this strict classification, we are influenced by historical considerations to adopt a different one: despite his errors, the work of Abelard may be connected closely with that of Hugh

${ }^{1}$ Burger, op. cit. (Der Katholik, August, r9o2, p. 135).

${ }^{2}$ ENDREs, Lanfranc, etc., p. 23 x. 
of St. Victor. Abelard's errors did not long survive him : among his immediate disciples the influence of Hugh of St. Victor is easily perceptible.

\section{The Argumentative Theologians. School of Abelard and} St. Victor. - The reasoned or dialectic theology, which constitutes scholastic theology proper, was developed mainly in two great schools, that of Abelard and that of St. Victor.

Abelard's Introductio ad Theologiam seems to be the first scholastic treatise to co-ordinate Catholic teaching. Its division of theology into three parts (faith and mysteries-incarnation and sacraments - charity) was faithfully retained in all the productions of the theological school of Abelard. Fr. Denifle, who has recently thrown considerable light on this school, has discovered fou Summat directly inspired by the Introductio ad Theologiam: (I) the Epitome Theologiac, heretofore attributed to Abelard himself, but really the work of a disciple who closely follows the master's guidance; (2) the Sententiae Rodlandi Bononiensis magistri auctoritatilus rationitus fortes, by Roland Bandinelli (Alexander 1II.), published by Gietl: (3) a Summa by Ognibene, a contemporary of Roland; (4) another anonymous Summa. Abelard, with his characteristic combativeness, turned to dialectic for weapons to fight the tritheism of Roscelin. But his zeal carried him too far: he fell into error in regard to the sphere of mystery-in good faith, according to many of his historians (174). This aroused the suspicions of the ecclesiastical authorities and fostered an excessive distrust of all philosophy in the minds of the more timid theologians. The school of Abelard survived the condemnation of its founder in I I 4 I (195), for the Summa of Roland is posterior to that date.

Fortunately the school of St. Victor knew how to avail of Abelard's didactic and constructive methods in theology without allowing them to transgress the limits of the most exact orthodoxy. It thus contributed no less powerfully than Abelard himself towards marking out the path which scholastic theology was destined to follow. Its wholesome influence is traceable in the works of Roland and Ognibene. HuGH OF ST. Victor is the leading representative of the school which takes its name from the famous home of medieval mysticism. His treatise $I_{e}$ Sacramentis is superior to Abelard's Introductio ad Theologiam. but it dates from a somewhat later period. As for the Summa 
Sententiarum, which is more directly inspired by Abelard's method, its authorship is vigorously disputed; but its exact reproduction of Abelard's teaching, and even of his errors, forbids us to attribute it to the author of the De Sacramentis. ${ }^{1}$

Abelard and Hugh of St. Victor were both theologians and philosophers. That is more than can be said for some other theologians of their time.

192. The Rigorist Theologians.-The abuses of the dialectic method inspired many with an excessive timidity about the use of it. We have first some higher mystics, like Walter of St. Victor, who were for condemning all natural knowledge, but were not heeded $(\S 2)$. Citeaux and Fonteavellana were the headquarters of this phase of reaction. We have especially the very influential group of rigorist theologians who, with Stephen of Tournai, were incensed against the "makers of new Summae"." St. Bernard, Arnold of Bonneval, Hugh of Amiens, Godfrey of Auxerre, John of Cornouailles, Peter the Chanter or Peter of Rheims, ${ }^{3}$ all blamed the dialectic method for the theological errors of Roscelin, Abelard and Gilbert de la Porrée. Whence many went on to condemn philosophy itself for daring to intrude on the theological domain.

But this was carrying accusations too far. Philosophy was not responsible for errors in theology; nor could the abuse of the dialectic method arrest or condemn the right use of it.

193. The Practical Theologians. - The over-sensitive theologians just referred to not only refused to touch the dialectic method but even proscribed the study of philosophy for its own sake. They thus ran directly counter to the two great scholastic leaders, Abelard and Hugh of St. Victor. Between those counter-currents another tendency interposed: that of a party of scholastics who were exclusively theologians and who saw in philosophy a mere auxiliary, an instrument that might perhaps be made to serve theology by the application of its methods or otherwise, but not an independent or autonomous science.

The most famous of all the sententiaries, PETER Lombard, called Magister Sententiarum (born at Novara in Lombardy, died

${ }^{1}$ Portalie, École théolog. d'Abélard (Dict. théol. cath., col. 54).

${ }^{2}$ Epist. ad R. Pont., quoted by Portalié, op. cit., col. 55 .

${ }^{3}$ Delatour, Pierre le Chantre (Bibl. Ec. Chartes, r897), and Gutjahr, Petrus Cantor Parisiensis (Gratz, 1898). 
Bishop of Paris, I 160 ), took the same general view. He drew on philosophy merely for the purpose of interpreting and illustrating dogma. He is not a philosopher: he is at most a writer with an external show of philosophy. ${ }^{1}$ His contributions to the science are fragmentary, incidental, indefinite and without originality. He is "an eclectic who draws informations from all sources, sometimes superficially, sometimes with rare penetration, to illustrate the doctrine of the Church ".. Nor indeed in theology itself can the Lombard claim any great originality." He imitated and borrowed from the Summa Sententiarum; so that Abelard and Hugh of St. Victor have a right to a large share of the immense prestige enjoyed by the Liber Sententiarum all through the Middle Ages." The Lombard's Book of Sentences is indeed the most marked success in medieval theology. The commentaries written upon it may be counted by hundreds. Down to the middle of the sixteenth century it was the classic which shaped thenlogical sturlies, and was read side by side with the Bible in the theological faculties of many European universities.

Among the first imitators of the Lombard, special mention is due to PETER OF Poitieks, chancellor of Paris, who compiled five books of sentences prior to i 75 . We may refer here also to an excellently arranged treatise on dogma, Catholicae Fiddei Libri Quinoue, written by Alan of Lille against the contemporary heresies of the Cathari and the Albigenses. We shall have more to say about its author when we come to deal with his philosophy. ${ }^{5}$

I This has been clearly established by ESPENBERGER, $o p$. cit.

2Ibid., p. II

* Espenberger denies that Peter Lombard was influenced by Robert Pulleyn (Robertus Pullus, died about I150, professor at Paris and Oxford, wrote Sententiarum Libri Octo, subsequent to the year 1136), and doubts the dependence of Peter on Master Gandulf. The Lombard's classifications betray the influence of the third part of St. John Damascene's $\pi \eta \gamma \grave{\eta} \gamma \nu \omega \dot{\sigma} \sigma \epsilon \omega s$ in Burgondio's version (132, iv.). We may mention among the other sentence-writers of the school of Hugh of St. Victor, Robert of Melun and Hugh of Rouen.

${ }^{4}$ On account of the great historical interest attaching to the Scntences of the Lombard it may be well to give, in bare outline, the contents of the work. The author deals successively with res, or things which do not signify any other thing, and of signa, or things that are themselves symbols of other things. The things comprise $(a)$ the object of our well-being: God (L. I.); $(b)$ the means of attaining to this object: creatures (L. II.); $(c)$ the virtues, which are both objects of enjoyment and means of arriving at happiness; men and angels, or the beings destined for this happiness (L. III.). The signa or symbols are the sacraments (L. IV.).

5 The name of Hildebert of Lavardin (1057-1133) must be removed from the catalogue of summists and philosophers, for the Tractatus Theologicus attributed to 
194. Conclusions. - ( I) The two most striking figures in the history of twelfth-century theology-Abelard and Hugh of St. Victor-were philosophers as well as theologians. As philosophers they aimed at formulating a rational explanation of the natural order of things by the light of reason alone. As dogmatic theologians they purposed to set forth systematically the contents of Catholic Belief, and used mainly the argument from authority for this purpose. But by the subsidiary use of the dialectic method, to the advantages of which they were fully alive, they assigned to philosophy the role of an auxiliary science and thus incorporated it in a unity of a higher order. We are thus enabled to understand how philosophy figures under two distinct titles in the Middle Ages: as having an autonomous value; and as a method to serve and strengthen the science of theology (ri5). Under the former point of view alone is it dealt with in this history.

(2) There were also theologians who would not be philosophers; so far as we know, there were no philosophers who were not, at some moments of their scholastic speculations, theologians also.

195. Theological Condemnations. The Church and Philosophy. -We have seen already how Abelard fell into errors about many dogmas, and notably about the Blessed Trinity. He taught that each of the three Divine Persons does not constitute the whole Divine essence, but each only a distinct modality of that one Divine essence,- - power, wisdom and goodness respectively. St. Bernard worked might and main against this heresy of Abelard, as he did afterwards against that of Gilbert de la Porrée. The De Unitate et Trinitate Divina was condemned at the Council of Soissons in I I 2 I ; the Theologia at the Council of Sens in I I $4 I^{1}{ }^{1}$

Gilbert, carrying his distinction between the singular and the universal into the doctrine of the Trinity, " made different things of God (Deus) and the Divinity (Divinitas), of the Father and Paternity, etc., even of the Nature and the Persons".2 This was tantamount to a denial of the Divine Unity. The Bishop of him is the work of Hugh of St. Victor (HAUREAU, Not.et Extr., etc., v., p. 25r); and the Philosophia Moralis circulated under his name belongs to William of Conches.

${ }^{1}$ As to the good faith of Abelard, Fr. Portalié writes: "Abelard was never a free thinker or unbeliever . . he was, and wished to be, a sincere believer" ( $o p$. cit., col. 4r).

${ }^{2}$ Clerval, op. cit., p. 263. 
Poitiers fell under suspicion for his teaching; but he succeeded in clearing himself and escaping condemnation.

The Church is often reproached with having condemned philwsophy in the persons of Roscelin, Abelard and Gilbert de la Porrée. Nothing could be farther from the truth. What the Church condemned was not the so-called nominalism, ${ }^{1}$ nor realism, nor philosophy in general, but simply applications that were considered dangerous ${ }^{2}$ of the dialectic method to matters of dogma, that is to say, to matters not philosophical..$^{3}$

In the thirteenth century, a whole legion of scholastics propounded and developed the theories of Roscelin and Abelard, and we hear of no councils summoned to condemn them.

196. Sources and Bibliography. - See theological works of Abelard, $\mathbf{1 8 0}$; of Hugh of St. Victor, Migne, P.L., I75-I77. Critical edition of the Sentences of the Lombard in the Quaracchi edition of the works of St. Bonaventure, t. i.-iv.; Migne has edited the Sentences of R. Pullus, t. I86, and of Peter of Poitiers, t. 21 I.

Protols, P. Lombard, son époque, sa vie, ses écrits, son influcnie (Paris, ISS1). Denifle, Abaclari's Sentenzen u. dic bearbeitung seincr Theologia (Archiv f. Litt. u. Kirchengesch. d. Mittelalt., I855, t. i.). A masterly treatment. Gietr, Die Sentenzen Rolands nachmals Papstes Alexander III., 189I. Text and critical study of great excellence. Portalié, École théol. d'Abélard (in the Dict. Théol. Cath., t. i., col. 49 sqq.). Excellent study; clear and up-to-date. Same author, Alexandre III. MigNon, Les origines de la scolastique et Hugues de S. Victor. H. Ostlek, Die Psychologie d. H. v. St. Victor. Ein Beatrag z. Gesch. d. Psychol. in d. Friuhscholastik (Beitr. z. Gesch. d. Philos., Munster, 1906). Claeys-Boü̈aert, La Summa Sent. atparticnt-elle à H. d. S. Victor? (Rev. hist. eccl., I909). EsplasBenger, Die Philos. d. Petrus Lombardus und ihre Stellung im zwölften Fahrh. (Beitr. z. Gesch. d. Pailos. d. Mittelalt., iii., p. 5, Igor). Traces the sources of the Lombard's philosophical teachings; useful. Vacandard, Vie de S. Bernard, 2 vols., 1895. Studies also the saint's place as a doctor. G. Rober T, Les écoles et l'enscignement de la théologie pendant la première moitié du xiie s., Paris, Igog.

\section{Scholastic Mrsticism.}

197. Mysticism and Scholasticism.-The development of orthodox mysticism was parallel to that of scholastic philo-

1 "Nominalism is the old enemy, as it is in fact the doctrine which, because it accords best with reason, is opposed most to the axioms of Faith. Dragged successively before numerous councils, nominalism was condemned in the person of Abelard. as it had been previously in the person of Roscelin" (HAUrÉAu, Hist. philos. scol., i., p. 292).

${ }^{2}$ In regard to Abelard, Fr. Portalie rightly remarks that the Church had every reason to take vigorous action, for she found herself in the presence of a strong and progressive theological movement which was offering a shelter to dangerous errors.

${ }^{3}$ Cf. Willmain, Gesch. d. Ideal., ii., p. 360. 
sophy and theology, was in fact an offshoot of the latter; but its first appearance does not date farther back than the twelfth century. For the scholastic theologians speculative mysticism constituted a department of the supernatural order; it was quite distinct from scholastic philosophy and therefore does not properly belong to this history. If we speak of it here, it is simply because, in the first place, most of the great medieval scholastics were philosophers, dogmatic theologians and mystic theologians all at once; and because, secondly, alongside Catholic and supernatural mysticism, there appeared in the Middle Ages mystic tendencies claiming to be natural, which may not be passed over in silence. A few leading notions will elucidate these distinctions.

198. Practical and Speculative Mysticism. - It is not easy to give a good definition of Mysticism. The word is from the root $\mu v$, which suggests the notion of closed up, concealed, secret, and designates in general a tendency which urges man to an intimate, personal, hidden union with the Infinite. Practical mysticism springs directly from religion. It flourishes more and more, according as the religious sentiment is deeper and more universal. On the other hand, religious scepticism withers and kills mysticism.

Speculative mysticism we may describe as a science that rests on this unitive tendency and has for its object to describe the relations of direct communication between the soul and God, and to explain the universal order of things by the union thus effected.

The communication in question is taught in the first place to involve contemplation, which reveals to the intelligence the grandeur and majesty of the Infinite, and to culminate in an affective movement of the soul rejoicing in the peaceful possession of God. This state of calm security induces a sort of passivity which may assume various forms (apathy, quietism, annihilation of consciousness, etc.).

In the next place the communication is understood to be direct. That is to say, it is not based on an ordinary, analogical knowledge of God, such as we have from creatures; but on an immediate intuition. Hence all the mystics recognize, besides senses and reason, other modes of knowledge, all of which we may include under the general title of internal visions. They admit, moreover, corresponding movements in the affective or emotional part of the soul. It is not so much that man casts himself on God; rather he is sought by God; God takes possession of him. 
Finally, this union becomes the culminating point of all psychic activity; all other pursuits, especially all philosophical studies, are subordinated to it.

199. Division of Mysticism.--Starting from the notions we have just outlined, we may divide mysticism, firstly into two great branches, pantheist and individualist, according to the way in which the direct communication of man with God is thought to take place. Some mystics conceive it as effected by an extraordinarily exalted activity of our cognitive and appetitive faculties. Others go farther in their effort to make the Divine commerce with the soul more intimatestill: they identify the very substance of man himself with God: they deify man to unite him with the Infinite.

A second division of mysticism will be into supernatural and natural, or into theological and philosophical, according as the mystic intuition is conceived to be due to the supernatural intervention of God, or regarded as merely the highest manifestation of the natural psychic life. The Indian philosophers, Plotinus and Scotus Eriugena, are representatives of philosophical mysticism; the scholastics professed theological mysticism. It is important to note that the principal historical forms of philosophical inysticism are likewise fantheistic.

200. General Characteristics of Mysticism.-What we have said will explain certain general traits that characterize all science based on mysticism. The higher planes of mystic contemplation. enveloped as they are in vague mysteriousness, lend themselves easily to the garb of imaginative and poetic description. Hence the mystic's liking for allegory, personification, parable, symbolism. in his writings. Again, since the mystic's highest aim is union of the soul with God, if he happens to be a philosopher he is sure to concentrate his attention on psychological and moral questions. Furthermore, the spirit of the mystic will pervade his philosophy through and through, giving it a peculiar tone and flavour all its own: following the advice of St. Augustine, he will study the interior man; and he will readily accentuate the dualism of soul and body, and the conflict the soul must sustain to free itself from the trammels of sense. Finally, the more exalted mystics display a haughty contempt for philosophy and philosophers. They regard these as demented creatures who are astray as to the meaning and value of human science: an evident exaggeration of 
an equally evident truth. These mystics dethrone reason and set up in its place affective, sentimental faith.

201. Two Forms of Medieval Mysticism.-The Middle Ages were ages of faith. And hence they constitute the golden era of mysticism: practical mystics buried themselves in cloisters to lead lives of deep devotion; speculative mystics wrote books. These writings bear witness to the existence both of indiridualist and of pantheist mysticism. The latter first appears in the person of Scotus Eriugena, then disappears, but comes to light again in the twelfth century (Art. III.). The former is a current of orthodox, theological mysticism which bases the ascent of the soul towards God and perfection on supernatural grace, the communication of which begins in the present life. Unless they were prepared to be illogical, scholastics could not admit a natural or philosophical mysticism. For, according to their account of the genesis of human knowledge, the intellect cannot know, and as a consequence the will cannot love, God, except through the medium of creatures. But such an indirect knowledge of the Infinite can furnish no basis for that direct communication which is the central phenomenon of the mystic life. Hence it is that those "mystic ways," those visions and ecstasies by which the soul is rapt up in God, and which are depicted in such glowing and enthusiastic language by a St. Bonaventure or a Hugh of St. Victor, must be essentially different from the philosophical knowledge of God which is reached by way of negation and transcendence or eminence. They are steps of a nobler ladder which it is not given to man to climb without the supernatural aid of grace from on high. ${ }^{1}$ It may be set down as generally true that scholastic philosophers, as theologians,

${ }^{1} \mathrm{M}$. Delacroix has established between scholasticism and mysticism relations which seem to us to be based on a confusion of ideas. "Scholasticism," he writes, " is inseparable from mysticism : for it is science applied to religion and starts from the assumption that everything may be made intelligible by theology and that therefore every thing is reducible to theology ; but the assumption itself implies that the thinker feels his dependence on God and is impelled to explore this feeling of dependence. Personal piety is thus made a condition requisite for science; and since this piety is identical with the feeling of the Divine, with the ascetic contemplation of the commerce between self or subject and God as object, it necessarily follows that Mysticism is at the very root of Scholasticism itself" (Essai sur le mysticisme spéculat. en Allem. au XIVe s., p. ro). The writer here confounds scholastic theology with scholastic philosophy, and is mistaken in thinking that piety is a necessary condition for philosophizing after the manner of the scholastics. 
had all their moments of mystic elevation. There is nothing incompatible in being all at once a scholastic philosopher, scholastic theologian and mystic.

202. Sources of Medieval Mysticism.- The mystic elevations of St. Augustine (99) found an echo in the Middle Ages. The Stromata and the Pedagosus of St. Clement of Alexandria, the De Institutione (oemobiom of Cassian and the I) Vita Contemplatica attributed to Prosper of Aquitaine, were additional sources of information to the medieval mystics. But it was primarily and mainly to Pseudo-Denis the Areopagite (in the version of Scotus Eriugena) that these had recourse; and we have already remarked that pantheistic as well as individualistic mysticism may be derived from the works of Pseudo-Denis ( $\mathbf{0 5}$ ). Finally, from the close of the twelfth century the influence of Arabian mysticism $\mathbf{2 1 5}$ sqq.) began to make itself felt.

203. First Scholastic Mystics. St. Bernard. - The ordinary practice of asceticism, rather than the higher theme of mysticism proper, was studied by Paulinus of Aquilein, Odo of Cluny, St. Ansela of Canterliury, Hildebert of Lavardin and others of lesser importance. Some mystic theories are also to be found in RUPERT (AF Deutz, Honorius of Autun, ODO OF TOURNAI and WALTER OF LILLE; but the systematic study of the higher spheres of perfection originated in the twelfth century.

The first great name that occurs is that of ST. BERNARD (Doctor Mellifluus, I091-1153), who may be regarded as the founder of scientific mysticism. For him science is nought but a means of spiritual regeneration; the supreme object of life is the love of God: this comprises four degrees; and it is reached by twelve stages of humility.

HONORIUS OF AUTUN is a complex personality, a solitary writer who lived through the second quarter of the twelfth century in the household of Christian, abbot of Ratisbon; a popularizer rather than a scholar; a poet too at times; his literary output - on the most varied topics-amounts to no less than thirty-eight distinct works or opuscula. ${ }^{1}$

204. Mysticism of the School of St. Victor. Hugh of St. Victor-For a complete code of the laws that govern the ascent of the soul to God, we must turn to the great sanctuary of medieval mysticism, the monastery of St. Victor. Hugh of Sit. Victor was 
the initiator and prime representative of a remarkable current of thought that pursued its course through the whole of the twelfth century. Born at Hartingam, in Saxony, in the year I096, he first entered the monastery of Hammerlève and then the convent of St. Victor at Paris. Here, about the year I I 25, he assumed the direction of studies, holding this office till his death in II 4 I.

Besides his works on the Scriptures, his De Sacramentis Christianae Fidei (191) and his Eruditio Didascalica, a treatise on method, Hugh has written numerous works on mysticism, such as De Arca Nö̈ Morali, De Arca Nö̈ Mystica, De Vanitate Mundi, De Arrha Animae, De Amore Sponsi ad Sponsam, etc.

In regard to philosophy he does not adopt, as is commonly thought, the attitude of haughty contempt that characterizes both his own successors and a group of ascetic theologians who were his contemporaries. Hugh was himself a philosopher as well as a mystic. His Eruditio Didascalica is a sort of encyclopedic review of all the known sciences (126). Developing the plan suggested by Boëthius, it worked out a classification which clearly inspired much of the speculation put forth in the thirteenth century on the divisions of human knowledge. Moreover, Hugh took part in the philosophical discussions of his own time. $\mathrm{He}$ gives us an atomistic interpretation of the matter and form theory on the constitution of bodies; he discusses the Universals problem; and in general he follows the trend of the current Augustinian or pseudo-Augustinian theories.

But for him, knowledge is not an end in itself; it is only the vestibule of the mystic life. Mystic theology deals with the faith both in its objective data (fides quae creditur, materia fidei) and particularly in the affective feeling to which it gives rise (affectus, fides qua creditur). After the manner of St. Augustine, whom he follows closely, Hugh describes the various steps or stages in the ascent of the soul towards God. Cogitatio, which sees God in the material world ; Meditatio, which discovers Him in the interior of the soul ; Conteinplatio, which gives us a supernatural intuition of $\mathrm{Him}$ : such are the three functions of the threefold eye of the soul. ${ }^{1}$ Hugh's interpretation of the Scripture is moral and mystical : his thought moves perpetually in a world of allegory.

1 There are numerous other states leading up to that of perfect contemplation : soliloquy, circumspection, rapture, etc. 
After Hugh's lifetime, mysticism flourished exuberantly at St. Victor. A growing tendency asserted itself to regard the act of faith as a purely affective sentiment, even independent of the motives of credibility. Philosophy came to be regarded as useless surplusage; and we can understand how the disputes between the schools of Ste. Geneviève and Notre Dame about realism, contributed to foster this attitude by bringing discredit on scholastic discussions. And once philosophical speculation fell into disrepute with the mystics, scholastic theology itself, as speculatively expounded in the works of the Summists, was also condemned and discarcled.

RICHARD OF ST. VICTOR, prior of the convent from II 62 to 173 , was a pupil of Hugh, and is almost as distinguished as his master. He is the author of: De Exterminatione Hali et Promotione Boni: De Statu Interioris Hominis; De Enuditione Interioris Hominis; De Praeparatione Animi ad Contemplationem: Libri Quinque de Gratia Contemplationis; De Arar Mystica. Contempt for speculative learning is manifest in the writings of ACHARD and GODFrEY of St. Victor. It culminates in Richard's successor, WALTKR, for whom dialectic is the devil's art. He is the author of a book, referred to above (190), In (Quatuor lablyrinthos firanciate.

The same tendencies may be traced outside the Convent of St. Victor, in the works of ADAM THE PREMONSTRATENSIAN and ADAM OF PERSEITINE.

205. Bibliography.-A. ENures, Honorius Augustodunensis. Beitrag zur (ieschichte des geistigen Lebens im 12 Fahrh. (Munchen, 1906). Collects materials for history of this hitherto little-known personage. On his stparate works, see numerous monographs of J. KFLLE, IgoI-Igo6, in the Setzungsber. der K. Akad. d. Wissensch. in Wien. Philos.-histor. Klasse. VACANDard, Vie de S. Bcrnard, abbe de Clairnaux, Paris, 1895,2 vols. Good. A. Mignon, Les Origines de la scolastique et Hugues de S. Victor. Good. Quite a number of unauthentic works were circulated in the Middle Ages as writings of Hugh. Cf. HAURÉAU, Les oeuvres de Hugues de S. Victor, 1886, and Not. et Extr., etc., passim. J. Kilgenstein, Die Gotteslehre d. Hugo von St. Victor nebst cinen einleitenden Untersuchung über Hugo's Leben und seine hervorragendsten Werke, Wurzburg, I898. BuoNamici, Riccardo da S. Vittore, sagi di studio sulla filosofia mistica del sec. XII, Alatri, 1898.

For works of Hugh of St. Victor, see Migne, t. 175-177. For those of Richard, t. 194. For works of St. Bernard, see Mabillon's edition, 1696. 
ART. III.-THE NON-SCHOLASTIC PHILOSOPHIES OF THE TWELFTH CENTURY.

206. Various Forms of Non-scholastic Philosophy.-Every theory that denies the spirituality of the soul, or the personality of man, or the distinction between God and the creature, is subversive of the fundamental positions of scholasticism. Hence we must classify as adversaries of scholasticism all who teach materialism, or the transmigration of souls, or atheism, or pantheism. $^{1}$

207. The Materialism of the Cathari and the Albigenses.The Cathari and the Albigenses, two sister sects, exceedingly widespread in the twelfth century throughout Italy and France, professed, in opposition to scholastic monotheism, a dualism borrowed from the Manichaeans, which was really tantamount to atheism. Alongside and independent of God, the principle of Good, they recognized also a principle of Evil.

At the same time the Cathari taught in their psychology that the human spiritus perishes with the body, just as the spiritus of the lower animal. " $\mathrm{Hi}$ autem volunt dicere ideo resurrectionem non futuram, quia anima perit cum corpore, sicut nostri temporis multi falsi christiani, imo haeretici." 2

Alan of Lille, who directly attacked them, has preserved many of their arguments in his works. Thus, they claim in favour of their teaching the opinion of many scholastics (e.g., Adelard, William of Conches), that all vital principles are immaterial; arguing thus: "Si incorporalis est (spiritus animalis) sicut spiritus humanus, qua ratione perit cum corpore et non spiritus hominis ? Qua enim ratione aut vi conservabitur potius anima humana in corpore quam anima bruti?" 3 Their favourite sources, however, were Epicurus and Lucretius, whose materialistic atomism they reproduced. And, having disposed to their satisfaction of the immortality of the soul, they boldly denied the doctrine of reward and punishment for good and evil. The conduct of

${ }^{1}$ We are happy to be able to quote in support of this classification the authority of Professor Baeumker of Strassburg : "Any historical system which in its thoughtcontent and in its method of presentation falls completely outside the limits of this scholastic tradition-as, for instance, mysticism and certain pantheistic systems, may indeed be included in medieval, but not in scholastic philosophy" (Die Europäische Philosophie des Mittelalters, p. 290).

${ }^{2}$ Alan of Lille, Contra Haeret., i., 27 (col. 238). $\quad{ }^{3}$ Ibid. 
their lives was an unabashed application of these materialistic principles. $^{1}$

From Alan of Lille we also learn that according to Albigensian theory the souls of some privileged and superior men are really fallen angels, condemnerl to abide for a long period of time in successive generations of human bodies (Pythagorism). ${ }^{2}$

208. Pantheism. - The intellectual impulse which sooner or later works out an idlea into its ultimate logical consequences, was bound to push realism into pantheism. And it did. A

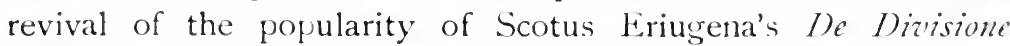
Naturae, marks the appearance of pantheism in this period.

(I) The Pantheism of Chartres.-Some time between I I 45 and I I53, Bernard OF Tours (Silvestris), an intimate friend of the Chartres teachers, composed a treatise De Mundi (iniversitate, which he dedicated to Theoderic of Chartres. It bristles with Neo-Platonic and Pythagorean theories. On a basis of Divine monism and emanation, it builds up a philosophy closely resembling the Alexandrian systems. "Ea igitur noys summi et exsuperantissimi Dei est intellectus et ex ejus divinitate nata natura." ${ }^{3}$ It deduces its metaphysics from the Pythagorean monas. The whole volume De . Mundi ('niversitate is an allegorical poem, part rhyme and part blank verse, in which metaphysical concepts are all anthropomorphized and transformed into so many stage actors.

(2) Amalric or Amaury, of Bine and the Amauritian Sect.AMALRIC OF BENE, born in the neighbourhood of Chartres in the second half of the twelfth century, was undoubtedly influenced by the Chartres theories, but he spent his life at Paris, where he taught in philosophy, and afterwards in theology, a sort of pantheism intermingled with theosophic rationalism. All that is, is One; God is immanent in all things, for the being of all things is based on the Divine being. "Omnia unum, quia quidquid est, est

${ }^{1}$ Alan of Lille, Contra Hacret., i., 63. Marbodius thus describes their materialism: "Inter quos habitus non ultimus est Epicurus-Ex atomis perhibens mundi consistere molcm.--Iste voluptatem summum determinat esse-Perfectumque bonum, quo quisque fruendo beatus-Congaudensque sibi sine sollicitudine vivat;-Scilicet aut animas cum corporibus perituras-Aut nullum credens meritum post fata manere -. . Quis numerare queat regiones, oppida, vicos,-Urbes atque domos Epicuri dogma sequentes?" (Liber decim capitulorum, c. 7. Quoted by Phitrpe, Lucrice dans la théologie chrétienne, etc., p. 6-).

"Anticlaud., q. i., II, I2, 3is CD.

"De Mundi Unizers., i., z. 
Deus." Thus humanity is deified, and every man is an apparition of the Divinity just as Christ was. "Nemo potest esse salvus nisi credat se esse membrum Christi." 1 The Scripture texts that refer to the Divinity may be literally applied to each one of us. There can be no doubt about the kinship of these ideas with Scotus Eriugena's. It was detected by Amalric's own contemporaries; and both master and disciple were involved in a common condemnation. For Amalric's theories were being exploited by numerous heretical sects, so that the Church had to take action. $\mathrm{He}$ was called to account for his teachings; and he retracted before his death in 1204.

But his theories made progress notwithstanding. His deification theory was put into practice by the heretics, who publicly preached to the crowds that man, being a member of God, cannot sin, and that after a few years (about i 2 ro) every man would be the Holy Ghost! Such notions as these were persistently propagated in the early years of the thirteenth century byamong others-a certain GoDINus and a goldsmith named WILliam. Their preachings have an evident kinship with certain other extravagant theories circulated independently about the same time by one JOACHIM DE FLORIS ( $\dagger_{\mathrm{I}} 2 \mathrm{O} 2$ ); and they must have met with a willing welcome from the followers of the Evangelium Aeternum, ${ }^{2}$ who sought to identify the succession of the great periods of the world's history with the procession of the Divine persons, and to justify disorderly, immoral lives on the ground of the abiding immanence of the Divinity in human nature.

The orthodox theologians rose up against the Amauritian doctrines. An anonymous treatise Contra Amaurianos, dating from I 208 or I 2 IO, and attributed by Baeumker ${ }^{3}$ to GARNERIUS OF ROCHEFORT, ${ }^{4}$ examines and refutes their principal errors. As a source of information on the Amauritian theories it is invaluable.

${ }^{1}$ Baeumker, Ein Traktat gegen die Amalricianer, etc., pp. 386-4I4.

${ }^{2}$ Denifle, Das Evangelium Aeternum und die Commission zu Anagni (Arch. $\mathrm{f}$. Litt. u. Kirchengesch. d. Mittelalters, i., I885, p. 49).

${ }^{3}$ BAeUmKer, op. cit., p. 346.

${ }^{4}$ Garnerius of Rochefort, who was a Cistercian monk, was Bishop of Langres in I I92, and died at Clairvaux after the year I215. He composed sermons, drawing from the writings of Peter of Poitiers and John Beleth. He did not escape the influence of Eriugena, though he never fell under suspicion of pantheism. Baeumker's attribution of the treatise is rejected by Mandonnet ( $R$. Thomiste, i., p. 261), who regards Rodolph of Namur as its author. See Baeumker's reply in the Fahrb. $f$. Philos. u. spek. Theol., I894. 
These were condemned at a synod held in Paris in 1210; a number of priests and clerics were likewise condemned for having encouraged the heresies; and these censures were renewed about five years later by Robert de Courçon at Paris, and again by the I ateran Council in 1216.

(3) David of Dinant.-Independently of Amalric of Bène, David of Dinant in Belgium, or OF Dinan in France-a philosopher of whose life we know practically nothing, but whose works have won considerable celebrity-propounded an out-andout materialistic pantheism in the closing years of the twelfth century. The very title of his work, De Tomis, id est de Divisionibus (also quoted under the name of Quaternuli), suggests the influence which Scotus Eriugena's writings must have had in shaping David's pantheism. David may have been acquainted also with Avicebron's Fons Vitae, but his pantheism has nothing in common with the De Unitate of Gundissalinus. The latter work is conceived in the spirit of Scholastic individualism, and historians have been mistaken in connecting it with David's pantheism. ${ }^{1}$ We owe our knowledge of David's teaching to the criticisms which Albert the Great and Thomas Aquinas have levelled against it, and to the ecclesiastical censures of which it has been the object. God is the matter which constitutes the inmost core of things." David indeed distinguishes three classes or categories of substances: God, souls and matter; but all three are merged in one, single, numerical unity. Albert the Great has preserved his subtle line of reasoning for us: "In order that two things differ, we must find in them a common element and a differential element. But if spirit differed from matter, there would be needed a second matter in this matter, and we should thus have to go on ad infinitum." 3

The Quaternuli were condemned at a council assembled at Paris by Peter of Corbeil, Archbishop of Sens, in the year 12 Io. Five years later the Paris Faculties of Theology and Arts were forbidden to read the works of David, by Cardinal Robert de Courçon. This prohibition embraced also the works of MAURICE OF SPAIN. ${ }^{4}$

'We correct, in this sense, our Histoire de la Philos. scol. dans les Pays-bas, etc., p. 36 .

¿ Sт. Thомas, Summa Thcol., i., q. iii., art. 8, in corp.

"Alb. Maginus, S. Theol., p. ra, tr. 4, q. 20, m. 2.

: Chartul. Univers. Paris., published by Denifle and Chatelan, i., p. zo. 
Amalric of Bène and David of Dinant appear at the dawn of the thirteenth century but belong historically to the twelfth. In the thirteenth century anti-scholasticism will again be found under various forms, still attacking the triumphant scholastic system.

209. Sources and Bibliography.-BARAch and Wrobel have edited the De Mundi Universitate Libri Duo, sive Megacosmus et Microcosmus of Bernard of Tours (Silvestris) (Bibl. Philos. Mediae Aetatis, 1876).

Baeumker, Ein Traktat gegen die Amalricianer aus dem Anfang d. xiii. Fahrh. (Jahrb. f. Phil. u. spekul. Theol., r893, p. 346). This is a first-class source of information on Amauritian theories. The other sources are Caesarius of Heisterbach, William the Breton and an account of the acts of the council at which Amalric was condemned, published by MARTÈne and DuRAND, Thaesaurus Anecdotorum, iv.,p. 163. On Amalric, see Delacrorx, op. cit., ch. ii. Jourdain, Mémoires sur les sources philosophiques des hérésies d'Amaury de Chartres et David de Dinant (Excursions, etc., I888, p. 10I). Conclusions need to be revised. On the Cathari, the Waldenses and the Amauricians, see P. AlPHANDÉRY, Les idées morales chez les hétérodoxes latins au debut $d u$ xiï ${ }^{e}$ siècle (Biblioth. Ec. Htes. Études, sc. relig., xvi., I, Paris, I903). The author investigates only moral ideas, and mainly in their popular form. The ethical system of the Cathari, he tells us, is based on the principle that, sin being enslavement by matter, perfection consists in detachment from all that is corporeal. He regards the theories chronicled by Alan of Lille (207) as "deviations from the genuine teaching of the Cathari" (p. 67).

\section{Second Section. Byzantine Philosophy. ${ }^{1}$}

210. General Characteristics.-Banished from Athens by the decree of Justinian in 529, and driven out of Alexandria by the invasion of Arabs in 640, Grecian philosophy betook itself to the capital of the Eastern Empire (89-91). There it lived on all through the Middle Ages, but its development was slow and irregular, like that of the Byzantine genius itself. Although the tradition of ancient philosophy was caught up at first hand, and in its ancient form, by the Byzantine current, still its influence on this current was far more superficial than on the streams of Arabian speculation which it reached and permeated through other channels (Third Section). On the whole, the Byzantine philosophy is meagre; it is encyclopedic rather than fertile and original ; its leading exponents shelter their not very striking personalities under the great names of Plato and Aristotle.

211. Leading Representatives. - The latest exponents of NeoPlatonism, Themistius and Proclus $(\mathbf{8 9}, \mathbf{9 0})$, had intercourse with Byzantium. But we meet with no remarkable name earlier than the eighth century. In the face of the many serious difficulties 
presented by the troubled reigns of the Isaurian dynasty, ST. John DamASCEne $(† 754)$ attempted a reconciliation of Aristotelian and Neo-Platonic doctrines with Catholic teaching. His $\pi \eta \gamma \dot{\eta} \gamma \nu \dot{\omega} \sigma \epsilon \omega s$ may be regarded as a first endearour to construct a philosophic synthesis. His divisions are arranged and worked out according to a gradated order, and each division is prefaced by

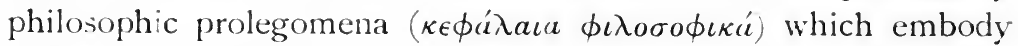
numerous Aristotelian doctrines on logic and metaphysics. The work of St. John Damascene was widely known and studied even throughout the West (181).

Michaer, PSEllus the Eldek and the patriarch Photius are the two striking figu ss of the ninth century ; especially the latter, who was a distinguished philologist as well as the leading philosopher of his time. He was an ardent promoter of Aristotelianism and criticized severely the realism of Plato.

What Photius attempted in the ninth century for Aristotle, his disciple, Arethas, attempted in the tenth century for Plato. Arethas belonged, like Nicetas the Papillagonian, and Suidas, the author of a well-known lexicon, to an enlightened and influential circle of savants who encouraged and promoted the cultured and liberal views of the Emperor Constantine VII. (Porphyrogenitus). The tenth century was indeed the brightest in the Byzantine world, as it was the darkest in the West. Still the spirit that moved the Byzantine culture of this century had not the fresh promise of originality. Its scholars had no higher ambition than to save from oblivion the grand literary legacy they inherited from the ancient world, by collecting all the works in existence in their own time. And needless to say, philosophy, no less than the other human sciences, profited much from this conserving care.

In the eleventh century the name of Michael Pseldus tire YOUNGER stands out prominently. Prime minister of Michael Parapinakes and professor at the Academy of Constantinoplea recent achievement of the Emperor Constantine MonomachusPsellus initiated a literary movement which culminated, without any break of continuity, in the Platonism of the Italian Renaisance. He was something more than a compiler: he professed an eclectic philosophy, tinged with Neo-Platonism and Aristotelianism. He wrote works on Plato's philosophy (c.g., Eis

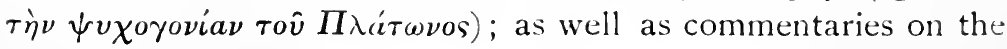


treatise of Porphyry, De Quinque Vocibus, and on Aristotle's $\Pi \epsilon \rho i$ 'E $\rho \mu \eta \nu \in i a s$.

The twelfth century, which marks the high-water level of Byzantine culture, is not so rich in philosophical literature. Its bestknown names belong to commentators of Aristotle: JOHANNES Italus, successor of Psellus at the Academy, Anna Comnena (I083-II48), daughter of the Emperor Alexis, MICHAEL OF Ephesus, a disciple of Psellus, and Eustratius of NicE. NichoLAS OF METHONE merely copied, in whole or in part, the treatise written in the fifth century by Procopius of Gaza against the

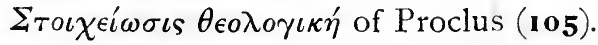

212. Relations of Byzantine to Western Philosophy.-The schism of 858 was the beginning of long ages of alienation and misunderstanding between East and West. Down to the thirteenth century, moreover, there was little or no intercourse between the two civilizations. Each of the two great families went its own way; there was no mutual interchange of knowledge or achievements. The crusades first, and more especially the fall of Constantinople in I 204, put an end to this isolation: in the thirteenth century Byzantine learning made its contribution to the development of Western philosophy.

2r3. Sources and Bibliography.-Ludwig Stern, Die Continuität der Griechischen Philosophie in der Gedankenwelt der Byzantiner (Archiv f. Gesch. d. Philos., Bd. ii., H. 2, 1896). K. Krumbacher, Gesch. d. Byzant. Litteratur, 2 Aufl.. München, I897. Articles by M. HurT in the Annales Philos. Chvétienne, I895.

\section{Third Section. Oriental Philosophies. ${ }^{1}$}

214. Philosophy among the Armenians, Persians and Syrians. -The history of philosophical theories among the Armenians, Persians, Syrians, Arabians and Jews, is more eventful and complicated than that of the Byzantine philosophy.

Little is known about the history of philosophy in Armenia. The name of one famous translator of Aristotle at least we do know: David The ARmenian (about 500 A.D.), a disciple of Olympiodorus (91).

In Persia, the hospitable court of Chozroës Nuschirwan extended a welcome to the last representatives of Grecian philosophy, Damascius The Syrian, Simplicius, and a crowd of Neo-Pla- 
tonists, on their banishment from Athens in $529(90)$. The advent of the refugees led to the initiation of a philosophical movement in the schools of Nisibis and Gandisapora. At the court of Chozroës, URANius translated Aristotle and Plato into Persian. But this current of ideas was soon arrested and there is no evidence that it ever touched or influenced Arabian philosophy.

It was the Syrians who took up the tradition of Grecian philosophy and transmitted it directly to the Arabians, and through them to the Jews. The expeditions of Alexander the Great had rooted Grecian traditions so deeply in Syria that for long ages the language of their former conquerors held undisputed sway in the religious and profane literature of the Syrians. In the fifth century, Theodore of Morsulstia, Theoderet of Crr, Ibas, Cumas and Probus, all of the famous Nestorian school of Edessa, translated Aristotle from Greek to Syriac, accompanying their versions with original commentaries. This school was suppressed by Zeno in 489; but in the sixth century the Monophysites of Resaina and Chalcis continued the work of translation. At Resaina, SER(iIUs translated the Catcorories of Aristotle, the Isaguge of Porphyry, the works of Pseudo-Denis and portions of Galen. He also composed various original treatises imbued with Neo-Platonic tendencies. JACOB OF Edessa in the seventh century, and various Nestorians of the seventh and eighth, completed other translations. The Syrian philosophers in general knew only the Urganon among Aristotle's works; and they always gave a marked preference to the Neo-Platonists, especially to Porphyry: which was only natural, seeing that he and Iamblichus were themselves Syrians by origin. This too accounts for the extraordinary popularity of Porphyry's Isagoge in Arabian philosophy, and for the numerous translations of this treatise from Syriac to Arabic. The older Greek-Syriac versions, especially those of the Resaïna school, were very defective: they were too literal, often failing to render intelligibly the sense of the original. ${ }^{1}$

215. Origin of Philosophy among the Arabians.-Even previous to the Hegira (622), and the Mussulman conquest by which they subjugated Persia and Syria, the Arabians had come into contact with the Christian civilization, "from which they received that treasure of learning they were afterwards destined to restore when

${ }^{1}$ Pollak, Entwickl. d. wah. u. juits he" 'hilns. im . Mittclalter, p. 206. 
they had made it fructify for centuries ". ${ }^{1} \quad$ The cultivation of the positive sciences, as well as the pursuit of religious knowledge, developed a characteristic Arabian philosophy, which, however, did not make any notable progress until it came into contact with Grecian thought. This was in 750, when the Abbassides replaced the Ommaīades and invited Syrian scholars to the court at Bagdad: the advent of the Syrians, under such high patronage, gave a decided impetus to intellectual culture. They proceeded to introduce the Arabians to the great monuments of Grecian philosophy by translating these from Syriac into Arabic. This movement was commenced under Caliph-Al-Mansour (753774) and was vigorously promoted by Al-Mamoun. The latter established at Bagdad, about the year 832, a school of translators under the direction of HONAÏN BEN ISAAC (the JOHANNITIUS of the scholastics, $† 873)$, a contemporary of Scotus Eriugena at the Palatine court and of Photius at Byzantium. The work of translation was continued in the tenth century by the Syrian Christians, among whom we may mention Costa BEN LuCA. And it embraced not merely works of Grecian philosophy but also works on medicine and mathematics. ${ }^{2}$ Their philosophical studies came after their scientific studies. And while the Syrians themselves confined their attention almost exclusively to the Organon (214), the translators made all the great works of Aristotle known to the Arabians. At the same time they transmitted the commentaries of Alexander of Aphrodisias, Porphyry, Themistius and Ammonius. Plato was less known, but Neo-Platonic traditions were fresh and vigorous. We meet them in one of the earliest of the translated works ( 840 at the latest), the famous Theology of Aristotle, falsely attributed to the Stagirite, being in reality a collection of the Enneads (iv.-vi.) of Plotinus, dating from the third or fourth century. ${ }^{3}$ As for Arabian commentaries on the Isagoge, over five hundred of them have been counted.

Under these influences Arabia developed a philosophy which flourished for about three centuries and a half, first in Arabia itself and afterwards in Spain.

${ }^{1}$ Carra de Vaux, Avicenne, p. 49 (Paris, I900).

2 There were also translations of certain Persian and Indian works of lesser importance (ibid., p. 37).

${ }^{3}$ A Latin paraphrase appeared at Rome in ${ }_{5} \mathrm{I}_{9}$ under the title: Sapientissimi Aristotelis Stagiritae Theologia sive mistica philosophia secundum Aegyptios noviter reperta et in latinum castigatissime redacta (quoted by CARRA DE VAUX, op. cit., p. 74). 
216. Leading Features of Arabian Philosophy.-(I) Respect for the teaching of Aristotle.-Aristotle was "The Philosopher" par excellence for the Arabians, and they possessed in a high degree the talent for condensing his doctrine. Scientists themselves, they knew how to appreciate and emphasize the empirical foundation on which his system is based. Yet, with all this, the Arabian conception of Aristotelianism is not accurate nor faithful: the number of languages intervening between the original text and the Arabic version (Syriac, sometimes Hebrew also), added to the defective method of over-literal translation, secured at best only imperfect, obscure and often misleading copies of the original. Noreover, his Arabian disciples often interpreted Aristotle through the commentaries of Alexander of Aphrodisias or the Neo-Platonists; they, furthermore, modified or gave a definite interpretation to teachings that were only vaguely suggested in the master's own writings-especially in regard to the human intellect. Finally, they combined Aristotelian theories with other elements that were entirely alien, if not even opposed to, peripateticism. This suggests a second characteristic :-

(2) A synortism peculiar to Arabian philosophy itself.-The Arabian attempt at a rational explanation of the world is based on certain theories about the emanation of the spheres and the human intellect. Accepting Aristotle's teaching on the eternity of the world, the Arabian peripatetics of the East, from Alkindi to Avicenna, tried to tone down the dualism resulting from such a view, by the theory of Emanation: and all the more readily because they found the theory propounded in a Pseudo-Aristotelian work of great celebrity, the Theology of Aristotle, referred to above. ${ }^{1}$ The theory of the extra-human existence of the human intellect has had its origin in an obscure text of Aristotle, badly translated by the Syrians and interpreted in the light of Neo-Platonic assumptions. The Arabians espoused Aristotle's conception of philosophy in its relation to the other sciences, and, after his example, devoted themselves freely to the investigation of special scientific questions: this accounts for their popularity with the scholastics. Some elements of the Alexandrian Gnosis are apparent in the Arabian teachings on mysticism, on the vov̂s, on emanation, ecstasy, etc. - so perceptible indeed as to give a fresh Neo-Platonic tinge to

${ }^{1}$ Worms, Die Lehre von a. Anfanglosigkeit d. Welt bei den mittclalt. arabischen Philos. d. Orients, etc., p. 13 . 
scholasticism as soon as the latter came into contact with Arabian culture in the thirteenth century. These Neo-Platonic elements were erroneously attributed to Plato, whom the Arabians triedin vain-to reconcile with Aristotle, in the name of unity of philosophical tradition. ${ }^{1}$ Finally, we find among the Arabians some traces of ancient Grecian science; the psychologists especially adopt the physiological theories of Galen and other Greek physicians, with all their materialistic leanings.

(3) The conciliation of Philosophic thought with Mussulman dogma was always one of the main concerns of the Arabian philosophers. It accounts for the numerous controversies between the "Motakallimîn" or orthodox Mahometan philosophers and various heretical sects which cannot be mentioned here. ${ }^{2}$ We may designate as Arabian or Mussulman scholasticism this philosophy in harmony with the Koran. ${ }^{3}$ But at the same time we must not lose sight of the fact that it had a value of its own as a rational explanation of the universe, independently of its relation to the Koran. We may indeed apply to this relation all we have said above (112, I14) about the relation of Western scholasticism to Christian dogma.

217. Oriental Branch of Arabian Philosophers Proper. Alfarabi. Avicenna. - The motazilite ${ }^{4}$ AN-NAZZAM (about 835 ) is set down as the first Arabian philosopher. He studied Alexander of Aphrodisias and espoused the latter's defence of human freedom. A little later, AlKindi ( $\nmid$ about 873), a contemporary of Scotus Eriugena, wrote, collected and translated an extensive philosophical literature, especially in the domain of logic. His writings are to be had only in recently published Latin versions, made by Gerard of Cremona and John Avendeath (226, II.). He probably recast an original Arabic version of the Theology of Aristotle.

Another philosopher of the school of Bagdad, better known to the scholastics, is Alfarabi ( $\uparrow 950)$, the greatest Arabian philosopher prior to Avicenna. He not only translated but interpreted and extensively annotated the Grecian philosophers, and has left many important treatises on the various branches of philo-

1 CarRa de VAux, op. cit., pp. 79, 272.

"The "motakallimin " were the philosopher-theologians of Islamism (PollaK, op. cit., p. 2r4).

${ }^{3}$ CaRRa de Vaux, op. cit.

"The " motazilites" were the first Arabian thinkers who attempted to " rationalize" the unquestioning, fatalistic beliefs of Mahometanism. 
sophy. Among those on logic, which testify to his profound knowledge of Aristotle, are his commentary on the Posterior Analytics, a treatise De Ortu Scientiarum, and another De Intellectu et Intelligibili often quoted in the Middle Ages. The germ of pantheism is contained in his metaphysics, which embodies the Neo-Platonic theory of Divine Emanation and issues in mystic tendencies. Alfarabi is credited by Carra de Vaux with the honour of propounding clearly the theory of the active intellect (intellectus agens) as a pure form, separate from matter. The same author describes him as "a really powerful and singular personage ... more fascinating than Avicenna, more impetuous and daring in his intellectual flights, more agile in his retorts. His thought usually attains to the elevation of the lyric; his logic is keen, clever and bold; and he gives expression to a flow of profound speculation in language that has the rare merit of simplicity and conciseness." 1

Alfarabi's successor, IBN-SinA or AVICENNA (980-1036), while also a theologian and a physician, must be regarded as one of the greatest of the Arabian philosophers." Though his life was one of many vicissitudes, he is said to have written over a hundred distinct works. He is, among all the Arabians, one of the most faithful interpreters of Aristotle. Starting with the system of Alfarabi, he freed it from many Neo-Platonic theories in order to bring it nearer to genuine peripateticism.

Among his general treatises on philosophy, we may mention the Chifâ, called by the scholastics Sufficientiae (logic, mathematics, physics and metaphysics: the Metaphysica Avicennae, published at Venice in I499, appears to be a portion of the Chifia); the Nadjat, an abridgment of the former; the Book of Theorems; the Guide to IVisdom; the Philosophy of Aroudi; the Philosophy of Ala. His special treatises deal with a variety of subjects; and he has also left numerous works on mysticism and on science (especially medicine and astronomy).

His logic, which is clear and concise, is a running commentary on Aristotle, emphasizing definition and inference. Logic is not itself philosophy but a means or instrument for attaining to philo-

${ }^{1}$ Op. cit., pp. 102 and 116.

"The "brothers of purity" who appeared about this time were encyclopedists and popularizers; they also formed a mystic sect. DIETERICI has published extracts from their writings. 
sophy. Avicenna's classification of the philosophical sciences was widely adopted by the scholastics of the thirteenth century and later. Physics, mathematics and theology, each having a pure and an applied part, constitute speculative philosophy; ethics, economics and politics constitute practical philosophy (see below, Gundissalinus).

To metaphysics Avicenna gives the place of honour in his philosophy: and the main problem that occupies him is that of the procession of Being, the generation of the manifold in the bosom of Unity. At the highest height of the metaphysical empyrean is enthroned the First Being, God, the Perfect Intelligence, the Absolute Good. From this First Being proceeds the first caused being. From the latter's knowledge of the former there proceeds "an intelligence which is next in order below the first caused being, that namely of the sphere of Saturn. But the first caused being also knows itself as necessarily caused by the First Being, and from this knowledge flows a soul which is that of the limiting sphere; and from the same caused being knowing itself as possible in itself, there comes into existence a body which is that of the limiting sphere. The procession thus goes on according to the descending astronomical order of spheres. From the intelligence of Saturn, knowing God, proceeds the intelligence of the sphere of Jupiter; from the same intelligence, knowing itself, proceed the soul and the body of the sphere of Saturn. This mode of derivation continues down to the intellectus agens, where it stops; for, observes Avicenna, there is no need that it continue indefinitely." 1

This theory of the procession of the spheres is supplemented by a theory of their motion; and both together offer a synthetic or deductive explanation of the astronomical data of the Arabians. The circular motion of the spheres has its ultimate ground and cause in the finality exercised by God, the intelligent soul of each sphere seeking the Supreme Good, by the knowledge of which they are attracted. The active intellect, which is the last engendered of those pure intelligences, governs our earth: from it proceed, through the influence of the heavenly motions, all substantial forms destined to actuate sublunary matter. The active intellect, therefore, is no mere psychological factor in the genesis of knowledge, but a metaphysical principle from which

1 Carra de Vaux, op. cit., p. 247. 
human souls emerge in the emanation process in the same way as all other terrestrial forms. As for matter, it is not, as Alfarabi taught, an outflow of the soul, but an eternal element, co-existing with God, though affected with an absolute indifference to exist or not to exist.

His theory of causes, his Aristotelian solution of the Universals problem, and especially his thesis of the individuality of substances and of the three states of the essence (ante multitudinem, in multiplicitate, post multiplicitatem), give his other metaphysical doctrines a frankly Aristotelian spirit which won for them the attention of the Western scholastics. ${ }^{1}$

In psychology Avicenna follows the main lines of Aristotle's teaching on the faculties of the soul. Though reducing their number, which the "brothers of purity" had excessively increased, he still allows himself to drift into exaggerated developments in detail. Thus in the speculative understanding (or passive intelligence, proper to each individual man) he admits five distinct states or stages, corresponding to successive actuations, -in addition to the intervention of the intellectus agens, the separated form whose illumination is necessary for all intellectual activity whatever. These stages are: the material intelligence or absolute potentiality of knowledge; the possible intelligence, endowed with primary truths; the intelligence in act, or completely prepared to receive additional knowledge; the acquired intellect, in possession of this further knowledge; the holy spirit, or mystic intuition, reserved for favoured souls. Other faculties, like the cogitativa, are submitted to an interesting analysis. Preexistence and metempsychosis are rejected. Abundant proofs are forthcoming for the spirituality and immortality of the soul. And this immortality is to be personal: another instance of the individualism by which Avicenna endeavours to counterbalance the pantheistic tendencies of his emanation theory. As with Alfarabi, so with Avicenna, philosophy leads up to mysticism, making way for numerous degrees of ecstasy and prophecy (Neo-Platonism).

218. Orthodox Theologians and Mystics. Gazali.-GAZALI (or ALGAZEL) (IO5S-IIII) is the most important of the group of orthodox theologians who opposed the philosophers in the interests of the Mussulman faith. In his chief works, The De-

${ }^{1}$ Logic, Venice edit., I508, fol. I2, V.A. 
struction of the Philosophers and The Renovation of the Religious Sciences, he rejects as heretical many of the philosophers' conclusions, especially the eternity of the world and the procession of the spheres. ${ }^{1}$ For their rationalistic science he would substitute an orthodox theology; not rejecting the services of speculation, provided it be humble, submissive, free from vain subtleties, and, above all, from the pretension to serve as a foundation for the truths of faith. Gazali's theology is that of the Koran. So too is his ethical teaching, though this bears evidences of Greek and even of Christian influences: it is also indissolubly bound up with his mysticism.

The orthodox mysticism of the Mussulman "sufis" or mystics is not a direct, exclusive product of the Koran: it is the issue of three great combining influences, the Indian, the Neo-Platonic and the Christian, the latter perhaps predominating. Gazali was endowed with a deeply mystic temperament: he studied all the degrees of the "intuitive science" which is the work of faith and asceticism, whilst ordinary knowledge is the product of senses and reason. Like the Christian mysticism, that of Gazali and the sufis is free from pantheism. And this is all the more remarkable inasmuch as it places ecstasy within the natural reach of man, while Christian mysticism holds this to be supernatural (199). ". . . Gazali and the orthodox sufis regarded asceticism as the ordinary means of attaining to science, expecting ecstasy to follow naturally, after a more or less protracted interval, on exercises of asceticism. No such doctrine, as we have already remarked, could be entertained by a Christian philosopher: the idea that God can be tracked down as it were in the inner sanctuary of His presence by a stern perseverance in rigorous asceticism, has no parallel outside India." 2

Alongside their orthodox mysticism, the Mussulmans had also from the time of Avicenna a Neo-Platonic form of mysticism, called the "illuminative philosophy," which became very widespread and prominent about the middle of the twelfth century.

219. Western Branch of Arabian Philosophy. Averroës.After the time of Avicenna, Arabian philosophy declined in the

1 The theory of the eternity or non-eternity of the world was a party shibboleth between believers and non-believers (Worms, op. cit., p. 268).

${ }^{2}$ CARRA DE VAux, Gazali, p. 207: to this work we are indebted for the exposition of Gazali's system above. 
East but began to win renown in its new home in Spain. Spain in the tenth century was the rendezvous of a variety of races; and thanks to an untrammelled freedom of speculation, it continued to foster an active and intense movement of thought for the next few centuries.

Among the Arabian philosophers of Spain the most notable

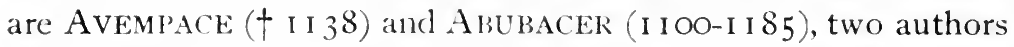
of a rather mystic tendency, and above all, AvERrokis, whose influence on Western medieval philosophy is considerable.

Averroës was born at Cordova in I 26 . He was a physician, like Avicenna, and led a life quite as eventful as the latter's. For, after he had been the recipient of honours at the court of the great, Averroës incurred their displeasure and fell into disgrace. He died in IIg8. He is, before all else, a commentator on Aristotle, for whom he had an almost superstitious reverence. And yet he does not give us the genuine doctrine of Aristotle, any more than Avicenna does, and for precisely the same reasons. Averroës is also the author of original works. Among others he wrote the Destruction of the Destruction, in reply to Gazali; the Quaesita in Libros Logicae Aristotelis; four treatises on the unity of the intellect; the De Substantia Orbis. The salient characteristics of the Arabian mode of philosophizing find in Averroès their most marked and vigorous expression. The following are his principal theories:-

(I) The intelligence of the Spheres, their emanation and orderly arrangement. The heavens are composed of numerous spheres, each endowed with an intelligence which is its form. The prime mover sets the first sphere in motion and it in turn moves the spheres of the planets. The moon is moved by the human intellect (intelligentia vel motor Lunae)-the intellect that figures in our acts of knowledge, and which has evidently a metaphysical role in the philosophy of Averroës, as in that of Avicenna.

(2) The eternity and potentiality of matter.-Whilst the Oriental Arabians followed the Neo-Platonists in consigning matter, as the principle of imperfections, to the region of non-being, Averroës, on the contrary, makes it no mere void but a universal potency containing in itself the germ of all forms. He thus professes the doctrine of a clearly marked cosmic dualism. In presence of the eternal matter, the prime mover (extractor) disengages (extractio) the active forces of the latter: the material world is 
the manifestation of an uninterrupted series of these developments: a series of generations which is necessary and infinite both $a$ parte ante and a parte post.

(3) Monism of the human intellect and denial of personal immortality.-By forcing the meaning of a text of Aristotle, Averroës makes the human intellect the last of the planetary intelligences, an immaterial, eternal form, separate from individual men, and itself numerically one. And these are attributes not merely of the active intellect but even of the material or possible intellect. The whole human understanding is impersonal and objective; it is the torch-light which illumines individual souls and thus secures for humanity a perennial participation in the great eternal truths. ${ }^{1}$

In the individual man, therefore, the act of understanding is performed in this wise: By its action on the sense images, proper to each individual, the separate intelligence effects an accidental union with the individual, without suffering any detriment to its numerical unity from these manifold unions. ${ }^{2}$

1 " Cum ex hoc dicto nos possumus opinari intellectum materialem esse unicum in cunctis individuis, possumusque adhuc ex hoc existimare humanam speciem esse aeternam, . . . ideo opportebit intellectum materialem non posse denudari a principiis universalibus natura notis universae humanae speciei" (De Anima, iii., ed. Juntes, Venice, ${ }_{55}$ o, p. $16_{5}$, R.B.).

2 " Et, cum declaratum est ... quod impossibile est ut intellectus copuletur cum unoquoque hominum, et numeretur per numerationem eorum, per partem quae est de eo quasi materia, secundum intellectum materialem, remanet ut intellectorum continuatio cum nobis hominibus sit per continuationem intentionis intellectae cum nobis, et sunt intentiones imaginatae," etc. (ibid., p. I $\sigma_{4}$, V.A.). Many historians of the Averroistic doctrine attribute unity to the active intellect alone ; representing this as acting on the material or passive intellect proper to each individual. But Averroës goes farther, as we may see from the texts just quoted. $C f$. the whole commentary on the De Anima, iii., and the opuscula on the separate intellect. So too, St. Thomas in his treatise De Unitate Intellectus, Dante in his Purgatorio, xxv., 64 , and the Averroïsts of the thirteenth century (cf.e.g., Siger of Brabant), who were careful and exact commentators on Averroës, all attribute to him the thesis of the unity both of active intellect and of possible intellect, referring to the unity of the human intelligence simply and without any limitation. The complex terminology to be found in Averroēs, in common with all other Arabian philosophers, is the source of this diversity of view as to his meaning. In places, he enumerates as many as five intellects: active, passive, material, speculative, acquired. $C f$. Avicenna (217). Renan himself, the chief writer who speaks of the unity of the active intellect alone, admits that for Averroës the material intellect-meaning by this the "capacity of knowledge"-is incorruptible, eternal, unique, similar in everything to the active intellect. See Averroès et l'Averroïsme, $5^{\text {th }}$ edit., pp. 139, I 40. 
This first stage of possession engenders in the individual the acquired intellect, which might be described as " the impersonal reason, participated by the personal being," "but there are still more intimate unions of the individual human being with the universal intellect, and notably those achieved in mystic contemplation.

This doctrine involves the extinction of the individual consciousness and the impersonality of life after death: human individuals die, but humanity is immortal in the eternity of the objective, universal intelligence. Aristotle hesitated about these inferences; Averroës definitely embraced them.

(4) Allegorial interpretation of the Koran and of philosophy.Many of the teachings of Averroës run counter to the Mussulman religion. It was indeed because the caliphs had reason to suspect his orthodoxy that they persecuted and banished him. But Averroës had foreseen the trouble; and he tried to meet it by distinguishing between the literal interpretation of the Koran, which was all right for the illiterate, and its allegorical interpretation, which was the proper one for the educated. The latter alone gives us access to the higher truths. It need not necessarily be in harmony with the literal interpretation, which is powerless of itself to show forth the splendour of the truth. This principle of a twofold interpretation was employed especially in order to reconcile Gazali's teaching on the temporal origin of the world with Aristotle's teaching on its eternity. Averroës wrote a special treatise" to effect the desired reconciliation. Here we have the first foundations of the doctrine of the two truths, so extensively promulgated by the Averroists of the Middle Ages (Second Period). The line of Arabian philosophers proper may be said to have terminated with Averroès; but their influence continued to be felt in the philosophy of the Jews, and even more perceptibly in the Western philosophy of the thirteenth century.

220. Philosophy among the Jews. Saadja.-The Jewish

${ }^{1}$ ReNan, op. cit., p. I fo.

"Published by Worms, op. cit. According to a study of M. Miguel Asin y Palacios, El Averroïsmo Teologico di Sto Tomas di Aquino (Saragossa, 1904). Averroês established between reason and faith a system of harmonical relations analogous (mutatis mutandis) to that established by St. Thomas. According to this author, Averroës would not have admitted any contradiction between the Koran and philosophy, nor between the allegorical and the literal interpretation of the former. On this point Averroës would have followed Gazali. Cf. 339, n. 
philosophy-as distinct from the mysticism that centred around the Cabala -is characterized by its blending of Judaism with Grecian philosophy. This was perceptible even in Philo's system (83) and reappeared in the Middle Ages; but for the Grecian element assimilated by the Jews the latter are indebted to the Arabians. It has even been said that "the Jews alone made a really serious study of Arabian philosophy". Among the writers on philosophy prior to the eleventh century, are ISAAC ISRAELI († 940), physician and logician; DAVID BEN MERWAN the caraite, and especially his contemporary and opponent, SAADJA (892-942), who is called the first Jewish philosopher. His principal work, "Amânât," the Book of Faith and Science, is the cornerstone of the religious philosophy of the Jews. It is an exposition and philosophical defence of the Jewish faith, composed about 933, with a view to showing the harmony that exists between reason and Jewish dogma. Its author is eclectic, drawing his arguments from Greeks and Arabian rationalists as well as from the orthodox Arabian writers. He wrote in Arabic, but there are two Hebrew versions of his work, one of which was completed in I 86 by Jehuda Ben Saul Ben Tibbon.

It was, however, chiefly in Spain that Jewish philosophy as well as Jewish science and literature flourished, owing to the large measure of freedom the race enjoyed under the rule of the Spanish Mussulmans.

221. Avicebron. Maimonides.-SAlOMOn Ben GebIrol (AviceBron or Avicebrol, Latinized forms of his supposed Arabian name, I020-1070), born at Malaga, is one of the leading Jewish philosophers. He displays much originality of thought, although considerably under the influence of Arabian NeoPlatonism. God, the Supreme Being, one and unknowable (Plotinus), is the incorruptible source of all reality. He first produces the cosmic spirit, composed of matter and form. This cosmic matter and cosmic form are two universal principles, joined in indissoluble union by the will of God and shared by every finite creature. From the unchangeable generating power of the cosmic matter and form spring all other beings, spiritual and corporeal, through an orderly series of intermediaries; and each of these finite beings bears in itself not only the common cosmic matter and form, but also proper matters and forms peculiar to itself 
and constitutive of its own specific and individual perfections. Thus there are in man, besides the cosmic matter and form, principles of corporeity and spirituality, and, notably, three distinct souls as principles of vegetative, sentient and intellectual life. All beings tend towards God or the Supreme Good, as their last end. These two ideas, pantheistic emanation and plurality of matters and forms in individual beings, are the guiding principles of Aricebron's metaphysics. The system is expounded in his monumental work, the Fons litae, the only work of his that was known to the thirteenth-century scholastics, and one that exercised a far-reaching influence on many of their speculations.

With the name of Avicebron we may link that of JoskPH BEN $Z$ LDDIK ( $\left.\dagger_{\text {I }}+9\right)$. His Microcosmos marks the transition from the religious science with which the Motakallimin opposed philosophy, to the Jewish Aristotelianism as propounded by Moses Maimonides.

Moses Mamoxines (II35-I2O4, in his Guide of the Doubting, attempts a reconciliation of Aristotle with Judaism. The true knowledge of God is the ultimate object towards which both religion and science should converge. While avoiding the excesses of the extreme allegorical method, Moses Maimonides qualifies the use of literal exegesis by the contention that the Bible text ought to be so interpreted as not to conflict with scientific truths that have been established with certitude: ${ }^{1}$ a principle that aroused animated controversies in the Jewish schools. Maimonides wished to establish the philosophy of Aristotle; but his Aristotle was the Aristotle of Averroes: with the latter's teaching indeed the system of Vaimonides presents many parallels. Of God, we may say that $\mathrm{He}$ is not, rather than that $\mathrm{He}$ is. A hierarchy of spheres connects Him with the beings of this sublunary world. The eternity of matter is not affirmed. The human intellect, however, is one and separate: only the acquired intellect is multiplied numerically in individual men. A higher illumination of this torch of truth - to which every man may aspire-brings about the prophetic state, which consists in the highest knowledge and happiness.

Maimonides is the last great representative of Jewish philosophy: The tinge of rationalism in his religious system aroused

'Poldak, of. cit. (Arih. Gesch. Philus., rgof, p. 453). 
the opposition of the more conservative theologians and led to long controversies in the Jewish schools of the thirteenth and fourteenth centuries.

222. Bibliography.-Broad, general viezes will be found in MUNCK, Mélanges de Philosophic juive et arabe, etc., Paris, $\mathbf{1 8 5 9}$; and in articles by Stein in the Arch . f. Gesch. d. Philos., vii., 3, p. 353, I894: pp. 4I2 sqq., I898: p. 379, I899. J. Pollak, Entwicklung d. arab. u.jüdischen Philos. im Mittelalter (ibid., xvii., pp. rg6, 433). Good. Boer, Geschichte d. Philosophie in Islam (Stuttgart, rgor). Excellent. C. Sauter, Die peripatetische Philosophie bei den Syrern u. Arabern (ibid., xvii., p. 5r6, 1904). Forget, Les Philosophes Arabes et la Philosophie scolastique (Congrès scient. internat., Brussels, I895, p. 233). Horten, Das Buch der Ringsteine Farabis, etc. (Beitr. z. Gesch. d. Philos., Münster, I9o6). Brockelmann, Geschichte d. Arabischen Litteratur, Bd. i., ii. (Weimer, I898-I902). CARRA DE VAux, Avicenne, Paris, Igoo. Good; contains also a history of Avicenna's forerunners. Same author: Gazali, Paris, 1902. Deals also with Mussulman theology and mysticism. Horten, Das Buch der Genesung d. Seele (tr., Leipzig, 1907-1909). Miguel Asin has published a critical study: Algazel, dogmatica moral ascetica, Zaragoza, rgor, and promises a technical dictionary of Mussulman philosophy and theology. Steinschneider, Alfarabi des Arabischen Philosophen Leben und Schriften (Mem. of the St. Petersburgh Imperial Academy of Sciences, 7 th series, vol. xiii., 4, I869). Worms, Die Lehrev. d. Anfanglosigkeit d. Welt bei d. mittelalt. arab. Philos. d. Orients und ihre Bekampf. durch d. arab. Theologen (Beiträge 2. Gesch. d. Philos., iii., 4). Examines the influence of NeoPlatonic and Aristotelian teachings on the question. Renan, Averroès et l'Averroisme, 5 th edit. First part. Good. D. NEUMARK, Gesch. d. jüdischen Litteratur d. Mittelalters nach Problemen dargestellt (Berlin, I898), i. and ii. GutTmann, Die Religionsphilosophie des Saadja, Göttingen, I882. Studies Grecian and Arabian sources. W. ENGELKEMPER, Die religionsphilosophische Lehre Saadja Gaons über d. hl. Schrift. Apologetic study of the third part of the Amanat. Guttmann, Die Philosophie d. Salomon ibn Gabirol, Göttingen, r889, and introduction to Wittmann's monograph referred to, 310: Dr. Whitrmann, Zur Stellung Avencebrol's (Ibn Gebirol's) im Entwicklungsgang d. arabischen Philosophie (Beitr. z. Gesch. Philos. d. Mittel., v., r, Münster, 1905). Shows Avicebron's deviations from Plotinus. Max Doctor, Die Philosophie des Fosef (Ibn) Zaddik, etc. Münster, 1895 (Beitr. z. Gesch. d. Philos. d. Mittelalters, ii., 5). Steinschneider has written many excellent works on Arabian Philosophy.

In the fifteenth and sixteenth centuries there were published Latin versions of Alfarabi, Gazali, Avicenna and Averroës. Of the latter especial y there were many editions, and his commentaries were included in editions of Aristotle. But all those works have become rare, and critical editions are badly needed. The works of Isaac Israeli were published in Latin in I515-16. The Amânât of Saadja was published in Arabic by Landauer; a Hebrew edition in 1562 and again in 1789 , and a partial German version by Block in 1879 . Dieterici, Die sogenannte Theologie d. Aristoteles, 2 vols., Leipzig, r882-83, text and German translation. Dr. A. NAGY has edited Alkindi's opuscula, Die philosophischen Abhandl. des Al-Kindis, I897 (Beitr. z. Gesch. d. Phil. d. Mittelalt., ii., 5). 


\title{
SECOND PERIOD.
}

\section{MEDIEVAL PHILOSOPHY IN THE THIR'TEENTH CENTURY.}

\section{CHAPTER I.}

\author{
GENERAL VIEW
}

223. Western, Arabian, Jewish and Byzantine Philosophies.The thirteenth century is the golden age of medieval philosophy, and the West is the seat of its greatest triumph. At the end of the twelfth century. Western philosophy came into contact with the Arabian, Jewish and Byzantine philosophies: to its own exclusive advantage. Indeed we may regard the Arabian and Jewish philosophies as having run their course; while the Byzantine genius slumbered on to the Renaissance.

The line of Arabian philosophers became extinct with Averroës: the mystics who succeeded him are of very minor importance in the history of philosophy. Nor did the Jews do any further original work. The discussions on the philosophy of Maimonides were confined to the synagogues of Provence, Catalonia and Arragon, whither the Jews had been driven by the fanaticism of the Almahades; and although the philosophers triumphed in their controversies with the theologians, they closely adhered to the Guide of the Doubting. Then also the Jewish writers fell more and more completely under the ascendant of Averroës. The works of SAMUEL BEN TiBbon (The Opinions of the Philosophers, early in the thirteenth century), JUDA BEN SAlomo CoHen, a protégé of Frederick II. (The Search for IVisdom, i 247), Falandera (a Spaniard, born about I 226 ), GErson BEN SALOMON (Gate of Heaven, second half of thirteenth century), are little better than encyclopedias of the teachings of Averroës. Numerous Hebrew versions, dating from the thirteenth 
century, also bear witness to the esteem in which the works of Averroës had come to be held by the Jews of this period.

The output of Byzantine philosophy in the thirteenth century is represented by the work of a few men who were compilers rather than original thinkers: NICEPHORUS BLEmmides (middle of thirteenth century) and GEORGE PACHYMERES (1 242-I310). The extent of his scholarship has won for the former of those the title of Philosopher ( $\left.\dot{o} \phi \lambda \lambda^{\prime} \sigma o \phi o s\right)$. The latter wrote a compendium of Aristotelian philosophy and published a well-known paraphrase of the works of Pseudo-Denis. But these efforts are very poor in comparison with the great syntheses of Western scholasticism. It is, therefore, mainly to the latter that we shall devote our attention in the history of the present period.

224. Division of the Second Period.-Scholasticism did not win without a struggle; it had to wage an intellectual crusade against powerful rival theories. Two chapters will deal respectively with : The Scholasticism of the Thirteenth Century (Ch. III.); The Anti-scholastic Philosophies of the Thirteenth Century (Ch. IV.).

Then there were secondary philosophical currents, such as the experimental, the Neo-Platonic, the theosophical. These were represented by some striking, though isolated personalities. It will be convenient to place these in a class apart (Ch. V.). For, on the one hand, they introduce elements foreign to scholasticism into their conception of the universe, while they retain many of the leading scholastic principles; and on the other hand, their systems can hardly be described as anti-scholastic, for whenever they joined in the struggle between scholasticism and Averroissm their attitude towards the latter philosophy was consistently aggressive. Their systems had a well-marked individuality of their own, and they did much to foster the intense intellectual activity of the thirteenth century.

Before taking up these divisions in detail we must sketch briefly, in general outline, the scientific and philosophical renaissance of the thirteenth century (Ch. II.).

225. General Sources and Works on Western Philosophy in the Thirteenth Century.-One of the chief sources is the Chartularium Universitatis Parisiensis, edited by Denifle and Chatelain, first two vols., Paris, r889I89 I, containing documents relating to the history of the University of Paris from 1200 to 1350 : a work of the highest value not only for the history of the organization of the University, but also for information on the philosophical doctrines of the thirteenth century. The scholia published in the large Franciscan edition of the 
works of St. Bonaventure (Quaracchi, I8\$2-1902) contain a number of doctrinal documents in which the theories of st. Bonaventure are compared with those of the other leading cholastics of the thirteenth century. Among the general reviews of the grat doctrinal movement, scholastic and anti-scholastic, of the thirteenth century, we may set down the splendid work of Pére Mandonnet, Siger de Brabant et l'averuisme latin au xibie siècle, part ii. (and edit., Louvain, in preparation). Hurter, Nomenchater Litterchilus (rog-1563), Innsbruck, Igo6. 


\section{CHAPTER II.}

THE PHILOSOPHICAL RENAISSANCE - OF THE THIRTEENTH CENTURY.

THE sudden and widespread outburst of philosophical speculation which lights up the opening years of the thirteenth century, is traceable to three main causes: (I) the introduction of the Western intellectual world to a rich and hitherto unknown philosophical literature; (2) the creation of the Universities, especially of Paris and Oxford; (3) the rise of the mendicant orders in the Church. To those extrinsic causes we may add an internal factor: the vital force developed in philosophical speculation by the preparatory labours of the preceding period ( $\mathbf{9 5}$ ).

\section{$\S$ I. The New Philosophical Revival in the West.}

226. History and Chronology of the New Latin Translations. -For the second, or even the third time, the West discovered a portion of the philosophical treasures of ancient Greece. At the same time it came into contact with the genius and the works of a strange race. All these treasures reached the Western philosophers in Latin translations. These we may divide into three groups :-

I. Translations of Greek Works.-Here we must carefully distinguish those made directly from the Greek, from those that came through the Arabic.

(I) The Greek-Latin versions are the best. During the twelfth century, French scholars visited Greece, Sicily and the East. Then the capture of Constantinople in I 204 brought East and West into relations of closer intercourse. Yet the translations made directly from the Greek were less numerous and less known than those made through the Arabic.

Prominent among the translators from the Greek is Robert Grossetête (1175-1253), professor at Paris and Oxford, and 
afterwards Bishop of Lincoln. He is the author of a Breve Compendium in VIII Libros Physicorum, ${ }^{1}$ a commentary on the Analytica Posteriora and an original treatise, Summa Philosophiae, ${ }^{2}$ often confounded with the De Divisione Philosophiae of Gundissalinus. According to Herman the German, he wrote a commentary on the Nichomachaean Ethics, with possibly a translation, which, however, if it existed, has never been discovered. ${ }^{3}$ Jomn Basingstock and Tiomas of Cantimpré have left fragmentary translations from the Greek. Albert the Great used Latin versions of the Phacdo and the Weno. An unknown writer of the second half of the thirteenth century made a little-used version of the Hypotyposes Pyrrhonienses of Sextus Empiricus: ${ }^{4}$ of whom we notice a like ephemeral appearance in the philosophy of the Byzantine, Cabasilas, early in the fourteenth century (see Third Period).

Special mention must be given to the Dominican, William OF MOERBEkE, who undertook, at the request of St. Thomas, the task of translating all Aristotle, ${ }^{5}$ or revising existing translations of certain portions. The great doctor-to the credit of his critical exactness be it said-would have nothing to do with translations made from the Arabic: in his eyes they had no sufficient warrant of fidelity." William of Moerbeke, born

${ }^{1}$ Printed in Venice, $1498-1500$; and in Paris, 1538.

2 This treatise is of considerable historical importance: various English versions of it are extant. It was noticed and identified by BAUr, D. Gundissalinus de Divisione Naturae, p. 153 (242).

3 “Et postmodo reverendus pater magister Robertus Grossi capitis, sed subtilis intellectus, Linkolniensis episcopus, ex primo fonte unde emanaverat, greco videlicet, ipsum est completius interpretatus et grecorum commentis praecipuas annexens notulas commentatus" (Prologue to Herman's version of the Ethics). Cf. MARChesi, L'Etica Nicomachea nella tradizione latina medioevale, 1904, p. 57. HAUREAU attributes to Robert certain commentaries on the mystical theology of Pseudo-Denis (Hist. Phil. scol., ii., I82).

${ }^{4}$ Jourdain, Excurs. hist., etc. (I888), p. I9I ; Baeumker, Arch.f. Gesch. Philos., iv., p. 574 (I $89 \mathrm{I})$.

${ }^{5}$ William of Tocco says in his life of St. Thomas: "Scripsit etiam super moralem et super metaphysicam, quorum librorum procuravit ut fieret nova translatio quae sententiae Aristotelis contineret clarius veritatem" (Acta Sanctorum. I643, Mensis Martii, i., 665).

${ }^{6}$ According to a hypothesis of Marchesi, op. cit., p. 6o, st. Thomas approached two Hellenists of his order, William of Moerbeke and Henry of Brabant, suggesting a division of the enormous task, in order to make sure of its achievement. The claim in behalf of Henry is established by Aventinus (Anno Christi r271, Henricus Brabantinus, dominicanus, rogatu D. Thomae e greco in latinam linguam, de verbo 
about I 2 I 5, orientalist and philosopher, Archbishop of Corinth from 1278 to his death in I 286 , was one of the most distinguished literary men of the second half of the thirteenth century. $\mathrm{He}$ translated all the works of Aristotle, notably the Politics, of which he was the first translator. His versions of the Liber de Causis and of the Elementa Theologica of Proclus became the main sources from which the thirteenth-century Neo-Platonists drew their inspiration. William's versions are literal; though wanting in elegance, they are careful and accurate and may still be consulted with profit. ${ }^{1}$

BARTholomew of Messina, who lived at the court of Manfred, king of Sicily, has left a version of the Magnorum Moralium; also $^{2}$ of the Problemata, the Liber de Principiis, the De Mirabilibus Auditionibus, the Physionomia, the De Signis, informing us that these translations were made at the king's order. Nicholas OF SiCILY, who translated the Liber de Mundo, and Durandus of AUvergne are of less importance. Certain Italian manuscripts contain, besides, anonymous versions of the Physics, the De Anima and the De Coelo et Mundo. ${ }^{3}$

ad verbum, transfert omnes libros Aristotelis, Annalium Boiorum, Lipsiae, r71o, I, vii., 9, p. 673); not so solidly, however as in the case of William. On the latter's behalf we have the contemporary testimonies of Roger Bacon, dating from 1272, and of one Bernard Guidon (Fr. Wilhelmus Brabantinus, Corinthiensis, transtulit omnes libros naturalis et moralis philosophiae de greco in latinum ad instantiam fratris Thome, Arch. Litt. u. Kirchengesch. Mitt., ii., 226). See other sources, MarciesI, p. 6r. Henry of Brabant is certainly the translator of a portion of the Book on Meteors, and Marchesi also connects his name as translator with the Liber Ethicorum which St. Thomas used as basis for his commentaries on the moral teaching of Aristotle. Marchesi, without indicating proofs, identifies Henry of Brabant with the Henry Kosbien mentioned by Echard, Scriptores Ordinis Praedicatorum, i., $46 \mathrm{~g}$. But he proves clearly his contention that the Nichomachaean Ethics form a group, distinct from the other writings of Aristotle, and separately known to the scholastics of the end of the thirteenth century through the following five sources: (I) Greek-Latin versions: (a) the Ethica Vetus (2nd and 3 rd books), anonymous, but possibly coming from Boëthius; (b) the Ethica Nova (rst book), which appeared early in the thirteenth century; $(c)$ the Liber Ethicorum, referred to above, containing all the books and not earlier than St. Thomas' time. (2) Arabic-Latin versions: $(a)$ the middle commentary of Averroës on the Ethics, translated by Herman the German in 1240 (Liber Minorum Moralium, Liber Nichomachiae); (b) a popular compendium, by the same, translated into Tuscan by Taddeo in the second half of the thirteenth century and used by Brunetto Latini for his Thaesaurus. MARchesi, op. cit., p. 26.

'Suseminl, who has published a critical edition of Aristotle's Politics, has annexed to it the version of William of Moerbeke.

2 In a Paduan codex of the fourteenth century, described by MARCHEsi, p. 9.

${ }^{3}$ Marchesi, pp. II, I5. 
The scholastics of the thirteenth century were also acquainted with certain Byzantine works. For instance, Albert the Great and St. Bonaventure had the treatise of EUsTRATIUS (211) on the Ethics of Aristotle, in the version of some unknown translator. Conversely, the Byzantines, on coming into contact with the West, translated some Latin works into Greek. The first of these Byzantine translators was Maximus Planudes (I $260-$ I 3 IO) whom Andronicus II. sent on a scientific mission to Venice, I 296. He translated the works of Cicero, Macrobius and Boëthius. His version of the De Consolatione Philosophiae is still used in teaching the elementary humanities.

(2) Arabic-Latin versions of Greek works.-Ancient Greek philosophy found its way to the IVest mainly through Arabian channels: translations through the Arabic to Latin were earlier known and used than translations directly from the original Greek. When we remember that the thought of Aristotle had to pass from its original emborliment in Greek, through Syriac, Arabic, Hebrew - and sometimes a vernacular in addition ${ }^{1}$ before it came to be expressed in I atin, we need not be surprised at the preference shown by the scholastics for versions directly from the Greek, in comparison with the older versions through the Arabic. For these latter all conformed strictly to this stereotyped canon of translation: "The Latin word to cover the Arabic word as the piece covers its place on the chessboard ".:

(a) Works translated.-These were, above all, the works of Aristotle, more especially the Physics, the Metafhysics ${ }^{3}$ and the De Anima. Next come a number of scientific treatises, notably on mathematics, with the works of Ptolemy and Galen. These, lending themselves readily to practical uses, were translated into Latin before the works on philosophy proper. It was at second hand and mainly through the Arabians that the scho-

1 "The method of the medieval translators is well known. A converted Jew [or Mahometan, Arabian] translated into the verracular-Spanish, for example-the Arabic version of the Greek text, and it was this vernacular version that was translated into Latin by the final 'translator' to whom the Latin version was attributed."-Lucquet, Hermann le Dalmate (Rev. Hist. Relig., t. 44, p. 415).

${ }^{2}$ Jourdain, op. cit., p. ig.

3 Through Aristotle's Metafhysics the earlier Grecian physicists were known. In the $D_{\epsilon}$ Unitate Intellectus, St. Thomas informs us that the last books of the Metaphysics, dealing with separated substances, were not at that time translated. 
lastics knew the Greek commentators on Aristotle; but St. Thomas had access to a version of the commentary of Themistius on the De Anima.

It is certain that Aristotle's treatises did not all become known at the same time in the West: they found their way gradually, one after another, into circulation, during the closing years of the twelfth, and the opening years of the thirteenth century. University records attest that the Physics and Metaphysics were known from I 2 13. Radulfus de Longo Campo, in his commentary on Alan of Lille, dating from about 1216 , does not mention those treatises, for the reading of them had just been forbidden, but he does mention the De Anima, the De Somno and De Vigilia, along with various writings of Averroës and Avicenna. William of Auvergne, who taught in 1228, was more familiar with the philosophy of Aristotle in its fulness, and Albert the Great wrote commentaries on the whole collection of the works of Aristotle.

(b) Principal workers and centres of translation.-The ArabicLatin translations of the twelfth century (by Constantine the African, Adelard of Bath, Herman the Dalmatian) were, and remained, isolated phenomena. It needed an organized, collective enterprise in translation to familiarize the West with the works of Aristotle: of this enterprise Toledo was the centre.

The archbishop of that city, RAYMOND ( I I 26-I I 5 I), established a college of translators which became famous on account of the inestimable services it rendered to Western culture and learning. Best known among its members are the names of Dominicus Gundissalinus or Gundisalvi ; Johannes David, a Jew (otherwise known as Johannes Hispanus and John Avendeati); DAvid and JehudA Ben Tibbon, also Jews; the Englishman, Alfred OF MORLAy (translated the first three books of the Meteors and the De Vegetalibus) and Gerard of Cremona. Somewhat later the same school produced two other well-known translators, Michael Scot and Herman the German.

II. Translations of Jewish and Arabian Works.--Here we have (I) Arabic-Latin, and (2) Arabic-Hebrew versions.

(I) Arabic-Latin Versions. It was through the Toledo translators, especially Johannes Hispanus, ${ }^{1}$ D. Gundissalinus and GERARD OF CREMONA, ${ }^{2}$ that the Western scholastics, about the end of the

${ }^{1}$ Translated Avicenna's Logic. See bibliogr. Beitr. z. Gesch. d. Philos., I., i., p. 32.

${ }^{2}$ He made known Arabian scientific works especially, translating over 200. 
twelfth century, came to know the works of Alkindi. Alfarabi, Gazali, Avicebron, Avicenna and Averroës. The commentaries of the great Arabian philosophers on the work of Aristotle were translated simultaneously with the text of Aristotle itself. For instance, Gundissalinus added the commentaries of Averroës to the translations of the $D_{t}$ Anima, the four books of the Physics and the ten books of the Metaphysics. Herman the Germannot to be confounded with Herman the Dalmatian- "translated, in I 240, the middle commentary of Averroess on the Nichomachaean Ethics; in 1244, an Alexandrian compendium of the Ethics; about 1250, a work of Averroes on Rhetoric, after having translated the opening glosses of Alfarabi on that work, ... to which translations he subsequently added an original treatise on Rhetoric; and, finally, in 1256 , the commentary on the Poetics". There is no ground for the supposition that he lived in Sicily. He spent his life in Spain, probably as Bishop of Astorga, from 1266 to his death in I 27I. Michael Scot translated Averroess" commentaries on the De Coelo et Mundo and the De Anima: " and these commentaries were known in the West at the commencement of the thirteenth century.

The court of Sicily, under Frederick II. and his son Manfred, was another centre of Arabian culture: and of Grecian culture as well, for it produced some Greek-Iatin versions in addition to Arabic-Latin ones. We meet here Michael Scot and Bartholomew of Messina. ${ }^{3} \quad$ irederick II. set great store on the commentaries of Averroess and did much to popularize them: by the middle of the thirteenth century Paris was in possession of all the writings of Averroës except his commentaries on the Organon and his Destructio Destructionis.

${ }^{1}$ Lucquet, op. cit., p. 421.

'Also, adds Renan, the other commentaries usually found with these in the manuscripts, on De Generatione et Conceptione, on Meteors, on the Parva Naluralia, and the version of the De Substantia Orbis (Renan, op. cit., pp. 206, 207. Cf. Hauréau, Hist. Phil. scol., ii., pp. 127 sqq.).

${ }^{3}$ LUCQUET has corrected a commonly received, though erroneous, interpretation of an oft-quoted passage from Roger Bacon: "infinita quasi converterunt in latinum ... Gerardus Cremonensis, Michael Scotus, Alvredus Anglicus, Hermannus Alemannus et translator Meinfridi nuper a domino rege Carolo devicti" (Opus tertium, ed. Brewer, p. 9). Translator does not refer to Herman, who, on the supposition that it did, was thought to reside at the court of Manfred; it refers to some other noted translator residing at that court. very probably Bartholomew of Messina. 
These scholars were moreover no mere interpreters of Arabian scientific thought: their knowledge embraced the works of the Patristic and early medieval Christian periods. Many of them also found, in the rich material they were dealing with, ample inspiration for quite original philosophical treatises. Michael Scot, for instance, composed a Divisio Philosophiae; but it was inspired by the similar treatise of Gundissalinus. The latter indeed merits a special place as a philosophical writer. He will be dealt with later on. ${ }^{1}$

(2) Arabic-Hebrew Versions.-In the thirteenth century many works were translated from Arabic into Hebrew. "When the Jewish civilization was driven northward from Mussulman Spain into Provence and the regions around the Pyrenees, Arabic, which had been the vernacular of the Jews, was gradually abandoned by them in their new surroundings, and they began to feel the need of translating all their important works on science and philosophy from Arabic into their own Hebrew." ' This task was carried on mainly by the members of one family, the Tibbonides, established at Lunel. It was confined almost exclusively to the works of Averroës, especially his commentaries on Aristotle, and to the text of Aristotle itself. Some of these commentaries are extant in a number of distinct Hebrew versions.

III. Some Apocryphal Works, translated from the Arabic and mostly attributed to Aristotle, all tinged with Neo-Platonism. Among these the principal are :-

(I) The Secretum Secretorum, a compendium of scientific lore, translated by a cleric of Tripoli.

(2) The Theology of Aristotle, also known as the De Secretiori Aegyptiorum Philosophia (215).

(3) A pseudo-Aristotelian treatise, De Anima.

(4) The Liber de Causis, quoted under various titles by the scholastics, translated by Johannes Hispanus or Gerard of Cremona between II67 and II87; annotated by Albert the Great and St. Thomas Aquinas, who refer it to Proclus; attributed subsequently to Aristotle and included in his works. The maxims

1 The Westerns also became acquainted with the religion of the Arabians. As early as the twelfth century, Peter the Venerable, Abbot of Cluny, had the religious books of the Saracens translated into Latin and opened a polemic against Islamism (V. Mandonnet, Pierre le Vénérable et son activité littéraire contre L'Islam, R. Thomiste, 1894).

${ }^{2}$ RENAN, op. cit., p. 185 . 
gathered from this small treatise attest to its widespread popularity in the thirteenth century and afterwards. It is in reality an extract from the $\Sigma_{r o \iota \chi} \epsilon i \omega \sigma \iota \theta_{\epsilon o \lambda o \gamma \iota \kappa}$ of Proclus. Guttmann attributes it to Johannes Hispanus. It has been edited by Bardenhewer after an Arabian manuscript of the year I $97 .^{1}$ Like the works of Pseudo-Denis and the hermetic writings, the Liber de Causis lends itself to different interpretations and was quoted in support of conflicting theses. Indeed it seems to have been utilized not so much for any new doctrines it might yield as for the purpose of defending old ones.?

(5) In addition to these Pseudo-Aristotelian works, we find also an Elementa Theologiae, wrongly attributed to Proclus, and other treatises wrongly attributed to Empedocles (on the five elements) and Pythagoras, groing the rounds of the medieval schools.

227. General Influence of those Translations on the Philosophy of the Thirteenth Century.-We must distinguish between the influence of the works of Aristotle and that of the Arabian and Jewish writings.

(I) Influence of the Aristotelian treatises.-The greater works of Aristotle directed the attention of the scholastics to new problems; and they also suggested solutions which were destined to be sifted, corrected and completed before being finally incorporated in the scholastic synthesis (116). In another direction Aristotle helped to build up and establish the didactic methods of the thirteenth century (see below).

(2) Influence of the Jewish, Arabian and apocryphal treatises.To the writings of the Arabians and Jews the scholastics are indebted for a number of Neo-Platonic notions and a large contribution of scientific data, especially of a psycho-physiological character; also for a number of interpretations of Aristotle's doctrine. which are seen to be identical in Arabian and in scholastic philosophy. It was Avicenna especially who contributed very largely in this way to the development of many scholastic theories.

It must not, however, be inferred that the scholastics either

I Bardenhewer, op. cit., 229 ; Guttmann, Die Scholastik d. xiii. Fahrh., etc., p. 54 .

2Daniel of Morlay, a pupil of Gerard of Cremona, attributes to Aristotle a "Liber de assignanda ratione unde orte sunt scientiae." which is in reality the De Divisione Philosophiae of Gundissalinus (Rose, Hermes, viii., 332, A.). 
adopted or even countenanced the philosophical systems of the Arabians. To see that they did not, we have but to observe their attitude towards those of the latter who influenced them most : towards Avicenna and Averroës among the Arabians, and towards Moses Maimonides, Avicebron and Isaac Israeli among the Jews. Averroës, in fact, they regarded as the initiator of a sort of pseudo-peripateticism to which they offered a determined and unrelenting opposition. He was for the anti-scholastics of the thirteenth century what Scotus Eriugena had been for those of the preceding period. Avicenna likewise had his own special theories and his misleading interpretations of Aristotle, opposed by the thirteenth century scholastics. Anyhow, his influence in the schools was never so great as that of Averroës: there was a Latin Averroism in existence for centuries; there was never a Latin "Avicennism". Avicebron, whom none of the scholastics thought to be a Jewish philosopher, transmitted theories of considerable importance to some of their schools: Duns Scotus was glad to follow his guidance. But the doctrines thus transmitted were freed from their monistic tendencies and transformed by the infusion of a totally new spirit. Moreover, Avicebron's pantheism and emanation were expressly and specifically combated (cf. Ir6). Maimonides arrested the attention of the scholastics mainly by his attempt to harmonize Aristotelianism with the Bible: they were reminded to address themselves to the similar task of harmonizing their philosophy with Catholic dogma. Apart from this happy suggestion, the philosophy of Maimonides met with no better reception from the scholastics than that of Averroës.

228. Prohibitions of Aristotle's Works at Paris.-Early in the thirteenth century the works of Aristotle were repeatedly condemned by the ecclesiastical authorities. A council convoked at Paris in 1210 by Peter of Corbeil forbade the teaching, whether public or private, of the Natural Philosophy and the commentaries of Averroës (nec libri Aristotelis de naturali philosophia nec commenta legantur Parisius publice vel secreto), ${ }^{1}$ at the same time as it condemned the teachings of Amalric of Bène and ordered the Quaternuli of David of Dinant to be publicly burned. It is likely that the libri de naturali philosophia included not only the Physics of Aristotle, but also his Metaphysics. Five years later, the 
Papal legate, Robert de Courçon, renewed these censures at the seat of the youthful university: while allowing the Ethics, he expressly prohibited the Physics, the Metaphysics and the Summae de eisdem. ${ }^{1}$ And this time again Aristotle was reckoned with the heretics: the followers of David, of Amalric and of Maurice of Spain. ${ }^{2}$

There were various reasons for those ecclesiastical censures. The immense volume of new philosophical material, brought to light by the introduction of the greater works of Aristotle, could not fail to produce confusion in the schools. The theologians became alarmed at certain teachings which ran counter to Catholic dogma: the theory of the eternity of the world, for instance. The Arabian commentaries aggravated the heterodoxy of those theories and introduced others that were no less objectionable, and always under cover of Aristotle. And then, too, the badly translated texts of Aristotle lent themselves to divergent interpretations, thus favouring the designs of all who wanted to propound novel or dangerous teachings (see Ch. IV.).

As soon as the first panic subsided and the scholastics got time to make a closer acquaintance with the new peripatetic theories and see what in them was compatible with Catholic dogma and what not, the Church quietly relaxed the rigour of its early prohibitions. If these were not expressly withdrawn ${ }^{3}$ they were allowed to fall into disuse; the authorities took no notice of things, and so usage abrogated the law. In r 23 I Pope Gregory IX., a sincere patron of learning, entrusted to three theologians (William of Auxerre, Simon of Authie and Stephen of Provins) the task of correcting the condemned books, evidently with the intention of putting the amended editions on the programme of the Paris Faculty of Arts, ne utile per imutile vitictur; and he delegated to the abbot of St. Victor and the prior of the Dominican

1 Robert de Courçon († r I2S) is the author of a Summa devoted to questions in moral theology and canon law. One of the most interesting portions of it, dealing with usury, has been published by G. LEFÈvre, Le traité de Usura de Robert de Courçon (Lille, 1902). It is noteworthy that the author does not invoke (as later authors do) certain texts of the Ethics and the Politics in condemnation of usury. From this M. Lefèvre infers that the opposition to usury grew up spontaneously prior to the thirteenth century, without any support from the authority of Aristotle.

Chartul., i., p. 78 .

: We find them reiterated in 1263 in a document of Urban IV., confirming the University statutes of Gregory IX. (ibid., p. 427). 
convent the power of absolving those who had incurred the ecclesiastical censures. $^{1} \quad$ These first steps seem to have been ineffectual ; but from I 255 onward the Physics and Metaphysics were regularly prescribed by the Faculty of Arts for the University courses. ${ }^{2}$ The fact that the ecclesiastical authorities did not then interfere is a sufficient proof that the prohibitive measures were allowed to become and remain a dead letter; henceforward the authorities dealt only post factum with those who sheltered themselves behind the name of Aristotle for the purpose of teaching error. We may add that the censures of I 2 IO and I 2 I 5 had no binding force outside Paris, ${ }^{3}$ and that the honour Aristotle received at Paris afterwards amply condoned for the suspicion with which he was treated there in the beginning.

229. Bibliography.-Jourdain, op. cit., r6o. F. Wustenfeld, Die Uebersetzung arabischer Werke in das Lateinische (Abhandl. der Kön. Ges. d. Wissenschaften zu Göttingen, lxxii., I877). STEInSCHNEIDER, Die Hebräischen Uebersetzungen des Mittelalters u. d. Fïd:n als Dometscher, 2 Bd., Berlin, 1893; Die Arabischen Uebersetzungen aus d. Griechischen; Die Europäischen Uebersetzungen aus d. Arabischen bis Mitte des 17 Fahrh., Vienna, 1904 (Akad. Wissensch. Wien). Excellent. See note by PÈre Mandonnet, Siger de Brabant et l'Averrö̈sme latin (and edit. Louvain, in the press), pp. 9-II, on the translations of Aristotle. A. VACANT, Les versions latines de la Morale à Nicomaque, Paris, I895. C. Marchesi, L'Etica Nicomachea nella tradizione latina medioevale, Messina, I904. Utilizes data from Italian MSS.; publishes the Ethica vetus, nova, and L. Ethicorum. Renan, op. cit., ch.ii., § I-3. Lucquet, Hermann l'Allemand (R. Hist. relig., rgor, t. 44, p. 407). Corrects errors about biography and authorship. J. W. Brown, An Inquiry into the Life and Legend of Michael Scot, London, x897. On William of Moerbeke, see our Histoire de la philosophie en Belgique, and edit., in the press. Baeumker has published the text of Avicebron's Fons Vitae in the Latin translation of D. Gundissalinus and John Hispanus (Beiträge, etc., i., 2-4, 1892-95). According to Baeumker, the translation of Alhacen's Optics is scarcely the work of Witelo, to whom it has been commonly attributed. ForSTER, De Aristotelis quae feruntur secreta secretorum Commentatio, Kiliae, I888, and Scriptores Physiognomici, etc., ii., pp. r88-222, Lipsiae, r893. BARDENHEWER, Die Pseudo-Aristotelische Schrift über das reine Gute, Fribourg, 1882 , pp. 37 and $5 \mathrm{x}$. There is also a PseudoAristotelian work, De Anima. Cf. Löwenthal, op. cit., 246. Lucquet, Aristote et l'université de Paris pendant le xiiie sc. (Bibl. Htes. Études, sc. relig., xvi., 2, r904). Studies the Council of r2xo. The author announces a general work on the knowledge of Aristotle's writings and teachings in the Middle Ages. Mandonnet, Siger de Brabant, ch. i. See works of Talamo, Schneid, Chollet, etc., rzo. Guttmann, Die Scholastik d. xiii. Fahrh. in ihren Beziehungen z. Fudcnthum u. z. jüdischen Litteratur, Breslau, I902: especially the preface; the author follows out those influences in separate chapters for the leading scholastics of the thirteenth century. Wit tmann, Die Stellung $d$. hl. Thomas v. Aquin zu Avencebrol, pp. 15-53 (quoted further on).

${ }^{1}$ Chartul., i., pp. 138 and $143 . \quad 2$ Ibid., p. 278. Cf. 231.

${ }^{3}$ We find the Toulouse masters boasting of the fact in r229 (ibid., p. r3r). 


\section{\$2. THE RISE OF THE UNIVERSITHEs.}

230. Foundation and Organization of the University of Paris. - The circulation of the new Aristotelian literature synchronized with the erection of the University of Paris. This originated in the closing years of the twelfth and the opening years of the thirteenth century, from the combination of all the masters and scholars attached to the schools of Notre Dame Cathedral and subject to the jurisdiction of its chancellor unieresitas magistrom et scholarimm. Little by little identity of interests drew the masters into four groups or liaculties: the theologians; the artists or philosophers; the canonists; the physicians. In the course of the thirteenth century, scholars' unions made their appearance under the name of nations: Picards, Gauls, Normans, English. Strictly speaking, these unions comprised only the masters and pupils of the Faculty of Arts, but as these were the most numerous, and as, moreover, after having completed the study of arts, both masters and pupils remained incorporated in their respective nations, these latter really represented the entire unirersity. Very soon a struggle commenced between the rector, or head of the nations, and the chancellor of the cathedral. It lasted for a century and a half, during which time the authority of the chancellor was slowly but steadily supplanted by that of the rector, who was thenceforth recognized as the chief of the university.

The growth of the l'aris University was remarkably rapid on account of the numerous privileges with which it was favoured by popes and kings. All the great theologians and philosophers passed through its schools. Its elaborate disciplinary organization was the work of its own time; it was taken as a model by all the other universities of the Middle Ages. We shall confine our attention to a few noteworthy points in connection with the teaching of philosophy and theolosy.

231. The Study of Philosophy and Theology.-Just as philosophy was subordinate to theology, so was mastership in the arts a necessary preparation for degrees in theology.: Non est consenescendum in artibus, sed a liminibus sunt salutandac. The teaching organization of the University is a faithful reflex of the

1 The latter replaced by the Allemani after the hundred years' war.

${ }^{2}$ And also for studies in law and medicine. But at the Paris University philosophy and theology eclipsed all other studies. 
general social condition of the Middle Ages: its underlying idea is the view of secular knowledge as leading up to the sacred science. But the master of arts (magister artium), when he became a theologian, was not likely to lay aside the habits of mind engendered by his philosophical training. And moreover, the growth of the dialectic method in theology encouraged the professors to make long and frequent incursions into the domain of philosophy. Add to this the absence of a sufficient philosophical grounding in many of their auditors, thereby necessitating a recapitulation, in theology, of arguments and matters that should have been assumed as already known. All this explains the fact that the philosophical teaching of the Paris masters must be sought in their theological, as well as in their philosophical, lectures.

Two features characterize the university teaching at Paris: internationalism of students and masters, and freedom ot instruction. Students flocked to Paris from every country of the West. There was no matriculation: the student selected a master; and he was known to his university only through his master. "Nullus sit scolaris Parisius qui certum magistrum non habeat." ${ }^{1}$ It was in the master's school and under his direction that the student should accomplish all his scholastic acts and exercises. The freedom of teaching enjoyed is manifest from the plienomenal extension of the mastership or professorial office. By fulfilling a few easy formalities, whoever had talent enough could become a professor. The university studies were in fact a long apprenticeship to the professoriate, and the student might be described as a candidate for the latter. He became professor by professing. Another index to this freedom of teaching is the language used by some of the masters-as testified by the questions sometimes discussed at the quodlibetic disputations. ${ }^{2}$

The series of academic acts varied with the epoch. In I215, Robert de Courçon laid down as the minimum age for teaching: twenty-one for the arts, thirty-five for theology; and as the minimum term of preparatory studies: six years' study for the arts, eight years' study for theology. The bachelorship or baccalaureate (baccalareatus, determinantia) was the lowest degree

${ }^{1}$ Organic articles given by Robert de Courçon in 1215 (Chartul. Univ. Paris., i., p. 79).

${ }^{2}$ The Quodlibeta of Godfrey of Fontaines are significant in this connectıon. See art. Un preux de la parole au xiiie s., in the Rev. Néo-scol., I90, , p. $4 \mathrm{I} 6$. 
in the arts faculty. In the beginning of the thirteenth century the candiclate was examined by a board of three masters of the arts faculty: later on there were four. If considered sufficiently qualified, he was admitted to the determinatio, a solemn academic test which took place about the next pasch following the examination; under the direction of his own master, the bachalariandus undertook a public defence of a number of theses proposed for discussion. The ordeal was a long one: it was supposed to commence infra octaz'as cinerum and to last for totam quadragesimam. In a concluding session the candidate summed up his conclusions, he "determined" the solutions to be given to the various questions raised, and answered difficulties (quarstionem determinare); thereupon he received the title of determinator, determinans. ${ }^{1}$ Between the baccalaureate and the second degree, the licence, there usually elapsed an interval of two or three years: although often, especially in the earlier days, we find instances of candidates who obtained all three degrees of the faculty within the space of a single year. The recipients of the second degree, the licentiati, were qualified by its reception to give their first or inaugural lecture as masters (incipere in artibus). On delivering this lecture they became entitled to be called incipientes, and the procurator of the nation admitted them to the rank of mastership (mayister). Most of the "incipient" masters of arts never delivered a second lecture in Paris: they either went elsewhere to teach, or else betook themselves to other studies at the University: these were called the magistri non regentes. The magistri actu regentes were the masters actually appointed by the nations for the regular work of teaching: they gave the ordinary university courses in the public class-halls of the various nations. or in their own private halls. ${ }^{2}$

The degrees in the Faculty of Theology were conferred in much the same way. To the baccalaureate there were three stages: the student became successively biblicus ordinarius, scntentiarius and bacchalarius formatus. In the fourteenth century "each 'formed' bachelor undertook four defences of theses against his colleagues: one 'aulica' (in aula episcopi), a second 'vesperalis,'

${ }^{1}$ Chartul., i., p. 563, and ii., p. 673 ; Auctarium, i., p. xxix.

2 Auctarium, i., p. xxviii sqq. Cf. Chartul., i., p. 530, the ordinatio facultatis artium de determinantibus, de baccalareis et de magistris, of 1275 ; the indexes of the Chartul.; and Thurot. 
a third 'sorbonica,' during the holidays at the Sorbonne, and a fourth in Advent 'de quolibet".." Not till then was he entitled to be presented to the chancellor for his licence: then, after a mere formal examination, the chancellor conferred upon the aspirant, with much pomp and ceremony, the licentia to undertake the office of teaching and preaching. Having gone through all those stages the licentiatus was admitted to the full and official exercise of the duties he had been hitherto discharging as an apprentice. As for mastership, or incorporation in the group of masters, the academic acts which qualified for it (vesperiae, aulica and resumptum) were rather of an honorary character. As Thurot well remarks, "the mastership was to the licence what the nuptial festivities are to the marriage blessing". The masters actu regentes, or those who, after obtaining their mastership, continued to teach and were not content with the mere honorary title of masters (actu non regentes), went on giving their public lectures and conducting disputations like the bachelors.

Lectures and disputations may be distinguished as two forms of teaching. The professor read (legere, we have still the German Vorlesungen), that is, he took up as the basis of his instruction some text which he explained and developed. In theology the first text was the Bible, which was studied from the literal standpoint (lectores biblici). Then came the Sentences of the Lombard (bachalarei). Finally the masters (magistri) undertook the real or scientific exposition of the Bible. ${ }^{2}$ In the Faculty of Arts the programme of lectures or lectiones was roughly outlined in Robert de Courçon's constitution of 1215 . We know it in detail from two sources dating from the middle of the thirteenth century: the statutes of the English nation (1252) regulating the conditions for the admission of bachelors to the Lenten determinatio ; ${ }^{3}$ and especially a statute of the Faculty of Arts (1255) "de modo docendi et regendi in artibus deque libris quae legendi essent". ${ }^{4}$ We learn from this latter document that the following

1 Thurot, De l'organisation de l'enseignement dans l'Université de Paris, Paris, I850, pp. I49 and 150 .

${ }^{2}$ Denifle, Quel livre servait de base a l'enseignement des maîtres en théologie dans l'Université de Paris? (Rev. Thomiste, r894, pp. r49-6r).

${ }^{3}$ Chartul., i., p. 228.

${ }^{4}$ Ibid., pp. 277 sqq. This statute dates from March I9, and settles a difficulty about "magistris aliquibus lectiones suas terminare festinantibus antequam librorum quantitas et difficultas requireret". 
books were read: the Vetus logica (videlicet liber Porfirii, praedicamentorum, periarmenias divisionum et thopicorum Boëcii), Priscian (major and minor), the Logica nova (the topica, elenchi, priora and posteriora); the Nichomachaean Ethics (only the first four books are mentioned); the Liber Sex Principiorum of Gilbert de la Porrée; the treatise of Donatus on Barbarisms (the third book of his Ars Major), that of Priscian on Accentuation; Aristotle's Physics, Metaphysics, De Animalibus, Liber coeli et mundi, First Book on Meteors, De Anima, De Generatione, De Causis, Books on Senses and Sensations, on Sleep and Vigil, on Plants, De Memoria et Reminiscentia, Costa Ben Luca's De Differentia Spiritus et Animae, ${ }^{1}$ and the Book De Morte et Vita. On comparing the branches enumerated in this programme with the classification of the philosophical sciences (given below), we can see the parallelism there is between them.

In the disputations, questions were treated by way of objection and answer: this was more animated, for all were invited to shed what light they could upon the matter under discussion. These dialectic exercises and disputationes magistronum in studio solempni formed part of the ordinary curriculum in the arts schools." Similar in character were the disputationes generales de quolibet in the schools of theology. ${ }^{3}$

${ }^{1}$ Edited by Barach, Biblioth. Philos. Med. Actatis, 1878 , ii.

${ }^{3}$ The statute of 1252 lays down this condition of admiscion: "per duos annos ... disputationes magistrorum in studio solempni frequentaverit, et per idem tempus de sophismatibus in scholis requisitus responderit" (Chartul., i., p. 228).

${ }^{3}$ These are to be distinguished from the Quaestiones Ordinariac. They were "extraordinary disputations conducted by the masters once or twice a year, about Easter and Christmas. They differed from the ordinary disputations in this that the topics discussed at them were more numerous and varied; masters, students and auditors being free to propose questions. The master, or the bachelor under his guidance, replied to the difficulties proposed on each topic; then, on the morrow or some subsequent day, the master summed up the questions and difficulties dealt with in his school: he arranged the topics-often very varied-in the best order possible and gave his definitive and final replies to the difficulties. This closing academic act was known as 'determining' or 'determination'. The voluminous literature that has come down to us from the second half of the thirteenth century under the general title of Quodlibeta, is nothing else than the product of those closing exercises, the extraordinary or 'quodlibetic' disputations" (Mandonnet, Siger de Brabant et l'averroisme Latin au xiiie siècle, pp. xcix-c, Fribourg, I899). Whilst the ordinary lectures of the masters and bachelors were of necessity confined to the Bible, the quodlibetic exercises ranged through all the known domains of science. Alongside questions on theology we find in them questions from philosophy, moral theology, canon law: also occasional questions on hotly disputed 
232. Rise of the Universities of Oxford and Cambridge.-Oxford dates from the middle of the thirteenth century. It acknowledged the supremacy of Paris, to which it was indebted for its organization and its best professors. ${ }^{1}$ The University of Cambridge came later, not taking definite shape until the fourteenth century. ${ }^{2}$ The "scientific pilgrimage" of the English to Paris commenced about the middle of the twelfth century. ROBERT GROSSETÊTE and the chancellor William OF SHYRESWOOD attended Paris; the Franciscans, ADAM OF MARISCO and RICHARD CORnUbiensis, and many others, taught at Paris before teaching at Oxford.

233. Bibliography.-The sources for the history of the University of Paris have been published in the Chartul. Univ. Paris. (225). See especially the introductions. The notes appended to the documents contain copious information on the medieval doctors. Same authors: the Auctarium Chartul. Univ. Paris. T. I. Liber procuratorum nationis Anglicanae (Alemanniae) ab anno $\mathrm{I}_{333} \mathrm{-r} 4 \mathrm{O} 6$ (Paris, I894); T. II. ab anno I406-I466 (I897). Maxwell, History of the University of Oxford. H. Rashdall, The Universities of Europe in the Middle Ages (Oxford, r895).

Denifle, Die Universitäten d. Mittelalters bis 4400 (Berlin, 1885). Excellent account of their beginnings. $\mathrm{C}_{\mathrm{H}}$. ThURoT, De l'organisation de l'enseignement dans l'Université de Paris (Paris, I85o). Excellent on many points, though wanting also on many. Is still the best general work on the subject. Ought to be re-edited, incorporating the data brought to light in the Chartularium. Worthy of note also are the works of Douais and Felder, 237. Luchaire, L'Université de Paris sous Philippe-Auguste (Paris, I899). Short monograph. E. Coppi, Le Univers. Ital., 2nd edit. Dr. Liessen, Die quodlibetischen Disputationen an d. Universität Köln (Progr. d. K. Wilhelm Gymnasium zu Köln, r886, pp. 58-70).

\section{§ 3. The Mendicant Orders.}

234. Conflicts between Regulars and Seculars.-Immediately on establishing themselves at Paris (1217 and I219-20), the Dominicans and Franciscans sought to occupy chairs of theology in the University: they succeeded too, but not without some difficulty. After a general strike of the masters, resulting from a disagreement between the Bishop of Paris and the chancellor of Notre Dame, the Dominicans obtained a chair of theology

topics of the time. Those quodlibetic disputes became excessively common in the fourteenth century.

1 Towards 1240, Robert Grossetete requested the professors of theology at Oxford to follow the order of lectures adopted in Paris (Chartul., i., p. 169). In 1246, Innocent IV. made the same recommendation to Robert himself (i., p. r89).

${ }^{2}$ Denifle, Die Univers. d. Mittel., p. 37 x. 
(I 229). ${ }^{1} \quad$ They secured a second chair in I23I, and about this date also the Franciscans were offered a chair in the faculty. The first Dominican master was Roland of Cremona, the first Franciscan master, Alexander of Hales. Between 1233 and I 238 the Franciscans appear to have filled a second chair: the one given to John de la Rochelle, who was proclaimed magister regens simultaneously with Alexander of Hales. ${ }^{2}$ The rights of the mendicant orders were based on sound titles. But the seculars, who were unsuccessful in opposing their incorporation in the first instance, were consistently hostile to them and showed their animosity in various ways. From 1252 to 1259 there were entanglements arising from the presence of regulars in the Faculty of Theology. The seculars, led by Niciolas of Lisieux, Gerarn of Abbevili,e, and especially by the turbulent Wilidam of ST. Amour ( $\dagger_{1272}$ ), wanted to carry a rule to the effect that each religious order should be limited to one chair in the University. The quarrel was settled by the intervention of Alexander IV. : the Dominicans held their two chairs, the Franciscans one; and the pope condemned William of St. Amour and the other ringleaders and ordered them to leave France.

The hostilities also assumed the form of interminable controversies on the nature and excellence of the religious state: these commenced in I 255 with the publication of William of St. Amour's De Periculis Novissimorum Temporum, and they ramified into almost all the theological controversies of the thirteenth century. $^{3}$ Still more embittered opposition was aroused by the Bull of Martin V., Ad Uberes Fructus, wherein the pope granted important privileges to the regulars in regard to faculties for hearing the confessions of the faithful. Whatever side the regulars

${ }^{1}$ Mandonnet, De l'uncorporation des Dominicains dans l'ancienne Université de Paris (R. Thomiste, 1896, p. 133).

${ }^{2}$ This new conjecture is well defended by H. Felder, O.C., Geschichte d. wissenschaftl. Studien im Franziscanerorden bis in die Mitte d. 13 Fahrh., 1904, pp. 216-3r. He rightly remarks that in the thirteenth century wherever there are two magistri regentes there are two distinct, parallel schools. The number of chairs in theology grew imperceptibly. Not before the middle of the thirteenth century was the number definitely limited. So, too, during the early years of the century the term of mastership was not defini ely fixed either with Dominicans or Franciscans.

3 There was quite a storm of controversial pamphlets. Mandonnet (Siger de Brabant, etc., pp. cvi-cviii) gives an outline of the history of these struggles. St. Thomas made his contribution to them in $\mathbf{1 2 5 7}$ by his treatise Contra Impugnantes Cultum Dei. 
might take in the philosophical questions that usually divided them among themselves, they always stood shoulder to shoulder against the seculars in defence of their common canonical privileges. ${ }^{1}$

235. Influence of the Mendicant Orders on Scholastic Philosophy.-The Dominicans and Franciscans exercised a very marked influence on the destinies of scholastic philosophy. These great religious corporations insisted on the education of their members in order to foster in the latter a taste for learning: they thus gave the philosophy of the thirteenth century some of its most illustrious exponents. The regulations of the Dominican order, though minute and ample from the beginning of the thirteenth century, afford but little information on the earlier organization of its studies. Distrust and opposition had to be overcome before the cultivation of philosophical studies was recognized along with the study of theology. But this early hostility gave way to an enthusiastic attachment, once Albert the Great and St. Thomas Aquinas vindicated for the secular branches of study their rightful place in the temple of knowledge. Soon, in addition to the studia solemnia, proper to each province, there were established studia generalia, common to the whole order, for the more advanced study of philosophy and theology. "Paris, to which each province had the right to send three students, became at once, and always remained, the most important centre of these studia generalia." ${ }^{2}$ The Franciscans likewise had their studia particularia in each province and their studia generalia for higher theological studies at the great university centres. These studia generalia of the mendicant orders were not autonomous or independent teaching centres, but formed part of the university organism in proportion as the theological faculty of the university recognized chairs of theology held by the regulars. In the same manner, the magistri regentes who happened to wear the religious habit, shared in the jealously guarded privileges of the faculties. The rivalry between

${ }^{1}$ In 1387 a new quarrel broke out between the Dominicans and the University, this time about some advanced theological theses propounded by the Dominican, John of Montesono. It led to a temporary expulsion of the Dominicans from the Faculty of Theology.

${ }^{2}$ Douars, Essai sur l'organisation des études dans l'ordre des Frères-Prêcheurs, p. ז30. The general chapter of 1248 decided on erecting four new studia generalia : that of Cologne, organized by Albert the Great on his departure from Paris, and those of Bologna, Montpellier and Oxford. 
the Franciscans and Dominicans stimulated the zeal of all. Other religious orders also fell in with the intellectual movement and obtained theological chairs: ${ }^{1}$ so much so indeed that in $127 \mathrm{I}$ Roger Bacon could say-with a small stretch of imagination, no doubt - that for forty years the seculars had not composed a single treatise on theology or philosophy."

To the Dominicans chiefly, on account of the gigantic labours of St. Thomas and Albert the Great,- - but to the Franciscans also in a lesser degree, ${ }^{3}$-belongs the honour of carrying into execution the ambitious project of Gregory IX.: the correction of the works of Aristotle (228). In this way did the two great orders of St. Dominic and St. Francis contribute its peripatetic elements to scholasticism. Neither the Dominicans nor the Franciscans, however, followed out uniform, unchanging philosophical traditions. A part altogether from the testimony of St. Bonaventure, that the Friars Minors aimed at unction rather than speculation-differing in this from the Friars Preachers, ${ }^{4}$ - the Franciscan school developed two decidedly different tendencies: (I) the early philosophical line marked out by Alexander of Hales, pursued by St. Bonaventure, and ending in a compromise between Aristotelian theories and theories inspired from other sources; (2) the later direction, towards purer peripateticism, initiated by Duns Scotus. This latter was the more influential current. Of secondary importance are the naturalist impulse due to Roger Bacon, and the theosophic tendency of Raymond Lully. What is known as the "terminist" movement appeared at a later period with William of Ockam and extended rapidly outside the Franciscan order. The earlier Dominicans first rallied to the body of doctrines then current, constituting the older scholasticism; but from the time of St. Thomas, they all, with a few exceptions, espoused one single philosophical tradition: that of scholastic peripateticism, as propounded by Albert the Great and St. Thomas.

${ }^{1}$ The Cistercians were allowed to teach in 1256 , the Hermits of St. Augustine towards 1287 (Giles of Rome), the Carmelites in 1295. According to THURoт, op. cit., p. II2, " in 1253 , out of the twelve chairs required by the number of students in theology, no less than nine were in the convents of the regulars".

2 Opera inedita, Brewer's edit., p. $4^{28}$.

3 Père Mandonnet attributes this too exclusively to the Dominicans. It is certain that on many points Alexander of Hales made Aristotle known to medieval scholasticism.

'Opera, Quaracchi edit., v., p. 440. 
236. Secular Colleges. The Sorbonne. - It was probably the recognized necessity of counterbalancing the influence of the regulars that first led to the erection of great colleges open to secular students only, and organized after the model of the convent schools. The most famous of those thirteenth-century colleges was the Sorbonne, founded in I 253 by ROBERT OF SORBON (I 2OI-I 274), chaplain to Louis IX. It admitted a certain number of theological students for the purpose of training them for preaching and scholastic controversy. They were bound to live in common, under the direction of a provisor. The masters called themselves-after the fashion of the mendicants-pauperes magistri de Sorbona. Among the writings left by Robert of Sorbon, the most remarkable are the De Conscientia and the De Tribus Dietis. The former deals with the last judgment, which the author compares with the licentiate examination: preserving from oblivion in this way many curious and interesting facts and theories on matters pedagogical. The latter treatise has for subject the roads that lead to Paradise.

The courses at the Sorbonne were closely connected with the teaching in the Faculty of Theology, for the Sorbonne disputations were not private exercises confined to the intern students, but were public and open to all. ${ }^{1}$

237. Sources and Bibliography.-Quetrf-Echard, I24. Denifle, Quellen zur Gelehrtengeschichte d. Predigerordens im $\mathrm{I}_{3} u$. $\mathrm{I}_{4}$ Fahrh. (Arch. f. Litt. u. Kirchengesch. d. Mittel., ii., pp. r65 sqq.). Mandonnet, De l'incorporat. des Dominic. ds. l'ancienne univ. de Paris (R. Thomiste, iv., I896). Sketches the early struggles. Douars, Essai sur l'organisation des études ds. l'ordre des Frères-Prếcheurs (Paris, 1884). Good, clear and full. Wadding, Scriptores O. M. (Romae, I60o). With supplement of Sbaraglea (Romae, I806), annalist of Franciscans: needs revision. An "Archivum Franciscanum Historicum" has been published at Quaracchi since I908. EHRLe, Die Spiritualen, ihr Verhältniss z. Franziskanerorden $u . z u$ d. Fraticellen, in the Arch. f. Litt. u. Kirchengesch. d. Mitt., i., ii., iii., iv. Same author: Die altesten Redactionen d. Generalconstitutionen d. Franziskanerordens, ibid., vi., I and 86 . SABatrer, Collect. de documts. pr. l'hist. rélig. et litt. du m. âge (Paris, I898-1902: 4 vols.). DE MARTigné, La scolastique et les traditions franciscaines (1888). Studies carefully the two doctrinal tendencies in the order.

I In the fourteenth century an act entitled "Sorbonic" was demanded from every master in theology. "The example of the "Sorbonic," "says Thurot, "shows how the colleges multiplied the public acts within the Faculty. ... It is to the confusion of the regime of the colleges and convents with that of the Faculty that I attribute this change in the theological teaching; and this confusion was natural inasmuch as the Faculty had few if any students outside the colleges and convents" (Thurot, op. cit., p. 134). 
Dr. P. H. Felder, Gesch. d. wissenschaft. Studien in Franziskanerorden bis in die Mitte d. I3 Fahrh. (Fribourg, 19o4). Utilizes all available documents: supplies a want in the history of ideas in the thirteenth century; many of its positions are much disputed. See SePPELT in the Kirchengeschichtliche Abhandlungen of SDralek, Bd. iv. (Breslau, Igo6). French tr. of Felder's work by Eusebius, Bar le Duc (Paris, I9oS). Denifle, Quellen zur Gelehrtengesch. d. Carmelitenordens im 13 $u$. I4 Fahrh., in the Archiv f. Litt., etc., v., 349; the historical works of Denifle and Ehrle are of the highest value. Numerous disconnected informations on the colleges will be found in FERET's work mentioned above $(\mathbf{1 2 5}, 5)$. There is in MS. a treatise of Claudius Hemerius, Sorbonae origines, disciplina et viri illustres (Bibl. Nat. lat., n. 5493), and also an anonymous MS. tract: Domus Sorbonae historia (Bibl. Arsenal, Paris, nn. Iozo, IO2I). Franklin, La Sorbonne, ses origines, etc. (r875). F. Сhambon, $R$. de Sorbon (1903). Full bibliorraphy; gives life and publishes with notes the De Conscientia and the De Tribus Distis. 


\section{CHAPTER III.}

SCHOLASTIC PHILOSOPHY.

\section{ART. I.-GENERAL NOTIONS.}

238. General Features.-The thirteenth century marks the culmination of scholasticism. Facing all the problems that confront a complete philosophy, scholasticism gave them char. acteristic solutions, all harmonized into one grand and imposing synthesis. Its great, leading principles were accepted by all scholastics. "No one has ever seriously denied that there was an agreement on fundamentals which authorizes us to regard scholasticism as a system, a school of philosophy." 1

At the same time, the individuality of the scholastics is very striking. Like all the fertile periods in human thought, the thirteenth century was rich in men of genius. The forms assumed by scholasticism were numerous and noteworthy: each of the great scholastics realizing in the concrete, according to the bent of his own peculiar genius, the one dominant abstract synthesis (II8-120). The thirteenth century was likewise the golden age of speculative theology.

Philosophy now addressed itself by preference to questions in psychology and metaphysics, the metaphysical point of view predominating. And here too a progressive development is noticeable. The contemporaries of William of Auvergne (in the second and third decades of the thirteenth century) attend mainly to problems about knowledge, the origin and duration of the world, the nature of immaterial substances and of the human soul. ${ }^{2}$ With Albert the Great, all the great doctrines of psychology make their appearance; while the exhaustive study of the great problems of metaphysics (as, essence and existence, principle of

${ }^{1}$ EHRLE, Stimmen aus Maria-Laach, r88o, p. 28.

${ }^{2} C f$. Baumgartner, Die Erkenntnislehre d. Wilhelm v. Auvergne, p. to (see 246). 
individuation, matter and form, causes) lead to the gradual exploration of the whole philosophical domain.

239. Division.-The scholasticism of the thirteenth century contains a large variety of systems, but each of them may be attached to some one of a few groups which followed one another in logical as well as chronological order.

(I) The older scholasticism of the thirteenth century, embracing the pre-Thomistic systems (Art. II.).- Though the earlier thirteenthcentury scholastics assimilated the peripatetic principles embodied in the translations of Aristotle, they still held on to what they had inherited from the preceding period, though much of this was really incompatible with peripateticism: for much of it was of Augustinian and Platonic origin (126). Then too, they were unable, in the opening decades of the century, to grasp the real sense of all the Aristotelian theories and to appreciate the value and bearing of each upon the entire synthesis of which each formed a part. And, besides, they accepted Neo-Platonic and Arabian accretions, coming from the Spanish commentators, as the authentic teaching of Aristotle. These are some of the causes which account for the doctrinal incoherences of the early scholastic systems: incoherences which do not indeed compromise the organic unity of scholasticism, as certain syntheses of the earlier Middle Ages did, but which certainly do diminish and loosen its compactness. It is this lack of sure and definite convergence that distinguishes the earlier from the later systems of the thirteenth century: the latter are based more firmly on peripateticism, and by reason of their greater consistency and harmony of parts will always rank as the most characteristic and enduring monuments of the medieval scholastic genius.

Among the foreign elements found in the earlier scholastic systems, these are the more important: the predominance of the notion of the good as compared with that of the true, and the corresponding primacy of will over intelligence in God and in man ; the necessity of a direct, illuminating act of God in certain of our intellectual processes; the minimal yet positive actuality of primal matter apart from all "informing" influence of substantial form; the presence, in the former, of germinal principles, or rationes seminales of things; the hylemorphic composition of spiritual substances; the multiplicity of forms in natural beings, especially in man, and the individuality of the soul 
independently of its union with the body; the identity of the soul with its faculties, and the "active" character of the soul's representative processes; the impossibility of creation of the world $a b$ aeterno.

This collection of views has been called Augustinism, and the group of philosophers who propounded them the Augustinian wing of scholasticism (as opposed to the peripatetic wing). But this style of description is open to serious objections. In the first place, such a description would be justified only if the one section propounded the doctrine of St. Augustine alone and the other that of Aristotle alone. ${ }^{1}$ But some Augustinian doctrines, such as that of Exemplarism, became part of the common patrimony of all scholasticism, being found in St. Thomas the "peripatetic" no less than in St. Bonaventure the "Augustinian". Moreover, the groundwork of the teaching which is coloured by the Augustinian influences, is itself peripatetic throughout, as, for example, the teaching about matter and form, about potency and act, etc. And finally, the "peripatetic" Duns Scotus espouses many of these "Augustinian" theories: yet he is never classified among the Augustinians of the thirteenth century. The description is objectionable because, in the second place, "Augustinism" as summarized above, may be really resolved into groups of theories issuing from three or even four distinct sources. Some of them are certainly of Augustinian origin, as, for instance, the identity of the soul and its faculties, the primacy of will over intellect, the substantial independence of the soul in regard to the body, the absence of causal activity in the object of the act of cognition, the theory of the rationes seminales ( $c f$. 126). But others of them are in opposition to the genuine teaching of St. Augustine; they are Neo-Platonic and Arabian distortions of the saint's real teaching (e.g., the special illumination theory). Others again were propagated by the parallel but preponderating influence of the peripatetic writings of the Arabians and Jews : the matter and form theory and its application to immaterial substances, evidently inspired by Avicebron. ${ }^{2}$ Then, finally, theories like that of the plurality of forms are entirely foreign to Augustin-

1 This is the view of Grabmann, Die philos. $u$. theolog. Erkenntnislehre des Kard. Mathaeus ab Aquasparta, etc., p. I9 (Vienna, I906); and of P. DE GRoot, Het Leven van den hl. Thomas (Amsterdam, 1907), p. 3 r3.

${ }^{2}$ See St. Bonaventure, below (Art. II., §3). 
ism and come exclusively from Arabian sources. For all those reasons we think that the title of Augustinism, usurping as it does the name of a great philosopher and of a distinct and wellknown system in the history of philosophy (100-ro3), should give place to some wider designation: earlier scholasticism of the thirteenth century, or, pre-Thomistic systems.

It is further to be noted that the characteristic elements of these systems are floating, and variable from one individual scholastic to another; that they are but loosely laid alongside Aristotelian teachings; and that they are understood and expounded with many varying shades of meaning. It would be difficult to draw up a common list of them for all the teachers of the time. Thus Alexander of Hales rejects the theory of the identity of the soul with its faculties; St. Bonaventure adopts it with hesitations and reserves; while others regard it as fundamental. So too, the theory of special illumination is understood in all sorts of ways and rejected by not a few.

We should bear in mind especially that the weakening elements were evacuated by scholasticism as time went on: the great scholastics steadily eliminated all inconsistent and jarring opinions from their teaching. If we compare, for instance, the philosophy of William of Auvergne with that of St. Bonaventure, we shall be struck at once with the superiority of the latter. We cannot, therefore, put upon the same level the systems of the precursors, the more comprehensive system of Alexander of Hales and the still more fully co-ordinated system of St. Bonaventure. In some of its doctrines, too, the older scholasticism outlived even the triumph of peripateticism.

(2) The peripateticism of the Albertino-Thomistic School (Art. III.).-As we advance in the thirteenth century and see the censures against Aristotle gradually relax in rigour (228), there appears, alongside the earlier traditions, a new movement of an avowedly peripatetic tendency. It finds full expression in the philosophy of Albert the Great. But it was St. Thomas who set it forth as a grand and enduring system, while he at the same time dismantled many a theory that had previously loomed large in the schools. Thenceforth the scholastic synthesis appears in all its fulness and power.

(3) The conflict of Thomism with the earlier scholasticism (Art. IV.).- Thomism was bound to come into immediate conflict with 
the older scholasticism, for it rejected many of the current promiscuous theories, as inconsistent with its own principles. This collision of the old thought with the new, was often animated and sometimes even violent; and it took place in various and unexpected ways. The struggle issued in the formation of three groups : the irreconcilable opponents of Thomism, headstrong partisans of the old, received opinions ( $(\mathrm{I})$; the loyal and wholehearted supporters of Thomism ( $(2)$; and finally a group of more or less moderate, eclectic thinkers, Thomists on some points, adherents of traditional views on others, themselves innovators in not a few $(\S 3)$.

(4) The peripateticism of Duns Scotus and the Franciscan School (Art. IV.).- - In the closing years of the thirteenth century, Duns Scotus formulated a system of philosophy on a peripatetic basis, but deviating both from St. Thomas and from the lines of the older scholasticism. These latter lines had been followed by practically the whole Franciscan order down to Scotus's time, but he led the order in a partly new direction.

240. Bibliography.-Cf. I20. EhrLe, Die päpstliche Encyklika v. 4 Aug. I879 $i$. die Restauration des christ. Philos., in the Stimmen aus Maria-Laach, 1880. Four articles, of which second concerns scholasticism in the thirteenth century. Same writer: Beitr. z. Gesch. d. mittel. Scholastik. II. Der Augustinismus u. d. Aristotelismus in d. Scholastik gegen Ende d. 13 Fahrh. in the Arch. f. Litt. u. Kirchengesch. Mitt., r889, Bd. v., pp. 603-35. Publishes important texts of Robert Kilwardby. F. Peckham ïber d. Kampf d. Augustinismus u. Aristotelismus in d. 2en Hälfte d. 13 Fahrh. in the Zeitschr. f. Kathol. Theol., r889, Bd. xiii., pp. I72-93. Texts from Peckham. Two articles of great value. Same writer: Das Studium der Handschriften d. mittelalterl. Scholastik mit besonderer Berücksichigung d. Schule d. hl. Bonaventura (Zeitsch. f. Kath. Theol., I883, pp. I-50). Contains (pp. 40-5I) a classification of the earlier Franciscan schools into five groups. Mandonnet, Siger de Brabant, etc., pp. 62 sqq. Studies well the two tendencies, but neglects, wrongly as we think, the Aristotelian elements in the Augustinian schools. De Wulf, Le traité De Unitate Formae de Gilles de Lessines (Louvain, rgor, tom. i., des philosophes Belges). Text and study: ch. ii. deals with classification of schools in thirteenth century. PortaliE, s.v. Augustinisme in the Dict. de Theol. Cath. (t. i., cols. 2506-25 14 ). Sums up and arranges the conclusions of previous investigations. $C f$. the Scholia of the large edition of St. Bonaventure for the history of individual theories in the earlier scholasticism. DE MARTIGNe, op. cit., 237. Simmler, Des Sommes de théologie (Paris, r87r).

\section{ART. II.-THE EARLIER SCHOLASTICISM : PRE-THOMISTIC THEORIES.}

241. Subdivision. - In the earlier scholasticism of the thirteenth century we may distinguish: (I) the precursors $(\S \mathrm{I}) ;(2)$ the 
Franciscan schools: Alexander of Hales (\$2), St. Bonaventure $(\$ 3)$ and the disciples of St. Bonaventure $(\$ 4)$; (3) the Dominican schools $(\$ 5)$. Among the teachers of both orders, there are many about whom little is yet known: their works lie still unedited and neglected. We must await the publication of texts and monographs, before the place and influence of each of these teachers can be definitely settled.

\section{$\$$ I. The Precursors.}

242. Who are the Precursors?-The title of precursor, in the doctrinal sense in which we use it, may be fitly applied to Gundissalinus, whose philosophy is a connecting-link between the Arabian and the scholastic philosophies; and to William of Auvergne, the first scholastic, we may say, to avail himself, in his writings, of the new ideas. In both these authors there are frequent incoherences and unsuccessful attempts at compromise between irreconcilable theories. A place of minor importance belongs to Alfred of Sereshel.

243. Dominicus Gundissalinus, Archdeacon of Segovia, is not only remarkable as one of the Toledo translators (226), but also as a philosophical writer of considerable importance in history. Five of his treatises are extant: De Divisione Philosophiare, De Immortalitate Animae, De Processione Mundi, De Unitate, De Anima. The three latter, borrowing from the Fons Vitae of Avicebron, are posterior to the translation-in which Gundissalinus himself collaborated-of this work. Baur, the editor of the De Divisione Philosophiae, places it at a date subsequent to $\mathrm{I} 240$.

Gundissalinus is an eclectic compiler, susceptible to the influence of other men's ideas, accustomed as he was to the work of translation. He was an Aristotelian in metaphysics and psychology, but drew from commentaries and Arabian texts instead of the original sources. As a consequence, his Aristotelianism is tinged with Neo-Pythagorism and Alexantrian NeoPlatonism, like his Arabian sources. But he strips these foreign elements of the pantheism they breathed in the Neo-Platonists and in more than one of the Arabians too; for Gundissalinus is an individualist. And this in turn he owes to a third-the Christian-influence, especially of Boëthius and St. Augustine. The most noteworthy among his teachings are those that refer to 
the classification of the sciences, to metaphysics and to psycho$\log y$.

He undertakes a classification of the philosophical sciences in a didactic sort of treatise, entitled De Divisione Philosophiae: a large compilation from Alfarabi's De Scientiis and various writings of Ammonius, Isaac Israeli, Avicenna, Boëthius, Isidore of Seville and Venerable Bede. He emphasizes the distinction between theology, the Scientia Divina (Deo auctore, hominibus tradita) and philosophy, the Scientia Humana (quae humanis rationibus adinventa esse probatur); he propounds this principle which was advocated by all the great scholastics: nulla est scientia quae philosophiae non sit aliqua pars; he offers approvingly no less than six definitions ${ }^{1}$ of philosophy; and he sketches a scheme of division which runs mainly on Aristotelian lines.

The philosophical sciences proper (scientiae sapientiae) include a theoretical and a practical group. The former embraces Physics, Mathematics and Metaphysics. As subdivisions of Physics (scientia naturalis, de his quae non sunt separata a suis materiis) we find the following branches enumerated: medicina, indicia, nigromantia, ymagines, agricultura, navigatio, specula, alquemia. Mathematics (de his quae sunt separata a materia in intellectu non in esse) include the following branches: arithmetica, geometria (with optics), musica, astrologia, scientia de aspectibus, de ponderibus, de ingeniis. Metaphysics is a scientia divina which treats de his quae sunt separata a materia in esse et in intellectu. Practical philosophy is divided into politics, economics and ethics.

Logic, according to the Arabian idea, is an instrumentum preliminary to philosophy and presupposed in a certain sense in the acquisition of knowledge of whatsoever kind; but in another sense it is a part of philosophy, and is itself preceded by other sciences.

These latter form a third group called the propedeutic sciences: the scientia litteralis, or grammar; and the scientiae civiles, or poetry (including history) and rhetoric.

After outlining this classification, Gundissalinus takes up and explains each branch in detail. His effort in this work of

1 “ Assimilatio hominis operibus creatoris secundum virtutem humanitatis-tedium et cura et studium et sollicitudo mortis-rerum humanarum divinarumque cognitio cum studio bene vivendi conjuncta-ars artium et disciplina disciplinarum-integra cognitio hominis de seipso-amor sapientiae." We quote from BAUR's edition. 


\section{XIII. CENTURY : PRE-THOMISTIC SCHOLASTICISM}

classification was the starting-point of a genuine onward movement, both scientific and didactic, and his influence is manifest in all the thirteenth-century works dealing with this problem. The treatise of his contemporary, Michael Scot, Divisio Philosophiae, ${ }^{1}$ is merely a compendium of the work of Gundissalinus. He also inspired the work of Albert the Great $;^{2}$ and Robert Kilwardby, who did much for the classification of the sciences, acknowledges his deep indebtedness to Gundissalinus.

In metaphysics, Gundissalinus is Aristotelian, as we might infer from the attention he pays to the scientia prima in the De Divisione Philosophiae. The object of Metaphysics is Being, with the consequences of Being (consequentia entis: substance and accident, universal and particular, cause and effect, act and potency). His treatment of these topics is inspired mainly by Alfarabi and Avicenna; yet we find in the De Unitate traces of the Alexandrian and Arabian theories of emanation and mystic gradations in the scale of beings. Unity is set forth after the manner of the Neo-Platonic pantheists as the constitutive principle and ground of all things. God is the creatrix unitas whence the creata unitas springs. The derivation of the creature is not by way of emanation from the bosom of God, as with Avicebron, but by a general creative participation, on the nature of which the $D_{\boldsymbol{e}}$ Unitate says nothing. Intelligence, world-soul and bodies are three successive steps which mark the appearance and development of unity in creation: moreover, every being, with the sole exception of the First Being, is composed of matter and form, two opposite principles held together by the cohesive force of unity. Those theories are evidently borrowed from the Fons Vitae, which Gundissalinus had studied and translated.

The De Immortalitate Animae is a small treatise on rational psychology. Its plan is original, and it presents a curious mixture of Aristotelian and Neo-Platonic (Arabian) theories. Its author propounds the theory of abstraction as described by Avicenna, the distinction between intellectual and sense knowledge, the individuality of the real beings to which our universal concepts apply; he then undertakes to prove the immortality of the soul, with rigorous cogency, by the famous Aristotelian argument

${ }^{1}$ Fragments of this treatise are reproduced in the Speculum Doctrinale of Vincent of Beauvais : edited by Baur in an appendix.

${ }^{2}$ Baur, Dominieus Gundissalinus, De Divis. Philos., pp. 365, 375. 
based on the characteristics of thought; but this teaching is all interspersed with Arabian and Neo-Platonic theories. Such, for instance, is the theory regarding rapture (raptus): when the flesh is subdued and its resistance to the higher aspirations of the spirit diminished, the latter can launch itself in ecstasy upon the intelligible world and thus attain to the most complete emancipation from the servitude of the body: whence the author concludes (with Plato, and against Aristotle) that death, by severing the bodily trammels of the soul, secures for it the plenitude of its perfection. This proof of immortality was exceedingly popular in the thirteenth century. ${ }^{1} \quad$ Another Alexandrian conception to which Gundissalinus gave a peripatetic meaning, is that of man as a "microcosm". Finally, his close contact with Arabian philosophy accounts for his close attention to psycho-physiological doctrines. His influence in psychology is traceable in Helinandus of Frigidimonte, in John de la Rochelle, and in a lesser degree in Albert the Great and St. Bonaventure. It is most apparent, however, in William of Auvergne, who plagiarized the De Immortalitate Animae.

244. William of Auvergne.-Born at Aurillac in Auvergne, William became one of the most distinguished philosophers and theologians of the University of Paris. He was appointed to the episcopal see of Paris in 1228 (hence called William of Paris) and died in I 249. Of his works, the De Trinitate is theological; the De Universo, his principal work, written between I23 I and I236, is a metaphysical study ; his De Immortalitate Animae is an almost literal reproduction of the treatise of Gundissalinus; while his De Anima develops and completes the conclusions of this latter.

Whether we consider his metaphysics or his psychology, we find in the Bishop of Paris a typical representative of the period of transition and elaboration to which he belongs. William knew all the works of Aristotle, but he failed to imbibe their peripatetic spirit; he made no large use of them: the peripatetic elements in his teaching are but scattered and sporadic. He also collected Arabian and Jewish theories, especially from Avicebron, whom he believed to have been a Christian and held in high esteem (unicus omnium philosophantium nobilissimus). And this blend of Aristotelian and Neo-Platonic theories is strangely

${ }^{1}$ Bülow, pp. Ir5 sqq. (246). Des Dominicus Gundissalinus Schrift v. d. Unsterblichkeit, etc. 
allied with the doctrines of the older scholasticism: William endeavours to fit in the new teaching with that inherited from the past, and wherever he fails to harmonize them he holds by the traditional teaching. All this results in a characteristic lack of doctrinal cohesion in his teaching. ${ }^{1}$

In metaphysics, although he propounds the distinction between act and potency, William does not grasp the full significance of the distinction (see below). He appears to have been the first scholastic to teach the doctrine of real distinction between essence and existence: ${ }^{2}$ having learned it from Avicenna. Establishing a relation between primary matter and quantity, he denies hylemorphic composition to spiritual beings such as the angels. His proufs of the existence of God are mainly drawn from the earlier scholasticism, especially from St. Augustine, but to some extent from Arabian sources also. The peripatetic argument for a Prime Mover is missing, while on the other hand we meet with a priori arguments on the lines of St. Anselm's reasoning. ${ }^{3}$ Although he opposes the Arabian doctrine of emanation, as incompatible with the creative causality of the First Being, he adopts the pantheistic formula that God is the esse formale rerum and makes an honest effort to give it an individualistic meaning.

In psychology, William follows St. Augustine in identifying the soul and its faculties and propounding the substantial dualism of man: which, nevertheless, does not prevent him from adopting Aristotle's definition of the soul. The whole interest of the De Anima turns on the problem of the origin of our ideas, which is here plainly raised for the first time in scholasticism. William distinguishes three distinct groups of objects in our knowledge: the external world; the soul itself; first or self-evident principles of demonstration. ${ }^{4}$

(a) On the external world we have two essentially distinct sources of knowledge, sense and intellect. The sense faculty receives a sensible form (Aristotle), which William, with the Arabians, conceives as a mere physical impression. The intelligible form is drawn out by the intellect from within itself on the

1 This estimate of William is confirmed by Baumgartner, Bülow and Schindele in the monographs mentioned below, 246.

${ }^{2}$ Schindele, Beitr. z. Metaph. d. Wilhelm v. Auvergne, p. 23.

${ }^{3}$ Ibid., pp. 45, 46 .

${ }^{4}$ We are here following Baumgartner, Die Erkenntnislehre des Wilhelm von Auvergne. 
occasion of sense representations (St. Augustine). This is truncated Aristotelianism, for William drops out of his psychology altogether the intellectus agens, not requiring it for the production of the species intelligibilis. His arguments are based partly on the simplicity of the soul (St. Augustine), which he holds to be incompatible with this duplication of the intellectual faculty, and partly on the inadequacy of the current explanations of the intellectus agens. He simply declines to accept the theory of the separated intellect-which he takes for the genuine expression of the thought of Aristotle. He likewise refuses to admit the theory of the "spiritualized phantasma" propounded by some of his contemporaries: the view that the species sensibilis is transfigured or transformed into a species intelligibilis by the purifying influence of the intellectus agens. It would be interesting to know who these contemporaries were, who, with the full text of Aristotle's De Anima before them, went astray from the start, like his Greek commentators, by taking a wrong view of the species intentionales (53). Their error was quite a common one in the thirteenth century (30o). In rejecting it, William displays considerable acumen and a firm grasp of the ideological problem. By the intelligible forms the intellect knows, in the first place, individual substances (as against Aristotle's view); then, later, the abstract and universal reality; thirdly, and in a distinct manner (modus per connexionem sive per colligationem), by the aid of a habit acquired by personal exercise or else divinely infused, we judge and reason and call up at will into the field of present consciousness the memory of past experiences.

(b) In regard to the knowledge the soul has of itself, few scholastics have laid more stress than William on the value of immediate evidence of conscious facts (St. Augustine). Not only does consciousness directly testify to the existence of the soul, but also to its essential properties, its immateriality, its simplicity, its indivisibility. Furthermore, consciousness reveals a whole category of rational truths for which William reserves a place apart. These are the first principles of scientific demonstrations.

(c) First principles, such as the principle of contradiction, have a value that is both real and ideal, and this independently of the existence of the contingent world. Whence William goes on to conclude-wrongly too, and in opposition to Aristotle's real teaching-that consideration of the world cannot give rise to 18 * 
them within the mind. Where, then, do they come from? The intellect sees them directly in God, by virtue of a special illumination. Here evidently we have the influence of Arabian mysticism : the Bishop of Paris is interpreting the Arabian theory of special illumination of the individual mind by the separate active intellect in a Christian sense-and endeavouring at the same time to conform his teaching with St. Augustine's "exemplarism". His dissertations on Divine illumination, ecstasy, prophetic vision and pathological hallucinations recall the NeoPlatonic themes of the I) Immortalitate Animae, just as his conception of the soul on the horizon of two worlds reminds us of the Alexandrian theory of the descending scale in the emanation of things.

245. Alfred of Sereshel (Alfredus Anglicus), a contemporary and perhaps a disciple of Alexander Neckam (died about I2 I 7 ; described by Hauréau ${ }^{1}$ as a realist of rare candour), wrote a number of psychological tracts between the years 1220 and 1227 . In one of these, a small treatise De Motu Cordis, we find the Arabian tendencies in physiology and psychology imbibed by Alfred during his travels in spain. His teaching occasionally borders on the materialism of the ancient Grecian physicians. Life he defines as the actus primus format, presupposing the material body already constituted.:

246. Sources and Bibliography.-Correns, Die dem Bö̈thius fälschlich zugeschriebene Abhandlung d. D. Guthdisalvi De Unitate (Beitr. z. Gescin. d. Philos. Mitt., rogr, i., r): text and brief study. Dr. G. Bülow, Des Dominicus Gundissalinus Schrift v. d. Unsterblichkeit d. Seele, etc. (ibid., ISgr, ii., 3) : contains the De Immortalitate Animae of William of Auvergne. Exbres, Die Nachairkung von Gunlissalinus De Immortalitate Animae (Philos. Jarhrb., xii., 4, I399). LiWwenThal, Pseudo-Aristotelisches ïber d. Secle (B-rlin, ISgr), has published the $D e$ Anima. Menendez Pelayo, Historia d. l. Heteroll. Espanoles, i., 69i-7ir : publishes the De Processione Mundi. Baur, Dominicus Gundissalinus, De Divisione Philosophiae (Beitr., etc., I903, iv., 2 and 3 ) : text and exhau-tive study of doctrinal sources. BaEumker, Les écrits philos. de D. Guntissalinus (R. Thomiste, ISg8, p. 72i) : brief general review. Editions of the works of William of Auvergne (Venetiis, I59I, and Aureliae, I674): contain sume unauthentic treatises. Hauréau, Not. et Extr. qles. ms. lat. See tables. N. Vallors, Guillaume d'Auvergne, évêque de Paris (Paris, ISSo). Werner, Wilhelm's von Auvergne Verhältniss z. d. Platonikern d. xiii. Fahrh. (Vienna, IS 73 ): not easy to understand. Schindele, Beitr. $z$.

${ }^{1}$ Hist. phil. scol., ii., p. 64 .

${ }^{2}$ Windelband, Zur Wissensihaftgesch. d. roman. Volker, p. 569, describes Alexander Neckam and Alfred of Sereshel as precursors of the empirical tendency inaugurated by Roger Bacon. 
Metaph. d. Wilhelm v. Auvergne (München, rgoo): promises an exhaustive work on the subject; treats only of the notion of being. Gutrman, G. d'A. et la littérature juive, in the Revue des études juives, xviii., pp. 243 sqq. Baumgartner, Die Erkcnntnislehre d. Wilhelm v. Auvergne (Beitr. z. Gesch. d. Philos. d. Mitt., ii., x, Münster, r893) : good. BüLow, op. cit. The De Motu Cordis of Alf. Anglicus has been edited by Barach, Bibl. Phil. Med. Aetatis, t. ii., 1878: this treatise is not a translation. HAURÉAu, Not. et Extr., etc., v., 20 r.

\section{\$2. Earliest Franciscan Schools. Alexander of Hales.}

247. Life and Works. - The date and place of Alexander's birth are not accurately known. He studied at Paris before entering the Franciscan order. Roger Bacon informs us that when Alexander was master of arts the Physics and Metaphyics of Aristotle had not yet been translated. ${ }^{1}$ This would point to a period prior to I 2 IO. The year he entered the order, the theological chair of the Paris house was incorporated with the University, and Alexander was its first magister regens. It is likely that he held this position till his death, in I 245 .

Numerous works have been erroneously attributed to Alexander. His great, and perhaps his only, work is the Summa Theologica. It was commenced not earlier than I $23 \mathrm{I},{ }^{2}$ and its author did not live to finish it. A document of Pope Alexander IV., dated 28th July, I 256, mentions him as author of the work and recommends William of Melito to complete it. ${ }^{3}$ The latter did add to it, and others after him. Thus the Summa de Virtutibus, which fills a large break in the third part (qq. 27-69), is subsequent to St. Bonaventure, by whom it is manifestly inspired. ${ }^{4}$

248. His Place in Scholasticism.-The Summa contains a theological as well as a philosophical system. The same is true of all similar Summae of the thirteenth century. The development of scholastic theology owes to Alexander the perfecting of a teaching method (249), the application of dialectic to dogma (18I), the raising of new questions, but not any new or final

${ }^{1}$ Opus Minus, Brewer's edit., p. 326.

2 The Summa quotes from the commentary of Thomas Gallo, abbot of Vercelli, "super Hierarchiam" (Pseudo-Denis). But the latter work is not earlier than 1224-1226 (FELDER, op. cit., p. I95).

${ }^{3}$ Chartul., i., p. 328.

${ }^{4}$ St. Bonaventure, Opera, Quaracchi edit., t. x., Dissertatio, p. 3. It is well known that Roger Bacon denies to Alexander the authorship of the Summa in question: "Fratres adscripserunt illi magnam summam illam, quae est plusquam pondus unius equi, quam ipse non fecit sed alii. Et tamen propter reverentiam ascripta fuit, et vocatur Summa fratris Alexandri" (Opus Minus, p. 326). 
solutions of those questions or others. Even in his own order, his theology was supplanted by the theology of St. Bonaventure, and, later on, by that of Duns Scotus. ${ }^{1}$ Alexander follows the divisions of the Lombard's Sentences; his own general plan of treatment was adopted by most of the Summae of the thirteenth century. $^{2}$

It is in this theological setting we must search for the philosophy of Alexander. He was the first to make use of practically all Aristotle's works: just then, about I 23I, their great worth was beginning to be appreciated. It was the Arabian commentaries, especially Avicenna's, that Alexander studied. His philosophy is in substance peripatetic; but it lacks the rigorous consistency and unity of the great, masterly syntheses that followed it. He takes his opinions and arguments from conflicting authorities: notably, he adopts from the earlier scholasticism many theories that are really irreconcilable with the peripatetic elements of his teaching. Often too, he lacks conviction, giving in a mixed and tedious fashion the various solutions that might be offered to the questions proposed, without himself espousing any of them.

St. Thomas and St. Bonaventure pay high tributes to the genius of Alexander. Even Bacon, who is so fond of maligning, has a good word to say of him, for he joins the name of Alexander with that of Albert the Great, calling them duo moderni gloriosi. ${ }^{3}$ The real value of Alexander's contribution to scholastic philosophy and theology has been long unduly underrated, for the simple reason that it was eclipsed by the brighter galaxy of writers who immediately succeeded him. ${ }^{4}$

249. His Philosophy.-Alexander brought to perfection an important teaching method in scholastic philosophy and theology. After giving the reasons for and against a given view, like Peter Abelard (174)-reasons drawn from Grecian, Arabian and Jewish sources, in addition to the traditional ones-he goes on to discuss the proper answer to be given to the proposed question, and the arguments brought forward on either side. This triple

1 "Exemplar apud fratres putrescit et jacet intactum" (ibid., p. 326).

${ }^{2} \mathrm{His}$ Summa was divided into four parts, the first treating of God, the second of creatures, the third of Christ, the fourth of the sacraments and last things.

${ }^{3}$ Communia Naturalium, Liber i., c. 3, quoted by Charles, R. Bacon, p. 375. Cf. FELDER, op. cit., p. 187 .

The charge of plagiarizing from Alexander, preferred against St. Thomas, is without foundation (Vacant, Dict. Théol. Cath., rgoo, s.v. Alexandre). 
division of the question - the pro, the contra and the resolutio-is found in all the scholastic works of the thirteenth century.

In metaphysics, Alexander teaches that God is pure actuality, actus purus, while every other being, whether spiritual or corporeal, is composed not only of essence and existence, ${ }^{1}$ but also of matter and form, that is to say, of potency and act. This is like Avicebron's teaching (221), though the name of the Jewish philosopher is not mentioned. There are, however, essential differences between the Jewish and the Christian philosopher. For Alexander appeals to the peripatetic doctrine of potency and act in justification of his theory. $\mathrm{He}$ also guards the materia universalis from all suspicion of monism, realizing the incompatibility of scholasticism with pantheism. He therefore rejects the Arabian doctrine that the soul is an emanation from a higher intelligence, and the view of David of Dinant (208) that God is the materia prima of all things, particularly of the human soul. ${ }^{2}$ Then, too, the spiritual matter is not subject to local motion, nor does it serve as a basis for substantial change (nec est subjecta motui nec contrarietati) - in contrast with terrestrial matter which is subservient to both, and with celestial matter which is subject to local change alone. ${ }^{3}$ The whole Franciscan school, with the exception of John de la Rochelle, accepted this fundamental theory of the hylemorphic composition of all contingent things. It had a companion theory in the doctrine of the plurality of substantial forms: a view that was almost universal before St. Thomas's time. Alexander recognizes this plurality in composite things (mixta), whether living or inorganic.

In psychology $y^{4}$ Alexander makes a bold but unsuccessful

${ }^{1}$ Contrary to what we find usually stated, Alexander admitted a real distinction between essence and existence. Certain commentaries on the Metaphysics, wrongly attributed to Alexander, being in reality the work of another Alexander of Alexandria, deny a real distinction. Hence the error. We therefore correct our previous edition on this point. $C f$. Schindele, $Z u r$ Geschichte $d$. Untersuchung von Wesenheit $u$. Dasein in d. Scholastik (München, rgo8) : contains notes on the question, pp. 26 and $27(246)$.

2Alexander's doctrine has no real, historical connection with Rhaban Maur's teaching on the corporeity of all things, though both views have certain analogies with each other (126).

${ }^{3}$ Guttmann, op. cit., p. 39, doubts about Alexander's drawing from Avicebron, inasmuch as the latter advocates the homogeneity of primary matter, while the former rejects this view.

${ }^{4}$ According to ENDRES (252). 
attempt to fuse together the doctrines of Aristotle and those of St. Augustine. He examines seven definitions of the soul, taken from the De Spiritu et Anima, and endeavours to reconcile them with the definition given by Aristotle. ${ }^{1}$ To understand the nature of the soul, we must seek its ultimate causes (Aristotle): God is its efficient cause, and happiness is its end, or final cause: it is composed of matter and form-just as the body too possesses its forma corporalis. The union of soul and body (unio nativa) is effected ad modum formae cum materia. This multiplicity of real elements is in keeping with Alexander's Metaphysics; it accentuates the independence of the soul in regard to the body (St. Augustine); but it jeopardizes the unity of the composite human individual.

Dealing with the activities of the soul, Alexander timidly ventures to question the theory of the identity of the soul with its faculties (anti-Augustinism). He makes a ris naturalis the principle of life, with the heart for organ: following in this the physiological teaching of Alfred of Sereshel in the De Motu Cordis. On the other hand, when he comes to treat of the intellect and knowledge he holds to the Augustinian division of the mind into ratio, intellectus and intelligentia, having for objects, respectively, the knowledge of the corporeal world and judgments relating thereto, the knowledge of created spirits, and the knowledge of the rationes aeternae and of first principles. Then, by a curious turn of speculation, he partially applies to this Augustinian doctrine the peripatetic theory of abstraction: the intelligible forms of the ratio are abstract; and their genesis is effected by the combined action of active and possible intellect-two spiritual faculties within us-together with the co-operation of a third intellect, the intellectus materialis, of the material and perishable order, and really identical with the phantasia or vis cogitativa. ${ }^{2}$ The domain of abstraction he confines to the corporeal world; the rationes aeternae or deductive knowledge of creatures in the Divine essence (Exemplarism), and the knowledge of first principles, are implanted in us by a special Divine illumination.

1 "Substantia, non tantum ut forma substantialis, sed ut quod ens in se, praeter hoc quod est actus corporis . . est substantia praetcr substantiam corporis" (S. Theol., q. 59, m. 2, § I, res).

$2 C f$. Averroës, who gives the intellectus materialis a different meaning. 
Alexander was one of the first, in dealing with the will, to distinguish between synderesis and conscientia.

250. Disciples of Alexander of Hales. John de la Rochelle.From an examination of the Chronica Fabrianensia, Felder, the recent historian of Franciscan studies, has proved that seven minorites received the bachelorship or mastership under Alexander of Hales. The bachelors were: John of Parma, Richard of Cornouailles, St. Bonaventure and William of Melito. The latter, besides completing the Summa of his master (247), has written some Quaestiones and Quodlibeta. The masters were: Robert of Bastia; Odo Rigaldi, whose Commentary on the Sentences is probably the earliest work of its kind among the Franciscans ; and JOHN DE LA ROCHELle. ${ }^{1}$ After St. Bonaventure, the latter is the best known of Alexander's disciples. Born about 1200 , he became magister regens before 1238 . Thomas of Cantimpré mentions him in the latter year as "determining" in scolis propriis. ${ }^{2}$

He would thus, according to a theory mentioned above (234), have occupied a second recognized chair of theology in the Franciscan convent, from about I 233 to I238. John was more didactic than his master and subscribed to almost all the latter's conclusions. He has left a treatise De Anima, in which we find the Augustinian theory of the identity of the soul and its faculties, the false interpretation, already referred to, of the species, and an exaggerated account of the role to be ascribed to the physiological concomitant of sensation.

25I. The Franciscan School at Oxford.-The organizer of studies among the Franciscans at Oxford was Robert GROSSETÊTE, a fellow-student with Alexander of Hales at Paris (226). Although chancellor of the University at Oxford, he lectured in the Franciscan convent there until he was appointed Bishop of Lincoln in 1235. He then discontinued his lectures, but not his active interest in the studies of the Order. On his recommendation, three other secular priests succeeded to the Franciscan chair (a certain Magister Petrus, Roger Westram and Thomas Wallensis). With AdAM OF MARISCO commences a long line of Franciscan masters. From the correspondence of Robert Grossetête with Adam we learn that the latter was

${ }^{1}$ Felder, op. cit., p. 297.

${ }^{2}$ Bonum universale de apibus, 1. i., c. 20, quoted by FELDER, op. cit., p. 212. 


\section{master of theology at Oxford in I 248. He was succeeded by Ralph of Colebruge (about i 250 ), Eustachius of Norman- VILLE and THOMAS OF YORK; this latter being the author of commentaries on Aristotle's Metaphysics. ${ }^{1}$}

252. Sources and Bibliography.-The best edition of the Summa of Alexander of Hales is the Venice edition, 1575,4 vols. The Franciscans of Quaracchi are preparing a critical edition which will shed new light on the history of the time. The best monograph on Alexander is that of Exdres, Des Alexander च. Hales' Leben u. psychologische Lehre (Philos. Jahrb., 1888). On his didactic method $c f$. Picavet (v. 180). Relations with Avicebron: Guttmann, op. cit., pp. 32-64 (v. 229). Vacant, Alexandre de Hales (Dict. Cath. Théol., I9oo, t. i., cols. 775-\$5): superficial; contains many errors. $C f$. EHRLE, FELDER and DE Martigné (237). Stevenson, Robert Grosseteste, Bishop of Lincoln (London, r899). The De Anima of John de la Rochelle was edited by Domenichelli in I882. With this work, Hauréau collates (Not. et Extr., etc., v., pp. 45-48) an anonymous treatise De Definitione Multiplici potentiarum Animae.

\section{$\S$ 3. St. Bonaventure.}

253. Life and Works. - St. Bonaventure (John of Fidanza) was born in I22I at Bagnorea in Tuscany. About $123 \mathrm{~S}$ he entered the order of St. Francis and was sent to Paris in 1242. There he followed the lectures of Alexander of Hales, whom he calls pater et magister, ${ }^{2}$ and in $12+3$ received the licentia publice legendi. Most of his theological works were commenced about this period. In 1255 he was mixed up in the disputes between the seculars and the regulars, and made a bold defence of his position in conjunction with St. Thomas, for whom he cherished a deep and close friendship. It was not until the 23 rd October, 1257 , that the University, in obedience to Papal injunctions, conferred the title of magister on himself and St. Thomas. That same year St. Bonaventure was made general of his Order. In I26o he drew up the new Franciscan constitutions at the chapter of Narbonne. He was created cardinal in 1273 and assisted at the council of Lyons, but died the next year while the council was yet in progress. His successors gave him the title of Doctor Devotus; but since Gerson's time he has been better known under the title of Doctor Seraphicus.

The following, among his authentic theological works, are of most importance for the understanding of his philosophy: ${ }^{3}$ (I) Commentarii in 4 l. Sententiarum P. Lombardi, commenced about 1248 , in which St. Bonaventure, while following his master, Alexander, rises far above the latter in the elevation and clearness of his teaching. The extracts from Alexander's Summa, believed to have been plagiarized by St. Bonaventure, are, on the contrary, interpolations introduced into the Summa after St. Bonaventure's time, in accordance with the latter's teaching. (2) Quaestiones Disputatae (especially De Paupertate); (3) Breviloquium (prior to 1257); the famous Itinerarium Mentis in Deum (1259); (4) De Reductione Artium ad Theologiam, a classification of the sciences. His chief works on mystical theology are De Triplici l'ia and the Soliloquium, modelled on the writings of Hugh of St. Victor.

${ }^{2}$ Felder, op. cit., pp. 284-30r.

${ }^{2}$ Ibid.

"According to the dissertations in t. x. of the Quaracchi edition of his works. 
254. Personal Influence of St. Bonaventure.-In philosophy, as in theology, St. Bonaventure stands forth as the champion and promoter of tradition. He makes the claim himself more than once, as, for instance, in the Praelocutio ad L. II. Sententiarum: "At quemadmodum in primo libro sententiis adhaesi et communibus opinionibus magistrorum, et potissime magistri et patris nostri bonae memoriae fratris Alexandri, sic in consequentibus. . . . Non enim intendo novas opiniones adversare, sed communes et approbatas retexere. Nec quisquam aestimet quod novi scripti velim esse fabricator," etc. His philosophical system is altogether in the conservative spirit of the earlier scholasticism, of which he may be taken as perhaps the last great representative. $\mathrm{He}$ is Augustinian by inclination as well as by tradition; yet the Augustinian elements of his philosophy are incorporated into what is fundamentally a peripatetic system. And although he defended to the last the great organic ideas of the earlier school, his works are free from all trace of direct opposition to the Thomistic innovations. He was too gentle by temperament as well as by virtue, and too intimate a friend of St. Thomas, to identify himself with the attacks directed by other Augustinians against the teaching of the great Dominican master. Let us add, moreover, that St. Bonaventure's conservatism was far from making him a slave to the tradition of the past. $\mathrm{He}$ exposed and rejected errors not merely in Aristotle and the Arabians, but in the work of his own master, Peter Lombard, and was the first to compile from the Sentences a list of false theories unanimously repudiated by his successors.

St. Bonaventure is, in the next place, the very incarnation of the purest theological mysticism of the thirteenth century. But he does not allow his mysticism to weaken or obscure in any way his genius for pure speculation, as has been often erroneously asserted of him $;^{1}$ on the contrary, he controls and masters his mysticism. In giving expression to it he is influenced by the Fathers of the Church, by Pseudo-Denis and St. Bernard, but still more deeply and directly by the Victorine tradition.

Many writers have drawn a parallel between St. Bonaventure and St. Thomas. The domination of the mystic tendency in St. Bonaventure accounts for his attachment to the synthetic method

1 The Quaracchi editors point out that only one out of the nine volumes of his complete works, and that in part only, is devoted to his writings on mystic theology. 
and his constant care to bring all psychological and metaphysical problems into relation with God, as the great centre of philosophical investigation. St. Thomas, less ardent and more calmly logical, gives greater organic coherence to the component elements of his great philosophical structure. He had also more time to perfect his work; for St. Bonaventure's scholastic labours were interrupted, from the age of thirty-five, by the distracting cares of his office as general of his Order.

255. Philosophical Teaching.-St. Bonaventure is at one with all the great masters of the thirteenth century upon an imposing array of fundamental doctrines. Their adversaries are his: he misses no opportunity of striking a blow at Averroissm and pantheism (notably at that of David of Dinant). The Scholia of the Quaracchi editors have brought out clearly this important fact, and it deserves to be carefully noted. Deferring to Art. III. the doctrines he taught in common with all the leading scholastics, we will indicate here the theories by which he made a personal impress on the philosophical teaching of his age.

I. On the relations between fhilosophy and theology, St. Bonaventure subscribes to the common opinion; but he makes theology a practical, rather than a speculative, science, ${ }^{1}$ and accentuates its affective (emotional and volitional) elements and significance. In this, perhaps, we may recognize an echo of the favourite Augustinian theory of the primacy of will over intellect and knowledge.

II. In his Metaphysics three main positions call for some attention. Firstly, in all creatures we must recognize a real distinction not merely between essence and existence, but between matter and form. Act and potency, form and matter, are convertible pairs of correlatives. The angels, therefore, are not formae subsistentes. Though matter cannot exist without form, yet it has a representative idea in the Divine mind, for it is a reality, though an indeterminate one; and if we abstract from the forms which differentiate it, we must admit it to be homogeneous in material bodies and spiritual beings (as against Alexander of Hales). This theory of the hylemorphic composition of immaterial substances, as understood in the peripatetic sense

${ }^{1}$ The Quaracchi editors are of opinion that St. Bonaventure's formula differs little (parum differt, distat) from that of St. Thomas Aquinas (Opera, t. i., p. 13). 
by the earlier scholastics, is a legacy from Avicebron. But St. Bonaventure seems unaware of its origin; for he does not mention the name of the Jewish philosopher; he even tries to trace it to St. Augustine; and the Franciscans after him appeal more and more to the authority of the Fathers rather than to that of the Jewish philosopher (see $\mathbf{2 4 3}$, and below).

The plurality of substantial forms is a second theory, imbibed by St. Bonaventure from the teaching of his master, Alexander. Not that he rejects the formula, Unius perfectibilis una sola est perfectio, but he contends that the forma completiva, which gives the being its ultimate, specific perfection, is not incompatible with other subordinate substantial forms which would be principles of inferior perfections;--and this view he applies not only to organic and inorganic compounds (mixta), but even to the elements in Nature. The plurality theory was accepted and defended universally in the Franciscan schools.

Thirdly, between the specific essence and the individual essence there is no real distinction, the principle of individuation is neither matter alone nor form alone, but both together.

III. The Existence of God, Divine Exemplarism and Creation, are the great characteristic themes of St. Bonaventure's Theodicy. God's existence is proved a posteriori. "Deus qui est artifex et causa creaturae, per ipsam cognoscitur." 1 But if we consider the Divine essence in itself, or suppose an intelligence endowed with a proper, and not merely negative and analogical, idea of that essence, for such an intelligence the Divine essence would indeed imply existence. This is the commentary of St. Bonaventure on the argument of St. Anselm. ${ }^{2}$

Secondly, in regard to Exemplarism, there are numerous passages in the Commentaries on the Sentences, in the Itinerarium Mentis in Deum and in the Hexaemeron, as well as a Quaestio disputata de cognitionis humanae suprema ratione, ${ }^{3}$ in which St. Bonaventure expressly examines the famous Augustinian texts to the effect that all knowledge takes place ratione lucis increatae

${ }^{1}$ In I. L. Sent., t. i., p. 72.

${ }^{2}$ Such is the interpretation of the Quaracchi editors, t. i., pp. I55, I56. DomeT DE VORGes (op. cit., p. 294) also observes that St. Bonaventure reproduces St. Anselm's argument only with characteristic reserves.

${ }^{3}$ First published in the De Humanae Cognitionis Ratione Anecdota Quaedem S.D.N. Bonaventurae, etc., Quaracchi, $188_{3}$; reproduced with slight additions in the Quaestiones Disputatae de Scientia Christi, q. iv. (t. v., p. 17). 
or rationibus aeternis, that God is present by $\mathrm{His}$ truth to all intelligences, etc. It is certain that St. Bonaventure did not understand those texts in an ontologistic sense ${ }^{1}$ while his opposition to the Averroist theory of the unity of the human intellect (hic error destruit totum ordinem vivendi et agendi), and his own ideology, clearly imply the view that man is himself an efficient cause of his intellectual activities. He merely throws into bold relief and expounds more eloquently than the other great scholastics, the Augustinian theory on the Divine ideas as objective foundations of truth and certitude, and the illumination of the human intelligence by a light that is Divine (Ioo and roz). This illumination consists firstly in the Divine resemblance imprinted on our intelligences by the creative act itself, and secondly in the immediate concursus of the First Cause with every exercise of thought. We do not think that St. Bonaventure accepted the theory of a special illumination, which, according to some of his contemporaries and immediate predecessors, representing the earlier scholastic tradition, would be something distinct from God's general or ordinary co-operation with the creature. On this important point of Augustinian exegesis-important in theodicy, in metaphysics and in ideology-St. Bonaventure thinks with St. Thomas and Duns Scotus: only in his mode of expression does he appear to differ from them."

1 See the Scholion on the Itinerarium, t. v., pp. 313-516.

2 The Quaracchi editors have rightly insisted on this point. See especially the Scholion to d. 24 , p. I, In II. L. Sent. (t. ii., p. 570): “Manifeste ostenditur S. Doctorem ab aliis principalibus Scholasticis in hac doctrina [i.e., de ratione cognitionis humanae] non discrepare nisi in modo loquendi, vel in re exigui momenti". Cf. t. i., p. 7o. So too in the dissertatio dealing expressly with this questionprefixed to the question referred to in note $\mathrm{I}$. So, finally, in this other text (t. $x$., Dissertatio de Scriptis, p. 3r), which sums up St. Bonaventure's ideology and shows how he considers St. Augustine to have united Plato and Aristotle: "Licet anima secundum Augustinum connexa sit legibus aeternis, quia aliquo modo illud lumen attingit secundum supremam aciem intellectus agentis et superiorem portionem rationis, indubitanter tamen verum est, secundum quod dicit Philosophus, cognitionem generari in nobis via sensuum, memoriae et experientiae, ex quibus colligitur universale in nobis, quod est principium artis et scientiae. Unde quia Plato totam cognitionem certitudinalem convertit ad mundum intelligibilem, ideo merito reprehensus fuit ab Aristotele. Et hoc ponendo, licet (Plato) videtur stabilire viam sapientiae, quae procedit secundum rationes aeternas, destruebat tamen viam scentiae, quae procedit secundum rationes creatas. Et ideo videtur, quod inter philosophos datus sit Platoni sermo sapientiae, Aristoteli vero sermo scientiae. Ille enim principaliter aspiciebat ad superiora, hic vero principaliter ad inferiora.Uterque autem sermo, scilicet sapientiae, et scientiae, per Spiritum Sanctum datus 
Creation, which offers the only intelligible explanation of the origin of the world, took place in time: an eternal creation implies a contradiction. On this question, so hotly debated in the thirteenth century, St. Bonaventure defends with great energy the view of the earlier scholastics, not only against Aristotle and the Averroists, but also against the more moderate conclusions of Thomism.

IV. In Physics and Psychology respectively, we may note the theory of the rationes seminales and the doctrine on the nature of the soul and its relation to its faculties. Primary matter is not purely passive. It contains within itself, in an undeveloped and imperfect state of being, the various substantial forms with which it is destined to be united under the operation of natural agencies. It is in order to distinguish the transformations of natural substances from creation and annihilation that St. Bonaventure has recourse to the rationes seminales. He thus reinstated the old Augustinian doctrine, ${ }^{1}$ and the authority of his great name was quickly claimed by the promoters of a movement of reaction against Thomism towards the end of the century (312).

On the delicate question of the distinction between the soul and its faculties, St. Bonaventure propounds, though not without hesitation, ${ }^{2}$ a sort of compromise between the old Augustinian and the new Thomistic theory. On the one hand, he does not allow with the Thomists that the three great faculties of the soul are superadded, distinct realities; but neither, on the other hand, does he admit identity of essence between the soul and the principles of action which emerge from the soul: they are, however, con-substantial with the soul. ${ }^{3}$ Supporting the peripatetic ideology, he denies that we have any innate ideas, but we have an innate intellectual habit which he calls the naturale judicatorium. Then, also, he holds with St. Augustine that the will is the noblest of our faculties.

est Augustino tanquam praecipuo expositori totius Scripturae satis excellenter, sicut ex ejus scriptis apparet" (Sermo, t. v., p. 572). Aristotle is the savant, Plato the sage, Augustine both the savant and the sage.

1 " Hanc positionem credo esse tenendam non solum quia eam suadet ratio, sed etiam quia confirmat auctoritas Augustini" (t. ii., p. r98).

${ }^{2}$ See Scholion, t. ii., p. 78.

3 " Istae potentiae (memoria, intelligentia, voluntas) sunt animae consubstantiales, et sunt in eodem genere per reductionem, in qua est anima. Attamen, quoniam egrediuntur $a b$ anima-potentia enim se habet per modum egredientis-non sunt omnino idem per essentiam" (In L. I. Sent., D. III., p. 2, art. i., q. 3, t. i., p. 86). 
In accordance with the general principles of his metaphysics he distinguishes in the human soul a forma and a materia spiritualis, and in the individual human being a plurality of forms. His teaching is peripatetic in regard to the nature of the human compositum, and on the spirituality and immortality of the soul.

256. Mysticism of St. Bonaventure. - Intimate union with God is the term of all knowledge (De Reductione Artium ad Theologiam). It is achieved by a process with several distinct stages, all of which are described by St. Bonaventure, on the lines of the Victorine mysticism, in a comprehensive work entitled Itinerarium Montis in Deum. Besides the eye of the flesh (oculus carnis) and the eye of reason (oculus rationis), there is also in every man an eye of contemplation (oculus contemplationis) (198).

Firstly, we may know and love God in Nature, which was made to His likeness (vestigium). This knowledge (cogitatio, theologia symbolica) we reach (a) by the external senses (per vestigium), and (b) the imagination (in vestigio). Thus the Saint completely justifies his holy founcler's fervent outbursts of love for even the lowliest of God's creatures in the hallowed regions of Assisi.

Secondly, we may know and love God in His image (imago Dei), i.e., in our own soul. This is meditatio, theologia propria. We see God thus, through our soul (fer imaginem) and in our soul (in imagine): (a) through our soul when its three faculties, memory, understanding and will, by mirroring the Blessed Trinity in us (St. Augustine), raise us up towards God. Nemory preserves for us the Divine deposit of first principles. Will can be moved only by having presented to it the ideal good which is God. Understanding grasps the supreme and immutable truth of things only in virtue of an illumination from on high, which unites it with God (255, III.). The supernatural aid of Divine grace, though helpful to the advance of the soul along those first three stages, is not formally required until the fourth stage is reached. (b) For this fourth stage the preceding stages are but a preparation: here we see God in the soul (in imagine): for this, Divine grace and the theological virtues are communicated to us.

Thirdly and finally, after having learned to know God in His works, we attain to a direct knowledge of Him. His grace reveals Him to us successively $(a)$ in His Being and $(b)$ in the 
boundless Goodness of the Blessed Trinity: upon which revelation there follows a seventh and final stage of indescribable bliss and repose, the state of ecstasy which marks the culmination of the soul's ascent towards the Deity. Carried up to this highest apex of the mystic life (apex mentis), we are in the enjoyment of the Infinite. Here we have contemplation par excellence: the real object of the theologia mystica. We need scarcely observe that this outpouring of love between Creator and creature in no way compromises the substantial distinction between them (199-201).

Posterity bows reverentially before this great master of contemplative mysticism.

257. Sources and Bibliography. - The great critical edition of St. Bonaventure's works, published at Quaracchi, I882-rgo2, is a scientific monument of the highest excellence and a model of the best style of editing scholastic works. Vols. i -iv. contain the Commentaries on the Sentences. Each volume contains critical prolegomena, a critical edition of the text, and, after the principal questions, scholia which are veritable monographs on the history of the theories dealt with in the questions. Vol. v. contains eight theologico-philosophical opuscula. Vols. vi.-ix. contain but little of interest to philosophy. Many portions of the text, especially the Quaestiones Disputatae (except the De Paupertate) are here published for the first time (vol. v.). The prolegomena to vol. iii. give tables of philosophical divergences of view between St. B. and St. Thomas Aquinas in their Commentaries on the Sentences. Vol. x. gives a dissertation on the life and writings of the Saint: very useful. See too a list of the principal scholia of the first four volumes-and a study of some I08 apocryphal or doubtful writings. The scholastic side of the Saint's life and personality is excellently handled.

Joannes de Rubino et Antonius Maria a Vicetio, Lexicon Bonaventurianum (Venice, r880). The materials for a comprehensive review of St. Bonaventure's philosophical writings and their place in history, are collected in the scholia of the Quaracchi edition, but such review has not yet appeared. A. DE MARGERIE, Essai sur la philosophie de S. Bonaventure (Paris, 1855 ): insufficient. De Martigne, op. cit., 237. KRAuse, Die Lehre d. hl. B. über d. Natur d. körperl. u. geistigen Wesen $u$. ihr Verhältniss z. Thomismus (Paderborn, I888): special question, well treated. Same author: Comment. plitlos. Quomodo S. B. mundum non esse aeternum sed tempore ortum demonstraverit (Brunsberg, r89o). On Exemplarism: De Humanae Cognitionis Ratione Anecdota Quaedam Seraphici D. S. Bonaventurae et nonnullorum ipsius discipulorum, edita studio et cura PP. Coll. a S. Bonaventura (Quaracchi, I883) : an excellent monograph followed by text of a question and sermon of St. B. (supra, 255, III., note), questions of Matthew of Aquasparta, John Peckham, Eustachius, Roger the Englishman and Richard of Middleton, on the foundations of human certitude. ZIESCHE, Die Lehre v. Materie u. Form bei B. (Philos. Jahrb., rguo, p. r); Die Naturlehre Bonaventura's (ibid., rgo8). Eduard Lutz, Die Psychologie Bonaventuras nach Quellen dargestellt (Münster, rgog). 


\section{§. The Disciples of St. Bonaventuke.}

\section{First Disciples. Matthew of Aquasparta and John} Peckham.-During the few years he devoted to teaching, St. Bonaventure made disciples. The influence of his lectures survived him in the schools. His immediate successors, MATTHEW of Aquasparta and John Peckinam, are most deserving of note.

Matthaeus ab Aquasiakta (I 235 or I 240-I 302), master at Paris and at Bologna, was the second of his order called to Rome as lector of the Sacred Palace (I28I), where Innocent IV. had established a Studium Generale. He was elected general of the order in 1287 , made cardinal in 1288 , and bishop of Porto soon afterwards. He wrote Commentaries on the Sentences, Quodlibeta and Quastiones Disputatae - the fruit of his teaching at Rome and Bologna. Imbued himself with the teaching of St. Bonaventure (from whom he borrowed liberally, e.g., his arguments against the eternity of creation and his theory of the hylemorphic composition of spiritual substances), Matthew imparted to Duns Scotus not a few of his own favourite theories. IVe can form an estimate of his personality as a scholastic from some questions of his recently edited De Fide et De Cognitione Humana, selected from his Quaestiones Disputatac. These reveal their author as a writer of undoubted talent, with a sober, clear and manly style, and a depth and richness of thought which place him abreast of even the best known among his contemporaries.

The De Fide gives his system on the foundations of faith and its relations to reason. It is worthy of note that he restates and refutes the reasonings of Abelard, observing that the latter's teaching still found many adherents (alii dixerunt et multi adhuc dicunt). ${ }^{1}$

The De Cognitione contains a whole psychology. It opens with an exhaustive discussion on the foundations of human certitude and the vision of truth in the "rationes aeternae". The author's sympathies with St. Augustine are manifest on every page. In

${ }^{1}$ Quaracchi edit., p. 63: "In istum errorem lapsus fuit Petrus Baalardi". He also chronicles the theory of Frederick II., denying the existence of all positive law. "Istius erroris dicitur fuisse Fredericus, qui fuit imperator; qui omnes legislatorec reputabat truffatores" $\left(\mathrm{r} . \mathrm{s}_{3}\right)$. 
fact it is difficult tu find, in the theses of the philosopher-cardinal, anything else than the doctrine of his favourite master; and his exposition of it appears to us more lucid and concise than St. Bonaventure's. In the first place, the truth of things has its objective basis in the "rationes aeternae". Moreover, God is not only the creator of the human understanding $;{ }^{2}$ He conserves it and concurs in every single one of its operations. ${ }^{3}$ This immediate concurrence, essential to the activity of all created being whatsoever, is in keeping with the inner nature of each created agent. Matthew next insists, with St. Bonaventure, on the special resemblance (imago similitudo) the intelligent creature bears to his Creator. This resemblance springs from the very power of understanding, and it is in this sense that the Divine concursus, as applied to the act of understanding, gets the special name of an illumination. ${ }^{4}$

In Matthew's doctrine on ideas we find the following peculiarities: (a) Cognition is an active phenomenon. Though endowed from birth with a judicatorium naturale, we have no innate actual idea of the external world ( $c f$. St. Bonaventure, supra, 255, IV.). All our ideas come from without, through the channels of the senses. But the sense object does not act upon the soul. On the contrary, the latter forms within itself, on the occasion of the sense impression, a corresponding sensation. And the same is true of

1 "Quidditas ipsa concepta ab intellectu nostro, relata tamen ad artem sive exemplar aeternum" (p. 233). See whole of q. i.

${ }^{2}$ That, he remarks, would not contain the whole meaning of St. Augustine's teaching.

3'Lumen ergo illud, movendo nostrum intellectum, influit quoddam lumen menti nostrae, ita quod per lucem divinam videt objective et quasi effective, sed per illud et in illo lumine videt formaliter; quod quidem lumen continuatur et conservatur in mentibus nostris ad praesentiam divinam. Nec alicui subtrahitur cognoscenti, immo omnibus bonis et malis indifferenter assistit secundum ordinationem et dispositionem immutabilem suae sapientiae, qua cooperatur in intellectuali operatione" (p. 255). " Ratio cognoscendi materialis est ab exterioribus, unde ministrantur species rerum cognoscendarum, sed ratio formalis partim est ab intra, scilicet a lumine rationis, partim a superiori, sed completive et consummative a regulis et rationibus aeternis" (p. 26r).

4 " Operatio intellectualis circa naturalia naturalis est. Deus autem operatur et cooperatur in operationibus creaturarum secundum modum et exigentiam suae naturae, ut visum est. Et quia creatura rationalis imago Dei est vel ad imaginem, ipsa ratio imaginis exigit, ut in ejus operationibus cooperatur secundum modum objecti moventis, eo quod mens nata est moveri et illuminari illa luce" (ad. i., p. 262). C $f$. ad. 5, where he contrasts the influentia generalis et communis with this influentia of the illuminative order. 
thought : the intellectus agens transforms the species sensibilis (" et illud vocat Philosophus abstrahere") and determines the intellectus passivus, without any causal intervention of the external object. This is pure Augustinism (239) with the Aristotelian theory of the intellectus agens forcibly attached to it. ${ }^{1}$ (b) We know individual things, each by its own proper individual species." Matthew here expressly refers to the Thomistic opinion (30o), which he holds to be insufficient, that the "intellectus singulare cognoscit per quandam reflexionem ". ${ }^{3}$ (c) The soul has a direct consciousness or cognition of itself. Though it is not itself the primary object of its own knowledge (" nec primus actus cognitionis potest esse in semetipsam; quantum ad cognitionis initium indiget . . excitatione a corporis sensibus"), nevertheless, as soon as it comes into possession of species abstracted from without, it can know itself and its internal states not merely by inference but by intuition: "sua interiora... (potest)... directo aspectu cernere et intueri, ita quod semetipsam et habitus existentes non cognoscit tantum per arguitionem sed per intuitionem"." That the Augustinian view is here meant to be conveyed, we may gather from the author's refutation of St. Thomas's position, that the soul becomes aware of its existence and states only in the actual crercise of its activities: "percipit se esse et habitus sibi inesse per actus". 5

Those Augustinian positions do not prevent Matthew from subscribing to the doctrine of natural and substantial union between soul and body. ${ }^{6}$ He was led to study this question in considering those higher mystic states of rapture and ecstasy, which he regarded with St. Bonaventure as of the supernatural order, and as originating in the intelligence but completed and perfected in the will ${ }^{7}$ ( $f$. 198 and 256 ).

Jom PeCKhily, a pupil of St. Bonaventure at Paris, afterwards

1 "Sic igitur dico sine praejudicio, quod anima sive intellectus accipit sive capit species a rebus extra, non virtute rerum corporalium agentium in animam vel intellectum sed intellectus sua virtute facit et format. Huic sententiae Augustinus corcordat in auctoritatibus adductis in opponendo; concordat nihilominus Philosophus : et ideo huic positioni ad praesens adhaereo" (p. 29r). The whole responsio must be read (pp. $27 \delta$ sqq.).

2 “ Dicendum sine praejudicio, quod revera intellectus cognoscit et intelligit singularia per se et proprie, non per accidens, ita quod singularia cognoscit per species singulares, universalia per species universales" (p. 309).
${ }^{3}$ Op. cit., p. 307.
4 P. 329.
5 P. 326.
${ }^{6}$ P. $42 \mathrm{I}$.
${ }^{7}$ P. 405 . 
taught there himself towards I 269, and later at Oxford, where he was master. He next became lector of the Roman Curia, and finally Archbishop of Canterbury in 1279. A number of Quaestiones Disputatae and Quodlibeta, a Tractatus Sphaerae and treatises De Perspectiva, De Numeris and Super Ethicam, are set down in his name in various manuscripts. These works being still unedited, the doctrines of Peckham are not well known. We can gather, however, from certain of his letters, that he was an ardent admirer of tradition ${ }^{1}$ and a vigorous supporter of received doctrines as against the innovations of Thomism (312).

Besides Peckham and Aquasparta, we may also mention, among the earlier disciples of St. Bonaventure: WILLIAM DE LA MARE (wrote Commentaries on the Sentences and Quaestiones Disputatae, still unedited); a Brother EUSTACHIUs (author of some Quaestiones Disputatae) whom the Quaracchi editors propose to identify with Eustachius of Arras $;^{2}$ a Brother Srmon; and WALTER OF BRUGES (Bishop of Poitiers, 1279-1307, author of Quaestiones Disputatae and Commentaries on the Sentences).

259. Peter John Olivi (I 247-I 298) occupies a place apart in the history of the Franciscan order towards the close of the thirteenth century. His efforts in regard to disciplinary reform in his order are no less noteworthy than his teachings in philosophy and theology.

He ventilated the question De usu paupere-endeavouring to interpret evangelical poverty as the use of the minimum necessary for subsistence. He gathered around him a party called "spirituals," who got into conflict with the community. In I 282 a chapter of the order, at Strassburg, decided to examine into Olivi's doctrines. The following year, a meeting of Franciscan university doctors condemned thirty-four propositions taken almost exclusively from his Quaestiones. He was not cited to appear in his own defence, but he sent his judges a long written justification of his teachings. The condemnations were

${ }^{1}$ In the De Humanae Cognitionis Ratione, etc., we find a quaestio disputata of John Peckham on the "rationes aeternae". His view coincides with St. Bonaventure's: in every act of intellectual cognition the "lumen increatum supersplendens" concurs with the "lumen intellectus creatum" and the "intellectus possibilis" (p. I8r).

2 They publish a quaestio of Eustachius on the foundations of human knowledge (op. cit., pp. I79 sqq.), in which the problem is solved in the sense of St. Bonaventure and St. Thomas. 
directed in part against certain philosophical views to which Olivi had given expression: most notably against his teaching about the plurality of substantial forms in the individual.

Olivi regarded the principles of vegetative, sensitive and intellectual life as three distinct substantial parts or portions, all alike rooted in a common spiritual matter, and uniting with one another to form by their union one single human soul (anima rationalis) in each individual man. There was no novelty, at that time, in the doctrine of a plurality of forms in the individual, nor in the doctrine of a spiritual matter. The Dominican, Kilwardby, and even Richard of Middleton, who was one of Olivi's Parisian examiners, subscribed to both doctrines in practically the same terms as the latter. But Olivi advanced, in addition to these, some new and dangerous theories. He maintained that the intellectual part (pars intellectiva) does not directly "inform" the human body, but only through the intermediary of the sensitive part: its union with the body, though substantial, is not formal. ${ }^{1}$ The bitter complaints of the Franciscan community against this teaching induced Pope Clement V. to take cognizance of the dispute." Protracted negotiations, opened in 1309 , led up to the council of Vienne in Dauphiné, in I3II. One of the propositions condemned at the council concerned the union of the soul and body. It is dealt with under this formula: “... Quod si quisquam deinceps asserere, defendere seu tenere pertinaciter praesumpserit, quod anima rationalis seu intellectiva non sit forma corporis humani per se et essentialiter, tanquam haereticus sit censendus". This definition does not touch the

${ }^{1}$ See Olivi's arguments in his works and in Duns Scotus. The same opinion was defended by Petrus de Trabibus, a faithful disciple of Olivi (Arch. f. Litt. $u$. Kirchengesch. d. Mitt., iii., 459). Cf. Zigliara, op. cit., p. ror: "Dico quod anima rationalis sic est forma corporis quod non est per omnes partes suae essentiae, utpote non per materiam nec per partem materialem, nec per partem intellectivam, sed solum per partem sensitivam". The anima rationalis would, therefore, be itself composed of substantial parts, namely, the pars sensitiva, the pars intellectiva and the pars materialis.

2In the complaint formulated by the community against the "spirituals," in I $3 \mathrm{I}$, we read: "Item docuit, quod anima rationalis non est forma corporis humani per seipsam, sed solummodo per partem sensitivam; adjiciens, quod si esset forma corporis, sequeretur, quod aut communicaret corpori esse immortale aut ipsa non haberet esse immortale de se; ex quo posset inferri quod Christus, qui veraciter nostram humanitatem assumpsit, non fuit inquantum homo ex anima rationali et humana carne compositus et subsistens, sicut fides docet catholica" (EHrLe, Arch. f. Litt., etc., ii., p. 36). 
question of the number of forms in man, but it implies that if there be many, each of them informs the composite individual essentially and of itself. The doctrine of Olivi was condemned, but the controversies on the unity or plurality of forms in the individual were left free and untouched.

260. Later Disciples of St. Bonaventure. Richard of Middleton.-To the second generation of Franciscan masters who drew from St. Bonaventure, belong the following: William of FALGAR, third lector at the Sacred Palace, Bishop of Viviers in I284, author of Quaestiones Disputatae; NichOLAS OCKAM; John of Persora; Hugh of Petragoris ; Roger Marston, of whom more below (Ch. V.); Alexander of Alexandria, general of the order, died I314, made a compendium of St. Bonaventure's Commentaries on the Sentences, author of Quaestiones Disputatae and Commentaries on Aristotle's Metaphysics, published in 1572 as the work of Alexander of Hales. Of greater importance than any of those is RICHARD OF MIDDLETON.

In $\mathrm{I} 28 \mathrm{I}$ we find Richard occupying the chair of the Franciscans and commenting on the Sentences of the Lombard. In I 283 he was one of the judges of Peter John Olivi (259), and from 1285 till his death, about the end of the century, he was tutor to St. Louis of Toulouse. Among his numerous works are the Quodlibeta, Commentaries on the Sentences, Quaestiones Disputatae of great value, and Commentaries on the Quodlibeta of Peter of Auvergne and of Henry of Ghent. All these works are still unedited. Richard was a loyal disciple of St. Bonaventure, but on certain points he follows the Thomistic tradition. He defends the temporal creation of the world, the identity of the soul with its faculties, the plurality of forms; he rejects the doctrine of the rationes seminales; he is doubtful about the hylemorphic composition of spiritual substances, and he does not differ from SS. Thomas and Bonaventure in his interpretation of the Augustinian theory of the rationes aeternae. ${ }^{1}$ Richard was highly esteemed among the Franciscans: he was their greatest master during the interval between St. Bonaventure and Duns Scotus : his disciple gave him the title of Doctor Solidus, Fundatissimus.

At the end of the thirteenth, and all through the fourteenth century, St. Bonaventure's Commentaries on the Sentences were

${ }^{1}$ Judging from the extracts from the "quaestio disputata," published in the $D e$ Hum. Cognit. Rat., etc., pp. 220 sqq. 
themselves the text of numerous commentaries in the various branches of the Franciscan order. The Quaracchi editors enumerate seven philosopher-theologians whose exegesis of St. Bonaventure remains still unedited, and twenty-three whose works have been printed. ${ }^{1}$ However, the success of Scotism lessened and finally extinguished the study of St. Bonaventure among the Franciscans.

26r. Sources and Bibliography.-Mathalis ab Aquasparta, $Q:$ aestiones Disputatae Seiectae, t. 1., Quaestiones de Fide et de Cognitione (Quaracchi, 1903): critical edition. The same editors are preparing an edition of the works of Richard of Middleton. The Quollibeta of Olivi were found in 1878 in the Borghese Library. EHRLE, Das Studi'm d. Handschriften, etc. (240); Dissertatio de Scriptis of St. Bonaventure in the Quaracchi edit., t. x.; the De Humanae Cognitionis Ratione, etc., Prolegomena (257). Grabmann, Die phzlos. u. theol. Erkenntnislehre des Kard. Mathaeus r'. Aquasparta (Beitrag z. Gesch. d. Verhältn. zwischen Augustin. und Aristotelismus im mittelalt. Denken, Vienna, I906). Controversy on the definition of the Council of Vienne, between PaLmieri (Anthropologia, 1875) and ZigLiara (De Mente Concilii Vienniensis, 1875); Palmieri, Animadversiones in Recens (jpus de Mente Concilii Vienn. The question has been settled by Ehree, Olivi's Leben und Sihriften (Arch. f. Litt. u. Kirchengesch. d. Mitt., iii., 409, I88); $Z$ Zur Vorgeschichte des Concils von Vienne (ibid., ii., p. 353, I886; iii., p. I, 1887). Ein Bruchstück d. Acten des Concils von Vicnne (ibid., xviii., p. 36r); cf. 237. B. Jansen, Die Definition d. Koncils v. Vienne (Zeitsch. für. Kath. Theol., 1908, pp. 288, 471): gives a résumé of the whole matter.

\section{§ 5. The Dominican Masters and tile Earlier Scholasticism.}

\section{The First Dominicans at Paris. Peter of Tarantaise-} The first magistri who occupied the Dominican chairs at Paris taught the older scholasticism, because they were themselves trained in the older system prior to the Albertino-Thomistic innovations, and were not much influenced in their convictions by the latter. Chief among them are ROLAND OF CREMONA, first licentiate of the order; JOHN OF ST. GILES, first titular of the second Dominican chair; Hugh of SANCTO CARO, who was the second magister actu regens, about 1230 ; and, more especially, PETER of TARANTAise.

Actu regens at Paris in 1259, archbishop of Lyons (1 272), of Ostia (1273), and pope under the name of Innocent V., Peter of Tarantaise is the author of several works on Scripture, of commentaries on the Sentences, and of four philosophical treatises: De Unitute Formae, De Materia Coeli, De Aeternitate Mundi, De 
Intellectu et Voluntate. He emphasizes the practical side of the science of theology, combats the theory of eternal creation, hesitates between the hylemorphic composition of spiritual substances and their simplicity-the former opinion being planior, facilior, the latter subtilior ${ }^{1}$ - is rather favourable to the theory of the rationes seminales, but advocates a real distinction between the soul and its faculties. $\mathrm{He}$ is in the main faithful to the earlier traditions, without, however, joining actively in the opposition movement against Thomism (Art. IV., § I).

263. The First Dominicans at Oxford. Robert Kilwardby.At Oxford the most noted Dominican master was Robert Kilwardby. ${ }^{2}$ He defended most of the characteristic theories of the earlier school and took up an aggressive attitude against Thomism (312). He was successively professor at Oxford (I 248-I 26I), provincial of his order (I 26I-I 272), archbishop of Canterbury (1272-I 278). He wrote commentaries on the Prior Analytics and on the Sophistical Reasonings. $\mathrm{He}$ is also the author of a treatise De Ortu et Divisione Philosophiae, which marks an advance on the similar treatise of Gundissalinus and is described by Baur as the most remarkable work of the Middle Ages on the classification of the sciences. ${ }^{3}$ It unites the classifications of the schools of St. Victor with those of the Arabian school of Toledo. It is noteworthy not so much for any new ideas as for the author's care to show the peripatetic spirit of the work and to study in close detail the mutual relations of the various branches. The mechanical arts appear in philosophy alongside ethics; and logic, while contrasted as the scientia rationalis with all scientia realis, is incorporated into philosophy proper. ${ }^{4}$

264. Bibliography. - The works of the earlier Dominicans are still unedited. Baur gives the table of questions treated in the De Ortu et Divis. Philos. (op. cit.), p. 246.

${ }^{1}$ Edit. of St. Bonaventure, t. ii., p. 94. Scholion.

${ }^{2}$ Before him is mentioned ROBERT FitzACRE, reputed author of some commentaries on the Sentences.

3 Op. cit., p. 368.

4 Baur also thinks he detects in Kilwardby the influence of St. Thomas. This is doubtful : Kilwardby was the uncompromising opponent of Thomistic theories. Here is Kilwardby's scheme of philosophy: I. Philosophia rerum divinarum (naturalis, mathematica, metaphysica). II. Philosophia rerum humanarum: (I) Practica. (a) Ethica (solitaria, privata, publica). (b) Artes Mechanicae. (2) Logica, scientia rationalis. Compare with St. Thomas's scheme: I. Philosophia Realis: (I) Theoretica vel speculativa (naturalis, mathematica, divina). (2) Practica (ethica vel monastica, oeconomica, politica). II. Philosophia Rationalis, Logica. 


\section{ART. III.-THE PERIPATETICISM OF ALBERTUS MAGNUS AND ST. THOMAS; THE SCHOLASTIC SYNTHESIS.}

265. Outline.-The scholasticism of St. Thomas Aquinas ushered in much that was new into the teaching of the Friars Preachers, and into the schools of the thirteenth century generally. It differed from all preceding systems in its more thoroughly peripatetic basis and in its superior doctrinal consistency. This new Domincian scholasticism was commenced by Albert of Bollstädt and brought to completion by St. Thomas of Aquin.

When St. Thomas had completed his work, Medieval Europe found itself in possession of one of its most remarkable monuments of constructive speculative thought. The scholasticity of the teaching shines out more clearly in the philosophy of St. Thomas than in any other system. By reason of its marked superiority (309) the Thomistic scholasticism enables us to grasp with greater ease those great, underlying, organic and constitutive ideas which characterize the scholasticism of the thirteenth century in general. We cannot study a system to better advantage than in the works of its ablest and most authoritative representative. It is for this reason, and not as giving him any undue monopoly of philosophical genius or knowledge, that we have decided to set forth the system admitted in common by all scholastic philosophers as such, in conjunction with our exposition of St. Thomas's own personal teaching $(\mathbf{1 1 8}, \mathbf{2 3} 8)$.

When we remember that the scholasticism of the thirteenth century occupies a central place in the evolution of ideas in the Middle Ages; that it unifies, completes and consolidates the doctrines of the earlier Middle Ages (134); that it inspires all the speculation of the few subsequent centuries, and is therefore rightly regarded as the culmination of Medieval Scholasticism; we can understand why this thirteenth-century teaching deserves the name of Scholasticism, simply and without qualification.

We shall deal successively with Albert the Great ( $\S$ I) and with St. Thomas and the scholastic synthesis $(§ 2)$.

\section{§ I. Albert the Great.}

266. Life and Works. -Albert of Bollstädt, commonly known as Albertus Magnus or Albert the Great, was born of the lamily of the Counts of Bollstädt in the year I193, or, according to others, in 1206 or 1207 . He took the habit of St. Dominic in 1223. A lengthened scientific education, combined with much travel, 
had wonderfully developed his great natural genius. He tells us himself that he took observations of a comet in Saxony (1240), and went abroad to study the nature of the metals. From 1228 to 1245 he taught successively at Cologne, Hildesheim, Freiburg, Ratisbon, Strassburg, then again at Cologne, where, in 1245, he had among his pupils Thomas Aquinas. It was in Paris, from 1245 to 1246 , that he taught theology as magister with exceptional renown. It was then he commenced the publication of his vast scientific and philosophical encyclopedia. This was practically finished in 1256 , but he kept on perfecting it to the end of his life. ${ }^{1}$ When he returned to Cologne, in 1248 , to establish the studium generale that had been decided on at the general chapter of the order in June, he had Thomas Aquinas again among his pupils. In 1252 Albert himself recommended his eminent pupil to the magister regens of the order at Paris for promotion to the bachelorship. Subsequent to this date, Albert's numerous judicial labours, his cares as provincial of the German province from 1254 to 1257 , and later as bishop of Ratisbon (1260-1262), drew him away somewhat from study. After resigning those charges he withdrew to the convent of Cologne, which he made his habitual residence, teaching and writing there. In 1270 we find him in correspondence with Giles of Lessines on the subject of the theses condemned a few months subsequently by Stephen Tempier ( $\left.3^{1} 3\right)$, and when in 1277 the condemnations of the bishop of Paris touched the doctrine of Thomas Aquinas, Albert travelled to Paris to defend the teachings of his former pupil. He died at Cologne, on the ${ }^{5} 5^{\text {th }}$ of November, $1280 .^{3}$

Even during his own lifetime, Albert had earned a world-wide reputation as a man of science. Roger Bacon, though no friend of his, bears testimony to this fact. In Albert's case an exception was made to the general rule recognized in the thirteenth century, of not quoting living authors by name. The illustrious Dominican was declared the equal of Aristotle, Avicenna and Averroës. ${ }^{3}$

The works of Albert form a library in themselves. To convince ourselves of this we have only to consult the catalogue of the abbey of Stams-an invaluable repertory of Dominican works down to the third decade of the fourteenth century, continued and completed by Lawrence Pignon ( $\left.\mathrm{I}_{449}\right){ }^{4}{ }^{4}$ The following are Albert's principal works :-

(1) Philosophical Writings.-(a) Paraphrases: De Praedicabilibus; De Praedicamentis; De Sex Principiis; Perihermenias; Analytica; Topica; Libri Elenchorum; Physica; De Coelo et Mundo; De Natura Locorum; De Proprietatibus Elementorum; De Generatione et Corruptione; De Meteoris; De Mineralibus ; De Anima; De Sensu et Sensato; De Memoria et Reminiscentia; De Intellectu et Intelligibili; De Somno et Vigilia; De Spiritu et Respiratione; De Motibus Animalium; De Morte et Vita ; De Vegetalibus ; De Animalibus; Metaphysica; Ethica (two separate works); Politica; and various smaller treatises.

${ }^{1}$ Mandonnet, in the Dict. de Theol. Cath., t. i., col. 666.

${ }^{2} \mathrm{DE}$ LOË terminates his account of Albert's regesta with this well-deserved judgment: "nullus eo tempore in tam diversis negotiis simul tantus exstitit" (De Vita et Scriptis, etc., $c f .27 \mathrm{I})$.

3 “ Nam sicut Aristoteles, Avicenna et Averroës allegantur in scholis, sic et ipse" (R. Bacon, Opera Inedita, Brewer's edit., p. 30). Similarly Giles of Lessines writes: " haec est positio multorum magnorum et praecise Domni Alberti quondam Ratisponensis episcopi" (De Unitate Formae, De Wulf's edit., p. 36).

4 This catalogue is published by Denifle, Quellen z. Gelehrtengesch. d. Predigerordens, etc. See 237. 
(b) More original treרtises: De Unitate Intellectus contra Averröstas; Quindeccm Problemat ‘ contra Averroïstas; De Causis et Processu Universitatis, - a study of the gradations of order among created things. The Summa Philosophiae Naturalis, or Philosophiı Pauperum, of which the authenticity is contested, sums up his teaching on the natural sciences.

(2) Theological Writings, all of which contain much philosophy: Commentaries on the Sentences of Peter Lombard; the Summa Theologiae (numerous doctrines, as well as plan of the whole, borrowed from Alexander of Hales); the Summa de Creaturis, which reconsiders some of the matters contained in the second part of the Summa Theologiae and the De Anima.

267. Influence of Albert the Great on Philosophy.-Albert popularized Aristotle. He conceived and executed the great project of "reconstructing Aristotle for the use of the Latins". To make the Stagirite "intelligible" he wrote a free paraphrase of all the latter's works, following the titles and the order of the various treatises (32). "He did not undertake to write a commentary on the text of Aristotle, but borrowed from him a doctrinal scheme which he filled in copiously from the materials furnished both by Aristotle himself and his commentators, adding thereto opinions and speculations of his own." ${ }^{2}$ This plan makes it somewhat difficult to get at Albert's own philosophical views. Sometimes his commentaries are plainly the simple exposition of the views of others, views with which his own personal opinions are irreconcilable. At other times he approves of the view he is expounding. ${ }^{3}$ The value of his paraphrases in relation to his whole philosophical system varies from one passage to another, and only a detailed study of them could lead to any accurate estimate.

The erudition of Albert the Great was prodigious. He was familiar not merely with Aristotle but with more of the Jewish and Arabian authors than any other scholastic ; ${ }^{4}$ and his attain-

${ }^{1}$ Mandonnet, Siger de Brabant, etc., p. li. "Nostra intentio est omnes dictas partes (physicam, metaphysicam et mathematicam) facere Latinis intelligibiles" (Phys., Lib. i., tr. I, cap. I).

2 Ibid., p. liii.

${ }^{3}$ See Schneider's Introduction, Die Psychol. Alberts d. Grossen. In the Summa de Homine and in the Summa Theologiae we find Albert's own psychological views. In the De Anima, the Libri Ethicorum the De Intellectu et Intelligibili it is necessary to pick and choose. Schneider adopts the following criterion: Albert may be taken as admitting all the theories reconcilable with Christian dugma (pp. 3-7).

+ He calls Costa ben Luca by the names of Constabulus, Constabulinus. Costabenluce; John Avendeath he calls Collectanus (for Toletanus). Schneider, op.cit., pp. 9, I3. 
ments went far beyond philosophical writers merely. ${ }^{1}$ Though a scholar, however, he was not a historian ; in the history of philosophy he made some astonishing and almost unpardonable blunders.

Albert was the greatest scientist of his time. He boldly and repeatedly proclaimed and upheld the rights of observation, experience and induction, thus directing the attention of his contemporaries towards the facts of Nature: "oportet experimentum non in uno modo, sed secundum omnes circumstantias probare". ${ }^{2}$ He was well versed in zoology, botany, geography, astronomy, mineralogy, alchemy and medicine; in all these branches he had recourse to exact observation, and many of his theories marked a step forward in their progress. ${ }^{3}$

Albert's teaching methods were unfortunately defective in many respects. His colossal paraphrase sins by excess; we must, however, remember that it reproduces an oral exposition and was meant to be a work of popularization. We encounter another defect in the interminable digressions into which he lapses, especially in the De Anima and the Metaphysics. His diction is uncouth; his language loose and often ambiguous.

Peripateticism, which forms the substance of Albert's philosophy, was subjected by him to a twofold process of purification. On the one hand, the Dominican master divests Aristotle's own thought of the garb of the Jewish and Arabian commentaries, often contrasting the latter with the former and refuting the principles of Averroës and Avicenna; ${ }^{4}$ on the other hand, he corrects and completes many of Aristotle's own theories in accordance with the characteristic spirit and genius of scholasticism. Thus, he clearly propounds the doctrine of personal immortality and substitutes for the notion of the Prime Mover that of the Infinite Being. In this way Albert the Great prepared the way for St. Thomas; he advocated many a doctrine attributed too exclusively to his pupil. It is only a detailed study of his works that can show how far history has been unjust to the philosopher

${ }^{1}$ Gutrmans, op. cit. (229), pp. 47-r20: Seine Kenntniss d. nichtphilosophischen jüdischen Litteratur.

${ }^{2}$ Ethic, Lib. vi., tr. 2, c. 25. Cf. MiсHAёL, Kulturzustande d. deutschen Volkes während d. xiii. Fahrh., iii., pp. 446 sqq.

3 There are in existence numerous special works on the place and influence of Albert the Great in each of those sciences. Enumerated by MIснAёL, op. cit.

${ }^{4}$ See his treatise against Averroës. Cf. GuttmanN, op. cit., pp. 62, 78. 
of Bollstädt, or in what degree it has unduly lessened his lustre by its unmeasured laudations of the "Angel of the Schools".

If we look, not at this or that particular doctrine, but at Albert's whole philosophical system, in itself and abstracting from the difficult circumstances in which it appeared, we cannot fail to see that it lacks organic unity in many departments. A very vigorous effort was needed to plant the Aristotelian doctrine in positions previously occupied by the older scholasticism. But Albert was unable to free himself sufficiently from traditional influences that were irreconcilable with his new standpoint, or even, sometimes, from the Neo-Platonic influences of the Arabians. We may apply to his philosophy in general what Schneider has said of his psychology: "Nothing could be more misleading than to consider it as a single, closed system. No doubt, the influence of Aristotle is predominant, but the co-existence of traditional and Arabian elements forbids us to speak of one Albertine system of psychology." ' Albert amasses the doctrines, but St. Thomas corrects the defects in his master's presentation of them. "Albert's claim to renown lies less in the building up of an original system of philosophy than in the genius and industry he has shown in placing within reach of the medieval world of letters the previously acquired treasures of human knowledge, in starting a new and vigorous and fertile intellectual movement during his lifetime, and in winning over to Aristotle the best intellects of the Viddle Ages." 2

268. Albert's Influence on Theology.--The very titles of his works bear witness to the clear distinction he established between rational knowledge and revealed knowledge. The study of Albert as a theologian does not belong to this history. We can merely point to the progress he realized by initiating a new application of

${ }^{1}$ Op. cit., p. $\mathrm{x}$ and $\mathrm{I}$.

${ }^{3}$ Mandonnet, Dict. Théol. Cath., t. i., col. 672. Dr. Baeumker passes the following judgment on Albert the Great, a propos of Schneidcr's work, in a notice of the latter in Ebbinghaus's Zeitsihrift für Psychologic (Igo8, p. 4+0): "The method observed by Albert in his work is of great importance to the historian of philosophy. It enables the historian to watch the gradual growth of scholasticism in the early Middle Ages; for it reveals to him, now in parallel channels, now in conflict, the various forces that were gradually to merge together in the furmation of a great synthesis. Aristotelianism, Neo-Platonism, Augustinism, a philosophy developing independently from within, and a dominant theology: all are to be seen in their separate, original forms in Albert, even when the blending process has already commenced." 
the dialectic method (190). He made use of Aristotle for the defence of Catholic dogma, and showed the power of the new philosophy in the service of theology. This apologetic work was to receive a masterly completion from the hands of Thomas Aquinas. Theology was considered by Albert, as well as by St. Bonaventure, a practical rather than a speculative science.

269. Philosophy of Albert the Great.-St. Thomas and Albert having a great many doctrines in common, the system of the disciple will throw considerable light on that of the master, and will at the same time give us an opportunity of noticing their chief points of difference. Moreover, the scholasticism of Albert is not so well known as that of St. Thomas. ${ }^{1}$ The connection between Albert's various works will show that he classified the philosophical sciences in the same way as his contemporaries. The following few leading notions will be here sufficient.

A supporter of the doctrine of matter and form, he gave a peripatetic meaning to this organic theory, but he did not carry it to its ultimate consequences. Without using the term materia, he admits that "separated" substances (the angels) are composed of substantial parts, that their form requires a fundamentum although this latter has no relation to quantity. ${ }^{2}$ The doctrine of Albert would thus be equivalent to that of St. Bonaventure, and would belong to the earlier scholasticism. ${ }^{3}$ On the other hand, Albert did not succeed in ridding his metaphysics of the theory of plurality of forms; and hence his teaching upon the unity of being has not the same significance as with Thomas of Aquin. It has been justly observed ${ }^{4}$ that the full and complete solution of the problem of the Universals was formulated by Albert, before St. Thomas of Aquin, and in the same sense (287).

The concept of infinity, perfecting the Aristotelian notion of pure actuality (45), is the soul of Albert's theodicy. The distinction between creature and Creator is boldly asserted, especially against Avicebron, whose doctrine of emanation Albert was the first to criticize. ${ }^{5}$ Like his predecessors, he combats the doctrine of the eternity of matter, and shows the impossibility of eternal creation (293).

${ }^{1} C f$. SchneIder, op. cit., p. vii.

2 "Ergo necesse est ponere substantiam communem quae sit in eis et haec'meo judicio non dicetur materia, sed fundamentum" (In II. L. Sent., dist. 3, a. iv.).

"This is the opinion of the Quaracchi editors of St. Bonaventure, t. ii., pp. 93, 94.

4 Willmann, Gesch. d. Idealismus, ii., p. 357 . 'Guttmann, op. cit., p. 83. 
His study of the motion and substantial change of bodiesaccording to a rhythmic evolution directed by finality - is imbued with the peripatetic spirit ${ }^{1}$ (294). But in two theories Albert subscribes to the earlier scholasticism :-

(I) He re-affirmed the doctrine of the rationes seminales, thereby deviating from the peripatetic notion of primal matter, purely potential ;

(2) His doctrine of the permanence of the elementary forms in the mixed body is a corollary from that of the plurality of forms. ${ }^{2}$ We shall see, moreover, that in the human organism the soul is not the forma corporeitatis: Albert was not so richly endowed with that deep insight, which is characteristic of genius, as was the distinguished disciple in whom he so much admired its highest manifestations. In the opinion of his latest historian, ${ }^{3}$ the coexistence of Augustinian and Arabian elements, badly combined with the fundamental ideas of peripateticism, deprives Albert's psychology of all organic unity: it is not unusual to find the philosopher defending opposite and incompatible theories in the course of the same work. ${ }^{4}$ The soul is the substantial form, that is to say, the first actuality (303), of the human body (Aristotle). There are not three souls in man, as the consistent pluralists maintained, but one vital principle only. Yet, with manifest inconsistency, Albert refuses to attribute the state of corporeity to the determining influence of the soul; although no mention of

${ }^{1}$ This doctrine of final causes, says Schneider, appears to have a Neo-Platonic turn in certain parts of the Ethics and Metaphysics. "All things tend towards the Divine, i.c., towards the Sovereign Good, which contains and sums up in itself supreme goodness. . . . This idea was develoned by Albert in a Neo-Platonic sense, apparently without his being aware that he was deviating from Aristotle" (op. cit., p. 28r). But even if the theory as such comes from the Neo-Platonists, it seems to us to have assumed a new and siholastic meaning with Albert, because it was stı ipped by him of all its originel emanation elements.

${ }^{2}$ This theory is clearly explained in the De Coelo et Mundo, Lib. iii., tr. 2, c. I, to which we refer the student. There the author says: "Elementorum formae dupliciter sunt, scilicet primae et secundae. Primae quidem sunt a quibus est esse, elementis substantiale sine contrarietate, et secundae sunt a quibus est esse elementi et actio. Et quoad primas formas, salvantur meo judicio in composite . . . et quoad secundas formas sive quoad secundum esse non remanent in actu sed in potentia." Cf. De Generatione et Corrupt., Lib. i., tr. 6, c. 8. This is the theory of Avicenna.

${ }^{3}$ Schneider, op. cit., pp. 2 and foll.

${ }^{4}$ Op. cit., p. 8. Sources of the psychology of Albert: the Summa de Homine, a systematic account; and some passages of the Summa Thcologica; to which must be added the Commentaries on Aristotle's psychological treatises. 
the forma corporeitatis ${ }^{1}$ is to be found in any of his treatises. The soul is substantial form by the totality of its being; and all its intellectual faculties are immanent (against Averroës). Albert subscribes alternately to two conflicting solutions ${ }^{2}$ on the question whether the union of the soul with the body is immediate, as peripateticism demands, or is rather effected by intermediaries (media), as certain Augustinians admitted.

Considered in itself, the soul is really distinct from its faculties. It is immaterial, and hence immortal, chiefly by reason of the independence it manifests, in its superior operations, in regard to matter (Aristotelian proof).

There are three groups of faculties, corresponding to the operations of the vegetative, the sensitive (knowledge and appetite), and the intellectual (knowledge and will) life. Vegetative life comprises the potentiae nutritiva, augmentativa, generativa, whose functions the learned Dominican studied at great length. In plants, the vegetative soul appears owing to the development of the ratio seminalis, and the same holds of the animal; but the human soul, which includes within it the perfections of the inferior vital principles, is created by God. Of the sense faculties some are external (Vires apprehensivae de foris), and amongst these Albert places the sensus communis; others internal ( $v$. a. deintus, imaginatio, aestimatio, memoria, reminiscentia). He has long psycho-physiological dissertations on dreaming, sleeping and waking (proprietates animae sensibilis), and on the functions of the brain. On the intellectual faculties, the active intellect and the passive intellect, Albert takes the peripatetic view; and his ideology was taken up and perfected by his disciple. ${ }^{3}$ Arabian monopsychism, in its different forms, is the object of repeated refutations (300).

His doctrine on the appetitive faculties, and especially on the will, is rather wavering. Liberty is at one time represented as the fundamental prerogative of the intellectus adeptus (i.e., of the intelligence endowed with knowledge), at another as that of the libera voluntas. We have here the struggle of the intellectualist (Aristotle) with the voluntarist (Augustine) point of view : a problem that occasioned long controversies towards the middle of the thirteenth century upon the relative nobility of the psychical faculties.

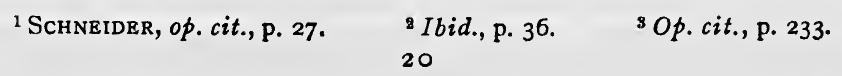


270. Disciples of Albert.-Albert the Great founded a school. John of Freiburg, Hugin of Strassburg and John of LICHTENBERG followed up his doctrines. Giles (Aegidius) of Lessines was his pupil (313). Apart from St. Thomas of Aquin, the most faithful and representative of Albert's disciples is UlR CH OF STRAsSburg (Ulricius Engelberti). He heard Albert's lectures at Cologne and became himself lecturer on theology at Strassburg (about I 248), and provincial of the Dominican order. In 1277 , the very year in which certain Thomistic doctrines were condemned, he repaired to Paris to obtain the title of magister, but he died there without passing beyond the degree of bachelor.

The Summa of Ulrich betrays the same imperfections as the work of his master. Its publication will provide us with new documents for the study of the doctrinal transition from Albert the Great to St. Thomas of Aquin.

27r. Sources and Bibliography.-The edition of Albert's works by the Dominican, Jammy, comprises 2 I folio volumes (Lyons, 1657). Reprinted by Borgnet from I 890 onward ( 36 vols.). Neither of these editions is critical, and the authenticity of the various works is not fully established. Edition of the De Quindecem Problematibus in Mandonnet, op. cit., 345. Biography: DE LOE, De vita et scriptis B. Alberti Magni, in the Anal. Bollandiana, v. 19, p. 257, and v. 20, p. 273: an enumeration of all ancient sources relative to the life of Albert from fourteenth to sixteenth century; edits an unpublished life of $\mathrm{I}_{4} \mathrm{~S}_{3}$; a brief record of the regesta of Albert, very complete. Those documents form the freambula to the life of Albert which the Bollandists are to publish. Utilizing those data, Michaïl, Gesch.d. deutschen Volkes während des xiii. Fahrh., gives a detailed biography of Albert, in which he takes up and completes an article of the Zcitsch. f. Kath. Theol. (v. 25, igor, pp. 37 and ISI). (i. von Hertling, Alb. Magnus, an oration (Bonn, i880); Van Weddingen, A. le Grand, maître de Thomas d'Aquin (Brussels, i881). These two pamphlets contain general considerations. Weiss, Primordia Novae Bibliographiae Beati Alberti Magni (Paris, and edit.). So also Mandonnet's article in the Dictionn. Théol. Cath. Schnerder, Die Psychologie Albertsd. Grossen nach d. Quellen dargestellt, i. and ii. (Beitr. z. Gesch. Phil. Mitt., Ig03 and I906): an excellent monograph; studies the peripatetic, the Neo-Platonic and the Augustinian elements. Mavsion, L'Induction chez A. le Grand (R. Néo-Scol., Igo6).

M. Grabmanv, Studicn ü. Ulrich von Strassburg, I. Leben u. Personlichkeit U. v. S. (Zeitsch. f. Kath. Theol., 1905). Announces that Prof. Muller of Strassburg is preparing a critical edition of the Summa.

\section{§ 2. St. ThOmas of AৃUin and the Scholastic Synthesis.}

272. Life and Works. - Thomas, a child of the illustrious family of the counts of Aquin, was born in $1225^{1}$ at Rocca Secca. He commenced his early education at

${ }^{1}$ Others give 1226 or 1227 . The place of his birth is disputed. Rocca Secca and Belcastro contend for the honour. In favour of Rocca Secca, v. Pellegrini and Scandone, Pro Roccasecca, patria di S. Tommaso d'Aquino, Napoli, 1903. Scan- 
Monte Cassino. He completed it at Naples in.a school (founded by Frederick II. in 1224) where he had for masters Petrus Martinus and Petrus de Hibernia. Entering the order of St. Dominic at Naples (1 243), he set out in 1245 for the convent of Cologne and henceforth his life was closely bound up with that of Albert the Great. He followed his master to Paris in 1245 or 1246 , then back to Cologne in 1248 ( $c f$. $235, \mathrm{n}$.). In 1252 the general of the order called Thomas to teach at Paris. This was the period of his public lectures, first as bachelor, afterwards as master. It was likewise the period of his first vindication of the rights of the mendicant orders, and of his polemic against William of St. Amour. The official recognition of his title of Magister in 1257 (and of that of St. Bonaventure, $c f .253$ ) put an end to the opposition aroused against the regulars by the secular theologians. In 1260 or I26r, Thomas was summoned to Italy either as Magister Sacri Palatii or professor at the Studium Curiae, founded in 1243 at the papal court. He resided at Rome and perhaps at other towns of Italy, making the acquaintance of William of Moerbeke, and forming (1260) a close friendship with Reginald. Thomas returned a second time as professor to the Parisian schools in the end of 1268 or beginning of 1269: this exceptional return to the Paris monastery can be accounted for only by the great repute in which he was held, and the serious character of the doctrinal controversies ${ }^{l}$ which were being then carried on at the University. Thomas set himself to combat the Averroïsm of Siger of Brabant on the one hand, and on the other to meet the new attacks of Gerard of Abbeville and Nicholas of Lisieux on the rights of the mendicant orders. When he retired to Italy for a second time (1272), at the call of his superiors, his withdrawal occasioned deep regret in the University circles of Philosophy and Arts. The masters of the Faculty inform us that Thomas, when leaving, promised to send them certain philosophical works, which he had planned or in preparation. Of these the De Coelo et Mundo alone has come down to us. ${ }^{2}$ In vain did the rector and masters of the Faculty endeavour to secure the return of Thomas, who was commissioned to organize a Studium Generale at Naples, probably at the instance of King Charles of Anjou. St. Thomas died in $\mathbf{2 7 4}$, at the age of forty-eight years, on his way to Lyons, whither Gregory $\mathrm{X}$. had summoned him to assist by his great talents at the work of the General Council.

The following is a classification of the works ${ }^{3}$ that bear the name of St. Thomas:-

First sojourn in Paris: De Ente et Essentia (first work, towards 1252); De Prin. cipiis Naturae; Contra Impugnantes Dei Cultum (1257, reply to the De Periculis Novissimi Temporis of W. of St. Amour); Commentary on the Four Books of the Sentences (his lectures as bachelor at Paris); De Veritate; Commentary on the Gospel of St. Mattherw (about 1258).

First sojourn in Italy: Catena Aurea; Office of the Blessed Sacrament (1264); Summa contra Gentiles (completed at Rome, 1264); Contra Graecos et Saracenos; Quaestiones Disputatae: De Malo; De Anima; De Virtutibus; De Unione Verbi

done has published a genealogy of the family of Aquin. From the same author: Documente e Congetture sulla famiglia e sulla patria di S. T., Napoli, rgor. Cf. P. DE GROOT, op. cit., 3ro.

${ }^{1}$ Mandonnet, op. cit., pp. cii and ciii.

${ }^{2}$ Chartul., i., pp. 504, 505. C $f$. Mandonnet, p. cexvi. The De Coelo et Mundo was completed by, or under the direction of, Peter of Auvergne, master of the Faculty.

${ }^{3}$ We give them according to the chronology adopted by P. DB Groot, Het Leven van den hl. Thomas, 1907. 
Incarnati; De Spiritualibus Creaturis (the De Veritate belongs to an earlier, the De Potentia Dei, to a later date); Commentaries on the Physics, Metaphysics and Ethics of Aristotle; Summa Theologica (commenced about 1265 ; continued to the end of his life; left unfinished by him: the final portion, Pars Tertia, stops at Question 9o; a supplement, completing the work, was compiled by an unknown author from the Commentaries of St. Thomas on the $4^{\text {th }}$ Book of the Sentences, and has been always annexed to the various editions of the Summa. The names of Peter of Auvergne and Albert of Brixia are mentioned in connection with it. See Quetif-Echard, Scriftores, i. pp. 29 I sqq.); numerous Opusiula written the request of correspondents, such as: De Regimine Principis (of which the last two books are not authentic); De Regimine Fudacorum (a letter to the Duchess of Brabant); De fudiciis Astrorum, De Occultis Opiribus Noturae. There are in all about forty authentic Opuscula; needless to mention all here.

Second sojourn at Paris: De Perfectione Vitae Sfiritualis contra Doctrinam Ketrahentium a Religione (1270); De Anima Intellectiva (1270, against Siger of Brabant); Di Unitate Intellectus contra Averroïstas; numerous Commentarics on the Scriptures; Quacstiones Disputatae: De Potentia, De Spiritualibus Creaturis: Disputationes de Quolibet; Commentaries on the De lnterpritatione (incomplete), Analytica Posteriora, De Coclo et Munio (commenced at Paris: authentic only as far as L. III., I. S) and Dc Causis of Aristotle.

Second sojourn in Italy: Commentaries on the Scriptures; on the books of Boèthius, De Hebdomadibus and De Trinitate; on the De Dirinis Nominibus of Pseudo-Denis; on the De Generatione ct Corruptione and the Politics of Aristotle (of the latter the first two books and the first eight chapters of the third book are authentic: the remainder doubtful).

No certain date can be fixed for the Commentaries on the De Anima (according to the catalogue of Baluzius, the first book does not belong to St. Thomas), the Parva Naturalia, the De Substantiis Separatis (incomplete); the Compendium Theologiae (incomplete) dedicated to Regrinald; the De Acternitate Mundi: the De Princifio Individuationis.

Doubtful and non-authentic works: De Pulchro et Bono, the commentary on the De Nominibus Divinis of Pseudo-Denis, Totius Logicae Summa, an interrupted commentary on the Sentences, De Potentiis Animae, De Natura Syllogismi, De Inventione Medii, De Demonstratione, De Natura Acidentis, De Natura Generis, De Pluralitate Formarum (different treatises on forms have been falsely attributed to St. Thomas), De Intellectu et Intelligibili, De Universalibus, Eruditio Principum, De Professione Honachorum, De Usuris. Later on several compendiums were drawn up by his disciples from the authentic doctrine of the master, and given to the wor'd under the name of St. 'Thomas.'

Here are a few leading facts upon the chronology-as yet ill-defined-of St. Thomas's works: The Commentaries on the Sentences constitute his first great work. They are subsequent perhaps to the De Ente et Essentia and De Principiis Naturae (about 12.48-1252), which would date from his stay at Cologne. The Summa contra Gentiles was begun at Paris (first sojourn). The De Substantiis Separatis is not earlier than 1260 . From 1265-1268 dates the writing of the Prima

The catalogue of Baluzius quotes some works which are not authentic, but drawn up from the saint's lectures or sermons (alii recollegerunt post eum legentem vel praedicantem): Lectura super Paulum ab XI cap. I ae etist. ad Corinth.; Super Fohannem; S. 4 nocturnos; Collect. de Pater Noster et Credo; de Decem Praeceptis; S. Matthiam; S. Primun de Anima. 
Pars of the Summa Theol.; I261-I264, Quaestio Disputata de Anima. From his second stay at Paris date the De Spiritual. Creaturis; Quodlibeta (the first dates from r269). From I270 dates the treatise De Perfectione Vitae Spiritualis. The $D e$ Coelo et Mundo is subsequent to $1270 .^{1}$

The two Summae, the Quaestiones Disputatae, the Quodlibeta, some of Opuscula and the Commentaries on Aristotle, have a special interest for the historian of philosophy.

273. Place in Philosophy.-St. Thomas of Aquin owes to Albert the Great his vocation to philosophy and his initiation to peripateticism, but he surpassed his master by all the distance that separates genius from talent.

St. Thomas substituted the more critical procedure of the literal commentary on Aristotle for the running paraphrase which he found in vogue as a means of popularizing. It was in order to understand Aristotle that he took such care to procure faithful versions of the Greek text (226). The knowledge he had of Aristotle's system is much more profound than that of which Albert gives evidence.

Besides, his historical sense is remarkable for a man of his epoch. He was among the most accurate of his age in expounding the teachings of the Grecian philosophers, the Fathers of the Church, and the Arabian and Jewish philosophers. Still, his anxiety to make their writings, especially those of Aristotle and St. Augustine, subserve what he believed to be the truth, betrayed him very often indeed into the sort of historical errors and mistakes so common among the philosophers of the Middle Ages (281).

St. Thomas's brilliant talent as a teacher drew around his chair crowds of seculars and regulars alike. It won for him the willing praise of the Faculty of Arts, and of several of his contemporaries. $^{2}$ The two Summae were drawn up to serve as hand-books of study, and were adopted both in lay and in religious circles. ${ }^{3}$

St. Thomas's language is clear, simple, precise and scientific.

${ }^{1}$ Wittmann, Die Stellung d. hl. Thom. v. Aquin zu Avencebrol, pp. 3I, 38, 68, 7 r Mandonnet, op. cit., p. IO2 ; $c f$. Jourdain, Philos. S. Thomas, t. i. According to MARchesi, $o p$. cit., pp. 67,72 , St. Thomas would have written no commentaries on Aristotle prior to $126 \mathrm{r}$.

2 W. of Tocco, his biographer, says on this subject: "Sub cujus Doctoris lucida et aperta doctrina floruerunt quamplures magistri religiosi et saeculares propter modum docendi compendiosum, apertum et facilem" (Bolland. Acta SS. Martii, vol. i., vita, cap. 4 , n. 18, p. 663 ).

${ }^{3}$ In 13 I9 a witness at the process of his canonization declares that "etiam laici et parum intelligentes quaerunt et appetunt ipsa scripta habere" (ibid., p. 713). 
His method is orderly, free from glosses and digressions; his explanations are concise; he finds its proper place in the whole for every single detail ; his thought travels straight and steadily to its intended term; towards this he makes everything else converge. He boldly grapples with difficulties before which his master, Albert, either remains puzzled or beats a retreat.

The characteristic features of his doctrine proper will be more easily indicated after the exposition of it given below (309).

274. Place in Theology.-St. Thomas is also the prince of thirteenth-century theologians. He expanded theological teaching ; gave new and complete solutions of a multitude of questions; and, above all, co-ordinated the materials of Catholic theology in a monumental system which has won the admiration of posterity. He utilizes the two constructive methods of scholastic theo$\log y$ : Authority, embodied in the Scriptures and Tradition, furnishes theology with its own proper and cogent arguments; the contribution of Dialectic, ${ }^{1}$ or philosophical reasoning, is subsidiary and of secondary importance $(\mathbf{I} \mathbf{8} \mathbf{i})$.

To this latter method, nevertheless, St. Thomas is constantly recurring: in the employment of the peripatetic philosophy for the defence of dogma the Angelic doctor is unsurpassed. And as a result of this combination of arguments from reason and from faith, theology assumes in his hands a speculative and rational appearance which not one of his predecessors-not even his own master-had succeeded in giving it. ${ }^{2}$

275. Philosophical Teaching.-The exposition we now subjoin has a twofold object in view: to point out the great organic and fundamental doctrines which may be said to constitute the scho-

${ }^{1}$ See Prologue to the Commentiry on the Sentences, art. v. Fr. Gardeil has clearly expounded the relations of these two methods in an article entitled $L a$ Réforme de la Théologie catholique. La Documentation de Saint Thomas (Revue thomiste, May-June, 1903, pp. I99 and foll.).

${ }^{2}$ A contemporary of St. Thomas, the Dominican, Raymond Martin, is the author of a polemical treatise on apologetics, Pugio fidei adversus Mauros et $\mathcal{F}$ udaeos (printed in $\mathrm{I}^{6}{ }^{7} 7$ ), several passages of which occur, almost word for word, in the Summa contra Gentes. Martin was distinguished for his knowledge of rabbinical Hebrew and Arabic, throughout the schools of Spain, where the provincial chapter of Toledo (1250) had ordered the establishment of chairs for the teaching of the Oriental languages. He made use of many Arabian works, especially those of Averroës. In the opinion of M. Mrguel Asin y Palacios, St. Thomas was acquainted with this work of Martin and utilized the latter's knowledge of Arabic as he did the acquirements of William of Moerbeke in Greek (El Averroïsmo teologico de Sto. Tomas de Aquino, pp. 322-24). 
lastic system; and to indicate the special doctrines peculiar to Thomism. $^{1}$ Without pretending to exhaust all the possible points of view, we propose to study consecutively: a group of preliminary, propaedeutic questions (I.); the doctrinal content of the system proper, namely (I) logic (II.); (2) speculative philosophy: (a) metaphysics and theodicy (III.), (b) physics (IV.), and more especially psychology (V.); (3) practical philosophy: (a) ethics (VI), (b) esthetics (VII.); and, in conclusion, the characteristics of scholasticism in general and of Thomism in particular (VIII.).

\section{Propaedeutic.}

276. Résumé.-These preliminary questions concern the division of scholastic philosophy; its relations to theology, to the special sciences and to medieval civilization ( $c f$. extrinsic notions, 107); its didactic methods.

277. Division of Philosophy.-Philosophy, understood by all scholastics in the same manner, was treated, in the thirteenth century, to a UNIFORM division, ${ }^{2}$ mentioned though not employed by Boëthius, taken up by Hugh of St. Victor (204), popularized by Gundissalinus (243) and perfected by Robert Kilwardby (263). In it the peripatetic influence (34) is manifest, entirely supplanting the spirit of the Platonic classification (126). It will form the setting of the exposition given below. ${ }^{3}$

278. Relations between Philosophy and Theology. - Over and above the relations of origin and of teaching methods ( $\left.\mathbf{I 1}_{3}\right)$, there are doctrinal relations which we find CATALOGUED and VINDICATED in the introductions to the thirteenth-century Summae Theologicae (150).

(I) Distinction between the two sciences (I06), and consequent complete independence and autonomy in their specifying elements. For the scholastics the criterion of distinction between sciences is not the identity or diversity of their subject-matter (material object of science), but the manner in which they deal with that subject-matter (formal object). Now, the FORMAL OBJECT of

${ }^{1}$ The common scholastic theories are printed in ordinary type; the theories peculiar to St. Thomas or to other individual scholastics, in italics. Reference will be made to the Aristotelian sources wherever scholasticism draws on the teachings of the Stagirite.

${ }^{2}$ BAUR, op. cit., p. 202, emphasizes this unanimity of the great scholastics.

${ }^{3}$ See 263 , n. 4 , division adopted by St. Thomas. 
theology is not that of philosophy: the former studies the supernatural order as revealed in the word of God, the latter examines the natural order by the light of reason. Diversity in formal object involves diversity in PRINCIPLES and in CONSTRUCTIVE METIOD. The study of dogma rests on authority; the rational study of the universe, on scientific demonstration.

(2) Subordination-material, not formal-of philosophy to theology. That is to say, while each science preserves its formal independence, there are certain MATTERs in which philosophy cannot contradict theology, those, namely, which are common to both sciences. The scholastics justified this subordination because they were most profoundly convinced that in Catholic dogma they possessed the word of God, the infallible expression of the truth. The truth or falsity of this thesis-the existence of a Divine Revelation-does not fall within the competence of philosophy itself. But, the thesis once granted, the consequence is obvious: as truth cannot contradict truth, reason must avoid all OPposition to dogma. The reasoning that enjoins this prohibition ${ }^{1}$ is simply the application of a universal law of relationship between all sciences that deal with a common (material) object under different (formal) aspects proper to each.

(3) Co-ordination of the two sciences. Reason demonstrates the motives of credibility for the faith.

These vieu's are expressed more comprehensively by St. Thomas than by Albertus Magnus or any other scholastic of his time. No one has ever blended together philosophy and theology more completely or harmoniously than St. Thomas has-in the domain of their common material object, where alone such union is possible. On the one hand, by an intense and sustained application of its own natural powers, human reason can demonstrate several of the truths which are contained in the deposit of Divine Revelation and belong on that account to theology (e.g., the existence and attributes of $\mathrm{God}$ ); on the other hand, it bow's indeed before mysteries, but so far from turning away-cither respectfully or disdainfully-it show's that the supra-rational is not anti-rational. As regards the co-ordination of the two sciences, we know what a generous use the theologian may make of the dialectic method in showing the groundlessness of objections against revealed doctrine and in sus-

${ }^{1}$ A Statute of the Paris Faculty of Arts, in 1272, forbade philosophers to teach anything contra fidem (Chartul., i.,p. 499). It did not order them to plead profide 
taining a positive defence of dogma (274). St. Thomas as philosopher did not consider himself in any way positively bound to demonstrate all the conclusions of the theologian. Of this we have a striking example in his attitude regarding the eternity of creation.

279. Relations of Philosophy to the Special Sciences.-To understand these relations, one must first have grasped the idea of the hierarchical gradations of human knowledge, culminating in philosophy. The special sciences study Nature in detail, each embracing some one group of things under the special aspect which constitutes its formal object. In accordance with the principles of scholastic ideology (300) the sciences of observation come first in the ascending scale of knowledge. We need only examine the regulations issued by the Paris Faculty of Arts in I 255 (231) to see that the full programme embraced purely scientific branches: astronomy, botany, physiology, zoology, chemistry and physics (in the modern sense). But these fragmentary, encyclopedic, ANALYTIC items of knowledge do not satisfy the mind. In the view of Aristotle and the scholastics, science par excellence (sapientia), or philosophy, is a sYNTHETIC knowledge of Nature. It is in a sense the knowledge of all things: in this sense, that the thought-object which it considers in the abstract, permeates the whole vast region of the real, and is the common intelligible element of every single reality in Nature. This common intelligible object is either movement, quantity or being, abstracted in the study of physics, mathematics or metaphysics, respectively: these latter forming the famous trilogy of the speculative sciences. In this view the experimental sciences are preparatory to physics, or the philosophical study of Nature. ${ }^{1}$ Moral philosophy is accompanied, in this scheme, by historical studies, especially Bible history; by the science of education; and by a portion of that very wide department included in what are now called the social sciences. Logic is introduced by the preliminary study of grammar, or the forms of language. Hence we conclude :-

(I) That the SPECIAL SCIENCES-at that time in a very rudi-

${ }^{1}$ The philosophical study of Nature is thus distinguished from such scientific encyclopedias as the Speculum of Vincent of Beauvais, the Thesaurus Magnus of Brunetto Latini and the De Proprietatibus Rerum of Bartholemew the Englishman in the thirteenth century. 
mentary state-were studied rather as a PREPARATION FOR PHILOSOPHY than for their own sake.

(2) That according to its very conception philosophy is SCIENTIFIC. The synthetic interpretation of the material universe must rest throughout on analysis. Without such permanent contact with the details of things, it would be devoid of reality.

(3) That between the special and the philosophical sciences there is no essential distinction, all alike being the natural outcome of one and the same intellectual process of abstraction; but only a difference in degree, corresponding with the degree of abstraction.

(4) That "like science, like philosophy". The Middle Ages knew no distinction between what we nowadays call scientific knowledge and common knowledge, respectively. Ordinary, unskilled observation, provided it was accurate, could and did lead to right synthetic views and generalizations; misinterpretations of facts naturally led to wrong generalizations.

280. Scholastic Philosophy and Civilization.-Western medieval civilization proclaimed the supremacy of the Catholic Faith. Just as religious sentiment pervaded and inspired its political institutions, its art and literature, the public and private life of its citizens, so too was all its knowledge regulated by the root principle of the convergence of all the profane sciences towards theology. But this principle, so far from interfering with the autonomy of the sciences, only reduced them to proper order. It accounts for the organization of schools for the people, for the established code of chivalry, for the manner of growth of the universities, for their ecclesiastical character, for the relations between masters and pupils and the gradation of the faculties. We have already seen the place occupied by philosophy in this intellectual world.

But did scholasticism influence the other factors of medieval civilization? Works like those of Dante are an eloquent proof of its empire over the general culture of the time; and its influence has also been traced not merely in painting and sculpture, but even in the current popular form; of speech. ${ }^{1}$ These latter

${ }^{1}$ See, e.g., Willmann, Gisch. d. Idealismus, ii., p. 330. From Zingerle's Deutsche Sprichwörter d. Mittelalters (Vienna, 18>4) he gathers expressions indicative of the scholastic ideology. E.g., "Erfahren macht Klug; Erfahrung ist der Narren Vernunft'. 
investigations, however, belonging as they do to the domain of sociology, are still only in their infancy.

28I. Didactic Methods. - These were the fruit of a long and laborious elaboration: the ripening process reaching its completion in the thirteenth century. With the forms of oral teaching we are already familiar: the LECTIO, in which the text of some book was analyzed for the purpose of explaining it, either by way of exegesis (St. Thomas) or of paraphrase (Albertus); and the QUAESTIO, or freer method of treatment, availed of in discussions and disputes (23I). To these we might add SERmons, which often-in the thirteenth century-embodied philosophical dissertations. ${ }^{1}$

The Books which have come down to us, reveal this threefold oral method. But besides those there are numerous treatises not written for teaching purposes: miscellaneous monographs and pamphlets in abundance. ${ }^{2}$

The thesis to be expounded is always submitted to a triple process (the pro, the contra and the solution) which is in logical connection with the Aristotelian doctrine of the ámopía (cf. $\mathbf{3 8}$, 174, 249). In the exposition of the pro and contra, the scholastics draw from the history of philosophy. In fact the sole use of the latter was to furnish reasons in defence of what was regarded as the true teaching. History was not studied for its own sake; and this accounts somewhat for the uncritical attitude of the scholastics as regards the accurate determination of the historical fact, and for their anxiety to interpret texts in favour of their theses even at the risk of misrepresenting the testimony invoked. Here, too, the syllogistic form of reasoning holds undisputed sway. Finally, the intermingling of philosophical and theological questions is still in evidence; for its causes are deeply rooted in the teaching organization of the universities no less than in the very genius itself of medieval civilization. It was of most frequent occurrence in the theological courses; the "artists" were forbidden over and over again (more especially in 1272) to trespass on the theological domain.

${ }^{1}$ See, e.g., St. Bonaventure's Sermon, De Humanae Cognitionis Ratione, etc., p. xiii (257).

${ }^{2}$ The freer forms of philosophical teaching make their appearance later on: sermons, poetic pieces and prose writings in the vernacular. Dante and Eckhart are exceptions in the thirteenth century. 


\section{Logic.}

282. Logic. - In the thirteenth century, no less than previously, Aristotle was the undisputed master of dialectic, and the great scholastics considered they could do no better than write commentaries on his teaching $(\mathbf{3 5 - 3 8})$. Logic is only an instrument to be employed in acquiring scientific knowledge, but it is closely allied to metaphysics and psychology. Albert the Great and his successors explicitly formulated the relations between the science of concepts and the science of realities. Logic is the vestibule of philosophy: a scientia specialis, preparatory to philosophy, somewhat as drawing is to painting. Hence we find all sorts of dialectical exercises cultivated in the schools of the thirteenth century, but always as a training for more fruitful controversies later on. The syllogism holds the place of honour. It is supplemented by theories on method and on science, both of which were worked out by scholasticism on Aristotelian lines. The analyticosynthetic method it is that fructifies philosophical researches. Science is of the universal and necessary, scientia non est particularium, singularium, corruptibilium (300). ${ }^{1}$

During this epoch the value of logic was estimated with all due moderation. Later on, the logical excesses of the decadent scholastics began to make their appearance, but these consequences of degeneration left the doctrinal synthesis of the thirteenth century intact.

\section{Metaphysics and Theodicy.}

283. The Categories and Transcendental Attributes.-The scholastic conception of metaphysics is taken from Aristotle (39). Although it treats of Being as such, and is therefore the highest product of mental abstraction, it has nevertheless for its primary object the substance of the things of sense, and is thus anchored to the firm rock of reality. It adds to the peripatetic portion-the general study of Being-a new and original chapter on the transcendental notions. These are certain very wide and general aspects-such as unity, truth, goodness (unum, verum, bonum)-which bring out into bolder relief the content of the simple yet comprehensive concept of Being.

\footnotetext{
${ }^{1} \mathrm{ST}$. Tномаs, In II. l. De Anima, 2.
} 
284. Act and Potency.-Here, as with Aristotle (41), the theory of the actual and the potential occupies a prominent place: more prominent even than with the Grecian philosopher, seeing that scholasticism derived from the development and application of his idea, consequences quite undreamt of by himself. Act and potency, together with the kindred notion of movement (motus), are primarily employed for the purpose of explaining CHANGE. But the theory was extended. The two notions became synonymous with "being determined and being determinable". Outstepping its original domain - the process of organic change-the theory was applied universally within the real order, and pervaded and penetrated every possible composition of contingent being, of being limited in its reality. ${ }^{1}$ The act and potency couple is found in such fundamental compositions as those of substance and accident, matter and form, common essence and individualized essence. To it, moreover, is attached the theory of causes.

285. Substance and Accidents (40). - The substantial reality of a being that is in its own constitution and of itself capable of "subsisting" (potency), receives adventitious ontological determinations (acts) which are called accidents (ac-cidere). Scholasticism took up and developed very considerably the study of the nine categories of accidents, especially those of quality, quantity, relation, time and space.

The study of quality ("accidens modificativum substantiae in seipsa") raised some important questions not dealt with by Aristotle-particularly that of the distinction between a substance and its operative powers. Can action result immediately from the substance of a contingent being; or can the latter act only by means of faculties? A much debated question in the thirteenth century, and one whose solution involved important metaphysica: and psychological considerations. St. Thomas advocated the doctrine of a real distinction between the faculties and the substance of which they are qualities; he pointed to the accidental character. of all activity in contingent things, and to the necessary identity of nature between this activity and its proximate principle. This view is in exact conformity with his metaphysical system. We

${ }^{1}$ It is even found in the domains of logic and moral; and everywhere it expresses the same primordial relation of determinable and determinate: the genus is to its species, the free act is to its intrinsic end, as potency is to act. 
have seen other scholastics establish closer connections between the substance and its faculties.

286. Matter and Form.-Purely cosmological in their original meaning, the concepts of matter and form were widened by the scholastics, as by Aristotle (42): in the logical order, formalis and actualis, materialis and potentialis, are synonymous.

Matter and form are correlative elements. ${ }^{1}$ The scholastics were unanimous in recognizing the hylemorphic composition of corporeal substances, all of which they taught to be composed of matter (principle of indeterminateness, potency) and form (principle of determinateness, actuality). But they hotly disputed two questions, of which the second especially-the one most controverted - had not attracted the attention of Aristotle (42).

(a) Can matter exist without a substantial form? The earlier scholastics were inclined to attribute to frimal matter an existential reality independent of form. Albert the Great and still more St. Thomas, opposed this view, which they regarded as destructive of peripateticism. St. Thomas held that the factors of the corporeal compound were so intrinsically and essentially dependent on each other that Almighty God Himself, unable to effect the impossible, could not give existence to the indeterminate primal matter, without a substantial form as determining principle: the potential, as such, cannot be actual. On the other hand, St. Thomas's rivals at Oxford and Paris were unwilling to follow him in this rigorous interpretation of peripateticism.

(b) Does substantial composition extend to immaterial substances, to the human soul, and especially to the angelic nature - that connecting-link in the hierarchy of essences between man and God? Angelic life was deeply studied by scholasticism; the scholastics made use of the purest principles of intellectual and appetitive activity to construct an angelic psychology, or rather an "eidology," which has nothing in common with Aristotle's uncertain pronouncements on the motor-intelligences of the world-spheres.

The earlier scholasticism, chiefly of the Franciscan schools, estab-

${ }^{1}$ In the logical order the notions are purely correlative. Matter and form here mean simply the determinable and the determinant. E.g., the concepts of genus and species represent objective aspects of the same reality, perfectible the one by the other. In the real order some scholastics admitted the correlation only with reserves. 
lished a complete identity, in the real order, between the two pairs of concepts, act and potency, form and matter; and accordingly they regarded hylemorphic composition as the essential mark of all contingent substances. St. Thomas was the first to protest boldly against this teaching, which had influenced even his own master (269). It is an interesting fact that while St. Bonaventure and his followers were claiming St. Augustine as the first authoritative exponent of their theory, St. Thomas, in the De Substantiis Separatis, traced the theory to its real source: ${ }^{1}$ it is a Jewish importation, he wrote, and the philosophy of the Fons Vitae, so far from being a source of life, is a channel of stagnant water which poisons the pure current of Aristotelianism. ${ }^{2}$

In opposition to Avicebron's teaching, St. Thomas propounds the theory of the simplicity of immaterial beings-a doctrine more in keeping with the principles of Aristotelianism. CORPOREAL substances alone, have primal matter as a constitutive element; this is the principle of their spatial extension, of their numerical multiplication and of their imperfection generally.

The angelic nature, then, is a "forma separata"- - form free from matter. Here is St. Thomas's explanation: Seeing that it is the form that actualizes matter and endows the compound with its perfection, and not vice versâ, there can be no contradiction in the concept of "formae subsistentes"-forms subsisting without any admixture of matter. These pure intelligences, intrinsically possible, subsisting apart, or "separated" from matter, are nevertheless contingent and finite, for they are an admixture of act and potency and their essence is limited by their existence. "Quia forma creata sic subsistens habet esse et non est suum esse, necesse est quod ipsum esse sit receptum et contractum ad terminatam naturam. Unde non potest esse infinitum simpliciter." 3

In determining the functions of matter and form, scholasticism merely recapitulates peripateticism, with perhaps some slight developments (42). Matter is the passive, homogeneous substrate, incomplete substantially, the principle of change, not itself either being or non-being, and not eternal any more than motion is eternal (293). Form is the determining, constitutive

1 Wittmann, Die Stellung d. hl. Thom. z. Avencebrol, p. 40.

${ }^{2} C f$. Dв Wulf, Treatise De Unitate Formae, Introduction, pp. 20, 21.

${ }^{3}$ Summa Theol., ra, q. 7, a. 2. Some later scholastics admitted the possibility even of simple corporeal beings, in reference to the heavenly bodies (295). 
cause of every being, the standard and measure of its perfection, the principle of its intelligibility, the source of its activities, ${ }^{1}$ the seat of those directive, natural inclinations by which it tends towards the realization of its end. Being likewise a principle of unity, it may be understood to gather up, as it were, into one single substantial unit, the scattered elements of the extended matter of corporeal being.

In this connection there arose a controversy which added to Aristotle's teaching and attracted considerable attention during the second half of the thirteenth century: How are we to understand this unitive function of the form? Can a thing be intrinsically endowed with more than one substantial form?

We have seen alveady how deeply rooted the theory of the plurality of forms was in the earlier schools, when St. Thomas made his appearance there." He seems to have been influenced by it himself in his student day's. His Commentaries on the Sentences-where, indeed, we find more than one doctrinal peculiarity that disappears in his later and maturer works-contain some texts which betray" a certain amount of hesitation and seem to admit a "forma corporeitatis" as the "prima forma substantialis" of bodies." But subsequently, throughout all his voluminous writings, St. Thomas defended the unity of the substantial form with a long array of powerful arguments which were called forth by the needs of controversy and which leave no shadow of doubt as to what his real opinion was in the matter. Among his metaphysical arguments is one connecting the unity of form with the transcendental unity of the thing (" nikil est simpliciter unum, nisi per formam unam per quam habet res esse" 4 ), and with the very notion of substantial being ; in physics he offers unity of form as an explanation of the generation and corruption of substances; in psychology it explains for him the manifest solidarity of the various vital functions in the

1 The substance or essence, considered as the internal, root principle of the activities of a being, is styled NatURA; it is through the form (id quo) that the complete, individual essence (id quod) fulfils the function of nature.

27. Peckham could still say about the theory: "tenuit hactenus totus mundus" (Ehrle, F. Peckham, etc., f. I78 (240)).

${ }^{3}$ In I. L. Sent., d. viii., q. 5, a. 2 ; and II. L., d. iii, q. I, a. I. See DE Wulf, Le tratté De Unitate Formae de Gilles de Lessines, ch. iii. : Thomistıc innovatıons of principles.

4. Theol., q. 76, a. 3, c. 
individual living thing, the identity of the living man with the individual after resurrection, etc. ${ }^{1}$

This teaching on the unity of substantial form in the individual has exerted a far-reaching influence on Thomism; it knits together and co-ordinates quite a number of doctrines. St. Thomas owes it neither to his master, who interpreted it in another way, nor yet to the Averroists, ${ }^{2}$ but to his own personal penetration of the peripatetic genius of scholasticism.

Similarly, it is not St. Augustine, but Avicenna and the Arabians, that St. Thomas accuses of having been the first to give currency to the pluralist doctrine.

287. Common Essence and Individualized Essence ( $c f .43$ ). - The Universals controversy was regarded as settled in the thirteenth century: scholastics unanimously accepted the solution arrived at towards the close of the twelfth. "The individual is the real substance, the universal reaches its fully developed form only through a subjective elaboration of the mind." The most exacting dialecticians merely reproduce these stereotyped scholastic teachings; even Duns Scotus takes no exception to them. But no one is so precise and accurate in these delicate points of doctrine as the Angelic Doctor. It is as a tribute to his marvellously clear exposition of the doctrine, and not as claiming for him the credit of discovering it, that posterity has called moderate realism by the name of Thomistic realism (137). Of all the solutions of the Universals problem, it is the one that fits in best with the whole scholastic system.

Appropriating a formula that was current in the schools, St. Thomas thus gives expression to the doctrine of Albert the Great and Avicenna ${ }^{3}$ on the relation of the individual to the universal: The reality of any essence or thing may be considered in three states or stages: ANTE REM, IN RE, POST REM. The Universals ANTE REM are described and dealt with in the theory of Exemplarism with an Augustinian freedom of fancy which borders on the erroneous system of Avicenna. The Universals IN RE confront us with the

1 DE Wulf, S. Theol., q. 76, a. 3, c.

${ }^{2} V .312$, the insinuations of Peckham on this point.

${ }^{3} C f$. 217. These formulae go back at least to the time of Proclus. See his

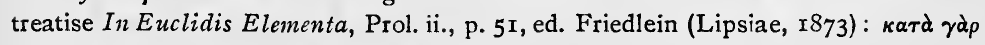

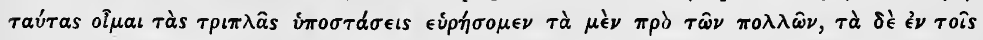

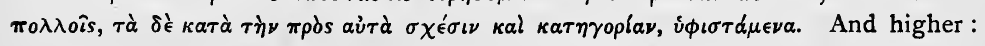

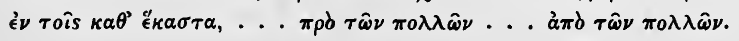


physical side of the problem : the separate subsistence of individual things and the principle of their individuation. ${ }^{1} \quad$ The Universals POST REM involve that subjective elaboration to which the mind submits all essences when it considers them apart from their individualizing conditions. Formally (formaliter) the universal exists only in the mind, but it has its foundation (fundamentaliter) in things. ${ }^{2}$

Apart from the fourteenth-century terminists who denied the real, extramental validity of our universal presentations, and who thus betrayed the first symptoms of scholastic decadence, all agreed in recognizing a distinction-in every created substance-between the essential determinations that are similar in all the representatives of a species, and the individualizing determinations that differentiate these representatives from one another. The former are to the latter as determinable to determinant, as potency to act.

What is the nature of this distinction? In St. Thomas's vieze the concepts of specific essence and of individual essence correspond to different constitutive realities in the thing ("distinctio realis"). Others regard the diversity in the case as a mere logical distinction ("distinctio rationis"). Duns Scotus introduces here a "distinctio formalis a parte rei" (329). But none dare repeat the audacious language of Gilbert de la Porrée (176).

But another question arose, one that was much debated in the thirteenth century: What is the principle of individuation? In other words, if we are to reconcile the fixity and similarity of essences with the marvellous variety of their individuations, the question arises: how comes it that there are numerous individuals in one and the same species? Here is a scholastic controversy par excellence, presupposing as it does, at least up to a certain point, the peripatetic solution of the Universals problem. The medieval philosophers all admit that the basis of individuation ought to be essential and intrinsic; but they take divergent views on the question whether it is the matter or the form or the union of both principles that necessitates the individuation of things.

'St. Thomas thus formulates the fundamental error of exaggerated realism, already at that time hopelessly discredited: "Credidit (Plato) quod forma cogniti ex necessitate sit in cognoscenti eo modo quo est in cognito, et ideo existimavit quod opporteret res intellectas hoc modo in seipsis subsistere, scilicet immaterialiter et immobiliter" (S. Theol., Ia, q. 84, art. I).

${ }^{2}$ In Lib. Sent. I., d. I9, q. 5, a. I. 
We find the Aristotelian system in St. Thomas, but so amplified and developed that the traditional portion is well-nigh imperceptible among the many innovations. Aristotle had shown why the form, being an indivisible principle, is incapable of multiplying itself; but he left the individualizing functions of the matter in obscurity. These St. Thomas analyzed, teaching clearly that the principle of individuation is not the matter in a state of absolute indeterminateness-as some clumsy exponents of Thomism have represented, thus exposing the system to the charge of inconsistency-but " materia signata," that is, the primal matter endowed with an intrinsic aptitude for occupying certain dimensions of space. ${ }^{1}$ As the process of natural change is conditioned by the presence of due proportions between the form and the dispositions of the matter, it follows that if natural agencies effect a change in these dispositions they will thereby bring about the introduction of a new form. And in this sense, the primal matter of any body in Nature becomes in the process of natural change the individualizing principle of the type or species into which that body passes.

From all this we see that it is only in the corporeal world the question of individuation can have any meaning for St. Thomas. More logical even than the Stagirite, ${ }^{2}$ he teaches that in the world of "separated" forms each individual is a complete species. To understand his teaching about the heavenly bodies, which, though composed of matter and form, are each unique of its kind, we must consult the general principles of scholastic physics (295).

288. Essence and Existence.-This kind of composition, left untouched by Aristotle, now becomes the object of fine and delicate discussions. The terms of the debate are not the respective CONCEPTS of essence and existence, nor a POSSIBLE essence on the one hand and an EXISTING FSSENCE on the other : all recognized a real distinction between the terms of each of those comparisons. But, following up the analysis, they asked the question whether IN ANY ONE ACTUAL BEING its fundamental constitutive reality is one thing (" essentia, quod est"), and the act or actuality by which that reality exists, another thing (" esse, quo est").

Opinions differed. St. Thomas held a real distinction, the sub-

' $V$. Opusc. De Principio Individuationis. Same theory in Albert the Great, coloured by the doctrine of the "rationes seminales".

${ }^{2} C f$. ZkLler, Die Philos. d. Griechen, ii., 2, p. 339, n. 3 . 
stance of his teaching being that existence is of the essence of God alone, the Pure Act. In creatures, on the other hand, whether material or spiritual, the perfection signified by the word EXIST is contracted and circumscribed within the limits of the essence which it determines. ${ }^{1}$ Essence is to existence as potcncy is to act. ${ }^{2}$ But being becomes actual only in the measure in which it is caprole of actuation; for the degree of being is measured by its connatural potency. Therefore a contingent essence can receive existential actualization only within the limits of its owen contingency.

This theory is no special discovery of St. Thomas. The meet it frequently among the representatives of the older scholasticism. But none penetrated its meaning so deeply as he. And when we consider the general structure of Thomism, we cannot help being struck at the organic and unifying role played by this thesis in connection with the other leading theories of scholasticism. The real distinction between essence and existence places in bold relief the contingency of the creature; it accounts for the existential unity of beings that are composed of matter and form-consubstantial principles, severally incomplete and mutually irreducible,-and of beings that exert their activities by means of faculties really distinct from one another.

289. Causes of Being. - The study of causes is pursued on the lines laid down by Aristotle (44). Being, whether in its substantial or accidental state, exists in its causes or in potency before appearing in act or in reality. ${ }^{4}$ This realization, which is effected by motion or change, it is beyond the power of any being to confer on itself : "Quidquid movetur ab alio movetur" (efficient cause). The doctrine of creation modifies the Aristotelian theory of the eternity of matter and motion. Under the influence of the efficient cause, the subject (matter) receives the

1 "Unde esse earum non est absolutum sed receptum, et ideo limitatum et finitum ad capacitatem naturae recipientis" (De Ente et Essentia, cap. 6).

${ }^{2}$ See Cajetan, commentary on this passage.

${ }^{3}$ See Schindele's Dissertation, quoted 3ro. This writer believes St. Thomas drew from Pseudo-Denis and Boethius (p. 9). We may note that if the idea of the participation of being is found in Pseudo-Denis there is no trace of a comparison of essence with existence.

4"Quamvis autem causae sint quatuor, tres tamen earum, scilicet, efficiens formalis et finalis concurrunt in idem, unde relinquitur quod ordo naturae sit duplex, unus quidem secundum rationem causae materialis. . . . Alius autem ordo naturae est secundum rationem aliarum trium causarum, secundum quam perfectum est prius imperfecto et actus potentia" (Sт. Тномаs, Quodl., а. I9, с.). 
perfection (form) for which it had the capacity. By their mutual union and intercommunication, these latter-the receiving subject and the received determination-exercise a constitutive causality on the new being, or on its new state. They are constituent causes of the being, either of its very substantiality (primary material cause, formal substantial cause), or of some of the modes consequent on its substantiality (secondary material cause, accidental formal cause). The efficient cause is influenced by some realizable good (final cause), for the actual realization of which it exercises its efficiency. This stimulation of efficiency by finality is manifested more especially in the marvellous order and beauty of the universe. Were order the exception, it might be the result of some chance convergence of motor causes. But its actual permanence in time and universality in space, are alike inexplicable unless by means of an internal tendency which, being implanted in the acting causes, secures their constant co-ordination in carrying out the designs of nature. Thus, the scholastic teaching on finality completes the philosophy of being.

290. Connection of Theodicy with Metaphysics. - Metaphysics, when dealing with corporeal substances-the proper object of human knowledge (300) - not only seizes their being, apart from matter (immaterial negatively, or by abstraction), but at the same time supplies us with a number of concepts and judgments which can be applied by analogy to what is immaterial positively, or of its very nature. Thus it is we can justify the employment of the term theology (rational) by Aristotle, the Arabians and some of the scholastics, as a synonym for metaphysics.

Already in Aristotle we find the great division of beings into two categories : on the one hand, those composed of act and potency, beings which, before actually possessing a perfection, exist in a condition deprived of that perfection; on the other hand, the Pure Act, free from all potentiality, God (45). The medieval scholastics took up these Aristotelian data, completed and enriched them and carried them into regions of thought unknown to Aristotle. Combining them with certain theories of the Fathers of the Church, especially of St. Augustine, the scholastics built up a new theodicy which replaced the peripatetic notion of an immovable motor, wrapt up in self-contemplation, by the theory of the Ens " $a S e$," infinite in Its actuality. 
291. Proofs of the Existence of God.-With the exception of a few erratic geniuses of the epoch of decadence, all scholastics have unanimously held that the study of the contingent universe yields (a posteriori) proofs of the existence of God. They emphasize the Aristotelian proof of the Prime Mover: the actual is prior to the potential; first absolutely comes the Perfect Being, without which no single actual being would be realizable. ${ }^{1}$ Many other proofs are drawn from St. Augustine, but not all scholastics admit the fazourite proof of the African philosopher, drawn from the universality and immutability of first principles (100). St. Thomas rejects St. Anselm's "ontological" reasoning. Indeed we may say" that all the great scholastics reject it when we remember the reservations made by St. Bonaventure, the strongest disciple of Anselm among the thirtenth-century doctors ${ }^{2}$ (cf. 255).

292. God Considered in Himself.-Our knowledge of the Divine essence is derived solely from the study of creatures. Reason proves for us that all created perfections must be found in an eminent degree (eminenter) in God. We know the perfections of God, says St. Thomas, by analogical concepts. In one long corollary we derive His attributes from His substantial existence "esse" per essentiam"). Thus, God is perfect knowledge; as He is also perfect love, though Aristotle is silent about this attribute $(46)$ : and there is no shadow of doubt about the Divine personality.

The multiplicity of the Divine perfections is lost in the unity of the Infinite. But the scholastics do not agree about the distinction between those perfections, nor about their relative pre-eminence. St. Thomas holds a virtual distinction " distinctio rationis cum fundamento in re"), and, true to his intellectualism, emphasizes the role of the Divine Science (302).

293. God and the World.-Here new differences arise between the peripatetic and the scholastic philosophy: the absolute subordination of the being composed of act and potency to the being that is unmixed actuality, does away with the awkward dualism of finite and infinite which troubled Aristotle in common with

${ }^{1}$ G. Grunwald, Geschichte der Gottesbeweise in Mittelalter bis zum Ausgang der Hochscholastik (Beitr. z. Gesch. d. Philos., etc., Münster, rgo7). Cf. monograph by BAEUMKER in his work on Witelo (see below).

2 " We do indeed find in the great scholastics of the thirteenth century, teachings which partly imply the view-point of St. Anselm. But we always find them qualified with reservations which remove the principal defect of the latter" (DOMET DE Vorges, S. Anselme, p. 295). 
many of the ancient philosophers. ${ }^{1} \quad$ It likewise preserves the substantial distinction between God and the world. Scholasticism is the sworn enemy of pantheism in every shape and form. The great medieval scholastics all refute not alone the pantheistic systems of the Greeks so far as they knew them, but also the materialistic pantheism of David of Dinant and his followers, and the emanation theory of Avicebron, Avicenna and Averroës. ${ }^{2}$

The subordination of the world to God is illustrated in the three theories of Exemplarism, Creation and Providence.

(I) Exemplarism. In this doctrine, St. Augustine is undisputed teacher of the scholastics (10o). God knows all created beings, independently of their existence in time. Before creating the universe $\mathrm{He}$ conceived its majestic plan; for He has wrought all things with weight and measure (Pythagoras). God's ideas, says St. Thomas, have no other reality than that of the Divine essence. Since He fathoms the infinite comprehensibility of His being, He not only knows His essence in itself ("objectum primarium"); He sees also the relations between it and creatures, which are its faint, far away imitations ("objectum secundarium"). If other scholastics conceive otherwise the nature of the Divine ideas, all admit, with St. Augustine, that they are the ultimate foundation of the REALITY of CONTINGENT ESSENCES, of their COGNOSCIBILITY, and of the CERTITUDE of all our knowledge: not that we know all things in God (ontologism), but that by synthetic reasoning we see how the attributes of all things necessarily reproduce their uncreated exemplar. These synthetic speculations-together with the inborn tendency of the intellect towards truth, the final cause of its acts (289)-reveal the common view-point of the epistomology of the thirteenth century. ${ }^{3}$

(2) Creation (96). According to those Divine ideas, which are the exemplar-cause of the world, God brings forth from nothing, by His creative act, all contingent realities. Scholasticism

${ }^{1}$ This, says RITTER, is a noteworthy advance : "darin muss man einen bedeutenden Fortschritt erkennen" (Gesch.d. Philos., viii., p. 25r). Cf. WillmanN, op. cit., ii., p. 340 .

2 Seeing that scholasticism rejects the leading principle of Plotinism (viz., emanation), we cannot understand why M. Picavet in a recent book, supports the contention that Plotinus and not Aristotle is the real parent of scholasticism (Esquisse d'une histoire des philosophies médiévales, rgo5).

${ }^{3}$ Hence the scholastics approached the problem of certitude from the METAPHYSICAL rather than from the PSYCHOLOGICAL point of view. 
thus improves on Aristotle, not only by its concept of exemplarcausality which would have been incompatible with the immobility of the peripatetic deity, but also by its theory of efficient causality ("id a quo aliquid fit," 44). The latter sort of cause Aristotle would have more correctly called motor (motus denoting any and every sort of change in a subject), because efficiency, in his concept, does not extend to the production of the original subjects themselves of motion or change. These are presupposed as eternal, like the world resulting from their combination, and motion is regarded as the necessary outcome of their juxtaposition. With the scholastics, on the contrary, not only is the motion of things due to the Divine efficiency, but even their very substance in its deepest and innermost reality. This development of the notion of efficiency may well be said to have made scholasticism more peripatetic than Aristotle himself. The scholastics invariably animadverted on the relations established by the Stagirite between God and the world.

As to the question whether God created the world in time or from all eternity, St. Thomas took up a position which no one hefore him had ventured to sustain: he declared himself unable to see any contradiction in the concept of eternal creation. ${ }^{1}$

(3) Providence. The Creator retains sovereign power over the creature called into being at the behest of His almighty will. In a manner agreeable to the nature of each created being, He confers existence (esse) on the latter, conserves its essence in existence and co-operates with its activities ("concursus congruens naturae creaturae")." He guides and watches over it as Providence. He is also, and in a deeper sense than Aristotle suspected, the final cause of the universe. All things tend towards God: a thesis closely connected, in the case of intelligent creatures, with the scholastic teaching on future life and happiness. The confusion of thought, observable in Aristotle, between motion proper (efficiency) and tendency or inclination by appetite $(\mathbf{4 4})$, is satisfactorily cleared up by means of the creation theory. The application of scholastic metaphysics to theodicy

1 The influence which Moses Maimonides is supposed to have exerted on St. Thomas, has been commonly exaggerated.

${ }^{2}$ Applied to the act of the intellect the Divine concurrence is often called illuminatio; applied to the act of the will it gives rise to the time-honoured controversy between the advocates of a physical premotion or predetermination and the advocates of a simultancous concurrence. 
gave the latter an amplitude and depth which it did not possess either with the Fathers of the Church or with the earlier scholastics. The theodicy of the thirteenth century is one of the most powerful assertions of theism to be found in all history.

\section{General Physics.}

294. General Principles. - The great, striking phenomenon, the study of which enables the "physician" to ascend beyond the details of nature and embrace it all in one synthetic view, is the all-pervading fact of movement or change. On corporeal motion and its divisions, as well as on the theory of substantial change, scholasticism has recourse to Aristotle (50). ${ }^{1} \quad$ But it can lay to its own credit some all-important developments on the rhythmic evolution of forms (5o) and on the finality of the cosmos.

Matter is a storehouse of potentiality. Still, the pliability in virtue of which it assumes divers forms successively, is not without due limit and direction. Nature never changes a stone into a lion; in its evolution it obeys a law of progress the particular applications of which it is the duty of the special sciences to discover. In scholastic language: the primal matter relinquishes its form, not in order to assume any other form at haphazard, but to assume THE ONE special form that corresponds to the immediately neighbouring type in the natural hierarchy. By a special predetermination, matter thus traverses a series of admirably arranged progressive stages. ${ }^{2}$ Hence it is that the human body, prior to its union with the spiritual soul, assumes successively a number of intermediate forms, until the natural agencies at work have given to the embryo an organic constitution sufficiently advanced and complex to call for the ultimate formative principle, the spiritual soul. Such is the full meaning of the formula: "Corruptio unius est generatio alterius".

This process, productive of forms ("eductio formarum e potentia materiae"), is rightly regarded as one of the most difficult doctrines

1 The concept of quantity is, however, accentuated. Throughout all the scholastic systems, the primary matter which unites with the form for the constitution of bodies is invariably conceived as having a primordial relation to quantity: quantity, or the passive diffusion of a body in space, is the fundamental attribute of the corporeal substance, and is a function of its primary matter; as the reduction of its manifold elements to substantial unity is a function of the form.

${ }^{2}$ The scholastics use the term privatio to indicate the absence of the formal principle demanded by the state in which the matter actually is. 
in scholasticism. The leading doctors all admit the intervention of three distinct factors: the general concurrence of the First Cause; the pre-existing matter ready to unite with the new form for the formation of the new body; and the natural agent or efficient principle which actualizes the receptive subject. But they disagree about the role to be assigned to each of these three factors respectively. St. Thomas lays special stress on the "virtus activa" of the natural agent and the passivity of the primary matter ; in opposition to Albert the Great and St. Bonaventure, he aigorously objects to the Augustinian theory of the "rationes seminales" 239), which was then the commonly accepted view; and to account for the evolution of natural substances he assigns as an adequate explanation the simple, natural predestination of matter to receive a successive serie's of perfections. ${ }^{1}$ By thus reducing the problem of the appearance and disappearance of substantial forms to the simple actualization of a potency in a pre-existing subject, St. Thomas may be said to have once more accentuated the peripatetic character of his system.

Design pervades the entire series of cosmic changes; such is the profound interpretation of Nature bequeathed to us by the Stagirite. But the medieval doctors never regarded Nature as an organism, endowed with a real, physical unity, after the manner of the ancients, including Aristotle himself $(\mathbf{5 0})$. To all questions about the term of cosmic evolution, the scholastics find an answer in the relation of the world to God. The creature can have no other end but the glory of the Creator. This glory is primarily revealed in the contemplation of the cosmic spectacle by the Infinite Intelligence; a secondary manifestation of it consists in the knowledge which intelligent creatures possess of the wonderful order of the universe. Such is the answer to the question which Aristotle had asked without answering: How is God the final cause of the material universe?

295. Celestial and Terrestrial Substances.-Astronomical physics and mathematics, the teaching about sublunary bodies and about the action of the heavens on terrestrial substances, were all deduced from an erroneous postulate borrowed by scholasticism from Aristotle (51): the superior perfection of the astral substance as compared with the terrestrial.

(I) The celestial substance is the nobler both by its constitu-

${ }^{1}$ Summa Contra Gentes, L. iii., c. 22. 
tion and by its movement. It is immutable, because the heavens are not subject to generation and corruption. Albert the Great, St. Thomas and Duns Scotus explain these cosmological properties by saying that the heavenly bodies are in reality made up of matter and form, like terrestrial bodies, but that in the former those two elements are indissolubly united to each other. Hence, as matter only lays aside one form to clothe itself with another ("corruptio unius est generatio alterius"), the celestial body can neither come into being, nor pass out of being. Other scholastics, less numerous, however, have recourse to a inore radical hypothesis, recognizing in the stars simple substances, exclusive of matter. ${ }^{1}$ From the immutability of the stars, the scholastics do not conclude, like Aristotle, to their eternity, their system on this point being rather in conformity with their teaching on creation (293). But they defend the unicity of the sidereal type, the form either existing alone or determining all the matter it is capable of "informing".

Motion being regarded by the physicists of the Middle Ages as a necessary manifestation of the essence of bodies, every specific substance ought to possess a specific motion: this is the theory of the "natural motion" and "natural place": one of the antitheses to modern mechanics. It means simply that if a body be displaced by an efficient cause, it determines and directs its local motion, conformably to its nature, in the direction of a place which is natural to it. The heavenly body, superior in constitution to the terrestrial body, is endowed with a nobler mode of motion, viz., circular motion. The movements of the fixed stars are explained by the rotation of concentric spheres, that of the planets by various subsidiary hypotheses: homocentric cycles, and excentric circles or epicycles. Who gives the impetus to the spheres? Not astral souls, intelligent and Divine forms, as Aristotle taught. St. Thomas admits that intelligent motors, extrinsic to the spheres, may communicate to them a gyratory motion. ${ }^{2}$ In connection with this geocentric astronomy, let us emphasize this significant remark of St. Thomas, for it

${ }^{1}$ Cf. P. Tedeschini, Dissert. historica de corpore simplici quoad essentiam (in the Institut. Philosoph. of Palmieri, iii., pp. $32 \mathrm{I}$ sqq.), not free from errors and exaggerations.

2 "Ad hoc autem quod moveat, non oportet quod uniatur sicut forma sed per contactum virtutis sicut motor unitur mobili" (S. Theolog., i., q. 70, a. 3). 
weakens many an accusation brought against scholasticism (v. Fourth Period). Speaking of the motion of the planets, he says: "Licet enim talibus suppositionibus factis apparentia salvarentur, non tamin oportet dicere has suppositiones esse veras, quia forte secundum aliquem alium modum nondum ab hominibus comprehensum apparentia circa stellas salvantur".

(2) The terrestrial or sublunary body: Reference is everywhere made to Aristotle for the theory of the four elements, their qualities, and their rectilinear motion indicative of their relatively inferior natures.

(3) The action of the heavens in producing generation and corruption in sublunary matter is interpreted as in Aristotle. ${ }^{2}$ This supposed influence explains the exagrerated importance attached to the stars in the Midclle Ages-and also the vogue of the various arts which investigated that influence: magic, which interrogated the secret powers of the heavens; astrology. which explained their influence on man's destiny; alchemy, which sought to substitute for the ordinary course of terrestrial transformation an artificial mode of which man was supposed to be master, and to direct the mysterious power of the heavens so as to make the primary matter pass through all the sublunary forms.

\section{Psychology.}

296. Place and Order of Questions. - According to the scholastic classification, psychology forms a chapter of physics, but the most important one: because man is the microcosm and the central pivot of all nature. The full development of psychology coincides with the culmination of the philosophic spirit in the thirteenth century. Instead of the rragmentary and incoherent essays of the earlier period we have here comprehensive and unified studies. To convince ourselves of this we need only take a glance at the matters treated in questions 75 to go of the Pars Prima of the Summa Theologiae of St. Thomas. These hundred pages, moie or less, could be easily' detached from the work of the master and edited under the form of a special treatise on psychology. In conformity with the plan of studies generally followed in the thirteenth century, we may divirle the problems of scholastic psychology

${ }^{1}$ In Lib. II. de Coelo et Mundo, lect. xvii. Cf. S. Theolog., Ia P., q. 32, a. I, ad 2 .

${ }^{2} \mathrm{~S}$. Thomas, S. Theol., Ia, q. I I5, a. 3. 
into two groups, the one relative to the nature of man, the other to his activities.

297. The Activities of the Soul (53). - The faculties with which these are connected, acquire, by repeated exercise of their actions, a growing facility for acting, and this permanent disposition to act in a given groove is called by the name of habitus. For a solution of the question whether the faculties have a reality other than that of the soul, or whether they are merely different modes of applying the same energy to various objects, we must consult the metaphysical discussions that determine the relations of the contingent substance to its operative power (285). St. Thomas reaches the conclusion that there is a real distinction between the soul and its faculties, and between the faculties themselves; adding to certain arguments of the metaphysical order this other consideration: that the adequate distinction between the various vital operations argues a similar distinction between the immediate subjects (faculties) from which they spring. The Angelic Doctor differs here both from Aristotle, whose view is not clear, ${ }_{1}$ and from the Augustinians who regard the soul and its faculties as one and the same reality.

The scholastics distinguish in man three groups of vital functions : the lower functions of the vegetative life, such as nutrition and reproduction; the cognitive functions; the appetitive functions. They were chiefly concerned with the two latter groups, which sum up the whole psychic life proper. And as all the scholastics, by reason of their common spiritualism, distinguish psychic phenomena into two irreducible orders, the sensible and the supra-sensible, we must apply this division to the study both of knowledge and of appetite. Let us, therefore, briefly outline these departments.

298. Knowledge in General. - A recognized authority on scholasticism, Fr. Kleutgen, ${ }^{2}$ reduces to three general principles the teaching of the scholastics on the nature and origin both of sense knowledge and intellectual knowledge :-

(I) The object known is in the knowing subject, as a mode of being of the latter. "Cognitum est in cognoscente secundum modum cognoscentis." This is an application of the more general

${ }^{1}$ PIAT, Aristote, pp. 156 and 157.

${ }^{2}$ Kleutgen, La Philosophe Scolastique (French translation), v. i., pp. 36 sqq. (Paris, I868). 
principle: "Receptum est in recipiente secundum modum recipientis".

(2) Knowledge arises in the subject knowing, after the manner of an image representative of the object known. "Omnis cognitio fit secundum similitudinem cogniti in cognoscente."

(3) This representation is engendered by the concurrence of the knowing agent and the known object: a co-operation which guarantees the real objectivity of our knowledge.

299. Sense Knowledge.- The different forms of sensation are studied as in Aristotle (53). But to the internal senses, the aestimativa in the animal, or cogitativa in man, was now added. This is the sense which, instinctively in the former case and under the direction of the intellect in the latter, perceives the concrete relation of the useful or the hurtful. Vaguely hinted at by Aristotle, this faculty was treated to long commentaries by the Arabian philosophers; and it is from the latter that the teaching of the thirteenth-century scholastics draws its inspiration.

The seat of sensation is the organism, that is to say, the body "informed" by the soul. Under the influence of two distinct currents of Arabian thought, issuing the one from Monte Cassino (126), the other from the Arabian schools of Spain (216), Western philosophers were inclined to fix their attention exclusively on the physiological side of sensation: more than one of them drifted dangerously near materialism in their conclusions. But the scholastics of the thirteenth century soon set things to rights : not ignoring the physiological aspect of the process, they took care to give the psychical aspect its true value as well; they proclaimed the irreducibility of the two phenomena, the physiological and the psychical; while at the same time they recognized in the interdependence of these phenomena a fundamental law of sense life, and, consequently, of all perceptive and appetitive activity.

While the Augustinians considered sensation as a psychical phenomenon which the soul produces in itself on the occasion of a sense impression, Albert the Great, St. Thomas Aquinas, St. Bonaventure even, Henry of Ghent, Duns Scotus-in a word, all the great scholastics-adopted the peripatetic explanation of the grenesis of sensation. This, briefly, is their theory: The sense faculties are passive powers. ${ }^{1}$ The stimulus of the exterior

${ }^{1}$ A technical expression, often misunderstood and misused. Froschammer, one of the historians of St. Thomas, failing to understand it aright, has accused the 
object gives them the initial impulse, without which they would remain inactive. On receiving this determining impulse, the passive faculty reacts, and this reaction completes the process of cognition, impressed and expressed (SPECIES SENSIBILIS IMPRESSA, EXPRESSA); or again, representation impressed from without, and expressed from within, are the terms employed to mark the two stages of the perceptive process. This latter is accomplished entirely within us, but parallel to this PSYCHIC doctrine, scholasticism also developed Aristotle's theory of the PHYSICAL MEDIUM (53).

The leading scholastics, St. Thomas and Duns Scotus, to mention no others, set forth in all their fulness and purity the genetic laws of sensation ; they draw a clear distinction between the PSYCHIC transformation ("immutatio psychica") wrought by the object on the sense, and the PHYSICAL phenomenon which take place in the medium. But many of their predecessors and contemporaries were led astray by the false interpretation placed upon Aristotle's "species sensibilis" by certain of his commentators. For these, the "impressed species" is not a psychic determinant, an effect produced by the object and received in the faculty, but rather a miniature portrait of the external thing, a tiny image which traverses the intermediate space between the object and the organ, a substitute for the reality, coming finally into contact with the sense organ, and assimilated (intussusceptio) by the latter, thus producing knowledge. On disappearing from the field of consciousness, the sensation leaves a trace, an image (phantasma). This latter survives in the imagination, and its principal function is to contribute, in the absence of the object, to the production of thought.

30o. Intellectual Knowledge.-Scholasticism is peripatetic in its theories on the nature of the intellectual act and on its essential difference from sensation: whilst the sense knows only the particular and the contingent, the intellect reaches realities, whether substantial or accidental, by divesting them of the individualizing features with which the things of sense are affected

Angelic Doctor of making knowledge a purely passive phenomenon. Same error in Erdmann, Gesch. Phil., i., p. $45^{2}$ (Berlin, 1892); in Werner, Foannes Duns Scotus (Vienna, r88I), p. 76. A passive faculty is not a non-acting faculty, but a faculty which is passive before being operative, a faculty which must be "informed" by something other than itself before exercising an activity: as opposed to the active power, which has no need of any such foreign influence, but passes to the act as soon as the conditions required for this purpose are verified. 
(abstraction). The object of the concept, because abstract, admits of generalization, i.e., of being referred to an indefinite multitude of individuals. The intellect can know all Being, owing to this process of abstraction. But its strictly proper and natural object is the quiddity or essence of sensible things; it is only by analogical and negative concepts that we grasp the nature of the soul and of supra-sensible beings in general. The existence of the Ego alone is an intuitive datum, implied in all conscious activity: according to the expression of St. Augustine, "ipsa (anima) est memoria sui".

But if the human understanding perceives in things universal realities only, must we refuse it all direct knowledge of the individual? So St. Thomas thinks, and his conclusion is logical. To meet the difficulties which at once spontaneonsly arise, he admits that the intellect has a certain knowledge of singular beings in virtue of some sort of a "reflexio" on the sense data, or an "appiicatio" the nature of which is one of the obscure points of Thomism. Other scholastics take the course of admitting in the intellect, in addition to abstract knowledge, an intuitive knowledge, about which we shall hear more later.

Abstraction was and is the keystone of scholastic ideology. It also offers a definite solution of the criteriological problem and of the question of the Universals. The metaphysical aspect of the question and the "three states of the essence" have been already referred to. This latter formula, so often explained by St. Thomas, bears more directly on the psychology of the problem: the essence of a thing can be the object of a threefold subjective consideration, secundum esse in natura, secundum se, secundum esse in intellectu. "Secundum esse in natura," it is singular (287); "secundum se," it is the simple quiddity of the thing, abstracting from the mental or extramental existence of the latter; "secundum esse in intellectu," it is universalized, conceived in relation to an indefinite multitude of beings in which it can be found. The process of universalization as such is subjective; it is superadded to a previous process of abstractive segregation, which apprehended the objective being or essence.

The genesis of concepts was another favourite subject of research during the thirteenth century. The formula "nihil est in intellectu quod prius non fuerit in sensu," enunciated the senseorigin of ideas and the dependence of even the highest operations 
of our soul upon the organism. The determining influence of the intelligible object on the passive faculty of the understanding and the causal intervention of the sense image (phantasma) and of a special abstractive force or faculty (intellectus agens) to produce this determination, are regarded as indispensable for the generation of thought. The theory of St. Augustine, who did not acknowledge this causal intervention, is abandoned. ${ }^{1}$ St. Thomas criticizes Plato's ideogeny and declares the function which the latter assigns to the object to be insufficient ("excitant animam intellectivam ad intelligendum"). ${ }^{2}$ His criticism tells with equal force against the explanation of the Augustinians. The scholastics are furthermore unanimous in maintaining, against the Arabian philosophers, that the principles of thought are internal to the soul: they reject the separate existence of the intellectus agens and the intellectus possibilis. But the question of the respective functions of the two intellects and of the phantasm remained open to free discussion.

According to St. Thomas Aquinas and Duns Scotus, it is the sense-reality that acts on the understanding through the intermediate agency of the phantasm, but this latter exercises only an instrumental causality, conjoined with, and subordinate to, the efficiency of an immaterial faculty, the "intellectus agens". By virtue of this concurrence of a higher force, the sense-image-and in ultimate analysis the external object-call forth the exercise of the passive understanding ("species intelligibilis impressa"), an exercise of immanent activity in which the cognitive representation properly socalled is achieved and completed "species intelligibilis expressa")." It is noteworthy that from the beginning of the thirteenth century the false theory of the "spiritualized phantasm" gained credit with a large number of scholastics (244). It implies an erroneous notion of the "species intelligibilis," arising from the incorrect conception of the "species sensibilis" referred to above. This latter solution of the ideological problem, leading as it does to the overthrow of scholastic spiritualism, has given rise to interminable misunderstandings (see below).

${ }^{1}$ Matthew of Aquasparta is one of the few scholastics who adopt the Augustinian ideology pure and simple (258).

${ }^{2} S$. Theolog., i., 84, 6 .

${ }^{3}$ This terminology is common among the contemporaries of St. Thomas. St. Thomas himself usually means by species the species impressa; the species expressa he prefers to call the verbum (mentale). 
3or. Sensible and Rational Appetites.-A great law governs the entire appetitive life: "Nihil volitum nisi praecognitum". Every appetition presupposes the knowledge of the object clesired. The sensible appetite is the tendency of the organism towards a concrete object presented by the senses as a concrete good. Intensity of appetite gives rise to the sensible passions-a fruitful fiekl for observation and classification, and one in which the scholastic genius gave itself free scope. The rational appetite, or the will, acts consequently to the presentation of an abstract good. Here also the motive or mainspring of the appetitive tendency is the perfection of the appetitive being: "bonum est quod omnia appetunt". . Some volitions are free.

302. Relations between Intellect and Will.--These furnished matter for lively controversies among the contemporaries and successors of St. Thomas. The alternative solutions have been recently described by a pair of epithets borrowed from modern philosophy: voluntarism and intellectualism. Lest the employment of this terminology in the domain of medieval scholasticism should prove in any way misleading, it is important to note that neither the roluntarists who emphasized the primacy of the will, nor the intellectualists who defended the primacy of the intellect, at all wished to overthrow or interfere with the hierarchy of the psychic functions. The dictum "Nihil volitum nisi cognitum" had the same absolute value for both parties; and hence the controversies of the thirteenth century on the "primacy" of intellect or will, had none of the criteriological significance which attaches to such controversies since the rise of the Kantian philosophy. They first arose from the opposition offered to the traditional teaching of St. Augustine and the earlier scholastics: the doctrine that the will plays a preponderating part in the psychic life. St. Thomas Aquinas was the leader of this opposition, and his teaching here inaugurated new traditions in scholasticism. His intellectualism shows itself:-

(I) In the superior nobility which he claims for the intellect. This superiority results principally from its way of attaining its object.

(2) In the dependence of the voluntary act on the intellectual act. The action of the will is necessitated if the absolute good be presented

${ }^{1}$ As for pleasure and pain they follow upon appetition, reside formally in the appetitive faculties, but may have their source in any conscious activity whatsoever. 
by the intellect; it is free only when the good presented is contingent and accordingly unable fully to satisfy the will. Even the free choice of a particular good presupposes an irresistible tendency towards the good in general as perceived through abstraction.

(3) In the extensive scope of the normal power of the intellect. The special illumination which, in the view of some scholastics, removes from the empire of normal knowledge the acquisition of certain truths (see e.g., $\mathbf{2 4 4}$ and $\mathbf{3 2 3}$ ) is incompatible with Thomistic intellectualisin.

(4) In the respective moral roles of intellect and will, and in the act which puts us in possession of happiness. Finally, the intellectualism of St. Thomas is reflected by analogy in his study of the Divine life and of the angelic life; just as voluntarism applies to these same beings its theories on the will of man.

303. Human Nature (54).-The soul is the substantial form of the body. It is the man, and not the soul alone, that is the proper object of scholastic psychology. Now man is a substantially compound being, of which the soul is the substantial form, the body the primal matter. This at once shows the solidarity of the two constituent elements of our being: their mutual relations are explained by the general theory of hylemorphism (286). Thus it is that the soul gives the body its substantial perfection, its actual existence, its life; and that it is, in the human nature ("id quod agit"), the formal principle ("id quo agit") of all human activities. The thirteenth century definitively rejected the Augustinian doctrines of the preceding period. ${ }^{1}$

If, however, all the great scholastic doctors agreed in explaining human nature by the hylemorphic theory, each of them drew on his own metaphysics to decide whether the formal causality of the spiritual soul excluded the presence of other substantial forms in the composite individual, and notably of the "plastic mediator" or forma corporeitatis. It was in psychology, as may easily be understood, that the respective partisans of the unity and the plurality of forms fought their fiercest fights. The reader is already aware of the view St. Thomas defended in this matter,

'The theory of the spiritus physicus, bequeathed to the Middle Ages by Grecian antiquity, was still maintained; but this spiritus was now no longer, as it had been with Alan of Lille for example, a third factor serving as a sort of connecting-link between soul and body; nor was it identified with the human soul as in the materialistic psychology of the Renaissance; it was conceived as springing from the informing principle, and disposing the brute matter for the activities of inorganic life. 
in spite of the determined opposition of his contemporaries (286): that view finally prevailed, but the contrary doctrine was never wholly abandoned.

The soul is spiritual and immortal. If scholasticism disowned Plato and St. Augustine in their theory of the union of soul and body, it availed of their arguments in establishing the spirituality of the soul. Those scholastics who claimed for human reason the power of demonstrating the spirituality of the soul-and they were the great majority-appealed, above all, to its independence as regards matter, in its highest operations. ${ }^{1}$ Breaking with Aristotle, scholasticism attributed immateriality not to the active intellect or to a faculty of the soul merely, but to its very substance; and since immortality has for its intrinsic foundation the immateriality of our intellectual cognitions, and of our volitions, what will survive the body is not the active intellect, sterile in its isolation (Aristotle), but the soul in the full enjoyment of its conscious life and the full exercise of its hisher activities. ${ }^{2}$

St. Augustine's waverings between traducianism and creationism had awakened echoes down into the twelfth century. But from the commencement of the thirteenth the scholastics appear to have taught unanimously that the direct and daily intervention of the creator can alone call into existence souls destined to animate human bodies. There can be no need to observe that creationism has nothing in common with the Platonic doctrine of the preexistence of souls, nor with the system of Aristotle which makes the human body and the intellectus possibilis subject to the laws of natural generation, while attributing to the intellectus agens an ill-defined extrinsic origin $(\theta \dot{p} \rho a \theta \epsilon \nu)$.

${ }^{1}$ St. Thomas brings forward this other argument, little in harmony with his thesis on the natural union of soul and body, and which seems very like a concession to traditional views: He remarks that the more the soul frees itself from the body, the more capable it becomes of the work of high speculation. Whence he concludes that death, or complete detachment from the body, cannot be for the soul the signal of its annihilation (Contra Gentiles, ii., 79. Cf. 243).

${ }^{2}$ More solicitous for philosophical truth than historical accuracy, the medieval doctors readily excused Aristotle, and forced the meaning of his theories. Speaking of the corruptibility of the possible intellect, St. Bonaventure says: "Illud verbum Philosophi debet pium habere intellectum" (II. Sent., d. I9, a. I, q. I, ad 3. Cf. ST. Тномаs, S. Theol., i., q. 89, a. I, ad I. Cf. 28I). 


\section{Moral Philosophy.}

304. General Ethics (55).-The thirteenth century broaches fundamental moral questions and treats them from a philosophical view-point (126). Every system of ethics implies a theory on MAN'S END and on the HUMAN ACT. In fact, ethics is only the study of human acts in their relation to this end.

(I) Man's end.-The human act par excellence is the free act, which alone is moral or immoral. God is the end of man. Possession of Him is the object of the natural tendencies of our highest psychic activities. The Moral Law is but the application to man of the Eternal Law (Lex Aeterna); and by this latter, we are to understand the adaptation of all creatures to their end by the Divine Wisdom Itself: scholastic ethics is thus seen to assume a metaphysical aspect. The scholastics demonstrate that knowledge (visio) and love (delectatio) of the Creator constitute the most perfect activity of which man is capable; that the act which puts us into possession of happiness is an act of knowledge (St. Thomas), or of volition (Duns Scotus), or of both together (St. Bonaventure).

(2) Duty.-On MORAL OBLIGation the scholastics have a theory unknown to Grecian philosophy. Obligation, St. Thomas Aquinas teaches, is based primarily on the very nature of our acts: for this nature serves as foundation for the "lex naturalis" which is the reflex of the "lex divina aeterna". Our consciences are steeped in that natural law, and every positive law borrows its authority from it. But it is in the Divine order and law that the binding force of all other law is to be finally sought.

(3) Moral conscience.-Being morally obliged to tend towards its good, human nature is obliged, by way of a corollary, to employ the means that are NECESSARY for this end. The habitus principiorum rationis practicae, which scholastics call synderesis, ${ }^{1}$ brings us to the knowledge of the ways that lead to this end. Under the influence of the synderesis, the intellect formulates those great, general principles which are the rules of the moral life; moral conscience, overlooked by Aristotle, is merely the application of these universal principles to particular cases.

It is interesting to note that the elements of the moral good-

${ }^{1}$ St. Thomas calls it: "lex intellectus nostri, inquantum est habitus continens praecepta legis naturalis" (S. Theol., ii., q. 94, a. I). 
ness of an act (object, circumstance, end), determining the convergence of the act to its end, are at the same time the elements of the ontological perfection of that act. By the degree of actuality or perfection in an act is measured its degree of morality: here once more we witness the systematic solidarity of the great leading ideas of scholastic philosophy.

305. Special Ethics. Social Right (56).-Following the example of Aristotle and the ancients, and in accordance with the traditions of the early . Widdle Ages, the scholastics applied themselves to the detailed study of the moral virtues, of the different forms which our moral activity assumes amid the ever-varying circumstances of life. After investigating the general notion of morality, they take up in turn the concrete relations which specify our acts: family, religious, social and political relations. Private ownership and monogamous and indissoluble marriage are of the natural law. As for social life, it has its reason proximately in the nature of man and ultimately in the will of God; but man is free to fix and arrange, according to circumstances, the manner of delegating and exercising social authority. St. Thomas does not appear to have studied the origin of civil authority in process of formation, but he deals with the various conceivable forms of government and declares them all alike legitimate, provided the authority sorerns with "riew to the common grood. After the manner of the ancients, notably of Plutarch, the social classes are compared to the different members of a living body, without, however, attributing to this image the real significance which certain organicists of our day would claim for it. We find also in the social theories of the Middle Ages some few traces of the organization of communal and feudal life. Finally, the thirteenth century justifies the subordination of the temporal to the spiritual power. But from the beginning of the fourteenth century theorists begin to show themselves influenced by the spirit of opposition which animated kings and princes against the papacy.

\section{V11. Esthetics.}

306. Its Place in Scholasticism.-Esthetics might be assigned to the group of sciences which preside over the production of

${ }^{1}$ The individual is not for the State, but the State for the good of the individuals. IVillmann compares this theory with the moderate realism of scholasticism (op. cit. vol. ii., p. +38 ). 
exterior things; but scholasticism did not so assign it because it did not devote any special treatises, nor assign any separate place, to the study of beauty. The thoughts that are to be found on the subject are scattered through metaphysical or psychological treatises, or contained in commentaries, notably in the commentaries on the treatise of Pseudo-Denis, De Nominibus Divinis.

307. Esthetic Problems (57). - The beautiful is a complex notion, an impression (subjective aspect) having its cause in an object adapted to produce it (objective aspect). ${ }^{1}$

This impression may be analyzed into disinterested contemplation by the intellectual faculty, accompanied by a specific enjoyment. In this way scholastic esthetics improves upon the esthetics of Aristotle.

Scholasticism also perfects the Aristotelian notion of objective beauty. Entire and complete order, which is the object of esthetic perception, is in fact connected with the substantial form of the being, with the principle of its unity.

Finally, scholasticism, by the theory of the "claritas pulchri," establishes between the objective and subjective elements of beauty a relation of causality, and an adaptation, not to be found in Aristotle: the "claritas pulchri" being that property of things in virtue of which the objective elements of their beauty (order, harmony, proportion) are revealed to the mind with distinctness, and elicit the full and free contemplation of the intelligence.

\section{Conclusion.}

\section{Definition of Scholasticism by its Doctrinal Characters. -} After all those rapid sketches, let us now revert to the question raised above (118): in what does a REAL and INTRINSIC definition of scholastic philosophy consist? It will be taken from the very heart of that philosophy, from its fundamental doctrines. To lay bare the essential features of the scholastic system, we need only take up in order the groups of solutions it offers us, and study their distinctive features. Each of these solutions will mark scholasticism with a definite seal, with an impress of its own; and the sum-total of these distinctive traits will give us the essential features of scholasticism. Any one of these marks, taken separately, may be common to scholasticism and other philo-

1 "Pulchra enim dicuntur quae visa placent; unde pulchrum in debita proportione consistit" (S. Theol., i., 4, ad I). 
sophical systems; but the SUM-TOTAL of them belongs to scholasticism alone.

Let us now trace some of the outlines of this descriptive definition. First of all, scholasticism is not a MONISTIC system. The DUALisil of the Pure Act (God) and of beings composed of act and potency (creatures), makes scholasticism the irreconcilable enemy of all pantheism. The compositions of matter and form, of the individual and the universal; the distinction between the reality of the subject knowing and that of the object known, between the substance of the soul in heaven and that of the God Who satisfies all its longings: are all so many doctrines entirely incompatible with monism. The theodicy of scholasticism is CREATIONIST and PERSONALIST. Its metaphysic of the contingent being is at once a MODERATE IMNAMIsi (act and potency, matter and form, essence and existence) and a frank assertion of INIIVIDUALISV. This same DNAMISM regulates the appearance and disappearance of natural substances; from another point of view the material world receives an EvolutionisT and FINALIST or TELEOLOGICAL interpretation. Further, scholastic psychology is SPIRITUALIST and not materialist; EXPERIMENTAL and not aprioristic or idealist; UMJECTIVIST and not subjectivist: its very definition of philosophy implies the possibility, for the intellect, of attaining to extramental reality. Supported by the data of psychology and metaphysics, its logic vindicates the rights and claims of the MALYTICO-SYNTHETIC method. As for its ethics, they borrow from psychology most of their distinguishing features: they are EUDEMONISTIC and LIBERTARIAN.

We might add other view-points and look at the scholastic synthesis in other ways, and so find other intrinsic characteristics whereby to define it. An integral definition should exhaust these fully. All, moreover, are organically connected and complete one another in the whole: it is natural that they should, since the different doctrinal departments to which these features belong, are all knit together in the closest organic unity.

309. Doctrinal Features of Thomism. - ( I) Doctrinal solidarity.In the Thomistic synthesis we are struck with the close doctrinal solidarity, the masterly co-ordination of the great leading ideas: everything is here inter-related and unified. And this is precisely the reason why Thomism has ever and always held its place as one of the most masterly presentations of scholasticism. 
(2) Innovations. - This solidarity of doctrine is secured by a masterly use of the common fundamental theories, together with the introduction of a number of new theories calculated to strengthen the cohesion of the whole system. By embracing those new theories, St. Thomas breaks with the tradition of the earlier scholasticism: he emphasizes the close relationship between philosophy and theology; he coinbats plurality of forms by unity of substantial principle; to the theory of the "rationes seminales" he opposes that of the passive evolution of matter; to the hylemorphic composition of spiritual substances he opposes the doctrine of subsisting forms; against the Augustinian theory of the identity of the soul with its faculties he advocates the theory of their real distinction; instead of the voluntarism of the Augustinians he embraces an intellectualist conception of the psychic life. It is in these doctrinal innovations, combined with his profound grasp of the common theories, that we are brought face to face with the unrivalled excellence of St. Thomas's philosophical achievements. ${ }^{1}$

And St. Thomas is bold and thorough in his advocacy of his new theories: he follows out their logical consequences in all directions. In this he excels both Albert his master and St. Bonaventure his friend. ${ }^{2}$ At the same time he is moderate and tolerant. In his scientific relations with others he never tries to propagate his views by sharp or imperious controversy, but always by mild persuasiveness: adversaries like Peckham bear witness to his dignified and pacific attitude in the midst of heated controversy. ${ }^{3}$

It has been thought possible to detect in the earlier works of St. Thomas a tendency to admit the earlier scholasticism, before strik-

${ }^{1}$ It is remarkable how strongly his disciple, William of Tocco, has emphasized those innovating tendencies of his master's teaching: "Erat enim novos in sua lectione movens articulos, novum modum et clarum determinandi inveniens et novas inducens in determinationibus rationes, ut nemo qui ipsum audisset nova dicere et novis rationibus dubia definire, dubitaret quod eum Deus novi luminis radiis illustraret, qui statim tam certi coepisset (esse) judicii, ut non dubitaret, novas opiniones docerc ct scribere, quas Deus dignatus esset, novitcr inspirare" (Acta SS., vii Martii, n. I5).

${ }^{2}$ Compare, for instance, the theory of unity of form in Albert and in St. Thomas; or the hesitating view of St. Bonaventure on the distinction between the soul and its faculties with the frank and firm attitude of St. Thomas.

${ }^{3}$ See a descriptive essay-historical, though a little fanciful-on the scenes to which we allude, by Père Facquin (under the n.d.p. M. Delengre) in the Annales Dominicaines (5th March, 1904) : "S. Thomas d'Aquin, un épisode de sa carrière universitaive à Paris". Cf. ३ıII. 
ing out on his own personal lines ( $c f$. 286). It is only natural that in his youth he would have adopted the teaching of his masters (he was only eighteen when studying under Albert at Cologne). This fact is of interest; for it helps us to a "psychological study" of St. Thomas; but it does not affect in any way his final and mature philosophical synthesis.

(3) Peripateticism.- Though personal in his choice of new doctrines, and eclectic in his details and illustrations, the Angelic Doctor's genius has a close kinship with that of Aristotle. But so far was he from imitating the Averroists in their servile abdication of personal thought that he proclaimed the argument from authority to be the last and weakest of argunents in philosophy" "locus ab auctoritate. . . est infirmissimus"). He extended the scope of reripateticism; he developed its teachings in the direction of a strongly marked individualism, whilst Duns Scotus was to give them rather a more distinctly realist interfretation.

3ro. Sources and Bibliography.-W W WLIAM OF TOCCO, who was in personal touch with many of the circumstances of St. Thomas's life, has left a biography utilized in the Bollandists' Life of St. Thomas, Acta Sanctorum, $7^{\text {th }}$. Iarch. Quetif and Echard. De Groot, Het Leven van den hl. Th. v. Aquino (Utrecht, 1907, 2nd edit.) : excellent for biography, chronology, authenticity of works, etc.; cf. Endres, in the Histor. Fahrb., Igos: Studien z. Biographic d. hl. Thomas von Aquin. A Life of St. Thomas by Père Sertillanges is announced in the series Les (irands philosophes.

We possess two ancient catalogues of the works of St. Thomas. The first is that of Stams, v. 266. The other, drawn up from the depositions of a witness in the canonization process, is published by Baluzius, Vitae Paparum Avcnionensium (Paris, r693), t. ii., p. 7. Cf. the dissertations of De RubeIs in the second Venice edition. Mandonnet, Des écrits authentiqucs de S. Thomas (Revue Thomiste, I9og): excellent classification of sources.

The complete works of St. Thomas have been many times edited. Among the ancient editions we may mention those of Rome (1570, edit. of Pius V.), Venice (1592), Antwerp (1612), Paris (1660), Venice (1787). In 1852 his works were reedited at Parma. In I882, under the auspices of Leo XIII., a new edition was commenced at Rome by the Dominicans. T. i. Comment. on the Perihermen. and the Post. Anal. (1882); t. ii. on the Physics (1884); t. iii. on the De Coclo et Mundo, De Gen. et Corrupt. and Meterolog. (1886); t. iv.-xii. Summa Theol. (1888-1906), with Cajetan's commentaries. There are numerous partial editions, especially of the Summa Theologica, which cannot be mentioned here. DE. MARIA has pub. lished, in three vols., the Opuscula Philosophica et Theologica and the Quodlibeta (r886, Città di Castello); Prof. Thiéry, the Commentary on the De Anima (Louvain, 1907). The De Pulchro et Bono, which UckLli has published, according to what he claims to be an autograph MS. of St. Thomas (Naples, 1869), is merely an extract from the commentary of Albert the Great on the De Divinis Nominibus of Pseudo-Denis. Scнürz, Thomas Lexicon (2 Aufl., Paderhorn, 1894) : very useful.

lourdain, La philosophie de S. Thomas (Paris, is58). Werner, D. hl. Th. ". 
Aquino (1858). Plassmann, Die Schule d. hl. Thomas v. Aquino (1858-186r). Froschammer, Die Philos. d. Th. v. Aquino, krit. gewürdigt (1889). All those are insufficient. Willmann, Geschichte d. Idealismus, ii., \$\$ 74-79. Rousselot, L'Intellectualisme de $S$. Thomas (Paris, 1898 ) : a very excellent and very much discussed book; see our notice in the Revuc Néo-Scolastique, Feb., I9og. Same author: Pour l'histoire du problème de l'amour au moyen âge. Cf. R. Néo.Scol., Feb., rgog. GUtberlet, Voluntarismus (Philos. Jahrb., rgo.): exposition of intellectualist and voluntarist arguments. Denove, Essai sur le vealisme thomiste (Lille, rgo8). Numerous studies in Thomistic philosophy have been published everywhere since the Encyclical, Acterni Patris, of Leo XIII. was issued; especially in the following reviews : Philosophisches Fahrbuch, Fahrbuch f. Philos. u. spek. Theol., Zeitschr.f. Kathol. Theologie, St. Thomas Blätter, Revue Thomiste, Revue Néo-Scolastique, Revue des Sciences Philosophiques et Théologiques. Few of those studies, however, are historical.

Sснӥтz, D. hl. Th. u. seine Verständniss d. Griechischen (Philos. Jahrb., I895). Miguel Asin y Palacios, El Averroismo teologico de Sto. Tomas de Aquino (Extracto d. homenaje a Fr. Codera), Zaragoza, I904, pp. 27 I-92; new theses: that in the question of the relations of philosophy to theology St. Thomas followed Averroës, through the medium of Raymond Martin. Opposed by Getino, who has published a reply under the same title. Relations with other philosophers: VACANT, Litudes comparées sur la philos. de S. Thomas d'Aquin et sur celle de Duns Scot (Paris, 1897). Guttmann, Die Verhältniss d. Th. v. A. zur Füdischen Litteratur (I89r). Wittmann, Die Stellung d. Th. v. Aq. zu Avencebrol: good. Von Hertuing, Augustinus-Citate bei Thomas, Akad. Bair., iv., 535-602. For relations with Siger of Brabant, see Mandonnet, op. cit. Maurenbrecher, Thomas v. Aquino's Stellung z. Wirtschaftsleben seiner Zeit. (H. I, Leipzig, I898): seeks evidences and analogies bearing on communal organization in the works of St. Thomas; further studies promised. DE WULF, Études historiques sur l'esthétique de S. Thomas d'Aquin (Louvain, 1896).

For the scholastic system of philosophy generally, the following may be consulted: Kleutgen, Die Philosophie d. Vorzeit, French trans., La Philosophie scolastique, 4 vols. (Paris, 1868-1870): contains valuable dissertations on special questions. Same author: Beiträge zu d. Werken über d. Theol. u. Philos. d. Vorzeit (Münster, I875). Willmann, op. cit., ii., §§ 67-73. DE Wulf, Scholasticism Old and New (Dublin, 1907), §§ 12-17. BAUR, Gundissalinus, etc. (246) : ch. iii. contains a good history of medieval classification of the sciences, clearer and more methodic than Marí́tan's (135). Schindele, Zur Gesch.d. Unterscheidung v. Wesenheit u. Dasein in d. Scholastik (München, 19oo): notes on the leading scholastics of the thirteenth century. A. LALANDE, Histoire des sciences. La Physique du moyen age (in the Rev. de synth. histor., Oct., rgo3): a study of the experimental sciences rather than of Physics as understood in the Middle Ages. J. Laminne, Les quatre ćléments, lc feu, l'air, l'eau, la terre (Brussels, rgo 4 ). BRANTs, Esquisse des théories économiques professées par les écrivains des xiiie et xive s. (Louvain, I895) : good. Kantorowicz, Albertus Gandinus und das Strafrecht d. Scholastik (Berlin, rgo8). Cf. Domet De Vorges, La philos. thomiste pendant les années r888-r898 (in the Congrès Bibliograph. Internat., Paris, r899), and Grabmann, Studium d. Thomasphilosophie (in the Jahrb. f. Philos. und spek. Theol., r9oo, pp. 137 sqq.): gives numerous bibliographical references. Perrier, op. cit., 120. 


\section{ART. IV.-.THE CONFLICT BETWEEN THOMISM AND THE EARLIER SCHOLASTICISM.}

\section{$\S$ I. AdVERSARIES OF ThOMISM.}

\section{I. Two Forms of Opposition. Tracts against Thomism.-} The new Thomistic doctrines threatened to drive many venerable old theories out of the schools, and this naturally aroused the opposition of the masters who were brought up in those earlier theories. Excessively suspicious of Thomism, they withdrew into the fortress of their traditional inheritance and defended themselves and it against the supposed enemy. This reactionary party was recruited not merely from the seculars and the Franciscans, but even from among the Dominicans themselves. John Peckham informs us that St. Thomas's teaching on the unity of substantial form was combated, even in the heyday of his renown at Paris (1269-127I), by his own brother-religious of the convent of St. James, "etiam a fratribus propriis arguebatur argute"." So, too, at Oxford, for many years the leader of the opposition to Thomism was a Dominican. The hostilities assumed two distinct forms: the Thomist doctrines were attached in pamphlets and condemned by censures.

Only incidental refutations of Thomism appear in the writings of Matthew of Aquasparta, ${ }^{2}$ but other Franciscans wrote pamphlets expressly against Thomism. The Correptorium Fratris Thomae, by WILLIAM DE LA MARE, a pupil of IVilliam Varo, is a veritable manifesto, a rallying cry to the older scholasticism against Thomism. ${ }^{3}$ The attacks were directed mainly against the theory of the unity of substantial form. RICHARD OF Middleton composed a treatise De Gradu Formarum ${ }^{4}$ in defence of plurality. John PECKHAM, who was all his life an intemperate opponent of Thomism, relates in a boasting way, in 1285, how he took St. Thomas to task (in I269-1271) on the unity of form, in a scholastic tourney before the bishop of Paris and the masters of theology. Were we to believe Peckham, he alone defended St. Thomas as far as truth permitted. "Nos soli

${ }^{1}$ Letter of J. Peckham, Ist June, 1285. Chartul., i., p. 634.

"And also most probably in the authors mentioned, 260, and not yet studied.

' He also wrote Quaestiones Disputatae and a commentary on the Sentences.

+ Which we discovered in a Paris MS. immediately preceding the De Unitate Formas of Giles of Lessines. 
ei adstitimus, ipsum, prout salva veritate potuimus, defendendo ;" and, finally, the adversary, driven to bay, was obliged to submit his theses humbly to the censorship of the Faculty, "donec ipse omnes positiones suas quibus posset imminere correctio, sicut doctor humilis subjecit moderamini Parisiensium magistrorum ". ${ }^{2}$ But we must largely discount this version of the matter. BARTHOLOMEW OF CAPUA, a witness in the process of canonization of St. Thomas, paints the scene in very different colours. Peckham apparently tried by using strong language to exasperate St. Thomas, but elicited in return only words of sweetness and humility. ${ }^{2}$ There is also preserved a letter from the Dominican, ROBERT KILWARDBY, to his confrère, Peter of Conflans, archbishop of Corinth, complaining of the many inconvenient consequences of the new doctrines.

Hostility to Thomism also issued in a series of official condemnations. The history of these makes some of the most lively and interesting pages in the University annals of Paris and Oxford.

312. Condemnations of Thomism. - Let us deal firstly with Paris. As early as I 270, a move was made to include in the inquiry that led up to the condemnation of Averroissm on the Ioth of December (344), two favourite theories of St. Thomas: his doctrine on unity of substantial form in one of its theological applications, and his doctrine on simplicity of substance in the angels. ${ }^{3} \quad$ That same year, indeed, St. Thomas had maintained, in his third quodlibetic disputation, practically all the new, theories in which he parted company with the earlier scholastics. This first attempt to involve him failed, but seven years later a similar plan was again set in motion. On the 18th of January, 1277, John XXI., informed that Averroïstic errors were being taught at Paris, ordered the bishop, Stephen Tempier, to hold an investigation. The latter, accordingly, convening an assembly of the masters of theology, proceeded without delay (on the 7 th of March) to condemn 219 propositions, bearing mainly on Averroïsm (344), but some of which embodied Thomist doctrines, notably the doctrine on the principle of individuation (theses 81 , 96, I9I). ${ }^{4}$ It is surprising that such an indignity could have been

${ }^{1}$ Chartul., i., p. 634. $\quad{ }^{2}$ Ibid., p. 635.

3 We owe this information to Giles of Lessines (3r3).

4 The 96th error was thus stated: "Quod Deus non potest multiplicare individua sub una specie sine materia". Error n. 7 is interesting inasmuch as in it is con- 
inflicted on St. Thomas-to associate his doctrines with those of the Averroists, his adversaries, and to strike them with the same censures for the same ostensible reasons. It was undoubtedly the supporters of the earlier or Augustinian scholasticism that secured the condemnation, but it is likely that they were aided and abetted by other opponents of St. Thomas: the partisans of William of St. Amour, Nicholas of Lisieux and Gerard of Abbeville would have used all their influence to bring suspicion on one of the most redoubtable champions of the rights of the mendicant orders. Those condemnations of Tempier had no binding force outside the University and diocese of Paris. They were, however, no mere isolated fact, but rather part of a wider plan of campaign of which the ramifications extended to Oxford.

Oxford, under the jurisdiction of the archbishopric of Canterbury, was in fact a centre of active opposition to the new Thomistic theories. The supporters of the older scholasticism were led by two archbishops successively, the Dominican Robert Kilwardby and the Franciscan John Peckham and were accordingly described in the contemporary documents as the "Cantuarienses".

On the IStin of March, a few days subsequent to Tempier's decree at Paris, the archbishop of Canterbury, Robert Kilwardby, who had been leading the campaign against Thomism among the English Dominicans, got a series of theses in Grammar, Logic and Physics condemned by the masters of the University of Oxford. Chief among the theses in Physics (in naturalibus) are those relating to the Thomistic teaching about generatio, the passivity of matter, the unity of soul in man, and the appearance of new forms in the human body after death." Robert defended

demned the Platonic and Augustinian psychology: "Quod intellectus non est forma corporis nisi sicut nauta navis, nec est perfectio essentialis hominis". Cf. nn. I3. $I_{4}$ ("Opiniones ducentae undeviginti Sigeri de Brabantia, Boetii de Dacia aliorumque, a Stephano episcopo Pariensi condemnatae de consilio doctorum sacrae scripturae condemnatae," Chartul., i., pp. 543-60).

'See e.g., the De Unitate Formae of Giles of Lessines, p. I4 (DE Wulf's edit.): "Sic arguunt cantuarienses".

2 "Item quod forma corrumpitur in pure nichil (2); item quod nulla potentia est in materia (3); item quod privatio est pure nichil . . (4); item quod intellectiva introducta corrumpitur sensitiva et vegetativa $(7)$; item quod vegetativa, sensitiva et intellectiva sint una forma simplex (12); item quod corpus vivum et mortuum est equivoce corpus, et corpus mortuum secundum quod corpus mortuum est corpus secundum quid (13); item quod intellectiva unitur materie prime ita quod corrumpitur illud quod pratcessit usque ad materiam primam (r6) "(Chartul., i., p. 558). 
his action; to secure respect for his justification of the measures he had taken, he held out both threats and promises." "I do not condemn the theses as heretical, but I forbid them as dangerous," he wrote to Peter of Conflans (Petrus de Confleto). The latter, undertaking to plead with Robert on behalf of Thomism, drew from him a long justificatory letter ${ }^{2}$ which serves as a commentary on the decree. Besides the treatise $D e$ Ortu et Divisione Philosophiae (263), this document is all that has yet been studied of the works of Robert. It defends the doctrines of the earlier scholasticism: the rationes seminales (" evolutio illarum rationum et explicatio per res actuales fit per secula, materia naturalis prima . . . est quid dimensiones habens corporeas, impregnatum originalibus rationibus") ${ }^{3}$-and especially the plurality of substantial forms. Kilwardby distinguishes in the human individual three vital forms, all substantial, the union of which constitutes the one single human soul, ${ }^{4}$ and an additional form which gives the body its material plasticity. ${ }^{5}$ In justification of this multiplicity of forms, he appeals to the superiority of the soul over the body (see Alexander of Hales) and to the identity of the living body of Christ with the body during its three days' repose in the tomb. ${ }^{6}$ There was, in all probability, an understanding between Kilwardby and Tempier about this simultaneous condemnation at Oxford and at Paris, for we know that in the course of the same year, 1277, Tempier

${ }^{1}$ A Burgh. MS. adds to Robert's decree the words : "quicunque hec dicta non sustinet nec docet habet a fratre $R$. archiepiscopo XL dies de indulgentia, qui autem dictas positiones defendit..." (Chartul., i., p. 560, n. 3).

${ }^{2}$ Published by EhrLe in the Arch.f. Litt. u. Kirchengesch. Mitt., 1889, p. $6 \mathrm{I}_{4}$.

Ibid., p. 616; $c f$. p. 623, i., 5-1o. The Thomistic theory on privatio is struck by props. 3 and 4 .

${ }^{4}$ Prop. I2. ${ }^{5}$ Ehrle, op. cit., p. 635.

${ }^{6}$ The $3^{\text {th }}$ proposition condemned by the decree of 1277 is directly opposed to this teaching of St. Thomas: "Corpus Christi mortuum et vivum non fuit simpliciter idem numero, quia non fuit totaliter idem. ... Corpus mortuum cujuscumque alterius hominis non est idem simpliciter, sed secundum quid" (S. Theol., $3^{\text {a }, ~ q . ~ 5 o, ~ a . ~ 5, ~ i n ~}$ c., et ad Imam). But then, retorted his adversaries, you must hold that the bodies of the saints, venerated by the faithful, are not those that belonged to them when alive. "Nec aliqua sanctorum corporum tota vel secundum partes aliquas in orbe existere vel in Urbe, sed quaedam alia quae non genuerunt matres sanctorum." Letter of Peckham to the Chancellor of Oxford (Nov. the roth, 1284). See EHrLE, Zeitsch., etc., p. 174. So, too, in $\mathbf{1 2 7 1}$, Nicholas of Lisieux holds as erroneous : "oculum mortuum esse aequivoce oculum" (Quodl., iii., a. 4). 
was thinking of proscribing some additional theses, especially that which expounderl unity of substantial form. But in the meantime John XXI. died; and as the bishop of Paris was acting in conjunction with the Roman Curia, an order was issued by a number of the cardinals, during the vacancy of the Holy See (May the 2oth to Nov. the $23 \mathrm{rd}$ ), asking him to drop the matter and postpone his censures to some more opportune time. The Oxford decrees, too, got a wide publicity at Paris and were discussed there quite as energetically as those of Tempier himself.

The opposition became still more vigorous at Oxford under John Peckham, Kilwardby's successor in the see of Canterbury. But the constitution of the conflicting parties was somewhat changed. After the decision of the general chapter at Milan in I278, Thomism became the official doctrine of the Dominicans, at Oxford as elsewhere. Peckham's first move was to confirm the act of his predecessor, on the 29th of October, 1284.' Then, on the provocation of the prior of the Dominicans RICHARI KLAPWELL or CIAAPOEL), he renewed (April the 3oth, 1286) the prohibition of the disputed Thomistic theses." The eight propositions condemned this time regard the theory of the unity of substantial form both in its principle and in its more important consequences: ". . istos igitur articulos haereses esse damnatas in se vel in suis similibus . . denunciamus". Peckham inveighs with some ardour against the frofanas rocum ranitates of philosophers whom he describes as elatiores quam capaciores, audaciores quam potentiores, garruliores quam litteraciores. He advocates a return "to the sound and solid doctrine of the sons of St. Francis, Alexander of Hales and St. Bonaventure". ${ }^{3} \mathrm{He}$ would apply to a cancerous sore the balm of his pastoral prescriptions. ${ }^{*}$ He warns all against the "dangerous" theory of the unity of forms-and by a clever trick insinuates that the

${ }^{1}$ D'Argentré, Collectio Fudiciorum, t. i., p. 234.

${ }^{2}$ Ibid., pp. 237 and 238, text of articles and condemnation. Prop. viii. : "Octavus est quod in homine est tantum una forma, scilicet anıma rationalis et nulla alia forma substantialis: ex qua opinione sequi videntur omnes haereses supradictae"."

"Chartul., i., p. 634 .

4 "Volentes huic cancerosae prurigini quam poterimus adhibere pastoralis officii

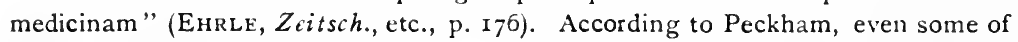
the Franciscans allowed themselves to be captured by Thomistic theories (ibid., p. 19I). 
theory may well be of Averroistic origin. ${ }^{1}$ In addition to the plurality of forms he supports the rationes seminales, the rationes aeternae and the theory of the identity of the soul and its faculties: "... Quidquid docet Augustinus de regulis aeternis, de luce incommutabili, de potentiis animae, de rationibus seminalibus inditis materiae et consimilibus innumeris". ${ }^{2}$ It is not philosophy he would condemn, but its abuse: "novitates (reprobamus) que contra philosophicam veritatem sunt in sanctorum injuriam citra viginti annos in altitudines theologicas introductae". The letter dates from the Ist of June, 1285 . The "novelties" were therefore introduced about 1265 : which brings us back to the second period of St. Thomas's teaching at the University of Paris.

\section{$\S$ 2. SUPporters OF THOMism.}

313. Dominicans. Giles of Lessines.-Unbending opposition from some called forth earnest and unflinching adherence from others. In the Dominican order the hostility was short-lived and soon gave way to an unbounded admiration for St. Thomas. When Albert the Great, now a venerable octogenarian, arrived at Paris to defend his old pupil, animosities were quickly banished from the convent of St. James. Proud of the already world-wide reputation of the Angelic Doctor, a general assembly of the chapter at Milan in 1278 discountenanced the reaction of which Oxford was the centre ${ }^{3}$ and another at Paris in 1279 commanded the entire order to adopt the teaching of St. Thomas, under threat of serious penalties. ${ }^{4}$

Among the many Dominicans who studied under St. Thomas himself, or lived in the later years of the thirteenth century, there do not seem to have been any philosophers of the first rank. Numerous works on philosophy, ${ }^{5}$ as yet undiscovered or unedited, are attributed to BERNARD OF TRILIA (about I240I 292), JOHN OF PARIS or QUIDORT (d. I 306, notably a treatise Contra Corruptum Thomae), PTOLEMY OF LuCCA (says himself

1 “ Nec credimus a religiosis personis, sed secularibus quibusdam duxisse originem cujus duo praecipui defensores vel forsitan inventores miserabiliter dicuntur conclusisse dies suos in partibus transalpinis" (EHRLE, op. cit., p. I75). Pìre MANDONNET has brought out clearly the force of this insinuation (op. cit., p. cxxv).

${ }^{2}$ Chartul., i., p. 634 . ${ }^{3}$ Ibid., i., p. 566.

${ }^{4} C f$. Ehrle, Archiv, etc., p. 605. Those injunctions were subsequently repeated.

${ }^{3}$ List published by DenIfLe, Quellen, etc., pp. 226-40. 
that he followed the lectures of St. Thomas in I272, "ipsius auditor fui": his De Regimine Princifum completes L. II. and adds L. III. and L. IV. ${ }^{1}$ to the work of St. Thomas), WILLiam OF Hotun (d. bishop of Dublin, I 298), HUGH, archbishop of Ostia (d. 1297 ; Contra Corruptionem Thomae), Bernard of AUvergnf, bishop of Clermont (thirteenth and fourteenth century), and William of Mackelfield (d. 1 304). Bernard of Auvergne undertook to defend all Thomism against the deviations of Godfrey of Fontaines and Henry of Ghent. William of Mackelfield wrote a treatise Contra Henricum de Gande quibus impugnat Thomam, contra corruptionem Thomae. RORERT OF ERFORT, another Englishman and an intrepid supporter of Thomism, wrote Contra Dicta Henrici de (rande and Contra Primum Egiani. Thomas SutTon, probably an Oxford man, wrote, about the close of the thirteenth century, a treatise De Concordia Librorum Thomae."

A special mention is due to Giles of Lessines. An intimate friend of Albert the Great, whose lectures he followed, probably. at Cologne, Giles taught as bachelor in the convent of St. James at Paris. It was he that wrote to Albert in 1270 (" patri ac domno Alberto, episcopo quondam ratisponensi") to warn him of the threatened condemnations (266 and $\mathbf{3} \mathbf{2}$ ) of Thomism. He requested enlightenment from his old master, and received it in the treatise De Quindecim Problematibus, in which Albert is not very explicit about the Thomist teaching. A treatise De Usuris. often attributed to St. Thomas, an undiscovered Tractatus de Praceptis, another De Concordia Temporum (a chronology of events down to 1304, whence Quetif and Echard conclude that Giles died about the latter date), and, more important than those, a treatise De Unitate Formae, constitute the whole literary legacy of Giles of Lessines. The De Unitate Formae, dated July, I278, is a controversial work written against Robert Kilwardby ("cantuariensis archiepiscopus"). ${ }^{3}$ In fact, Giles' exposition of the

${ }^{1}$ Quetif-Echard, Scriptores, i., p. 54 I.

${ }^{2}$ Denifle, op. cit., pp. 227, 233, 239. A master named John the Teuton (a common designation among the Dominicans of the thirteenth and fourteenth centuries) wrote against the real distinction between essence and existence. The text, taken from commentaries on the Sentences, is published by Grabmann, Die l.chre d. Fohannes Teutonicus O.P. über d. Unterschied v. Wesenheit u. Dasein (Cod. Vat. Lat., Iog2), in the Jahrb. f. Philos. u. spekul. Theol., 1902, pp. 43 sqq.

${ }^{3}$ Pp. ${ }_{3} 3$ and $\mathrm{I}_{4}, \mathrm{DE}$ Wulf's edit. 
pluralist theory, the special interpretation he gave it (functional subordination of forms), the arguments he set forth, and even his very forms of expression, are found in an apologetic letter of Robert Kilwardby to Peter of Conflans. Giles must have possessed a treatise by Robert, perhaps a treatise on forms, from which the latter made extracts in the letter referred to.

The treatise of Giles contains, in addition to the exposition of Robert's theory, two other parts, comprising respectively: (a) general notions on matter and form; $(b)$ the formulation and proof of the unity theory, together with a refutation of the opposite theory. The constructive portion of the work restates the arguments of St. Thomas, but as the treatise is mainly controversial it dwells at greater length on the difficulties of pluralism. The style is clear and the reasoning cogent and logical. In the closing portion especially the author gives us the benefit of his own personal views ("de quo principaliter describimus secundum intellectum nostrum").

The De Unitate Formae of Giles of Lessines occupies a leading place-if not the very foremost place-in the rich literature of the end of the thirteenth century on this controversy about forms. ${ }^{1}$

314. Other Supporters of Thomism.-(I) Thomism was not slow to gain partisans in the ranks of the other religious orders. Humbert of Prulli established it among the Cistercians; Giles OF Rome, among the Hermits of St. Augustine. The latter, however, influenced by a natural sympathy with the Doctor whose habit he wore, refused to relinquish certain Augustinian theses: he will be classified with the eclectics ( $\$ 3$ ).

(2) The Paris Faculty of Arts mourned the death of St. Thomas and long revered his memory. Many who had listened in admiration to his lectures, remained faithful to the new teaching and went to swell the ranks of his earliest disciples. Recruits were also drawn from among the clerics and the secular masters of the Faculty of Theology. Of the number of these latter is Peter of AUvergne (d. about I 305). He probably followed the lectures of St. Thomas, is the author of Quodlibeta (unpublished), and became rector of the University in 1275 .

${ }^{1}$ In the list of Dominican works, published by DenifLe, op. cit., pp. 238-40, there are treatises De Unitate Formae by William of Hotun, Hugh of Ostia and Thomas Sutron. Tolater dates (unknown, fourteenth or fifteenth century) belong the treatises of Joannes Faventinus and Janinus de Pistorio. 
Hauréau attributes to him certain Thomistic commentaries on Aristotle's Physics and Metaphysics. ${ }^{1}$ He completed the De Coelo et Mundo of St. Thomas (272).

It is customary to place among the faithful supporters of Thomism PETRUS Hispanus (1 226-1 277), who must probably be identified with the Portuguese Juliani, the future Pope John XXI. It was he who ordered Stephen Tempier to hold the wellknown investigation into the errors prevalent in the Paris schools. Besides certain writings on medicine, he is the author of Summulae Logicales, a compendium of the Paris teaching on logic-a treatise which shows what great store was set on proficiency in exercises of formal logic even in this, the great century of scholasticism. ${ }^{2}$ The Summulae was immediately adopted as a text-book in the schools. In addition to the matters treated in the Logica vetus and the Logica nova (231), the Summulae also contained certain new developments which were henceforth called by the title of logici modernorum. ${ }^{3}$ These are mainly studies on the properties of logical terms and their relations to grammatical terms. ${ }^{4}$

(3) The prestige of Thomism went on increasing in the schools from the end of the thirteenth all through the fourteenth century. The Oxford censures had never the force of law at the University of Paris; even the prohibitions of Stephen Tempier failed to suppress the free discussion of Thomist doctrines and interfered but little if at all with their success in the schools. ${ }^{5}$ Moreover. they were withdrawn by Bishop Stephen Borretus on the I 3 th of February, 1325, a year after the canonization of St. Thomas. There is no trace of a similar withdrawal at Oxford, but we

${ }^{1}$ Hist. de la Philos. Scolast. ii. ${ }^{2}$, p. I 57.

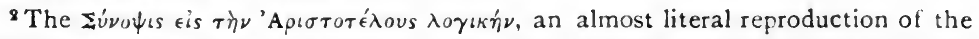
Summulae Logicales, is not a treatise of Psellus (eleventh century) translated by P. Hispanus, but is a Greek translation of the latter's Summulae by Georgios Scholarios (Gennadius), dating from the fifteenth century.

${ }^{3}$ UEBERWEG, op. cit., pp. rgo and zor.

4 The Syncategoremata formed a favourite theme for logico-grammatical studies in the thirteenth century. Hauréau calls attention to a treatise on the subject by Nicholas of Paris in the middle of the thirteenth century (Not. et Extr., etc., ii,, p. 43). On the sophismata an 1 general logical exercises in the th:rteenth century, see Mandonvet, op. cit., p. cxxxi.

'D'Argentré, Collectio fudic., i., p. 2r3, attributes to Giles of Rome this severe judgment on Tempier's censures: "nihil esse curandum, quia fuerunt facti (articuli), non convocatis omnibus doctoribus parisiensibus, sed ad requisitionem quorumdam cafitusorum". 
know otherwise that about the year I 288 the conflict between Peckham and the Dominicans was settled.

On the other hand, Thomism slowly found its way into the general intellectual atmosphere of the age. DANTE's Divina Comedia and VINCENT OF BEAUVAIS' works of popularization are proofs in point. The Speculum Magnum, a vast encyclopedia compiled by Vincent of Beauvais (d. about 1268 ) at the instance of Louis IX., gives an inventory of all the human sciences cultivated up to that time. He divides them into historical, natural and moral (speculum historiale, naturale, doctrinale), and in his speculum naturale it is to the Albertino-Thomistic teaching he gives his preference. ${ }^{1}$ As for Dante, the great philosopher-poet, his immortal stanzas have clothed in a fascinating symbolism the profoundest speculations of Albertus Magnus and St. Thomas. Led by Beatrice, the personification of the highest wisdom of theology, Dante enters the abode of the blessed and encounters, as he goes along, the great problems raised by the philosophy of his century. As a matter of fact, during the long pilgrimage consequent on his banishment from Florence, ${ }^{2}$ he had the opportunity of following the lectures of the great scholastics at the University of Paris. Not alone his Divina Comedia, but even still more his De Monarchia is steeped in Thomism. Improving on the Thomistic politics, from which he borrows his premisses, Dante sketches an ideal State in the form of a universal monarchy."

${ }^{1}$ Another encyclopedist, Bartholomaeus Anglicus, of the first half of the thirteenth century, compiled a treatise De Proprietatibus which deals mainly with knowledge of the sciences (FELDER, op. cit., p. 252).

2 Born at Florence in 1265 , Dante belonged to the Guelf party, and when Charles of Anjou captured the city, in r3or, the poet was obliged to go into exile for his political views. From this time he travelled much through Europe, dying at Ravenna in r32r. After he was exiled he inclined towards the Ghibeline party, without, however, joining the Imperialists.

${ }^{3}$ We may mention here, for want of a group in which to classify him, JAMES of Douar, a little-known writer of the thirteenth century. Hauréau quotes from a commentary of his, DE Anima (Hist. Litter. France, t. xxi., p. 157), texts which show their author to have been a moderate realist. But Hauréau's analyses are not exhaustive, referring only to the Universals controversy (II7). Cf. our Hist. Philos. Scol. ds. Pays-Bas, etc., p. $28 \mathrm{I}$. We may mention too, Sigrr of Courtrai, magister artium in 1309 , member of the Sorbonne in 1310 , later on master of theology, d. I34I, who has left four school-compendiums on logic: ars priorum; summa modorum significandi; a fragment on fallacies; a sophisma or dialectic exercise entitled "album potest esse nigrum". These will appear in 19 Io in our collection "Les Philosophes Belges". 


\section{ECLECTICS.}

315. Summary.-Between the irreconcilable adversaries and the uncompromising partisans of Thomism, we may recognize a third party which filled up the decades between the death of St. Thomas and the rise of the Scotist system in the schools. This was a group of eclectic, independent thinkers, supporting the older teachings on some points, Thomists on others, propounding solutions of their own on many. They were all contemporaries, many of them colleagues in the same Faculty; and so they enter the lists against one another and attack one another in their controversies. Chief among them are Godfrey of Fontaines, Giles of Rome, James of Viterbo and Henry of Ghent. The nearest to Thomism is Godfrey of Fontaines; the most closely akin to Duns Scotus is Henry of Ghent.

316. Godfrey of Fontaines: His Life and Works.--Born at Hozémont (Liége), Godfrey of Fontaines appears as magister theologize at Paris in 1286. He was actu regens for a period of thirteen years, covering the year 1292 . He was a canon of Liége, Paris and Cologne, and was chosen to be bishop of Tournai in 1300 , but renounced his claims, the election having been contested. He was a member of the sorbonne and bequeathed to it a large and valuable collection of manuscripts still preserved in the National Library at Paris. He died subsequently to 1303 .

The XIV Quodlibeta of Godfrey are probably his sole scientific work: they are to be found in numerous manuscripts, and must have been extensively multiplied and used throughout the schools of France, Italy and England. Henry the Teuton of the Hermits of St. Augustine made an epitome of them, Hervé of Nedellec abridged a portion of them, and the Sorbonnist, Regnier of Cologne (d. prior to 1338 ), made them the basis of a compendium of theology. The third Quodlibet dates from I286, the twelfth is posterior to I29o. Godfrey has also left numerous sermons. It is not certain that he is the author of a treatise against the mendicant orders and a series of Quaestiones, annexed to a copy of the Summo contra Gentiles bequeathed by him to the Sorbonne.

317. His Place in Philosophy. - Like all the masters of theo$\log y$ at this time, Godfrey was more than a simple theologian. His Quodlibeta show him to have been a versatile and manysided scholar: all at once dogmatic theologian, moralist, jurist. canonist, philosopher, pamphleteer and controversialist. With unrivalled freedom of language he states his views on all the vexed disciplinary questions that troubled the University life of his time. He openly takes Tempier to task for his ill-considered condemnations of Thomism, and even still more severely the latter's successor, Simon de Bucy, for not removing the censures. 
He also takes exception to the censures of Peckham and informs us that they were disregarded at Paris. On the other hand, he is a vigorous opponent of the privileges of the mendicant orders.

Godfrey's scholasticism is in substance Thomist. Though resolutely opposed to St. Thomas on the question of ecclesiastical privileges, he has left us an enthusiastic eulogium of the Angelic Doctor's prowess in philosophy. But Godfrey's own Thomism has a personal colouring: from his numerous original solutions of minor questions; from his combative attitude towards his contemporaries (Giles of Rome, James of Viterbo, Thomas Sutton and especially Henry of Ghent) $;^{1}$ and from the hesitation and reserve with which he accepts the innovations of St. Thomas in scholasticism. These evidences of indecision, while they point to a weakness in Godfrey, show clearly also that he appeared at a turning-point in the intellectual history of the thirteenth century: Thomism was indeed launched, but between the date of its construction and that of its decisive victory in the schools there was a transition period, in which Godfrey was a striking and characteristic figure.

318. His Philosophical Teachings.-I. Metaphysics and Theodicy.-There is no real distinction between essence and existence. On this important question, he holds against Thomism with Henry of Ghent. Nor does he shrink from the logical consequences of his view; multiplying the existential acts of the concrete being, even of the accidental being: tot sunt esse quot sunt essentiae. ${ }^{2}$

Individuation does not come from the primal matter (St. Thomas), but from the substantial form. The hierarchy of contingent essences is limited: a processus ad infinitum, as understood by Giles of Rome, involves a contradiction.

In the same way as Henry of Ghent, and for the same reasons, Godfrey denies that individuals have in God each its own proper idea, distinct from the idea of the species (324).

II. Physics.-Godfrey defends the theory of the simplicity of the astral substance (295). He holds quite a peculiar theory on

${ }^{1}$ An ancient table, which will appear in an appendix to the Quodlibeta of Godfrey of Fontaines, enumerates the points of doctrine on which the latter opposes St. Thomas, G. of Rome, J. of Viterbo, and T. Sutton.

${ }^{2} Q u o d l$., iii., I, p. 305, edit. of DE Wulf and Pelzer. "Praeter hoc esse (substantiale) sunt plura esse secundum quid et tot quot sunt ibi formae accidentales" (ibid., 4, p. 3Ir). 
transubstantiation, superadded to the generation theory (294), in regard to corporeal change: an existing body can be converted into another existing body in such sort that the substance of the former, now converted, remains somehow whole and entire in the second, both existing prior to the process of change. Nature offers us no instances of any such phenomena, but they are wrought by God, whose omnipotence can achieve all that is not self-contradictory. Since the thing to be converted must be potentially the other thing-according to a principle of metaphysics - the two things must agree in materia. ${ }^{1}$ And this is why God could change an egg into an ox, if He so wished, but could not change a material body into an angel, or vice versit. For a philosophic explanation of the evolution of the material universe the scholastic theory of generatio is sufficient, and the transmutatio advocated by Godfrey may be eliminated from cosmology.

1II. Psycholory.-Relying on the principle "quidquid movetur ab alio movetur," he works out a vigorous refutation of the Augustinian ideogeny of James of Viterbo," the special illumination theory of Henry of Ghent ${ }^{3}$ - to which he opposes the most pronounced intellectualism-and the false interpretation of the species intentionales, to which Henry of Ghent and very many others had subscribed. ${ }^{4}$ Godfrey propounds the peripateticoThomistic doctrines $(\mathbf{2 9 9}, \mathbf{3 0 0})$ with a clearness and penetration rarely equalled by any other scholastic. ${ }^{5}$ In order to fit in Aristotle's classifications of the faculties of the soul with the tripartite division of St. Augustine, he identifies the memoria of the latter with the two intellects of the former. ${ }^{\circ}$

In the study of the will even more than in that of the intellect. Godfrey directly attacks the teaching of Henry of Ghent. Almost the whole of the sixth Quodlibet is devoted to a critique of the latter's z'oluntarism (324), to which Godfrey opposes an intellectualism more marked than even that of St. Thomas. For, not only is the will not simpliciter activa, as Henry of Ghent taught, but even in the free volition of means conducing to an end there is, according to Godfrey, no element of self-motion: for the Thomist solution (302) he has only hard words. ${ }^{\top}$ The

${ }^{1}$ Qliodl., $\because .$, I and $x ., 1$.

$\because$ Ibid., ix., I9.

"Ibia., vi., 15 .

4 Ibil., ix., I9.

Ibid., v., io.

'Ihid., v., 8.

i "Qui vero ponunt quood movetur (voluntas) ab uno quasi a fine et non ab aliis videntur ponere irrationabilia et contradictoria : ubi invenitur eadem ratio movendi 
will, he teaches, is simpliciter passiva, always determined by the understanding, even when it freely follows this determination. After this it is quite superfluous to observe that Godfrey accentuates intellectualism in all its other applications (302).

While showing a preference himself for the Thomistic theory of unity of form in man, Godfrey declares that he is unable to refute the arguments in favour of pluralism. On this point he never got beyond the stage of hesitation and expectancy.

3rg. Giles of Rome: His Life and Works.-Giles of Rome (LEgidius a Columna or Egidius Romanus, "Doctor Fundatissimus") is the first philosopher of note among the Hermits of St. Augustine. According to William of Tocco, he followed the lectures of St. Thomas at Paris-the first of his order to do so-and then obtained permission, as master of theology, to teach at the University (between $\mathrm{x}_{2} 85$ and $\mathrm{x}_{28} \mathrm{C}_{7} .^{1}$ His teaching must have led to some commotion, for in 1285 Pope Honorius IV. made him retract, before the chancellor and masters of the University, certain theses the tenor of which is unknown, but which were probably of Thomistic inspiration. ${ }^{2}$ However, he was amply consoled throughout these troubles by the exceptional treatment he received from the general chapter of his order. Very few men have received such flattering eulogiums during their life-time : a general chapter held at Florence in 1287 paid a tribute to his world-wide reputation (" doctrina mundum universum illustrat") and commanded all who bore the habit of the order to embrace not only the doctrines Giles had already taught, but even those which he would teach in future! ("sententias scriptas et scribendas ")." In r2gr Giles was still teaching. The following year he was elected general of the order, and, in 1295, archbishop of Bourges. ${ }^{4}$. As director general of studies for the order ${ }^{5}$ at Paris, and invested with unlimited power in the choice of its future bachelors and masters, Giles occupied a place of considerable influence at the University and had intimate relations with Simon de Bucy and Philip IV. ${ }^{6}$

The Quodlibeta of Giles of Rome are well known and have been frequently edited. The Relatio on the council held at Paris in 1286-assumed to be the work of Godfrey of Fontaines-informs us that subsequently to this date (postea) Giles could be heard dealing with the question of the privileges in a $Q$ uodlibet that won for him no ordinary praise: "qui modo melior de tota villa in omnibus reputatur".7

Among the other works of Giles we may mention his commentaries on the logical treatises of Aristotle, on the Physics, the Rhetoric, the De Anima, the De Generatione; a treatise $D e$ Gradibus Formarum sometimes attributed to St. Thomas; Quaestiones de Materia Cocli, de Intell. Possibilis Pluralitate (against Averroës); Quaestiones Metaphysicales; De Regimine Principum; commentaries on the first three books of the Sentences; $Q$. de Esse et Essentia, de Cognitione Angelorum, de Partibus Philosophiae Essentialibus.

ponendum est quod si unum movet quod et aliud : et manifestum est autem quod voluntas deliberativa nunquam vult aliquid nisi secundum modum et formam apprehensionis" (Quodl., x., 14, according to MS. Bib. Nat., Paris, n. 15842).

IIbid., i., p. 406, and ii., p. 12.

${ }^{3}$ Chartul., i., pp. 626, 633 and 634. Cf. D'Argentre, Coll. Fud., i., p. 235.

${ }^{3}$ II., p. r2. Same prescriptions in the chapter of Ratisbon in 1290 , ii., p. 40.

${ }^{4}$ Ibid., n. $\quad{ }^{5}$ II., p. $39 . \quad{ }^{6}$ II., p. 61, $62 . \quad{ }^{7}$ II., p. ro. 
320. Philosophical Teaching. - Giles professes an eclectic Thomism, not sufficiently known. Following St. Thomas, he defends the real distinction between essence and existence, and between substance and faculties, the substantial simplicity of immaterial beings, the unity of form, ${ }^{1}$ the function of materia signata in individuation, the possibility of creation ab acterno. But his eclecticism is revealed in his attachment to certain clearly Augustinian theses: the rationes seminales in physics, voluntarism in psychology and ethics, and in his manner of conceiving the relations between the Divine Science and the Divine Volition." To reconcile the Augustinian trilogy of the powers of the soul (memoria, intellectus, voluntas) with Aristotle's ideology, Giles identifies the intellectus asens with the intellectus possibilis. This has the effect of disfiguring his theory of knowledge with doubts and inconsistencies. ${ }^{3}$

The treatise De' Partious Pluilowerliate Essentialibus reproduced the current thirteenth-century classification of the philosophical sciences (277): but Giles emphasizes the psychological grounds of this classification: the work thus contains some original views, and according to Baur ' it is the last treatise of its kind that possesses this merit.

321. James of Viterbo.-When Giles was proclaimed official doctor of the Augustinian Hermits, he formed around him a schold

1 The treatise $D_{e}$ Erroribus Philosupinorum, attributed to (iiles, opposes the unity of forms, whilst the De Gradibus formurum defends this theory. One or other is certainly not the work of Giles-the former in our opinion. DE Wulf, Le Traité de Unitate Formae de G. de Lessines, p. 176.

${ }^{2}$ In theology, (iiles emphasizes the practical and affective side of the science.

${ }^{3}$ According to Wrener, who attributes this theory to him (Der Aurustinismus des späteren Mittelalters, pp. 23, 130), Giles defended elsewhere the real distinction between the two intellects. According to the same author, the image of the Blessed Trinity in r.an would not affect the essence of his soul, but only the operative powers of the latter; and this would be a point of difference between the doctrine of Giles and that of St. Thomas (p. 20). So too, while admitting that the existence of God is proved a posteriori, Giles would also have held that the proposition "God exists" is per se nota, at least for the learned. Werner's exposition is not easy to follow. His assertions need verification.

${ }^{4} \mathrm{BAUR}$, op. cit., pp. $3 \mathrm{So}, 3 \mathrm{~S} 4$. The following is the classification given by Giles: Philosophia: I. Scientia de entibus causantibus nostram scientiam (speculativa): Physica-Mathematica-Theologia. 11. Scientia de entibus causatis a nobis (practica): de intentionalibus (logica)-de realibus (moralibus). Baur mentions, as devoid of all originality, a treatise of Arnulymus Provincialis, and certain anonymous tracts dealing with the same subject. 
which grew to be very extensive in the following century. One of his earliest disciples was JAMES CAPOCCI OF Viterbo (Jacobus de Viterbo, "Doctor Speculativus"), who like his master must have attained to celebrity in his order, seeing that in the year I 293 he was entrusted for a second time (de novo) with a master's chair at Paris. He taught alongside Giles, and like the latter wrote some Quodlibeta and finally exchanged the doctor's cap for the mitre. ${ }^{1}$ In the official assessment of the academic library, published by the University on the 25th of February, I 304, we find the Quodlibeta of James classified along with those of Giles of Rome and Godfrey of Fontaines among the classic works of the time. James also wrote a compendium of the Sentences of Giles. In 1295 the order requested him to publish his own works in sacra pagina. ${ }^{2}$ He seems to have followed closely the teaching of his master. His works are still unpublished and neglected.

322. Henry of Ghent: His Life and Works. - Recent research has revolutionized the traditional biography of HENRY of GHent, "Doctor Solemnis," and exploded the old legends which made him a member of the Goethals family at Ghent, of the Servite order, and of the Sorbonne. The exact year of his birth is unknown. He was canon at Tournai in 1267 , archdeacon at Bruges in 1276 , and from about this date took a prominent part in the University life of Paris. His name appears in many important decisions. In 1282 he took sides openly against the ecclesiastical privileges of the mendicant orders. He became doctor of theology in 1277 and died in r293. His principal works are the Summa Theologica and the Quodlibeta. The latter are especially interesting as a tableau of the principal questions disputed at Paris towards the end of the thirteenth century. ${ }^{3}$ Several of his quodlibetic disputes synchronized with those of his countryman, Godfrey of Fontaines, and the correspondence of the theses defended by the one and attacked by the other, cannot escape notice.

323. His Influence in Philosophy.-Henry of Ghent is the most remarkable among the eclectic philosophers who come between St. Thomas and Duns Scotus. We may describe him like Godfrey of Fontaines, and for the same reason, as a complex, many-sided personality. In philosophy, however, he is more original than the latter. His significance in the history of scholasticism is due to a series of original theses which he defended

${ }^{1} \mathrm{He}$ was archbishop of Beneventum in 1302 , and, later in the same year, of Naples (Chartul., ii., n. 62).

${ }^{2}$ Ibid.

${ }^{3}$ A commentary of his on the Physics of Aristotle and a Treatise on Logic have come down to us in MS. The Escurial Library possesses his Quaestiones super Metaphysicam Aristotelis. The Liber de Scriptoribus Illustribus, for a long time attributed to him, is probably not his work. 
with marked ability, without, however, succeeding in establishing them in the schools. On many points he was a precursor of Duns Scotus. He went back repeatedly on certain favourite questions drawn mainly from metaphysics and psychology. There is no ground for the not uncommon description of him as a Platonist. He did indeed take up certain Augustinian theories that had been current in the earlier scholasticism, but he knew how to modify them so as to adapt them to the remainder of his scholasticism, which is manifestly peripatetic.

324. Philosophical Teaching. - Henry of Ghent decides, in full agreement with St. Thomas, the relations between philosophy and theology: the opening section of his Summa, where he sets forth these relations, is a model of its kind (278).

I. Theolicy and Metaphysics.-.. In theodicy he attacks the Thomist thesis on the possibility of creation ab aeterno. He holds that God can produce directly the operations of created causes, and-in opposition to Duns Scotus-that the human mind can prove to itself this possibility. His conception of the Divine Science is peculiar. As God, he teaches, has no idea of number, but rather of the continuous as such, so $\mathrm{He}$ has no distinct idea of individuals, but knows them through His idea of their species (species specialissima). Does this teaching provide for the individuality of the things of Nature-an individuality accepted by Henry as a principle, according to the general teaching of Thomistic realism? It is hard to see how it does. ${ }^{1}$ Nor does the conception fit in any better with Henry's teaching on the Princifle of Individuation.

Opposing the Thomistic doctrine on Individuation, a doctrine which had, moreover, just been condemned (312), he taught that individuals have no positive essential properties other than those of the species. ${ }^{2}$ The principle of individuation is not matter; it is a property of the supfositum, as such, securing for the latter its distinction from every other being.

Form and Matt'\%, act and potency, are correlative pairs of concepts, though not entirely convertible. For the angels are subsisting forms, and on the other hand matter could exist without

'Duns Scotus, who is ever ready to criticize Henry of Ghent, attacks him triumphantly on this point. See In I. L. Sent., dist. 36, q. 4, p. 102 (Venice edit., 1583).

3 "Nihil rei addunt individua super essentiam speciei ad id quod est reale in ipsa" (Quodl., vii., r and 2). 
any form, should it please the Creator to derogate from the laws of Nature (against St. Thomas). And since quantity is an attribute of the compositum, and not of the matter, it follows that the possibility of the separate existence of matter involves the possibility of the existence of vacuum.

Even in the substantial compositum the matter has its own proper existence-in virtue of a principle to which Henry often reverts: Esse sunt diversa quorumcumque essentiae sunt diversae. Every real element of being has, therefore, a distinct existence. The existence of man, in whom we must distinguish a materia prima, a forma corporeitatis and a spiritual soul, is a conjunction of three existences. This brings us to Henry's psychology.

II. Psychology.-The most original of his theses on the nature of man is that of the forma corporeitatis, existing together with the soul, and necessary in his opinion to insure for the parents on the one hand and the Creator on the other an efficacious intervention in the generation of the human being. ${ }^{1}$ It is the only exception the solemn doctor makes to St. Thomas's teaching on unity of form in the individual. But it is sufficient to differentiate from each other the metaphysics of the two philosophers.

In Henry's theory of knowledge, we see the erroneous view of the species impressa once more making its appearance (299). He speaks of a substitute for the object in the sensation-process; but in the genesis of intellectual knowledge he rejects the species as a useless apparatus. Why? Because the species sensibilis, he says, when "transformed" by the intellectus agens, is sufficient to determine the cognitive act of the understanding.

Other theses of his in psychology are penetrated with Augustinism. Thus, intellectual memory gets an important place beside intelligence and will. He holds too, with St. Augustine, that the faculties are not really distinct from the substance of the soul. Finally and especially, the Summa Theologica opens with a brilliant and original paraphrase of the theory of Exemplarism. In fact, he engrafts upon the traditional Augustinian teaching (293) a theory of special illumination that recalls Dominicus

\footnotetext{
${ }^{1}$ Henry has recourse to other arguments, especially the necessity of explaining the incorruptibility of Christ's body during the interval between death and resurrection, and His abiding identity during life and after death. See our Hist. de la phil. scol. ds. Pays-Bas, etc., pp. III sqq.
} 
Gundissalinus and William of Auvergne. By the spontaneous action of the intellect we know things, and hence we can attain to truth. Nature suffices for acquiring the groundwork of human knowledge, and God intervenes only by His concursus gencralis.' But: "Aliud tamen est scire de creatura id quod verum est in ea, et aliud est scire ejus veritatem"." Now, to grasp the veritas or truth of things in its ultimate foundations, that is to say, in the transcendental relation of intelligible essences to the Divine Ideas, God must flood our intelligences with an increase of light. The mind would be incapable of effecting this "synthetic return," if a special Divine light, which God communicates to whomsoever He pleases, in addition to the general enlightenment of His ordinary concursus, did not perfect the native keenness of the mind by bathing it in a brighter illumination. ${ }^{3}$

Henry of Ghent is a voluntarist. The relations of reason to will, he writes, are those of servant to master, but then it is to bc remembered that the servant goes before the master, bearing aloft the torch to light the latter's steps. ${ }^{4}$ The respective domains of the two great psychic faculties being determined in this general way, the philosopher of Ghent follows out his voluntarism into all its various conclusions. Among his arguments for the superiority of the will there is one drawn from the very manner in which this faculty exercises its activity: while intellect is passive before being active (30o), will is simpliciter activa, and is independent of all intrinsic determination from without in its operations. In free volition-which is acutely analyzed by Henry-just as in necessary volition, the presentation of the good, whether partial or complete, is merely a conditio sine qua non, not a cause, not even a part-cause, of the functions of this faculty.

325. Sources and Bibliography.-EhrLe's essays, see 240. Peckham's letters have also been published by Wilkins, Concilia Magnae Britanniac et Hiberniae, ii., 107; Registrum epistolarum F. Peckham, MARTIN's edit., iii., 84o;

1 "Absolute ergo concedere opportet quod homo per suam animam absque omni speciali divina illustratione potest aliqua cognoscere et hoc ex puris naturalibus. . . . Dico autem ex puris naturalibus, non excludendo generalem influentiam primi intelligentis, etc." (Summa Theol., i., 2, n. II).

2 Ibid., n. I3.

3 “Nunc autem ita est quod homo ex puris naturalibus attingere non potest ad regulas lucis aeternae . . . non tamen ipsa naturalia ex se agere possunt ut attingant illas, sed illas Deus offert quibus vult et quibus vult subtrahit" (ibid., n. 26). For detailed exposition of those theories, see our Etudes sur Henri de Gand, ch. iv.

'Quodl., i., 14, in fine. 
some also in the Chartul., i. Denifle, Quellen z. Gelehrtengesch. d. Predigerord., see 237. We have edited the De Unitate Formae of Giles of Lessines, according to two MSS., Paris and Brussels, with a critical introduction. See 240. STapper, Die Summulae Logicales des P. Hispanus (Freiburg, 1897) and Papst Fohannes XXI. (Kirchenhistor. Studien, iv., Münster, I898). Walsh, Fohn XXI., Philosopher, Physician, Pope (American Eccles. Review, 1908). A. LeCLère, Le mysticisme catholique et l'âme de Dante (Paris, rgo6). CARBoni, La Sintesi Filosofica del Pensiero Dantesco (Pitigliano, 1899). P. Berthier, La Divina Comedia con Commenti secondo la Scolastica (Turin, 1893 sqq.). A. Niglis, Siger von Courtrai, Beiträge zu seiner Würdigung (Freiburg, 1903): life and analysis of works. DE Wulf and Pelzer, Les Quatre Premiers Quodlibets de G. de Fontaines (t. ii. of Les Philosophes Belges, Louvain, 1904): critical edition of a "textus reportatus" based on four MSS. Quodl. v.-xiv., after Godfrey's own text, will shortly appear (tt. iii. and iv. of the collection), together with an exhaustive study of the philosopher himself (t. v.) by a number of different writers. DE WULF, Ëtudes sur la vie, les oeuvres et l'influence de G. de Fontaines (Louvain, 1904; memoir crowned by the Belgian Academy). The principal works of Giles of Rome are to be found in numerous Italian editions of the fifteenth and sixteenth centuries, enumerated by WERner (see below), pp. 16 and 17 , note. $C f$. 344. The philosophy of Giles of Rome deserves to be better known. Lajard, Gilles de Rome (Hist. Litt. France, t. 30, pp. 421-566) : deals only with his life and works. WERNER, Der Augustinismus d. späteren Mittelalters (Vienna, I883), (t. iii. of the collection : Die Scholastik d. späteren Mittelalters): studies especially the doctrines of Giles of Rome and Gregory of Rimini; but Werner's historical views are unreliable. A number of writers (Kaufmans, etc.) have published (Herder, r904): Egidius Romanus de Colonna, Foh. Gersons, Dionys. d. Karthaiisers u. F. Sadolets pädagogische Schriften, German trans. The Quodlibeta of Henry of Ghent were edited at Paris (1518) and Venice (1608, 1623); the Summa Theologica, at Paris (1580) and Ferrara (1646): all very rare editions. We hope to publish a critical edition of both works in the collection Les Philosophes Belges. DE WuLf, Études sur Henri de Gand (1895): biographical researches and critical exposition of doctrines. This work is an extract from a larger volume: Histoire de la Philos. scolast. ds. les Pays-Bas et la Principauté de Liége jusqu'à la Revolut. Française (Louvain, 1895 ; memoir crowned by the Belgian Academy).

\section{AR'T. V.-JOHN DUNS SCOTUS.}

326. Life and Works. - Joнn Duns Scotus was born in 1274 according to some, according to others in 1266 . It is disputed whether he first saw the light in Ireland, Scotland or England: the probabilities seem in favour of Ireland. At an early age he was received into the Franciscan order. At Oxford he followed the lectures of William Ware, who, with Petrus de Trabibus, was fostering a new tendency in Franciscan studies. He also felt the influence of Roger Bacon, and the anti-Thomistic spirit of Oxford must undoubtedly have inspired him with many of his hostile criticisms of Thomism. He himself taught at Oxford in 1294, or perhaps earlier. Thence he passed to Paris in $\mathrm{r}_{304}$. While yet at Oxford he defended the Immaculate Conception of the Blessed Virgin, but it was not for the purpose of promoting a cause so dear to him that he left Oxford for Paris, as the legend would have us believe. In 1308 he set out for Cologne, on the order of his superiors. He died there that same year-at the early age of about thirty-four.

At Oxford, Scotus wrote his Commentaries on Aristotle (the Logic, the treatise 
De Anima and the Metaphysics; the authenticity of the commentaries on the Physics is doubtful); his great Commentary on the Book of Sentences (Opus Oxoniense); the De Rerum Principio; and the Theoremata. The works he wrote at Paris were collected by his disciples under the title of Reportata Parisiensia or Opus Parisiense. His Qundibeta, which form his last work, are the public defences which secured for him the degree of doctor of theology at Paris.

327. General Features of his Philosophy.-We may say that Richard of Middleton, who died about the same time as Duns Scotus, but without having undergone the influence of the latter, is the last representative of the older Franciscan school. We see, in fact, from the letters of Peckham, that about the year 1284 the Oxford Franciscans were showing inclinations to admit a larger element of Aristotelianism. ${ }^{1} \quad$ But it was Duns Scotus ${ }^{2}$ who really gave the studies of the order a distinctly new orientation. He brought into fashion a peripateticism that was sui generis: his personal genius gave an original stamp even to the earlier scholastic theories that survived in his philosophy. We therefore naturally find that philosophical parties and sections are much more numerous and sharply divided in the Franciscan than in the Dominican order.

Duns Scotus was a destroyer of systems. He attacked most of his contemporaries: St. Thomas, St. Bonaventure, Giles of Rome, Roger Bacon, Robert of Middleton, Godfrey of Fontaines, and more especially Henry of Ghent. He rarely referred to his adversaries by name, but those who were familiar with his controversies could not be mistaken about the identity of the various personalities attacked. This critical but courteous handling of the opinions of others contributed not a little to the freshness and popularity of Scotus's teaching. But oftentimes his long array of divergent opinions and his laboured load of arguments and refutations have the effect of obscuring the philosopher's own thought. The positive, constructive side of his system is less developed than the negative, critical side: whence results a want of equilibrium which diminishes the value of the whole and makes Scotism compare unfavourably with Thomism.

The study of the works of the earlier scholastic period is rendered more difficult by their defective methods of exposition and their obscurity and diffuseness of style. The Reportata mark

\footnotetext{
${ }^{1}$ Ehrle, Zeitsch., etc., p. 191, and Arch., etc., v., p. 605.

${ }^{2}$ Like many critically minded scholars, Duns Scotus eagerly pursued the study of mathematics, mainly owing to the influence of Roger Bacon.
} 
a distinct improvement in these respects. Yet all the writings of Scotus suffer from an excessive use of distinctions and a frequent ambiguity of thought which indicates a relapse into the earlier style of dialectic controversy. Hence they show to disadvantage in comparison with the calm, majestic sobriety of thought and language, of which St. Thomas possessed the secret. It was his own admirers who first called Duns Scotus the Subtle Doctor; but posterity has often applied in an uncomplimentary sense the title which he first received in flattery.

In his commentaries on Aristotle Scotus does not always interpret the teaching of the Stagirite in the same sense as St. Thomas. Neither does he, however, any more than the latter, follow Aristotle blindly, as one might be led to believe from a brief exposition of the Scotist system.

His system is indeed only a statement, coloured by personal variations, of the great, general scholastic synthesis. By going back to its principles we may easily mark out the stock of ideas it possesses in common with Thomism. This is admitted by the Franciscans themselves: "The divergence commences as soon as the two doctors begin to use this common stock for the purpose of enlarging the domain of knowledge and truth". ${ }^{1}$ Let us see what are the main points of divergence.

328. Mutual Relations of Theology and Philosophy.-While Scotus is faithful to fundamental principles concerning those relations (268), he develops and amplifies those principles in a sense profoundly at variance with the views of St. Thomas. In the first place Scotus lays extreme emphasis on the distinction between philosophy and theology. Not merely in their formal objects, but also in their material objects, do the two sciences differ : theology is exclusively concerned with supernatural data: while, on the other hand, whatever human reason can discover by the play of its own natural forces belongs to the domain of philosophy proper. Moreover, theology is neither a science of affection (St. Bonaventure) nor of speculation (St. Thomas), but a science of conduct, of morals, ${ }^{2}$ a practical science. Those new theories deserve the notice of the historian; they are symptomatic. Yet, the doctrine of Scotus has nothing in common with the Aver-

${ }^{1}$ De Martigné, op. cit., pp. 332 and 359. Cf. Pluzanski, op. cit. (336), pp. 6 sqq.; VACANT, op. cit. (Ann., I888-89, p. 465).

${ }^{2}$ In L. Sentent., Prol., p. 4, n. 42. 
rolstic theory of the two truths (339); for, if he lessens the harmony between the two sciences, Scotus, in the second place, proclaims the subordination of philosophy to theology. Indeed his deep conviction about the inferiority of philosophy makes him avoid even the possibility of a conflict between the two sciences. He is excessive in his misgivings about the unaided, natural power of the understanding, and retrenches perhaps unduly the scope of its investigations. He would have reason simply veil its face before mystery, with a docile and reverential silence. Nothing could be more remote from such an attitude than any suggestion of revolt; for, reason, in the third place, recognizes that nothing could be fossibly more conformable to reas $n$ (rationabilius) than faith in the word of (sod.

329. Matter and Form. - Here Scotus openly appeals to the authority of Avicebron (221), whom he took to be a Christian philosopher. ${ }^{1}$ He teaches, firstly, that all contingent beings are composed of matter and form; and he thus refers to its true source this theory, which his predecessors had fathered upon St. Augustine: in this he is at one with St. Thomas (255 and $\mathbf{2 8 6}$ ).

Scotus next distinguishes three kinds of primary matter: "materia primo prima, secundo prima, tertio prima". Materia frimo frima is the indeterminate element of contingent things, apart from union with any form. Devoid of all determinateness, it has nevertheless reality, in so far as it constitutes the term of God's creative activity. Matter does not exist in Nature in this initial state of absolute indeterminateness-as materia frimo prima-but God's omnipotence could call it into separate existence. By its first union with a substantial form, matter appears endowed with the attributes of quantity: as materia secundo prima. Subject now to the substantial changes of Nature it corresponds with what St. Thomas calls materia prima simply. ${ }^{2}$ Materia tertio frima, which serves as basis for acci-

${ }^{1}$ He knew no other Jewish philosophers than Avicebron and Maimonides. Avicebron's influence reveals itself chiefly in the $D_{\epsilon}$ Rerum Princifio (Guttmann, op. cit. (229), pp. $159 s q 7$.$) .$

${ }^{2}$ De Rer. Principio, q. 8, art. 3, r9, p. 51: "Voco materiam primo primam subjectam quamdam partem compositi habentem actum de se omnino indeterminatum ... sed illum actum habet a Deo efficiente; actum vero talem vel talem, habet a forma per quam et cum qua subsistit in composito. . . D Dicitur autem materia secundo prima, quae est subjectum generationis et corruptionis quam mutant et transmutant agentia creata." 
dental changes, is of minor importance, corresponding to the materia secunda of Thomism.

This materia primo prima gives the system of Scotus a marked individuality, for it is a something endowed with a real ${ }^{1}$ znity. Spiritual and corporeal substances thus possess not merely a homogeneous common element; a veritable community of essence envelops them all. In this sense it may be said that all contingent things share in a common element into which they plunge their roots, notwithstanding the individual differences between them. God, Infinite Actuality, on the one hand, on the other a created universe, knit with essential unity deep down in the very foundations of its contingency: ${ }^{3}$ such is the philosophical expression of that mysterious bond of union between all creatures, from which the sweet and tender effusions of St. Francis of Assisi derived their inspiration. The materia primo prima bccame, later on, a favourite target for Thomists in their attacks on the great rival system of metaphysics.

Scotus likewise extended the notion of form. Every substantial form is a principle of intrinsic determination, but not necessarily of complete determination, of its matter. After a form has spent all its perfection on given matter, the compound so formed can in turn serve as potency or matter for an ulterior substantial form from which it will receive a higher mode of being. We have thus a whole hierarchy of determining principles, from generic and specific forms down to the individual form itself which is the last and highest, and which gives the being its final perfection. ${ }^{4}$

330. Common Essence and Individualized Essence.-On the relation between individual and universal, Scotus teaches that

${ }^{1}$ Not a numerical unity; see recent study of P. PARthenius Minges, Der angebliche exzessive Realismus, pp. 16 sqq.

${ }^{2}$ De Rer. Principio, q. 8, art. 4, p. 52 sqq.: " Ego autem ad positionem Avicembronis redeo, et primam partem, scilicet quod in omnibus creatis per se subsistentibus tam corporalibus quam spiritualibus sit materia, teneo". Again, "Si ergo quaestio quaeret an omnia habentia materiam habeant unigeneam, vel univoce participant materiam, loquendo de materia Imo rma quae est in omnibus, dico quod sic".

${ }^{3}$ Ibid.: "Ex his apparet, quod mundus est arbor quaedam pulcherrima, cujus radix et seminarium est materia prima, folia fluentia sint accidentia; frondes et rami sunt creata corruptibilia, flos anima rationalis; fructus naturae consimilis et perfectionis natura angelica. Unicus autem hoc seminarium dirigens et formans a principio est manus Dei, aut immediate . . . aut mediantibus agentibus creatis."

${ }^{4}$ De Rer. Principio, q. 8, art. 4, 28, p. $53 b$ : "Nunc autem in toto opere naturae et artis etiam ordinem hunc videmus, quod omnis forma sive plurificatio semper est de imperfecto et indeterminato ad perfectum et determinatum. . . ." 
the individual alone possesses full and complete substantiality in nature (secundum naturam); the universal, as an independent form, is a product of thought (secundum intellectum). At the same time, the essence itself, which necessarily assumes individuality in the real world or universality in the sphere of intellectual thought, is something in itself (securdum se); it is ontologically anterior to the twofold determination. ${ }^{1}$ The essentia secuntum se, which St. Thomas holds to be only a concept of the individual substance apprehended under a certain aspect, is for Scotus an objective reality, sui generis, having a unity of its own. Not only is the materia frimo frima endowed with some special sort of real being, but each and every universal form, generic and specific, in a word, each sefarate element of essence, capable of entering as constituent into various substances, has its own special being or reality: which thus binds into a peculiar sort of real unity all the subordinate individual things in which that common or class element is found. Cuililiet universali correspondet in re aliquis sradus cntitatis in quo conveniunt contenta. How are we to reconcile this teaching with the distinct, substantial individuality of the things of Nature around us? Scotus offers a characteristically subtle explanation: the unity of essence which belongs to every element of essence prior to, and independently of, its "contraction" in the individual thing, is less than indizidual unity. It implies in fact not only the function of uniting all the individuals in a community of being, but also incapacity to give that complement of actuality which constitutes the complete and independent substance of the individual thing. And to mark this nice shade of discrimination between unity of essence and individual unity, Scotus invented a new distinction which he called the distinctio formalis a parte rei. While the distinctio realis exists between two really different things, and the distinctio rationis multiplies our concepts of one and the same thing, to enable us to consider it from different (d. rationis cum fundamento in re) or identical (d. rationis sine fundamento in re) standpoints, the distinctio

1. Licet enim (natura) nunquam sit realiter sine aliquo istorum, non tamen est de se aliquod istorum, ita etiam in rerum natura secundum illam entitatem habet verum 'esse' extra animam reale: et secundum illam entitatem habet unitatem sibi pronortionabilem, quae est indifferens ad singularitatem, ita quod non repugnat illi unitati de se, quod cum quacumque unitate singularitatis ponatur" (In L. Sent., 2, dist. iii., q. I, 7, p. 357. Cf. SróckL, op. cit., p. Sor). 
formalis a parte rei points, in one and the same individual substance, to the objective forms or formalities that are realized in it, and really in it, independently of any intellectual act of ours. Having once established this distinctio formalis a parte rei, Scotus makes extensive use of it in his metaphysics. It exists between materia primo prima and its various substantial forms, between God and His attributes, between the soul and its faculties, and in general between the metaphysical grades of being. It pervades the whole Scotist system, and has given the latter a name: by his "formalism" Scotus wished at all costs to remain true to scholasticism.

The Principle of Individuation-that which gives individual identity and distinguishes the individual from all other individuals of the same class-results, according to Scotus, from the determination conferred on the being by its most perfect form, the form which, in the genesis of things, is the term of their real production. This form puts a definite impress on the specific essence (contrahere speciem); it determines the latter to be this individual and not that or any other, ad esse hanc rem. This led Scotus's disciples to say that "haecceitas" is the Principle of Individuation. According to this teaching, spiritual beings and separated human souls are individualized within their respective species.

331. Essence and Existence.-Duns Scotus was anxious to establish between essence and existence a closer union than St. Thomas, without at the same time denying their objective diversity. By applying the distinctio formalis a parte rei, he treats this and similar delicate matters according to the general economy of his metaphysics.

332. Theodicy.—God in Himself.-The manifold Divine perfections commingle in the unity of the Infinite Essence. To this leading idea Scotus adds some secondary notions in keeping with his general metaphysics. Firstly, he asserts his "formal" distinction between the Divine attributes: which seems to endanger the unity itself of the Divine Essence. Then again, he makes the concept of being univocal. God and the creature are not indeed species of a common physical genus, Being. They are, however, included in one and the same metaphysical genus of Being. Being belongs properly to both; but God possesses it per se, the creature per participationem: in this restricted sense, Scotus would admit that the concept of being is applied univo- 
cally to God and contingent things. But while thus bolder than St. Thomas on this point of according to man, within the limits indicated, a proper knowledge of the hizing of God, Scotus on the other hand depreciates our intellectual faculties by denying them the power of demonstrating the life of God, or His omnifotence to accomplish directly, should $\mathrm{He}$ wish, the works of created causes. In conformity with the general theory of Scotus on the activities of spiritual substances, the will of God is conceived as nobler than $\mathrm{His}$ intelligence; and freedom is an essential property of all Divine volition (334). He gives expression again to this idea in dealing with the relations between God and the creature.

God and the creature.--The Divine ideas are not the very essence itself of God (293), for this would imply, according to Scotus, an objective dependence of the Divine essence on the creature, prior to all acts of intellect. They are rather objective presentations of the creature in the Divine intelligence. ${ }^{1}$ This is a mance of the exemplarism theory.

Scotus attacks the arguments brought forward by Henry of Ghent to prove that creation took place in tempore, and inclines himself towards the Thomist solution of the question. Not only does the existence of creatures depend on a decree of the Divine free will (293): their nature too has its ultimate foundation in the (free) will of God, and not in His intelligence (St. Thomas). Thus again, by another application of his "voluntarism," the limits of the natural and the supernatural are determined, not by the inner constitution of things, but, in ultimate analysis, by a volition of the Infinite Being. Similarly, contingent future events are conditioned in the Divine intelligence by the Divine will: sovereign mistress of the nature of things, the Divine will decides and fixes the moral law, the constitution of civil society, etc. $^{2}$ This same anxiety to safeguard, in the case of man, the essential freedom of all volition, made Scotus an opponent of the Thomistic pracmotio physica.

333. General Principles of Physics. - Scotus boldly rejects the theory of the rationes seminales, so dear to the earlier Franciscan school. He attacks St. Bonaventure's main argument for the inductio formarum in matter. ${ }^{3}$ Dealing with the interplay of the

${ }^{1}$ Report., i., dist. 36, q. 2. $\quad 2 \mathrm{VACANT}$, op. cit., p. 452.

s" Neque est necessaria haec ratio seminalis ad vitandam creationem aut annihilationem" (Report. Paris., L. ii., dist. I8, p. 354, t. xi.). Scotus gives a restricted meaning to ratio scminalis. 
three factors that concur in the generation of things, Scotus is inclined to lay great stress on the Divine intervention (294).

Vital action is irreducible to the plasticity of the matter in which it is found: it reveals an agency of a higher order. Wherefore, besides its material or corporeal form, every living organism possesses a distinct vital form. Scotus is more liberal than Henry of Ghent; but he does not admit the necessity of multiplying substantial principles in chemical combinations (mixta) (Alexander of Hales, Albert the Great), or, a fortiori, in the simple elements (St. Bonaventure).

334. Psychology.-Contrasting Duns Scotus with St. Thomas, it is customary to emphasize their divergences in psychology; yet we must not forget that even here the two great doctors subscribe to the same broad, fundamental principles. Bearing this in mind let us examine the main features of the Scotist psychology. These relate to the nature of the understanding and of the will, to the inner constitution of the human being and to the immortality of the soul. The "formal" distinction asserted by Scotus between the soul and its faculties, is merely an application of his metaphysics, as outlined above.

First, as to the intellectual faculty, its nature and acts. Claiming for the intellect an immediate apprehension of the individual reality, Scotus advocates, in addition to our abstract and universal knowledge of things, which is in its nature distinct, the existence of an antecedent, intuitive knowledge, which reveals to us in a confused manner the concrete, singular being (species specialissima). This concept of the singular arises on the first contact of our intelligence with the external object and is produced simultaneously with our sense knowledge of the latter ( $c f$. 244, 258). We may well demand in what this intuitive concept of the concrete differs from our sense perception of it, and whether the distinction between them is not a difference in clearness of product rather than in the nature of the mental process involved. But this is not all. For, although in the present state of life on earth the essences of sense-realities are the only proper object of our understanding, the intelligibility of these essences does not exhaust the representative capacity of this faculty considered in itself, absolutely, as a channel of knowledge. Indeed everything that has any real being can, absolutely speaking, fall within the scope of human intelligence, the suprasensible no less 
than the sensible; ${ }^{1}$ and it is always within the power of God's omnipotent free will to enlarge the sphere of action of our nature (332). As for the genesis of our ideas, all of them alike, the noblest no less than the lowliest, have their origin in the same sense process: Scotus has left us sorne severe but not unmerited criticisms of the special illumination theory propounded by Henry of Ghent and other Augustinians."

Secondly, as regards the will and its pre-eminence over intelligence: while St. Thomas is "intellectualist," Duns Scotus is "voluntarist". He sees the superiority of the will in its essential attribute of liberty, in its mode of action and in its ethical significance. All volition is free; the will is never necessitated by the intellectual presentation of the good. Even in presence of the absolute grood it retains its power of absolute self-determination, its freedom of action (libertus exercitii); for, says Scotus, it is always free to turn away from the intellectual presentation." Henry of Ghent maintains, with St. Thomas, the distinction between necessary volition and free volition; Duns Scotus rejects the distinction. Vihil aoluntas necessario oult. As to the manner in which the will exercises its activity, Scotus agrees with the explanation of Henry of Ghent (324). Knowledge of the good is a conditio sine qua non for volition, but nothing more. Abstracting from the general concurrence of God with the activity of all creatures, it may be said that the will is the sole and total cause of its determinations. Scotus and Henry again agree that the will is actiz'e, after the manner of the intellectus agens. In its etrical relation to conduct. the will is the sole subject of the moral virtues, for virtue is a habitus elections, and all electio belongs to the will. It is likewise the will that obtains for us, by the perfect exercise of its activity, the formal possession of our last end.

Thirdly, as regards soul and body, ${ }^{4}$ man is a composite substance, and the soul is the form of the body. But besides the

1. Objectum primarium potentiae assignatur illud quod adaequatur potentiae in ratione potentiae, non autem quod adaequatur potentiae ut in aliquo statu" (In $I$. Sent., d. iii., q. 3, n. 24 and 25. $C f$. Vacast, op. cit., Ann. phil. chrét., r888, pp. 450 sqq.).

In I. Sent., d. iii., q. 4 .

: “In potestate voluntatis est avertere intellectum a consideratione finis (ultimi), quo facto voluntas non volet finem, quia non potest habere actum circa ignotum " (op. cit., d. i., q. 4).

${ }^{4}$ Cf. SтӧскL, op. cit.. ii. ${ }^{2}$, pp. $8_{40}$ sqq. 
soul, there is in each individual a forma corporeitatis which endows the body with the organic structure it possesses. By this duality of formal principles Scotus did not wish in any way to compromise the unity of the human individual or the intimate, immediate union of all his constituent elements. This is sufficiently evident from the fact that Scotus was an active opponent of the teachings of his confrère, Peter John Olivi (259).

Fourthly and lastly, we have to notice the rather singular attitude of Scotus on the immortality of the soul and the proofs of a future life. Briefly, he holds that human reason is unable to prove peremptorily the immortality of the soul: faith alone can give us certitude on the matter. He examines the usual proofs brought forward in peripatetic philosophy and pronounces them wanting in cogency. The doubts of Scotus were collected by William of Ockam and were afterwards exploited against scholasticism by the Averroists and by the philosophers of the Renaissance. But it should be borne in mind that the teaching of Scotus on this point had an exclusively negative significance. He never for a moment dreamt of invoking positive arguments in favour of the mortality of the soul. His system has therefore in it no taint of anti-scholasticism: it differs profoundly both from the materialism that denies the immortality of the soul and the Averroïsm that makes immortality impersonal.

335. Conclusion.-The characteristic and original element in the philosophy of Duns Scotus, and the key to the understanding of his system, is its "formalism". It is this that colours his peripateticism, impregnates his whole system and makes it one consistent whole. It is this, too, that sets him over not only against St. Thomas, but also and equally against the representatives of the earlier Franciscan school. ${ }^{1}$ It was this, finally, that plunged him into a pathless ocean of metaphysical speculation which he confused, while exploring it, by creating fictitious, mis-

1 We heartily endorse this judgment of Père Portalié on the relations of Scotism to Augustinism: "It has often been said that Duns Scotus, in opposing Thomism, followed 'in the wake of Augustinism'. This is only partially true. For Scotus is himself also a peripatetic. No doubt he seems in places to be under the influence of certain theories of St. Augustine : he defends the pre-eminence of will over intelligence and the plurality of forms in things. But are these fundamental teachings of Augustinism? Are they in fact Augustinism at all, at least if we take account of the form they have in the thought of the subtle doctor?" (Dict. Theol. Cath., s.v., Historical development of Augustinism, t. i., col. 2512). 
leading and superfluous beacon-lights-in defiance of a precept which he himself pretended to approve of: Entia non sunt multiplicante practer necessitatem.

336. Sources and Bibliography. - The Opus Oxoniense was printed in $148 \mathrm{I}$, the Repurtata in 1518 . The first complete edition of Scotus is that of Lyons (1639), by Father Luke Wadding, the great annalist of the order. It was reprinted by Vivès at Paris in Isgr. A (non-critical) edition of a small treatise, Grammatica Speculativa, was published at Quaracchi in 1902 (by Father F. Garcia). ID. Scot. Capitalia Opera Collecta, edit. by P. Deodat de Baslij (Le Hava, 19o8). Lexicon for works of Scotus, 2nd edit. (Quaracchi, 1907). Werner, Duns Scotus (Vienna, 1881). De Martigné, op. cit. Pluzanski, Essai sur la phil. de Duns Scot (Paris, I887). Siebeck, Die Willenslehre bei Duns Scotus und seine Nachfolgern (Zeitsch. $\mathrm{f}$. Philos. u. philol. Kritik, I8g\$, pp. I82 sqq.). Vacavi, D'ois vient que Durs Scot the conçoit point la volonté comme S. Thomas d'Aquin (Fribourg Internat. Scient. Cath. Congress, 1898, pp. 631-45); La Philos. de Duns Scot comparie à celle de S. Thomas (Ann. Philos. chrét., I887-89). Sreberg, Die Theologie des D. Scotus (Leipzig, 1900). P. PARThenjus Minges, Ist Duns Scotus Indeterminist? (Beiträge z. Gesch. d. Philos. d. Mittelalt., Münster, 1905); Der angebliche exzessive Realismus des D. Scotus (ibid., IgoS); Duns Scoti Doctrina Philosophica et Theologica quoad res pracifuas proposita, exposita ct considerata (Ad Claras Aquas, I9o8). Other studies of Minges in the Philos. Jahrb.: Bedeutung v. Object, Umstanden und Zweck f. die Sittlichkeit cines Acktes nach D. Scot (1906); Beitrag z. Lehre D. Scotus über die Equivocation ". Seinsbegriffs (1907). Der Gottesbegriff d. I). Scotus auf seinen angeblich exzessiven Indeterminismus geträfft (Vienna, 1907); in the Catholic Encyclopedia (New York, vol. vi., I gog), art. on Fohn Duns Scotus. We cannot here analyze the works of MiNis: : they seem to revolutionize the traditional ideas about scotus and to diminish still more the difference between him and St. Thomas. Belmoni), L'existence de Dieu d'aprìs D. Scot (R. de Philos., 19oS); L'être transicndant d'apris I). Scot (ibid., 1909). P. SYMrhorien, La distinction fornelle de Scot et lis universalux (Et. Franciscaines, r9o9). Claverie, L'cristence de Dieu d'apris D. Scot (R. Thomiste, 1909). 


\section{CHAPTER IV.}

ANTI-SCHOLASTIC SYSTEMS OF PHILOSOPHY.

337. Division. - The Latin Averroism of the thirteenth century is the most notable and most important of the anti-scholastic systems ( $\$ \mathrm{I})$. Certain secondary forms, however, of anti-scholasticism also call for notice $(\$ 2)$.

\section{$\$$ I. LATIN AVERroÏsm.}

338. The Rise of Anti-scholastic Averroism. - Averroës, who was called the "Commentator" par excellence down to the close of the Middle Ages, became known to the Latin world in company with Aristotle: he was everywhere welcomed as the inseparable servant of the great master whose livery he wore. His Commenta were prohibited at Paris at the same time as the works of the Stagirite: they were involved in a common condemnation with the writings of David of Dinant and Amalric of Bène (228). But the preventive measures of 1210 and 1215 failed to banish Averroës, any more than Aristotle, from the Paris schools. From the early decades of the thirteenth century the name of Averroës was in every mouth. Most of the masters eschewed his teachings, but some must have given them their secret adherence. In 1256 Pope Alexander IV. requested Albert the Great to write a treatise ex professo, De unitate Intellectus contra Averrö̈m: a plain proof that Averroïsm had got a footing in the schools and was contending openly against scholasticism. Later on, it assumed a more menacing attitude. The ecclesiastical condemnations checked its progress for the time, but without killing it. In subsequent centuries it reappeared with renewed life and vigour. Even within the ranks of the scholastics, many were unable to guard themselves altogether from its influence: its taint is found in various special theories propounded by them (Ch. V.).

339. The Teachings of Anti-scholastic Averroïsm. - The scholastics appealed to reason as judge in their eclecticism (I16): to 
its test they submitted the doctrines of Aristotle no less than those of any other philosopher ("locus ab auctoritate est infirmissimus"). The Western Averroists, on the contrary, were veritable slaves of the Stagirite. He was for them the oracle of philosophical truth, and the sacred deposit of his teaching should be preserved pure and intact at any cost. Then, in the next place, since Averroës alone had fully understood this teaching, the commentaries of the great, impeccable commentator should be followed in their every letter. This philosophical infallibility of Aristotle and Averroës became a postulate with Averroïsts, not only in the thirteenth, but again in the fourteenth and fifteenth centuries. Slaves to such a withering prejudice, they abandoned all attempts at original thought. At the same time, moreover, they deviated somewhat from Averroës-though less than the latter did from Aristotle-and thus reached a peripateticism which is not the genuine teaching of Aristotle. In the history of medieval thought, Averroîsm derives its main interest from its anti-scholastic character. It solves in an anti-scholastic sense a number of problems which must ever be fundamental in any system of philosophy. Then, also, in interpreting and developing certain positions of Aristotle, Averroës and his followers on the one hand, and the scholastics on the other hand, were so much at variance in their applications and modifications of the original waching that they arrived at the very opposite poles of philosophic thought. Now, it is the sum-total of those anti-scholastic solutions of certain capital problems in philosophy', that constitutes, to our mind, Latin or anti-scholastic Averroism. It will be easily understood that, besides these fundamental divergences, Averrorsts and scholastics also differed on many points of detail: just as on a number of other points they were in entire agreement. This latter is especially true of the more openly and avowedly peripatetic wing of the scholastics: and the reason is evident. Thus it is, for instance, that St. Thomas holds with Siger of Brabant on the Universals question, on the unity of substantial form (which explains the insinuations of Peckham, 312) and on the principle of individuation in corporeal substances." From the official

'We do not think it can be said unreservedl, with Père ilandonnet, that "Averroism is contained implicitly or explicitly in Aristotle" (op. cit., p. clxxii).

${ }^{2}$ This common understanding explains the numerous references and anpeals to Averroès in the scholasticism of the thirteenth century. 
condemnations of Averroissm and from the Averroistic literature so far published, we collect the following as its principal antischolastic doctrines :-

Firstly, Unicity of the Human Intellect and Monopsychism. ${ }^{1}$ It was this thesis especially that aroused the most determined opposition from the scholastic doctors: witness the deluge of special pamphlets written in refutation of it. And this is intelligible: for the theory was incompatible with the fundamental principles of scholasticism on the origin of ideas; it implied a merely accidental union of soul with body; and it therefore also compromised human personality (300 and 303).

Secondly, the Denial of Personal Immortality is an inevitable corollary of the preceding thesis. ${ }^{2}$ Here Averroism is in direct opposition to the teaching of scholasticism on the future life with its rewards and punishments (303).

Thirdly, the Necessary Production of the $W_{\text {orld, }}^{3}$ by a Series of Intermediary Beings; and the Denial of Divine Providence in Mundane Affairs. ${ }^{4}$ God is not the direct efficient cause of the terrestrial universe; $\mathrm{He}$ produces separated intelligences and these in turn produce material things. All those productions take place by necessity. Wherefore, God has no concern with a world that is not immediately dependent on Him. Those theories are destructive of the scholastic teaching on Creation, Providence, Conservation and the Concurrence of the First Cause with the action of created causes. They also deny the freedom of the creative act (293).

Fourthly, Psychological Determinism, and the consequent

${ }^{1}$ Here are some formulae from the decree of 1277 : "Quod intellectus agens est quaedam substantia separata superior ad intellectum possibilem; et quod secundum substantiam, potentiam et operationem est separatus a corpore, nec est forma corporis (123). Quod intellectus agens non copulatur nostro possibili ; et quod intellectus possibilis non unitur nobiscum secundum substantiam. Et si uniretur nobis ut forma, esset inseparabilis" (Chartul., i., p. 550).

2 Prop. I16: "Quod anima est inseparabilis a corpore, et quod ad corruptionem harmonie corporalis, corrumpitur anima ".

${ }^{3}$ The Averroïsts make great dispute about the eternity $a$ parte ante and $a$. parte post of the sensible and suprasensible universe. See e.g., prop. 94. We have seen above that in the view of St. Thomas reason is unable to prove the impossibility of "creatio ab aeterno". But the Averroïst thesis is anti-scholastic, because it means that the very nature of the world itself demands that it be eternal.

${ }^{4}$ Props. $42-44,58,61,63,70-73,198,199$, etc. 
Menial of horal Responsibility.' This would overthrow the Ethical system of scholasticism ${ }^{2}(\mathbf{3 0 4})$.

Fifthly, the Thery' of the Troo Truths. The doctrines we have just outlined are in opposition to Catholic logma ; and yet the Averroists protested their respect and reverence for the faith and the Church. And to save their orthodoxy they had recourse to the principle ${ }^{3}$ that What is true in philosophy can be false in theologen, and vice versâ. ${ }^{4}$

The theory of the two truths is tantamount to a denial of the Principle of Contradiction, for the Averroists admitted the truth of the Christian revelation. The theory was aimed directly at the scholastic teaching on the relations of faith to reason $(\mathbf{2 7 8})$. This, however, did not prevent the Averroists from appealing to the authority of the Fathers of the Church in support of their teachings.

1 Props. $168-72$.

"Was there such a thing as a popular Averroism? That is to say, was there at special sect or heresy which applied the principle; of Averroism and drew practical consequences from them, especially in the domain of morals? William of Tocco speaks indeed of the "heresy of Averroess," that all men have one single, common intellect, an error which palliates the vices of the wicked and underrates the virtue of the just. He tells of a Parisian knight who, when recommended to confess, made this reply: "If the soul of St. Paul is saved, so will mine be also, for if we possess the same intellect we shall have a common destiny". The Directorium Inquisit. of Nicholas Eymerici says of this same doctrine: "from this we can infer that the unhappy soul of Judas is identical with the blessed soul of St. Peter; which is heretical". But the existence of a distinct heresy, distinct especially from, and independent of, the heresy of the Cathari, is not yet sufficiently proved: Averroïsm seems not to have got beyond academic and literary circles (AlPHANDÉry, $Y$ a-til eu un averroisme populaire aux xilie et xive siecles? in the Revue de l'histoire des religions, 1901, pp. 395 sqq.).

${ }^{3}$ The Averroistic origin of the theory of the two truths is contested by MiguEL Asin y Palacios, El Averroïmo télogico de Sto Tomas a Aquino (Zaragoza, 1904). The author quotes Arabic texts to show that $A$ verroees established relations of agreement between philosophy and Mussulman dogma. The Averroïsts would then have misconceived and misrepresented the real thought of their master on this point. Cf. 219 and 3 ro.

${ }^{4}$ The formula is expressly set down in an explanatory and apologetic exposition of the decree of 1277 : "dicunt enim ea esse vera secundum philosophiam, sed non secundum fidem catholicam, quasi sint due contrarie veritates" (Chartul., i., p. 543).

${ }^{5}$ See, for instance, the unedited Quaestio of Alexander of Alexandria, which thus outlines their reasoning: "Numerata substantia, numeratur illud per quod intelligimus, quia se ipsa virtus intellectiva intelligit. Si autem numeratur illud per quod intelligimus, impossibile est, quod diversi unum et idem et eodem modo intelligant; quod est falsum et contra Augustinum." $C f$. De humanae cognit. rat. anecdota S. Bonaventurae, etc., p. 220. 
340. Supporters of Averroïsm. - The Averroïsts whose memory is preserved in the history of the thirteenth century, adopted an aggressive attitude towards scholasticism. These are: Siger of Brabant, in the first place; then, of lesser importance, Boëthius the Dacian and Bernier of Nivelles. We know, moreover, that Siger had a strong following in the Paris Faculty of Arts, ${ }^{1}$ and the stirring episodes in the history of Averroïsm are a proof of the vitality of the anti-scholastic forces. ${ }^{2}$ Then, outside the universities, Averroïsm also took root in the court of Frederick II. of Sicily and his son, Manfred (226, II.). To Frederick is attributed the saying that Moses, Jesus and Mahommet were three impostors. $^{3}$ There is no truth in Renan's contention * that the Franciscan schools were centres of Averroism (351): the facts are all the other way. Renan failed to see that the doctrinal differences between the Franciscans and the Dominicans, at the time of the censures of 1277 , all concerned the opposition of the older scholasticism to Thomism, and that the two great mendicant orders joined their forces in the fight against Averroïsm. ${ }^{5}$

341. Siger of Brabant: His Life and Works. - We are certain of only a few meagre details in the life of Siger of Brabant. ${ }^{6}$ Renowned he certainly was in his day- " the professor of the rue de Fouarre "-winning honourable mention from that strange pamphleteer, Pierre du Bois, ${ }^{7}$ and flattering verses from Dante in his Divina Comedia $;^{8}$ dangerous too, in no less degree, for even the most illustrious of his contemporaries felt called upon to write in refutation of his teaching, and the ecclesiastical authorities to prohibit and condemn it. Master of Arts at Paris, he was for ten years a source of perpetual disturbance in the University. In 1266 he gave

${ }^{1}$ Chartul., i., p. 556.

${ }^{2}$ It is likely that further research will bring to light other Averroistic writers. Mandonnet quotes several anonymous texts (op. cit., ccxxxvii).

${ }^{3}$ The saying is referred to in the compilation De Erroribus Philosophorum, which attributes this error also to Averroës: "Quod nulla lex est vera, licet possit esse utilis" (MANDONNET's edit., p. I I). $C f$. decree of 1277 , props. 174 and 175 .

"Averroìs et l'Averroïsme, pp. 259 sqq.

${ }^{5} \mathrm{~K}_{\mathrm{ARL}} \mathrm{W}_{\mathrm{ENCK}}$, in the Historisch. Zeitsch., Bd. 94, I, connects with Averroïsm the reiterated accusations made against Boniface VIII.: War Bonifaz VIII. ein Ketzer?

${ }^{6}$ The attempt to identify Siger of Brabant and Siger of Courtrai has been finally abandoned.

${ }^{7}$ One of the most peculiar personages in the literary history of the fourteenth century, author of a treatise De Recuperatione Terre Sancte (edited by Langlois), in which he advocates, as a means for recovering the Holy Land, a number of educational and social reforms that seem centuries in advance of their time.

'Paradiso, X., v., 136. 
trouble to the legate, Simon de Brie, in matters of discipline, which were in them selves only youthful excesses, but which also revealed Siger's proud and unruly spirit. From 1272 to 1275 he defied the rector of the University, Alberic of Reims, and gathered around him a party of supporters. Finally and especially, he was the recognized leader of the Averroists at Paris during the sixth and seventh decades of the thirteenth century; and the talent he displayed in defending his opinions attracted a considerable section of the arts students (Scholares Golardize ${ }^{1}$ ) to his lectures. Censured first in 1270 , he still continued to propagate his views and to oppose the scholastic masters. A second condemnation in 1277 put an end to his teaching. Perhaps it was in connection with this condemnation that on the 23 rd of October, 1277, Simon Duval, the Inquisitor for France, summoned Siger to his tribunal. It is very likely. Anyhow Siger left Paris about this time and appealed from the inquisitor's jurisdiction to that of the Roman Court. He died prior to 1300 (for, that year Dante encounters him in his journey through Paradise) and perhaps prior to November, $1284^{2}$ The Brabantian continuator of the chronicle of Martin of Troppau ${ }^{3}$ adds that he died by the sword, assassinated by his clericus. "Qui Sygerus, natione Brabantinus, eo quod opiniones contra fidem tenuerat Parisius subsistere non valens, Romanam curiam adiit; ibique post parvum tempus a clerico suo quasi dementi perfossus periit." This text, discovered by Batumker. " throws a new light on the much disputed question of the end of Siger.

His principal work is the De Anima Intellectiva. It directly inspired the De Unitate Intellectus Contra Averroistas of St. Thomas. ${ }^{5}$ Both treatises were composed between 1266 and 1277 , in one of the periods of feverish controversy between scholastics and Averroists. ${ }^{6}$ Siger has also left a Quaestio De Aeternitate Mundi, two Quacstiones Naturales and three logical treatises-the latter of minor importance towards the study of his Averroistic teaching (the Quatestiones Logicales: a question Utrum hei sit veru "Homo est animal, nullo existonte"; and a collection of six Imtossibilia).

342. Philosophical Teaching.- - Siger of Brabant assumed the ambitious role of leader of a school of thought. He taught and wrote openly contra fracipuos airos in fhilosophia Albertum et Thomam, ${ }^{7}$ accusing them of misinterpreting Aristotle. He himself defended the whole Averroistic credo, as may be seen from the censures, which were directed against him mainly, and from the study of his own works. ${ }^{8}$ Mandonnet describes the close contest between Siger and St. Thomas on the crucial question of the numerical unity of intelligence in the human race; he sketches simultaneously the attack and the defence. Siger's line of ex-

${ }^{1}$ Garlande was the name of the school district.

${ }^{3}$ According to a hypothesis of Mandonnet, who sees an allusion to Siger of Brabant and Boëthius the Dacian in a letter of Peckham, dating from November, $\mathrm{I}_{2} 8_{4}$ (op. cit., pp. ccixx sqq.).

${ }^{3}$ Monumenta Germaniae Hist., t. xxiv.

4 Arch.f. Gesch. Philos., r899, p. 74. "Chartul., i., p. 487.

"Mandonnet dates them from 1270 , but without very convincing reasons.

${ }^{7}$ Chartul., i., p. 487 . ${ }^{8}$ Mandonnet, op. cit., ch. vi. sqq. 
position in the De Anima Intellectiva is as follows: In addition to the vegetative-sentient soul which "informs" each separate human organism, there exists an intellectual soul, apart and detached from the body by nature, but which effects a temporary union with the latter in order to elicit intellectual thought. This soul is immaterial; and, furthermore, it is unique, because it excludes that which is the very principle of individual or numerical multiplication, namely, matter. This single human soul, moreover, is never completely separated from all human bodies, for in it resides the entire essence of the race: men die, but humanity is immortal. ${ }^{1}$

In two chapters of the De Anima Intellectiva, and in the De Aeternitate Mundi, Siger proves, in support of his teaching on the eternity of creation, that in terrestrial species, where all the individuals appear by way of "generation," it is impossible to suppose a first generator. It is impossible also to suppose a beginning or an end to the life of immaterial beings. Hence in both departments of being the world is stamped with the seal of eternity. ${ }^{2}$ And therefore the question of immortality, of a future life, does not arise: it is already settled.

The theory of the "two truths"-the "philosophically true" and the "theologically true"-is constantly invoked by the philosopher of Brabant; and it covers his daring declarations with a veil through which it is difficult to determine the real state of his mind. Whether he used the double-truth theory as an expression of profane trifling or of a cynical scepticism, his procedure drew from St. Thomas some severe but well-deserved rebukes. ${ }^{3}$ The tone of the refutations in the De Unitate Intellectus is more grave and stern than in any other of the Angelic Doctor's works.

343. Boëthius the Dacian and Bernier of Nivelles.-About BoËTHIUS THE DACIAN (Boëthius de Dacia), a contemporary of

${ }^{1}$ Mandonner, $o p$. cit., pp. clv, clxxxiii and foll.

3 Ibid., p. clxxxii.

${ }^{3} \mathrm{De}$ Unitate Intellectus, c. vii., and a sermon of St. Thomas. Cf. Mandonnet, p. clxx. There is no end to conjectures as to why Dante places his eulogium of Siger in the mouth of St. Thomas. The following is Baeumker's highly probable explanation (op. cit., pp. 97 sqq.): The poet of the Divina Comedia followed his personal sympathies in dealing with the men of his time and was not sufficiently au courant with academic controversies to take up any deliberately reasoned position on matters philosophical. Just as he makes St. Bonaventure sing the praises of Joachim of Floris, so he makes St. Thomas proclaim the merits of Siger of Brabant. Mandonnet has a different hypothesis (op. cit., cexciii $s q q$.$) .$ 
Siger of Brabant, we know very little. He probably shared in the fortunes of the latter. His writings are chiefly on logic, ${ }^{1}$ and Hauréau draws attention in one of them to a number of theses, unimportant in themselves, but corresponding to propositions condemned in 1 277." We learn further, from a Sorbonne manuscript, that Boëthius was directly censured by the bishop, Stephen Tempier; and the name of Boëthius is connected by Raymond Lully with that of Siger of Brabant.

Bernier of Nivelles was, like Siger, a canon of St. Martin of Liége, and, like Siger too, was suspected of heresy in $12777^{3}$ and cited to appear before the tribunal of Simon Duval; but he was dealt with more leniently than Siger. ${ }^{4}$

344. Opposition to Averroism. - This took the shape of condemnations and of controversial pamphlets. The academic and ecclesiastical authorities grew alarmed at the progress of antischolastic Averroïsm and the danger that it would inflict grave injury on Catholic theology and belief. The first step taken to repress it ${ }^{5}$ was the promulgation of the decree of 1270 , wherein the bishop of Paris, Stephen Tempier, publicly condemned Averroism and its supporters. The following were the theses then censured: "Quod intellectus omnium hominum est unus et idem numero. Quod ista est falsa vel impropria: Homo intelligit. Quod voluntas hominis ex necessitate vult vel eligit. Quod omnia que hic in inferioribus aguntur, subsunt necessitati corporum celestium. Quod mundus est aeternus. Quod nunquam fuit primus homo. Quod anima, que est forma hominis secundum quod homo, corrumpitur corrupto corpore. Quod anima post mortem separata non patitur ab igne corporeo. Quod liberum arbitrium est potentia passiva, non activa; et quod necessitate movetur ab appetibili. Quod Deus non cognoscit singularia. Quod Deus non cognoscit alia a se. Quod humani actus non reguntur providentia Dei. Quod Deus non potest dare immortalitatem vel incorrupcionem rei corruptibili vel mortali." ${ }^{6}$

${ }^{1}$ Amongst them a Commentary on the Majus Volumen Prisciani, on the Octo L. Topicorum, on the two Analytica and on the Sophismata. HAUREAU, Fournal des savants, I886, p. I76. On the identity of Boëthius, see MaNDONNET, op. cit.. p. ccxlii.

${ }^{2}$ In Octo L. Topic. (ibid.).

+ MaNdonnet, op. cit., pp. cclxv and cclvii.

${ }^{5}$ The council held at Paris in 1210 had a merely preventive influence (228).

${ }^{6}$ Chartul., i., p. 486. 
Authority interfered for the sole purpose of terminating a doctrinal dispute, as we learn from a letter of Giles of Lessines ${ }^{1}$ to Albert the Great. The Averroist doctrine of the two truths seems to be aimed at again in a statute of the Arts Faculty in I 272 , forbidding the masters to touch purely theological questions "which are not their business" or to lay down propositions contrary to theology. ${ }^{2}$ It would seem, therefore, that notwithstanding the prohibitive measures of 1270 , the Averroists were still active. St. Thomas also informs us, towards the end of the De Unitate Intellectus contra Averroistas, that the latter were pronouncing on purely theological questions. "Non caret (he is speaking of Siger of Brabant) etiam magna temeritate quod de his quae ad philosophiam non pertinent, sed sunt purae fidei, disputare praesumit, sicut quod anima patiatur ab igne inferni." Anyhow the well-known censures of 1277 , already frequently referred to (312), were directed expressly against Siger of Brabant and Boëthius the Dacian and were sanctioned by grave penalties. They struck at all the Averroïstic theories not only in their principles but in their manifold applications. Those periodical decrees suggested the idea of collecting all the errors scattered through the schools. In some such collections we find not only the theses condemned by Stephen Tempier, but also those condemned at Oxford (312), and occasionally, as in the collection attributed to Giles of Rome, a résumé of the errors of Aristotle, Averroës, Avicenna, Gazali, etc. Those Compilationes errorum omnium in Anglia et Parisius condemnatorum saw the light about the end of the thirteenth and opening years of the fourteenth centuries. ${ }^{3}$

The second form of opposition to Averroism was the polemical.

${ }^{1}$ See Mandonnet, op. cit., pp. cxvii $s q q$. The first thirteen theses referred to in the letter of Giles are identical with those of the decree of $1270\left(3^{1} 3\right)$.

${ }^{2}$ Chartul., i., p. 499. As early as 1247 a similar prohibition had been laid on the professors of logic by the Papal Legate, Odo, bishop of Tusculum, in his condemnation of the errors of John of Brescain : “. . . ne puritas studii que hactenus Parisiis viget ex praesumptione quorumdam qui theologica logicis inserentes non intelligunt neque que loquuntur, neque de quibus affirmant" (i., p. 207). Cf. the oath administered to the incipientes in artibus (1280), (ibid., p. 586). Other enactments, and sometimes even those directed against the philosophers, sought to moderate the zeal of the theologians in their employment of the dialectic method. See e.g., the letters of Gregory IX. to the masters and scholars of Paris (ibid., p. ${ }^{18}{ }^{8}$ ). The legate, Odo, speaks of the "logici theologice et theologi philosof hice procedentes" (ibid., p. 207).

${ }^{3}$ Chartul., i., p. 556. One of those collections is published in D'ARgentre, Collectio Fudiciorum, i., p. 184 . 
Already in the De Universo of William of Auvergne, we find an article entitled: "Destructio erroris Aristotelis, Alfarabii et aliorum qui posuerunt omnes animas separatas unam esse, ipsaque separatione a corporibus unam fieri atque illas uniri". ${ }^{1}$ There is scarcely a single scholastic of the thirteenth century who does not deal with the theory of the unity of the human intellect, and always to refute it. Albert the Great (266), Thomas Aquinas (272), Giles of Rome (319), Raymond Lully (354), all wrote special treatises on it. Duns Scotus, speaking of the philosophical errors of Averroës, says that " talis errans esset a communitate hominum et naturali ratione utentium exterminandus"."

345. Bibliograplyy.-The leading work is that of PÉre MaNdoxinet, 225, P. i., Etude Critique (Louvain, in the press); P. ii., Textes (Louvain, Ige9). Publishes all Siger's works, including the Impossibilia; also an anonymous treatise, De Erroribus Philosofhorum, and the text of the 219 propositions condemned in 1277. RENan, of. cit., 222, P. ii., ch. ii., "L'averroïsme dans la philos. scolast."-contains numerous errors. PıCAvet, L'Az'croisme et les averroïstes du xiiic siécle: follow's St. Thomas, De Unitate Intell., etc. (Revue hist. relig., rgo2, r. p.): nothing new. Cholleit, Averroisme (1)ict. Théol. Cath., i., 2628): epitomizes Mandonnet and De Wulf.

BaEUMker, Die Impossibilia d. Siger von Brabant, eine philosoph. Streitschr. aus d. xiii. Jahrh. (Beitr. z. Gesch. d. Phil. d. Mitt., ii.. 6, I888). Unedited text, with study. Baeumker regards the work as a pamphlet published between $\mathrm{r}_{2} 88$ and $\mathrm{I}_{30}$ (p. 49) in which the theses declared impossible express the views of Siger, whilst the Solutiones or refutations would be the work of an adversary, to whom the pamphlet in its actual form must be attributed. Mandonnet, on the contrary, regards it as the work of Siger exclusively, classifying it among the collections of sophistical or dialectical exercises proposed and solved by the masters at the periodical public dis. putations. He observes that the doctrines embodied in the Resolutiones tally with those of Siger's edited writings; a decisive test in determining the authorship of the Impossibilia. Mandoninet, op. cit., publishes the following works of Siger: Quacs tion's Logicales; Utrum hec sit vera: homo est animal, nullo homine existcnte; Quacstiones Naturales; De Acternitate Mundi; Quacstiones de Anima Intellectiva. He publishes, besides, the De Quindecim Problematibus of Albert the Great, and extracts (first five chaps.) from the Tractatus de Erroribus Philosophorum attributed to Giles of Rome. Cf. our Hist. Philos. siol. Pays-Bas, etc., p. 275. For numerous controversies on the subject of Siger's death, see references in BAEUMKER, op. cit., p. $11_{4}$, and in the Arch. f. Gesch. Philos., I 899 ; MandonNet, op. cit., ch. xi. ; Gaston

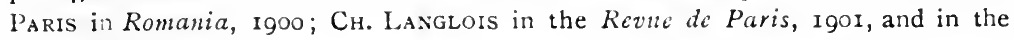
Grande Encyclopedie.

\section{$\S$ 2. Other Forms of Anti-scholastic Philosophy.}

346. Philosophical Sects.-Underlying many popular sects, which had their origin in the twelfth century, we find certain

${ }^{1}$ Prs. i., c. xi., p. 771, cdit. I591.

In IV. L. Sent., dist. 43, q. 2. 
philosophical doctrines. Such, for instance, were the tenets of the Amauricians, early in the thirteenth century $(\mathbf{2 0 8}, \mathbf{2 2 8})$. The most tenacious of all, in its variety of forms, was the heresy of the Cathari. Youthful "perfects" of the sect were wont to frequent the schools at Paris, or throughout Italy, in the later years of the Albigensian period, to attack the savants of the Dominican order. $^{1}$ The Albanian school which lasted, in Italy, down to the fourteenth century (in two sections, that of Balasinansa, bishop of Verona, and that of John de Lugio), professed an absolute metaphysical dualism (207), in opposition to the mitigated dualism of the sect of Bagnolo." The philosophical opinions of the Cathari are not yet sufficiently explored. ${ }^{3}$

347. Bibliography.-Menender y Pelayo, Historia de los hetorodoxos españoles (Madrid, r880). Alphandéry, op. cit., 209.

${ }^{1}$ Alphandéry, Les idées morales chez les hétérodoxes latins au debut du xiiie siècle, p. 92.

${ }^{2}$ Ibid., pp. 92-98, note. $\quad{ }^{3}$ Ibid., p. I4I. 


\section{CHAPTER V.}

\section{SOME NON-SCHOLASTIC IIRECTIONS IN PHILOSOPHY.}

\section{\$ I. Experimental Direction, Roger Bacon.}

348. Life and Works. - Roger Bacon was born in England about $1210-15$, studied at Oxford and then at Paris, where he afterwards taught (towards 1245). From early youth he devoted himself to the study of languages and of the natural sciences. Between $\mathrm{I} 25 \mathrm{I}$ and $\mathrm{r} 257$ he joined the Franciscans, probably at their Oxford house. Here he pursued his researches without interruption, notwithstanding the hostility of his superiors, who would not allow him to publish his works. The elevation of an intimate friend of his to the Papacy was a momentous event in his career: Clement IV., in a letter of June the 22nd, 1266 , requested Bacon to send him a copy of ti.e work he was anxious to publish, and this, notwithstanding the prohibition of the latter's superiors. In the course of 1267 , Bacon addressed to his protector the Ofus Majus and the Opus Minus, and, a little later on, the Ofus Tirtium. Other writings followed in quick succession. But a coalition was formed against him on the death of his protector. According to a chronicle of the twenty-four generals of the order of liriars Minor (first half of fourteenth century), Jerome d'Ascoli, the general of that time, sent Bacon to Rome in 1278 , to answer for his "suspected" doctrines, and the latter appears to have been confined for some time (ad tempus) in prison. ${ }^{1}$ The supposed imprisonment for a term of fourteen years is, however, not proven. He died about 1292 or 1294 .

The Ofus Majus, dedicated to Clement IV., is Bacon's chief work. It comprises seven parts: causes of our errors; relations of philosophy and the sciences to theology; linguistics; mathematics; perspective; experimental science; moral philosophy. The Opus Minus was intended by Bacon as an abridgment of the Opus Majus. But it contains, over and above, an exposition of speculative alchemy and an essay on the decadence of theology and its causes ("septem peccata studii principalis quod est theologiae"). ${ }^{2}$ The Opus Tertium sums up and explains the two previous works, examines some new scientific questions in detail and contains a good deal of information about Bacon's own career. Those three works were intended as a preamble to a more ambitious synthetic work, Scriptum Principale, of which Bacon has left us the plan, but which he never executed. It was to deal with: (I) grammar and languages; (2) mathematics; (3) natural sciences (the Communia Naturalium are data for this); (4) metaphysics and ethics. ${ }^{3}$ Besides commentaries written in his youth on various parts of Aristotle; a Compendium Studii Philosophiac

${ }^{1}$ D'Argentré, Coll. Fud., i., p. $226 . \quad{ }^{2}$ Brewer, p. xxxiv, 322.

${ }^{3}$ Bridges, i., pp. xiv sqq.; Brewer, pp. I sqq. The Opus Majus will be referred to in the text according to Bridges' edit., the Ofus Minus and Opus Tertium according to Brewer's. 
(towards 1271-76), in which he again animadverts on the current defects in those studies; a treatise De Multiplicatione Specierum (a study of the efficiency of physical agents); and a Compendium Studii Theologiae, Bacon's last work; a large number of neglected opuscula and treatises are also attributed to him.

349. The Personality of Bacon.-Bacon attached great importance to the natural sciences, mathematics, perspective and optics, geography, astronomy, alchemy and the study of languages. He was remarkably well versed in the sciences-better than any of his contemporaries. Not only did he make a powerful plea for the employment of the experimental method, but he was himself a skilled observer and experimenter. He surpassed the Arabians in some of his applications of geometry to physics; he constructed and improved optical instruments. Constantly and bitterly did he reproach his scholastic contemporaries with their negligent attitude towards scientific observation and research. Bacon was certainly remarkable as a scientist: it is his strongest title to renown.

He was fully au courant with every phase of the intellectual movement of his time, and for this reason his works form a valuable source for the history of ideas in the thirteenth century -a source that has yet to be used to full advantage. They call, however, for some caution: Bacon's judgments on men and events must be taken with careful reserve; they are inspired by a discontent which often betrays him into injustice. An enthusiastic admirer of Aristotle, he blames his contemporaries for often misrepresenting the Stagirite in their faulty Latin versions of the latter's works. Better for them to know nothing at all of Aristotle than know him in such detestable caricatures! "Si enim haberem potestatem super libros Aristotelis, ego facerem omnes cremari." 1 On the earliest Latin versions of Aristotle, ${ }^{2}$ on the state of studies in the Franciscan order, on the teaching of theology, ${ }^{3}$ on many of the well-known scholastics - William of Auvergne, ${ }^{4}$ Robert Grossetête (of whom he speaks repeatedly), Adam of

${ }^{1}$ Compendium Philosophiae, Brewer, p. 469.

${ }^{2}$ See, e.g., Opus Majus, iii., p. 66.

${ }^{3}$ The "seven sins of theology," according to the Opus Minus (p. 322 sqq.), are : the incursions of theologians into the domain of pure philosophy; their ignorance of the sciences; the undeserved ascendancy accorded to the two principal theologians, Alexander of Hales and Albert the Great ("de aliis nulla est vis ") ; the preference accorded to the Book of the Sentences over the Bible; the corruptness of the Vulgate text of the latter; errors in exegesis ; the ignorance of the preachers.

${ }^{4}$ Opus Majus, iii., p. 47. 
Marisco, Alexander of Hales, ${ }^{1}$ Albert the Great ${ }^{2}$ and several others-Bacon has left us much valuable information, mingled as it oftentimes is with palpable exaggerations. The history of the Grecian, Patristic and Arabian philosophies receives detailed and extensive treatment at his hands $:^{3}$ for a special reason to which we shall presently revert. Written in a lively and vigorous style, his works do not follow the pedagogical order that was customary in his time, but are freely developed according to the needs of the matters under treatment.

350. Philosophical Teaching.-Taken as a whole, Bacon's philosophy approximates closely to the earlier scholasticism : for example, he admits plurality of forms, ${ }^{4}$ the existence of a materia spiritualis ${ }^{5}$ and of rationes seminales. ${ }^{\circ}$ His metaphysics, especially his theory on the universals, deserves to be better known ${ }^{7}$ it has not been sufficiently analyzed in hitherto published works. There are in the Opus Majus and in the Opus Tertium passages on the evolution of genera and species and on the hierarchy of forms and matters, in which his latest historian ${ }^{9}$ professes to discover points of resemblance with the Scotist loctrine (329). But Bacon's repeated refutations of all theories claiming numerical unity for matter ("pessimus error") absolve him certainly from holding the Scotist view about materia prima. He notes expressly that pantheism is the logical issue of that dangerous view ("ita omnia erunt unum et idem ") and that the unity of matter would involve its infinity. Bacon himself, on the contrary, accentuates individualism in metaphysics, for he admits a specific diversity of matters corresponding to diversity of forms: "Forma differt a forma secundum se, et materia a materia per suas naturas

${ }^{1}$ Opus Minus, pp. 325-27. $\quad 2$ Opus Tertium, p. 30.

3 The Opus Majus, i., pp. 45-54, contains an outline of the history of philosophy.

${ }^{4}$ Opus Tertium, p. I23. $\quad{ }^{5}$ Ibid., p. I21.

"Gasquet, Bacon's letter to Clement IV. (English Historical Reviei", p. 513).

${ }^{7}$ Cf. Opus Majus, i., p. 42. In the De Multiplicatione Specierum there is a curious passage on the action of the universal. The whole treatise is an interesting study on the efficiency of natural agents and the transmission of forces. By species we are to understand the primus effectus agentis (Bridges, ii., p. 4ro); the species intcntionalis is only a class or kind of action, namely, that which is received in a cognitive subject. Bacon teaches that the universal elements of a being produce univer:al species and the individual element singular species: "sicut rerum quaedam sunt universales, quaedam singulares sic species fiunt ab his et aliis".

sOpus Majus, i., pp. ${ }_{44}$ sqq.; Opus Tertium, pp. ז20-23, 131.

${ }^{9}$ Delorme, in the Dict. Théol. Cath. 
proprias, ita quod diversitas materiae non est a forma sicut nec e converso". 1

351. Anti-scholastic Views.-Bacon's originality is seen principally in the views which put him in opposition to scholasticism. Of these the following are the more important:-

(I) The mutual relations of theology, philosophy and the sciences. The question of these relations is all-important in Bacon's philosophy: it occupies the entire second half of the Opus Majus. From the essential unity of all knowledge and the essential primacy of theology, he infers that the sole raison d'être of philosophy and the sciences is to explain the contents of the Scriptures. "Una est tantum sapientia perfecta quae in sacra scriptura totaliter continetur." ${ }^{2}$ In itself, philosophy is of no value: "philosophia secundum se considerata nullius utilitatis est" $;{ }^{3}$ it is but the instrument of dogma: "philosophia non est nisi sapientiae divinae explicatio per doctrinam et opus"." Strange words in the mouth of an ardent natural scientist.

But Bacon goes even farther: he inaugurates what is a veritable traditionalism. God alone can have taught men to philosophize, by revealing the truth to them. Without books and teachers, the solution of the Universals problem would never have been reached. And so of all philosophy: "revelatio necessaria est in hac parte (veritate universalium); et cum haec sint puerilia et minima, multo fortius erit hoc in tota sapientia philosophiae" ${ }^{5}$ "Impossibile fuit homini ad magnalia scientiarum et artium devenire per se, sed opportet quod habuerit revelationem ". 6 And here are the consequences: the plenitude of philosophic wisdom was coeval with the cradle of humanity: "Eisdern personis data est philosophiae plenitudo quibus et lex Dei, scilicet sanctis patriarchis et prophetis a mundi principio".7 But the wickedness of men drew down the anger of God; ${ }^{8} \mathrm{He}$ dispensed philosophic truth to them with a sparing hand and allowed them to mingle errors with it. We should therefore seek in the books of the ancient philosophers the soul of truth that revelation placed there; we should follow up the traces of Christian dogma in paganism and thus add all we can to our inherited treasure "usque ad finem mundi, quia nihil est perfectum in humanis

\footnotetext{
'Opus Tertium, p. 126.

${ }^{2}$ Opus Majus, iii., p. 36.

${ }^{3}$ Ibid., p. 69.

$\$$ Ibid., pp. 68, 52, 53, 76, etc. This idea recurs repeatedly.

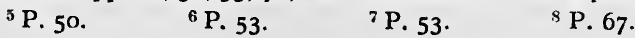


adinventionibus". ${ }^{1} \quad$ But in order to discover this treasure in the philosophy of the ancients, we must interrogate history. Knowledge of languages thus becomes a primary requisite for wisdom." On the study of languages should follow the study of mathematics, for these are required for the various sciences that interpret nature, ${ }^{3}$ as well as for philosophy: " tota philosophiae intentio non est nisi rerum naturas et proprietates evolvere" 4 -and for the understanding of the facts of Scripture. The study of philosophy properly terminates in ethics, for this branch has the most direct and intimate bearing on theology.

(2) The theory of the Intellectus Agens. The intellectus agens, which determines the passive intellect to elicit the act of "understanding," is not a part of the soul. It is the sun of our intelligences and illuminates them with its truth. ${ }^{5}$ The connection between Bacon's ideology and his traditionalism is unmistakable: "quia istud est necessarium ad propositi persuasionem, ut ostendatur quad philosophia sit fer influentiam divinae illuminationis, volo istud efficaciter probare, praecipue cum magnus error invaserit vulgus philosophantium in hac parte". " Aristotle, St. Augustine and all the "sapientes antiqui experti," he adds, were agreed on the separation of the two intellects. It is likewise, he urges, the view of Robert of Lincoln and Adam of Marisco. "And on two occasions, he informs us, I have heard William of Auvergne defend it".

Of all the interpretations of the Augustinian theory of Divine illumination, that of Bacon-who thinks he is merely paraphras-

${ }^{1}$ P. 66.

$\because$ Pp. 97, 98.

3 P. iv.

+ T. iii., p. $5^{2}$.

5 "Intellectus agens, secundum majores philosophos, non est pars animae, sed est substantia alia et separata per essentiam ab intellectu possibili" (Opus Majus, iii., p. 47).

${ }^{6}$ Ibid., p. 45 .

7 "Nam universitate convocata bis vidi et audivi venerabilem Gulielmum Parisiensem Episcopum felicis memoriae coram omnibus sententiare quod intellectus agens non potest esse pars animae, et Dominus Robertus Episcopus Lincolniensis et frater Adam de Marisco et hujusmodi majores hoc idem firmaverunt" (p. 47). With some reserves, the relation propounded by Bacon agrees with the theory of William of Auvergne. See 244. The incident to which Bacon refers here is again mentioned in the Opus Tertium, pp. 74 and 75 . He opposes his theory to that of the moderni for whom the intellectus agens is a pars animae. Concerning Adam of Marisco he adds: "unde quando per tentationem et derisionem aliqui Minores praesumptuosi quaesiverunt a fratre Adam, 'Quid est intellectus agens?' respondit 'Corvus Eliae'; volens per hoc dicere quod fuit Deus vel angelus". 
ing the others-is by far the most daring. It borrows half its ideology from Averroïsm, since it does not admit an intellectus agens for each individual man; but it rejects the other half, inasmuch as it does endow each individual with a proper intellectus possibilis of his own. In his Communia Naturalium, Bacon insists on the difference there is between his theory and that of the Averroissts. ${ }^{1}$

(3) All cognition is intuitive: intellectual as well as sensible. For, all cognition is a direct union of the knower with the known. The universal notes, which exist in the individual things of Nature, determine in us cognitions (species) of the universal, just as the individual notes, which envelop the universal, effect in us the cognition of the singular. Bacon describes every action of one being on another as a species, and so cognition is but a particular case of the interaction of cosmic agencies. ${ }^{2}$

(4) Experience and the methods of acquiring knowledge. There are three methods of acquiring knowledge: per auctoritatem et rationem et experientiam. ${ }^{3}$ But authority is unsatisfactory without reasoning; and even reasoning does not secure the tranquil possession of truth unless experience confirms its findings. ${ }^{4}$ Experience is thus the sole source of certitude. The argumentum to which Bacon opposes experientia is apparently the hollow reasoning exemplified in the sophismata of the schools, or also the reasoning based on alleged but unverified facts, or finally the reasoning which, in the investigation of the laws of nature, would foolishly try to dispense with experience altogether. ${ }^{5}$ But he admits that demonstration based on established facts leads to

${ }^{1}$ P. iv., c. 14, quoted by Bridges, i., p. 38, n. Cf. Renan, op. cit., p. 262. Renan relies on the text quoted in the preceding note to include Bacon and the earlier Franciscans in the Averroist school. But Bacon is no Averroïst ; and he is, moreover, an exception among the Franciscans, for these agree with the Dominicans in making the intellectus agens a pars animae.

2 Hadelin, Une theorie intuitionelle au xiii siècle (R. Néo-scolast., rgo6, pp. 382 sqq.).

${ }^{3}$ BREWER, p. 397.

4Opus Majus, ii., p. 77 : "Duo enim sunt modi cognoscendi, scilicet per argumentum et experimentum. Argumentum concludit et facit nos concedere conclusionem, sed non certificat neque removet dubitationem ut quiescat animus in intuitu veritatis, nisi eam inveniat via experientiae, quia multi habent argumenta ad scibilia sed quia non habent experientiam, negligunt ea, nec vitant nociva nec persequuntur bona."

"Ibid., p. 201. 
science. ${ }^{1}$ Anyhow, the exclusive claims set up by Bacon for the experimental method must not be understood in the absolute sense of modern positivism.

This is certain; for after concluding "Oportet ergo omnia certificari per viam experientiae," he immediately adds "duplex est experientia". The one is external ("per sensus exteriores"). ${ }^{2}$ The other is internal ("scientia interior") and is the fruit of divine inspirations ("divinae inspirationes"). But the first of the seven degrees of this scicntia interior consists in illuminationes pure scientiales. And this brings us back to that whole body of scientific and philosophic knowledge engendered in us by the illumination of God, the intellectus agens of our souls; a view that seems to corroborate our interpretation of the muda demonstratio. The objects of the remaining six illuminations are: moral virtue; the gitts of the Holy Ghoit; the evangelical beatitudes; the sensus spirituales; the fructus de quibus est far Domini; and, finally, the higher intuitions of the state of rafus or ecstasy. Some of those degrees are obviously the supernatural states experienced in catholic mysticism.

352. Conclusion.-Bacon is faithful to scholasticism in the main drift of his teaching. But he espouses at least two fundamental theories which cannot be reconciled with scholasticism; hence it is that we give him a place apart in our classification. His denial of an autonomous value to philosophy runs directly counter to philosophy as conceived by the thirteenth-century scholastics. Then, too, his traditionalism and his theory of the intellectus agens seriously compromise the objectivity of knowledge and the soul's efficient causality: if God determines the intellectus possibilis to elicit the act of understanding, it is $\mathrm{He}$ who forms ideas in us; it is no longer the soul that abstracts them with the Divine concurrence. ${ }^{3}$

1 "Quod ergo dicit Aristoteles quod demonstratio syllogismus est faciens scire intelligendum est si experientia comitetur, et non de nuda demonstratione" (ibid., p. 168$)$.

"In sensation he distinguishes the actual sensation, the memoria and the cogitativa. This latter is the domina sensitivarum virtutum, logistica, and belongs to animals as well as to man. It is the vis aestimativa of scholasticism. Opus.Majus, t. ii., pp. 79 and r27. Cf. 350, n. 7 .

: The mind's native incapacity to reach truth, and the consequent necessity of a Divine revelation, recall the errors of De Bonald; but between him and Bacon there is this capital difference: for the former the revelation was made in the beginning and its data are transmitted by language; for the latter the revelation or illumina- 
353. Bibliography.-Editions of the Opus Majus in 1733 and 1750 . Recent edition by BRIDGES, 3 vols. (Oxford, r897-rgoo): very defective. Vol. iii. is a re-edition of a portion of vol. i., according to a new MS. At the end of vol. ii., the De Multiplicatione Specierum. Under the title, An Unpublished Fragment of a Work by $R$. Bacon, Dom Gasquet has published in the English Historical Review (1897) a long letter of Bacon's to Clement IV., which he believes to be the introduction to Bacon's work. The leter does bear directly on the work. Brewer, Fr. R. Bacon Opera hactenus Inedita (in the Rerum Britannicarum Medii Aevi Scriptores), published in I859. Contains the Opus Tertium and the Opus Minus, both complete, and the Compendium Philosophiae. Duhem, Sur un fragment, inconnu jusqu'ici, de l'opus tertium de R. Bacon (Arch. Francis. Histor., rgo8). Robert Steele has begun to edit Bacon's metaphysics. The Communia Naturalia are still in MS. Their publication will be of great importance for the study of Bacon's metaphysics. PERE HADELIN, O.M.C., a former pupil of ours, is preparing an edition of them, and will also publish a study on Bacon's philosophy. Portions of this work have already appeared in the Revue Néo-scolastiquc, 1906-rgog. Cf. La sy'nthèse doctrinaie de $R$. Bacon (Arch. f. Gesch. d. Philos., I907) by the same.

The editions of BRIDGES and BrEWER contain biographies of Bacon and studies on his works. Charles, R. Bacon, sa vie, ses ouvrages, ses doctrines (Paris, $186 \mathrm{I}$ ). Delorme, Bacon (in the Dict. Théol. Cath., t. ii., I9o3): good (see 352, n. 2). Narbey, R. Bacon ct le mouvement scientifique du xiiie s. (Rev. Quest. Histor., Jan., I894). Felder, op. cit., 237; Das Schulprogramm, pp. 380 sqq. A. Döring, Die beiden Bacon (Arch. f. Gesch. d. Philos., rgo4, xvii., 3): unimportant. FlüGEL, Roger Bacon's Stellung in d. Gesch. d. Philologic (Wundt's Philosoph. Studien, xix., 1902, pp. $6_{4}$ sqq.). PiCAvet, Nos vieux maitres, Picrre de Maricourt, le Picard, et son influence sur R. Bacon (Rev. Internat. Enseignem., r9o7). A fuller bibliography will be found in Delorme's art. in the Dict. Théol. Cath., and, from the scientific point of view, in Lalande's art. (310). Pierre Duhem, Un fragnent inédit de l'opus tertium de R. Bacon, Ad Claras Aquas, rgog. Texte et Êtude.

\section{§ 2. NeO-Platonic Direction.}

353(b). General Features. - Through the influence of Arabian works, and, more directly, of the Liber de Causis and the Elementa Theologica of Proclus in the version of William of Moerbeke (226), numerous theories of Platonic origin found their way into the philosophy of the thirteenth century. Though appearing only intermittently in Albert the Great and St. Thomas, they occupy a sufficiently important place in the works of others to warrant

tion is special and varies from man to man. Père Delorme, of the Friars Minor of Bordeaux (353), tries at all costs to assimilate the philosophy of Bacon with that of the other Franciscans of the thirteenth century, and criticizes us-with a suspicion of irony-as having misrepresented Bacon in the first edition of the present work. A more careful consideration of the texts has only confirmed us in our view. Père Delorme's article is not quite free from bias and inaccuracy. It is not true that Peckham, scotus and St. Thomas adhered to Bacon's ideological teaching (p. 14): all three hold the intellectus agens to be a part of the soul (cf. 359). Nor is it true that no other scholastic attributed to reason any greater influence than Bacon did (p. 22); quite the contrary. 
us in recognizing a Neo-Platonic direction of a strictly philosophical character in the thought of the thirteenth century. Those who represent this current of ideas admit the doctrines of the earlier scholasticism into their conception of the world, just as they admit Thomistic and Aristotelian elements, but they mould all alike in a Neo-Platonic setting and harmonize all more or less successfully with Alexandrian theories.

Yet there is a profound difference, which cannot be too strongly emphasized, between the ancient Neo-Platonism and the medieval: the monism or pantheism, which is the very soul of the writings of Plotinus and Proclus, is not only absent from those of Witelo and Theoderic of Freiburg - the two best known NeoPlatonists of the thirteenth century-but is expressly refuted by both the latter. Otherwise we should be obliged to regard their philosophy, like that of Scotus Eriugena, as anti-scholastic. Then, too, this Neo-Platonic current is of little importance ${ }^{1}$ as compared with scholasticism, or even with Averroism. For those two reasons Plotinus was no more the master of the philosophy of the thirteenth century than of that of the preceding centuries.

It is interesting to note that the Neo-Platonists we are about to deal with, were all remarkable as men of science, well versed in physics and mathematics.

353(c). Witelo: Life and Works. ${ }^{2}$ - Born about $1230 \mathrm{in}$ Salesia, a region that was slow to awaken to intellectual life, WrTelo was educated in philosophy and the sciences in the University of Padua. Later on, at Viterbo, he met William of Moerbeke, whose influence on him was considerable. It was at the instance of William that he wrote his Perspectiva (about 1270 ) ${ }^{3}$ dedicating it to the latter. In this treatise Witelo describes the laws of the propagation of light, according to Alhacen; it contains many striking and original observations on the function of mental association in the sensation-process, especially in the visual perception of the third dimension of space.

Witelo is probably the author of another unfinished work, De Intelligentiis, which Dr. Baeumker attributes to him, and which he apparently interrupted in order to write the Perspectiva. It is more philosophical in its contents than the latter. Witelo's other works are lost. He seems to have had some connection at Viterbo with the Roman Curia. He died soon after the year 1270, probably at Vicoigne lez Valenciennes.

I “ Unsere Schrift (De Intelligentiis) zeigt wie auch die neuplatonische Strömung einen wenn auch kleinen Kreis ergriffen hat." BAEUMKER, Witelo, ein Philosoph und Naturforscher des xiii. Jahrhunderts (Beiträge z. Gesch. d. Philos. d. Mittel., Münster, rgo8, p. I88. Cf. p. 604).

2 Our materials here are taken from BAEUMKER's recent work on Witelo.

"About the same time Bacon and Peckham also wrote treatises on Persfective. 
353(d). Philosophical Teaching.-Witelo's doctrines in metaphysics and psychology deserve some notice: they are an alloy of Neo-Platonism, as dominant element, with certain data from Aristotelianism and the earlier scholasticism.

The De Intelligentiis - which sets forth all its theses according to a rigorously deductive method-studies, in two parts, God, the First Cause, His nature and His knowledge (P. i.); and the primary Intelligences, their powers of cognition and of motion ( $P$. ii.). The starting-point of this metaphysical system is not being-ingeneral (Aristotle), but the infinite being, God. All other things are but participations, in a descending scale, of the Divine being (Neo-Platonism); as the manifold can issue only from the One, and the simple includes all the perfections of the composite. The identification of being with light is one of the peculiarities of the treatise ( $c$. Plotinus). God is light; $\mathrm{He}$ is also act and substance (Aristotle). All other beings are light participated (St. Augustine). Though this notion of the diffusion of light serves to illustrate the mutual relations of all beings, ${ }^{1}$ especially the relations between God and the world, there is nowhere any hint of emanation, and the idea of monism is entirely absent.

Witelo's psychology is Platonic and Neo-Platonic; but at the same time it incorporates Aristotelian theories on the formation of ideas. The soul is a simple, independent substance. The action of light explains not only the spatial arrangement of bodies, but the vital force of living organisms and even the process of conscious cognition itself. The sensation, like the concept, is an essentially active phenomenon of the soul (virtus activa, Plato), while it is at the same time representative of reality (virtus exemplaris). Such activity and such reproduction can belong only to a spiritual substance, and since it is light, the active, reproductive phenomenon of cognition is not the reception of any action from without, but an auto-diffusion of the ego (sui multiplicatio). The role of the active and passive intellects (Aristotle) is thus modified; the active intellect has now not only to

${ }^{1}$ It is interesting to note that St. Thomas combats the Neo-Platonic notion that "omne quod influit in alia est lux vel naturam lucis habens," with express references to texts of the $D e$ Intelligentiis, the author of which he does not mention by name: "Contrarium concedimus, quamvis liber De Intelligentiis non sit auctoritatis alicujus, nec etiam verum sit quod omnis influxus sit ratione lucis" ( $Q$ uodl., vi., q. II, art. Ig. BAEUMKer, op. cit., pp. 420 sqq.). 
produce a determination on the sense-images, but to know the reality of things. ${ }^{1}$

353(e). Theoderic of Freiburg: Life and Works.-The Dominican, TheOderic of Freiburg (Theodericus Teutonicus de Vriberg, probably Freiburg in Saxony), appears at 'aris, first as a student (prior to $12 \$ 5$ ) and then (towards r297) as master in theology. He tells us that on the question of the eternity of the world he assisted at the disputes of a solemnis magister-Henry of Ghent, no doubt -whose opinions on that matter he afterwards criticized. He occupied im ortant administrative positions in his order. The latest certain information we have about him dates from I 3 IO. It would have been in the opening years of the fourteenth century that he wrote his principal works. These bear witness to an astonishing fecundity and to an extensive and varied store of learning. Of most importance are: $D_{c}$ Lucc et Ejus Origine'; De Coloribus: De Iride et Radialibus Impressionibus; $D_{\epsilon}$ Miscibilibus in Mixto; De Intelligentiis et Motoribus Coclorum; De Tribus Difficilibus Articulis: De Cognitione Entium Separatorum; De Habitibus; and especially the $D_{\varepsilon}$ Intellectu ct Intelligibili, in which he sums up his very original systematic conceptions.

353(f). General Influence.-From three points of view Theoderic of lireiburg has an interest for the historian of ideas in the thirteenth century. As a man of science, he formulated a striking and original theory on the rainbow, a theory taken up afterwards by Descartes. He informs us that when he expounded it to the provincial of his order, the latter recommended him to commit it to writing. As a mystic he had many ideas in common with Echhart. As a philosopher, he was a bold and original thinker. He readily differed from the communiter loquentes and the doctors of his own order; and he boasts of it. But then, he was at the same time an energetic upholder of the doctrinal innovations of Thomism on the great fundamental and much debated questions of scholasticism: unity of substantial form; passivity of primal matter and its essential incapacity to exist without some form or other; denial of the intrinsic impossibility of creation ab acterno. On the other hand, he perpetuated the teaching of the earlice scholasticism on many points, favouring theories of Augustinian origin. He subscribed to doctrines such as the distinction between the two intellects, the essential difference between sensation and thought, the composition of bodies from matter and form: all doctrines which attach him as a member to the family of the scholastics.

${ }^{1}$ In the Pcrspectiva, Witelo solves the Universals problem after the manner of Bacon. There are in all things individual marks (intentio es individuales) and specific features (intentiones speciales), to which correspond sense knowledge on the one hand and general knovledge on the other (ibid., p. 626). 
But all those Thomistic and Augustinian elements are incorporated in a system that is more Neo-Platonist than Witelo's. The Elementa Theologica are quoted repeatedly, and Proclus is put on a level with Aristotle and St. Augustine. To believe the Dominican philosopher, those three great thinkers are entirely at one upon the doctrines expounded in his treatises. Like Witelo, it is principally his metaphysics and psychology that have an interest for the historian.

353(g). Philosophical Teaching.-At the foundation of his metaphysics is the theory of the production ${ }^{1}$ of beings by intermediaries, in a descending scale of causality, secundum modum emanationis. The emanation idea, absent from Witelo's system, is dominant here, bringing Theoderic another step nearer the Alexandrian conception of things. The production of beings is not the direct work of God (against the common opinion). By what he describes as an ebullitio, the Deity produces pure intelligences (not to be confounded with the angels); from these in turn proceed the spirits that animate the heavenly bodies; from these again the visible beings of our earth. To the primordial act, the Divine $\lambda$ óros, from which the pure intelligences receive their being, belongs exclusively, in Theoderic's theory, the title of creative act, in the scholastic sense of the word. ${ }^{2}$ Since every agent in the causal hierarchy has both its being and its causality ultimately from God, it follows that the production of the celestial intelligences and the visible universe is indirectly His work. Furthermore, since finite beings are not mere prolongations or forms of the Divine energy (Neo-Platonism, $c f .85$ ), but substances distinct from God and from one another, Theoderic clearly repudiates all suspicion of pantheism and transposes the Neo-Platonic theme, so to speak, into a key that is frankly scholastic.

It would be unreasonable, he further teaches, to deny the possibility of an eternal world (against Henry of Ghent ; $c f$. St. Thomas). Nay, even although the world had no beginning, it would not be coeternal with God. For, God is supereternal (superaeternitas);

1 This production he calls interior transfusio, qua aliquid fluit in aliud (p. 129); ebullitio; ordo emanationis ut scilicet unus ab alio et ab isto alius et sic deinceps fluat in esse (p. 133).

2 ". . . hoc tamen in omnibus salvo quod solus Deus creat. . . quia quicquid agit causa secunda in essentialiter ordinatis agitur a causa superiori " (p. 132). 
the pure intelligences, including the intellectus agens, are eternal; the heavenly bodies had a beginning, but will have no end; terrestrial substances alone exist in time.

Common principles regulate all processes of intellectual production: every intelligence that proceeds from an anterior one receives and conserves its being from the contemplative act by which the generating intelligence knows the generated. The latter in turn knows the principle from which it proceeds (Proclus). The very being of every pure intelligence is thought (against St. Thomas); it is intellectus in actu per essentiam.

Corporeal substances are composed of matter and form. Matter is indeterminate and, as such, incapable of receiving the existential act (St. Thomas; against Henry of Ghent); the form is unique, the sole determining principle of the individual (St. Thomas); spiritual substances are not composed of matter and form (St. Thomas).

The soul, which is the substantial form of the body (Aristotle), is identical with its faculties (St. Augustine). For, the mysterious principle of its being is intellectus agens (abditum mentis; principium causale essentiae animae); but the latter is a pure intelligence, born of the Divine dóyos; whence it follows that, in the soul, being and action are identical. The soul's activity is differentiated only by the directions in which it is employed conformably to its natural inclinations (habitus, respectus). In the soul, everything is activity. It acts, as the stone falls, when the conditions for action are present.

All cognition is an active phenomenon. Sensation takes place not through the causal influence of the external object, but on the occasion of its presence. The ideology of Theoderic assumes a peculiar complexion from the application of his principles regarding the intellectus agens to the origin and genesis of our ideas. Rejecting and refuting the monopsychism of Averroës, he attributes to each individual man an intellectus agens which knows God, its Producer, and sees in Him the exemplar-ideas of all things: so that we can thus be said to know all truth in the rationes aeternae. What a novel and curious paraphrase we have here of the Augustinian thesis of the illuminatio divina! The intellectus agens, thus enriched with specics intelligibiles of all things, transmits them to, or produces them in, the intellectus possibilis on the occasion of sense-perceptions, determining thereby 
the actual cognition of the abstract essences of things. The passive understanding is, in every man (against Averroës), a product of the active intellect; and if the latter does not incessantly fructify its treasures of wisdom in us, it is because the body is an obstacle to the soul's clearer vision. Another corollary is this : the passive intellect knows not only species intelligibiles and, through these, external things, but it also knows the intellectus agens, which, by knowing the passive intellect, gives the latter its being.

The will is a natural inclination of the soul, consequent on the presentation of a particular good by the vis aestimativa. It is necessarily moved towards the object so presented; it is a principium non effectivum, sed tantum inclinativum. ${ }^{1}$ The universal representation, which is the product of the understanding, has nothing to do with our moral life.

353(h). Bibliography.-BAeumker, Witelo, ein Philosoph und Naturforscher des xiii. Fahrh. (Beitr. z. Gesch. d. Phil. d. Mittel., Münster, rgo8). Publishes the De Intelligentiis for the first time. Very exhaustive study on Witelo's life and works. It includes many important monographs on the medieval history of the proofs of the existence of God, on the philosophy of light, on the medieval Platonic ideology and on the theory of Intelligences. ENGELBERT KREBS, Meister Dietrich (Theodericus Teutonicus de Vriberg), sein Leben, seine Werke, scine Wissenschaft (Beitr. z. Gesch. d. Philos. d. Niittel., Münster, I906) : an excellent study. Krebs publishes in extenso the De Intellectu and the De Habitibus.

\section{$\S$ 3. RAymond LULly.}

354. Life and Work.-We know little of the youth of RAYMond LuLLY (Raymundus Lullus, 1235-1315). He was born in the island of Majorca, and after spending some years at the Court, devoted himself passionately to the study of Arabic and logic, renounced the world and took the habit of St. Francis. Thenceforward he laboured with an astonishing energy in the pursuit of one single object : the extirpation of Averroism and the triumph of Catholic teaching over infidelity. Not content with writing incessantly throughout his whole life a library of works which some biographers estimate at over a thousand volumes, he also preached the apostolate of his own doctrines, making three separate pilgrimages into Saracen regions to refute the Averroït philosophy. Legend has largely distorted the career of Lully. We may note that, like Roger Bacon, he carried on a campaign in favour of the introduction of linguistic studies into the universities." Lully is not merely a philosopher ; he is also a mystic, a scholar, a linguist, and the most brilliant Catalonian writer of the Middle Ages. ${ }^{3}$

${ }^{1}$ De Cognitione Entium Separatorum. KreBs, p. 96.

${ }^{2}$ In r 298-99 he wrote for this purpose to the University of Paris and to the king of France (Chartul., ii., pp. 83, 84). In I3II he set out for Vienne to obtain a decree of the Council in favour of compulsory teaching of the languages.

${ }^{3}$ According to GröBER, in the Grundr. d. Romanischen Philologie, ii., 2 (1893), p. I05, Raymond wrote in Catalonian several works which his disciples must have 26 * 
355. Philosophical Teaching.-Being some years older than Duns Scotus, Lully did not fall under the latter's influence. $\mathrm{He}$ pursued his own course. The original element in his philosophy consists in the elaboration of a theosophical system and the planning of the "Ars Magna". 1

Lully is the sworn enemy of Averroïsm. In his Declaratio per modum Dialogi contra aliquorum philosophorum et corum sequacium opiniones - also entitled Liber contra Errores Boëtii et Sigerii-he takes up in his own order the 219 propositions condemned by the decree of I277. Against the Averroïst theory of the two truths, Lully sets up a theosophic conception of the relations between philosophy and theology: the whole content of faith being reasonable, reason can and ought to demonstrate cverything, even mysteries ( $c f$. 158). There is no dividing line between the rational and the supra-rational, between natural truth and revealed truth. To convert the Mahometans, there is no need to prove that their beliefs are false, but merely to demonstrate that Catholicism is true. Herein exclusively lies the function of philosophy. Lully thus perverts the scholastic system of relations between philosophy and theology ; and, furthermore, he confounds the latter with apologetics. To the error of Averroism he opposes the opposite error. It is indeed true that the fundamental principle of Lullism just mentioned, is somewhat balanced and supplemented by this other principle: that faith is a preliminary condition required for all intellectual knowledge whatsoever. Faith is not an end in itself; it is but a preparatory disposition by virtue of which reason is enabled to deduce a priori all truth, natural and supernatural. It grows in intensity with increase of knowledge ; to use the philosopher's favourite figure, it is like the oil which ever mounts with the water, but never mingles with it. Lully follows out the applications of his principles in various works (Liber de Quatuordecim Articulis; Disputatio Fidelis et Infidelis; Liber Magnus Contemplationis) and undertakes to demonstrate Catholic dogma in all its details.

translated into Latin. The Catalonian texts that have come down from him have been edited by Geronimo Rosse.lo. Numerous philosophical works were translated into Catalonian in the fourteenth century: among others the Secretum Sccretorum; certain tieatises of Cicero, Seneca, St. Augustine and Boēthius; the Dragmaticon of William of Conches; some writings of Hugh of St. Victor, etc. (ibid., pp. 92-1or and $\mathrm{ro2}-\mathrm{Ir}$ ) .

'We pass over his mystical works here. 
For the purpose of carrying out a detailed, deductive exposition of all truth, Lully claimed to have discovered a logical method which he called the Ars Magna, Scientia Generalis-a method which, in the mind of its author, was to complete the ordinary methodological teaching of scholasticism. This latter he regarded as an ascensus setting out from sense-observation and rising to a knowledge of suprasensible realities. It must be completed by a descensus of the understanding, a deductive movement of thought. The Ars Magna was thus a sort of reasoning machine, consisting of general tables of ideas or termini, which, apparently, one would need only to combine according to a prescribed method in order to find the solution of any question whatsoever.

At first, these ideas were all referred either to God (figure A) or to the soul (figure S), and each of these figures was subdivided into a certain number of heads of ideas (e.g., the attributes of God; the faculties of the soul) capable of being combined according to certain "topical" terms, contained in a tabula instrumentalis (figure T). Combinations of letters stood for combinations of ideas, and Lully expressed them by means of synoptic tables and geometrical figures. Later on, the Ars Magna became more complicated ; it embodied schemata for theology, philosophy, law and medicine. The manipulation of its letters and figures was supposed not merely to furnish technical aids to memory, but to yield new positive knowledge. In this the Ars Magna differs essentially from the analytico-synthetic method of scholasticism which guides us in the pursuit of knowledge, but has no pretensions to create knowledge. In philosophy, a pure deductive method is of course a pure chimera. Lully was hunting after the philosopher's stone for science, just as many others in the Middle Ages were hunting after the philosopher's stone for the metals.

356. Conclusion. Lullism.-A part from the two theories just outlined, Lully maintained the traditional teaching of scholasticism. We find its doctrines incorporated promiscuously in novel and artificial settings invented by a fertile and uncontrolled imagination. We may mention, as an example, the Duodecim Principia Philosophiae in which Dame Philosophy complains to Lully of the injury done her by Averroism and presents him with her twelve constitutive principles: forma, materia, generatio, 
corruptio, elementativa, vegetativa, sensitiva, imaginativa, motus, inte lectus, voluntas, memoria.

Lully had many admirers and disciples. $\mathrm{He}$ was called Doctor Illuminatus, Tuba Sfiritus Sancti. His theosophy was less lasting than his Ars Magna. The automatic processes of the latter had a certain fascination for all who ever afterwards sought to build up philoiophy according to the deductive, mathematical method. Giordano Bruno, Agrippa, Lavinheta and Leibnitz all speak of it with enthusiasm.

Towards 1372 the Dominican, Nicholas Eymerici, brought forward complaints against the doctrines of Lully. ${ }^{1}$ A process of inquiry was opened by Pope Gregory XI. ; but whether it terminated in a condemnation is not known. In his Dialogus contra Lullistas and in his Directorium Inquisitionum, Eymerici published a Papal Bull of 1376 , ordering the works of Lully to be withdrawn and prohibiting the latter's teaching. But the Lullists accused Eymerici of imposture, and the long-standing dispute about the authenticity of the Bull is not yet settled.

357. Bibliography.-Complete edition of the works of Lully, r721-1742 (Sal. zinger). The treatises bearing on the Ars Magna (Ars Brevis, De Auditu Kabalistico, Dnodecim Principia Philos phiae Lullianae, Dialectica sen Logica, Rhetorica, Ars Magna) had previously gone through many editions. OBRadoz Y BENNASAR has commenced a critical edition (t. i., r9o6: obres doctrinales, Palma de Mallorca). Bové, El Systema cientifico Lulliano. Ars Magna. Exposiciony critica (Barcelona, 19oS). OTto Kelcher, R. Lullus und seine Stellung zur arabischen Philosophic. Mit Anhang enthaltend die zum ersten Male veroffentliche Declaratio Raymundi fer molum Dialogi edita (Münster, Igog).

A Rerista Lulliana was started in Barcelona in Igor. Julrax Riberka, Origenes de la filosofia de R. Lullo (Madrid, I899). Devifle, Zur Virdammung d. Schriften d. Raimond Lull. (Arch. f. Litt. u. Kirchengesch., etc., I888, p. 352). Jourdain, Un Collige orientaliste an xiiie s. (in the Excurs. histor, etc., p. 219).

\section{\$ 4. Certain Other Directions in Philosophy.}

358. Roger Marston.-The English Franciscan, ROGER Marston (or Merston), who followed Peckham's lectures at Paris and taught at Oxford in the second half of the thirteenth century, bases his ideological teaching on the identification of

${ }^{1}$ The masters of the University of Paris (1310), Philip, King of France (1310) and the chancellor of Paris (I II I), testify publicly that the works of Lully contain nothing contrary to faith and morals. But Denifle asks are those protestations authentic (Chartul., ii., Pp. 142, 144, 149). And we have reason to doubt it when we remember that no one called the orthodoxy of the works into question at that date. 
God with the intellectus agens. ${ }^{1}$ Some of his contentions are characteristic and deserve to be noticed. I know well, he writes, that my contradictors, intoxicated by the nectar of philosophy (philosophico nectare inebriati), interpret the Divine illumination of which St. Augustine speaks, as signifying a mere resemblance between our created intelligences and the Increated Light, just as a copy is the imitation of its model. But this is perverting the meaning (perverterunt) of St. Augustine. If he meant nothing more than this, his reasoning would have no point. ${ }^{2}$ The active intellect is not a lumen creatum, distinct, although derived, from the Lux Increata (St. Thomas, e:c.), it is the Lux Increata itself. "Anima actum intelligendi non elicit formaliter mediante aliqua luce creata in mentem nostram derivata, sed lux divina menti nostrae active imprimens derelinquit in ea passivam impressionem qua elicitur actus intelligendi." 3 Roger Bacon differs in no way from this. And Marston alleges, in support of his thesis, this Augustinian position of which the Averroists also (339) were making great capital : the identity of the Divine light which enlightens every intelligence coming into this world, can alone explain the unanimous accord of the whole human race upon fundamental truths. ${ }^{4}$ This light, with which God inundates us, is therefore not a gratuitous gift, a supernatural strengthening of the native powers of our understanding; it is simply the actual functioning of those powers, and is therefore a part of our nature. $^{5}$

Yet the English philosopher does not want to abandon the scholastic traditions; he qualifies his statements and tries to attribute to the intelligence a certain intervention in the cognition of the eternal truths. Notably he makes it furnish the concepts

\footnotetext{
${ }^{1}$ According to a Quaestio disputata Fr. Rogeri Anglici, in the De Humanae Cognit. Rat., etc.

2 "Adversarius dicit hanc conclusionem sic intelligendam [quod omnia videmus in lumine quod est supra mentem], quia videlicet in lumine derivata a lumine quod est supra mentem. . . . Si non intenderet Augustinus plusquam isti dicunt, falleret et deficeret ejus argumentum" (ibid., pp. 203 sqq.).

${ }^{3}$ Ibid., p. 216, n. r. "Firmiter teneo, unam esse lucem increatam, in qua omnia vera certitudinaliter visa conspicimus. Et hanc lucem credo quod Philosophus vocavit intellectum agentem. . . . Necesse est dicere, quod sit substantia separata per essentiam $a b$ intellectu possibili, prout hoc sentiunt Alfarabius in libro de Intellectu et Intellecto, et Avicenna in multis locis, et alii expositores Philosophi quam plurimi" (p. 207).

${ }^{4}$ Ibid., p. 203. $\quad{ }^{3}$ Ad I4am., p. 216.
} 
that appear as extremes in certain judgments (apprehensio extremorum). Though it is true that the certitude of the judgment rests formaliter on the evidence shed upon the extremes by the Divine light, it is no less true that the soul is the inchoative principle of this certitude (inchoatio). ${ }^{1}$ In this sense Marston speaks even of a twofold intellectus agens: the one, a part of our soul (pars animae), corresponds to a simple natural predisposition of the soul to know the truth: the other, separate from us, completes this inchoatio of nature. ${ }^{2}$ Here indeed is a strange termi ıology. Though Marston appeals to the identity of God with the active intellect only in order to explain our cognition of truth in the rationes aeternae, ${ }^{3}$ his illumination theory remains nevertheless very different from the scholastic theory of exemplarism. It goes farther than the special illumination theory of Henry of Ghent, for the latter maintains the causality of the active intellect as a part of the soul-fars animae,-while Marston suppresses the activity of the created cause in the production of the cognitional determinant. ${ }^{4}$

We are not acquainted with Marston's other theories, as his works are not yet published.

359. Vestiges of Averroïsm. - It is evident from the idleology of Bacon and Marston that the discussions on the active intellect had given rise to an equivocal terminology in the schools, since for some this meant a faculty of the soul, for others God Himself, for the Averroïsts an independent substance. Even in scholastic circles, where the active intellect was regarded as a faculty of the soul, pars animae, concessions were made to the formulas of Averroïsm, though not to its doctrine. As an illustration of this we may refer to two texts from St. Thomas, which have often been interpreted in a wrong and unfavourable sense.

${ }^{1}$ Pp. $2 \mathrm{Ir}$ and 215, ad r zam. et rzam.

2 "Intellectus enim agens, secundum quod dicitur ab actu illuminandi ipsum intellectum possibilem aliquo modo incomplete, dicitur esse pars animae, sicut perspicuitas naturalis in oculo. . . Sed secundum quod intellectus agens dicitur ab actu illuminandi complete et principaliter, est substantia separata, Deus ipse" (ibil., p. 208. Cf. p. 216 ad r 5 am.).

"For cognitions "quae per tempora variantur," there is a lumen naturale, derived from the lux aeterna (p. 205).

* The Quaracchi editors observe that on the question of the rationes acternae, Matthew of Aquasparta and Fr. Eustachius held a different view. Similarly, EHRLE thinks that the theories of Marston should be taken with caution (Das Studium der Handschriften, etc., p. $\left.4^{8}\right)$. 
The first is from an article in the Summa Theologica, ${ }^{1}$ where the doctiinal question "utrum intellectus agens sit aliquid animae" is plainly proposed and no less plainly answered: "respondeo dicendum quod intellectus agens de quo Philosophus loquitur, est aliquid animae". Which does not prevent us, continues St. Thomas in answer to a difficulty drawn from texts of Aristotle, from calling God, as First Cause, the intellectus agens of our souls. But he takes care to add that we are also endowed with created active intellects, the work of the Increated active intellect. For otherwise man alone would be an exception to the law that contingent beings carry within them the principle of their activities. ${ }^{2}$ The thought of the Angelic Doctor is perfectly clear: only prejudice could lead to a misconstruction of it.

The second text, occurring in the Commentary on Book II. of the Sentences, ${ }^{3}$ refers to an attempted adaptation of the same formula to a point in theology. Having remarked that most philosophers after Aristotle agree in recognizing a substantial distinction between the active and the possible intellects, and make supreme happiness consist in the union of man with the active intellect, St. Thomas adds: "Quidam catholici doctores, corrigentes hanc opinionem et partim sequentes, satis probabiliter posuerunt ipsum Deum esse intellectum agentem; quia per applicationem ad ipsum anima nostra beata est". The latter words and the whole context show that there is question here of the supernatural order. These theologians call God the intellectus agens, inasmuch as the possession of $\mathrm{Him}$ by the understanding constitutes beatitude. In the natural order God is not the intellectus agens of our souls. St. Thomas takes care to demonstrate this, in the same article, lest he should be misunderstood. And he concludes with these words: "Et ideo, remotis omnibus praedictis erroribus, dico ... intellectum possibilem ... in diversis diversum esse, et multiplicari secundum divisionem materiae in diversis individuis ... et superaddo etiam intellectum agentem esse in diversis diversum ". ${ }^{4}$

${ }^{1}$ Pars I a, q. 79, a. 4.

2 "Nulla autem actio convenit alicui rei, nisi per aliquod principium ei inhaerens. ... Ergo oportet virtutem quae est principium hujus actionis (scil. facere actu intelligibilia) esse aliquid in anima."

${ }^{3}$ Dist. 17 , q. 2 , art. 1 , in c.

${ }^{4}$ Has Père Delorme (op. cit., p. 12) not read this passage? How can he invoke St. Thomas in support of Bacon's ideology? $C f \cdot 352$, n. 3 . 
360. Ontologism.-The ideology of Bacon and Marston is tainted with Ontologism. This erroneous theory, according to which the intellect would see directly in God Himself the objects of its ideas, was not without its defenders in the medieval schools. We find in the writings of the leading scholastics repeated refutations of ontolngism $;^{1}$ and among the 2 I 9 propositions condemned in 1277 , we also find mention of ontologistic doctrines. The names of the medieval ontologists are, however, unknown to us.

${ }^{1}$ See refutation of ontologism in St. Bonaventure, De Hunanae Cognit. Ratione, etc., pp. 22 sqq.; in Peter Olivi, ibid., pp. 245-47. Cf. Dissertatio, c. i., p. 7 ; in St. Thomas, In I. Lib. Sent., d. I7, G. I, a. 4. 


\section{THIRD PERIOD.}

\section{MEDIEVAL PHILOSOPHY DURING THE FOURTEENTH AND FIRST HALF OF THE FIFTEENTH CENTURIES.}

\section{CHAPTER I.}

\section{General Outline.}

361. Byzantine Philosophy.-Throughout the fourteenth century and down to the fall of Constantinople in 1453, Byzantine philosophy lingered on feebly without shaking off its long lethargy (210). Devoid of all originality, it went on commentating the two great philosophers who furnished it with all its inspiration. Gregory Palamas, ${ }^{1}$ archbishop of Thessalonica (about

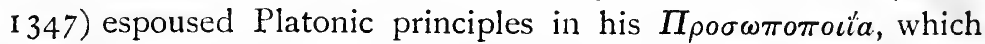
might be described as an indictment of the body by the soul, followed by the body's defence against the charges. NiCEPHORUS GREGORAS, likewise, boldly advocated Platonic principles. On the other hand, the Emperor JoHn VI. Cantacuzenus, pleaded vigorously for Aristotle, paraphrasing the earlier books of the Nichomachean Ethics. Theodore Metochita and Sophonias wrote commentaries on other treatises of Aristotle. Another remarkable personage of the time, Nicholas CABASILAS, wrote a refutation of the Hypotyposes Pyrrhonienses of Sextus Empiricus, an author who had been driven out of literary circulation since the fifth century through the influence of Christian ideas. All those theologians and philosophers contributed at the same time to the Byzantine Renaissance of the ancient classics.

${ }^{1}$ D'Argentre, op. cit., i., p. 322, relates of him that in the year 1330 " lumen quoddam increatum et coaeternum Deo commentus est, quod quidem oculis nostris aspectabile esset. Praeterea, ipsas virtutes Dei ab essentia revera distinctas esse dicebat." D'Argentré connects this latter error with those of Gilbert de la Porrée and John of Brescain. 
Notwithstanding the steadily increasing intercourse of Byzantium with Western civilization, its philosophy never received from the philosophy of the West anything approaching what it contributed to the latter. We may, however, mention a few translations from Latin to Greek, as a result of the movement inaugurated by Maximus Planudes (226). GeOrgios Scholarios (Gennadius, died about 1464) translated the Summulae of Petrus Hispanus, the Liber de Sex Principiis of Gilbert de la Porrée, and some of St. Thomas's treatises; and Demetrius KyDONES translated several of the works of St. Thomas.

362. Jewish Philosophy.-During the first half of the fourteenth century, the Jews of southern France continued to translate Averroes from Arabic into Hebrew. CAlonvmus of ARLes, SAMUEL beN JUdA BEN Meschullam of Marseilles and Todros Tonkosi were the chief translators of this later school. There were also Hebrew versions of some of the works of Albert the Great, St. Thomas and Giles of Rome. ${ }^{1}$ Levi BEN GERSON (born about 1288 ) and MOSES (OF NARBONNE were the principal philosophers of this Provençal school. They wrote commentaries on Averroess, and original treatises, in which they fostered the rationalistic tendencies introduced by Maimonides. Thus, for instance, Levi ben Gerson unhesitatingly admits the eternity of the world. ${ }^{2}$

363. Western Philosophy. - The West continues the main seat of intellectual progress. As before, we shall divide its philosophy into three parts, to be considered successively:-

I. Scholastic philosophers (Chapter II.);

II. Non-scholastic philosophers (Chapter III.);

III. Some secondary lines of philosophical thought(Chapter IV.).

364. Bibliography.-See works mentioned, 213. The work of Gregory Palamas was re-edited in $188_{5}$ by HaLix. The Commentaries of Sophonias are published in the Commentaria in Aristotelem Graeca, Bd. xxiii. (Berlin, 1883-84). Cf.

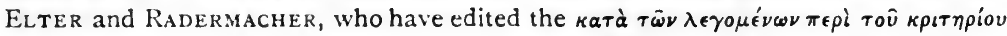

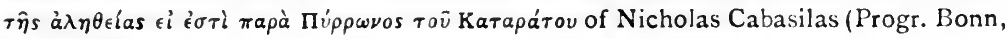
I899). ReNaN, op. cit., part ii., ch. i.

${ }^{1}$ ReNan, op.cit., pp. Igo sqq.

${ }^{2}$ Renan writes of him: "His glosses were regarded by some of his disciples as inseparable from the text of Averroës, just as the latter was from that of Aristotle" (op. cit., p. 193). 


\section{CHAPTER II.}

\section{SCHOLASTIC PHILOSOPHIES.}

\section{ART. I.-GENERAL OUTLINE.}

365. Decadence of Scholastic Philosophy.-The decay of scholasticism followed closely on its period of maturity. The causes that undermined its influence on the history of subsequent philosophical thought, corroded the great monument by a slow but steady and persistent process of disintegration. The succeeding generations were unequal to the task of preserving the work achieved by the master minds of the thirteenth century. Broadly speaking, we may attribute the decay of scholastic philosophy to three main groups of hostile influences: dearth of philosophers, relaxation of studies, and the steady inroads of antischolastic systems.

I. Under the head of dearth of scholastic philosophers we have to note a want of originality as a first symptom of exhaustion. From the beginning of the fourteenth century there was an enormous increase in the numbers of those who studied philosophy. ${ }^{1}$ With the spread of the universities arose greater facilities for philosophical study(II.); whole orders of religious threw themselves into the thick of the controversies of the schools. But these legions of philosophers merely formed parties and followed catch-cries and shibboleths under the banner of some illustrious doctor or other, to whose great name they clung as a talisman of their school or section. Instead of trying to think for themselves, they aimed merely at producing commentaries on the thought of their predecessors. It was the epoch of compendiums; and it was also the epoch of apocryphal writings, for numbers of those compendiums, instead of being attributed to their compilers, were attributed by the latter to the illustrious doctors compiled.

${ }^{1}$ In 1406 , the Arts Faculty at Paris numbered $\mathrm{I}, 000$ magistri and 10,000 members (supposita) altogether (Chartul., t. iii., p. 604). 
As the schools multiplied, the great fersonalities grewe rare. The thirteenth century was a century of personalities; the fourteenth and fifteenth are centuries of impersonal thought. With the exception of Terminism, we may say that the scholastics subsequent to the thirteenth century discovered no fresh or original line of speculation. There is, however, one special direction in which we do note a development. The thirteenth century had been timid and reserved on questions of social and political economy; but with the growth of commercial activity in the fourteenth, these came well to the front: numerous treatises were written on usury, annuities, coinage, exchange, etc.; and it was the terminists who generally led the way in all those discussions. $^{1}$

In the second place, the doctrinal system of scholasticism, in its structure and arrangement of parts, was gradually modified. The new notions on systematization, broached by William of Ockam, were not in keeping with the scholastic synthesis, though they did not run directly counter to any of its great organic principles. They show a weakness of structure and a want of coherence and harmony in the whole. Then, too, the impassioned disputes between Terminism, Thomism and Scotism, had the effect of disturbing the general economy of scholasticism. And the same may be said of the absurd dialectical discussions that were allowed to monopolize attention, in certain of the schools, to the exclusion of all serious philosophical study. With the lapse of time we note a gradual vitiation of that doctrinal purity which had been the strength of thirteenth-century scholasticism.

In the third place, there was something even worse than unfortunate inovations, namely, culpable ignorance. William of Ockam, with his earlier disciples and opponents, knew the philosophical systems of the thirteenth century. But the generations that followed grew more and more ignorant even of the essentials of that scholasticism which they professed to follow or to refute. Among the numerous advocates of dangerous innovations in the fourteenth and fifteenth centuries, we meet with many mere youths who had evidently spared themselves the pains of prosecuting any deep or systematic course of philosophical study at any university centre. Nor do the university authorities seem to have taken any steps to arrest the growth of the evil (II.): with the

${ }^{1}$ Brants, op. cit., pp. I4 sqq. 
result that in the next period scholasticism failed altogether from sheer ignorance of itself.

Fourthly, the scholastics of this period are accountable for admitting a decay in their language and methods. Their writings fall away more and more from the clear and simple language of the thirteenth century. Barbarisms, which had hitherto appeared but rarely, and for the most part only in the ArabicLatin translations, spread very rapidly in the fourteenth century. Even the orthography of some of the masters displays an unpardonable ignorance of Latin. ${ }^{1}$

Terminism and Scotism are mainly responsible for this decay. And as defect of form begets confusion of thought, we observe a parallel decline of efficiency in didactic method. Under pretext of clearness, we are confronted with multitudes of distinctions and sub-distinctions and syllogisms and counter-syllogisms: a veritable parody of the procedure in honour among the great scholastics : a spectacle which Stöckl has described, in accurate if not very elegant language, as scholasticism suffocated by its own luxuriance.

Finally, those abuses of the scholastic philosophers were fostered by the gradual spread of an altogether excessive attention to dialectic. In the thirteenth-century scholasticism, logic occupied its rightful place. It was, both in theory and in practice, a discipline of the mind, a preparation for the study of physics, metaphysics and ethics (282). Once disturb this subordination, or suppress this dependence of formal logic on the other branches of philosophy, and the newly emancipated assistant will soon become a despot. And this is what happened at the close of the thirteenth century. The first symptoms of the intellectual malady are perceptible early in the fourteenth; and the disease slowly came to a head, until it utterly poisoned the writings of the subsequent period. We shall see later how the formalism of the Scotists and the terminism of the Ockamists fostered the evil. It was also propagated by the Summulae of Petrus Hispanus: for this treatise called forth quite a forest of commentaries

${ }^{1}$ Chartul., t. iii., Introd., p. xi. During the last quarter of the fourteenth century there was a reaction at Paris. Some distinguished scholars-Nicholas Poillevillain (de Clamengis), John of Montreuil (de Monstero'io), Peter D'Ailly, John Gerson and John Courtecuisse (Breviscoxae)-made a vigorous effort to purify scientific Latin. Unfortunately their influence was short-lived (ibid.). 
which were in character both superficial and long-winded, worthy of sophists rather than philosophers.

II. A relaxation of studies set in both in the religious orders and at the universities. The religious orders were still, as in the past, the principal nurseries of science. But love of study declined as discipline grew lax. ${ }^{1}$ Among the legions of those monastic masters, fond of easy work and ready results, we might count on our fingers all who, by personal and persevering efforts, raised themselves out of the rut of an all-pervading mediocrity.

The University of Paris fell away rapidly from its early splendour: and scholasticism, which had flourished in it, was dragged down with its decline. Degraded by intrigues of all sorts, the Faculty of Theology ignored all the requirements of the academic statutes; through favour, or even through bribery, the "actus scholastici" became little better than formalitie;, the course of study was shortened and the standard of examination lowered. The majority of masters in theology began to be attracted not so much by a thirst for knowledge as for snug ecclesiastical benefices. The Arts Faculty drifted down the same easy incline. The study of the arts being a necessary introduction to theology, it was obviously the interest of ambitious place-hunters and money-grabbers to curtail the arts course as much as possible. Hence university chairs were filled by beardless youths whose ignorance was surpassed only by the amazing audacity of their teaching. Categorias, Perihermeneias, in cujus scriptura summus Aristoteles calamum in corde tinxisse confingitur, infantili balbutie resonant impuberes et imberbes. ${ }^{2}$

Other causes also contributed to the decline of the University. Not to mention the wars with the Flemish and English and the terrible plague of the middle of the fourteenth century, Paris had in time to cope with the competition of the newer universities. ${ }^{3}$ Whereas in the thirteenth century the Universities of Paris, Oxford and Cambridge alone could confer the mastership in theology, in the fourteenth other "studia generalia" obtained, or even usurped, the power of conferring theological degrees $;^{4}$

${ }^{1}$ Chartul., ii., p. xi.

${ }^{2}$ Ricardus de Bury, Philobiblon, anno r 344 , c. 9, p. 87 (edit. r 388 ), quoted in the Chartul., ii., p. viii.

${ }^{3}$ Chartul., ii., p. xii.

${ }^{4}$ We may mention Toulouse, Pisa, Prague, Florence. See table of universities anterior to the fifteenth century in Denifle's Die Universitäten des Mittelalters 
and the fewer students these new centres had to commence with. the easier they made the conditions for promotion to degrees, in order to attract greater numbers of students. The multiplication of such independent universities thinned the enormous current of which Paris had long held the monopoly. ${ }^{1}$ But all those influences unfortunately tended to lower more and more the standard of theological-and consequently of philosophical-studies.

III. Finally, the inroads of anti-scholastic systems hastened the downfall of scholasticism. The controversies of the thirteenth century had strengthened scholasticism: it emerged from all of them victorious. Those of the fourteenth and fifteenth centuries weakened it: its adversaries gained confidence and prepared the way for the coalition which was to attack and overthrow the traditional philosophy in the following period.

366. Division of Scholastic Philosophy.-The Thomist (Art. IV.) and Scotist (Art. III.) schools monopolized attention at the commencement of the fourteenth century; but a third school was soon to rival both: the Terminist school. We shall commence our study of the scholastic systems of the present period by Terminism (Art. II.), which began to take shape soon after the death of Duns Scotus. Certain mystic systems, many of which sprang up side by side with the speculative, will finally (Art. V.) call for mention.

367. Bibliography.-Willmann, Gesch. d. Idealismus, ii., $\$ \S 80-85$. Werner, Die Scholastik d. späteren Mittelalters, comprises 4 vols.: I. Fohn Duns Scotus (v. 336); II. Die nachscotistische Scholastik; III. D. Augustinisnus d. späteren Mittelalters; IV. Der Endausgang d. mittelalt. Scholastik. Contents of three latter volumes will be given later on.

bis 1400. In the fifteenth century other universities sprang up in France itself, for example, at Dol (I42 I), Poitiers (I43r), Caen (1432), Bordeaux (1440) (Chartul., iv., p. viii). Louvain University was founded in $\mathrm{r}_{425}$.

1 Paris University sank rapidly during the period of the Great Schism, though at no time of its history did it enjoy such extensive prestige, or boast so much of its greatness. The Sorbonne and Navarre colleges alone made efforts to emulate the glorious past. The trouble was largely due to the departure of many of the best masters for other universities, which profited by their renown. Thus Henry of Hesse went to Vienna and Marsilius of Inghen to Heidelberg (Chartul., iii., pp. xiv and $x v)$. During the first half of the fifteenth century the University retained its political influence in France. Finally Charles VI. took away its independence, and, in $\mathrm{r}_{44} 6$, made it subject to Parliament. The rules of the Faculties were reformed, in I425, by Cardinal Estontevilla. 


\section{ART. II.-THE TERMINIST SCHOOL.}

\section{\$. Generit, Outhine.}

368. Leading Features of the Terminist School.-(I) Exce'ssiz'e Simplicity. - The terminism of the fourteenth century was a reaction against the formalism of Duns Scotus. The subtle doctor had peopled his philosophy with chimerical entities, and his immediate disciples had multiplied these still more. It was inevitable that this tendency to "realize" abstractions should meet with opposition. The first opposition came from the Thomists; but another group of scholastics carried the reaction too far: these were the terminists. Taking as its motto, fluralitas non est ponenda sine necessitate, terminism made a veritable hecatomb of metaphysical notions; and in doing so it often merely disfigured what it thought to simplify. At the same time, nevertheless, the terminists are indebted to Scotism for many of their scholastic theories, and-what is more important-for a characteristic turn of thought, namely, scepticism.

(2) Scepticism. - There is no question here of the deceptive theory which proclaims all certitude illusory: terminism, like all other scholastic systems, was essentially dogmatic in its teaching about certitude (308). "Scepticism" here denotes an anxiety to restrict the sphere of those truths that can be demonstrated by reason, a tendency to depress fallible reason and exalt infallible faith. The ambit of indemonstrable truths kept steadily widening. Those waverings about the power of reason are not in themselves anti-scholastic (328), but they fostered an unwholesome attitude of thought, a distrust that was dangerous and unwarrantable: they excited among students in the following period the suspicion that scholasticism was wholly and entirely unsound and that its teachings ought to be rejected in globo.

(3) Encroachment of Logic.-The study of Ockam's system will show how the terminists mutilated metaphysics. And after destroying this, they used the debris for the decoration of logic. What they declared illusory in the world of realities they subjected to excessive analysis in the world of mental representations. And so terminism gradually developed the tendency to exaggerate the role of dialectic. William of Ockam himself made much of such logico-grammatical notions as suffusitio, sirnificatio, etc. but he observed some moderation. His disciples, however, seizing 
on the Summulae of Petrus Hispanus, abandoned themselves to an orgy of quibbling and sophism which the Paris Faculty of Arts was powerless to remedy. ${ }^{1} \quad$ And with all the logician's fondness for terminology, the Ockamists multiplied endlessly new words, barbarisms and classifications.

369. Division.-William of Ockam is the real founder of terminism, although he had precursors in the new theory $(\$ 2)$. After his time terminism was all the fashion, but many of its exponents exaggerated the theories and teachings of its founder $(\S 3)$.

$\S$ 2. William OF OCKam AND The Precursors OF TERMINISM.

37o. Durandus of S. Pourçain and Peter Aureolus-two deserters, the one from Thomism, the other from Scotism-may be regarded as the principal precursors of terminism. DURANDUs of S. PourÇAIN, a Dominican of the Paris convent, licentiate of theology in I 312 , bishop successively of the sees of Limoges (1317), of Puy (1318) and of Meaux (1326), was known by the title of Doctor Resolutissimus. He wrote a commentary on the Sentences of Peter Lombard. With Thomas Walleis, Armand of Beauvoir (de Bellovisu) and the masters of the Paris Faculty of Theology, he combated the rash teaching of John XXII. on the beatific vision. $^{2} \quad$ Petrus Aureolus, Doctor Facundus, author of a commentary on the Sentences and of some Quodlibeta, became master of theology in 1318, minister of the Franciscans of Aquitaine in 1319 , and bishop of Aix in 1321 . He died early in $1322 .{ }^{3}$

Those two men, setting out from different principles, arrived at practically identical conclusions on a number of philosophical problems. They denied the reality of Universals, the existence of species intelligibiles, the accepted function of the intellectus agens, the real distinction between essence and existence, and between the soul and its faculties. But they lacked the power of unifying and synthesizing their teaching. The real architect of the system, or, as his disciples described him, the venerable promoter of the new doctrine-venerabilis inceptor-was William of Ockam.

${ }^{1}$ See Ch. III., § 3. Cf. Prantl, op. cit., iv., pp. I sqq.

2 The documents on this questions are published in the Chartul., t. ii.

I Ibid., pp. 225 and $7 \mathrm{r} 8$. 
37. William of Ockam: His Life and Works.-William of Oскам, born at Ockam in the County of Surrey in England, earned a great reputation towards 1320 in the University of Paris, where he had followed the lectures of Duns Scotus, his brother in religion. It is likely that William also taught in England. The early portion of his career was devoted mainly to science. From this period date those great works in which he formulated his new theories: the Super IV.L. Sentent., the Quodlibeta, the commentaries on Aristotle (Expositio Aurea super Totam Artcm Vetercm) and the Tractatus Logices. He resigned his chair in 1323-to devote himelf to politics and to religious and ecclesiastical polemics. He defended the disciplinary reforms advocated by the "spirituals" (259); he conducted a campaign against Boniface VIII. and John XXII. and refused to recognize the temporal power of the Popes.

The fourteenth century was marked by events of grave import for Christianity: in the bosom of the Church itself the struggle: of the Great Schism; in the world the insurrection of the Empire against the Paracy. It was realized, little by little, that the great intellectual and social organization of the West was being severely shaken. While in the scientific order philosophy sourht to rid itself of the protection of theology, in the political order the modern nationalities were slowly emerging and shaking off the supremacy of the popes. In to the details of these latter long-drawn-out hostilities it is not our business here to enter. In the order of ideas, William of Ockam led the campaign, publinhing pamphlets and manifestoes in quick succession: the Dialogus, the Ofus nonaginta dirum, the Compendium Errorum Foannis Papae XXII., the Quaestiones octo de Auctoritate Summi Puntificis. Cited to appear before the ecclesiatical court, he managed to escape from Avignon where he had been detained prisoner (1328). With his friends, Michael Cesena and Bona Gratia of Bergamo, he reached the court of Louis of Bavaria, where two years previously John of Jandun and Marsilius of Padua had taken refuge. All historians registcr Willian's salute to the haughty monarch: Tu me defendas gladio, cgo to defendam calamo. And when the latter wanted to have his son's adulterous marriage declared valid, in opposition to the laws of the Church, William defended the absolute omnipotence of the State in this as a political matter. He died probably about $13+7$.

372. William's Philosophical Teaching. Relations of Philosophy to Theology. - Following Scotus he separates altogether the material object of philosophy from that of theology. Like him, he forbids reason to explore the truths of faith; while he enlarges, to the detriment of philosophy, this forbidden region wherein he believes the intellect to be incapable of reaching certitude. Thus the disciple emphasizes the scepticism of the master. Between the two systems there is in this matter a difference of degree, but not of kind. ${ }^{1}$

${ }^{1}$ Stöckl (Gesch. d. Philos. d. Mittelalters, ii., pp. 986 sqq.) points out how in matters purely theological Ockam propounds anti-rational theories, c.g., that God could have become incarnate in an ox or in a stone. In this way Ockam and his successors gave the opponents of Catholic theology a pretext for saying that not only must reason refrain from attempting to demonstrate the truths of theology, but that the latter are represented as actually contrary to reason. 
373. Kinds of Composition in Contingent Being.-William of Ockam admits composition of matter and form (286); but he denies the distinction between the universal and the individual. Not only is " the individual ... the true substance, while the universal gets its characteristic, independent form from the action of the intellect" (287), but furthermore, the universal has no reality at all outside us, for it does not exist in any shape or form in Nature. This extreme thesis, directed as it is against the common essences of Duns Scotus (nullo modo est res extra animam quodcumque universale ${ }^{1}$ ), also strikes St. Thomas's theory of similar essences (nullum universale est extra animam existens realiter in substantiis individuis, nec est de substantia vel esse earum $^{2}$ ). The problem of individuation has therefore of course no sense in metaphysics. So too he denies all distinction between essence and existence (essentia et existentia idem omnino significant). The universal is in fact entirely banished from metaphysics and transported into psychology and logic. ${ }^{3}$ We shall understand his system better when we see his treatment of the psychological aspect of the Universals question.

374. Theodicy. - The very first page of Ockam's theodicy contains a bold application of his scepticism: the Existence, Unity and Infinity of God are indemonstrable by reason and must derive all their certitude from revelation. The attributes of God are in no way distinct from His essence: they are merely different names arbitrarily applied by us to the same identical reality: the virtual distinction of the Thomists has no more real foundation for it than the formal distinction of the Scotists. The same terminist influences colour his teaching on the Divine Ideas.

375. Psychology. - The originality of Ockamism is best seen in the domain of psychology. In accordance with William's simplifying tendencies, all the psychical faculties are regarded as identical with one another and with the substance of the soul.

Three new theories characterize his psychology: the theory of the sign; terminism; and his criticism of the species intentionales. Every cognitive representation is essentially a sign (signum), which, as such, holds the place (supponere) of the object signified.

${ }^{1}$ Quodl., v., q. I2. $\quad 2$ Expos. Aurea, Praedicab., Proem.

3 “ Et ideo non est universale nisi per significationem, quia est signum plurium" (Log., L. i., c. I4). 
This sign, also called a term (terminus), is natural, in opposition to artificial signs (secundum institutionem voluntariam) such as language and writing. There are three distinct cognitions or natural signs of things: (intuitive) sense cognition, intuitive intellectual cognition and abstract intellectual cognition. Here we find the dual division-into sense and intellect-fundamental in all scholastic ideology. But between sensation, which has for object the sensible qualities of things, and the abstract concept which signifies some note or attribute referable to an indefinite multitude of the things of sense, or else seizes on some determination irrespective of its existence or non-existence, ${ }^{2}$ Ockam inserts an intermediate cognition, the intuitive concept, which grasps the concrete existence or non-existence of singular things (334) and serves as basis for the knowledge of contingent truths. ${ }^{3}$ And he adds: "Notitia abstractiva praesupponit intuitivam ".

We have next to consider terminism as an answer to the question: What relation is there between the signs and the things signified, between those various cognitions and the objective reality? Here we must distinguish. Every intuitive cognition, whether by sense or by intellect, attains to the real thing, as it exists outside us. ${ }^{5} \quad$ Let us note this admission: it will protect William of Ockam against the undue suspicion of subjectivism. But have our abstract concepts the same real objectivity? No. They have no value, IVilliam teaches, outside us ; for the abstract and

1 " Signum accipitur pro illo quod aliquid facit in cognitionem venire et natum est pro ipsum supponere" ( $\log _{\text {. }}$, L. i., c. 1$)$. "Intentio est quoddam in anima quod est signum naturaliter significans aliquid, pro quo potest supponere" (ibid., c. 12).

2 “" Notitia abstractiva potest accipi dupliciter: uno modo quod sit respectu alicujus abstracti a multis singularibus . . . aliter ... secundum quod abstrahit ab existentia et non-existentia" (Sent., Prol., q. r).

3 “ Notitia intuitiva est talis notitia virtute cujus potest sciri utrum res sit vel non sit. ... Similiter notitia intuitiva est talis qua, cum aliqua cognoscuntur quorum unum inhaeret alteri, vel unum distat ab altero loco . . . statim virtute illius notitiae incomplexae illarum rerum sciret, si res inhaereat vel non inhaereat, distet vel non distet, et sic de aliis veritatibus contingentibus" (Quodl., vi., q. 6). "Propositio contingens potest cognosci evidenter ab intellectu, puta hec albedo est, et non per cognitionem abstractivam, quia illa abstrahit ab existentia per intuitivam. Ergo realiter differunt" (Quodl., v., q. 5).

"Quodl., i., q. 14.

5 "Singulare... est primo cognitum ... quia res extra animam quae non est signum tali cognitione primo intelligitur" (Quodl., i., q. 3). "Notitia intuitiva est talis, quod.... si Socrates in rei veritate sit albus ... potest evidenter cognosci quod Socrates est albus" (Sent., Prol., q. r). 
universal, to which they lead us, has no existence in the world of reality (373). The universal concept (intentio secunda) has for its direct term mere mental, internal representations, fabricated entirely by the understanding; and we have no right to transport into the real world of Nature the laws which regulate the ideal world of the phenomena of Mind. But if so, what use are Universals, or why does the mind have recourse to such artificial forms? Here is Ockam's answer: The universal holds the place (supponit), in the mind, of the multitude of things to which the mind attributes it. ${ }^{1} \quad$ By the universal, we conceive realities as if they were common to many things; and the products of those universal conceptions serve as predicates in our judgments.

This body of doctrine constitutes what we have already described as conceptualism (137); and it certainly does violence to the thought of Ockam to represent him as a nominalist. He himself protested in advance against the absurd theory that would deny to the understanding the power of abstracting and thus identify sensation with intellectual thought. If the abstract concept has no real value, it cannot be denied at least an ideal value ${ }^{2}$ in our understanding there are objects that are common, general, universal. The universal, therefore, is not a mere word (vox, nomen) devoid of thought-content, an empty sound (flatus vocis $^{3}$ ), a verbal label, but a conceived object (intentio, terminus), a mental substitute (suppositio ${ }^{4}$ ) for a greater or less number of individual realities, according to the degree of its universality. We therefore reject the common classification which places Ockam's

1 " Et ideo genus non est commune pluribus per identitatem in eis, sed per quamdam communitatem signi, quomodo idem signum est commune ad plura signata" (Expos. Aurea, Praedicab. de Genere).

${ }^{2}$ On this distinction, see 137 .

3 "Quarta posset esse opinio quod nihil est universale ex natura sua, sed tantum ex institutione, illo modo quo vox est universalis . . . sed haec opinio non videtur vera" (In L. Sent. I., dist. ii., q. 8).

4 "Quodlibet universale est intentis animae, quae secundum unam probabilem opinionem ab actu intelligendi non distinguitur; unde dicunt quod intentio qua intelligo homines est signum naturale significans hominem, ita naturale, sicut gemitus est signum infirmitatis vel doloris; et est tale signum quod potest stare pro hominibus in propositionibus mentalibus" (Summa Tot. Log., L. i., c. 15). Similarly: "intentio animae dicitur universalis quia est signum praedicabile de multis" (ibid., L. i., c. 14). And again: "Illud quod praedicatur de pluribus differentibus specie, non est aliqua res quae sit de esse illorum de quibus praedicatur, sed est una intentio in anima naturaliter significans omnes illas res de quibus praedicatur" (Expos. Aurea, Praedicab. de Genere, quoted by Prantr, iii., n., p. 789). 
philoiophy among nominalist systems; and, adopting his own terminology, we will apply to the conceptualism inaugurated by him the title of terminism or intentionalism.

As might be anticipated, the objection was raised against Ockam's system, that it made all science an illusion, since science is concerned with the universal, that is to say, with a figment, a non-entity! Yes, he replied, science is about the universal, in this sense, however, that the object of science is not a chimerical universal reality, but rather the universal term (or intentio) in the mind. But this mental term is referred to a greater or less number of individual real beings, independent of one another; it has therefore extrinsic relations with the outer world, and so science keeps its hold on reality. ${ }^{1}$

Thirdly, we have to note in connection with the terminist theory of the genesis of our inowuledge William's bitter criticism of the scholastic teaching about "species intentionales". Cognition is not the intussusception of an image (species) resembling the thing known, but an immanent act (actus intelligendi) which becomes the sign of the thing. Hence the species intentionalis, whether sensible or intellectual, is a useless fiction which should be banished from psychology. Frustra fit per plura, quod potest fieri per fauciora. And since the function of abstracting such species is illusory, so also is the intellectus agens to which that function is attributed.

But William of Ockam understood the species in an incorrect sense, to which we have already called attention $(\mathbf{2 9 9}, \mathbf{3 0 0})$; and of course he demolished the crude conception of the cognitive process involved in that crroneous view. But his criticisms leave intact the true notion of the species intentionalis; in fact his own conception of the genesis of our ideas differs in no way from that of St. Thomas, since he admits with the Angelic Doctor an action of the outer reality on the intelligence: for both masters alike, the terms passive and active intellect denote the passive and active states of the mind in reference to the known object. ${ }^{2}$

Following Scotus, William of Ockam professes the most ab-

1 STöckl, of. cit., p. 964 .

2 "Intellectus a yens et possibilis sunt omnino idem re ac ratione. Tamen ista nomina vel conceptus connotant diversa; quia intellectus agens significat animam. connotando intellectionem procedentem ab anima active; possibilis autem si znificat exmdem animam, connotando intellectionem receptam in anima: sed idem omnino est efficiens et recipiens" ( $I n L$. Scnt. II. q. 25). 
solute voluntarism. The will intervenes even in the discursive operations of the understanding - with which, in any case, it is identical, according to the general theory of the psychical faculties. William also teaches the most entire self-determination of volition; confounding merely spontaneous, with deliberately free, action. He remarks, moreover, that since will is identical with the essence of the soul, and the essence of a thing is incompatible with increase or diminution, there can be no such thing as variation in the degree of liberty. Another corollary from the same principle is that the question of the primacy of volition over cognition is idle and meaningless. Applied to the Deity, this absolute autonomy of volition makes the Free Will of God the sovereign arbiter of moral good and evil. But if nothing is of itself morally good or evil, the study of nature can teach us nothing about morality: intelligence is powerless to instruct us on the requirements of the Divine Law. Thus, by another new breach, Ockam exposes psychology to the assaults of "scepticism".

On the main questions regarding the nature of the soul Scotus is closely followed. Besides the intellectual soul, man possesses a forma corporeitatis (334) and a sentient soul. And of the intellectual soul, human reason left to its own unaided powers, can establish neither the spirituality nor the immortality.

376. Logic.-Ockam gave logic a renewal of popularity, adopting all the prolix divisions of the Summulae of Petrus Hispanus. He ignored the metaphysics of all questions concerning the Universals and transferred the latter to formal logic, which he described as omnium artium aptissimum instrumentum. ${ }^{1}$ Logic deals with the propositions of science; it regulates the mental judgments by which we compare abstract concepts that have no reality corresponding to them.

377. William of Ockam, Roscelin and Abelard.-Those three names are often connected by historians of medieval philosophy, with a view to establishing analogies between them, or even asserting that all three arrived at the same solution of the Universals problem $(\mathbf{1 4 6}, \mathbf{1 7 4})$. But we need only compare the doctrines of Ockam and of Roscelin to see how utterly misleading it is to label both of these philosophers alike as " nominalists ". ${ }^{2}$

${ }^{1}$ For a detailed exposition of Ockam's logic, see PRANTL, op. cit.

${ }^{2}$ UeBerWeg (op. cit., p. 305) calls William of Ockam "der Erneuerer des Nominalismus". 
The two systems have nothing in common save the denial of extreme realism. Roscelin's so-called nominalism suffers from mere poverty of ideas, but if taken in its proper historical setting it may be regarded as an eariy and unformed attempt at moderate realism. Ockam's so-called nominalism, on the other hand, was the fruit of a well-informed criticism of mature and fully developed doctrines, and it is a clear and unequivocal expression of conceptualism. From this we draw the conclusion that extreme nominalism never had any representatives among scholastics. If we want to find it, we must leave the Middle Ages and search in the non-spiritualist philosophies that suppress all distinction of nature between sensation and thought.

Neither is it without important reserves that Abelard's socalled conceptualism can be compared with the terminism of Ockam. Abelard prepared the way for Thomism and worked towards the Thomistic solution of the problem; Ockam combated that solution. The former simply did not assert explicitly the real validity of the universal, because he did not formally raise that point in the discussion; the latter explicitly and deliberately denied the real validity of the universal, in order the better to vindicate, as he thought, its ideal validity.

378. Conclusion.-Conceptualist terminism and the theory of the sign; a preponderance of logic, the scientia rationalis: such are the special features of the philosophy of William of Ockam. Did these so influence and colour his system that it ought to be classified among anti-scholastic systems, as an affirmation of subjectivism? We do not think so. Ockam made no attempt to upturn the foundations of medieval dogmatism, any more than, for example, Duns Scotus sought to be a pantheist. Intuitive cognition was held by William to be endowed with a full and complete objectivity. And even if a searching criticism shows that Ockam's conception of science and of the universal contains the seeds of subjectivism, still it is only fair to remember that he himself never formulated those dangerous consequences, which, however, became for his disciples the credo of a new philosophy (Ch. III., §3). Then, as for his other theories, they are based on commonly accepted data, although it must be admitted that in them purity of doctrine steadily declines. From all of which we draw this conclusion: William of Ockam was a scholastic and remained such; but his unfortunate innovations and the general 
tendencies of his system bear witness to a gradual wane of forces within the sphere of scholasticism.

379. Bibliography.-The Commentaries and the Quodlibeta of Aureolus were edited at Rome in 1596 and 1605 . The Commentarics of Durandus were edited many times during the sixteenth century. On Durandus, Aureolus and Ockam, see Werner, Die nachscot. Scholastik. Each chapter examines a group of doctrines.

Ockam's Commentaries on the Sentences were edited in 1483 and 1495 (Lyons); the Quodlibeta in 1487 (Paris), 1491 (Strassburg); the logical treatises repeatedly at Paris, Bologna, Venice (fifteenth and sixteenth centuries). On Ockam see StöckL, op. cit., ii., pp. 976 sqq.; and PRAntL, iii., pp. 33r sqq. (125). SIEBecK, Occam's Erkenntnislehre in ihrer historischen Stellung (Arch. f. Gesch. d. Philos., 1897, pp. 317 sqq.) : good.

\section{§3. The OCKamist OR Terminist School.}

380. Influence of the Terminist School. Prohibitive Measures. - The teaching of William of Ockam was taken up enthusiastically in the philosophical schools of the Paris University in the fourteenth and fifteenth centuries. Even in its founder's lifetime ${ }^{1}$ it attracted a large following. Of this no better evidence could be forthcoming than the long roll of the supporters of the venerabilis inceptor and the repeated efforts on the part of the ecclesiastical authorities to stem the rising flood of terminist teaching. Ockamism was a reaction and it was novel: those two facts in its favour were stronger than all the official prohibitions. The history of these ecclesiastical measures throws a new light on the later fortunes of Ockamism. We will examine them briefly, to see what was the spirit that animated them.

In 1339 the Paris Faculty of Arts banished from its chairs the Ockamist doctrine, which certain masters, as the statute relates, were not only teaching in their public lectures but propagating privately, and in conventicula. ${ }^{2}$ The Faculty wanted to return to the traditions of the thirteenth century and appealed to reasons of discipline: academic regulations should be respected by those who have sworn fidelity to them, and no one can be allowed to

1 The Reg. Procur. Nat. Angl. for I34I make use of the term Occhaniste: ". . Statutum facultatis contra novas opiniones quorumdam, qui vocantur Occhaniste" (Chartul., ii., p. 507, n.). Gerson speaks of controversies between the formalistae and the terministae; P. Nigri uses even the term conceptistae.

2 "Statuimus quod nullus de cetero predictam doctrinam dogmatizare praesumat audiendo vel legendo publice vel occulte, necnon conventicula super dicta doctrina disputanda faciendo " (Chartul., ii., p. 485). 
read books other than those prescribed by our predecessors. The appeal was without effect, for fourteen months later the Faculty had to renew its prohibitions. This time, however, its tone is changed; it raises a cry of alarm: the new teachings are full of danger and form a tissue of intolerable errors calculated to compromise both philosophy and theology. This statute of I 340 is of considerable interest, for it contains a collection of the teachings it was thought advisable to proscribe and banish from the schools.

It states that the Ockamists inherit the dialectical spirit of their master and bestow great attention on the logico-grammatical matters brought into vogue by Petrus Hispanus. If separated in the least from the real content of the terminist philosophy, this formal logic leads inevitably to verbal discussions, to mere juggling of words, worthy of the sophist rather than the philosopher. We may judge from an example. The masters aimed at by the statute admit only sufpositio personalis ("Quod nullus dicat simpliciter vel de virtute sermonis omnem propositionem esse falsam, que esset falsa secundum suppositionem personalem terminorum ... actores enim sepe utuntur aliis suppositionibus") and literal interpretation ("Quod nullus dicat propositionem nullam esse concedendam, si non sit vera in ejus sensu proprio . . . quia Biblia et actores non semper sermonibus utuntur secundum proprios sensus eorum"). They reduce science to a study of concepts and words, not of things ("Quod nullus dicat scientiam nullam esse de rebus que non sunt signa, id est que non sunt termini vel orationes" ${ }^{1}$ ).

But the Faculty refers to a second class of propositions which contain the real cause of the war that was declared against Ockamism: certain supporters of the new doctrines, misconstruing Ockam's theories and interpolating foreign elements, had arrived at conclusions that were openly anti-scholastic (402). It was his anxiety to safeguard both the traditional scholastic philosophy and the orthodox theology that prompted Pope Clement VI., in I 346 , to write to the masters and students of the University of Paris to warn them against those variae et extraneae ${ }^{2}$ doctrinae sophisticae. The germ of error, says Clement, is latent

${ }^{1}$ Chartul., ii., p. 506.

"Ricardus de BURy, op. cit., says of the Paris masters of 1344: "Anglicanas subtilitates, quibus palam detrahunt, vigiliis addiscunt" (ibid., p. 590, n.). 
in those dangerous theories; they will make those who should defend the good cause proselytes of the evil one. ${ }^{1}$

Now it is a remarkable thing that although Ockamism was solemnly condemned three times within seven years, yet it continued to spread and prosper at Paris; most of the masters in arts espoused it either publicly or privately, and, what is stranger still, even in the time of Clement VI. himself, one of the most distinguished professors of the University-John Buridan-who was also rector, openly defended the new doctrines of William of Ockam. In this situation we have such a conflict between right and fact as can be explained only by a consideration of the motives that prompted the condemnations. What alarmed the ecclesiastical authorities was the conduct of certain doctors who were prostituting Ockam's teaching to the defence of anti-scholastic theories: there was the evil to be avoided. But besides those deserters and traitors $(\mathbf{4 0 2})$ there were crowds of Ockamists who wished to remain, and, in spite of their weaknesses, did remain, scholastics. The teaching of these latter could not give such cause for alarm; and if they were hit by the letter of the prohibition they were spared by its spirit and intention. It is in this section of the Ockamists that we find the most distinguished names. ${ }^{2}$

In other universities, Ockamism triumphed without an effort and even became the official teaching: as in Vienna and Cologne, which followed the teaching of Buridan; and in Heidelberg, which adopted the ideas of Marsilius of Inghen. ${ }^{3}$ In 1425 we find the prince elector calling on some of the Cologne masters to justify their action in taking as their guides the antiqui alti sermonis doctores (Albert the Great and St. Thomas Aquinas) instead of the magistri moderniores. ${ }^{4}$

1 " Plerique quoque theologi . . philosophicis questionibus et aliis curiosis disputationibus et suspectis opinionibus . . . se involvunt . . . sic quod, unde deberent prodire fructus uberes sicut antiquitus reficientes fideles ... pestifera pullulant quandoque semina."

2 In the fifteenth century again the prohibitions were renewed. In 1473 Louis XI. tried to banish Ockamism from Paris and France and to substitute for it the realism of the thirteenth century. After eight years ( $\mathrm{I}_{4} 8 \mathrm{I}$ ), the prohibitions were removed (Chartul., iii., p. x).

3 Thus, in 1406, Jerome of Prague got into difficulties at Heidelberg for having in an actus scholasticus attacked Marsilius of Inghen, Buridan and other " nominalists" (PRANTL, op. cit., iv., p. 39).

${ }^{4}$ EhrLe, Die päpstl. Encycl., etc., p. 316 (240). The Franciscan convent at Oxford had a party of Scotists and a party of Ockamists (D'ARgentre, op. cit., i. p. 342). 
381. Earlier Ockamists. John Buridan.-The Franciscan, ADAM GoDnam or Voddam, the Dominicans, Armand of BEAUvOIR, master of the Sacred Palace (I 328-I 340), and ROBERT Holcot (died I 349), are mentioned among the first supporters of Ochamism. The new doctrines were also embraced by a section of the Hermits of St. Augustine (391). But the recognized leader of Ockamism in the first half of the fourteenth century was John Buridan.

JOHN BURIDAN, born at Béthune towards the end of the thirteenth century, attended Ockam's lectures at Paris. He was rector in 1328 , and for a quarter of a century he exercised a preponderating influence in the Arts Faculty and in the University generally: Not only did the official prohibitions fail to prevent Buridan from teaching Ockamism, but two years after the letter of Clement VI., August the 5 th, I 348 , the rector and procurators combined to give their colleague an unequivocal proof of their confidence and support: another indication, apparently, that the Arts Faculty had no mind to banish Ockamism, but rather to repress certain abuses fostered by a section of malcontent disciples. It is not true that Buridan taught at Vienna, nor that he was driven out of Paris with Marsilius of Inghen. His relations with John of Navarre belong likewise to the domain of fable. ${ }^{1}$ He died subsequent to I 350 , leaving a Summa de Dialectica, a Compendium Logicae and commentaries on Aristotle's Physics, Metaphysics, Ethics, De Anima and Parva Naturalia.

The problem of free will received special attention from Buridan. He is known as a partisan of psychological determinism. Every good presented to us by our intelligence, exerts on our will, which is of its nature undetermined, a certain natural attraction; and if we abandoned ourselves to this complacentia, we should necessarily select whichever of two goods appeared to us the greater. But the liberty with which the will is endowed enables it to suspend its choice and command the reason to examine anew the alternatives in question. Our choice will be moral if we take as standard in this comparison the end of our nature, the ordinatio finalis. The will may multiply those delays as it pleases; but when, finally, it accepts the judgment of the reason without further appeal, it will necessarily choose the good

\footnotetext{
${ }^{1}$ Chartul., ii., p. $6+6$, n.
} 
which appears to it the greater: this, for Buridan, is the very essence of moral freedom. ${ }^{1}$ This doctrine is remarkably like that illustrated by Leibnitz, where he speaks of the motionless balance with the two equal weights. In connection with Buridan's teaching, too, every one knows the story of the ass dying of hunger midway between two hay-ricks of equal size and quality. No reference to any such illustration is found in Buridan's own writings; it was probably his contemporaries who made use of it to throw ridicule on his theory. Possibly, however, Buridan himself may have used it in his oral teaching to illustrate the difference between the free act of man and the necessary act of the beast ${ }^{2}$ while the latter of necessity follows the stronger attraction, and cannot reach a decision if we suppose his sense appetite at the dead point between two equal pleasures, the former finds in his own power of reflection the means of ultimately determining the greater good and embracing it.

As a confirmed Ockamist, Buridan denies all distinction between the faculties of the soul. Voluntas est intellectus et intellectus est voluntas. ${ }^{3} \quad$ Nevertheless cognitive activity is superior to volitional and plays a preponderating role in the moral life.

382. Marsilius of Inghen and Peter D'Ailly.-These two philosophers were the leading Ockamists of the second half of the fourteenth century. MARSILIUS OF INGHEN ( I $_{3} 396$ ) won a high reputation at the University of Paris, where for many years he advocated the theories of William of Ockam. ${ }^{4}$ He had so many auditors when he was magister regens in the Faculty of Arts that special provision had to be made to secure sufficiently large halls for his lectures. ${ }^{5}$ He held the position of rector in 1367 and again in $137 \mathrm{r}$, and took a leading part in all important University affairs, especially in those of the great Schism. The disturbed state of the University may have led to his departure from Paris (about I 379). He went to Heidelberg and became the leading spirit of the new University there. He was appointed its first rector in 1386 . His chief work is the Quaestiones supra IV. Lib. Sentent.

${ }^{1}$ We do not refer to the necessary volition of the good in general, which Buridan explains like the Thomists.

2 This is Siebeck's explanation, op. cit., p. 204.

${ }^{3}$ In Eth. Arist., L. x., q. i., fol. 204, Paris edit., 15 r3.

${ }^{4}$ Chartul., iii., pp. 93, 555. $\quad{ }^{5}$ Auctarium Chartul., i., p. xxiii. 
Peter D'Allly, surnamed the Eagle of France (Aquila Franciae), was born at Compiègne in 1350 , studied theology in the Navarre College at Paris (1 372 ), was promoted to the doctorate in I 380 , became successively chancellor of the University (I 389 ), bishop of Puy and of Cambrai, and cardinal (I 4 I I). He died in I 425 . His numerous works, which include Commentaries on the Sentences and a treatise De Anima, show him to have been a faithful disciple of William of Ockam. He was also deeply versed in mysticism (394).

383. Other Advocates of Ockamism.-Among other notable terminists were HeNRY OF Hesse (Henricus Heynbuch de Hessia, I325-1397), who was an important figure at the University of Vienna about the year I 385 ; AlbekT OF SAXONY (de Saxonia de Halberstadt, $\dagger$ I 390 ), who taught at Paris from 1350 to I 360 , and at Vienna, making a great display in terminist logic $;^{1}$ Nicholas OF OREsMe, master of theology in 1362 , bishop of Lisienx in I 377 , died in I382; JOHN DORP OF LESIEN, who, after having taught in Paris at the end of the fourteenth and the beginning of the fifteenth century, passed to Cologne, where he promoted Ockamism and published commentaries on the writings of Buridan. Henry of Hesse and Nicholas of Oresme are also known in the history of economic theories in the fourteenth century, the one by his Tractatus de contractious et origine censumm, the other by an important treatise on currency and exchange. ${ }^{2}$

384. Sources and Bibliography. - Buridan's logical writings were edited in ${ }_{14} 87$ (Paris) and $x_{4} 89$ (Venice); his commentaries in $1_{4} 89,1500,1516,1518$ (Paris), and at Oxford in 1637 and I640. SІЕвеСк, op. cit., pp. I99 sqq. (336), and Beiträge z. Entstehungsgeschichted. neueren Psychol. (Progr., Giessen, I89r). De Wulf, Hist. Phil. scol. Pay's-Bas, etc., p. 293. Strassburg (I 490) edition of P. D'Ailly's Comment. on the Sent. E. HARTMAN, Die sinnliche Wahrnehmung nach $P$. D'Ailly (Phil. Jahrb., r9o3, FP. 36 and 139): a good analysis; shows clearly that D'Ailly rejects only the false theory of the specics. Fo. D'Ailly's theology and his share in the Council of Constance, see Salembier, in the Dict. Théol. Ca h., t. i., 6.42 (I900). The logical treatises of Albert of Saxony were edited in I 497 at Venice, his Quacstiones on Ockam's logic in the Expositio Aurea of the latter. MEUnier, Essai sur la vie et les ouvrages de N. d'Oresme (Paris, 1857 ); and Jourdain, $N$. d'Oresme et les astrologues de la cour de Charles V. (Excurs., etc.). On Albert of Saxony and Leonard de Vinci, v. Duнem, Etudes sur Léonard de Vinci. Ceux qu'il à lu ct ceux qui l'ont lu (Paris, I906 and 1909).

${ }^{1}$ Author of a treatise on Logic, of Quaestiones on the Logic of William of Ockam and on Aristotle's Sophismata (Prantr, iv., p. 6o).

2 Brants, op. cit., p. 20. 


\section{ART. III.-THE SCOTIST SCHOOL.}

385. General Features.-Scotus had all the qualities of a founder of a school; his philosophy was consistent and his innovations organized and well thought out. He rallied around him the most influential section of the Franciscan order. He was proclaimed the doctor ordinis, though we do not know at what exact date; ${ }^{1}$ and down to the middle of the fourteenth century but little attention was paid to any of the other great doctors who had shaped the earlier philosophical traditions of the Franciscans. The disciples advanced on the teaching of their master. They accentuated his formalism and multiplied his abstractions. At the same time their language became cumbersome and confusing, like their method; and they contributed no less than the terminists to the decadence of scholastic teaching. We ought, therefore, to distinguish between the philosophy of Scotus and Scotism.

386. Leading Scotists. - FranCIS OF MAYRON († I 325) was the first-and the worst-of those misguided Scotists who destroyed the master's metaphysics with a crop of subtle and chimerical entities that provoked the attacks of Thomists and Ockamists; he was the most characteristic and influential of the immediate followers of Scotus, and by his exaggeration of his master's. principles he got the title of Magister Acutus Abstractionum." Besides him we may mention, among the principal Scotists of the fourteenth century, the Franciscans Antonio AndREAE (Doctor Dulcifluus, $\dagger$ I 320 ), Johannes Canonicus ( $†$ I 320 ), JOHN DE LA Rive, GERARD ODO, JOHN OF BASSOLES, one of Scotus's favourite pupils, John Dumbleton, Nicholas OF LyRE ( + I 349$).^{3}$ WALTER BURLEIGH (Galterus Burlaeus, called Doctor planus et perspicuus, 1275-1 342), a secular cleric, wrote commentaries on Aristotle, in which he defended a sort of realism resembling that of St. Thomas. $\mathrm{He}$ is the author of a number of Tractatus Philosophici often attributed to St. Bonaventure. ${ }^{*}$ AleXANDER OF ALEXANDriA († I 314), author of Commentaries on Aristotle's Metaphysics (260, p. 382, n. 5), professed pure Scotism ; and the same may be said of LyCHETUS OF BRESCIA, who commentated the Opus Oxoniense

${ }^{1}$ EHrLe, Die päpstl. Encycl., etc., p. 292, n. I.

${ }^{2}$ His supposed actus Sorbonicus is a legend (Chartul., ii., p. 273).

${ }^{3}$ Labrosse, Oeuvres de Nicolas de Lyre (Etudes Franciscaines, 1908); Bibliographie de Nicolas de Lyre (ibid., 1907).

* Dissert. de Scriptis seraph. doctoris, in t. x. of the Quaracchi edit., p. 26. 
towards the end of the fourteenth century, and of Nicholas DE ORBELlis ( $\dagger$ 1455), whose commentary on the Sentences was adopted as text-book in the Franciscan schools of the fifteenth century.

The Scotist school was never so widespread as its more powerful rivals. $^{1}$

\section{AR'T. IV.-THE THOMIST SCHOOL.}

387. Thomism in the Fourteenth Century.-Thomism remained the better part of scholasticism in the fourteenth and fifteenth centuries. St. Thomas had been elevated to the altars of the Church, the prohibitions against certain points in his teaching had been withdrawn, and even William of Ockam had admitted that those prohibitions had been superfluous. The Cistercians and Carmelites gave numerous supporters to Thomism during this period. Among the latter, the prior general, GERARD of Bologina ( $†$ I3I $)$, was an avowed opponent of the Scotistic formalism. We may also mention RALPH THE BRETON (first half of fourteenth century), and the Sorbonne master, JOHN DE POUILLI (first half of fourteenth century), as liberal-minded Aristotelians and supporters of moderate realism.

But the great mass of militant Thomists belonged to the order of irias-Preachers. The Dominicans of the early fourteenth century are better known than their immediate predecessorsthe men who were formed in the schools of the great masters themselves. Among the most vehement opponents of Duns Scotus were Hervé of Nédellec, John of Naples († I 330 ) and Peter De Pallude († I 344). Hervé of Nédellec, who was sreneral of the Dominican order in I 3 I 8 and died in 1323 , deserves to be better known than he is. He wrote Commentaries on the Sentences, Quodlibeta and a number of controversial tracts against Henry of Ghent. ${ }^{2}$ Durandus of Aurillac, a!so called DURAN-

${ }^{1} \mathrm{Among}$ the promoters of the study of St. Bonaventure in the fifteenth century ivas BERTRAM OF ALEN, who wrote an explanatio of the "Itinerarium Mentis in D)um" under the title of "Liber de investigatione Creatoris per creaturam" (ibid., p. II, and t. v., p. xxvi).

"According to the catalogue published by Denifle, Quellen, etc., p. 228. The Quodlibeta include a treatise De Formis : in addition to which EHRLE indicates two other tracts of Hervé "de formis," Alemannus, etc., t. iii., 2, p. ix. Manuscripts containing a reportatio of various Quodlibeta of Godfrey of Fontaines attribute the treatise to Hervé of Nédellec or Henry the Teuton, of the Hermits of St. Augustine. 
DELLUS, wrote a tract in which he refuted the opinions by which his namesake, Durandus of S. Pourçain, separated from the teaching of St. Thomas. ${ }^{1}$

Over and over again the general chapters of the Dominican order renewed the solemn mandates of I 278 and I279. It was with legitimate pride they established in all their schools the doctrines of the great philosopher whom an episcopal decree of the year I 323 did not hesitate to describe as " ecclesiae lumen praefulgidum, gemma radians clericorum, flos doctorum, Universitatis Parisiensis speculum clarissimum et insigne, claritate vitae, famae et doctrinae velut stella splendida et matutina refulgens". ${ }^{2}$ For the most part, those chapter statutes, commanding the whole order to conform to the doctrines of St. Thomas, were issued in order to bring back to Thomism some fractious monk or other whose secession was giving scandal. Thus, for instance, the statute of the general chapter of Bologna, in I 3 I 5 , synchronizes with the censure inflicted by the provincial chapter of Aretium on brother UBERTUS GUIDI. ${ }^{3}$ Similarly, the general chapter of Brives, in 1346 , renews the order to follow St. Thomas, simply because a number of Dominicans, at Paris and elsewhere, had drifted into the anti-Thomist movement of Ockam's followers. ${ }^{4}$

388. Thomism in the Fifteenth Century. Capreolus. Antoninus of Florence.-The best known among the Dominicans who defended the flag of Thomism in the fifteenth century is John CAPreolus. Born about I 380 at Rodez, where he received his early education and imbibed his love for St. Thomas, he finished his studies at Paris (about 1409), then went to Toulouse and finally back to Rodez, where he died in I444. It was at the convent of his native town that he completed (about I 432) the monumental work, Libri Defensionum, which has won for him the title Princeps Thomistarum. The one single aim of this work, he tells us himself, was to restate and establish the teaching of St. Thomas and defend it against the objections of "Aureolus,

DE WULF, Étude sur la vie, les oeuvres et l'influence de G. de Fontaines, pp. 65, 66. Herve is probably not the author of a Totius Logicae Summa wrongly attributed to St. Thomas.

${ }^{1}$ In the catalogue of Dominican works published by Denifle there are also mentioned logical treatises by AlberT of ERFort (before 1400 ) and by Gratiadeus Esculanus (about $\mathrm{r} 34 \mathrm{I}$ ).

${ }^{2}$ Chartul., i., pp. 280 and 28r. $\quad 3$ Ibid., ii., pp. 173 and 174 .

${ }^{4}$ Ibid., pp. $59 \mathrm{r}$ and 592. 
Scotus, Durandus, John de la Rive, Henry of Ghent, Warron, Adam and other adversaries of St. Thomas". ${ }^{1}$ The writings of Capreolus are therefore an authentic source of ihomist teaching, brought into comparison with Scotism and Ockamism; they constitute an encyclopedia of the scholastic controversies of two centuries. Unfortunately they are not free from certain defects of method which mar the scholasticism of the decadence.

Antoninus of Flokence (1 389-1459) became a Dominican in 1406 and bishop of Florence in I 446. His principal work, a Summa Theologica, embodies the discussion of important questions on social, political and domestic right $(\epsilon . g$. ., riches, means of production, value, price, money, property, labour-contract; prudentia regnativa, de dominis temporalibus, the rights of war; education). The treatment is mainly from the point of view of general ethics; but his work contains valuable data for the history of economic and social theories in the fourteenth and fifteenth centuries. Convinced adherent of St. Thomas as he was ("quem omnibus propono," he writes in his Prologue), Antoninus of Florence knew how to apply his master's principles to new materials in fresh departments of research.

389. Denis the Carthusian. Gerson.-A mystic writer of great renown, DENis THE CARTHUsian may be classed as a 'Thomist. He was the most remarkable scholastic in the Low Countries during the fifteenth century. Born at Ryckel, in Limbourg, in 1402, he received his early education at St. Trond, became master of arts at the University of Cologne, entered the Carthusian monastery of Roermonde in 1423 and died in $147 \mathrm{I}$.

His principal philosophico-theological works are his Commentaries on the Sentences and on the De Consolatione of Boëthius, the Summa Fidei Catholicae, the Compendium Philosophicum and Theologicum and the Dialogon de Fide Catholica. Those are real scholastic manuals, clear and concise and deliberately free from the perplexing controversies that encumbered the scholasticism of the time. ${ }^{2}$ Their author was a convinced and ardent disciple of St. Thomas. In his Summa Fidei Catholicae (L. i.-iii.), which he himself calls "medulla operum S. Thomae," he follows faithfully the matters treated by St. Thomas in his Summa Theologica. On some particular points, however, he disagrees with the Thomist

1 Proëmium.

2"Impertinentes subtilitates vitare propono" (In Psalmos, Proëmium). 
teaching: thus, in his Commentary on the Sentences he declares that he has changed his opinion on the question of the relation between essence and existence, and that although he defended the real distinction theory in his thesis for mastership at Cologne, he has since embraced the opposite opinion.

We may also connect with the Thomism of the fifteenth century the name of another great mystic whose philosophy is little known and who is sometimes classified with the terminists: JoHN GERSON (394), chancellor of Paris. Living at the great centre of philosophical agitation, Gerson could not well avoid taking part in scholastic controversies. In two books, the Centilogium de Conceptibus, de Modis Significandi, and the De Concordantia Metaphysicae cum Logica, he attacked the formalism of the Scotists, which he suspected of pantheism.

390. Sources and Bibliography. -Quodlibeta Undecim, etc., of Hervé of Nédellec (Venice, 1513). Contains also the following treatises of Hervé: De Beatitudine, De Verbo, De Acternitate Mundi, De Materia Coeli, De Relationibus, De Unitate Formarum, De Virtutibus, De Motu Angeli: rare edition. A portion of the De Unitate Formarum, which the editors of Alamannus attributed to St. Thomas, and which is given in extenso in the $\mathrm{I}_{5} \mathrm{I}_{3}$ edition, has been reprinted by EHRLE in an appendix to the works of Alamannus, t. iii., pp. 523-82 (Paris, r894). See Prolegomena to Part ii. The works of Capreolus were edited in $1_{4} 8_{3}, 1_{5} 1_{4}, 1_{5} 19$. New edition of the Defensiones theologicae, by PaBAN and PÈGues (Tours). Five volumes appeared from Igoo to Igo4.-PÈGues, La biographie de F. Capreolus (Rev. Thomiste, July, r899). Editions of the Summa Theologica of Antoninus of Florence, I 480,1781 , etc. IlGNer, Die volkswirtschafl. Anschaunngen Antonins v. Florenz (Paderborn, 1904): Good. New edition of the complete works of Denis the Carthusian, by Dom BARET, commenced in $\mathrm{I} \delta 96$ at the Chartreuse N.-D. near Montreuil, completed at Tournai. T. 15 and 16 : Comnentaries on Pseudo-Denis; t. 17 and 18: "Summa Fidei orthodoxae et Dia'ogon de Fide"; t. I9 to 24 : Comment. on the Sentences; t. 36 was published in 1908. A. Mougec, Dionysius der Kartheuser (1402- $\mathrm{I}_{47} \mathrm{I}$ ), sein Leben, sein Wirken, eine Neuausgabe seiner Werke (Mulheim, 1898). Published at Montreuil also from 1897 to rgor in 8 vols. : Annales Ordinis Cartustcnsis ab anno ro84 ad annum 1429 , by Le Couteulx. Editions of Gerson's works, Cologne, $1_{4} 83$; Strassburg, I488-1502; Paris, I521 and r6o6; Antwerp, 1706. On Gerson, see 395 .

\section{ART. V.-THE AEGIDIAN SCHOOL.}

391. The Aegidian School.-As an offshoot of Thomism, there arose in the fourteenth century an Aegidian school proper $(\mathbf{3 2} \mathbf{I})$. It was formed in the Augustinian order and faithfully transmitted the eclectic teachings of Giles of Rome. In addition to JAMES OF VITERBO (32I), its leading representatives are GERARD OF SIENNA, Augustinus TRIUmphus of AnCONA ( $\uparrow_{1}$ 328) and more especi- 
ally Thomas of Strassibrg (prior-general in 1345 , died in I 357), author of Commentaries on the Sentences.

GREGORY OF RIMINI († I358), the successor of Thomas of Strassburg, and who has also left Commentaries on the Sentences, brought about a doctrinal schism in the order. His teaching has close affinities with that of William of Ockam: intuitive and direct cognition of the individual ; conceptualism; identity of the soul with its faculties; hylemorphic composition of all creatures; doubts about the demonstrative force of the arguments for the creative causality of God, etc. Gregory of Rimini had a following; but towards the middle of the fifteenth century, doctrinal unity was re-established in the order. It was mainly in Italy that the Aegidian school recruited its philosophers and theologians.

392. Bibliography.-Ossinger, Bibliotheca Augustiniana (Ingolstadt, i768). On Gregory of Rimini, see Werner, op. cit., 325.

\section{ART. VI.-ORTHODOX MYSTICISM.}

\section{General Features of Mysticism in the Fourteeenth and} Fifteenth Centuries. - The fourteenth and fifteenth centuries saw a vigorous awakening of mystic life and teaching. The sterility of the controversies in the schools, and the errors into which they had betrayed not a few theologians (Ch. III., § 3), made many thoughtful people chary of speculation and disposed rather to devote their attention to the contemplative life. The author of the Imitation of Christ gave expression to the prevailing attitude of mind when he asked at the head of his book: "What have we to do with those disputes of the schools about genera and species?" (I., 3).

Among the masses of the people, too, there were formed powerful associations for the promotion of piety: the popular turn of the mysticism of the period is evidenced by the fact that the leaders of the movement wrote most of their works in the language of the people.

According as they asserted or denied the essential distinction between Creator and creature, those writers moved in a sphere of thought compatible or incompatible with scholasticism. The orthodox mystics excelled both in number and in ability. The best known among them are Ruysbroeck, Gerson, D'Ailly and Denis the Carthusian. They belong more properly to the history 
of mystic theology, but they have an interest also for the history of philosophy (201).

394. Principal Mystic Writers.-JoHn Ruysbroeck (I 293I 38 I) "the Admirable," a priest of Ste. Gudule at Brussels, withdrew to the Augustinian convent of Groenendael and gave himself up to contemplation for the remainder of his life. He combated the unsound mysticism propagated in the province of Hainault by the Porrettists and the followers of Blommardine (401). Gerson suspected Ruysbroeck of pantheism; but unjustly as it seems, for in the mystic life as described by the latter-that "fertile union" of the soul with God, which incessantly renews itself by love and consists in a "superessential contemplation of the Trinity, a feeling that baffles description, a sublime ignorance" -the essential distinction between Creator and creature is respected. Ruysbroeck's influence had much to do with shaping the vocation of GERARD GROOT (I340-I384), the founder of the Brotherhood of the Common Life. It was one of the communities of this brotherhood, at Deventer, that gave Thomas à Kempis (1 $380-147$ I) to the Church.

Twenty years later, JoHn Gerson (Johannes Arnaudi de Gersonio, I 364-1429) was to France what Ruysbroeck was to the Low Countries-with the advantage of the great prestige enjoyed by the French mystic owing to his high social position. Gerson followed the lessons of Peter D'Ailly in the Paris Faculty of Arts, commenced theology in $\mathrm{r} 38 \mathrm{I}$ and became chancellor of the University in 1395 . Two years later, when he was making a special study of his favourite author, St. Bonaventure, he lived for a time at Bruges-the country of Ruysbroeck, the Beghards and the Brothers of the Common Life. This sojourn drew him still more to mysticism, which he used exclusively for the service of the Church (Doctor Christianissimus). From I4OI to 1407 he again taught at Paris; later on he took an active part in the events of the Great Schism; but from 1419 political troubles obliged him to keep away from Paris. In his seclusion at Lyons, where he died, he wrote numerous works on mysticism, the chief of which are: Considerationes de Theologia Mystica Speculativa, De Theologia Mystica Practica and a Tractatus de Elucidatione Scholastica Mysticae Theologiae. These describe the soul supernaturally enraptured by Divine love. In this state of ecstatic joy the lower functions of the soul are suspended; but Gerson is at 
great pains to distinguish this expansion of the creature in the Creator from pantheistic union, which he condemns in all its shapes and forms ( $c f . \mathbf{3}^{\mathbf{8 9}}$ ).

Gerson's mysticism was inspired by St. Bonaventure. That of PETER D'AILLY the Ockamist $\mathbf{3 8 2}$ ) on the other hand, as revealed in his Speculum Considerationis and his Compendium Contemplationis, describes the various stages of mystic contemplation after the manner of Richard of St. Victor (204).

DENIS THE CARTHUSAA (389) embraces in his voluminous writings all departments of philosophy, theology, exegesis and mysticism. All those sciences point upwards for him and converge towards the illuminations of the contemplative life. In his mysticism he follows Pseudo-Denis the Areopagite and Ruysbroeck. All speculative knowledge he holds to be merely a preamble to the acts of the interior life. He describes all the sweetnesses of ecstasy, and the path which leads to them, in his commentaries on Pseudo-Denis and in his numerous treatises De Oratione, De Weditatione, De Contemplatione, De Donis Sfiritus Sancti, etc. He has merited the surname of Doctor Fistaticus.

395. Sources and Bibliography. - The works of Ruysbroeck, written in Flemish, were translated by GERARD Groot, his disciple, and by Surius. Chief among them are: The Preparation of the Spiritual Espousals, which is regarded as his masterpiece; The Treatise on the Christian Faith; The Spiritual Tabernacle; The Seven Cloisters; The Seven Degrees of Love. Fur editions of the works of Ruysbroeck, see AUGer, Étude sur les mystique's des Pays-Bas an inoyen âre (Brussels, 1892) : a valuable study of mysticism. Opera Gersonii. editions of $1+83$ r4 38. etc. r 70 (Antwerp). On Denis the Carthusian, see 390. 


\section{CHAPTER III.}

\section{ANTI-SCHOLASTIC PHILOSOPHIES.}

396. Various Forms of Anti-Scholasticism during this Period.Averroism was still the most formidable rival scholasticism had to encounter in the fourteenth and fifteenth centuries $(\S \mathrm{I})$. Then there arose also certain forms of heterodox mysticism of no great historical importance $(\S 2)$. Finally we may note some parasitic systems, which, although not themselves durable, are symptoms of approaching decay ( $(3)$. The kinship of many of these latter with Averroism is easily recognized.

\section{$\S$ I. LATIN AverroÏsm.}

397. Averroïsm at Paris. - In spite of all the official condemnations and all the opposition offered by succeeding generations of doctors, Averroïsm steadily gained a growing number of supporters. Its leaders were men of ability and daring. Certain of Ockam's disciples went over to its standard: indeed they had to take but a small step to reach the theory of the two truths, and we can understand how they were not always able to keep out of an error on which Ockamism bordered so closely.

398. John of Jandun or John of Ghent. - The recognized leader of Parisian Averroïsm in the fourteenth century was JOHN OF Jandun or John of Ghent (de Genduno, de Ganduno ${ }^{1}$ ). There is some doubt about the identity of the philosopher who composed the influential writings attributed to John of Jandun. Historians have confounded John of Jandun-magister artistarum in the Navarre College at Paris, afterwards master of theology, author of the De Laudibus Parisius (1323) and of the Defensor Pacis, forced to take refuge on account of his political theories, in company with Marsilius of Padua, at the court of Louis of

${ }^{1}$ We find both forms in the manuscripts. 
Bavaria ${ }^{1}$ - with John of Ghent, a quiet theologian who was pastor of Kieldrecht and canon of Paris. This latter John of Ghent was teaching theology at Paris in 1303 , whereas in 1316 John of Jandun had not yet become master of arts.

Which of those two men was the Averrorst leader? It is not easy to determine. An argument for John of Jandun may be drawn from the fact that he received through Marsilius of Padua, and expounded in his lectures, a treatise (Expositio Problematum Aristotelis) by the Italian Averroïst, Petri D'Abano. However this may be, the commentaries on the De Anima, the De Coelo et Mundo, the Metaphysics and the Phy'sics of Aristotle, on the Expositio and on the Sermo de Substantia Orbis of Averroës, ${ }^{2}$ are certainly all stones of the same edifice, carved by the same workman. And they contain the most typical Averroissm. There is not a page of them free from the blind Ipsedixitism that robbed this system of all freshness and originality. John of Jandun declares himself the monkey of Aristotle and Averroës, ${ }^{3}$ the imperfect imitator of the perfect work of those two great greniuses; blaming anyone who would dare to hint that there are contradictions in the Commentator. John of Jandun wrote dissertations on all the leading doctrines of Latin Averroism (339): he proves the eternity of the world and of movement, ${ }^{4}$ the necessary realization of possibles, ${ }^{5}$ the absence of all evil in eternal beings, ${ }^{6}$ the impossibility of God's creating beings, or knowing anything except Himself. In psychology he teaches the separate, eternal existence of one, single, human intellect: "Unus substantialiter est omnium intellectus, non plurificabilis seu multiplicabilis ad corforum multi-

${ }^{1}$ At the court of Louis of Bavaria, they drew up, against Pope John XXII., the Defensor Pacis (1327), which was condemned in the year of its publication. D'ARGENTRE (op. cit., i., p. 397) quotes, under the year I376, the words: "adversus errores Marsilii de Padua et J. de Janduno in Gallicum sermonem translatos".

${ }^{2}$ We have been unable to verify this of the Quodlibeta attributed to John of Jandun. The author of the commentary on the $D_{\varepsilon}$ Anima refers incidentally to many other works from his pen: Quaestiones de Formatione Foctus, Quaestiones de Gradibus et Pluralitate Formarum, Tractatus de Specie Intelligibili, Duo Tractatus de Sensu Agente; stating also that one of the latter was his first work.

${ }^{3}$ Comm. on the Metaph. (Venice, ${ }^{2} 5$ ), f. 84.

4"Totum mundum ingenitum secundum totum necesse est esse" (De Coelo et Mundo, l. i., q. 29 ; Phy's., 1. viii., q. 3).

5 Metaph., 1. ix., q. 5: "Utrum aliquid sit possibile in rerum natura quod nunquam erit". The author replies in the negative.

${ }^{6}$ Ibid., l. ix., q. I2. $\quad{ }^{7}$ Ibid., f. I42, c. 3 . 
plicationem...."1 The intellectual soul cannot, therefore, be the unique and single form of the composite human individual: it is really distinct from the sensible soul ${ }^{2}$ and although this way of explaining the constitution of our being involves the author in a multitude of difficulties, he declares it more satisfactory than the scholastic theory. ${ }^{3}$ In ethics, John confounds the free with the merely voluntary, in order the better to defend psychological determinism: " Liberum arbitrium est quod est gratia sui ... ergo liberum habet illud quod est gratia sui, licet ex necessitate agat ". ${ }^{4}$ Here certainly is anti-scholasticism. And the author's efforts to protect his faith as a Christian are decidedly interesting. Although I hold as true before my reason all the teachings of Averroïsm, nevertheless, he explains to us, I consider them false before my religion: herein, as St. Augustine informs us, lies the merit of our faith. "Ibi cessat meritum, ubi ratio praebet experimentum." And, to cap the climax: The wonderful omnipotence of God knows no limits, not even the impossible. " Responderem breviter concedendo tamquam possibilia apud Deum omnia ad quae illae rationes deducunt tamquam impossibilia." ${ }_{5}$ This discovery apparently puts him at ease and gives him the illusion of reconciling the irreconcilable. ${ }^{6}$

After this, it is not surprising to find that John of Jandun or John of Ghent did all in his power to lessen the great repute in which St. Thomas was held at the University of Paris. He belittles and affects to despise the commentaries of the great interpreter "qui putatur fuisse melior inter Latinos," and concludes thus: "Sed re vera salva reverentia hujus hominis, ipse inaniter laborat contra commentatorem sicut et in aliis philosophicis in quibus ei

${ }^{1}$ De Anima, 1. iii., q. 57.

2 "Anima sensitiva et intellectiva sunt diversae substantiae et formae" (ibid., 1. iii., q. I2).

3 “Quamvis igitur difficile sit intelligere quomodo ex materia et forma subsistente, non inhaerente, fiat unum, tamen multo difficilius est hoc intelligere de anima intellectiva et humano corpore secundum positionem catholicam quam secundum positionem commentatoris" (ibid., f. 65).

${ }^{4}$ De Coelo et Mundo, f. $22 . \quad{ }^{5}$ De Anima, f. 66, c. 1.

6 “Quod si alicui primo adspectu non videretur sufficere ad solutiones rationum, non tamen propter hoc debet conturbari, quia certum est quod auctoritas divina majorem fidem debet facere quam quaecumque ratio humanitus inventa " (De Anima, f. 6o, c. r). And in Metaph., f. I3, c. I : "Credo melius esse quoad salutem animarum nostrarum assentire et simpliciter credere, quam rationibus sophisticis ea probare et rationes ex sensibus electas debiliter et minus evidenter annotare". 
objucit. . . Dico quod ego non credo ei in hoc, sicut nec in aliis conclusionubus philosophicis in quilus contradicit commentatori." John was one of the leaders of the Averroïst school : he himself frequently refers in his writings to monographs written by one or other of his confederates ("socii") on special questions in the Averroïstic philosophy.

399. Averroism in Italy. - From the middle of the fourteenth century down even to the seventeenth, the north of Italy, and especially the University of Padua, remained a hotbed of Averroism. The University adopted the teaching of John of Jandun, openly acknowledging its indebtedness to him. The Averroist school owed its origin there to a physician named PETRI D'Abano († I3I6). It had as masters the Servite, URBAN OF

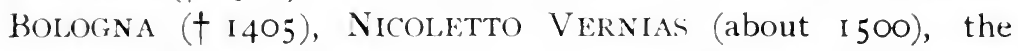
Hermit, Paul of Venice ( $†$ 1429) and Cajetan of Thiene (Thienaeus). The Summulae Logicae of Paul of Venice were adopted as a text-book at Padua by a decree of 1496.

As time went on, the Averroists showed themselves less and less concerned to preserve even the semblance of an agreement between philosophy and theology. And finally, when the Renaissance came, it made Averroism openly and avowedly independent of all relations with Christian dogma.

400. Sources and Bibliography. - The Commentaries of John of Jandun were printed at Venice in 1522. See Werner, Dit Averroismus in d. christl. feripatet. Psychol. d. speiteren Mittclalters (Vienna, 1881), for details about John of Jandun. The information given above, on his Averroïsm, was communicated to us by M. PELZER, who is preparing a dissertation on the subject. On Italian Averroïsm: Werner, Der Endausgang d. mittclalt. Scholastik, I., Abschnitt 3; and a recent work by SANTr Ferrari, Pietro d'Abano.

\section{\$2. Heterodod Mysticism.}

40I. General Features. - Some of the great mystic associations that sprang up in the fourteenth and fifteenth centuries came gradually to assume an attitude of hostility to Catholicism: they propounded heterodox doctrines and thus prepared the way for the Reformation. Their favourite theme was the pantheistic effusion of God and of the soul. Thus MARguerite PORRETTE published a book, condemned by the Paris theologians, in which she taught "quod anima annihilata in amore conditoris sine reprehensione

\footnotetext{
${ }^{1}$ Physics, f. 95, c. 4 ; f. 97, c. 2.
} 
conscienciae vel remorsu potest et debet dare naturae quidquid appetit vel desiderat". ${ }^{1}$ Similar views are found in BLOMMARDINE.

Heterodox mysticism was addressed to the ordinary people rather than to scholars. Having indicated its general tendency, we need not dwell on it any longer. ${ }^{2}$

\section{§ 3. OTHER FORMS OF AnTi-SCHOLASTICISM.}

402. Their Origin. -Ockam's system contained the germ of much that is anti-scholastic. He himself never formulated those anti-scholastic implications. But he had scarcely disappeared from the life of the University when the philosophers and theologians, brought up in the new theories, began to stretch the master's statements, and even to distort his conclusions. Thus, terminism and the theory of the sign served as a pretext for the most excessive subjectivism: the view that we know directly only the mental sign, and not the thing signified. The logicogrammatical method of Ockam was abused still more by applying to matters of philosophy and theology the exact and elaborate rules laid down about the proprietates terminorum, the consequentiae, the obligatoriae and the insolubilia. ${ }^{3}$ This process led to paradoxical and erroneous conclusions of which some specimens will be given below. It was probably the rash views of certain Ockamists that called forth the prohibitions of 1339 to I 346 , and it was indeed during this decade that the University was disturbed by the most daring innovators.

In the doctrines of these, however, we encounter not only Ockamist elements but also foreign and heterogeneous elements such as theistic and theological determinism. Still other theories, of doubtful or unknown origin, seem to have been promulgated apparently with the sole object of giving scandal, or because of their very incoherence. The promoters of such novelties were assuredly wanting in the qualities that make serious philosophers. The most important of the novel theories were the determinism of Thomas Bradwardine and the doctrines

${ }^{1}$ Chartul., ii., p. 143.

${ }^{2} C f$. Delacroix, Essai sur le mysticisme spéculatif en Allemagne au xive siècle, ch. iii. and iv.

${ }^{3} C f$. PrantL, op. cit., p. I sqq. 
of Nicholas of Autrecourt, John of Mirecourt and Ægidius of Medonta. ${ }^{1}$

403. Thomas Bradwardine, born about I290, was one of the most distinguished scholars of Merton College ${ }^{2}$ and Oxford University, where he was professor and procurator (1325). Subsequently he became chaplain to Edward III., accompanied the latter on his triumphal expedition to France in 1346 , and became archbishop of Canterbury in the year of his death, I 349. Besides his great and noted work, De Causa Dei contra Pelagium et de Virtute Causarum, ad suos Mertonenses (between 1338 and I 346), Bradwardine also wrote treatises on Mathematics, commentaries on the Sentences, a Summa Theologica or Summa Scientiarum, etc.

Bradwardine was an able theologian and philosopher. Though influenced in a certain degree by the teachings of his two fellowcountrymen, Scotus and Ockam, he built up a system of theodicy and ethics which was largely original and which made a deep impression on the philosophers and theologians of his time. Pelagianism, which Bradwardine set himself to refute in certain forms it had taken in his day, brought up the important problem of human freedom and its relations with the Deity. The question had become just then a burning one (sciens in flammam terribilem manum mitto.$^{3}$ For the solution of it Bradwardine thought out a sort of Theistic determinism, the leading ideas of which are as follows :-

God is Infinite Intelligence and Will. The Free Will of God is sovereign arbiter of the essences and the existences of all contingent things (Duns Scotus, cf. 332); it is the norm of man's nature and of the morality of his acts. "Non est ratio nec ulla lex necessaria in Deo prior ejus voluntate." 4 It follows from this, concludes the English philosopher, that the Divine Will is the necessitating cause (necessitas antecedens) of all contingent

${ }^{1}$ Of theological interest only are the "opiniones phantasticae" of RICHARD of Lincoln, whom Benedict XIII. forbade to teach, and who did not recover permission to read the Sentences until ${ }_{13} 43$, from Clement VI. ; the theories of JoHN Guyon, condemned in 1348 (Chartul., ii., pp. $54 \mathrm{I}$ and 622); of the minorite Denis FoulleCHAT (r364 and 1369); of a certain Simon de Brossa? (about r35I); of JohN de la Chaleur; of Nicholas of Esperanco; of Johin of Montesono (Chartul., iii., p. 488).

${ }^{2}$ Founded at Maldon in 1264 , transferred to Oxford in 1274 .

${ }^{3}$ Bradwardine's Praefatio. $\quad$ Causa Dei, i., 21, p. 233 A. 
activities, and therefore also of our volitions. Man is free only in the measure in which his act is independent of everything else except God: of the intellect and the conditions of sense-activity (libertas a necessitate naturali; Bradwardine refutes the psychological determinism of the Averroïsts); of external agencies and the influence of the heavenly bodies (libertas a necessitate fatali); and of all external violence (libertas a necessitate violenta). Freedom is thus reduced to spontaneous volition. ${ }^{1}$

Bradwardine's restrictions really eliminate genuine human freedom, and with it the whole scholastic system of ethics (304). They lead by another way to the Averroïstic view which he wished to avoid. In vain does he struggle to safeguard human responsibility and merit. His principles should force him to confess that God is the total cause of all cosmic evil and of all sin; but he repudiates such consequences and takes refuge in subterfuges.

Bradwardine's followers - and they were numerous, especially in Paris where the Causa Dei was held in high repute-were not slow to carry to its logical consequences the teaching of the "doctor profundus". This is especially true of Nicholas of Autrecourt, John of Mirecourt and John Wycliff. Among the opponents of Bradwardine were Peter Plaout and John de la Rive. $^{2}$

404. Nicholas of Autrecourt. - This restless and erratic philosopher was the soul of the anti-scholastic movement at Paris about the middle of the fourteenth century. In 1340 , when he was master of arts and had not yet got beyond bachelorship in theology, he was summoned, with six other students of theology, ${ }^{3}$ by Pope Benedict XII., before the Roman tribunal, to answer for several doctrinal errors. He was the only one of the crowd severely censured: a fact which points to the leading part he must have taken in fomenting the agitation. Only six years

1 "Sufficiat homini ut sit liber respectu omnium citra Deum et tantum modo servus Dei, servus inquam spontaneus, non coactus" (ibid., iii., 9, p. 667 E.). "Nihil est in potestate nostra, nisi secundum quid tantummodo, scilicet subactiva, subexecutiva et subserviente necessario, necessitate scilicet naturaliter praccedente respectu voluntatis divinae: quod ideo dicitur in nostra potestate, quia cum volumus, illud facimus voluntarii, non inviti " (p. 675 C.). The exposition above is according to HAHN. See below.

${ }^{2}$ D'ARgentré, op. cit., i., p. 328.

3 John the Servite, Elias of Courson, Guido of Veeli, Peter of Montregali, Henry the Englishman. 
afterwards the Curia condemned a collection of propositions from his teaching, deprived him of his mastership in arts and vetoed his promotion to degrees in theology. This condemnation was prior to the May of 1346 , and it was on the 20 th of this month that Clement VI. sent to the University of Paris the letter already referred to 380 . Nicholas retracted in $1347 .{ }^{1}$

We learn from the condemnations that Nicholas wrote nine letters to one of his opponents, BERnARD OF AREzzo, and a pamphlet of which we know only the opening words: Exigit ordo executionis. Among the propositions examined at the Roman court there are many which show clearly that their presumptuous author wanted to impose them on the University. He gave it to be understood that he was inspired by God and had a mission to regenerate science. ${ }^{2}$ The sophistical tactics of the Ockamist logician are plainly manifest in the manner of his discussion with his adversary. He himself describes the method adopted, in one of the documents of his trial: "When master Bernard and myself," he says, "engaged in a discussion, we agreed on a universally accepted first principle which was to serve as a guide to us in the interchange of our arguments, namely, the principle of contradiction, formulated by Aristotle in Book IV. of the Metaphysics"." Presupposing this, Nicholas proceeded to advance, by the aid of abundant dialectic quibbling, a long series of anti-scholastic theories. We find these jumbled together pell-mell in the documents relating to his condemnation, but we can piece together the logical chain that connects a number of them, from a reply made to the first two letters of Nicholas. ${ }^{4}$ He was answered not by Bernard-who does not seem to have been strong in philosophy-but by a certain master named Giles. The reasoning of Nicholas seems to have run in this wise: Since the principle of contradiction is the only principle that is certain and evident in

${ }^{3}$ Chartul., ii., p. 505.

${ }^{3}$ Ibid., pp. 580, $58 \mathrm{r}$.

3 "Quando magister Bernardus precictus et ego debuissemus disputare, concordavimus ad invicem disputando conferre de primo consensu omnium principio, posito a philosopho IIIIo Metaphisice, quod est 'Impossibile est aliquid eidem rei inesse et non inesse,' loquendo de gradu evidentie qui est in lumine naturali strictissimus. Istis suppositis dixi in predictis epistolis, eo (sic) quod tales conclusiones nec implicite continebant contradictionem nec explicite." Later he reduces this first principle to the principle of identity: "Item, quod hoc est primum principium et non aliud: si aliquid est, aliquid est".-P. 583 (53).

"Published by Hauréau (op. cit., 407), p. 332. 
itself, no truth can be certain unless it can be reduced to this primordial dictate of the mind. Certitude can have no degrees: it either exists or does not exist. ${ }^{1}$ But in order that a truth be capable of reduction to the principle of contradiction, the antecedent and consequent, or, in ultimate analysis, the subject and predicate, of the certain proposition embodying it, must be identical. This consideration Nicholas pushed so far as to grasp the intellect in the vice of subjectivism: declaring it unlawful to pass from the knowledge of one thing to the knowledge of another thing, under the pretext that the thing which is ex hypothesi another cannot be identical with itself, and that, therefore, the judgment which attributes a predicate to a subject different from this predicate, cannot be reduced to the principle of contradiction. ${ }^{2}$ Whence it follows that the principle of causality is worthless ${ }^{3}$ and that the observation of our psychic acts does not warrant us in asserting the existence of faculties. ${ }^{*}$ The existence of an external world, too, is indemonstrable: ${ }^{5}$ to argue from the presence of phenomena to the presence of a permanent reality underlying them would be to infer one thing from another: a procedure condemned by logic. ${ }^{6}$ From this he passes on to discount Aristotle,

${ }^{1}$ Chartul., ii., p. 576 (9).

2" Ex his infertis talem conclusionem: quod ex eo quod una res est cognita non potest evidenter, evidentia reductibili in certitudinem primi principii, inferri quod alia res sit" (HaurÉAu, op. cit., p. 333. Cf. Chartul., ii., p. $576(5,6,7)$ ).

${ }^{3}$ Chartul., p. 576 (5); 577. "Hec consequentia : $a$ est et prius non fuit, igitur alia res ab $a$ est, non est evidens evidentia deducta ex primo principio." $C f$. pp. $578(29)$ and $580(2)$. The argument is well developed by Giles, p. 334 .

4 "Iste consequentiae non sunt evidentes: actus intelligendi est; ergo intellectus est. Actus volendi est : igitur voluntas est" (p. 578 (30)).

5 "Quod in lumine naturali intellectus viatoris non potest habere notitiam evidentie de existentia rerum, evidentia reducta seu reductibili ad evidentiam seu certitudinem primi principii" (p. 583).

6 " Ex his conamini probare quod Aristoteles non habuit evidentem notitiam de aliqua substantia, et cet., quia de tali vel habuisset notitiam ante omnem discursum, quod non potest esse, quia non apparent intuitive et etiam rustici scirent tales substantias esse, nec per discursum, inferendo ex perceptis esse ante omnem discursum, nam probatum est quod ex una re non potest evidenter inferri alia. Item, demonstrato ligno vel lapide, arguitur sic: cum omnibus apparentibus ante omnem discursum, potest esse per aliquam potentiam, puta divinam, quod substantia non sit ibi, igitur in lumine naturali non infertur evidenter quod substantia sit ibi" (p. 333). Yet Nicholas admits the existence of the soul: "Item dixi epistola secunda ad Bernardum quod de substantia materiali alia ab anima nostra non habemus certitudinem evidentie" (Chartul., p. 577 (10)). His not very clear statement about. Aristotle is examined by Giles, who sums up Nicholas's second letter before replying to it: "Aristoteles nunquam habuit notitiam evidentiae de aliqua substantia alia ab anima 
asserting boldly that there are barely a few things certain in all his philosophy. ${ }^{1}$ Human knowledge, for Nicholas, is reduced to a small bundle of intuitive cognitions, sensible and intellectual, without any order or any bond of logical connection. He would make a clean sweep of the abstractions of Aristotle and Averroës and keep in close, direct contact with singular phenomena. ${ }^{2}$

This peculiar phenomenism, with its Ockamist reminiscences, is the most obvious element in the sophistical elaborations of Autrecourt. Elsewhere he shows, by other logical artifices, that it is practically the same to say: God exists, or, God does not exist ; ${ }^{3}$ that God and the creature "non sunt aliquid " ; ${ }^{4}$ that the acts of the soul are eternal, ${ }^{5}$ that all will attain in the end to the satisfaction of all their desires. ${ }^{6} \quad$ But perhaps those are mere whims or displays of dialectic prowess. What is more important to note is the fact that Nicholas denies substantial changes in Nature and explains the generation and corruption of things in accordance with the atomist theory by the agglutination and disintegration of atomic particles. ${ }^{i}$ Finally, he is just as clearly anti-scholastic in his teaching about the Deity: a holy and inviolable necessity has obliged the Almighty to realize the order of the cosmo; from all eternity ; ${ }^{*}$ and all activities in the universe are due to the immediate action of the First Cause. This latter point recalls the teaching of Bradwardine. ${ }^{\theta}$ The appli-

sua, intelligendo per substantiam quamdam rem aliam ab objectis quinque sensuum exteriorum, et a formalibus experientiis nostris" (p. 333).

${ }^{1}$ Chartul., p. 334 .

2 "Quod de rebus per apparentia naturalia nulla certitudo potest haberi; illa tamen modica potest in brevi haberi tempore, si homines convertunt intellectum sum ad res et non ad intellectum Aristotelis et commentatoris." - P. $5^{80}(\mathrm{r})$.

3 "Item, quod propositiones: Deus est, Deus non est, penitus idem significant, licet alio modo."-P. $580(3)$. Cf. p. 578 (33): "Item dixi in quadam disputatione quod contradictoria ad invicem idem significant".

${ }^{4} \mathrm{P} .578\left(3^{2}\right)$. This thesis is expressly reproduced in the prohibition of 1340 by the Arts Faculty: "Item quod nullus asseret sine distinctione vel expositione quod Socrates et Plato, vel Deus et creatura nichil sunt" (Chartul., ii., p. 506).

${ }^{5}$ P. $5^{82}(45)$ and $(47) . \quad{ }^{6}$ P. 583.

${ }^{7}$ P. $5^{8}$ I (37). "In rebus naturalibus non est nisi motus localis, scilicet congregationis et disgregationis, ita quod quando ad talem motum sequitur congregatio corporum athomalium naturalium, colliguntur ad invicem et sortiuntur naturam unius suppositi, dicitur generatio; quando segregantur, dicitur corruptio; et quando per motum localem athomalia sunt cum aliquo supposito, que fiunt talia, quod nec adventus illorum facere videtur ad motum suppositi vel ad id quod dicitur operatio naturalis ejus, tunc dicitur alteratio."

${ }^{8}$ Chartul., ii., p. 58I (39). $\quad{ }^{9}$ Ibid., p. 577 (14). 
cations of those principles to $\sin$ and to human conduct in general concern theology rather than philosophy. ${ }^{1}$

405. John of Mirecourt. - The influence of Bradwardine is much more traceable in the work of another bachelor of theology of this period, the Cistercian, JOHN OF MIRECOURT, condemned in I 347. His book on the Sentences follows out the applications of theological determinism to human conduct till it issues in absolute fatalism. There is no such thing as free will, since it is not we that will, but God that wills in us. ${ }^{2}$ Even sin is His work, and hence there can be no harm in committing it. "Quod Deus est causa peccati ut peccatum est." 3 John of Mirecourt is merely formulating the logical consequences of Bradwardine's system.

406. The Pantheism of Guido. - The denial of activity to created causes leads logically to pantheism. It is not surprising, therefore, to find among Bradwardine's followers some who explicitly formulated this conclusion also from his system. Such ivas the teaching of a certain GUIDO, whom the editors of the Chartularium identify with EGIDIUS of MEDONTA. From his retractation of his errors (I 354) we see that after denying moral freedom ${ }^{4}$ he openly propounded pantheism."

407. Sources and Bibliography.-Bradwardine's Causa Dei was edited, with a biography, by SAville of Merton College (London, r6r8). His mathematical treatises (De Proprietatibus Velocitatum; De Arithmetica Speculativa; De Geometria Speculativa) were edited at Venice in $\mathrm{r}_{502}$ (?) and $\mathrm{r}_{5} 05$. Dr. S. HAhN, Thomas Bradwardinus und seine Lehre v.d. menschlichen Willensfreiheit (Beitr. z. Gesch. d. Phil. d. Mittel., v., 2, I905): good. Werner has made a study of Bradwardine in Der Augustin. d. späteren Mittel., pp. 234 sqq.; but, as Hahn rightly remarks (p. 12), he is not always intelligible. The reply of Giles to Autrecourt is published by Hauréau, Notices et Extr., etc., t. xxxiv., Pt.ii., p. 332 (1895). Dr. Hastings Rashdall, Nicholas de Ultricuria. A medieval Hume (Proceedings of Aristot. Society, 1907). J. LAPPE, Nicolaus v. Autrecourt. Sein Leben, seine Philosophic, seine Schriften (Beitr. z. Gesch. Philos. Mitt., Münster, 1908) : a critical study: publishes letters of Nicholas to Bernard, of Giles to Nicholas, and extract from letter of Nicholas to Giles.

${ }^{1}$ Chartul., p. 584 (58) and (59).

${ }^{2}$ Chartul., ii., p. 612, n. 35 . "Quod voluntas creata qualitercunque causat aliquid seu aliqualiter agit, illud agit seu taliter agit virtute prime cause moventis et sic causantis." N. 9: "Quod qualitercunque sit, Deus vult efficaciter sic esse, et quod voluntas divina cujuslibet rei ad extra, qualitercunque ipsa sit vel fiat $a b$ aliquo, est efficiens prima causa". $\quad{ }^{3} V$. nn. 9-18, 27-34, etc.

4 "Dixi quod bonum meritum est a Deo, ita quod nichil est a voluntate" (Chartul., iii., p. 22, n. 5. Cf. n. 6).

5 " Dixi et scripsi quod nulla creatura rationalis specialiter est in se, nisi quia Deus est sibi inesse. Ex hoc intuli in eodem scripto, quod in omni eo quod non est Deus, essentialius est non-esse, quam ipsum esse" (ibid., n. 8). 


\section{CHAPTER IV.}

SOME NON-SCHOLASTIC LINES OF PHILOSOHHCAL, THOUGHT.

408. Deviations from Scholasticism. - Ve may bring under four heads the various secondary systems which, while retaining some of the doctrines of scholasticism, assimilated more or less freely various foreign principles: certain systems influenced by Averroism ; the German mysticism of Eckhart and his school; the theosophy of Raymond of Sabunde; the theosophic mysticism of Nicholas of Cusa.

\section{\$. INFHTRATIONS OF AVERROÏSU.}

109. John of Baconthorp.-Besides avowed Averroists (Ch. 111. \$ 1), we find in the present period, as in the thirteenth century $(\mathbf{3 5 8}, \mathbf{3 5 9})$, a number of scholastics who fell more or less under the influence of Averroism in their philosophical teaching : how much exactly in any individual case, it is difficult to estimate. One of the most distinguished doctors anong the Carmelites, and provincial of the order, JOHN OF BACONTHORP (Johannes Baco, died 1346), the author of commentaries on the Sentences and the intimate friend of Thomas Bradwardine, fell under the suspicion of Averroissm. Though admitting plurality of forms in inan and teaching that the intellectual soul in all its completeness is the form of the body, he doubts about the cogency of St. 'Thomas's arguments against the Averroistic teaching on the intellectus agens, ${ }^{1}$ and seems inclined to subscribe to the latter. His philosophy is not sufficiently known. The influence of some of the theories of Latin Averroism on scholasticism has yet to be studied. $\mathrm{We}$ believe this influence has been exaggerated-by Renan, ${ }^{2}$ especially, who describes "decadent scholasticism" as Averroîsm, and puts on the same plane such philosophers as Baconthorp, Peter of Tarantaise (262) and Gabriel Biel (462). ${ }^{3}$

'Werner, Der Averroïsmus in d. chris. peripat. Psj'ch., etc., p. $23 \mathrm{I}$.

${ }^{2}$ And by Werner, op. cit. ${ }^{3}$ Renan, op. cit., p. 320. 


\section{§ 2. Master Eckhart and German Mysticism.}

4ro. Life and Works.-The Dominican, Master Eckhart of Hocheim, born about 1260, studied successively at Cologne and Paris, where we find him in r 302 and r3rr. His life was given to preaching and contemplation. He had gathered around him, at his convent in Cologne, a large crowd of followers, when the archbishop of Cologne took proceedings against his doctrines in the year 1326. The following year, which was that of his death, Eckhart appealed to the Holy See. But in 1329 John XXII. condemned twenty-eight propositions taken from his Latin writings. Eckhart has left numerous sermons in German as well as an important Latin work called the Opus Tripartitum (comprising a liber propositionum, a liber quaestionum and an opus expositionum).

4II. Philosophical Teaching.-Eckhart propounded an equivocal sort of mysticism which it is not easy to absolve from the charge of pantheism. Before attempting an outline of it, let us glance at the metaphysical system which permeates it and supports it on all sides. Eckhart is thoroughly imbued with the doctrines of scholasticism, save on the one question of essence and existence; and here we get a full view of the characteristic-and fundamental--error of his whole philosophy. God alone, the Actus Purus, is His own being. In the creature, on the contrary, the essence or quiddity is distinct from the existence (288). Yet, an intimate bond attaches the creature to God, for God is the existence of the creature; the latter has no being (existence) other than God in Whom it subsists (Esse est Deus). God, therefore, constitutes the actuality of the world (Deus est primus actus formalis in omni opere artis et naturae); $\mathrm{He}$ is to the contingent essence or quiddity what act is to potency, what form is to matter, what unity is to number. Since the created essence is held to be distinct from God (esse rerum extra, in rerum natura) and has corresponding to it, as such, an idea in the Divine Mind of the Creator (omnis creatura habet esse unum in causis suis originalibus, scilicet in verbo Dei), Eckhart's is not a system of pantheistic emanation wherein all things would be reduced to mere phenomena or moments of the Divine Life. But still, the identity of existence which envelops Creator and creature, and in which Eckhart finds a proof of the Divine Ubiquity and of the eternity of Creation (quod enim est inquantum hujusmodi, non fit, nec fieri potest), seems to compromise the distinction between finite and Infinite: Eckhart, to say the least of him, borders perilously on pantheism. But let us add that he himself did not consider his theory as leading 
to those serious consequences. Cum dicitur Deum in omnibus nosse et amare solum esse et seipsum, quod est esse, hoc inquam dicentes non destruimus esse rerum, sed constituimus. ${ }^{1}$ Let us remember, too, that the German Dominican built on the basis of tradition, that he took from scholasticism his ideas, his terminology, and even his faults of method, and we will agree that Eckhart was not a renegade, but a scholastic of enlightened though unusual tendencies, who failed to free himself from an unfortunate confusion and misapplication of ideas.

This confusion is perceptible in his psychology also. The human soul is the being of God; in loving man, God loves Himself; He could not do without man, any more than man could do without Him. We must aim at freeing ourselves from ourselves and at being swallowed up in the abyss of the Deity; in this "deification" we shall find perfect happiness.

412. Eckhart and German Mysticism.-Eckhart is not the great man of genius it has been customary to represent him. History of course gives a large place to his name, but chiefly as the promoter of a national literature and of a new mystical movement called "German Mysticism".

This new mysticism was popular in its appeal. It was ern bodied mainly in sermons and was characterized by the language it made use of no less than by the teaching it contained. It created a German terminology and carried over the scholastic vocabulary into the language of the people: therein lay its great merit. Its favourite themes also were borrowed from the treasures of scholasticism: over and over again the German mystics studied the Deity in the majestic tranquillity and impenetrable mystery of His Being : exalted outpourings of the soul in the contemplation of the Divine Life, the Divine Knowledge and the intercommunications of Divine Love in the Blessed Trinity, are the constantly. recurring subjects of their writings and discourses.

Eckhart was not the founder of this mystic school, but he is its first great representative. ${ }^{2}$ His Latin works were forgotten even by his own contemporaries, but his sermons in the verna-

${ }^{1}$ Denifle, op. cit. (n. 420 ), pp. 494 sqq. To vindicate his "scholasticity" Eckhari submits the word esse to a series of distinctions some of which look like mere puns.

${ }^{2}$ Among his forerunners were Matilda of Magdeburg ( +1277 ) and especially ThFODERIC OF FREIBURG, "the first scholastic to preach in German after the manner of what is known as German mysticism" (DenifLE, op. cit.. p. 528. Cf. 353, e). 
cular were carried far and wide beyond the cloisters of the convent in which they were originally composed.

413. German Mysticism after Eckhart. - Eckhart formed a school in this sense that his successors were deeply influenced by the study of his writings. This is particularly noticeable in the Blessed Henry Suso (about I 300-1 366), in TAULER (I 290-1 36 I), and in the author of the German Theology. While Eckhart was more brilliant than his successors, many of the latter succeeded better than he did in defining the relations between Creator and creature. $^{1}$ But on the other hand, however, his mystical teaching was exploited and exaggerated by many popular sects in support of the growing practice of a pantheistic morality. In this way it contributed indirectly to that debasement of religion which culminated in the Reformation.

\section{§ 3. Raymond OF SABUNDE AND TheOSOPHy.}

4I4. Life and Works. - We have already made the acquaintance of theosophy as a peculiar kind of medieval rationalism, sprung from an exaggeration of the Christian Faith (158). It had a striking representative at the commencement of the fifteenth century in the person of RAYMOND OF SABUNDE ( $+\mathrm{r}_{43}$ ), a Spanish physician, philosopher and theologian. He was a professor at the University of Toulouse and wrote a Theologia Naturalis seu Liber Creaturarum, conceived entirely in the spirit of the Ars Magna of Lully. ${ }^{3}$

415. Philosophical Teaching. - According to Raymond of Sabunde, man reads truth in two books, the book of Nature and the book of the Sacred Scriptures. Their contents are identical : but to decipher the former we must have recourse to reasoning; to secure the latter we have only to believe in its instructions and precepts. "Quamvis autem omnia quae probantur per librum creaturarum, sint scripta in libro sacrae scripturae et ibi contineantur, et etiam illa quae ibi contineantur in libro Bibliae, sint in libro creaturarum, tamen aliter et aliter." 3 It is undeniable that the reading of the book of Nature must precede that of the inspired book, for to believe the word of God we must first know that God exists; and it is equally certain that there are truths, like the mystery of the Blessed Trinity, which reason could never discover from a study of the world; and others again which it could not discover in this way, had not revelation already pointed them out to us: those facts show clearly that man obtains his

\footnotetext{
${ }^{1}$ Denifle, op. cit., p. 53 r.

${ }^{2} C f$. SтӧскL, op. cit., ii. ${ }^{2}$, pp. 1055 sqq.

${ }^{3}$ Theol. Natur. (edit. of 1852 ), Tit. 212, p. 314.
} 
knowledge through two distinct channels which pour truth in parallel streams into his soul. Man is the connecting-link between visible nature and God. In this conception of the nature and state of humanity the Theologia Naturalis seeks an explanation of all the mysteries of the Christian Religion.

We need not follow Raymond's doctrine into its details: it is the principle of his theosophy that is of importance. His philosophy is a sickly brand of scholasticism. Inspired by a thirteenthcentury conception (355), it appeared at a critical epoch in scholasticism as a supreme but fruitless effort of the catholic mind to repulse the invasion of novel and dangerous tendencies.

\section{$\S$ 4. Nicitolas of Cusa.}

416. His Place in Philosophy.- How are we to classify Nicholas of Cusa, a man whose strange philosophy reveals so many diverse and conflicting tendencies? In him we hear the first faint murmur of the Renaissance war-cry: "Down with the Aristotelian faction!" But his invective is directed mainly against those dialecticians who opposed his mystic theory of the Coincidentia Oppositurum. ${ }^{1}$ Though his ideas are suggestive of coming upheavals in the world of speculation, they are in them selves rather a syncretism of the past, a fusion of mysticism, theosophy and quasi-pantheism. Nicholas is a discontented scholastic, but still a scholastic, imbued with the spirit of the schools: we will place him at the end of this third period in the history of medieval philosophy, at the very threshold of the Renaissance.

4I7. Life and Works. - Nicholas ChrypfFs, born at Cusa (hence the name Cusanus) in I 401 , got his initiation into mysticism from Gerard Groot at Deventer, studied law at Padua (1424) and gave himself up largely to the pursuit of mathematics. Entering Holy Orders, he took part in the dispute about the respective rights of Popes and General Councils. Later on he received some important commissions from Pope Eugene IV. and was created cardinal by Nicholas V. $\left(\mathrm{I}_{44} 8\right)$. He became bishop of Brixen in 1450 and got entangled in quarrels with the archduke Sigismund of Austria. He died at Todi in $\mathrm{I}_{4} 64$.

His busy and eventful life did not prevent Nicholas from devoting himself to science and philosophy. He has left very remarkable works on mathematics and astronomy. His principal works on philosophy are : De Docta Ignorantia, Apologia Doctae Ignorantiae, De Conjecturis.

1 "Unde, cum nunc Aristotelica secta praevaleat, quae heresim putat esse oppositorum coincidentiam, in cujus admissione est initium ascensus in Mysticam Theologiam . . ." (Apologia Doctae Ignorantiale, p. 64 of the Omnia Opera, Basle edit., 1565 ). 
418. Philosophical Teaching.- The three books of his great work, De Docta Ignorantia, are devoted respectively to God, or the Infinite; the universe and man, or the finite; and God the Redeemer, or the union of finite and Infinite. The influence of Neo-Platonism on the theories of Nicholas of Cusa was profound and far-reaching: he is much nearer Plotinus and Proclus than Witelo and Theoderic of Freiburg were in the thirteenth century.

The theosophical lines on which he establishes relations between philosophy and theology are likewise in keeping with his Neo-Platonic sympathies. His teaching is borrowed from the theosophy of Lully (355). On the one hand, the light of faith is indispensable for the discovery of truth (spiritus veritatis et virtus illuminativa caeci nati qui per fidem visum acquirit): without it the human spirit is like one born blind. On the other hand, reason is but a blossoming of faith, and can therefore attain to a demonstrative knowledge of mysteries. To get fully at the mind of Nicholas we must put this theosophical theory into relation with the mysticism of the Docta Ignorantia.

Our knowledge of God is negative. We cannot describe as truth either sense knowledge (sensus), or abstract, rational knowledge (ratio) based on the former, for both alike are changeable and fragmentary. Intellect alone, sustained by the supernatural aid of grace, can raise us up to the one, immutable Truth, which is God. Then we can understand how the Infinite is impene. trable and unknowable to us. And this consciousness of our own ignorance constitutes true wisdom, Docta Ignorantia: which should be made the basis of a new and negative theology to take the place of the false and misleading speculations of the current or positive theology ( $c f$. Pseudo-Denis, 1o5).

Whilst reason often arrives at divergent or contradictory conclusions, intellect attains to the intuition of the Divine Unity. In God, all contradictories will be found to merge and coincide (coincidentia oppositorum). Borrowing copious analogies from mathematics, Nicholas compares this coincidence of contradictories with the curve that becomes a straight line by lessening the curvature indefinitely, or with the hypotenuse which coincides with the other two sides of a triangle when the angle between the latter is increased indefinitely. God, says Nicholas, is infinitely great, and therefore, since He could not be any less than 
He is (!), He is likewise infinitely small. Excluding from His being everything opposed to Himself, God is the sole being; He is the complicatio omnium: in Him are all the manifold beings of the universe reduced to unity. Man can have positive knowledge of no essence whatsoever, because he can have no positive knowledge of God, Who contains them all. Consequens est omnem humanam veri positionem esse conjecturam. Here we touch the fundamental error of Nicholas's teaching: the theory he borrowed from the German mystics-who certainly influenced his philosophy profoundly - that God is a sort of consubstantial substratum or subsoil into which the whole universe plunges its roots. The universe contains explicitly what God contains implicitly; or, to make use of an appropriate and time-honoured expression, things are but Divine theophanies. Is the Catholic cardinal then a pantheist, like Scotus Eriugena, whose terminology he adopts, or like David of Dinant, for whom he does not conceal his sympathies? He defends himself vigorously against the charge in his Apologia Doctae Ignorantiae, against a certain Venchus who had attacked him and accused him of heresy. But we may say of him as of Eckhart, that he preserved his orthodoxy only at the expense of his $\operatorname{logic}$, and that it was only by a deliberate effort he repressed the natural conclusions from his premisses.

About the created universe, Nicholas taught that God created matter, or being in potency, but that matter cannot exist as such, that it needs a substantial form (286). And when he had described God as the form of all things, actus omnium, he added, in order to avoid pantheism, that God is in the creature only as the prototype of the latter, not as identical with its reality. Wan is the centre of creation and the most perfect image of God, for he embodies the universe in a manner within himself, by the mental representation he forms of it: as God also sums up in Himself the reality of all created things.

In the main lines of his psychology Nicholas is scholastic: the soul, the substantial form of the body, is spiritual and immortal (303). Our abstract cognitions have their origin in sense knowledge; but above reason there is intellect, which puts us into contact with the supreme 'Truth. In this exalted vision of things, wherein all the contradictions of human science are resolved, the union of the soul with God is so intimate that it is a sort of deification. 
419. Influence of Nicholas of Cusa. - The philosophy of Nicholas was connected with the past by its origin, and with the future by the influence it was destined to wield. At the time the German cardinal wrote, philosophy was at a turning-point in its history. Ideas were surging too feverishly through the minds of thinking men for the creation of a "Cusan school" proper, like the "Thomist " or "Scotist" schools." But numerous writers of the Renaissance, while groping their way to new orientations, undoubtedly fell under the ascendant of Nicholas's philosophical theories.

420. Sources and Bibliography for Chapter IV.-Johannes BAco, Super IV. L. Sentent. (Venice, I527). Pfeifer, Deutsche Mystiker d. 44 Fahrh. (Leipzig, 2 vols., I 845 and 1857 ), publishes 110 sermons, 18 treatises, 68 verses of Eckhart (in German). Sievers has brought to light twenty-six other sermons (Zeitschrift $f$. deutsches Altertum, I872). In I880 DENIFLE discovered and published, with a critical study, some fragments of the "opus tripartitum," Meister Eckeharts lateinische Schriften (Arch. f. Litt. u. Kirchengesch. d. Mitt., 1885). Denifle contends that Eckhart did not go so far as pantheism. According to Delacroix, on the contrary, who relies especially on the German sermons (op. cit., 201, pp. 135-62), Eckhart is a pantheist and "purports to explain All Being by the Sole Being, to analyze and follow the movement of evolution by which the Divinity issues fro. $\mathrm{n}$ itself, becomes God, and culminates in the universe" (p. 286). DenIfle, Die Heimath Meister Eckeharts (ibid., I889). On Eckhart and the popular mysticism of the fourteenth century see DeLACRorx, who gives a full bibliography and announces a special work on mysticism after Eckhart's time (pp. 3 and 4). Denifle, Die Schriften d. Seligen Heinrich Suse (Munich, 1876). Editions of the Theologia Naturalis of Raymond of Sabunde in $1488,1_{496}, 1_{507}, 1_{509}, 1852$. Edition of the works of Nicholas of Cusa in $\mathrm{I}_{4} 88$ (Strassburg); the Paris edition of $\mathrm{I}_{5} \mathrm{I}_{4}$ is fuller: 3 vols. Uebinger, Die mathemat. Schriften des N. Cusanus (Philos. Jahrb., I895-1897); Der Begriff Docta Ignorantia in seiner geschichtlichen Entwicklung (Arch. f. Gesch. Philos., viii., то). Duнem, Nicholas de Cues et Léonard de Vinci (Études sur Léonard de Vinci, 2nd series, Paris, 1909), pp. 97-279; De quelques sources auxquelles Nicolas de Cues à pu puiser (ibid., pp. 424-4I); Thierry de Chartres et Nicolas de Cues (Revue sciences philos. et théol., July, rgog).

' James LefÈvre D'Étaples (Jacobus Faber Stapulensis, r455-1537) spread the teachings of Nicholas of Cusa in France and edited his works, together with the works of Pseudo-Denis. His followers were known as the Fabrists. One of Lefèvre's disciples, Charles Bouillée (Carolus Bovillus, about 1470-1553), is the author of a number of works which clearly reveal, in addition to original thought, the influence of Nicholas of Cusa. Charles professes the purest theosophy (" Est enim intelligentia fidei consummatio, fides vero intelligentiae dispositio sacrumque initium "). Though he misconceives the nature of the species intentionales and ihe intellectus agens and gives arbitrary interpretations of many peripatetic theories, still he belongs to scholasticism even by a better right than Nicholas of Cusa, for he knew how to avoid all taint of pantheism in his teaching. 


\section{FOURTH PERIOD.}

\section{MEDIEVAL, PHILOSOPHY FROM THE MIDDIE OF THE FIFTEENTH TO THE SEVENTEENTH CENTURY.}

\section{CHAPTER I.}

\section{GeNFRAL, OUtLiNe.}

421. Brief Review of the Fourth Period.-.-The capture of Constantinople by the Turks, in $1+53$, is generally regarded as the close of the Middle Ages in the more proper sense of the term. In reality, the fall of the Byzantine Empire was only one episode in an era of great upheavals which compassed the ruin of medieval civilization and led up to the formation of the modern nationalities. The second half of the fifteenth and the whole of the sixteenth century witnessed a universal revolution in European life: not only in philosophy, but in the arts and sciences generally; not only in intellectual culture but in politics, in religion, in the fundamental conditions of economic and social life.

1. The dominant fact in politics was the formation of distinct nationalities. To the unity of the Christian Empire there succeeded a multiplicity of separate States, pursuing distinct and independent policies. National interests fomented the struggle of temporal princes against popes and stood in the way of a European coalition against the adrance of the Turks. In proportion as political and individual liberties asserted themselves, feudalism tottered to its fall and the great maritime discoveries shifted the axis of the world's economics.

II. In the intellectual order, a new spirit breathed over the face of Europe. This provoled the movement which is known as the Renaissance: the return to classical antiquity.

Italy was the cradle of the Renaissance: popes and princes 
were its patrons. Broken up into a mosaic of petty republics, the peninsula seemed as if specially prepared to foster the speedy expansion of the new ideas in all their astonishing variety. But from Italy the movement passed with something like lightning rapidity into France, England, Germany and the Low Countries.

Among the causes of the Renaissance, the invention of printing, combined with the exodus of Byzantine learning into Europe, holds the first place: it scattered in profusion over all Europe the new works that were being brought into Italy by the Greek scholars from Constantinople. It was not the fall of Constantinople in 1453 that brought about this great exodus of Byzantine savants into Italy: this had been going on for some years previously. Those émigrés of learning met with a royal welcome in the various cities of Italy. When they sang the glories of the ancient civilizations they found admiring and enthusiastic audiences for their classical themes. Literary and scientific relations between Byzantium and Italy, opened up in the thirteenth century, had steadily increased throughout the fourteenth: thanks to the growing commerce between the two civilizations and the attempts at a rapprochement between the Latin and Greek Churches (Council

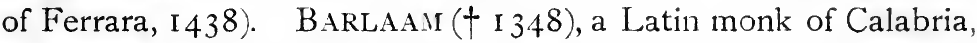
taught Greek to Petrarch (I304-I 374) and inspired the poet with his ardent enthusiasm for classic antiquity. LEONTIUs Pilatus, a disciple of Barlaam, was tutor to Boccaccio (about I 360), translated Homer, and held the principal chair of Greek literature at Florence. JOHN MALPIGHI, a pupil of Petrarch, taught Latin at Padua and Florence. The Byzantine Manuel Chrysoloras ( $\uparrow$ I 4 I 5 ) opened courses of instruction in the Greek language and literature and taught the celebrated humanist, LEONARDUS Aretinus (L. Bruni, † I444). In the fifteenth century, enthusiastic attachment to classical learning was universal.

The Renaissance found expression in a variety of forms. The first to manifest itself was a return towards the literature and art of Greek and Latin antiquity. Then, from this cult of the style of the ancient authors, their forms of literary and artistic expression, the transition was easy to an adoption of their ideas. Thus, paganism became the fashion in education and in manners, and philosophers admiringly revived the ancient systems in their archaic frankness and purity: accompanying the literary and artistic renaissance there was a renaissance in philosophy. We 
may further add that there was a scientific renaissance as well: or at least a new and rapid advance in science. The discovery of America in 1492 extended the horizon of the geographical world. as the discovery of the telescope afterwards was to roll back indefinitely the limits of the created universe. People grew accustomed to entertain large, ambitious views, and to cultivate, from a love for Nature, a strong and fruitful passion for the sciences of observation.

III. Nearly contemporaneous with the great intellectual revolution of the Renaissance, there appeared the great religious revolution known as the Reformation. Protestantism not only set up, in opposition to the ecclesiastical organization of the Universal Church, a variety of new hierarchies proper to each National Church, but it also modified Catholic teaching in several of its essential theses. The influences of the new Protestant dogma were indirectly felt in the domain of philosophy.

422. Division. - The new order of facts just outlined, in the various departments of human activity, were fraught with weighty consequences for the future. From another point of view they may be studierl as an outcome and continuation of the past. This is especially true of philosophy. Traditional theories did not disappear suddenly as soon as new systems arose: the traditional currents continued to mingle their waters with those of the newer sources. We have thus, in the fifteenth and sixteenth centuries, a number of transitional systems which prepared the way for modern philosophy all the while that they continued to preserve and transmit medieval modes of thought. It is under this latter aspect that we shall here study the philosophical systems of the Renaissance period. And we shall see that while all the newly conceived systems carried on an implacable war against scholasticism, they nevertheless borrowed from it a large body of their doctrines. ${ }^{1}$

Victory finally fell to the coalition of the non-scholastic forces. Having regard to this fact, we shall commence by a study of the non-scholastic systems (Chap. II.). There will be no need here, as for the preceding periods, to give a place apart to mere deviations from scholasticism. The paralysis of routine and ex-

${ }^{2}$ Even in modern philosophy we may trace the influence of scholasticism. See list of special works in our Scholasticism Old and New (Dublin, 1907), p. r6r, n. 2. 
haustion; the lack of all spirit of initiative; the necessity of focussing all available energy on the struggle for bare existence: all these causes at work in the various scholastic groups (Chap. III.), impeded such side-currents-which were always dangerous, but always interesting as unmistakeable evidences of a vigorous vitality. 


\section{CHAPTER II. \\ NON-SCHOLASTIC PHILOSOPHIES. ${ }^{1}$ \\ 1. Generil, Notions.}

423. Leading Features. - The first note of the non-scholastic systems of this period is their independence of Catholic dogma. The tendency to disregard Catholic teaching and to pursue philosophy in new domains and by new methods, is an almost universal characteristic of the systems sprung from the Renaissance. Some of them renounced all religious teaching, emphasizing the doubts of Scotists and Ockamists on the demonstrability of certain religious truths, and making capital out of these doubts to teach that all dogma is anti-rational. Others admitted new articles of faith, but reserved to themselves the right of picking and choosing. Rarely and by way of exception, some innovator made a show of safeguarding Catholic dogma.

A second striking fact about the Renaissance systems is their coalition against scholastic philosophy-a coalition joined even by those systems which professed submission to Catholic teaching (cf. 114).

Apart from this purely negative point of contact there was nothing common to the various philosophies of the Renaissance. Their heterogeneity may in fact be set down as a third great characteristic. Delivered up to themselves, they developed in diverging and often opposite directions: diversity of language, academic decentralization arising from the appearance of new universities, inanition of thought, the incorporation of a mosaic of theories-often mutually incompatible-into a single "system," -all these factors and features give the philosophy of the Renaissance a clearly marked individuality in history.

${ }^{1}$ On the philosophy of the Renaissance, see Höffding, History of Modern l'hilosophy, vol. i. 
Finally, the Renaissance systems all betray a want of that organic unity which constitutes the power and the beauty of a philosophic synthesis. There is a lack of originality and synthetic unity throughout. The philosophy of the time reminds one almost of a lunatic at large, engaging successively in a series of aimless and chimerical exploits.

424. Division. - In the first glow of intoxicated admiration for the past, the Renaissance scholars revived the philosophies of ancient Greece in their original, archaic forms. This effort at a restoration pure and simple of ancient systems, extended to the dialectic of the Rhetoricians ( $(2)$, Platonism ( $(3)$, Aristotelianism $(\S 4)$, Stoicism and some secondary systems $(\S 5)$. But this simple return to the past was soon to be modified by the results of new researches. These took two distinct turns: they explored the domains of Nature $(\S 6)$ and of Social Right $(\S 7)$. We may say generally of the earlier systems that they were independent of religious dogma. If, among their representatives, there were some who affected to harmonize their speculations with Catholic teaching, they made this a very secondary consideration, and generally solved the difficulty by espousing religious theories which had but little connection or kinship with the remainder of their philosophy.

There were other systems, however, whose supporters regarded religion as intimately related to philosophy, but for whom reason was the Supreme arbiter of religious beliefs. These beliefs were drawn mainly from the various forms of Protestantism ( $\$ 8)$. Reuchlin sought them in the Cabala; while many others fell back on Theism simply ( $(9)$.

This congeries of systems led some weak thinkers to despondency and distrust. And so, Scepticism is the epilogue to the long and painful parturition of the Renaissance philosophy ( $§$ IO).

\section{$\S 2$. HUMANISM.}

425. Influence of the Cult of Classic Philology on Philosophy. ${ }^{1}$ - The Renaissance devoted its earliest attention to the study of the pure forms of the Latin and Greek classics. It was believed that the study of the ancients could alone make perfect men (humanism, humanities), and, under the irresistible influence

${ }^{1}$ Cf. our Hist. de la phil. scol. dans les Pays-Bas, etc., pp. 317 sqq. 
of this conviction, most of the European universities introduced the study of the ancient grammars and languages. ${ }^{1}$

Is it any wonder that the admirers of the language of Cicero should conceive a strong distaste and disgust for the worn-out language-forms of decadent scholasticism? Its philosophic terminology, its uncouth and cumbersome phraseology, everything in it, in fact, was stricken with the universal reproach of "barbarism". And the same opprobrium which was cast on its form was allowed to fall on its matter also: the inference was made and accepted that those Boeotians, who were incapable of writing, were likewise incapable of thinking. In this way, humanism delivered a first and terribly reeling assault upon scholasticism by discrediting the "peripatetics"." This was the negative side of its work.

The native attempts of the humanists themselves in the domain of philosophy, are really laughable. The leading idea of their philosophy is the reduction of all philosophy to dialectic and the reduction of dialectic itself to rhetoric. They confound the science of things with the art of reasoning, and the art of reasoning with the art of expression. The greatest philosophers were Quintilian and Cicero, because they were the greatest rhetoricians!

426. Some Leading Humanists. - One of the most typical of these humanist "philosophers" was the Italian, Laurextius Valla (1407-1459), whose Dialecticae Disputationes contra Aristotelicos are little better than a sustained sneer at Aristotelian logic. Valla found an imitator in Rodolph Agricola (1442-1485), whose De Inventione Dialectica is written in the same strain. Those have an equal in the Spaniard, Ludovicus Vivis (1 $492-1540$; author of De Causis Corruptarum Artium, In Pscudodialecticos, De Initiis, Sectis et Laudibus Philosophiae). He contracted his hatred of scholasticism from the lectures of John Dullaert at Paris; propagated his humanist and anti-scholastic ideas in the Low Countries, especially at Louvain where he had relations with Erasmus; passed over to England for a time; but returned to die at Bruges in 1540.

Of more significance, though no less barren, were the views of MARIUS Nizolius of Modena (I49S-1575), who spent his life on the works of Cicero (Thaesaurus Ciceronianus) and attacked scholasticism in a treatise Contra Pseudophilosophos, edited by Leibnitz in 1670. Dialectic and Metaphysics are removed from the catalogue of the philosophical sciences to make room for Rhetoric. For the science of Being he substitutes the science of words, denying all reality to the universal.

The same general principles were strenuously advocated by the most influential of all those humanist-philosophers, Peter de LA RAmé (Petrus Ramus, 1515-1572). When he was yet scarcely twenty-one, he maintained in a public thesis that all Aristotle had taught was a pack of lies. This was the keynote to his scholastic

'Chartul., iii., pp. $x$ and $x$ i.

${ }^{2}$ The name given by many Renaissance writers to the scholastics. 
career. Thenceforth he dreamt of compassing a thorough regeneration of dialectic.

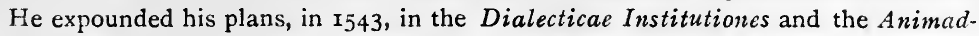
versiones in Dialecticam Aristotelis. These works provoked violent opposition. Ramus was silenced by order of Francis I. But on the latter's death, in the following year, he resumed the teaching of philosophy in the College of Presle and reedited his works. In ${ }^{562}$ he went over to Calvinism: this change of religion, while it won him sympathy in Germany, increased the opposition to him at Paris and obliged him to quit France. On his return there, in $157 \mathrm{r}$, he perished in the massacre of St. Bartholemew.

In his Dialecticae Institutiones, Ramus distinguishes natural and artificial dialectic, annexing the rules of the latter to the spontaneous functioning of the former. Dialectic, being merely the virtus disserendi, embraces the investigation of the common sources from which reasoning springs (inventio) and the application of the general principles found there to each particular process of reasoning (judicium). $\mathcal{F}$ udicium teaches us how to formulate consecutively isolated propositions, to arrange them in a scientific system, and ultimately to subordinate all the sciences to God. Dialectic exercises (interpretatio, scriptio, dictio) complete our training in artificial dialectic, and their supreme object is to endow us with the art of perfect discourse. For reasoning is united with discourse as the heart is with the tongue.

The collection of elementary precepts and platitudes which constituted the dialectic of Ramus, met with great favour among the many scholars who were captivated by the spirit of humanism. They set up the Ramist dialectic in opposition to the Aristotelian; and thus there arose two distinct parties, the Ramists and the Aristotelians. Johannes Sturm in Germany, Arminius in Holland, Nicholas du Nancel at Douai and in the Low Countries, William Temple (1533-1626) at Cambridge in England, are the leading names on the long list of the partisans of Ramus. Cornelius Martini (1567-1621) at Helmstadt ${ }^{1}$ and Everard Digby at Cambridge, were his most determined adversaries. The latter wrote, against Ramus, his treatise $D_{\varepsilon}$ Duplici Methodo. ${ }^{2}$

It was to the language and method of scholasticism that the humanists were primarily opposed : sections of them, however, were just as bitterly, and much more obstinately, hostile to its teachings.

\section{§. Platonism.}

427. The Platonist Renaissance in Italy. ${ }^{3}$ - From 1450 to I 550 , Italy worshipped Plato. It was introduced to his works in the original by the scholars from Byzantium, where Plato had come to be regarded as the equal of Aristotle from the time of the younger Psellus (211). In the poetic atmosphere of the Platonic dialogues, the Italian Renaissance found all the elements that fed and fostered its love for the beauties of classical antiquity. It is

${ }^{1}$ See our Hist. de la phil. scol. dans les Pays-Bas, etc., p. 34r.

'On Digby and Temple, see Freudenthal's articles in the Arch. f. Gesch. $d$. Phil., iv., 3 and 4 .

${ }^{3}$ Cf. Huit, Le Platonisme pendant la Renaissance (Ann. phil. chrétienne, 1895 to 1898$)$. 
easy to understand how artistic souls, in quest of beauty more than of truth, would turn away in disgust from the abstract discussions of Aristotle and the scholastics. Add to this that the Aristotle of scholasticism now saw rising up beside him an antischolastic Aristotle, the protagonist of a new and specific form of materialism; which disposed scholars to conclude all the more readily that it was not in Aristotle's writings, but in Plato's, the deposit of ancient philosophic truth was to be found.

428. Principal Platonists. - Barlaam taught Petrarch some of the Platonic dialogues. Aurispa and Traversari brought from Byzantium, in 1438, the first complete manuscript of Plato. Leonardo Bruni translated the choicest of the dialogues into Latin.

But the first real promoter of Platonism was Georgios Gemistos, called afterwards Pletho (1355-I450). He was a Byzantine savant, delegated by the emperor John Paleologus VIII. to attend the councils of Ferrara and Florence, whither the Holy See had invited the schismatical Greeks with a view to effecting, if at all possible, a reunion of the separated churches. Gemistos Pletho held up to the astonished Florentines the great rival of Aristotle, and induced the court of the Medici to found a Platonic Academy. His bitter diatribe against Aristotle, $D_{\varepsilon}$ Platonicat atque Aristotelicae Philosophiac Differentia, circulated in Florence in ${ }^{4}+4^{\circ}$, is full of exaggerations. As for his own philosophy, it was much more closely akin to Plotinus than to Plato. It is curious to see the Imperial envoy who was charged with the reunion of the Christian Churches advocating in his Nórot a universal theism with Plato as its Gospel. Pletho was supported by Argyropulus and Michael Apostolius; but he was ably opposed by the patriarch Gennadius at Constantinople (36r), and by the Aristotelians, Theodore GazA and George of TrEBIZOND.

Above the conflict between Aristotelians and Platonists was heard the conciliating voice of a disciple of Pletho, Cardinal BESSARIon (I403-I426). Of this Italianized Greek it has been justly said that "he was the most Greek of the Latins and the most Latin of the Greeks". In reply to the pamphlets of George of Tre-

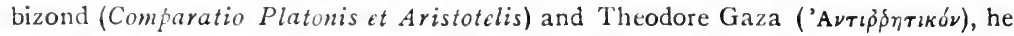
wrote a treatise In Calumniatorcm Platonis, in which he combined an avowed admiration for Plato with a respectful deference towards Aristotle. So far from setting them in opposition to each other as irreconcilable adversaries, he rather sought a means of harmonizing their philosophies, insinuating the opinion that was afterwards to meet with such universal favour: that the two great Grecian sages differed from each other more in the form than in the content of their teachings.

It was in the wealthy city of Florence, under the rule of the famous Medici. Cosmo and Lorenzo, at the head of the aristocratic and exclusive Florentine Academy, that the greatest representative of Italian Platonism, Marsilio Ficino (1433-1499), won an enduring reputation. At the request of his protector, Cosmo de' Medici, he translated all the works of Plato into Latin (about $\mathrm{I}_{453}$ ). The accomplishment of this task assured the success of the movement to popularize Plato. Besides translations of Plotinus, Iamblichus and Proclus, Ficino has left some original works, among which the Theologia Platonica de Animarum Immortalitate and the De Christiana Religione deserve mention. He admits innate ideas and the theory of the world-soul; his principal aim in the Theologia Platonica is to refute 
the Averroists and Alexandrists $(\S 4)$, whom he accuses of heresy, and to defend the immortality of the soul against them by all the arguments of the Phaedo. $\mathrm{He}$ takes an evident delight in expounding the Platonic theory of love and of the sovereign good.

Although imbued with Platonism and anxious to be true to Plato throughout (Nolim Marsilianam doctrinam opponere Platonicae), Ficino misunderstands the real import of Plato's philosophy. He realizes neither the important role of the Ideas in the economy of Platonism, nor the true significance of the pantheistic emanation theory in Neo-Platonism. Plotinus, from whom he borrows his poetic mysticism and his description of the hierarchical order of beings, he holds to be the faithful interpreter of Plato. And finally, under pretext of reconstructing the golden chain that links together all the great thinkers with the divine Plato, he welcomes into his hospitable synthesis the ideas of Hermes Trismegistus, Pythagoras, Zoroaster, Pseudo-Denis, and even the teachings of Magic and of the Cabala, which were steadily becoming the fashion of the time in intellectual centres.

The history of the Florentine Academy was as brief as it was brilliant. The death of Lorenzo de' Medici (1492), the political disturbances which centred around the Dominican monk, Savonarola, and especially the dearth of serious workers, led to the rapid decline of the great movement for the glorification of Plato. Amongst his numerous auditors, pompously described by Ficino as Complatonici mci, scarcely a name deserves to be saved from oblivion. The best known is Giovanni Pico, count of Mirandola (I463-I494), who compiled a strange medley of Grecian philosophy, magic and cabalistic doctrines. ${ }^{1}$

429. Conclusion.- There is nothing in the Platonic revival of the fifteenth and sixteenth centuries resembling the revival of Aristotle in the scholasticism of the thirteenth and fourteenth. The Platonists of the Renaissance went to Plato for enlightened recreation rather than for instruction. Their Platonism is largely Neo-Platonism, and their pretence of reducing Plato to Plotinus proves that they understood aright neither the one nor the other. The same may be said of Cardinal Bessarion's idea about the fundamental agreement of the teachings of Plato and Aristotle. Somewhat similar fancies had been entertained by certain Alexandrians of the Grecian decadence, who display a like sterility of thought and a like ignorance of history $(\mathbf{8 8})$.

The Aristotelianism of the Renaissance, set up in opposition to Platonism, displays the same characteristic shortcomings.

${ }^{1}$ In no other country of Europe was there such an outburst of enthusiasm for Plato as in Italy. Catholic Spain, which was always the faithful champion of Aristotle, gives Plato a place in its sixteenth-century mysticism. We may mention Leo Hebraeus (Leo the Hebrew, died about 1460-1463), a Jew of Lisbon, author of Dialogi di Amore. Neither Germany nor England favoured Platonism; its influence is revealed in a secondary and isolated way in such men as REUCHLIN and Blessed Thomas More. In France, a Platonic current was felt early in the sixteenth century: LE Roy (Regius, r5ro-r577) translated some of Plato's dialogues into French; De Serres (15.40-1597) made a new Latin translation of all Plato. 


\section{$\$$ 4. ARIStotelianism.}

430. Various Forms of Renaissance Aristotelianism.- IVas there any need of a revival of Aristotelianism? Was it not dominant for centuries in the medieval schools? Yes; but for the philosophers of the Renaissance the scholastic Aristotle was a truncated Aristotle: and they set themselves to revive the real Aristotle. They made their own of the reproaches cast upon St. Thomas and his contemporaries by the Averroists of the thirteenth century. And these "reproaches" were indeed well merited, for the scholastics took care to avoid the servility of their adversaries in the cult of Aristotle. There was another reason too for regilding the crest of the Stagirite. The doctrines of Plato had been put on the market anew: and it seemed incumbent on many to defend the centuried monopoly of the Prince of the I.yceum against this latest intrusion. Hence all those impassioned controversies between Italian Platonists and Italian Aristotelians of the fifteenth century.'

But the defenders of Aristotle were not agreed among themselves upon his doctrines. Some of them, perpetuating the antischolastic traditions of the fourteenth century, knew only the Aristotle of Averroës' commentaries; others, doubting the fidelity

'The disputes about the pre-eminence of Plato or Aristotle commenced at Byzantium. where Gexvadius fought in favour of Aristotle; then extended to Italy and Rome, where Michael Apostolius, Andreas Contrarius and Cardinal Bessarion took the side of Plato, while Theodore Gaza, George of TrebiLOND (1396-1584) and ANdronicus Callistus took the side of Aristotle. Towards ${ }_{4} 6_{3}-6_{4}$ there was quite a war of pamphlets, in many of which personal invective took the place of argument. Among the Aristotelians, Thronore GazA ( $\mathrm{I}_{47} 8$ ) may be ranked as equal to Bessarion among the Platonists. He was also a personal friend of Bessarion. Born at Salonika early in the fifteenth century, he shone for a time at Constantinople; then, like so many of his countrymen, he started for Italy long before the capture of that city. At the Papal court, which, in the pontificate of Nicholas V., rivalled that of the Medici, Theodore translated all the works of Aristotle. This was his principal achievement, and it was more highly valued than the similar enterprize of George of Trebizond, with whom he competed for the favour of the pontiff-king. There were other translators of Aristotle besides. Thus, the Byzantine, Јонn Argyropulus, who died at Rome in i 486 , translated, at the court of the Medici, the Organon, the Auscult. Phys., the De Coelo et Mundo, the De Anima and the Nich. Ethics. According to Steis, Der Humanist Theodor Gasa als philosoph (Arch. f. Gesch. d. Philos., I889, p. 426), Gaza is a faithful and conscientious translator who worked on Aristotle's original writings, rendering then without any controversial prejudices. A. Gaspakr, Zur Chronologie des Streites ibber Plate und Aristoleles im 15 fahrh. (ibid.). 
of the Arabian commentator, sought the new spirit among the Greek commentators, especially in Alexander of Aphrodisias. Hence arose the Averroist and Alexandrist parties, ${ }^{1}$ whose controversies sum up the history of philosophic thought at the two Italian centres of Aristotelianism, Padua and Bologna, in the fifteenth and sixteenth centuries. The immortality of the soul was their chief bone of contention. For the Averroïsts, defenders of monopsychism (339), immortality is impersonal; for the Alexandrists (74), the human soul perishes altogether with the body, as the form disappears in the dissolution of the compositum. Both parties agree in denying Divine Providence and human freedom. Those of either party who wanted to safeguard their Catholic belief, had recourse to the theory of the two truths. But most of them were quite unconcerned about the relations of their philosophy with Catholicism. The Fifth Lateran Council (I 5 I3) condemned as heretical the theory of the two truths, the theory of the unity of the human intellect, and the theory of the mortality of the human soul. ${ }^{2}$

43r. The Averroïsts. -Alexander Achillinus ( 1463 - I518, De Intelligentiis, De Orbibus, De Universalibus), Augustinus Niphus ( $(473-1546)$ and $Z$ Imara (died 1532) were the most noted among the Averroïsts of Padua at the beginning of the sixteenth century, ${ }^{3}$ not to mention the crowd of litterati of whom Petrarch speaks, and who thought it good taste to declare themselves Averroists. AcHillinus was called "the second Aristotle" on account of his commentaries on the Stagirite. Niphus was not a man of the same order of talent. After teaching pure monopsychism (De Intellectu et Daemonibus) like his master, Nicoletto Vernias, and editing the works of Averroës ( $1495-1497$ ), he modified his teaching to bring it into agreement with Catholicism. And when his rival, Pomponatius, began to teach in opposition to him, he was unable to defend the authority of Averroës against the latter's attacks. The De Immortalitate Animae (1518), in which Niphus replied to the similar work of Pomponatius (1516), is written in the spirit of the Lateran Council and borrows from Thomism its best arguments for Immortality. Z IMARA was more open in his Averroïsm than Niphus. $\mathrm{He}$ wrote commentaries on Averroës and edited the works of John of Jandun (398). ${ }^{4}$

432. The Alexandrists.-Averroism entered on a new and exciting phase, a phase of heated polemics, when Petrus Pomponatius (Pomponazzi, 1464-I524) set up the Aristotelianism of Alexander of Aphrodisias in opposition to that of Averroes. After completing his studies at Padua, Pomponatius taught at Ferrara and Bologna. In his Tractatus de Immortalitate Animae (1516) and in the Defensorium, which

${ }^{1}$ Here and there we find other early Greek commentators revived. Thus HerMOLAUS Barbarus, who translated the works of Aristotle, studied them according to Themistius. UeBerweg, op. cit., iii., p. I4, I888.

${ }^{2}$ WeRnER, Sitzungsberichte, etc., r881, p. 209.

${ }^{3}$ The first edition of Averroës appeared at Padua in 1472.

4 On the Averroïsm of the school of Padua, see Renan, op. cit., Part ii., ch. iii. 
contains his reply to Niphus, he contends that the substantial "informing" of the body by the soul, the materiality and mortality of the latter, and the evanescence of personality at death, are the genuine doctrines of Aristotle. He adopts the view of the Stoics on the relations between Providence and human liberty, and contends that reason has invented revelation (De Fato, Libero Arbitrio et Praedestinatione). Finally, in another treatise, De Incantationibus, he denies the existence of miracles, angels and demons, and attributes to the natural influence of the stars all the extraordinary phenomena that foster superstitions.

The daring and energetic attitude of Pomponatius secured him a considerable following. Simon Porta of Naples († 1555), the Spaniard Sepulveda († 1572) and Julius Caesar Scalgier $\left(1484-155^{8}\right)$ were the most noted among the Alexandrists. ${ }^{1}$

433. Conclusion.--Those Renaissance Aristotelians who attempted to reconstitute Aristotelianism according to the text of Aristotle himself, failed miserably in thein endeavours. On the other hand, the Alexandrists and Averroists made little scruple of interpreting to suit their own prejudices, the teaching of Alexander of Aphrodisias and Averroes-themselves untrustworthy interpreters of the Stagirite. Hence we may say of all the non-scholastic Aristotelianism of the Renaissance that in so far as it claims to be a genuine restoration of Peripateticism it is simply belied by the testimony of history.

\section{$\$ 5.5$ TOICISM AND ATOMISH.}

434. Stoicism. - The revival of ancient philosophies becoming the fashion at the Renaissance, it is not surprising to find certain humanists attach themselves to some or other of the secondary luminaries in the firmament of Grecian philosophy.

Justus Lipsius (1547-I606), a humanist rather than a philosopher, was professor at the University of Louvain, where he defended the ancient Stoicism (Mamuductio ad Stoïcam Philosophiam). He earned a widespread reputation but did not succeed in creating a school. Stoic doctrines are found, however, to

${ }^{1}$ Three other admirers of Aristotle, Jacob Zarabella (I532-I589). Francesco Piccolomini (1520-1604) and CAESAR CREMONini (I552-163I), are classified sometimes with the Alexandrists, sometimes with the Averroïsts: they borrowed theories from both sources. Cremonini, whose cult of Aristotle won for him the name of Aristotcles Redivivus, was intimate with Galileo, and it is told of him that he refused to look through the telescope for fear of finding Aristotle's Physics (Ch. III., \& 7) at fault! Between Alexandrists and Averroïsts comes the figure of Andreas CaEsALPINUS (1509-1603), who undertook the study of Aristotle in the original text, apart from all cummentaries. But the pantheistic sort of cosmology expounded by him in his Quaestiones Aristotelicae and his Demonum Investigatio proves pretty plainly that his purism did not enable him to grasp the real thought of the Stagirite. 
have permeated quite a number of the Renaissance systems. They are in evidence in the writings of Erasmus, Zwingli, Leonardo Bruni, Melanchthon and other representatives of Theism.

435. Atomism.-A place of equal importance in Renaissance philosophy must be assigned to Atomism, as taught by Democritus and Epicurus. Thus, we find it in the writings of DANIEL Sennert (1572-1637), of ERycius Puteanus (1574-1646), the successor of Justus Lipsius at Louvain, and others. The most noted among the atomists of the age was PETER GASSENDI (1 592-1655), author of Exercitationes Paradoxicae adversus Aristotelicos and De Vita et Moribus Epicuri. All these philosophers, especially the latter, waged an implacable war against Aristotelianism. They lent a willing hand to the scientists in throwing discredit on the antiquated Physics of the Stagirite and-as an inevitable, though illogical consequence-on the remainder of his philosophy as well (Ch. III., $\$ 7$ ).

\section{$\$ 6$. Nituralism.}

436. Various Forms of Naturalism.-Simultaneously with the revival of the doctrines of ancient philosophy, an earnest study of external Nature gave rise to original systems of philosophy. These we may designate by the general title of Naturalism. The Renaissance developed a passionate admiration for the beauties of the visible universe. In proportion as men reflected on it they were fascinated by its wonderful mysteries: it gradually won from them a worship which recalls the enthusiastic cult of the Alexandrians. In this devoted and sympathetic attachment to the beauties of Nature we have the real source and motive of those observations and researches which led to the marvellous discoveries of the seventeenth century in the domains of Physics and Astronomy.

But the results of an experience that was as yet exceedingly elementary and limited in extent, could hardly be expected to have satisfied the impatient longing of the human mind to pry into all the arcana of Nature: and so we find explorers appealing to Nature's hidden forces, interrogating the Cabala and the arts of magic and astrology. Physicians especially revelled in secret arts and introduced into philosophy the search for the elixir of life that was to confer perennial health and youth upon mankind. 
We may add that most of the naturalistic systems of the period were pervaded by a spirit of pantheism. Nature was not merely. exalted, it was deified: if Nature be understood to be a living manifestation of the Deity, no wonder it should be so astonishingly beautiful.

We have indicated the three main features of Renaissance naturalism: the spirit of observation, the pursuit of the occult sciences, the tendency towards pantheism. According as one or other of these predominates, we have (I) empiric naturalism, (2) occult naturalism, or (3) pantheistic naturalism.

437. Empiric Naturalism. Telesius.-BERNARdinus Telesits (1 508-1 588), the founder of Renaissance naturalism, deroted himself entirely to the study of the natural sciences, coupled with an acrimonious and lifelong campaign against the physics of the Aristotelians. He founded the Accademia Telesiana at Naples for the promotion of the natural sciences. His principal treatise, De Natura Rerum juxta Propria Principia, is the frank, yet logical, effort of a physicist pure and simple, to explain Universal Nature by the interplay of a limited number of physical forces.

Within the passive and inert mass of matter that constitutes the universe, God has created two active principles, heat and cold, the principle of movement and the principle of absolute rest. Those two forces, incorporeal and mutually exclusive, share between them the total quantum of created matter. Hence the great division of the created universe into the heavens which are the centre of heat, and the earth which is the centre of cold. Since each principle is endowed with a tendency to self-preservation, each possesses the faculty of feeling the destructive action of its opposite. This overthrows the Aristotelian theory of the four elements (295) and sets up the phenomenon of sensation as a cosmic fact. The individual things that people the earth arise from the contact of the radiant heat of the heavens with the icy surface of the earth: and the same law presides over the formation of minerals and the genesis of living things.

On those principles of physics, Telesius rears a new sort of vitalism which is interesting in its broad lines. The principle of animal life is a sfiritus, a modicum of heat, circulating through the body and presiding over all its organic functions. This theory of animal spirits was evidently a revival of the ancient doctrine of the $\pi \nu \in \hat{v} \mu a$, and became itself in turn the starting-point of 
the physiology both of Bacon and of Descartes. The spiritus is not, as in the scholastic system, an emanation from the formative principle (303, n. I); it takes the place of the substantial form itself : Telesius directed a violent criticism against the Aristotelian theory of hylemorphism. Sensation and appetite are merely modes of action of the spiritus; cognitive phenomena are reduced to transformations of sensation; moral phenomena are traced to the instinct of self-preservation. The human spiritus is more refined and subtle than that of the brute, but does not differ in nature from the latter.

It is true that Telesius corrects this excessive naturalism, like Cardanus and Paracelsus, by admitting the existence in man of a forma superaddita, immaterial and immortal, which enables man to know God (303); but about this form he is concerned only in a very secondary way: he admits it merely to save appearances, and it introduces into his psychology a dualism similar to that with which St. Thomas taxed the partisans of plurality of forms.

438. Campanella. - The Physics of Telesius was one of the most original and masterful productions of the Renaissance. Campanella (1568-1639) took it up and added to it a Metaphysics and a Politics. ${ }^{3}$ Being, as such, implies three "primalities" (primalitates) which are of its very essence (essentiatur): the power by which it can exist and act (potentia), the knowledge that reveals it to itself (sapientia), and the love which inclines it to will its good (amor). Inversely, pure non-being implies impotentia, insipientia and odium. God alone is pure Being and possesses all the fulness of the real primalities. Every creature distinct from $\mathrm{Him}$ is a mixture of being and non-being (traces of scholasticism); it possesses the essential primalities in the degree in which it has reality. Telesius had already attributed to physical forces the power of feeling: Campanella now gave to this cosmic panpsychism a metaphysical, universal significance.

His Politics he based on the love man bears to himself, and to society as a prolongation of himself. His Civitas Solis, which was in some measure inspired by More's Utopia, is a fanciful

${ }^{1}$ Amongst his very numerous works, re-edited in 1854 by D'Ancona, are the following: Prodromus Philosophiae Instaurandae; Realis Philosophiae Partes Quatuor; Philosophiae Rationalis Partes Quinque; Universalis Philosophiae seu Metaphysicarum Rerum juxta Propria Principia Partes Tres. 
description of an ideal State in which individual liberty is regulated in all its details with a view to the common good.

We may add of Campanella that he was deeply devoted to the chimeras of astrology and magic. Through them he hoped to attain to a knowledge of the inner antipathies and sympathies of things, and of the cosmic function of the world-soul--that great, benign power charged by God with the maintenance of order in the universe. It is, however, in the naturalism of Paracelsus and Cardanus that the occult sciences are found to dominate.

439. Naturalism and the Occult Sciences. - It was mainly the medical profession that produced those naturalists who tried to substitute for the ancient physics a new philosophy based partly on observation, partly on the data of the Cabala, astrology, magic and alchemy.

PARACElsus of HoHeNHeIM (1493-154I) opens the list of those medical innovators by a series of works composed by him in German and translated into Latin by his disciples. We may mention the Opus Paramirum, Die srosse Wundarmei, De Natura Kerum. He conceived the science of medicine to be supported on four pillars: theology, philosophy, astrology and alchemy.

The same medley of cabalistic doctrines with alchemy, magic and astronomy; is found in the works of another famous physician, who appears to have arrived at conclusions analogous to those of Paracelsus without having linown the latter's writings: the Italian, Hieronymus Cardanus (150I-1576), author of the treatises De Varietate Rerum and De Subtilitate.

440. Pantheistic Naturalism.-Of all the conceptions that emphasize the esthetic optimism of Nature, pantheism is the most alluring. The deified cosmos is endowed with one all-embracing life, and all the palpitations of this colossal organism are explained on the ancient theory of the world-soul.

PAtRitius (Patrizzi, I 529-1597) was a Platonist, and one of Aristotle's most implacable adversaries. But the Platonism, or rather Neo-Platonism, which he advocated, was in the main a theory in explanation of the physical universe. Accusing scholasticism of doing ill service to the Catholic faith, he went so far as to request Pope Gregory XIV. to impose on the Christian Church the new philosophical synthesis of which he himself was the author. His principal work, Nowa de Lniversis Phil- 
osophia, is divided into four parts: Panaugia, Panarchia, Panpsychia, Pancosmia, devoted respectively to the study of light, of first principles, of life, and of the order of the cosmos. The Absolute One, Unomnia, Sole Reality and Supreme Goodness, produces within Himself the Blessed Trinity, and without Himself the universe, invisible and visible. In this process of descending emanation (Plotinus) the world-soul is one of the stages. Creation is meaningless, since the creature is a continuation of the Being of the Creator. It is the world-soul that communicates life and movement to terrestrial beings, man included. Patrizzi explains all the phenomena of physical Nature by a theory of light (Panaugia) analogous to that of Telesius.

GIORDANO BRUNO (I 548-1600) was another ardent champion of pantheism. He wrote many works in Latin and Italian : the principal are Dialoghi della Causa Principio ed Uno: Degli Evoici Furori; Dell' Infinito Universo e dei Mondi. He was influenced by Raymond Lully and still more by Nicholas of Cusa.

The entire immanence of God in the world is the fundamental thesis in Bruno's philosophy. God is the complicatio omnium, the coincidentia oppositorum (418); and the ever-changing flow of phenomena is but the explicatio of an eternal monist force, invariable in its substance, omnibus praesentissimus. The "accidents" of this substance spring from one original, underlying matter, which is the passive basis of all possibility. One single form, the world-soul-a universal intelligence which is the active principle of all possibility-vivifies this matter (as formal cause) and produces by its own internal plasticity (as efficient cause) the diversity of beings in the universe. At bottom, the original matter and the primitive form coincide, for they are only two aspects of the same reality. The matter is God by the same right and title as the form: in accordance with the teaching of David of Dinant, whose authority is invoked by Bruno (208). The world-soul plays the role of final cause also. The term of its evolutions, through which it passes consciously, is the realization of the best world possible. Everything in Nature is beautiful, because everything there lives with a Divine life.

Bruno explains in detail how this world-soul, identical with the Deity, comes to communicate itself to Nature. In his Physics he follows Telesius ; in his account of the universe he avails himself of the new Copernican theory. Psychology holds a secondary 
place in his system. Man is no longer the centre of philosophy, any more than the earth he inhabits is the centre of the universe. His soul, like his body, is an offshoot of the Divine, and if it is immortal, its immortality consists in its uniting with new material components after each successive dissolution. Needless to say, there is no place for free-will in this dynamic evolution of the Divine. The process of cognition is modelled after the general theory of the world, and, in its highest stage, it gives the mind an insight into the monism we have just outlined.

In his Latin writings Bruno toned down this pantheism somewhat, without, however, abandoning its main principles.

\section{\$7. The Philosophy of Natukal and Social Rigit.}

441. Thomas More. - The rise of independent States, the study of the political systems of ancient Greece and Rome, the kindling of a spirit of patriotism within the separate nationalities, both great and small, stimulated the growth of a philosophy of public right, based on a study of man himself. The originator of this new conception was an Englishman, BLessed THomas MoRe (MORus, I480-1535). His sensational work, De Optimo Rei Publicae Statu size de Vova Insula Utopia, written before the Reformation reached England, was conceived in the spirit of Italian Platonism. It contains two very distinct parts. The first sketches the plan of an ideal State, organized on the lines of Plato's Republic. The second part is of a more practical character, and gives a faithful reflex of the tendencies of the time: it is a plea for the mutual independence of both Church and State, and for a neutral attitude of the State towards the Churches.

The principles suggested in More's work were taken up and expounded more fully and systematically by Hugo Grotius.

442. Hugo Grotius.-Born in Holland, where the religious wars had led to religious indifference, HuGO DE GROOT (GROTIUs, I583-I645, author of De Jure Belli et Pacis) may be regarded as the great Renaissance legislator of Natural and Social Right.

The Right of Nature or Natural Right (Jus Naturale), which belongs to the individual, is the sum-total of his imprescriptible rights as revealed by the rational study of human nature. A fundamental characteristic of human nature is sociability, innate and instinctive.

Society has its origin in the social contract, the deliberate 
agreement of individuals who live together for the sole purpose and with the sole aim of better safeguarding their several rights. The State, therefore, exists only by and for the individual. This is the proclamation of the human origin of civil society and the State, in opposition to the scholastic theory of their Divine origin (305).

The people delegate their sovereignty: by a delegation which is for some irrevocable, for others revocable (germ of the theory of revolution).

Between human, rational right, and Divine, revealed right, there is an impenetrable wall of separation. Religious neutrality and unlimited tolerance on the part of the State, are corollaries from this separation of State from Church. Personally, Grotius was a believer in the Christian revelation.

Questions about natural and social right now assumed a great and growing importance. We shall see presently how scholastics (457) and Protestants (445) connected such questions with their theological and philosophical teachings.

\section{Protestant Philosophy and Mysticism.}

443. General Outline.-The theological controversies of the Reformation were inevitably bound to influence philosophy. The leading principle of Protestant theology was private judgment in interpreting the Scriptures and determining dogma. Now, when each decides his own dogma, he can have little difficulty in harmonizing it with a philosophy chosen no less freely. This accounts for the varied and often contradictory forms of the philosophical systems of the earlier Protestants (Neo-Platonism, Stoicism, Aristotelianism, pantheistic mysticism).

LUTHER (1483-I 546) was not a philosopher. He preached an irreconcilable opposition between reason and faith, the former being a work of the flesh (caro), the latter of the spirit (spiritus). $\mathrm{He}$ forbade philosophy to meddle with theology and bitterly reproached scholasticism with having profaned theology with its "sophisms". The main work of his life was the founding of a new dogmatic system, with a theory of justification as its basis. According to this theory, original sin corrupted the whole man in the very depths of his being; faith in the Gospel can alone restore him to justice and sanctity. This redeeming faith, springing from individual inspiration, unites man with God and con- 
ducts him to his final happiness, passively, without any effort of his own, nay, without the concurrence or assistance of any works of his whatsoever. If I.uther was not a philosopher, this reformed dogma of his implies a philosophy. The distinction between the "flesh" or the natural faculties on the one hand, and the "spirit" or Divine element in our being on the other, involves a psychological dualism that recalls the teachings of the Cabala. The passivity of man under grace and his subjection to an absolute predestination, lead directly to determinism. Some of Luther's disciples, more anxious than their master to justify their religious beliefs before the bar of reason, sought in one way or another to harmonize philosophy with the reformed dogma. The leading philosophers of the new religion were Zwingli, Melanchthon and Böhme.

444. Zwingli-the great Swiss reformer (1484-1531), was at one with I.uther in making justification by faith alone the basis of the new Christianity: Zwingli was an ardent humanist; he visited Italy and drank in the spirit of the Florentine Academy; his favourite author was Pico of Mirandola. He drew upon Neo-Platonism and Stoicism in defence of his dogma. Both systems sugrgested pantheistic immanence and the deification of man regenerated by the sovereign good. Seneca supplied him with arguments for the autonomy of the will, for absolute predestination of both the good and the wicked, and for moral determinism ( $\mathbf{7 2}$ ). Universal theism, or the unity of the Divine revelation throughout all the religions of the world, suggested itself to Zwingli as the natural conciliation of humanism and Protestantism.

445. Melanchthon-( $1497-1560)$, was not a creative genius, but an adapter of Aristotle to the defence of Protestant theology. He cultivated humanism only in order to get an understanding of ancient philosophy and to base upon the latter an apology of Christianity. His manuals on the Logic, Physics and Ethics of Aristotle are remarkable for their clearness and order, and won for him the title of Praceptor Germaniae.

Melanchthon was rather an eclectic than an Aristotelian. His peripateticism, which preserves a considerable purety in his Dialectic, is generally interspersed with Platonic and Stoic elements. ${ }^{1}$

${ }^{1}$ Dilthey, Melanchthon und die erste Ausbildung des naturlichen Systems in Deutschland (in the Arch. f. Gesch. d. Philos., vi., p. 225). Melanchthon followed Aristotle in Physics and threw discredit on the recent discoveries of Copernicus. 
So, for example, in his theory of knowledge : man has within him a lumen naturale (against Luther); innate principles inform him of the great truths of the speculative and moral orders (Stoicism, Cicero). The senses are indispensable purveyors of our certain knowledge (nihil est in intellectu quod non fuerit prius in sensu); they merely stimulate the activity of the lumen naturale (against Aristotle) and awaken slumbering representations. Our certitude of primary truths is immediate; they are rooted in our inner consciousness; not only the principles of mathematics and physics, but the existence of God, the immortality of the soul, human liberty (against Luther and Stoicism), the primary ethical and social truths, are all innate principles. It is the Graeco-Roman philosophy, especially peripateticism, that has best deciphered the instructions of the lumen naturale. But even this philosophy is necessarily incomplete, original sin having darkened the human understanding. It belongs to Faith and the Gospel to purify this source of our knowledge and restore it to its first brilliancy. In this way faith completes reason (against Luther); Grecian philosophy and Christianity teach the same truths, but with different degrees of clearness.

Melanchthon's Ethicae Doctrinae Elementa became the startingpoint of Protestant theories on Natural and Social Right : the decalogue is the summing up of the Jus Naturale; and the State, which is of immediate Divine origin, is independent of the Church. This thesis was vigorously opposed by the Catholic writers of Spain. ${ }^{1}$

446. Protestant Mysticism. Böhme.-Protestantism contained the germ of mysticism. The direct, personal interpretation of the Bible, and the denial of the ecclesiastical and celestial hierarchies, removed the Catholic intermediaries between the soul

${ }^{1}$ Like Melanchthon, Nicholas Taurellus (1547-I606) endeavoured to place Protestant dogma on a philosophical basis. But for the philosophy of Aristotle he substituted a philosophy of reason in conformity with the Gospel; for Lutheranism and Calvinism, an "integral Christianity" that toned down the gravity and consequences of the original Fall, leaving man in possession of a natural faculty of knowledge. This faculty is not a tabula rasa (Aristotle), but is stocked with a treasure of fundamental truths; it is identical in all and incapable of growth and diminution. All the varieties and modifications of our beliefs are due to obstacles opposed by the body to the cognitive faculty. The object of this faculty, and of philosophy of which it is the organ, is the knowledge of God, His attributes and His works. Theology on the other hand deals with the hidden will of God, as revealed to us by Christ. 
and God. As expounded by its chief representatives, Protestant mysticism is pantheistic.

This element of pantheism, already insinuated by Zwingli, pervades the mystic anthropology of SEBASTIAN FRANCK (I499I 542, author of I'aradoxa; De Arbore Scientiae Boni et. Mali) and, still more tangibly, the philosophy of Jacob Böhme. Brought up away from the influence of humanism, JACOB BöHme (I 575I 624) led a simple life, devoted exclusively to meditation. Apart from the writings of Paracelsus and his school, Jacob's system is drawn altogether from his own solitary reflexions. Besides his great work, the Aurora (1610), he wrote Tiersig Fragen won der Seele; Mysterium Magmum; Von der Gnadenwahl.

Böhme's originality displays itself mainly in his philosophical explanation of the simultaneous presence of good and evil in the universe. ${ }^{1}$ The opposition between good and evil is a primordial and connatural fact in God, and is, therefore, necessary. One day, seeing a tin vessel reflect the rays of the sunlight, Böhme thought to himself that without the tin, though dark in itself, the solar light would not be visible to us. The positive would be unknowable without the negative, light without darkness, good without evil. Now, the presence of good and evil in the bosom of the Infinite produces there a tension of opposing forces. But they exist there only in a potential state. What is it that actualizes them? Or, to use the metaphor of fire by which Böhme symbolizes life, what is it that sets good and evil aflame? The human soul, by an act of free will. To understand this reply we must note that the human soul is not a creature of God (theism), nor a mode of the Divine substance (ordinary pantheism); it is God Himself : the human soul, unique in all its human embodiments, is the primordial Divine condition, the bottomless "abyss," "containing heaven and hell in its immensity".

Clothing his metaphysics in poetic imagery, Böhme describes the " eternal nature of God" under the aspects of seven primary qualities: the first three representing evil, or the Divine anger; the last three representing good, or the Divine love; midway between good and evil, and sharing the nature of both, is the quality of fire, or the principle of life and of all that by living wears out and is consumed. This is the seat of the liberty of the

${ }^{1}$ Deussen, F. Böhme, über sein Leben und scine philosophie (Kiel, r897); and Boutroux, in the Études d'histoire de philosophic. 
human soul (or of God). By a free act the soul can turn towards good or evil. "The will of the soul is free, either to shrink back into itself, count itself for nothing, be but a branch of foliage shooting forth from the Divine Tree, and nourish itself with the Divine Love (the Good) - or to burst forth into flame itself (im Feuer aufzusteigen) with a view to becoming a distinct and independent tree ${ }^{1}$ (Evil)." This mysticism is accompanied by a complete dogmatic system. Original $\sin$ is the human soul choosing evil; Redemption is the human soul returning to good. Christ is not a personal God become man; he is only a part of deified humanity. ${ }^{2}$

\section{§9. Theism or the Philosophy of Religion.}

447. Causes of the Success of Theism.-The religious wars of the Reformation inspired many writers with projects for the reunion of all the churches. This in turn fostered the conviction that all religions possess a common fund of essential truths about the Deity, that they are really identical in content, notwithstanding the divergences between their dogmas. ${ }^{3}$ Luther was averse to this idea of a theistic residue in the various Christian religions, but $Z$ winglians and other sects of the Reformed Church were rather favourable to it (444).

Then, too, theism was in keeping with the independent spirit of the Renaissance, seeing that it is only a form of naturalism applied to religion. As a system of Natural Right had been constructed from an inspection of human nature, so too the light of reason was laid under contribution for the construction of a

1 Vierzig Fragen, ii. ${ }^{2}$.

${ }^{2}$ The Renaissance brought into fashion another form of mysticism, based on the Cabala. Although the latter is before all else a religious book, belonging to the cycle of Jewish writings on the Messiah, it also contains a world-philosophy, the central idea of which is Emanation. This Cabala mysticism dominates the writings of Reuchlin ( $4555-\mathrm{I}_{522}$ ), the most distinguished of the Renaissance Hebraists (De Arte Cabalistica and De Verbo Mirifico). He places the union of God with the mens or organ of the soul, in a direct illumination by the Divine light. When the soul is purified, it transcends the first and second worlds, of sense and intellect, and reaches the third or Divine world. God is the bottomless abyss (Ainsoph), manifesting Himself through ten attributes (Sephiroth). The direct intuition of the Divinity, face to face, is the supreme end of man.

${ }^{3}$ Dilthey, Auffassung und Analyse des Menschen im 15 und 16 Fahrh. (Arch، f. Gesch. d. Philos., I894 and I895); Das naturliches System der Geisteswissenschaften im 17 Jahrh. (ibid., 1895 and 1896$)$. 
Religion. Hence the vast multitudes who subscribed to theism, not only of Protestants, but of all classes engaged in the Renaissance movement. The influence of theism was felt in the moral, the social, and even the artistic life, of the sixteenth century. To it we may directly trace the theories on the separation of Church and State and on the neutrality and tolerance of the latter in matters of religion.

448. Leading Representatives. - At an earlier date (340) the identity of the great religions of the world had been propounded at the court of Frederick II. ERASMus defended the view that the pure religion of Christ is identical with the religion of Plato, Cicero and Seneca. A sort of primitive, fundamental Christianity, really identical with theism, was embraced by Gemistos PLeTHO (428) in the name of Platonism, by Reuchlis in the name of Hebraism and by KONRAD MUDT (Mutianus Rufus) and the humanists of Erfurt in behalf of philology. In Holland, so sorely rent by the religious wars, the subject of religious peace was broached by COORNHERT (born I522), who advocated the reduction of all the conflicting dogmas to their common elements. The project received considerable support. Thomas Moke approved of it and HugO GROTIUs promoted it with energy; later on, LORD HERBERT OF CHERBURY developed it ; and modern philosophy embraced it as one of its favourite theories.

\section{§ io. Scepticism.}

449. General Outline. - The endless controversies in religion, philosophy and science, led many to doubt of the capacity of the mind to discover truth. Renaissance scepticism is not a convincing critical arraignment of certitude, but rather a proof of the inadequacy of the then existing philosophical systems. It was a transition stage between the Middle Age philosophy and modern systems. On this account it has numerous analogies with Grecian sophism (12); both alike mark a transition to new speculations.

The best known among the Renaissance sceptics is MICHAEL DE Montaigne (I 533-I 592), whose Essays are, from the point of view of philosophy, a mere rehash of ancient Pyrrhonism. The author entrenches himself in doubt, confining his speculations to the study of the ego. His motto, "'Tis myself I paint," typifies the new knowledge he aimed at substituting for contemporary systems. Charron (154I-1603), in his treatise De la Sagesse, 
follows in the footsteps of Montaigne, drawing at the same time on Seneca also: he admits the existence of practical certitude, as a basis for morality, thus falling back openly on dogmatism. The same may be said of the Portuguese medical doctor, SANCHEZ (1562-1632). He shows the insufficiency of the received systems, only to infer therefrom the necessity for a new philosophy of experience, which, however, he did not show himself capable of constructing.

The bankruptcy of the Renaissance systems accounts to some extent for the rapid ascendancy of the ideas of Descartes and Bacon. 


\title{
CHAPTER III.
}

\author{
SCIIOLASTIC PHILOSOPHY.
}

\section{\$. General Outline.}

450. Leading Features. - The dearth of philosophers becomes more marked than in the preceding period. The various schools of opinion survive, but without much of their earlier influence. In the religious orders, in the universities and the colleges that sprang up within the universities, it became customary to accept the official leadership of some one or other of the great scholastic masters; and even the choice of these latter was not always determined by considerations of an intellectual order, but often by political caprice and intrigues. ${ }^{1}$ We can judge to what excess this miserable factionism was carried, from the fact that "Thomists" and "Albertists" formed antagonistic groups ${ }^{2}$-as if St. Thomas and his master did not hold the same views on all the great fundamental questions of philosophy.

Ignorance of scholastic teaching reached its lowest depth about the end of the seventeenth century. If the manuals still spoke of matter and form, it was to depict their union under some such metaphor as that of the espousals of man and woman followed by divorce and the contracting of new alliances. The explanatory value unduly claimed for the theory of the distinction between the various powers or qualities of things, gave Molière a pretext for his sneer about the "virtus dormativa" of opium. So also, the current misinterpretations of the scholastic theory of the "species intentionales" were justly and severely criticized by

${ }^{1}$ At Basle, in $\mathrm{I}_{4} 64$, there were four terminist professors (via modernorum) and three anti-terminists or realists (via antiqua): at Freiburg [Breisgau] the teaching was terminist from 1456 to $\mathrm{I}_{4} 84$, at which date realists were admitted, on the order of the Archduke Sigismund. Similarly, terminism was imposed on the rising universities of Tubingen (r 477), Ingolstadt (r472), etc. (PrantL, iv., p. I9o).

$2 \mathrm{As}$, for instance, at Cologne, where the St. Lawrence college defended the teaching of Albert the Great against the Montagne college which professed Thomism. 
Malebranche and Arnauld. It was mainly among the university professors, the "official Aristotelians," that this ignorance betrayed itself. This reproach, however, cannot be made general, nor can it be extended without reserve to the sixteenth century. For, the sixteenth century saw the rise of a new scholasticism which was wanting neither in originality nor dignity; and it saw moreover some illustrious commentators of St. Thomas and Aristotle, men who carried to a successful issue a useful and laborious undertaking in exegesis.

The attitude of the scholastics towards their adversaries cannot be condoned. When attacked in all their strongholds by the Renaissance coalition, the scholastics did not know how to defend themselves: they committed the double blunder of ignoring the history of contemporary philosophy and holding aloof from the advances of the special sciences. Bacon's reproach is just in substance, if exaggerated in its language: "Hoc genus doctrinae minus sanae et seipsum corrumpentis invaluit apud multos praecipue ex scholasticis, qui summo otio abundantes, atque ingenio acres, lectione autem impares, quippe quorum mentes conclusae essent in paucorum auctorum, praecipue Aristotelis dictatoris sui scriptis, non minus quam corpora ipsorum in coenobiorum cellis, historiam vero et naturae et temporis maxima ex parte ignorantes, ex non magno materiae stamine, sed maxima spiritus, quasi radii, agitatione operosissimas telas, quae in libris eorum extant, confecerunt". ${ }^{1}$

The scholastics neglected contemporary philosophy: both its attacks on themselves and its own new systematizations. If a few scattered scholastics, especially in the Spanish revival movement, did take note of the bitter complaints and reproaches of the humanists, the vast majority jogged on in the old rut of routine. And as for the new theories, the scholastics of this period, with very rare exceptions, not only abstained from refuting them, but deliberately avoided studying them. Contemptuous towards all rivals and full of self-sufficiency, they ostentatiously imprisoned themselves within the circumscribed and shrinking sphere of their own barren speculations. What weight or influence could they hope to retain in the world of learning-men who thus closed doors and windows against the outer world and neither felt nor professed any interest in the ideas of their time?

${ }^{1}$ Quoted by Brucker, Historia Critica Philosophiae, t. iii., pp. 877,878 . 
Very different was the attitude of St. Thomas and the thirteenthcentury doctors towards their adversaries in their day; and had they lived during the Renaissance they would have waged war to the death, and beyond doubt victoriously, against its rabble of puny philosophies, incomparably less robust as they were than the Averroïsts of the thirteenth century.

The scholastics also held aloof from the progress of the sciences: although in these domains there were great, revolutionary theories at work, and new syntheses were overthrowing many of the positions accepted by medieval science. Conceived outside scholasticism, these new syntheses ended by turning against scholasticism. We shall see this in our closing section $(\$ 7)$.

45I. Division. - As in the previous period, so now, the Thomist $(\S 2)$, Terminist $(\$ 4)$ and Scotist $(\$ 5)$ schools drew the vast majority of scholastics. From the middle of the sixteenth century there appeared in addition some secondary schools (\$6). But the great, leading event in this period of the annals of scholasticism is the brilliant outburst of the Spanish Renaissance ( $§ 3$ ). A final section will deal with the attitude of the scholastics of the seventeenth century towards the new scientific discoveries $(\S 7)$.

\section{$\S$ 2. The Thomist School.}

452. The Thomist School. - The line of Thomists who faithfully interpreted the master's teachings grew rich in numbers from the fifteenth into the sixteenth century. JOHANNES VERSOR ( ${ }_{1}$ 480) interpreted the principal works of Aristotle in the spirit of Thomism (Quaestiones super Veterem Artem; Super Omnes Libros Novae Logicae; commentaries on the De Ente et Essentia and on Petrus Hispanus). Petrus Nigri compiled a treatise, Clipeus Thomistarum. Groups of professors at Cologne defended St. Thomas and Albert the Great-against each other. Among the Thomists, the most noteworthy are HeIMERIC DE CAMPO

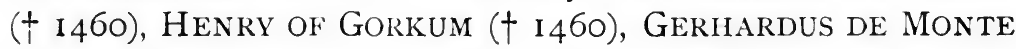
(1480, wrote commentaries on the De Ente et Essentia and an Apologetica... qua ostensorem concordiae inter S. Thomam et venerab. Albertum Magnum impugnat opprobriis, auctoritatibus et rationibus omissis) and LAMBERTUS DE MONTE († 1499, wrote commentaries on Aristotle in the spirit of St. Thomas). The principal protagonists of Albertus were GERHARD HARDERIVIJK 
( I $_{503}$, wrote commentaries on the Nova Logica and on Petrus Hispanus) and ARNOLD DE LuYDE (or of Tongres, $\uparrow 1$ 1540, wrote commentaries on the Organon and on Petrus Hispanus). Echoes of this Albertino-Thomistic controversy were heard outside Cologne.

Barbus Paulus Soncinas ( $\dagger$ I 494) summarized Capreolus, wrote commentaries on the Isagoge and the Categories and composed Quaestiones Metaphysicae. JoHANnES A LAPIDE († 1494) taught successively at Paris, Basle and Tübingen: wrote commentaries on the Organon, a treatise De Exponibilibus and Sophist. Argumentationes. Franciscus TAEgIUS wrote a commentary on St. Thomas's Opusculum De Fallaciis. MICHAEL SARAVETIUS undertook to defend Thomism against Scotism (Quaest. de Analogia contra Scotistas; $Q$. de Universalibus; De Prima et Secunda Intentione). DOMINICUS OF Flanders ( $†$ I 500 ) taught at Bologna (1470) and wrote on Aristotle's Metaphysics, Posterior Analytics and De Anima. ConRAD KöLlin, one of the ablest Thomists of this period, expounded St. Thomas at Heidelberg (1507) and Cologne, and published Quodlibeta. Martin Pollich at Wittenberg ( $†$ I 513 ) and ERASMus WonsIDEL at Leipzig wrote on the Thomistic Logic. The Dominican, Bartholomaeus Manzolus, attacked the logic of Paul of Venice with arguments drawn from Thomism (Dubia super Logicam $P$. Veneti). JAVELlus, in the opening decade of the sixteenth century, opened a long controversy with Antonius Trombeta. PETER OF BRUSSELS, or Peter Crockaert, after an ardent defence of Ockamism, which had been taught him by Johannes Major (46r), joined the Dominicans and went over to Thomism. With a sound judgment he combined an elegant literary style, thus communicating to his pupil, Vittoria, a taste for literary form. Besides commentaries on various treatises of Aristotle and on the De Ente et Essentia of St. Thomas, he wrote some Quodlibeta.

Of greater importance than those are the two famous commentators on St. Thomas, Sylvester Ferrariensis and Cajetan.

453. Sylvester of Ferrara and Cajetan.-FRANCISCUS SYLVESTER, born at Ferrara about 1474, became regent of the Dominican Studium at Bologna, afterwards general of the order, and died in 1528. His principal works are: In Lib. S. Thomae de Aquino contra Gentes Commentaria (about 1516); Comment. in Lib. Posteriorum Aristot. et S. Thomae; in Octo Lib. Physic. 
Aristot.; in 3 Lib. de Anima; and a treatise against Luther, pure in its diction and clear and logical in its style.

ThOMAS DE VIO, commonly called CAJETAN, was born at Gaëta in 1468 , joined the Dominicans and studied at the University of Padua, where he became acquainted with the humanist and Averroïst movements. From Padua he passed to the University of Pavia and thence to that of Rome. From I 507 he was high in the councils of the order, became cardinal in I 5 I 7 , bishop of Gaëta in I 5 I9, and then legate in Hungary. He devoted the closing years of his life to study and died in 1534 . Besides many works on Theology and Scripture, he wrote a number of important philosophical treatises: Commentaries on the De Ente et Essentia of St. Thomas; on the Categories, the Posterior Analytics and the De Anima of Aristotle; tracts De Analogia Vominum, De Sensu Agente et Sensibilibus, on the De Suhstantia Orthis of John of Jandun, on Metaphysics and on various subjects of minor importance. But the Commentaria on the Summa Theologica of St. Thomas form his great, capital work.

The commentaries of Sylvester and Cajetan on the two Summae recall the exegretical work of Capreolus. But whereas the latter rummages through the works of St. Thomas in order to put the master's teaching into the framework of the Lombard's Sentences, the former follow the order of the Angelic Doctor's text, writing orderly commentaries, the one on the Summa contra Gentes, the other on the Summa Theologica. Both of these great commentaries are remarkable for their clearness and penetration. Students of Thomism will always consult them with profit; and they have been deemed worthy of recent and careful re-editing. That of Cajetan is the better of the two. Besides an exposition of Thomistic teaching, it contains numerous polemics against Scotists and Averroissts whom Cajetan had met at Padua. On the question of the immortality oi the soul, so vehemently agitated by Pomponatius, Cajetan differs from St. Thomas. He holds the theory of Averroës to be that really propounded by Aristotle, and doubts, for his own part, about the power of reason in formulating its proofs of immortality. This explains how one of his brothers in religion, Bartholomew SpINA OF PISA, who was a violent adversary of his, involves him in a common condemnation with Pomponatius: Propugnaculum Aristotelis de 
Immortalitate Animae contra Thomam Cajetanum; Tutela Veritatis de Immortalitate Animae contra P. Pomponatium; Flagellum in Tres Libros Apologiae Ejusdem.

Cajetan exercised considerable influence on the philosophical training of Vittoria, the founder of the Salamanca school, thus establishing a bond of connection between Thomism and the Spanish scholasticism of the sixteenth century.

454. Sources and Bibliography.-Versor's Quaest. s. Vet. Artem are found in the incunabula of Venice ( 1497 ) and of Cologne (r486, 1497, 1503); the three latter containing also the Comment. s. Omnes Lib. Novae Logicae and on the De Ente et Essentia. The Comment. on P. Hispanus have been frequently re-edited. So too

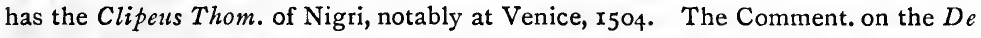
Ente et Essentia and the Apologetica of G. de Monte were printed at Cologne about I492, the Comment. alone in $\mathrm{I}_{48} 8 \mathrm{~g}$. The Comment. of L. de Monte were printed at Cologne, I488, r493, r505, I5 I I ; of G. Harderwijk at Cologne, r494 ; of A. de Luyde, Cologne, I496, 1500, I507; the Super Art. Vet. of Soncinas at Venice, r499, I587; the treatises of J. de Lapide at Basle; the De Fallaciis of Taegius at Pavia, I5II ; the treatises of M. Saravetius at Rome, $\mathrm{I}_{5} \mathrm{I} 6$; of D. of Flanders, at Venice, $\mathrm{I}_{5} \mathrm{I}_{4}$, 1587, at Cologne, 1621; of Manzolus at Venice, 1523; the Summularum Artis Dialecticae Interpretatio of P. of Brussels at Paris, 1508 ; the Quodlibeta of C. Köllin at Munich, r523. On all those personages see PrANTL, op. cit., iv., pp. 220 sqq., 273 $s q q$. , from which we borrow much of this bibliographical information. On $\mathrm{H}$. de Campo, D. of Flanders and P. of Brussels, see our Hist. phil. scol. Pays-Bas, pp. 309, $3 \mathrm{I}_{4}$ sqq.

The commentary of Sylvester Ferrariensis on the Summa contra Gentes went through numerous editions from $\mathbf{I}_{524}$, in the author's lifetime, at Venice, to the best edition at Paris in I66o. Sestili brought out the first volume of a new edition at Rome in 1898 . Sylvester's other commentaries have been edited at Venice, 1517 , 1577, I619, and at Rome. Cajetan's Opuscula have been edited at Venice (1506, 1587, r599, etc.), Rome, Paris, Bologna, etc. Still more numerous are the editions of his commentary on the Summa Theologica; the latest is that embodied in the Roman edition of St. Thomas (3ro). There is no complete edition of Cajetan's works. Two partial collections, covering the whole, appeared at Antwerp in 1612 and at Lyons in $154 \mathrm{I}$, respectively. For details of the various editions, see article by Mandonnet in the Dict. Theol. Cath. (1894, s.v. Cajetan). The three treatises of B. Spina were edited in 1518 .

\section{$\S$ 3. Spanish Scholasticism.}

455. General View.- The sixteenth century witnessed a remarkable restoration of scholastic philosophy and theology. The theological movement, which was the more important one, issued from a reaction against the Reformation. It was fostered by the deliberations of the Council of Trent (1563), and it drew its inspiration from the theology of St. Thomas Aquinas, who was declared doctor of the Church by Pope Pius V. in 1567 . It 
devoted special attention to all questions connected with the recent heresies of the Reformation.

Accompanying this theological activity there came a philosophical revival movement which advocated in the first place $a$ return to the great philosophical systems of the thirteenth century, and more especially to Thomism. Theories and arguments were closely studied and carefully criticized. The great, leading doctrines of thirteenth-century scholasticism (282-307) were interpreted in the light of another age, and new theories were broached. Spanish scholasticism was therefore an original and autonomous movement of thought, and its leaders may not be regarded as mere commentators - as their own modest declarations might suggest. Moreover, some of them reveal the influence of the new Renaissance speculations in the domain of political and social theories. And all of them return to the clear language and simple, direct methods from which the later adepts of the schools had fallen away. In this they were wisely turning to account the criticisms directed by the humanists against their predecessors and contemporaries.

With its centre in Spain and Portugal, this revival extended into Italy. It was cradled in the University of Salamanca: ${ }^{1}$ hence the title by which the movement is usually known-"Spanish scholasticism of the Sixteenth Century". Under the influence of Thomism, the University of Salamanca substituted for the Book of Sentences the Summa Theologica of St. Thomas as textbook in the schools. The other universities of Spain and of all Europe, gradually followed this example. The first fruits of the movement were textual commentaries like those of Cajetan and Ferrariensis: but as thought advanced, the commentary gave way to independent exposition and systematic treatises, which left freer scope for choice and arrangement of the matters to be treated. The revival was promoted first by the Dominicans, and then, even to a greater extent, by the Jesuits.

456. The Dominicans.-To FRANCIS OF VitTORIA (1480I 566) belongs the honour of having initiated the new orientation of scholasticism at the University of Salamanca. He had studied at Paris, under a scholastic of some genius, Peter Crockaert of Brussels (452). Vittoria not only advocated a return to the

${ }^{1}$ The universities of Alcala, Seville, Valladolid, Coimbra and Evora also promoted the movement. 
teachings of pure Thomism, but endeavoured to rid scholasticism of the impure accretions that discredited the works of his contemporaries. He edited the commentaries of his master, Crockaert, on the IIa IIae of St. Thomas.

Vittoria gained a large following. MELCHIOR CANUS (I 509I 560) and possibly Dominicus DE SOTO (I 496-I 560) count as his immediate disciples. Melchior Canus, professor at Alcala, was the most elegant writer of the whole group; his famous work, De Locis Theologicis, contains a complete scheme of reform for theology and philosophy. BARTHOLOMAEUS DE MEDINA (I 527I58I) undertook a commentary on the Summa Theologica, which was to sum up those of his predecessors. His own work embraced only the Ia IIae and the IIIa Pars and was continued by Dominicus BANNEZ (1528-1604) who wrote on the $I a$ and the IIa IIae. Later on came the Italian, ZANARDI ( $†$ I642), and the Portuguese Dominicans, Antonio DE SEna ( $\nmid$ 1584, wrote on the Summa and the Quaest. Disp. of St. Thomas) and JoHn of ST. Thomas (I 589-I644). This latter, a professor at Alcala and Salamanca, is well known from his excellent Cursus Philosophicus ad exactam, veram et genuinam Aristotelis et Doctoris angelici mentem, comprising logic, general and special physics and psychology.

457. The Jesuits in Spain. Suarez. - The Jesuits established themselves in Spain about I548, soon after the foundation of the order. St. Ignatius, who had learned to admire the doctrine of St. Thomas at Paris in 1533, chose the latter as Doctor of the Society. Following the wish of their founder, the general congregation of 593 obliged the members of the Society to rally round the Thomistic teaching in theology. It left them free in regard to purely philosophical questions, though even here precautions were taken to prevent any from lightly abandoning Thomism.

The Jesuits did not succeed in establishing themselves at Salamanca, but they created other centres of study. Such was the College of Coïmbra, where Petrus Fonseca (1 548-I 597), surnamed the Aristotle of Coïmbra, occupied the first chair. Under his direction the Jesuits carried to a successful issue an enormous commentary on the philosophy of Aristotle, known under the name of the Collegium Conimbricense, or Cursus Conimbricensium. It follows the thought rather than the letter of 
Aristotle. It is divided into Quaestiones, clearly worked out and grouped together. It also gives a critical résumé of the ancient commentaries. Sebastino do Couto ( $\left.f_{\mathrm{I}} 639\right)$ did the dialectic ; Manuel De Goes ( $560-1593$ ) the ethics and physics; MaGalliano, the De Anima; Fonseca († I 597) the metaphysics and dialectic. The Tractatus de Anima Separata of Balthazer Alvarès is the last of the Coïmbra commentaries.

The most famous of the whole line of Jesuit philosophers was FRANCISCUS SUAREz (Doctor Eximius), born at Grenada in 1548 , died at Lisbon in 1617 . He won great and lasting renown by his teaching in the principal universities of the Spanish peninsula. His great philosophical work, Disputationes Metaphysicae, is undoubtedly one of the ablest, fullest and clearest repertories of scholastic metaphysics. It is no commentary, but an original treatise on Being, its categories and its causes, a work in which all who would understand scholastic metaphysics will find a masterly presentation of the problems to be solved and of the author's solutions.

Suarez is the most eclectic of the Spanish scholastics. His philosophy is a remarkable interpretation of the scholastic synthesis. He borrows much of his materials from Thomism, but abandons it on important questions for views of his own. While freely recognizing his great merit, truth forbids us to allow him the title, "faithful commentator of the Angelic Doctor," which posterity has been pleased to bestow on him. Let us, for instance, enumerate a few of the leading theses of his metaphysics and psychology. In opposition to St. Thomas, he rejects the real distinction between essence and existence: ${ }^{1}$ whence he is led to admit that existence may be composed of partial elements, as essence is, and that the primal matter in natural substances has of itself and without the determining act of the form, an existence of its own, which God could preserve as such in a state of isolation from all form. Such theses, incompatible as they are with the doctrines of St. Thomas, remind us rather of the teachings of the Franciscan school. So, too, Suarez teaches that the

1" Existentia enim substantiae ita composita est, sicut essentia substantiae, et ideo, sine ulla implicatione vel repugnantia, potest Deus sicut formam sine materia, ita et materiam sine forma conservare" (Disp. Mct., D. 15, sect. 9, n. 5). The theory of the mere logical distinction between essence and existence obliges Suarez to explain many theological doctrines in a manner quite different from St. Thomas. It is not our duty to follow him into this domain. 
constitutive elements of each substance-and not its materia prima-are the principles of its individuation; and-with Scotus -that the metaphysical arguments alone have a demonstrative force in proving the existence of God. In psychology, it will be sufficient to note, for instance, that in common with Scotism Suarez accords to the intellect the power of forming a direct concept of the individual.

Finally, Suarez holds a high rank as controversialist among the Jesuits who opposed the Protestant teachings on social questions. $\mathrm{He}$ wrote a treatise De Legibus ${ }^{1}$ and discussed the question, made famous by the Protestants, concerning the immediate origin of civil authority. With Bellarmine he entered the arena to refute the so-called "Divine right" of kings, in support of which James I. of England had brought forward theological arguments. To the Protestant conception that kings held their power immediately from God, Suarez boldly opposed the thesis of the initial sovereignty of the people; from whose consent, therefore, all civil authority immediately sprang. So also, in opposition to Melanchthon's theory of governmental omnipotence, Suarez a fortiori admitted the right of the people to depose princes who would have shown themselves unworthy of the trust reposed in them.

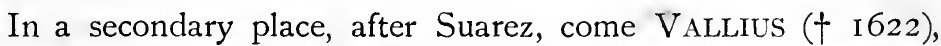
A. Rubius ( $\dagger_{\mathrm{I}} \mathrm{I}_{5}$ ), $\mathrm{F}_{\mathrm{R}}$. Alphonsus (i649), P. DE Mendoza $(\dagger \mathrm{I} 65 \mathrm{I}), \mathrm{F}_{\mathrm{R}}$. GonZaLEZ († I66I).

458. The Jesuits in Italy. - The theological and philosophical movement promoted by the Jesuits, extended to the universities they founded outside of Spain and Portugal (Ingolstadt, for example). In Germany, GREGoRy OF VALENCE, author of a commentary on the Summa (I59I), and in Belgium, BELLARMine and LESSIUS, made known the new tendencies.

In Italy especially, important centres of study were organized, the principal being the Collegium Romanum founded by St. Ignatius. This college had as professors J ACOB LEDESMA ( $†$ I 575) and F. Toletus (1559-1569), a pupil of Soto at Salamanca, author of excellent commentaries on Aristotle and of an Enarratio in Summam Theol. S. Thomae; also GABRIEL VASQUEZ $(\dagger \mathrm{I} 604)$, the great rival of Suarez and author of valuable Dis-

${ }^{1}$ D. de Soto and Molina also wrote treatises, De Fure et $\mathcal{F}$ ustitia. 
putationes Metaphysicae, as also of a fine commentary on the Summa Theologica of St. Thomas.

Under Vasquez and Suarez, from I584 to 1588 , studied Cosmus Alamannus, born at Milan (1 559), where he afterwards taught. From I6r 8 to I 623 he published a Summa Philosophiae in which he gave a didactic exposition of the philosophy of St. Thomas, grouping his subject-matter into various sections (logic, physics, ethics, metaphysics, see $\mathbf{4}^{\mathbf{6} \mathbf{r})}$ and noting carefully all the texts of the master referring to each topic dealt with.

Peter Arrubal, John de Lugo, Anthony Perez, Nicholas Martinez and Sylvester Maurus deserve special mention among the seventeenth-century professors at the Coliegium Romanum. MAURUS, born at Spoleto in 1619, began to teach in I653 and continued teaching till his death in I687. Besides numerous theological works, he wrote Quasstionum Philosophicarum L. Quinque, and also a paraphrase of all the works of Aristotle. This latter embodies the results of the great thirteenthcentury commentaries and is a model of clearness and conciseness. Maurus worked on the Greek text and the best Latin versions available in his time.

459. Other Religious Orders. - The Carmelites helped the Dominicans and the Jesuits in the revival movement. They published the Disputationes Collegii Complutensis, an encyclopedic commentary on Thomism. The Cistercians-among them Angelus Manriouez, B. Gomez and P. De Oviedo,- the Benedictines, the Trinitarians and others, ${ }^{1}$ followed the same philosophical traditions.

460. Conclusion. - The Spanish restoration offers a pleasing contrast to the general poverty of scholasticism in countries to which the movement did not extend. It stirred up a deep current of thought, which indicated what great vitality had been breathed into the organic doctrines of scholasticism as soon as these were mastered and utilized by capable and competent men. Amid the general European sterility, the branch that blossomed forth in Spain bore abundant fruit.

Unfortunately, however, the restoration remained local and ephemeral. It failed to take root outside Italy, Spain and

1 Manuel Da Natividade, of the order of Our Lady of Ransom, compiled a Philosophia secundum Mentem Angelici Praeceptoris, still in MS. (Ferreira, op. cit., p. 313). 
Portugal. The convulsions with which the Reformation rent central and northern Europe were an obstacle to its spread. Besides, the tendencies of the age in these northern countries were too varied and too distracting to allow scholasticism to gain the ascendant once again. To do this it would need to get into touch with the spirit of the age, otherwise than on the lines of the new scholastics in Spain. What a pity these latter did not pursue, beyond the domain of natural and social right, the investigations to which the Renaissance was inviting them! They would have been a match for the anti-scholastics of their time. But they failed to take account of, or adapt themselves to, the new lines of thought that were current in their age : this it was that paralyzed the influence of the Spanish movement. Although the revival dominated the sixteenth century and passed well into the seventeenth, it did not display the endurance which might reasonably have been expected from it.

On the other hand, there were groups of scholastics who continued, into the seventeenth century, to compromise scholasticism, by irreparable blundering and errors $(\S 7)$.

46r. Sources and Bibliography.-Numerous editions of the De Locis Theol. of M. Canus, especially that of Serry in r7r4. Article of Mandonnet in the Dict. Thíol. Cath. (s.v. Cano, 1904). Salamanca edition of Medina, 1577, 1582; Venice, I586 ; Cologne, I619, etc. ; of Bannez, Salamanca, 1584, I588, 1594. The Cursus of John of St. Thomas was edited at Lyons in 1633 ; previously several editions of various parts had appeared. Re-edited in 1883 (Vivès, 3 vols.). The works of $A$. de Sena were printed by Plantinus, 1569-1575. The Cursus Conimbricensis was printed as compiled at the end of the sixteenth century, and repeatedly in the early seventeenth. The Disp. Met. of Suarez, first edited in 1597 at Salamanca, has been many times reprinted: so too the $D e$ Legibus, which first appeared at Coïmbra in r6r2. Complete editions of Suarez, 23 folio vols., Venice, $174^{\circ}$; and Paris (Vivès), 1856. The Enarratio of Toletus was reprinted in Rome, r869. VAsquez, Commentariorum ac Disputat. in Iam p. Summae S. Thomae (Antwerp, I621).

The Summa Philosophiae of C. Alamannus was edited at Paris in 1638 -I639 by the Canons Regular of St. Augustine, especially by John Fronteau, chancellor of Ste. Geneviève and of the University. Alamannus having left the Metaphysics unfinished and the Ethics uncommenced, Fronteau finished the one and wrote the other according to the plan of Alamannus. Re-edited in three volumes (with Fronteau's additions) by Ehrle (Paris). $C f \cdot 387$, n. 2, and 390. The Quaestiones Philosophicae Lib. $V$. of Maurus were printed in 1658 and 1670 (Rome), and again in 1875 ; his commentaries on Aristotle in 1668 , and the portions dealing with ethics in 1696-1698. All his commentaries were re-edited by EhrLe (Paris, 1884): Aristotelis opera omnia quae extant brevi paraphrasi et litterae perpetuo inhaerente expositione illustrata a S. Mauro, 4 vols.

Numerous bibliographical references in WERNER, Die Scholastik d.späteren Mittelalters, IV.: Der Uebergang d. Schol. in ihr nachtrident. Entwickelungsstadium. 
Ehrle, Die päpstl. Encyclik, etc., 3rd art. (r20), pp. 388 sqq. Ferreira-Deusdado, La philos. Thomiste en Portugal (R. Néo-scol., I898, pp. 305 sqq.). Notes and documents on Suarez: Werner, Fr. Suarez u. d. Scholastik d. letzten Fahrh. (Regensburg, I86I); A. MARTIN, Suarez métaphysicien, commentateur de S. Thomas (Science cath., r898, pp. 686 and 8rg); Scoraille, Les écrits inédits de Suarez (Études relig., Jan., r895). On the Salamanca philosophers see excellent articles of EHRLE in the Katholik, $\mathrm{I}_{88}, \mathrm{I} 885$.

\section{$\S 4$. The OCkamist School.}

462. Leading Ockamists.-During the fifteenth century the Ockamists took the lead of all other scholastics in most of the ancient universities. They were called the moderni, and their teaching was known as the via modernorum, in opposition to the earlier scholastic systems, more especially to Thomism, the via antiqua.

Petrus Mantuanus (professor from I 393 to I 400), PaUl

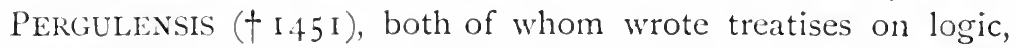
J. Wessel († I489) and GABriel Biel (about I425-1495), were militant Ockamists. Biel's Collectorium, so well known and so often edited, contains nothing original, but is rightly regarded as one of the most methodic and accurate expositions of Ockam's terminism. Biel has been called the last of the scholastics; the title, however, is unmeaning unless it be taken as referring to the rapid decadence of philosophy after his time. As a matter of fact, multitudes of "scholastics" came after Biel, but how few of them are of any importance! Here are some of the principal names: OLIVIER OF SIENA (doctor artium et medicinae, wrote a Tractatus Rationalis Scientiat, about I49I) and his disciples ALExANDER Sermoneta, Benedictus Victorius Faventinus, etc. ; ANtonius Syluester ( I $_{5}$ I 5 ); Sterhanus de Monte, professor at Padua in I 490 ; Judocus Isenacensis ( $†$ I 5 I9), BARTholoMAEUS ARNOLDI ( $\uparrow_{\text {I }} 532$ ).

The University of Paris remained one of the strongholds of terminism until a decree of Louis XI. (March the Ist, I 473) proscribed Ockam's doctrines, banished the works of his disciples from the schools and imposed the "realist" philosophy of St. Thomas or Duns Scotus. The last teacher of note, who drew disciples around him, was Johannes MAjOR Scotus (I 478 - I 540), author of numerous treatises on logic and of commentaries on the Physics and Ethics of Aristotle and on the Sentences of the Lombard, editor of Dorp's commentaries on Buridan. Among 
his disciples were DAVID CRANSTON of Glasgow ; the Spaniards, Antonius CORONEL and GASPaR LAX; the Belgian, JoHN DULLAERT of Ghent (born about I47I-I 523), who wrote a commentary on Aristotle and left such unfortunate memories in his pupil, Vivès. Henry Greve at Leipzig, Michael of Breslau at Cracow, John Altenstaig of Mindelheim and ConRad of BUCHEN may be added to the long list of decadent terministswhich a detailed examination of the university documents of the epoch would enable us to prolong almost indefinitely.

463. Sources and Bibliography.-Logica Mag. P. Mantuani (Venice, r492). Compendium of P. Pergulensis (Venice, r498). The last edition of the Collectorium circa IV. Lib. Sent. of Biel is the Lyons edition of r5Ig. The treatise of Olivier of Siena was published in r $49 \mathrm{r}$. J. M. Scotus: Quaestiones in Veterem Artem, etc. (Paris, 1528); Introductorium in Aristotelicam Dialecticam (ibid., 1527); In P. Hispani Summulas Commentaria. (Lyons, 1505, etc.) contains numerous dissertations on logic. See Prantr, op. cit., iv., pp. 194, 230 sqq. Ruch, art. on Biel in the Dict. Théol. Cath., rgo4.

\section{§ 5. The Scotist School.}

464. Principal Scotists. - Scotism remained the favourite system of the Franciscan order. There are no very noteworthy names among the earlier Scotists of this period. We may mention the Franciscans, Nicholas Bonetus at Venice ( $†$ I 360 ), Peter Thomas (wrote Formalitates), John the Englishman (I483, wrote a commentary on the Quaest. de Universalibus of D. Scotus), Antonius Sirectus (1484) and Nicholas TINCTOR, all extreme formalists. The editor of the latter's commentaries calls him Scotisans subtilis plurimum. STEPHANUS BRULIFER is more reserved, whilst ThOMAS BRICOT and GEORGE OF BRUSSELS-a pair whose works are closely related-incline towards terminism. The same is true of JOHANNES FABER DE Werdea (I 500) and of Petrus Tartaretus (1494), the most remarkable Scotist of his time, author of commentaries on the Physics and Ethics of Aristotle, on the Sentences of Peter Lombard and on the Quodlibeta of Duns Scotus. Petrus DE Aquila, author of a Scotellus, JoHANnes MAGISTRI (I 432-1482) who wrote Dicta . . Introductoria in Doctrinam Doctoris Subtilis, Antonius Trombeta ( $\dagger_{\text {I }}$ I8), who has left a treatise In Scoti Formalitates, MAURICE THE IRISHMAN, JoHn OF COLOGNE and a host of other secondary writers, advocate a return to the principles of pure Scotism. Towards the opening of the seventeenth 
century this ardent advocacy of Scotism was perpetuated by $\mathrm{J}$.

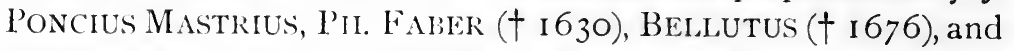
above all by ClaUdiUs Frassen (I620-I7I I), doctor of the Sorbonne and author of a Scotus Academicus, and Hieronvmus DE MontrFortino, whose Summa Theologica, published in 1720 , follows the plan of the Summa Theologica of St. Thomas.

465. Sources and Bibliography.-The Formalitates of P. Thomas (Venice, 1515). The I)icta Tinctoris super Summulas P. Hispani (1486). Bricot compiled a Textus abbreviatus Logices (Basle, 1492), on which G. of Brussels wrote a commentary (Lyons, 1504), completed by Bricot himself. The Commentarii or Expositio of liartarctus was reprinted many times between 149.t and I62I. The Scotcllus of P. de Aquila (Paris, 1585). The Dicta of J. Magistri (1490). The Quacst. Quodlibetalcs or In Scoti Formalitates of Trombeta (Venice, I 493). The works of Frassen and of $\mathrm{H}$. de Montefortino have been recently re-edited: Claudius Frassen, Scotus Academicus seu Unizersa Doctoris Subtilis Theolog. Dogmata, 12 vols. (Rome, ignz); Hifronymus de Montefortino, F. D. Scoti, etc. Summa Theologica $c x$ Universis Ofcribus cjus concinnata, juxta ordincm et dispositionem Summae Angclici Docturis S. Thomac Aq., 6 vols. (Rome, 1903). Prantr, op. cit.. iv., Pp. $20.5 \% \%$

\section{\$6. OTHLR SCHOLAstic Grouts.}

466. Other Scholastic Groups.-About the middle of the sixteenth century the Capuchins and Conventuals returned to the teaching of St. Bonaventure, the "ancient" teaching, which the success of Thomism and Scotism had so long eclipsed, even in the Franciscan order itself. In the year I622, Longus DF Cokiolss published a work on the Summa of St. Bonaventure, which led to the compilation of a lengthy series of commentaries on the Seraphic Doctor's writings.

In the sixteenth and seventeenth centuries there also reappeared a Schoia Aigidiana in which we meet EGIDIUS DE VITERBo († I 532), Raphael Bonherba, etc. Certain of the Hermits of St. Augustine, with ESTACIO DI TRINIDADE (born 1676 in Lisbon, author of a Summa Totius Philos. ex Doctrina D. Thomae extracta), joined the Spanish revival movement. The constitution of 1560 recognized St. Thomas as second patron of the order.

Henry of Ghent-after a long spell of oblivion-came into favour once more in the seventeenth century, when the Servites of Mary, espousing a legend which represented the Doctor Solemnis as a member of their order, adopted his philosophy as their official teaching. It received commentaries-al! of which are published- 
from Burgus, Lodigerius, Maria Canali, Gosius, Sogia and VENTURA.

Certain Carmelites revived the philosophy of John of Baconthorp (409). Thus, one Hieronymus Aymus published a Philosophia containing extracts from John's commentaries on the Sentences.

Finally many of the Benedictine communities followed the philosophy of St. Anselm.

467. Sources and Bibliography.-DE MARTIGNÉ, op. cit. (237), p. 429; Dissertatio de Scriptis Seraphici Doctoris (257), p. 37. WERner, Dor Augustin., etc. (325), pp. I6 and r7. Burgus, Henrici Gandav. Doct. Solemnis Ord. Serv. Paradoxa Theol. et Philos. (Bologna, 1627). Gosius, Summae Philos. ad Mcntem Henrici Gandav., etc. (Rome, I64I). SogIA, In rum et 2um Lib. Sent. Mag. Fr. Henrici Gandav. Quaest. Disp. (Saceri, 1689-1697), and Opuscula Theologica, etc. Ventura, Mag. Fr. Henrici de Gand., etc., Philos. Tripartita (Bologna, I7or). Hieronymus Aymus, Philosophia, etc. (Turin, I667).

\section{$\S 7$. The Misunderstanding Between Scholastics and Scientists in the Seventeenth Century.}

468. Scientific Discoveries and their Bearing on Scholastic Philosophy.-The controversies between the scientists and the Aristotelians form an epilogue to the decadence of scholasticism: unimportant in themselves, the episodes of these controversies have a considerable interest and significance owing to the circumstances of the age in which they occurred.

The great discoveries of Copernicus, Galileo, Kepler, Newton, Torricelli and Lavoisier effected a complete revolution in the sciences of astronomy, physics, chemistry and biology; whilst at the same time Descartes, Newton and Leibnitz were reconstructing the mathematical sciences on an entirely new basis. All this meant the destruction of the old theories in astronomical and general physics, as incorporated in the Middle Age synthetic conception of the Universe. For the Ptolemaic, geocentric system, Copernicus substituted the heliocentric system of astronomy. The telescope revealed stars travelling freely through the heavenly spaces, thus ruining the theory of solid celestial spheres. The elliptic orbits of the planets exploded the old notion of the perfection of circular movement. Above all, an ever-growing body of observations overthrew all hitherto received ideas about the nature of the various heavenly bodies. Galileo discovered new stars in many of the constellations; in I6I I the telescope revealed spots on the sun's disc, and from their displacement he 
inferred the rotatory motion of the sun itself; he distinguished the phases of the planet Venus, thus experimentally confirming the predictions of Copernicus; the moon too revealed its mountains and its valleys; a little later it was proved to demonstration that the magnificent comet of 1618 was no atmospheric will-o'-the-wisp, but a heavenly body pursuing its path through the interplanetary regions of space. Now, if there are spots in the sun, the heavenly bodies are neither immutable nor perfect; if stars appear and disappear, they cannot be "ingenerabilia et incorruptibilia"; and if all those special privileges and prerogatives of the heavenly bodies, as compared with terrestrial substances, are only so many chimeras, the stars can have no influence on the fate and fortunes of sublunary life and change.

Then, in another direction, the thermometer revealed the fact that heat and cold are but different degrees of one and the same state of matter, and not contrary properties; the barometer proved that the atmosphere has weight; and thus down went the theories of the locus naturalis of the elements, their independent and autonomous movements, and the irreducible opposition of their qualities (295).

But those theories in astronomy, chemistry and physics had been wedded for centuries to principles of general metaphysics and cosmology. Was not the lot of the latter, therefore, inseparably bound up with that of the former, and did not the overthrow of medieval science necessarily involve the destruction of medieval philosophy also?

No; not necessarily. And why? Because amid the ruins of medieval science there still stood erect and uninjured a sound and solid groundwork of observation and experience, quite sufficient to sustain the great organic and constitutional doctrines of scholasticism. These latter were still corroborated by elementary and unimpeachable facts of sense-experience : they had never depended, for their intrinsic truth and value, upon the worth of certain collateral postulates concerning the subject-matters of the special sciences: postulates, some of which had always rested on purely imaginary foundations (as, for instance, the postulate of the perfection of the heavenly bodies), and others on foundations that were at best exceedingly fragile (as, for instance, the theories of the locus naturalis, and of the conjunctions of opposite qualities in material things). 
469. The Attitude of the Aristotelians. - The scholastics should at least have followed with attention the revolution in the physical sciences, pronounced judgment on the possibility or impossibility of adapting the new discoveries to scholasticism, and realized without delay-when once convinced of the objectivity of the newly observed phenomena-that the destruction of the scientific theories of the Middle Ages did not at all affect the great, organic doctrines of the traditional scholasticism. It is thus the princes of the thirteenth-century scholasticism would have acted, had they lived at this turning-point in the history of human knowledge. Well-known texts already quoted from St. Thomas (295), clearly prove that the Angelic Doctor did not accept all the scientific speculations of his time as established theses, but rather as hypotheses; and that he would not consider his metaphysics in any way compromised by abandoning those hypotheses. When he wrote the words "Forte secundum aliquem alium modum nondum ab hominibus comprehensum apparentia circa stellas salvantur," ${ }^{1}$ he would seem even to have had a presentiment of the blunders committed four centuries afterwards by his less competent followers, and to have censured those blunders beforehand.

The regrettable attitude taken up by the peripatetics of the seventeenth century was very remote from what the events of the time demanded. So far from welcoming a rapprochement between scholastic philosophy and the new scientific theories which were then attracting such universal attention, they shrank back panic-stricken from the spectacle of their out-of-date theories melting into myth and mist in the light of newly discovered but undeniable facts. It is said that Melanchthon and Cremonini refused to look at the heavens through a telescope. And Galileo speaks of Aristotelians "who, rather than change the heavens of Aristotle, will impudently persist in denying the heavens they see in Nature". No; they ignorantly regarded Aristotelianism as a monument from which a single stone could not be taken without causing the whole edifice to crumble into atoms. Hence the amazing obstinacy with which they sought to defend the discredited astronomy and physics of the thirteenth century, and the ludicrous figure they cut in their controversies with the Cartesians.

It was in the universities especially that these controversies ${ }^{1}$ Giles of Lessines makes somewhat similiar observations (De Unitate Formae, p. 93). 
raged. At Paris, where the statutes of 1600 installed Aristotelianism as the official teaching, the Aristotelians appealed to authority to put a stop to the new theories. In I624 the Faculty of Theology requested Parliament to forbid certain philosophico-scientific theses in which an arts student named John Bitaud attacked Aristotle. In 167 I the king himself interfered; and there was another appeal to Parliament to insist on the doctrines of Aristotle being accepted. Is it any wonder that such measures provoked satire, or that Boileau should have compiled his Request in Favour of Aristotle to Our Lords of Mount-Parnassus, with the burlesque decree of the latter in answer to the petition? ${ }^{1}$

At Louvain, where the encounter between Cartesianism and Aristotelianism provoked violent contests, the attitude of the Aristotelians was no less obstinate. The trial of Martin Van Velden, prosecuted for having proposed to discuss the system of Copernicus, is an example. Here is another fact: Antonius Goudin, O.P., of Limoges (I639-1695), whose Philosophia juxta inconcussa tutissimaque I). Thomae Dogmata ${ }^{2}$ is consulted even at the present day, wrote therein that "the system of Copernicus cannot be admitted; it has been rightly rejected as temerarious because it makes the earth movable and displaces the centre of the universe". ${ }^{3}$

470. The Attitude of the Scientists. - We have just seen how short-sighted the seventeenth-century Aristotelians were; how they failed to distinguish the principal from the merely secondary, or to realize the possibility of abandoning certain groundless applications of metaphysics in the clomain of the sciences without abandoning the metaphysics as well.

Is it any wonder that they drew down on themselves the

${ }^{1}$ The decree ordained " that the said Aristotle be always followed and taught by the said professors and regents of the said university, without their being obliged, however, to read or to know anything of his philosophy," referring them, for his doctrine, to their copy-books. Then, descending into detail, it went on to speak of heart, nerves, chyle, liver, blood, etc.; restored "the entitez, the identitez, the petreitez, the polycarpeitez and other Scotistic formulae to their former good fame and renown"; rekindled "the fire in the higher regions of the air, according to, and in pursuance of, descents made upon these places"; and relegated "the comets to the concave side of the moon with a strict injunction never again to venture forth to spy what was going on in the heavens" (quoted by FERET, L'Aristotelisme et le Cartésianisme, in the Ann. Phil. Chrét., 1903, pp. 16 and I7).

${ }^{2}$ French tr. by Th. Bourard (Paris, I 865 ). ${ }^{3}$ T. iii., p. 154. 
contempt and ridicule of the scientists? And not only upon themselves, but upon the philosophy they professed, did this contempt and ridicule fasten. For, the scientists held scholastic philosophy responsible for the exploded myths of medieval science, from which scholasticism was declared to be inseparable. When we bear in mind that for very many scholasticism meant -and even still means-neither more nor less than the old systems of astronomy and physics, we can better understand the sarcasm which has been heaped upon it for ages. A system whose advocates could tolerate such proven absurdities was soon discredited; and scientists felt more and more urgently impelled to make a clean sweep of the past and start anew in quest of knowledge. With scholasticism condemned en bloc, some scientists now went on to anathematize all philosophy. And so, from this period of the dawn of the sciences of observation and experiment, we may date not merely a sharper line of demarcation between what is known as ordinary knowledge (cognitio vulgaris) and scientific knowledge proper (cognitio scientifica), but also an unfortunate divorce between the latter and philosophy. The more moderate scientists, who still recognized the need for some philosophy or other, heartily cursed scholasticism and gave their adherence to one or other of the many systems of modern philosophy: because the latter all took care to manifest a becoming respect for the marvellous discoveries of the new sciences of observation and experiment.

47I. Conclusions. - The conflict between philosophers and scientists in the seventeenth century did not really touch the substance of scholasticism, but only secondary points and side issues. But the misunderstanding was, in the circumstances, inevitable: and it lasts down to the present day. The scientists and scholastics of three hundred years ago are responsible for it: the scientists tried to fell the giant oak on the plea that it bore some rotten branches on its crown; the philosophers foolishly shrank from touching its hoary brow, lest by removing a withered twig they might deprive it of its life.

Scholasticism succumbed for want of men, not for want of ideas.

472. Sources and Bibllography.-Mолскамт, Histoire du cartésianisme en Belgique (Brussels, I886); Galilée et la Belgique; Essai historique sur les vicissitudes du système de Copernic en Belgique (Brussels, 1892). FERET, L'Aristotélisme 
et le cartésianisme dans l'Université de Paris au xviie s. (Ann. Philos. Chrét., April, 1903). Picavet, Galilée, destructeur de la scolastique et fondateur de la philosophie scientifique (Conférences de société d'études ital. de G. Guenard, I895, pp. I 6-r3o): a misleading title. DE Wulf, Hist. Philos. Scol. Pays-Bas, etc., pp. 343-92; Scholasticism Old and New (Dublin, I907), § r9. Proost, L'Enseignement philosophique des bénédictins de Saint-Vaas à Douai à la fin du xviie s. (Revue Bénédict., Jan., Ig00). 


\section{INDEX.}

The numbers indicate pages. Numbers in black type refer to places where the persons in question are specially dealt with.

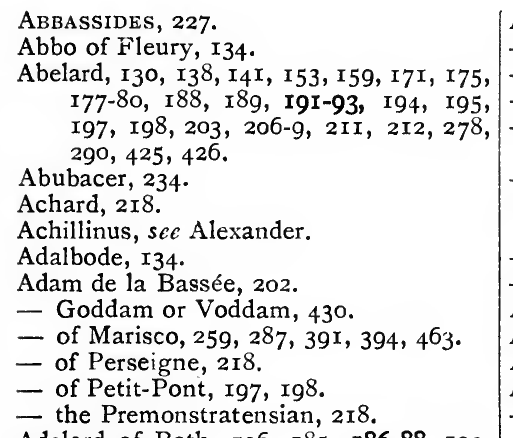

Adelard of Bath, 136, 185, 186-88, 19o, 192, 219, 247.

Adelman of Liége, $134,135,175$.

Adlhoch, I29, I60, I62, I67.

Adrastus, 67, I4I.

Egidius de Viterbo, 500.

- of Medonta, 446, 45 I (see Guido).

Aenesidemus, 68.

Agobard, r34, r55, I6r.

Agrippa, 406.

Alamannus, see Cosmus.

Alan of Lille, I29, I4I, I46, I78, I98, 200, 202-4, 205, 210, 219, 220, 247.

Alberic, 198.

$\rightarrow$ of Reims, 384 .

Albert of Brixia, 308 .

- of Erfort, 435.

- of Saxony, 432 .

- the Great, 106, I08, Ir4, I94, 205, 222, 244, 246, 249, 26I, 262, 268, 272, 273, 298-306, 307, 309, 312, $315,316,318,321,323,330,331$, $334,345,353,354,357,375,387$, $388,391,392,397,412,429,486$, 488 .

Albertus Gandinus, 347 .

Albinus, 72, I4I.

Alcher of Clairvaux, I42, 201, 202, 205.

Alcuin, I26, I29, I33-34, I42, I43, I47, $\mathrm{I}_{4} 8, \mathrm{I}_{58}, \mathrm{I} 68$.

Alexander III., Pope, 208.
Alexander IV., Pope, 260, 277.

- Achillinus, $47 \mathrm{I}$.

- Neckam, 276.

- of Alexandria, 279, 295, 382, 433.

- of Aphrodisias, 66, 67, 8I, 227, 228, 229, 47 I, 472.

- of Hales, 106, 192, 205, 260, 262, 268 , 270, 277-81, 282, 285, 300, 351, 352, $375,391,392$.

- Sermoneta, 498.

- the Physician, 185 .

Alexis, Emperor, 225.

Alfanus, 143.

Alfarabi, 229-30, 232, 248, 27I, 272, 388 .

Alfred of Morlay, 247.

- of Sereshel, 270, 276, 280.

Algazel, see Gazali.

Alhacen, 253, 398.

Alkindi, 228, 229, 248.

Al-Mamoun, 227.

Alphandéry, P., 223, 382, 389.

Alphonsus, Fr., 495.

Amalric of Bène, 220, 22I, 222, 223, 25 I, 252, 379 .

Amboise, 179, 198.

Ambrose (St.), 89, 90, I29, I42.

Ammonius, $83,227,27$ I.

- Saccas, 75, 82, 135 .

Anastasius, 168 .

Anaxagoras, 8, II.

Anaximander, 5 .

Anaximenes, 5, II.

Andreas Caesalpinus, 472.

- Contrarius, 470.

Andronicus II., 246.

- Callistus, 470.

- of Rhodes, 29, 66, 87 .

Angelus Manriquez, 496.

Anna Comnena, 225.

An-Nazzam, 229.

Anselm of Besate (Anselmus Pripateticus), I6I, I62.

- of Laon, 134, I79, I9I, I93.

- (St.) of Canterbury, I06, I28, I29, $I_{34}, I_{46}, I_{47}, I_{49}, I_{55}, I_{58}, I_{59}$, I62-67, I72, I75, I77, 203, 207, 2 I6, $274,285,326,500$. 
Anthony Perez, 496.

Antiochus, 65 .

Antoninus of Florence, 436, 437 .

Antonio Andreae, 433.

- de Sena, 493, 497.

Antonius Coronel, 499.

- Goudin, 504.

- Maria a Vicetio, 289.

- Perez, 496.

- Sirectus, 499.

- Sylvester, 498.

- Trombeta, 499, 500.

Apuleius of Madaura, 72, $\mathrm{I}_{4} \mathrm{I}, \mathrm{I}_{4} 8, \mathrm{I}_{5} 8$. Aquinas, see Thomas.

Arceselaus, 62.

Arethas, 22.4.

Aretinus, see Leonardus.

Argyropulus, see John.

Aristippus, 139.

Aristo, 66.

Aristotle, 28-52, and passim.

Armand of Beauvoir, 419,420 .

Arminius, 467 .

Arnauld, 487 .

Arnobius, 89.

Arnold de Luyde (or 'Tongres), 489, 491.

- of Bonneval, 209.

Arnolph of Salzburg, 134 .

Arnulphus Provincialis, 362.

Asclepius, 83, 148 .

Astier, 173.

Athanasius (St.), 89 .

Auger, 440.

Augustine (St.), 19, 90-98, I1 $3, \mathrm{II}_{4}, \mathrm{I}_{28} 8$, I30, I42, 148, 164, 165, I66, 216 , $266,267,270,274,275,276,280$, 286, 288, 290, 309, 319, 321, 325, $326,327,336,337,340,360,365$, $394,401,402,404,407$.

Augustinus Niphus, $47 \mathrm{I}, 472$.

- Triumphus, 437 .

Aureolus, see Petrus.

Aurispa, 468.

Avempace, 234.

Avendeath, see John.

Aventinus, 244.

Averroës, 233, 234-36, 238, 240, 241, 245, $247,248,249,25 \mathrm{I}, 280,301,305,3$ I0, $327,347,361,379,380,382,383$, $387,402,412,442,450,470,47 \mathrm{I}$, $472,490$.

Avicebron, 222, 237-38, 239, 248, 25I, $253,267,270,272,273,279,282$, $285,303,319,327,370,371$.

Avicenna, 228, 229, 230-32, 234, 247, $248,250,25 \mathrm{I}, 27 \mathrm{I}, 272,274,27^{8}$, $301,304,321,327,387$.

Bacon, see Francis and Roger.

Baeumker, Dr. Cl., 35, I22, I23, I30, I43, I $58,167,183,184,202,205,219,221$, $223,244,253,302,326,384,385,386$, 388, 398, 399, 403 .
Bainvel, 167.

Balasinansa, 389 .

Baldwin, r24.

Balthaser Alvarez, 494.

Baluzius, 308, 346 .

Banez, D., 493, 497

Bangulf, 133 .

Barach, S., 123, 162, 223, 258, 277.

Barbus Paulus, see Soncinas.

Bardenhewer, 250, 253.

Baret, 437.

Barlaam, 46r, 468

Bartholomew of Capua, 349 .

- of Messina, 245, 248 .

- of Spina, 490, 49 r.

Bartholomaeus Anglicus, 357.

- Arnoldi, 498.

- de Medina, 493, 497. Manzolus, 489 , 49 I.

Basil (St.) the Great, 89.

Baumgartner, I2 I, I29, I30, 139, 203, 204, $205,265,274,276$.

Baur, 244, 270, 271, 272, 276, 297, 311. 347,362 .

Bede, Venerable, 125, I26, I33, I43, I47, $\mathrm{I}_{4} 8, \mathrm{I}_{4}, 27 \mathrm{I}$.

Bellarmine, 495 .

Bellutus, 500.

Belmond, 378 .

Below, r 23.

Benedict XII., Pope, 447.

Berengar of Tours, 135, 174, I75.

Bernard Guidon, 2.45 .

- of Angers, 159.

- of Arezzo, $44^{8}, 45 \mathrm{I}$.

- of Auvergne, 354.

- of Chartres, $135,181-82,184,185,186$, I94.

- of Moélan, I8r.

- of Tours (Silvestris), I81, 220, 223.

- of Trilia, 353.

- St., 209, $211,216,283$.

Bernays, J., I 48.

Bernheim, E., I 2 I.

Bernier of Nivelles, $3 \delta_{3}, 386$.

Berthaud, 194, I 98 .

Berthelot, 122.

Berthier, 367.

Bertin, 167.

Bertram of Alen, 434.

Bessarion, 468, 469,470 .

Biel, see Gabriel.

Bitaud, J., 504.

Blanc, E., Iro, I 7 .

Blemmides, $24 \mathrm{I}$.

Bliemitzrieder, 205.

Block, 239.

Blommardine, 439, 445 .

Boccaccio, $46 \mathrm{r}$.

Boer, 239.

Boëthius, $84,128,129,131,134,135,138$, I39, 140, 144-45, $148,152,158,160$, I69, 186, 187, 19I, I92, 204, 217,245 , 
$246,258,270,271,276,308,311,324$, 404,436 .

Boëthius, the Dacian, $350,3^{8} 3,3^{84}, 3^{85}$ $86,3^{87}, 404$.

Boethus, 66 .

Böhme, J., $4^{80}, 4^{8 r-82 . ~}$

Boileau, 504.

Bollandists, 346 .

Bona Gratia of Bergamo, 420.

Bonald, see De Bonald.

Bonaventure (St.), ro6, 108, 242, 246, 262, $267,268,270,273,277,278,282-96$, 303, 315, 319, 326, 330, 334, 340, 34 I, $345,352,368,369,375,382,3^{85}, 433$, $434,439,440,500$.

Boniface VIII., Pope, $383,420$.

Borgnet, 306.

Bouillé, see Charles.

Bourard, Th., 504 .

Boutroux, 29, 33, 40, 4I, 482 .

Bové, 406.

Bradwardine, see Thomas.

Brants, 347, 4I4, 432.

Brewer, 262, 277, 299, 390, 39r, 395, 397.

Bricot, 499, 500.

Bridges, 39o, 395, 397 .

Brockelmann, 239.

Brown, J. W., 253.

Brucker, r r 8, 487 .

Bruhnes, r32, I47, r77.

Brunetto Latini, 245.

Bruni, see Leonardus.

Bruno, see Giordano.

- of Cologne, 155 .

Builow, 273, 274, 276.

Buonaiuti, I62, 205.

Buonamici, 2 I8.

Burger, W., I77, 207.

Burgondio of Pisa, see Richard.

Burgus, 501.

Buridan, see John.

Busse, 139 .

Cabasilas, 244.

Caesar Cremonini, 472, 503.

Caesarius of Heisterbach, 223.

Cajetan, 324, 346, 489, 490, 49r.

- of Thiene, 444 .

Caliph-Al-Mansour, 227.

Callippus, 44.

Calonymus of Arles, 4r2.

Campanella, $475,476$.

Candidus, r34, r6r.

Canella, G., I62.

Cantor, I22.

Capreolus, 435-36, 437, 489, 490.

Carboni, 367.

Cardanus, $475,476$.

Carneades, 62, 63, 65, 66.

Carra de Vaux, Iro, 227, 230, 231, 233, 239.

Carus, 122.

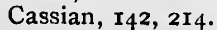

Cassiodorus, I34, I35, I44, 148 .

Celsus, 72.

Chalcidius, 83, I3 I, I39, r4I, I48, I87.

Chambon, F., 264 .

Charlemagne, I33, I47, I54.

Charles, 278, 397 .

- V., 432.

- VI., 4I7.

- Bouillée, 459

- of Anjou, 307, 357.

- the Bald, r68, r69.

Charron, 484 .

Chatelain, 222, 24r.

Chevalier, I2I.

Chollet, I I 7, 253, 388.

Chozroës Nuschirwan, 83 .

Chrodegang of Metz, 133 .

Chrypfts, see Nicholas.

Chrysippus, 54, I4 I.

Chrysoloras, see Manuel.

Cicero, 65-66, 9I, I35, I4I, I44, I85, r99, $246,404,466,48 \mathrm{r}, 4^{8} 4$.

Claeys-Bouüaert, 2 I2.

Claudius Frassen, 500.

- Hemerius, 254 .

- Mamertus, I40.

Claverie, 378 .

Cleanthus, 54, I4I.

Clement (St.) of Alexandria, 87, I42, 2 r6.

- IV., Pope, 390.

- V., Pope, 294.

- VI., Pope, 428, 429, 430, 446, 448.

Clerval, I35, I38, I47, I59, I75, I 8 I,

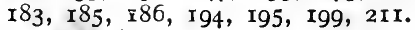

Cohen, sec Juda.

Commodius, 89 .

Conrad Köllin, 489, 49 r.

- of Buchen, 499.

Constantine VII. (Porphyrogenitus), 224.

- Monomachus, 224.

- the African, I30, I43, I85, I86, I88, 247.

- the Great, 89 .

Coornhert, 484 .

Copernicus, $480,501,502,504$.

Coppi, 259.

Cornelius Martini, 467 .

Cornificians, I83, I84, 199.

Correns, 276.

Cosmo de' Medici, 468.

Cosmus Alamannus, 437, 496, 497 .

Costa ben Luca, 227, 258, 300 .

Cousin, I03, I04, I10, I58, I62, I79, I80, I86, г89, г9o, г98.

Cremonini, C., 472, 503 .

Crockaert, see Peter.

Cumas, 226.

Cusa, Nicholas of, see Nicholas.

Cyprian (St.), 89.

Cyril (St.) of Alexandria, 89 .

D'ACHery, I9o.

D'Ailly, see Peter. 
Damascius, 82, 83, 225.

D'Ancona, 475 .

Daniel of Morlay, 250.

- Sennert, 473 .

Dante, 314, 315, 357, 383, 384 .

D'Argentré, 352, 356, 36 I, 387, 390, 4I I, $429,442,447$.

David, 247 .

- ben Merwan, 237.

- Cranston, 499.

- of Dinant, 222, 223, 251, 252, 279, 284, $327,379,45^{8}, 477$.

- the Armenian, 225.

De Bonald, 396.

De Groot, $267,307,346$.

- - see Hugo.

Dehove, 190, 347 .

Delacroix, I I 7, 21 5, 223, 445, 459 .

Delatour, 209.

Delengre, $3+5$ (see Jacquin).

De Laë, 299, 306.

Delorme, 392, 397, 4og.

De Lugio, 389.

De Lugo, 496.

De Margerie, A., 289.

De Maria, 346.

De Martigné, 263, 269, 282, 283, 369, 378, $50 \mathrm{I}$.

De Mendoza, P., 495.

Demetrius Kydones, 412.

Democritus, 9-10, 42, 60, 62, 115, 188, 473 .

Denifle, 124, 206, 208, 212, 221, 222, 24I, $257,259,263,264,299,353,354,355$, $367,406,416,434,435,454,455$, 459 .

Denis Foullechat, $4+6$.

- the Carthusian, $367,436,437,43^{8}$, 440.

Deodat de Baslij, 378 .

De Rémusat, 192 , 199 .

De Rubeis, 346.

Descartes, $400,475,485,50 \mathrm{or}$.

De Serres, 469.

Deussen, 482 .

Deutsch, 198 .

Dewey, in 7 .

De Wulf, II6, II7, I22, I23, I48, I62, $269,299,319,320,321,347,350$, $354,359,362,367,3^{88}, 43^{2}, 43.5$, 506.

Diderot, 104 .

Didot, 29.

Diego, 117 .

Dieterici, 230, 239.

Digby, E., 407 .

Dilthey, I23, 480, 4S3.

Diogenes of Apollonia, 5 .

Dionysius (the Elder and the Younger), I6.

Doctor, M., 239.

Domanski, 98, I 43 .

Domenichelli, 282.
Domet de Vorges, I29, I47, 158, 163, 164, I65, I67, 285, 326, 347 .

Dominic, St., 262, 298, 307 .

Dominicus Bannez, 493, 497.

- de Soto, 493, 495.

- Gundissalinus, see Gundissalinus.

- of Flanders, 489, $49 \mathrm{r}$.

Donatus, I35, I4I, I 55, 258.

Döring, 397.

Dorp, see John,

Douais, 259, 26r, 263.

Draesecke, 173 .

Ducange, 124 .

Duhem, 397, 432, 459 .

Dumbleton, see John.

Dümmler, r62.

Duns Scotus, 106, I08, 251, 262, 269, 278, 286, 290, 294, 295, 321, 322, 331, $334,335,337,341,346,347,358,363$, $364,367-78,388,397,404,417,418$, $420,421,424,425,426,433,436$, $446,495,498,499$.

Durand, I9\$, 223.

Durandus of Aurillac, 434.

- of Auvergne, 245.

- of St. Pourçain, $419,427,435,436$.

- of Troarn, I75.

EADMER, 166.

Ebbinghaus, 302.

Ebert, $12 \mathrm{I}$.

Echard, see Quetif-Echard.

Eckhart (Master), I 44,3 I 5, 400, 452, 453$55,45^{8}, 459$.

Edward III., 446 .

Ehrhard, I23.

Ehrle, 123, 124, 263, 265, 269, 294, 296, $320,35 \mathrm{I}, 352,353,366,368,408$, $429,432,434,497,493$.

Elias of Courson, $4+7$.

Elter, 4 I2.

Empedocles, 8. 9, ro, 250.

Endres, I22, I61, 162, I77, 192, 198, 207 . $216,218,279,282,346$.

Engelbert Krebs, 403.

Engelkemper, 239.

Epictetus, 64.

Epicurus, 59-62, I 26, 201, 219, 473.

Eracle of Lobbes, 134.

Erasmus, $466,473,4^{8} 4$.

- Wonsidel, 489 .

Erdmann, I04, IIO, I2I, 335.

Eric of Auxerre, 134, I46, I55, 158, 162.

Eriugena, see John Scotus Eriugena.

Erycius Puteanus, 473.

Espenberger, 129, 176, 210, 212.

Essenhardt, ${ }_{4} 8$.

Estacio di Trinidade, 500.

Estontevilla, 4 I7.

Euclid, 136, 186.

Eudoxus, 44.

Eugene IV., Pope, 456.

Eusebius, 98, 136 
Eustachius of Arras, 289, 293, 408.

- of Normanville, 282.

Eustratius of Nice, 225, 246.

Everard Digby, 467.

FABER, Ph., 500.

Fabricius, I 20.

Falaquera, 240.

Farabi, see Alfarabi.

Faustus, I4r.

Faventinus, B. V., 498.

Felder, 259, 260, 264, 277, 278, 281, 282, $357,397$.

Feret, I23, 264, 504, 505 .

Ferreira-Deusdado, 498.

Ferrère, 136, 147 .

Ficino, see Marsilio.

Finlay, 22.

Florus of Lyons, 174 .

Floss, 173.

Flügel, 397.

Fonseca, see Petrus.

Forget, 239.

Forster, 253.

Fouillée, I04.

Francesco Piccolomini, 472.

Francis Bacon, 475, 485, 487 .

- I., 467 .

- de Vittoria, 489, 49r, 492-93.

- of Mayron, 433 .

- St., 262, 282, 352, 37 I, 403.

Franciscus Taegius, 489, 49I.

Franck, 102, I24.

- Sebastian, see Sebastian.

Franklin, 264.

Frassen, 500 .

Fredegis, 134, r54, r6r.

Frederick Barbarossa, $\mathrm{r}_{43}$.

Frederick II., 248, 290, 307, 383, 484 .

Freudenthal, Iro, Ir7, 467 .

Friedlein, $32 \mathrm{I}$.

Friedrich, r3o.

Froschammer, 334, 347 .

Fulbert of Chartres, r35, r56, r8I, 207.

Fulco, 175 .

Fuzier, 167.

Gabriel Biel, 452, 498, 499.

- Vasquez, 495, 496, 497 .

Galen, 67, 98, 143, 185, 187, 226, 229, 246.

Galileo, 472, 50I, 503.

Gandulf, Master, 2 ro.

Garcia, 378.

Gardeil, 3 ro.

Garnerius of Rochefort, I7I, 22 I.

Gaspar Lax, 499.

Gaspary, 470 .

Gasquet, 392, 397.

Gassendi, 473 .

Gaston Paris, 388.

Gaunilo, 165 .

Gazali, 232, 236, 248, $3^{8} 7$.
Gemistos Pletho, see Georgios.

Gennadius, 356, 4I2, 468, 470 .

George of Brussels, 449,500 .

- of Trebizond, 468,470 .

- Pachymeres, $24 \mathrm{r}$.

Georgios Gemistos (Pletho), 468, 484.

- Scholarios, see Gennadius.

Gerard Groot, 439, 440, 456.

- Odo, 433.

- of Abbeville, 26o, 307, 350 .

- of Bologna, 434.

- of Cremona, 229, 247, 249, 250.

- of Sienna, 437.

Gerberon, 166.

Gerbert, 134, I36, I55-56, I6r.

Gerhard Harderwijk, $488,49 \mathrm{I}$.

Gerhardus de Monte, 488, $49 \mathrm{I}$.

Geronimo Rossello, 404.

Gerson, 282, 367, 415, 437, 438, 439-40.

- ben Salomon, 240.

Getino, 347 .

Gietl, 208, 2 12.

Gilbert de la Porrée, I29, I35, I46, I8I, I82, 193-96, I98, 206, 209, 2 II, 212, $258,322,4$ II, 4 I 2 .

Gilbert Mauguin, 177 .

Giles, $448,449,45 \mathrm{r}$.

- of Lessines, 299, 306, 348, 349, 350, $353,354-55,367,387,503$.

- of Rome, 262, 355, 356, 358, 359, 36r$62,363,368,387,388,412,437$.

Giordano Bruno, 406, 477-78.

Giovanni Pico (of Mirandola), 469, 480 .

Girard, 156.

Godet, $\mathrm{r}_{47}$.

Godfrey of Auxerre, 209.

- of Fontaines, 255, 354, 358-6r, 363, $367,368,435$.

- of St. Victor, I52, 2 I8.

Godinus, $22 \mathrm{r}$.

Goethals, 363 .

Gomez, 496.

Gonzalez, I Io, I2I.

- Fr., 495.

Gorgias, I2.

Gosius, 5or.

Gottschalk, r74.

Goudin, 504.

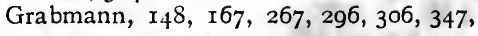
354 .

Grandegeorge, 90, 9I.

Gratiadeus Esculanus, 435.

Gregory Nazianzen, St., 89, r68.

- of Nyssa, St., 89, r68.

- of Rimini, 438 .

- of Tours, r25.

- of Valence, 495.

- Palamas, 4 II, 4 I2.

- the Great, St., Pope, I25, 143.

- VII., Pope, I63.

- IX., Pope, 252, 262, 387.

- X., Pope, 307 .

- XI., Pope, 406. 
Gregory XIV., Pope, 476 .

Gröber, 121, I5I, 403.

Grotius, sec Hugo.

Grunwald, I3I, 326.

Guenard, 506.

Guido, 45I (see Ægidius).

- of Veeli, 447.

Gundissalinus (or Gundissalvi), Dominicus, 203, 222, 23I, 244, 247-5I, 253, 270-73, 276, 297, 3 II, 347, 366.

Gunzo, 155 .

Gutberlet, 12.4, 347 .

Gutjahr, 209.

Guttmann, 239, 250, 253, 277, 279, 282, $301,303,347,370$.

HADELIN, II 7, 395, 397 .

Hahn, 447, 45I.

Halix, 4I2.

Harnack, 124.

Hartmann, 432.

Haser, 122.

Hastagen, J., I94.

Hauck, I24.

Hauréau, IO2, Io3, I04, II 5, I21, I23, I 24, I42, I 53, I 56, I 58, I59, I66, I 73 , I80, I83, I84, I87, I88, 202, 203, 205, 2II, $212,218,244,248,276,282,356$, Havet, 162. $357,3^{86}, 44^{8}, 449,45^{1}$.

Haymon, 162 .

Hefelé, I23.

Hegel, ro3.

Heimeric de Campo, 488, 49 r.

Heitz, I.47, I63, I9I, I98.

Helinandus de Frigidimonte, 273.

Henke, igs.

Henricus Aristippus, 139.

Henry Greve, 499.

- Kosbien, 245.

- of Andely, 136 .

- of Brabant, 2.4, 2.45.

- of Ghent, 295, 334, 354, 358, 359, 360, $363-67,368,374,375,376,400,401$, $402,408,434,500$.

- of Gorkum, 488 .

- of Hesse, 4I 7, 432.

- Plantagenet, 184,198 .

- Suso, 455, 459.

- the Englishman, 447.

- the Teuton, $35^{8}, 434$.

Heraclitus, 5, 8-9, 12, 19, 34, 55, 59.

Herbert of Cherbury, Lord, 484 .

Heriger of Lobbes, 175.

Herman the Dalmatian, $183,184,247$, 248.

- the German, 244, 245, 247, 248 .

Hermann, 20.

Hermes Trismegistus, 72, 469 .

Hermolaus Barbarus, $47 \mathrm{I}$.

Herrad of Landsberg, 126.

Hervé of Nedellec, 358, 434, 435, 437.

Hieronymus Aymus, 50r.
Hieronymus Cardanus, 476 .

- de Montefortino, 500.

Hilary of Poitiers, 193.

- St., of Poitiers, 89.

Hildebert of Lavardin, $184,210,216$.

Hincmar of Rheims, 174 .

Hippocrates, $143,185,187$.

Höfer, I22.

Höffding, 465 .

Hogan, ro3.

Homer, $46 \mathrm{r}$.

Honaïn ben Isaac (Fohannitius), I85, 227.

Honorius III., Pope, 173.

- IV., Pope, 36r.

- of Autun, I20, 184, 216.

Horace, 135.

Horten, 239.

Huber, I73.

Huet, ro3.

Hugh of Amiens, 209

- of Breteuil, I75.

- of Ostia, 354, 355.

- of Petragoris, 295.

- of Rouen, 2 ro.

- of S. Caro, 296.

- of Strassburg, 306.

- of St. Victor, I37, $142,207,208,209$, 2 IO, 2II, 2I2, 2I6-I8, 3II, 404.

Hugo Grotius (de Groot), 478-79, 484.

Huit, II $7,225,467$.

Hull, Miss E., I68.

Humbert of Prulli, 355.

Hurtaud, r67.

Hurter, I24, I25, 242.

IAмвLICHUS, 80, 82, 226, 468 .

Ibas, 226.

Ibn-Sina, see Avicenna.

Ignatius, St., 493 .

Ilgner, 437.

Innocent IV., 259, 290.

- V., see Peter of Tarantaise.

Isaac de Stella, I42, I7 I, 20I, 205.

- Israeli, I43, 237, 239, 25I, 27 I.

Isidore of Seville, 120, 125, 129, 142, 143, I $44, I_{4} 8,27$ I.

Ives of Chartres, $135,15^{8}$.

Јасов Вӧнме, $480-82$.

- Ledesma, 495.

- of Edessa, 226.

- Zarabella, 472.

Jacquin, II 7, I68, I 73, 345 .

James (Capocci) of Viterbo, 358, 359, 360, 362-63, 437 .

- I., of England, 495.

- Lefèvre d'Étaples, 459.

- of Douai, 357.

- of Venice, $138,140$.

Jammy, 306.

Janinus de Pistorio, 355.

Jansen, B., 296. 
Javellus, 489 .

Jehuda Ibn Tibbon, 237, 247.

Jerome d'Ascoli, 390.

- of Prague, 429 .

- St., 98, I20, I36.

Jessen, I22.

Joachim de Floris, 221, 385.

Johannes a Lapide, 489, 49r.

- Baco, see John of Baconthorp.

- Canonicus, 433.

- David, see John Avendeath.

- de Rubino, 289.

- Faber de Werdea, 499.

- Faventinus, 355 .

- Hispanus, see John Avendeath.

- Italus, 225.

- Magistri, 499, 500.

- Major Scotus, 489, 498, 499.

- Scottigena, I59.

- Sturm, 467 .

- Versor, 488,49 r.

Fohannitius, see Honain.

John Altenstaig, 499.

- Avendeath, 229, 247, 249, 250, 253, 300.

- Argyropulus, 468, 470.

- Basingstock, 244.

- Beleth, 22I.

- Bitaud, 504.

- Buridan, 429, 430-32, 498.

- Capreolus, see Capreolus.

- Courtcuisse, 4I5.

- Damascene, St., II7, I43, 206, 210, 224.

- de la Rochelle, 26o, 273, 279, 28r, 282.

- de la Chaleur, 446 .

- de la Rive, 433, 436, 447 .

- de Lugio, 389 .

- de Lugo, 496.

- de Pouilli, 434.

- Dorp of Leyden, 432, 498.

- Dullaert, 466, 499.

- Dumbleton of Oxford, 433.

- Fronteau, 497.

- Gerson, sec Gerson.

- Guyon, 446 .

- Malpighi, $46 \mathrm{r}$.

- of Baconthorp, 452, 459, 501 .

- of Bassoles, 433 .

- of Brescain, $387,4 \mathrm{II}$.

- of Cologne, 499.

- of Cornouailles, 209.

- of Fidanza, see Bonaventure.

- of Freiburg, 306.

- of Ghent, 44I-44.

- of Jandun, 420, 44I-44, 47I, 490.

- of Lichtenberg, 306.

- of Mirecourt, 446, 447, 45I.

- of Montesono, 26I, 446 .

- of Montreuil, 4I5.

- of Naples, 434.

- of Navarre, 430.
John of Paris (or Quidort), 353.

- of Parma, 28I.

- of Persora, 295.

- of Salisbury, II4, I30, I3I, I32, I40, I47, I59, I 78, I8I, I82, I83, I84, I86, I88, 190, 193-97, I98-201, 204 .

- of St. Giles, 296.

- of St. Thomas, $493,497$.

- Paleologus VIII., 468.

- Peckham, 269, 289, 290, 292-93, 320, $32 x, 345,348,349,350,352,357$, $359,368,380,3^{8} 4,397,398,406$.

- Philoponus, 83 .

- Ruysbroeck, 438, 439, 440.

- Scotus Eriugena, I28, I34, I39, I43, $I_{46}$, I49, I54, I55, I59, I63, I67-73, I74, I78, I97, 2I4, 2I6, 220, 22I, 222, 227, 25I, 398, $45^{8}$.

- the Deaf (or the Physician), I59.

- the Englishman, 499.

- the Servite, 447.

- the Teuton, 354 .

- VI., Cantacuzenus, 4 II.

- Wessel, 498.

- Wycliff, 447 .

- XXI., Pope, 349, 352, 356 (see Petrus Hispanus), 367 .

- XXII., Pope, 4I9, 420, 442, 453.

Joscelin of Soissons, r 90.

Joseph Ben Zaddik, 238.

Jourdain, $148,184,186,223,244,246$, 253, 309, 346, 406, 432.

Juda Ben Salomo Cohen, 240.

Judas, 382.

Judocus Isanicensis, 498.

Juliani, see John XXI.

Julian Ribeira, 406.

Julius Caesar Scalgier, 472.

Juntes, 235.

Justinian, 82, 83, 223 .

Justus Lipsius, 472.

Juvenal, I35.

KAISER, I9I, I98.

Kantorowicz, 347.

Kaufmann, 367.

Keicher, see Otto.

Kelle, J., 2I8.

Kent, I67.

Kepler, 5or.

Kilgenstein, 218.

Kilwardby, see Robert.

Kirsch, I23.

Kleinias, 6.

Kleutgen, 96, 333, 347 .

Knöpfler, I23.

Koch, 99 .

Konrad Mudt (Mutianus Rutus), 484 .

Krause, 289.

Krebs, see Engelbert.

Krumbacher, K., 225.

Kunstmann, I47.

Kurth, I48. 
LABROSSE, 433.

Lactantius, 89, I 42 .

L.a Forèt, 147.

Lajard, 367 .

Lalande, $347,397$.

Lambertus de Monte, $488,49 \mathrm{r}$.

Laminne, 347 .

Landauer, 239.

Lanfranc, I34, I58, I62, I 75, I76, 177, 207.

Langlois, Ch., $3^{83}, 3^{88}$.

Lappe, 45r.

Lasswitz, I22.

Laurentius Valla, 466.

Lavinheta, 406.

Lavoisier, $50 \mathrm{I}$.

Lawrence Pignon, 299.

Leclère, 367.

Le Couteulx, 437.

Lefèvre, I 79, I So, I 86, 252.

Leibnit $z, 406,431,466,501$.

Lentheric, I56.

Leo Hebraeus, 469.

Leonardus Aretinus (L. Brun1), 46r, 468, 473.

Leont:us Pilatus, $46 \mathrm{r}$.

Leucippus, 9, ro.

Le Roy (Regius), 469.

Lessius, 495.

Levi ben Gerson, 4 I2.

Liessen, 259.

Lindsay, i 7 .

Lodigerius, $50 \mathrm{I}$.

Loewe, I52, I62.

Lombard, see Peter.

Longus de Corioles, 500.

Lorentz, I 2 I.

Lorenzo de' Medici, 468, 469.

Louis IX., 357.

- of Bavaria, 420, 44I, 442.

- St., of Toulouse, 295.

- the Debonaire, r68.

- XI., 429, 498.

Löwenthal, 253, 276.

Luchaire, 259.

Lucquet, 246, 248, 253.

Lucretius, 59, 60, r26, I4 I, I42, 2 Ig.

Ludger of Milnster, I34.

Ludovicus Vivès, 466, 499.

Luigi Vigna, 167 .

Lully, si $e$ Raymond.

Lupus of Ferrières, I34.

Luther, 479-80, 481, 483 .

Lutz, E., 289.

Lychetus of Brescia, 433.

Mabilleau, i22, 2 I 8 .

Macrobius, 83, 140, 246.

Maimonides, 237, 238-39, 25 I, 329, 4 I 2.

Magalliano, 494.

Magister Petrus, 28r.

Maistre, 147.

Malebranche, 487 .
Malpighi, see John.

Mandonnet, $144,221,242,249,253,258$, $260,262,263,269,299,300,302$, $306,307,309,346,347,353,356$, $380,3^{8}, 384,3^{85}, 386,3^{87}, 388$, 49 I, 497.

Manegold of Lautenbach, $x 76$.

Manfred, 245, 248, 383 .

Mangenot, 124 .

Manlius, see Boẽthius.

Manser, Ir 7 .

Mansion, 306.

Manuel Chrysoloras, 46 r.

- da Natıvidade, 496.

- de Goes, 494.

Manzolus, +8 , , 49 r.

Marbodius, 220.

Marchesi, 244, 245, 253, 309.

Marcus Aurelius, 64.

Marechaux, I67.

Marguerite Porrette, 444.

Maria Canali, 501.

Mariétan, 135, 136, I $47,347$.

Marius Nizolius, 466.

- Victorinus, 83, 90, I35, I38, r39, 140.

Marsilio Ficino, 468.

Marsilius of Inghen, 4I 7, 429, 430, 43I.

- of Padua, $420,441,4+2$.

Martène, ig\$, 223.

Martianus Capella, 84 , I34, I35, 143-44, I $48,1_{55}, 1_{58}, 168,173$.

Martigné, see De Martigné.

Martin, A., 366, 498.

- J., 90, 97.

- of Tours, 134.

- of Troppau, $3^{9} 4$.

- Pollich, 489.

- V., Pope, 260.

- Van Velden, 505.

Matilda of Magdeburg, 454.

Matthew of Aquasparta, 289, 290-93, 296, $337,348,408$.

Maurenbrecher, 347 .

Maurice of Sipain, 222, 252.

- the Irishman, 499.

Maurus, S., 496, 497.

Mausbach, 97.

Maximus of Tyre, 72.

- Planudes, 246, 4 I2.

- the Confessor, 99, I43, I68.

Maxwell, 259.

Medina, see Bartholomaeus.

Meinecke, 123.

Melanchthon, 473, 480-81, 495, 503.

Melchior Canus, 493, 497.

Melissus, 7.

Menendez Pelayo, 276, 389.

Mercier, I50, I5I.

Mercurius Trismegistus, I4I.

Meunier, 432.

Michaël, 301, 306.

Michael Apostolius, $468,470$.

- Cesena, 420. 
Michael, De Montaigne, $4^{84}, 485$.

- of Breslau, 499.

- of Ephesus, 225.

- Parapinakes, 224.

- Psellus, the Elder, 224.

- - the Younger, 224, 225, 356, 467 .

- Saravetius, 489, 49 r.

- Scot, 247, 248, 249, 272.

- the Stammerer, I68.

Michel, M., I47.

Migne, I22, $147, x_{4} 8,153,162,166, x 73$, 177, 185, 186, 188, 190, 198, 202, 205, 212.

Mignon, 212, 218.

Miguel Asin y Palacios, 236, 239, 3 ro, 347,382 .

Minges, P., 37 r, 378.

Miraeus, r2o.

Molière, 486 .

Molina, 495.

Monchamp, 505 .

Monica, St., go.

Montaigne, see Michael.

More, see Thomas.

Morinus, II6.

Moses Maimonides, see Maimonides.

- of Narbonne, $4^{12}$.

Mougel, 437.

Müller, 306 .

Munck, 239.

NAGY, A., 239.

Narbey, 397.

Nemesius of Emessa, 98, 143.

Nestorius, 89 .

Neumark, 239.

Newton, 501 .

Nicephorus Blemmides, 24I.

- Gregoras, 4II.

Nicetas, the Paphlagonian, 224.

Nicholas Bonetus, 499.

- Cabasilas, 4II, 4 I2.

- de Orbellis, 434 .

- du Nancel, 467 .

- Eymerici, 382, 406.

- Martinez, 496.

- Ockam, 295.

- of Amiens, I94.

- of Autrecourt, 446, 447-5I.

- of Cusa, Ir3, I84, 452, 456-60, 477 .

- of Espernaco, 446 .

- of Lisieux, 260, 307, 350, 357 .

- of Lyra, 433.

- of Methone, 225.

- of Oresme, 432.

- of Paris, 356.

- of Sicily, 245 .

- Poillevillain, 455 .

- Taurellus, $48 \mathrm{r}$.

- Tinctor, 499 .

- Triveth, r84.

- V., Pope, 456, 470.

Nicoletto Vernias, 444, 47x.
Niglis, A., 367 .

Nigri, see Petrus.

Niphus, see Augustinus.

Notger, 134, I48.

Notker Labeo, 134, 155 .

Numenius, 72, 14I.

Obradoz y Bennasar, 406.

Ockam, see William.

Odo of Cluny, 134, 155, 216.

- of Tournai, $134,156-57,162,160$ I 7 I, 216.

- of Tusculum, 387 .

- Rigaldi, 281.

Oesterley, I2I.

Ognibene, 208.

Olivi, Peter John, 293-95, 296, 377.

Olivier of Siena, $498,499$.

Olympiodorus, $83,225$.

Orges, 20.

Origen, 87, 88, 98, 142.

Ossinger, $43^{\circ}$.

Ostler, H., 2 I2.

Otho, I33, I55.

Otloh of St. Emmeram, I76, I77.

Otric, I56, x6r.

Ott, 96.

Otto Keicher, 406.

- of Freising, 138, I59, 194.

Paban, 437.

Pachymeres, 24I.

Palmieri, 296.

Panaetius, 64 .

Pantaenus, 87.

Paracelsus, $475,476,482$.

Paris, Gaston, 388.

Parmenides, 7, I0, 12, I9, 34, 42.

Parthenius Minges, $37 \mathrm{I}, 378$.

Paschasius Radbert, I34, 175.

Patritius (Patrizzi), 476.

Paul I., Pope, I68.

- of Venice, $444,489$.

- St., 99, I4I, 382.

Paulinus of Aquileia, 2r6.

Paulus Pergulensis, 498, 499.

Peckham, see John.

Pègues, 437.

Pellegrini, 306.

Pelzer, 359, 367, 444 .

Pepin, I68.

Perez, 496.

Pericles, I3.

Perrier, II7, 347.

Peter Abelard, see Abelard.

- Arrubal, 496.

- Crockaert, 489 491, 492, 493.

- D'Ailly, 4I5, 43I, 438, 439, 440.

- Damian, St., I6r, I76.

- de la Ramée, 466.67.

- de Mendoza, 495 .

- de Palude, 434 . 
Peter Gassendi, 473.

- Helias, I99.

- John, see Olivi.

- of Auvergne, 295. 307, 308, 355.

- of Brussels, see Peter Crockaert.

- of Conflans (Petrus de Confleto), 349, $35 \mathrm{I}, 355$.

- of Corbeil, 222, $25 \mathrm{I}$.

- of Monteregali, $4+7$.

- of Poitiers, 206, 210, 21 r, 221.

- of Tarantaise, 296, 297, 452.

- Plaout, 447.

- St., 302 .

- the Chanter (of Rheims), 209.

- (the) Lombard, I29, 176, 206, 207, 209-10, 278, 282, 283, 295, 419, 490,49 s.

- the Venerable, 249.

- Thomas, 499, 500.

Petrarch, 46r, 468, $47 \mathrm{I}$.

Petri d'Abano, $44^{2}, 4+4$.

Petrus Aureolus, +19. 427, 435 .

- Baalardi, 290.

- de Aquila, 499, 500.

- de Hibernia, 307.

- de Orviedo, 496.

- de Trabibus, 29.4, 367.

- Fonseca, 493, 494.

- Hispanus, 356, 367, 412, 415, 419, $425,+28,489,49$ I, 500.

- Magister, 281.

- Mantuanus, 498, 499.

- Martinus, 307 .

- Nigri, 488,49 r.

- Pomponatius, 47 I, 472, 490, 49I.

- Ramus, see Peter de la Ramée.

- Tartaretus, 499. 500.

Pez, 19o, r9S.

Pfeifer, 459 .

Pfister, 147.

Philaretes, 185.

Philip IV., $36 \mathrm{r}$.

- King of France, 406.

Philippe, I20, I26.

Philo of Larissa, 65.

- the Jew, 73-75, I4I, I69.

Philolaus, 6.

Photius, 224, 227.

Piat, 15, 34, 36, 43, 45, 333 .

Picavet, IO2, I03, IO4, IIO, II 4 , I I 7 , I IS, I19, I22, I47, I62, I75, I77, I9?, I98, 282, 327, 388, 397, 5 o6.

Piccolomini, 472 .

Pico, see Giovanni.

Pierre de Maricourt, 397.

- du Bois, 383 .

Pignon, L., 299.

Pius V., Pope, 49 I.

Plassmann, 347.

Plato, 16-28, and passim.

Pletho, see Georgios.

Pliny, 136.

Plotinus, 75-79, 82, 88, 9o, 99, II 4, I22, Ratramn of Corbie, I74, I75.
I69, I7I, 21 4, 227, 237, 239, 327, $398,399,457,468,469,477$.

Plutarch, 72, I40, 201, 342 .

Pluzanski, 369,378 .

Pollak, 226, 229, 238, 239.

Pomponazi, see Petrus Pomponatius.

Poncius Mastrius, 500.

Poole, I23.

Poppo of Fulda, 155.

Porphyry, 79-80, 90, I 39 , I 40, I 52, I 53 , I 57 , I 58, I60, I72, I9I, I93, 200, $225,226,227$.

Porrette, sce Marguerite.

Portalié, 90, 91, 96, I 8 , I98, 209, 21 I, $212,269,377$.

Posidonius, $6_{4}, \mathrm{I}_{4} \mathrm{r}$.

Potthast, I2I.

Prantl, I22, I95, I96, 4I9, 423, 425, 429, $445,486,49 \mathrm{I}, 499,500$.

Priscian, I35, 199, 258.

Probus, 226.

Proclus, 8I-82, 98, 99, I I4, 223, 225, $245,249,250,32 \mathrm{I}, 397,398,402$, 457,468 .

Procopius of Gaza, 9S, 225.

Proost. 506.

Prosper of Aquitaine, 192, 2 I6.

Protagoras, I2, I6. 60.

Protois, 2 I 2.

Psellus, sce Michael.

Pseudo-Augustine, I42, I 58 .

Pseudo-Denis, 98-I00, II 4, I3I, I.40, I43, I68, I69, 216, 226, 24I, 24. 250,277 , $283,308,324,343,437,440,457,459$, ${ }_{469}$.

Ptolemy, I 83, 246.

- of Lucca, 353.

Pyrrho of Elis, 62.

Pythagoras, 5-7, I6, I7, I9, 34, 70, I3 I, 182, 250, 327, 469 .

QUARACCHI editors of St. Bonaventure, 2Sg, and passim.

Quetif-Echard, I 20. 2.45, 263, 308, 346, $35+$.

Quintilian, 135,466 .

Radbert, Paschasius, I34, I75.

Radermacher, 4 I2.

Radulfus de Longo Campo, 204, 247.

Ragey, 167.

Raimbert of Lille, I 56 .

Ralph of Colebruge, 232.

- of Laon, I34.

- the Breton, 434.

Ramus, see Peter de la Ramée.

Raphael Bonherba, 500.

Rashdall, 259, 45 r.

Ratbod of Trèves, 155.

Ratgar of Verona, I 55 .

Ratherus, I 34 
Raymond Lully, 262, 386, 388, 403-6, 457, 477.

- Martin, 3ro, 347 .

- of Sabunde, 452, 455-56, 459.

- of Toledo, 247.

Reginald, I99.

- Brother, 307, 308.

Regnier of Cologne, 358.

Reiners, I62, I9o.

Reinhard of St. Burchard, I55.

Reinwald, I98.

Remi of Auxerre, I34, I54, I55, I62.

Renan, 235, 236, 237, 239, 248, 249, 253, $383,388,395,4$ I2, 452, 47 I.

Reuchlin, $469,483,484$.

Reuter, I23.

Reynold of Tours, 134.

Rhaban Maur, I26, I29, I34, I42, I43, $\mathrm{I}_{47}, \mathrm{I}_{4} 8, \mathrm{I}_{58}, \mathrm{I}_{74}, 207,279$.

Ricardus de Bury, 4I6, 428.

Richard, II7.

- Burgondio of Pisa, I43, 2 Io.

- Cornubiensis, 259.

- Klapwell, 352.

- of Cornouailles, 28I.

- of Coutances, I82.

- of Lincoln, 446.

- of Middleton, 289, 294, 295-96, 296, 348,368 .

- of St. Victor, 218, 440.

- the Bishop, r8r.

Richer, I55, I56, I62.

Richter, I62.

Rickaby, II 7 .

Ritter, 327.

Robert, I47, I98, 2 I2.

- de Courçon, 222, 252, 255, 257.

- de Monte, I38, I40.

- Fitzacre, 297.

- Grossetête, 243, 259, 281, 282, 39r.

- Holcot, 430.

- Kilwardby, 269, 272, 294, 297, 3 I I,349, $350,35 \mathrm{I}, 354,355$.

- of Bastia, 28I.

- of Erfort, 354 .

- of Lincoln, 394.

- of Melun, 2ro.

- of Retines, 184 .

- of Sorbon, 263 .

- Pulleyn, 197, I98, 210, 2 r2.

- Steele, 397.

Rodolph Agricola, 466.

- of Namur, 22r. Roger Bacon, 245, 248, 262, 277, 278, 299,
$367,368,390-97,398,400,403,408$, 409, 4 Io.

- M., I47.

- Marston, 295, 406-8, 4 Iо.

- the Englishman, 289.

- Westram, 28r.

Roland Bandinelli (Alexander III.), 208.

- of Cremona, 260, 296.

Roscelin, I55, I58-60, I62, I65, I74, I75,
I8o, I9I, 192, 208, 209, 212, 425, 426.

Rose, 250.

Rousselot, 107, 347 .

Rubius, A., 495.

Ruch, 499.

Rufinus, 98, I42.

Rupert of Deutz, 134, 216.

Ruysbroeck, see John Ruysbroeck.

SaAdJA, 236, 237, 239.

Sabatier, 263.

Sadolet, J., 367 .

Saint René Taillandier, I67.

Salembier, 432.

Salomon ben Gabirol, see Avicebron.

Salzinger, 406.

Samuel ben Juda ben Meschullam, 4I2.

- ben Tibbon, 240.

Sanchez, 485 .

Santi Ferrari, 444.

Sauter, 239.

Saville, $45 \mathrm{I}$.

Savonarola, 469.

Sbaraglea, 120, 263.

Scalgier, 472.

Scandone, 306.

Schaarschmidt, 205.

Schindele, 274, 276, 279, 324, 347 .

Schmidlin, J., I94.

Schneid, II $7,253$.

Schneider, 300, 302, 303-6.

Schütz, 346, 347 .

Schwane, I23.

Scoraille, 498 .

Sdralek, I23, 264 .

Sebastian Franck, 482.

Sebastiao de Couto, 494.

Seneca, 64, I35, I4 I, I85, 404, 480, 484 , 485 .

Seppelt, 264 .

Sepulveda, 472.

Sergius, 226.

Sertillanges, 346 .

Servatus Lupus of Ferrières, $15^{8}, 174$.

Sestili, 49r.

Sextus Empiricus, 68, 244.

Siebeck, 57, I22, 205, 378, 427, 43I, 432.

Sievers, 459 .

Sigebert of Gembloux, 120.

Siger of Brabant, 258, 307, 308, 347, 350, 38o, 383-86, $3^{87}, 404$.

- of Courtrai, 357,383 .

Sigmund Barach, see Barach.

Sigismund, Archduke, 456, 486.

Simmler, 269.

Simon, Brother, 293.

- de Brie, 384 .

- de Brossa, 446.

- de Bucy, 358, 36r.

- Duval, 384,386 .

- of Authie, 252. 
Simon of Tournai, 197.

- Porta, 472 .

Simplicius, $81,82,83,225$.

Smith (and Wace), I24.

Socrates, 3, I1, 12, 13-16, 19.

Sogia, 50r.

Soncinas, B. P., 489, 491 .

Sophonias, 4II, 4I2.

Specht, I 47.

Stapper, 367 .

Steele, see Robert.

Stein, L., I2.4, 225, 239, 470 .

Steinschneider, I86, 239, 253.

Stephen Borretus, 356 .

- of Tournai, 209.

- Tempier, 299, 349, 350, 351, 352, 356, $35 \mathrm{~S}, 386,387$.

Stephanus Brulifer, 499.

- de Monte, 495.

Stevenson, 282 .

Stöckl, 22, I21, I42, 195, 372, 376, 415, $420,424,427,455$.

Stölzle, rgs.

Strabo, Walfred, I34.

Strato of Lampsacus, 54 .

Suarez, 493-95, 496, 497, 498.

Suidas, 224 .

Surius, +40 .

Susemihl, 245 .

Suso, sec Henry.

Switalski, I4s.

Sylvester II., sec Gerbert.

- Maurus, 496, 497.

- of Ferrara (Ferrariensis), 489, 490, $49 \mathrm{r}$.

Symphorien, 378 .

Synesius, $9^{5}$.

TADDEO, 2.45 .

Taegius, 489 .

Taine, II5.

Tajus, 192.

Talamo, II 7, 253.

Tannery, So.

Tauler, 455 .

Tedeschini, 321 .

Telesius, $474,475,477$.

Tempier, see Stephen.

Terence, 135 .

Tertullian, 88 .

Thales of Miletus, 3,5 .

Themistius, $81,223,227,247,47$ r.

Theobald, 198.

Theodore Gaza, 468, 470.

- Metochita, 4II.

- of Nopsuestia, 226.

Theoderet of $\mathrm{Cyr}_{\mathrm{r}, 2} 2 \mathrm{2}$.

Theophilus, 185.

Theoderic of Chartres, I35, 138, 182-84, I $86,194,19 S, 220$.

- of Freiburg, 398, 400-3, 454, 457.

Theodosius, II 7 .

Thiery, 3.46 .
Thomas, A., 159.

- à Becket, 198 .

- à Kempis, 439.

- Bradwardine, 445-47, 45 I, 452.

- Bricot, 499, 500.

- de Vio, sec Cajetan.

- Gallo, 277.

- More, $469,475,478,484$.

- of Cantimpré, 244, 28 I.

- of Strassburg, 438.

— of York, 282.

- P., IS6.

- (St.) of Aquin (Aquinas), ıo6, ro8, $194,222,236,244,246,249,26 \mathrm{I}$, $262,268,269,278,282-84,286$, 289, 292, 295, 297-99, 301, 303, 306-48, 349-60, 362-65, 368-70, 372, $374,376,380,3^{8}$, $3^{84}, 3^{85}, 3^{87}$, $388,397,399,402,408,409,412$, $42 \mathrm{I}, 42.4,429,433-36,443,45^{2}$, $470,475,486,487-94,49^{8}, 500,503$.

- Sutton, 354, 355, 359 .

- Wallensis, $28 \mathrm{r}, 419$.

Thurot, 257, 259, 262, 263.

Todros Todrosi, 412.

Toletus, 495, 497 .

Torricelli, 501 .

Traube, $12.4,167$.

Traversari, 468 .

Trendelenburg, 20.

Trithemius, I 20.

Trombeta, $499,500$.

Turner, 98, 173, r 98 .

Tyrannio, 66.

UBertus Guidi, 435.

Uccelli, $34^{6 .}$.

Ueberweg-Heinze, I04, IIo, I2I, I67, $356,425,47 \mathrm{I}$.

Uebinger, 459 .

Ulrich of Strassburg (U. Engelbcrti), 306.

Uranius, 226.

Urban IV., Pope, 252.

- of Bologna, 444 .

VACANDARD, 2I2, 218.

Vacant, 9o, 124, 253, 278, 282, 347, 369, $37+376$.

Vallius, 495 .

Vallois, 276.

Van Velden, Martin, 504.

Van Weddingen, $167,306$.

Varro, I44.

Vasquez, G., 495, 496, 497.

Vegetius Praetextatus, 83 .

Venchus, 458 .

Ventura, 50 I.

Vernet, 177.

Versor, see Johannes.

Vigna, L., I67.

Vincent of Beauvais, 272, 357 .

Virgil, I35. 
Vittoria, see Francis.

Vivès, L., 466, 499.

Vivès, $378,497$.

Von Eicken, I23.

Von Hertling, I23, 202, 306, 347.

Von Holtum, II 7 .

WACE, I24.

Wadding, 120, 263, 378 .

Walsh, 367 .

Walfred Strabo, r34.

Walter Burleigh, 433.

- of Bruges, 293.

- of Lille, 216.

- of Mortagne, 186, 188, I9o, I98.

- of St. Victor, 206, 209, 218.

Warron, 436.

Wattenbich, I2I.

Webb, 205.

Wehofer, I2I.

Weiss, 306.

Welte, I2t.

Wenck, K., $3^{83}$.

Werner, I21, I22, I86, 276, 335, 346, 362, $367,378,4 \mathrm{I} 7,427,438,444,45 \mathrm{I}, 45^{2}$, 47 I, $497,498,5$ OI.

Wessel, J., 498.

Wetzer, I24.

William de la Mare, 293, 348 .

- of Auvergne (or of Paris), 247, 265, 268, 270, 273-76, 366, 388, 39r, 394.

- of Auxerre, 204, 252.

- of Champeaux, I79-8I, I9I, I92.

- of Conches, I29, I81, 182, 184-86, 188, I98, 2II, 2 I9, 404.

- of Falgar, 295.

- of Hirschau, I77, I85.

- of Hotun, 354, 355 .

- of Mackelfield, 354 .

- of Melito, 277, 281.

- of Moerbeke, 244, 245, 253, 307, 3 Io, $397,398$.

- of Ockam, I08, 262, 377, 4I4, 4I8,4I9,
420-27, 429, 432, 434, 435, 438, 44I, $445,446,498$.

William of Shyreswood, 259

- of St. Am ur, 26o, 307, 350.

- of St. Theoderic, 185.

- of Syracuse, 187.

- of Tocco, 244, 309, 345, 346, 36r, 382.

- Temple, 467.

- the Breton, 223.

- the Goldsmith, 22I.

- Varo, 348.

- Ware, 367 .

Wilkins, 366 .

Willmann, 90, I03, IIo, II5, II6, II7, I21, I22, I26, 136, I37, I47, I48, 162, 212, 303, 314, 327, 342, 347, 417 .

Willner, 186, 187, I90, 192.

Windelband, I I0, I21, I50, 276.

Witelo, 130, 253, 398-400, 401 , 457.

Withers, 98 .

Wittmann, 239, 253, 309, 319, 347.

Worms, 228, 233, 236, 239.

Wonsidel, 489 .

Wrobel, 223.

Wustenfeld, F., 253.

Xenophanes, 7 .

Xenophon, $\mathrm{I}_{3}, \mathrm{I}_{5}$.

ZaNARDI, 493.

Zarabella, 472 .

Zeller, 4, I5, 20, 23, 29, 38, 77, I Io, I35, 323.

Zeno of Citium, 54, 62, 65 .

- of Elea, 7 .

- the Emperor, 226.

Ziesche, 289.

Zigliara, 294, 296.

Zimara, $47 \mathrm{I}$.

Zingerle, $3{ }^{1} 4$.

Zoroaster, $47 \mathrm{I}$.

$Z_{\text {wingli, } 473,480,482 .}$ 




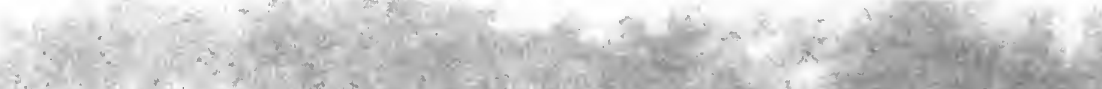

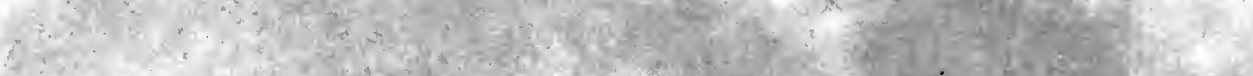

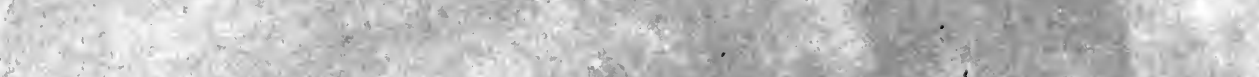

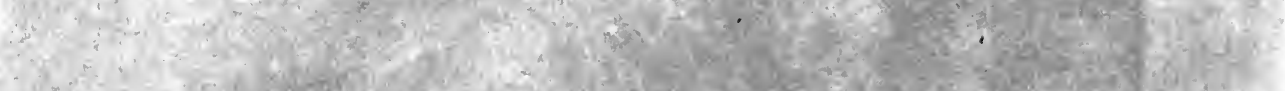

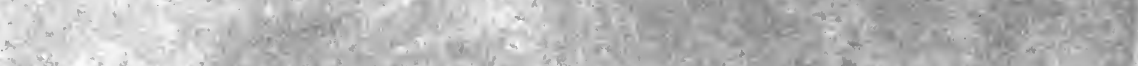

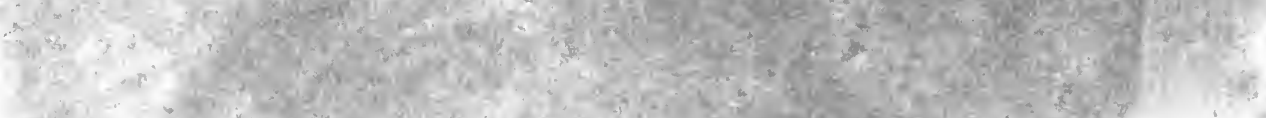

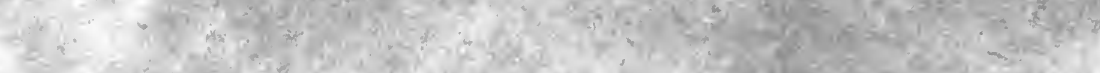

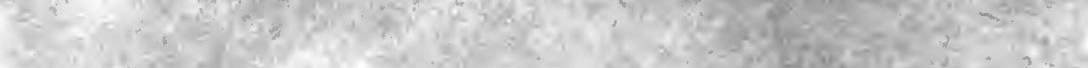

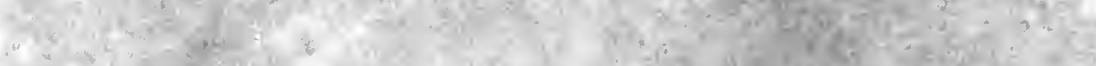

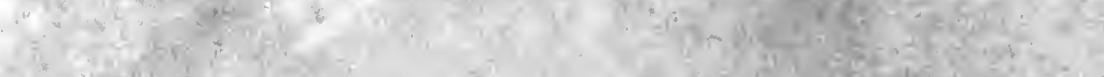
This

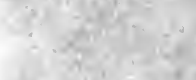

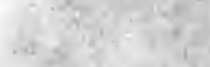

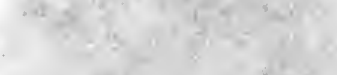
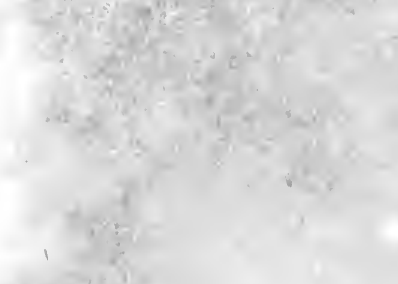

4

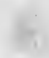

$+\frac{1}{2}$

$x^{2}+2$

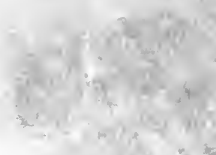

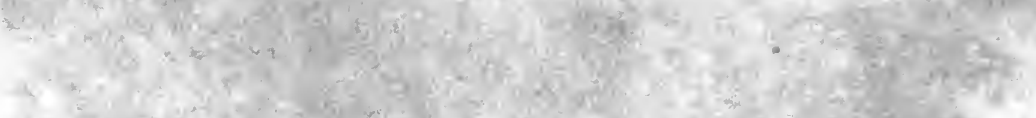

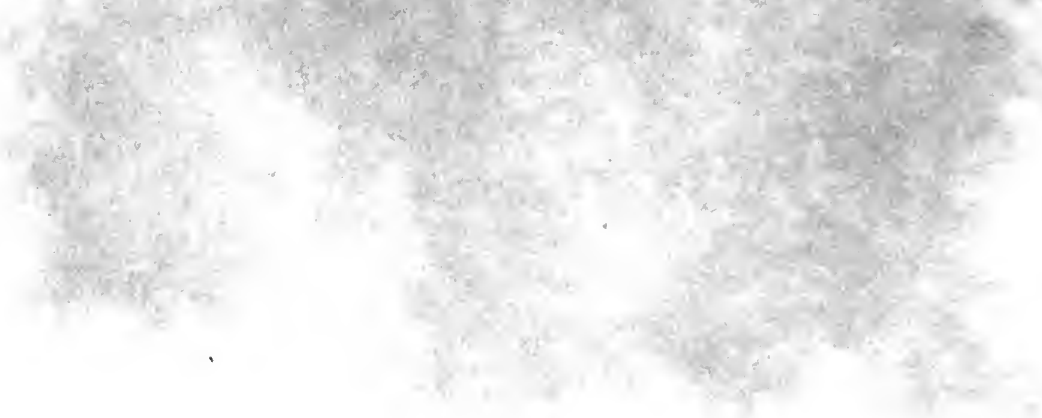


B 721 .W9313 1909 SMC Wulf, Maurice Marie Charles History of medieval philosophy 3rd ed. -- 

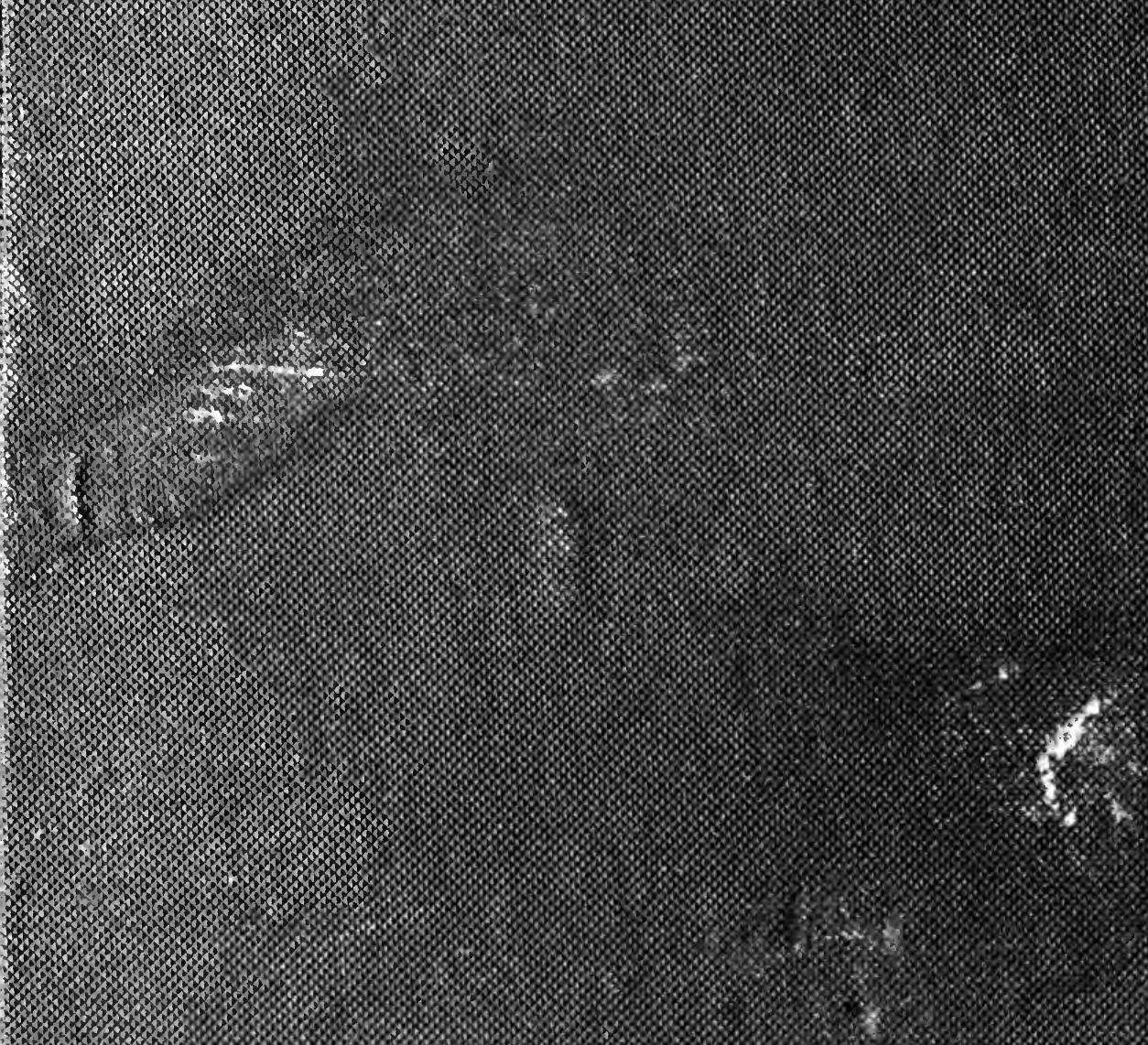